\title{
A monographic revision of the Neotropical dung beetle genus Sylvicanthon Halffter \& Martínez, 1977 (Coleoptera: Scarabaeidae: Scarabaeinae: Deltochilini), including a reappraisal of the taxonomic history of 'Canthon sensu lato'
}

\author{
Mario CUPELLO ${ }^{1,{ }^{*}} \&$ Fernando Z. VAZ-DE-MELLO ${ }^{2}$ \\ ${ }^{1}$ Departamento de Entomologia, Museu Nacional, Universidade Federal do Rio de Janeiro, UFRJ, \\ Quinta da Boa Vista, São Cristóvão, CEP 20940-040, Rio de Janeiro, RJ, Brazil. \\ ${ }^{1}$ Current address: Departamento de Zoologia, Universidade Federal do Paraná, Centro Politécnico, \\ Jardim das Américas, CEP 81.531-980, Curitiba, PR, Brazil. \\ ${ }^{1,2}$ Universidade Federal de Mato Grosso, Instituto de Biociências, Departamento de Biologia e \\ Zoologia. Av. Fernando Correa da Costa, 2367, Boa Esperança, Cuiabá, MT, 78060-900, Brazil. \\ ${ }^{2}$ Fellow of the Conselho Nacional de Desenvolvimento Científico e Tecnológico (CNPq). \\ *Corresponding author: mcupello@hotmail.com \\ 2Email: vazdemello@gmail.com \\ ${ }^{1}$ urn:1sid:zoobank.org:author:BDB03C18-7095-4EAA-8BDD-03CB4F79676D \\ ${ }^{2}$ urn:1sid:zoobank.org:author:2FF2B7D6-1A6B-43C1-9966-A1A949FB2B05
}

\begin{abstract}
Although extensively studied by different authors over the past 150 years, the taxonomy of Canthon Hoffmannsegg, 1817 and allied genera (which are here informally referred to as 'Canthon sensu lato') still remains problematic. With the aim of resolving some of the questions surrounding these taxa, the present work reviews the taxonomy of one of them, the genus Sylvicanthon Halffter \& Martínez, 1977. As defined here, Sylvicanthon is distributed mainly throughout the vast areas of tropical rainforests in the Neotropical region and includes 15 species divided into two groups: the enkerlini group, with a single species, S. enkerlini (Martínez et al., 1964) comb. nov., and the candezei group, with five subgroups: the candezei subgroup, with S. candezei (Harold, 1869), S. genieri sp. nov. and S. foveiventris (Schmidt, 1920); the aequinoctialis subgroup, with S. aequinoctialis (Harold, 1868) comb. nov. and S. proseni (Martínez, 1949) stat. et comb. nov.; the bridarollii subgroup, with S. bridarollii (Martínez, 1949), S. seag sp. nov., S. edmondsi sp. nov. and S. attenboroughi sp. nov.; the furvus subgroup, with S. furvus (Schmidt, 1920), S. monnei sp. nov., S. mayri sp. nov. and S. obscurus (Schmidt, 1920); and the securus subgroup, with a single species, S. securus (Schmidt, 1920) comb. nov. Three species originally included in Sylvicanthon are here (re)transferred to Canthon: Canthon xanthopus Blanchard, 1846 and C. machadoi (Martínez \& Pereira, 1967) comb. nov., as well as C. cobosi (Pereira \& Martínez, 1960) stat. et comb. nov., which had been previously in synonymy under C. xanthopus. Descriptions, redescriptions, illustrations and comparative tables on the external morphology (including the genital capsule) of the genus and its species are presented, as well as a detailed discussion on their biogeography, comparative morphology, hypotheses on their phylogenetic relationships, data on natural history and a detailed historical revision of the classification of 'Canthon sensu lato'. Finally, we also discuss the socalled 'species problem' (i.e., the definition of the scientific term 'species') and its consequences to dung beetle taxonomy and favour the solution offered by the Biological Species Concept.
\end{abstract}


Keywords. Systematics, taxonomy, Glaphyrocanthon, new species, Biological Species Concept.

Cupello M. \& Vaz-de-Mello F.Z. 2018. A monographic revision of the Neotropical dung beetle genus Sylvicanthon Halffter \& Martínez, 1977 (Coleoptera: Scarabaeidae: Scarabaeinae: Deltochilini), including a reappraisal of the taxonomic history of 'Canthon sensu lato'. European Journal of Taxonomy 467: 1-205.

https://doi.org/10.5852/ejt.2018.467

\section{Introduction}

As discussed elsewhere (Vaz-de-Mello \& Cupello in press; Edmonds \& Zídek 2012), the systematics of the New World dung beetles has witnessed a very active period of new landmark publications and unexpected findings, with a great number of modern taxonomic revisions published over the past 25 years (see Vaz-de-Mello \& Cupello in press: table 1). Nonetheless, some big challenges still face the scarabaedologists, including a complete revision of the megadiverse genera Dichotomius Hope, 1838, Canthidium Erichson, 1847, Ateuchus Weber, 1801, Uroxys Westwood, 1842, Onthophagus Latreille, 1802, Deltochilum Eschscholtz, 1822 and Canthon Hoffmannsegg, 1817. Some relatively small genera, however, despite their low number of species and the consequent supposed taxonomic simplicity, have also never had their taxonomy properly treated using modern standards, as, for instance, most of the groups in Deltochilini (sensu Tarasov \& Génier 2015; Tarasov \& Dimitrov 2016). In the present paper, we deal with the taxonomy of one of those small, poorly known deltochiline taxa, the genus Sylvicanthon Halffter \& Martínez, 1977.

Sylvicanthon was described by Halffter \& Martínez (1977) to include five South American species then placed in the genus Glaphyrocanthon Martínez, 1948: S. candezei (Harold, 1869) from the Amazon forest, S. xanthopus (Blanchard, 1846) from Bolivia, S. furvus (Schmidt, 1920) from Peru and Bolivia, S. bridarollii (Martínez, 1949) from Amazonia, and S. machadoi (Martínez \& Pereira, 1967) known from a single locality in the Brazilian state of Pernambuco only. As the new genus was established in the four-part revision of the 'Canthonina' genus-category classification by Halffter \& Martínez (1966, 1967, 1968 , 1977), special attention was given only to the description of Sylvicanthon and its relationships with other groups of 'Canthonina', and almost nothing was said about its alpha taxonomy. As a consequence, the only descriptions available for its species were the original ones, which, in most cases, are rather brief and focus on poorly informative characters. In addition, as no identification keys were published, a correct determination of specimens of Sylvicanthon was virtually impossible. Not surprisingly, the results of the present revision show that a great proportion of the specimens deposited in most of the studied collections belong to new species or have been misidentified, especially in the contexts of S. candezei and S. bridarollii. In addition, some synonymies proposed by Halffter \& Martínez (1977) have proven to be incorrect. The species distributions were also largely unknown. Usually, either the type locality was the only known provenance (e.g., S. xanthopus, S. furvus, S. obscurus, S. securus comb. nov. and $S$. machadoi), or, due to misidentifications, what is regarded as the geographical range of a single widely-distributed species was, actually, the distribution of a group of populations belonging to different species (as in the case of the distribution generally cited for S. candezei and S. bridarollii; see details below).

Apart from alpha taxonomy, we also found problems related to the limits of the genus and its species composition. It was discovered, for instance, that two of the originally included species - S. xanthopus and S. machadoi - belong, in fact, to another genus, while some species currently placed in Canthon actually have more affinities with those in Sylvicanthon. Also little discussed were the biogeography and the phylogenetic relationships of Sylvicanthon with other genera in Deltochilini.

Several doubts on the systematics of Sylvicanthon and its species remained, therefore, open. In the present work, based on an extensive revision of the historical bibliography, external morphology, male genitalia and distribution of the species in Sylvicanthon and related genera, we propose solutions to 
some of those problems. At the same time, however, we raise new questions about the phylogeny, biogeography and evolution of this interesting group to be addressed by future studies.

\section{Material and methods}

\section{Collections studied}

We examined 5487 specimens for this work representing all known species of Sylvicanthon as well as Canthon cobosi (Martínez \& Pereira, 1960), C. machadoi (Martínez \& Pereira, 1967) and C. xanthopus Blanchard, 1846. The specimens are housed at the following 31 collections (curators or contacts in parenthesis). Between the acceptance of the manuscript of this monograph and the production of its first proofs, the senior author (MC) was able to examine some additional specimens of Sylvicanthon, including some further paratypes of two of the new species, which are listed in Appendix 2.

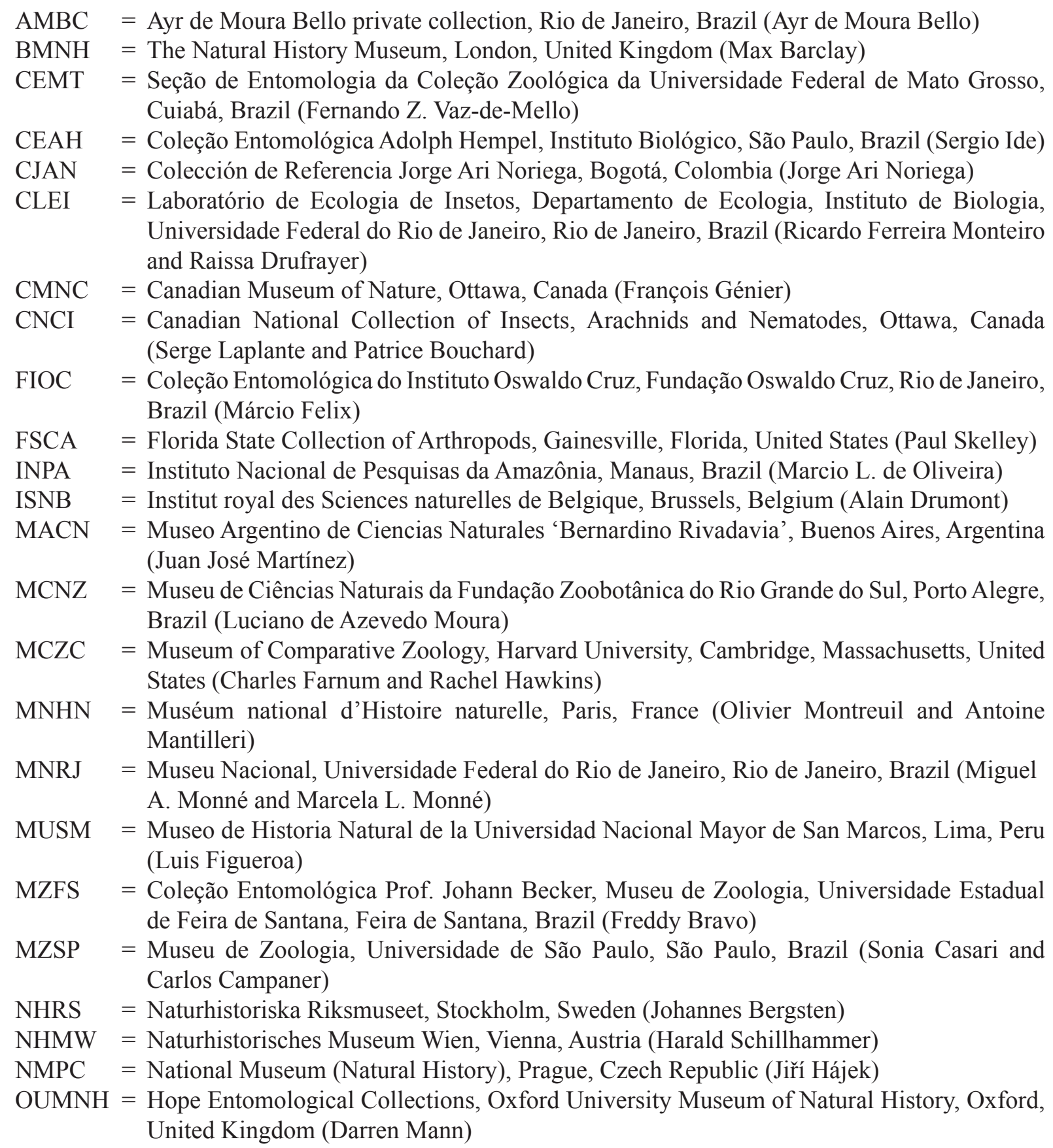




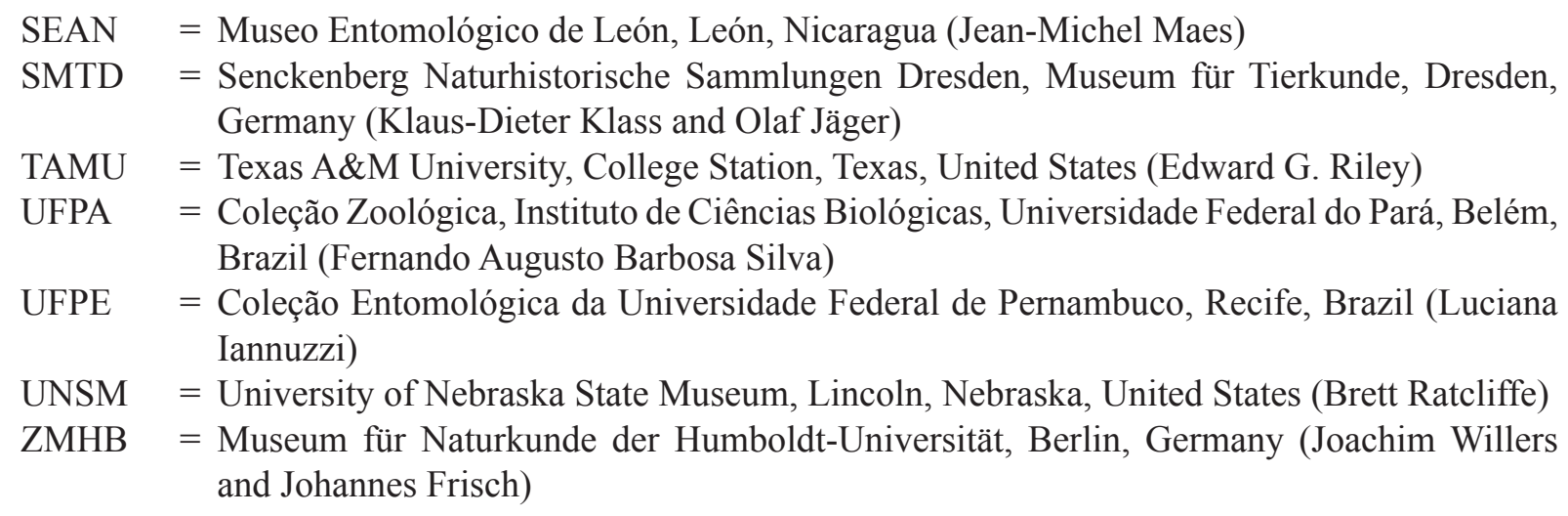

In the section 'Material examined', information for each specimen examined is listed alphabetically as follows: sex, collecting locality, collecting method, date of collection, collector (depository collection). In cases where the specimens were not examined microscopically, 'undetermined sex' is specified.

\section{Type material}

It was possible to study in person at least part of the type material of all the species-group names addressed in this work. To locate the whereabouts of some types, we consulted Horn \& Kahle (1935, 1936, 1937) and Evenhuis (1997a, 1997b). The great majority of the type material described by the French entomologist Émile Blanchard (1819-1900) and by the German coleopterist Edgar von Harold (1830-1886) was deposited in the MNHN, the latter via the collection of René Oberthür (1852-1944); some of Harold's type specimens studied for this work were also found at the ISNB and ZMHB.

The personal collection of the German scarabaedologist Adolf Schmidt (1856-1923), composed largely of Aphodiinae, but also including several type specimens of species of Canthon he described, was donated to the NHRS in 1924, one year after Schmidt's death, where it is still housed. Additionally, Additionally, Schmidt (1920), in a paper where he described four dung beetle species today placed in Sylvicanthon, stated that he had studied material from four other German collections: the Senckenberg Deutsches Entomologisches Institut, today in Müncheberg, but at that time located in Dahlem, Berlin (Gaedike 1995); the Zoologisches Institut und Zoologisches Museum, Universität Hamburg, in Hamburg; the ZMHB, in Berlin; and the collection of the firm Bang-Hass of insect dealers from Blasewitz, Dresden ("In letzter Zeit wurde mir freundlichst das zahlreiche Material des Museums in Dahlem und Hamburg, das der Firma Bang-Haas in Blasewitz und eine kleine Auslese aus dem Berliner Zool. Museum zur Verfügung gestellt [...]"). Studying a vast amount of dung beetle type material in several European museums in 2013 and 2014, FZVM located syntypes of the four nominal species established by Schmidt (1920) at the ZMHB, SMTD (ex Bang-Hass collection) and NHRS. Specimens deposited at the Hamburg museum are certainly lost, since a great part of its collection was destroyed by World War II allied bombings in 1943 (Klapperich 1948; Weidner, 1976). Finally, the Müncheberg collection was visited by MC in June 2016, but no syntypes of Schmidt's Sylvicanthon species were found there.

The type material of species described by the Argentinian Antonio Martínez (1922-1993) is divided between two collections: holotypes and allotypes are deposited at the MACN, while paratypes, along with the rest of his former personal collection, are at the CMNC (via collection Henry \& Anne Howden). Those species described in co-authorship with the Brazilian Padre Francisco Pereira (1913-1991) also have paratypes deposited at the MZSP.

For names currently borne by a series of syntypes, we designate lectotypes in accordance with Article 74 of the International Code of Zoological Nomenclature (ICZN 1999; hereafter, cited as 'the Code') in order to stabilize the nomenclature and to avoid any future misunderstanding. It is also important 
to highlight that the Code's Recommendation $73 \mathrm{~F}$ states that, when we have no data in the original description allowing us to know with certainty that the type series of a given name was composed of just a single specimen (and, subsequently, that specimen would automatically be the holotype of that name by monotypy), we should assume the type series was formed of two or more individuals, which, as a consequence, are the name's syntypes. That being so, even when we found just one specimen in the collections studied (e.g., for Canthon xanthopus and Sylvicanthon securus), we consider that specimen as part of a series of syntypes and, thus, eligible to be the lectotype of the name it bears.

\section{Publication dates of historical works}

Some $19^{\text {th }}$-century books cited in this work followed a very long and complicated process of publication, having been published in a series of independent fascicles (the so-called 'livraisons'; see Evenhuis 1997a). Years later, these were often bound under a single cover with a publication date, which usually reflects the date of the last part published. Consequently, the year printed on the cover not always corresponds to the real issuing date of all parts of the book.

As publication dates are essential in zoological nomenclature, we checked that information in specialized literature in every situation where we had doubts about the year of appearance of a book cited in this work. Thus, publication dates of the cited parts of the series Biologia Centrali-Americana (Bates 1887, 1889) were based on Lyal (2011), those of Dejean's catalogues (1833-1836, 1836-1837) on Madge (1988), of the Voyage dans L'Amérique Méridionale (Blanchard 1846) on Sherborn \& Woodward (1901) and Evenhuis (1997b), of Recueil d'observations de zoologie et d'anatomie comparée (Humboldt \& Bonpland 1805-1810) on Sherborn (1899) and Evenhuis (1997a), and of Histoire naturelle des insectes (Brullé 1838) on Brockhaus \& Avenarius (1839). Bouquest (2016), which appeared after the conclusion of the first draft of this work, was consulted in order to verify our previous datings.

\section{Terminology}

Throughout the descriptions of the external morphology, we employed the terminology established by Halffter \& Martínez (1966, 1967, 1968, 1977), Edmonds (1972) and Canhedo (2006), with the updates organized by Beutel \& Lawrence (2005) and Lawrence et al. (2010) based on more modern interpretations of the evolutionary development of the ventral sclerites of thorax and abdomen. For the microsculpture of the tegument surface, in particular, we followed Harris (1979) and Krell (1994) (see more details below in the section 'Comparative morphology of species of Sylvicanthon'). For the male genitalia, we adopted the terminology of Medina et al. (2013) (but see Zunino (2014) for some criticism).

\section{Measurements}

Using a ocular micrometer, specimens were measured as follows:

$\mathrm{EW}=$ greatest width of elytra

$\mathrm{PgL}=$ length of pygidium

$\mathrm{PgW}=$ greatest width of pygidium

$\mathrm{PL}=$ length of pronotum

$\mathrm{PW}=$ greatest width of pronotum

$\mathrm{TL}=$ total length

To each variable, we specify, in millimeters, the average and standard deviation (ME) and range with maximum $(\mathrm{MX})$ and minimum $(\mathrm{MN})$ values.

\section{Geographical distribution and maps}

The geographical distribution for each species is given in three different ways. The first is a general description of the species' distribution, citing relevant biomes where it occurs. The second is according 
to the division of the globe in ecoregions as proposed by Olson et al. (2001) (an interactive map with information about these ecoregions is available online by WWF 2006). Finally, the third way is based on the political division of each country. In this latter case, countries and first order subdivision (e.g., states, provinces or departments) are presented in a geographical order (i.e., in a sequence north-south and west-east), while lower divisions are given in alphabetical order. The only exception was French Guiana, an overseas department of the French Republic, but treated here as equivalent to the national category only for practical purposes. Information on the geographical distribution was mainly based on specimen labels. Information found in literature - which is often less reliable than specimen label data - was also included; in those cases, the locality is written in italics in the section 'Collecting sites' of each species.

Distribution maps presented in this work were made using the program ArcView GIS 10.2. Within this program, we used the shapefile of Löwenberg-Neto (2014) to confirm the presence of each species in the biogeographical provinces defined by Morrone (2014).

\section{Notes}

Notes in the text are explained in the Appendix at the end of the monograph.

\section{Species concept and species taxon recognition}

"When one is dealing with evolving biological populations - and that is what species of organisms are - one cannot expect the simplicity and unambiguousness that one encounters among parameters in the physical sciences."

Ernst Mayr (1988a)

Systematics ${ }^{1}$, like any other science, works through hypotheses raising and testing. Consequently, it is of utmost importance that systematists try to make as clear as possible the epistemological framework in which their research was developed. It is only in that way that the confrontation of antagonistic hypotheses taken by different authors to explain the same phenomenon is possible. For a systematic revision dealing essentially with alpha taxonomy, the concept most sensitive to debates and disagreements is, without doubt, that of the species category. As Ernst Mayr (e.g., 1982, 2004a) and others have stated several times, this is probably the most discussed topic in the entire history of the philosophy of systematics. Despite that, there has never been a consensus about the meaning of the word 'species', although, as shown by de Queiroz (1998, 1999, 2005a, 2005b, 2007), most of the modern concepts share a common basis. When a given group of organisms has its taxonomy revised by different authors with distinct stances on the definition of the species category, it is almost certain that the number of delimited species in that group will differ in the final results of those works (Mayr 1963; Cracraft 1997, 2000; Agapow et al. 2004; Zachos 2014), which may lead to the problem (or conflict) known as taxonomic inflation (Isaac et al. 2004; Zachos 2014) and its counterpart, taxonomic inertia (after Zachos 2018). Therefore, following what Ratcliffe (2013) listed as one of the good practices in taxonomic work, in the following paragraphs we present a brief summary of our ${ }^{2}$ current understanding of what is the best definition for the species category (i.e., what exactly we intend to refer to when using the word 'species'), and which are the criteria we use to recognize such entities. In other words, we will present our view on what de Queiroz (2007) defined as being species concept and species delimitation, respectively, - or Mayr's analogue terms species category and species taxon (Mayr 1963, 1988a, 2000, 2004a). It is important to stress that our somewhat long discussion on this topic is necessary because it will serve as a basis not only for the present study, but also for our future publications on alpha taxonomy.

Since the Darwinian revolution in the second half of the $19^{\text {th }}$ century, following through August Weismann's (1834-1914) Neodarwinism and the Evolutionary Synthesis in the 1930s-1940s, Darwinian evolutionism, based on the five or six main theories developed by Charles Darwin ${ }^{3}$, has become one of the unifying theoretical axis of the entire biology, connecting as distant fields as enzymology and 
astrobiology to marine biology, plant physiology and dung beetle taxonomy. As the famous phrase by Dobzhansky (1973) clearly summarized: "nothing in biology makes sense except in the light of evolution". Thereby, the best concept for the species category will be the one that refers to sets of organisms that, after being recognized by the taxonomist, have their historical origin explained by complex evolutionary processes and, at the same time, help to answer questions raised by evolutionary biology. Of little use are those taxonomic works that delimit species having as their sole goal the pure recognition of discrete morphological units serving uniquely to the daily work of the collection curator, but which have nothing to say about the evolutionary history of the taxon it is studying. The species listed by a taxonomist will only have meaning beyond simple classification if delimited in the light of evolution.

With that conclusion in mind, throughout this work the term species is employed based largely on the definition of the Biological Species Concept as presented by Mayr (1942: 120): "a group of actually or potentially interbreeding natural populations which are reproductively isolated from other such groups" (see also Mayr 1940, 1963, 1970, 1982, 1988a, 1988b, 2000, 2004a; and, more recently, Dubois 2011, where the biological species is called mayron). A given species may give rise to one or more daughter species through speciation processes (i.e., the rising of new discontinuities to gene flow), during which the ancestral species may or may not become extinct. It always depends on whether the speciation was dicopatric, on the one hand (when the ancestral species will cease to exist), or either peripatric or, much more rarely, sympatric by hybridization (when the ancestral species continues more or less intact and as cohesive as before ${ }^{4}$ ), on the other hand. We also agree with Hausdorf (2011) (a vision that had been championed earlier by Mayr 2004b) that the Evolutionary Species Concept (Simpson 1951, 1961; Wiley 1978, 1980, 1981; Wiley \& Mayden 2000 ) is, to a large extent, a different dimension of the biological concept (i.e., the opposition between nondimensional and dimensional species concepts as discussed by Mayr 1963). Evolutionary lineages can only remain integrated and independent (and, consequently, have their "own separate and unitary evolutionary role and tendencies", as argued by Simpson 1951) if, through time, they were reproductively separated from other such lineages; otherwise, they would simply merge into a single lineage.

Indeed, Simpson (1951: 290) himself stated that his new concept was simply a "shift of emphasis" in relation to Mayr's, whereas Wiley $(1978,1981)$ recognized reproductive isolation as one of the corollaries of his version of the Evolutionary Concept. The Unified Species Concept, as conceived by de Queiroz (2005b, 2007; see also de Queiroz 1998, 1999), on the other hand, although very close to the Biological Concept in stating that species are "Separately evolving metapopulation lineages", clearly argues that populations reproductively isolated from one another by means only of extrinsic barriers should also have their condition as independent species recognized by the taxonomist (e.g., de Queiroz 2005a, 2005b). That is, intrinsic interbreeding barriers would not be a necessary condition for a given group of populations to be recognized as a distinct species from its most closely related group of populations. Should the Unified Concept be largely employed, we would enter into a phase of wide classificatory instability, with historically ephemeral species being formed and merged at a much more accelerated pace, and in a much more confusing way, than if we recognize solely species separated by intrinsic reproductive barriers. In this latter case, although we still recognize the possibility of reticulate evolution (see below), the species would be more historically lasting and stable. It is also worth emphasizing that another distinction between de Queiroz's and Mayr's concepts is that the former author seems to be agnostic in relation to the cohesive factors that maintain a species united (e.g., de Queiroz 1999: 68), while the latter expressly asserts that interbreeding is the fundamental cohesive factor that, in combination with reproductive isolation, maintains the integrity and individuality of the species taxa through time and space (properties that, in turn, confer them the ontological status of logical individuals; see Ghiselin 1974, 1997; Hull 1976; Mayr 1988b).

It is important to stress that the Biological Concept as conceptualized by Mayr in no way resembles the simplistic version that several authors (both its critics and its enthusiasts) in general cite, where species 
would be separated by insurmountable sterility barriers. In that misleading version of the concept, to determine whether two individuals belong to the same species, it would be sufficient to obtain a hybrid between them and evaluate its fertility or viability. If the offspring were infertile or inviable, then the progenitors would belong to different species; on the other hand, if the offspring were fertile or viable, then the progenitors would be conspecific. Nothing could be more different from Mayr's concept (or from the one employed in this work).

As established in its original definition (Mayr 1940, 1942), the Biological Concept is populational, not individual; it does not work in an essentialist or determinist way, but rather it is probabilistic. Species may indeed show sterility barriers, but they may equally present hybridizing individuals or even populations. This stands clear when Mayr discusses topics such as reticulate evolution and hybrid speciation, when two formally independent species enter into physical contact and merge their populations, forming a single evolutionary lineage (e.g., Mayr 1963, 1970, 1982; see also Dubois 2011; Lamichhaney et al. 2018), introgression, secondary contact and secondary intergradation (Mayr 1963, 1970), the breakdown of isolating mechanisms (Mayr 1963), and the so-called 'difficulties' in the application of the biological concept (Mayr 1940, 1957, 1963). In that way, the biological species should be understood as a group of populations showing a broad reproductive transit and gene flow, and that, as a whole, is separated from such other groups of reproductively independent populations. Or, in other words, "different species, he [Ernst Mayr] believed, are those populations possessing any factors intrinsic to their member individuals that will act to prevent interbreeding between the populations of a degree as free as that within each population" (Wilson \& Brown 1953; their italics, our bold).

The misinterpretation that many authors give to the Biological Concept was already noted by Wilson \& Brown (1953) in the decade following the Evolutionary Synthesis. As discussed by them, several authors were not capable of understanding the probabilistic nature of the Biological Concept and, consequently, they converted it into a deterministic method of species delimitation where the hybrid barrier would function as a straightforward yardstick separating individuals belonging to a same species from those that should be classified in distinct species. ${ }^{5}$. The need felt by many taxonomists for a simple and universal concept for species recognition resembles largely the use of universal laws and principles in Newtonian physics. But evolutionary biology, unlike physics, deals with populations in gradual evolutionary change dictated by natural and sexual selection, mutation, migration, and genetic drift. Therefore, its objects of study are not fixed and discontinuous entities, but rather mutable lineages connected gradually and historically to other such lineages, which makes any form of essentialist philosophy or methodology extremely inadequate. As well argued by Mayr (1982, 2004b), it was Charles Darwin and his evolutionary theories that brought this completely unique character to biology.

Having discussed the meaning of the word 'species' (i.e., which species concept will be followed in this work), the second question to be answered is how to recognize biological species. Or, using the terminology of de Queiroz (2007), how to delimit them. In the present work, populations of Sylvicanthon were studied exclusively through individuals collected and stored dry in the 31 collections consulted. Thus, the two main sources of evidence for species recognition were the geographical provenance and, especially, the morphology of the specimens, in which this work actually followed most of the modern insect taxonomic revisions (although other methods might equally be employed, as discussed by de Queiroz 2005a, 2005b, 2007 and Mayr 1988a). Therefore, since it was not possible to observe directly how the populations of the studied species behave and interact in nature (and this would be almost impossible), all the taxonomic conclusions drawn here are based on the inference that, to some degree, distinct character conditions suggest distinct evolutionary histories (and, therefore, the existence of independent reproductive communities), whereas similar characters suggest a shared history (as stated by Mayr 1988a: "Species taxa [...] are based on inference from the species concept"). Hence, at a same locality, the more similar the individuals, the greater the confidence they belong to the same population, while the 
more similar two populations are (and this includes similitudes in intrapopulation variation, such as the one seen, for instance, in the micropunctation of the pronotal tegument of S. proseni (Martínez, 1949)), the greater the confidence they are conspecific. There are instances where the level of morphological distinction is such (that is, the volume of evidence that gene flow is minimal or has completely ceased), that there is little doubt we are dealing with distinct species (for example, S. foveiventris (Schmidt, 1920) and S. obscurus (Schmidt, 1920), two species with an overlapping distribution). On the other hand, there are cases where the distinction is tenuous enough to give us confidence we are dealing with a case of intraspecific variation, being it either intrapopulational or geographical (for example, colouration in S. obscurus).

Certainly, this method (which was called simply the "morphological method" in the revision of the operational criteria for species delimitation of Sites \& Marshall 2004) involves arbitrary aspects. Commonly, there is a grey area between what should be considered sufficient a distinction to categorize two populations as conspecific or as independent species (Mayr 1988a, 2004a; Zachos 2018); the cryptic species example well illustrates that this criterion of "degree of differences" has its flaws. But this is precisely the kind of situation we expect to find in a scenario where evolution exists, speciation is a gradual and populational process, and the species are historically and continuously interconnected throughout the tree of life (Wilson \& Brown 1953; Mayr 1963, 1988a; Hey et al. 2003; Ridley 2004; de Queiroz 2005a, 2005b, 2007; Zachos 2014, 2018). In a world where species were temporally fixed and speciation came about in sudden leaps, one would expect that species would be discontinuous entities and situations of uncertainty about the boundaries between a pair of them would be rare and, when occurring, highly problematic. As this is not the reality of the world in which we live, the uncertainty on the categorization as full species of two incipient and very similar lineages (or reproductive units) should be perfectly acceptable, especially if we are dealing with allopatric populations. The species taxa proposed here, as in any other revision, should be understood as hypotheses to be tested in the light of new evidence and interpretations. Consequently, no revision should hope to be the last word to be said on the taxon which it is dealing with, a hope that the present work certainly does not nurture.

\title{
Results
}

\author{
Phylum Arthropoda von Siebold, $1848^{6}$ \\ Subphylum Hexapoda Blainville, $1816^{7}$ \\ Class Insecta Linnaeus, 1758 \\ Order Coleoptera Linnaeus, $1758^{8}$ \\ Suborder Polyphaga Emery, 1886 \\ Superfamily Scarabaeoidea Latreille, $1802^{9}$ \\ Family Scarabaeidae Latreille, 1802 \\ Subfamily Scarabaeinae Latreille, 1802
}

Tribe Deltochilini Lacordaire, 1856

\section{A taxonomic history of 'Canthon sensu lato'}

The taxonomic history of Sylvicanthon is intimately associated with that of Canthon and allied genera. Thereby, a full understanding of the context within which the genus was established by Halffter \& Martínez (1977) is essential to any person interested in the taxonomy of Sylvicanthon, especially in the light of recent publications questioning the validity of the genus (Ratcliffe 2002; Solís \& Kohlmann 2012). As the last revision of this history was published over 50 years ago (Halffter 1961; Halffter \& Martínez 1968) and great taxonomic activity has occurred since then, we present here a brief discussion on the taxonomic history of Canthon and allied groups (hereafter referred as 'Canthon sensu lato' ${ }^{10}$ ) with the dual goal of presenting a historical background to the description of Sylvicanthon by Halffter \& 
Martínez (1977), and providing some basic information that shall help future taxonomic works in Deltochilini.

In his 1817 revision of the insects described by the French entomologist Pierre André Latreille (17621833) (Fig. 1B) in the work of Humboldt \& Bonpland (1805-1810), the German naturalist Johann Centurius von Hoffmannsegg (1766-1849) (Fig. 1A) proposed the genus Canthon for Ateuchus septemmaculatus Latreille, 1807 and 14 other species not cited by Latreille (1807). The type species of Canthon, Scarabaeus pilularius Linnaeus, 1758, would be designated only 120 years later by Paulian (1939: 22). Probably unaware of the description of Hoffmannsegg (1817), Latreille (1829) established the new genus Coprobius to accomodate several species that had already been transferred to Canthon by Hoffmannsegg. Even so, Latreille's new nominal genus was adopted by contemporary French entomologists such as Brullé (1838), Reiche (1841) and Dejean (1833-1836, 1836-1837). The German author Jacob Sturm (1843), in the second edition of the catalogue of his beetle collection, was the first to recognize the synonymy between Canthon and Coprobius, but, interestingly enough, he used the second name as valid and indicated the first edition of his own catalogue ('St. Cat.'; Sturm, 1826) as the original publication of Canthon. Nonetheless, by consulting Sturm (1826), we see that in that work the authorship of Canthon (there considered a valid name) was attributed to the German entomologist Johann Karl Wilhelm Illiger ('Illig.') and not considered a new genus. As far as we could find, Illiger never cited the name Canthon in his own works, neither before nor after Hoffmannsegg's description.
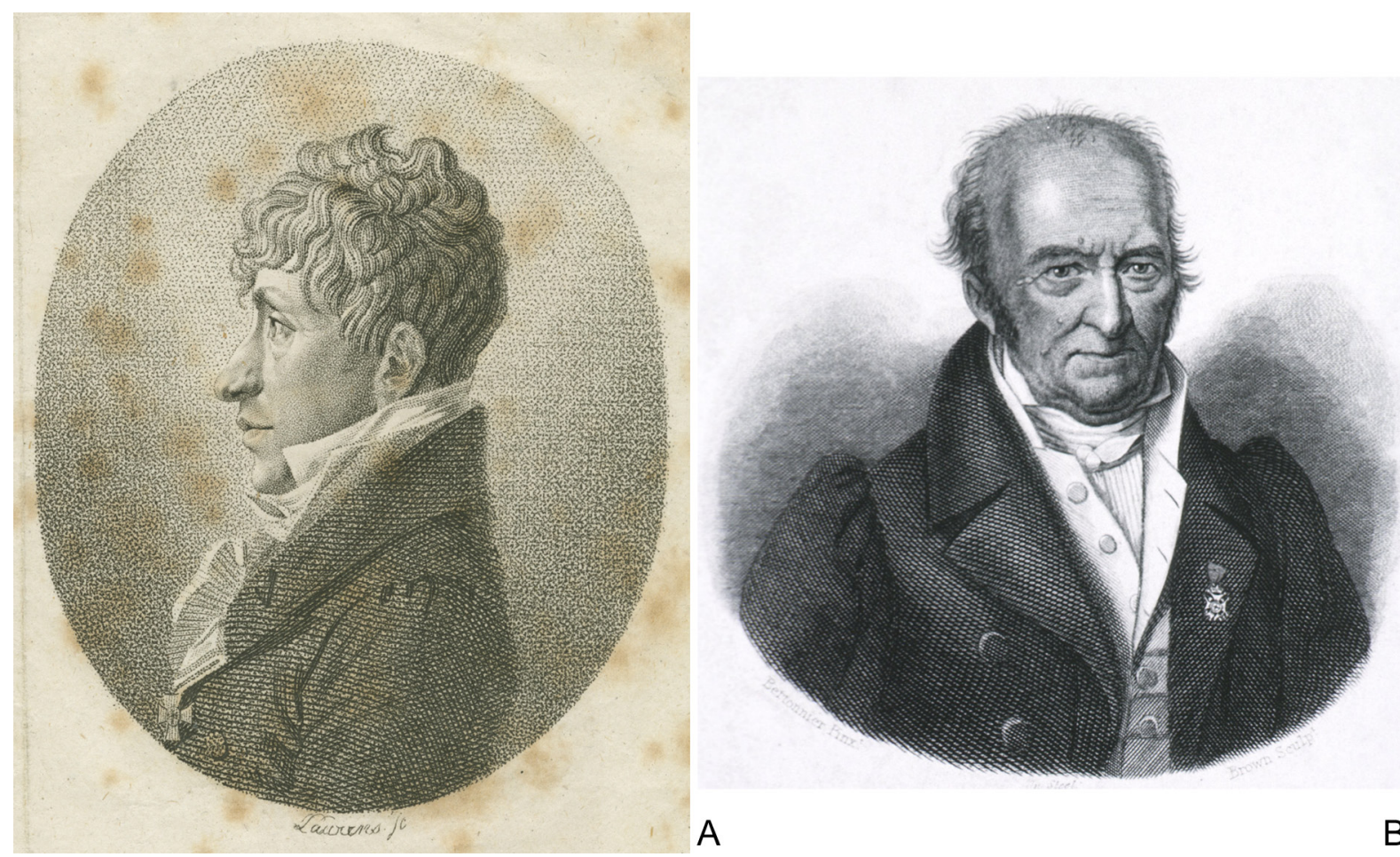

Fig. 1. Authors who initiated the studies on 'Canthon sensu lato' in the first half of the $19^{\text {th }}$ century. A. The German naturalist Johann Centurius Graf von Hoffmannsegg (1766-1849), author of the genus Canthon (image courtesy of Editha Schubert, from the archives of the Senckenberg Deutsches Entomologisches Institut). B. The French entomologist Pierre André Latreille (1762-1833), author of Ateuchus septemmaculatus Latreille, 1807, species treated in detail by Hoffmannsegg (1817) in his description of Canthon. Latreille was also the author of Coprobius, name considered valid for decades before being synonymized with Canthon by Harold (1868a) (image courtesy of the United States National Library of Medicine). 
Finally, Castelnau (1840) also recognized the synonymy between Canthon and Coprobius, but, contrary to Sturm (1843), he was the first to consider Canthon as the valid name in this synonymy, a decision that, with the notorious exception of Burmeister (1874), has been followed until the present day. A second name that is currently considered a junior synonym of Canthon, 'Coeloscelis', was proposed by Reiche (1841) to accommodate only 'C. coriaceus Dej.'. Erichson (1847) synonymized Canthon and Coeloscelis, but Lacordaire (1856) returned using Coeloscelis as valid and transferred some further species to this genus. The definitive synonymy would only come with Harold (1868a), in the first great comprehensive revision of the genus Canthon.

One of the greatest specialists of Scarabaeinae in the $19^{\text {th }}$ century, the German entomologist Edgar von Harold (1830-1886) (Fig. 2) was responsible for some landmark revisions of genera with a large number of species and a very complex taxonomy which are still fundamental to our understanding of the diversity of New World dung beetles. Among those works are Harold's revisons of Canthidium Erichson, 1847 (Harold 1867), Ateuchus Weber, 1801 (cited as Choeridium Lepeletier de Saint-Fargeau \& Audinet-
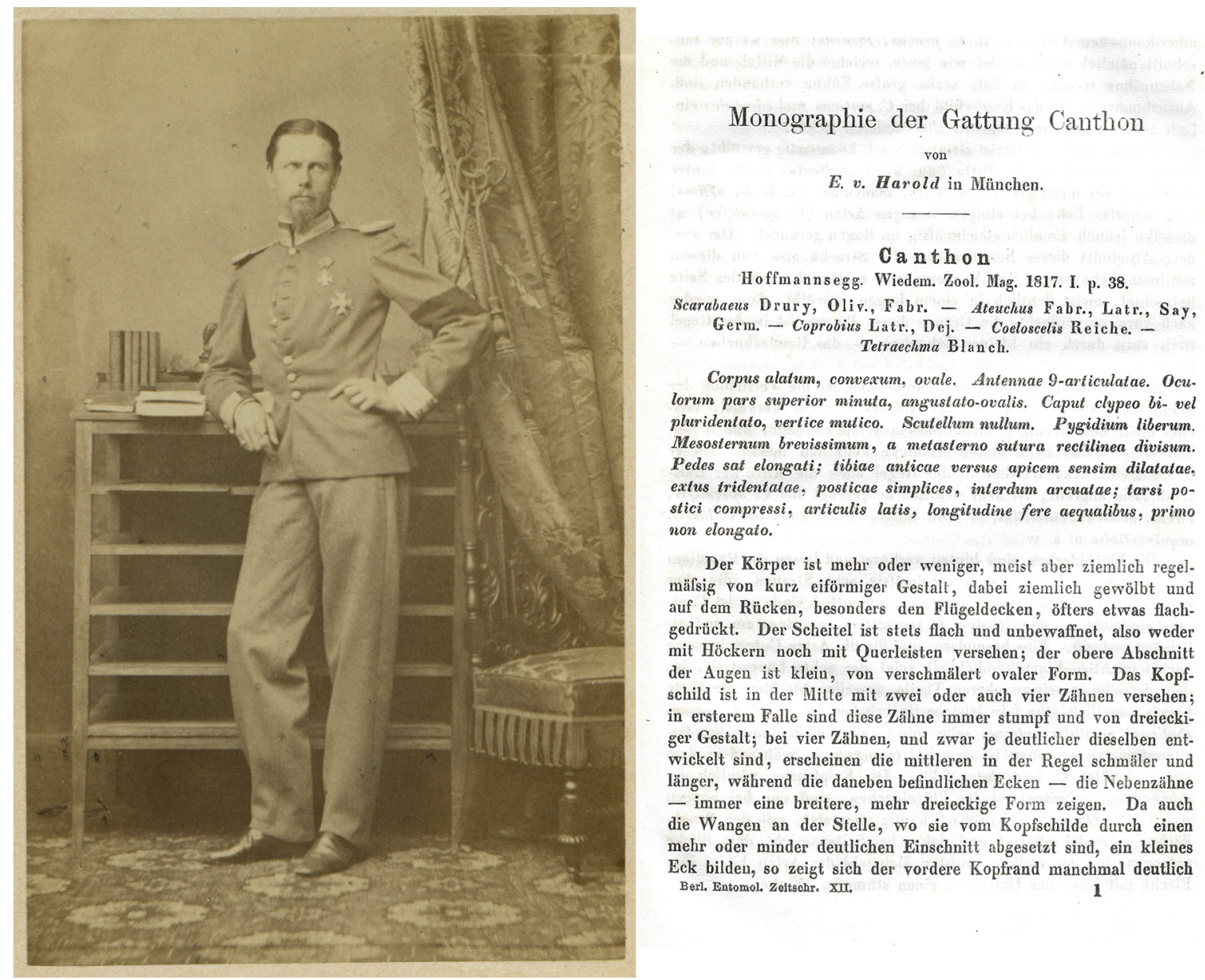
ato-ovalis. Caput clypeo bi- vel pluridentato, vertice mutico. Scutellum nullum. Pygidium liberum. Mesosternum brevissimum, a metasterno sutura rectilinea divisum. Pedes sat elongati; tibiae anticae versus apicem sensim dilatatae, extus tridentalae, posticae simplices, interdum arcualae; tarsi postici compressi, articulis latis, longitudine fere aequalibus, primo non elongato.

Der Körper ist mehr oder weniger, meist aber ziemlich regelmälsig von kurz eiförmiger Gestalt, dabei ziemlich gewölbt und auf dem Rücken, besonders den Flügeldecken, öfters etwas flachgedrückt. Der Scheitel ist stets flach und unbewaffnet, also weder mit Höckern noch mit Querleisten versehen; der obere Abschnitt der Augen ist klein, von verschmälert ovaler Form. Das Kopfschild ist in der Hitte mit zwrei oder anch vier Zähnen versehen; in ersterem Falle sind diese Zälne immer stumpf und von dreieckiger Gesialt; bei vier Zähnen, und zwar je deutlicher dieselben ent. wickelt sind, erscheinen die mittleren in der Regel schmäler und länger, während die daneben befindlichen Ecken - die Nebenzähne - immer eine breitere, mehr dreieckige Form zeigen. Da auch die Wangen an der Stelle, wo sie vom Kopfschilde durch einen mehr oder minder deutlichen Einschnitt abgesetzt sind, ein kleines Eck bilden, so zeigt sich der vordere Kopfrand manchmal deutlich Berl, Entomol, Zeitschr. xur.

Fig. 2. The German coleopterist Edgar von Harold (1830-1886), one of the first specialists in scarab beetles and author of the only $19^{\text {th }}$ century revision of Canthon Hoffmannsegg, 1817, in which 97 species were recognized as valid, 46 as new. Harold described two species today positioned in Sylvicanthon Halffter \& Martínez, 1977: S. aequinoctialis (Harold, 1868) comb. nov. and S. candezei (Harold, 1869) (portrait courtesy of Editha Schubert, from the archives of the Senckenberg Deutsches Entomologisches Institut; title page of Harold's revision of Canthon scanned from an original copy housed at the first author's personal library). 
Serville, 1828; Harold 1868b) and Canthon (Harold 1868a). In this latter work, Harold recognized Canthon as the senior synonym of Coprobius, Coeloscelis, and Tetraechma Blanchard, 1846, and being composed of 97 species - 46 of them new - distributed throughout the American continent. Twenty-three other nominal species were listed as of unknown assignment, the majority of them described by French entomologists such as Blanchard, Lucas, Castelnau and Guérin-Méneville, and the American LeConte, and whose type material Harold (1868a) did not have access to. Harold (1868a) also redescribed Canthon, discussed in fine detail the morphological variation observed in the genus, compared it to other taxa considered as close relatives such as Deltochilum, Anachalcos Hope, 1837 and Megathopa Eschscholtz, 1822 , and, perhaps his most important contribution, presented the first identification key to the species of Canthon. The following year, after examining some type material deposited in the MNHN, Harold $(1869 \mathrm{c})$ presented new information about some of the species considered as unknown to him in 1868.

During the second half of the $19^{\text {th }}$ century and the early $20^{\text {th }}$ century, the number of species in Canthon continued to grow. In the catalogue of Harold (1869b), 123 species were included in the genus, while that
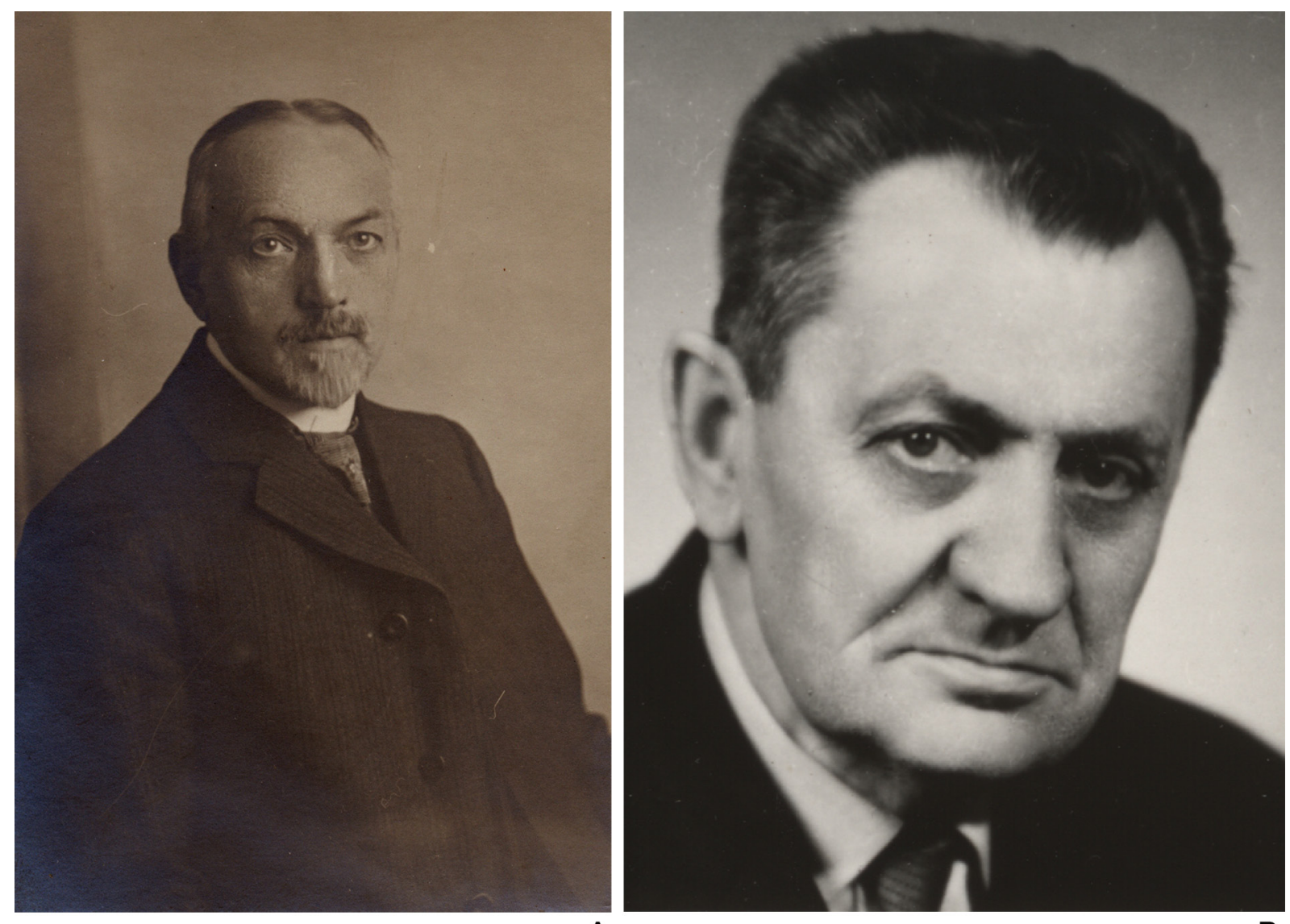

A

Fig. 3. The two great revisers of Canthon Hoffmannsegg, 1817 in the first half of the $20^{\text {th }}$ century. A. The German coleopterist Adolf Schmidt (1856-1923). After the publication of his two works on Scarabaeinae (Schmidt 1920, 1922), Canthon was composed of 143 valid species. Schmidt was the first author to recognize a group of species that, more than 50 years later, would constitute the core of the genus Sylvicanthon as proposed by Halffter \& Martínez (1977). B. The Czech coleopterist Vladimír Balthasar (1897-1978), one of the first authors to recognize explicitly the great heterogeneity and artificiality of Canthon and to propose its division into several genera and subgenera. (Both images courtesy of Editha Schubert, from the archives of the Senckenberg Deutsches Entomologisches Institut.) 
number rose to 144 in the catalogue of Gillet (1911). In the interwar period, Adolf Schmidt (1856-1923) (Fig. 3A), a German specialist in Aphodiinae, devoted himself to the elaboration of a second revision of Canthon, the only scarabaeine genus on which he has ever published (Vaz-de-Mello \& Cupello in press). In his first work, Schmidt (1920) described 26 new species-group taxa in Canthon. Shortly after, Schmidt (1922) proposed 27 additional new species and presented an updated identification key to 143 species of Canthon (not including 20 names he did not know how to apply to species taxa).

With the description of 16 additional new species, the Czech entomologist Vladimír Balthasar (18971978) (Fig. 3B) updated Schmidt's key in 1939 expanding it to encompass 162 species; 23 other names were not included by being of unkown application to species taxa. As Balthasar (1939) himself recognized several times throughout his text and even in its title ("Eine Vorstudie zur Monographie der Gattung Canthon", or "A Preliminary Sudy Towards a Monograph of the Genus Canthon"), his modifications were only a first draft towards a future revision of Canthon, a genus that, in his opinion, was extremely heterogeneous and ill defined. In the future, Balthasar (1939) believed, with a deeper analysis of the relationships between its species, groups of species and their morphological diversity, Canthon would inevitably be divided into several other genera and subgenera (e.g., on page 236, where he wrote "Die ganze Gattung [Canthon] scheint sehr heterogen zu sein und ich bin mir dessen gut bewusst, dass beim näheren Studium sich als notwendig zeigen wird, mindestens einige Arten als selbständige Gattungen abzugliedern").

In fact, this process of dividing Canthon into small, peripheral genera had already been started in the $19^{\text {th }}$ century. As examples, we can cite the description of Tetraechma Blanchard, 1846, Pseudocanthon Bates, 1887, Agamopus Bates, 1889 and, later on in the early $20^{\text {th }}$ century, Zonocopris Arrow, 1932, Plesiocanthon Gillet, 1933 (currently a junior synonym of Zonocopris) and Canthochilum Chapin, 1934. Furthermore, new species that, in the past, would probably have been positioned in Canthon, were being described in new monotypic or oligodiverse genera such as Sinapisoma Boucomont, 1928, Canthonella Chapin, 1930, Canthonidia Paulian, 1939, Canthotrypes Paulian, 1939, Paracanthon Balthasar, 1938 and Cryptocanthon Balthasar, 1942. Even so, the situation continued to be one of extreme chaos. On the one hand, there were disagreements over the validity of some of those names (Pseudocanthon and Tetraechma, for instance, were considered junior synonyms of Canthon by most authors almost until the second half of the $20^{\text {th }}$ century). On the other hand, the newly-proposed divisions helped little to reduce the great heterogeneity and artificiality of Canthon, since this genus continued to contain almost 200 species, while the other small genera were composed of at most three species.

The 1940s-1970s represented, however, a period of intense changes in that panorama thanks to the joint effort of three Latin American entomologists: the Brazilian priest Father Francisco Silvério Pereira (1913-1991) (Fig. 4A), the Argentinian Antonio Martínez (1922-1993) (Fig. 4B) and the Spanish-born Mexican Gonzalo Halffter (b. 1932) (Fig. 4C). In a series of taxonomic works (among them, we highlight: Pereira 1946, 1949, 1953; Martínez 1948a, 1948b, 1950, 1952, 1953; Martínez \& Pereira 1956; Halffter, 1958, 1961; Pereira \& Martínez 1956, 1959, 1960; Martínez et al. 1964; Vulcano \& Pereira 1964, 1966; Martínez \& Halffter 1972), culminating in the four-part major revision of the New World 'Canthonina' by Halffter \& Martínez $(1966,1967,1968,1977)$, new species were described and the genus Canthon was divided into a large number of taxa (sometimes categorized as its subgenera, sometimes as full genera). Halffter \& Martínez (1977), in the final part of their series of revisions, recognized 28 valid genera, with the genus Canthon itself divided into nine subgenera and its nominotypical subgenus into 22 groups or lineages ('lineas') of species.

Therefore, as discussed so far, the historical tendency in the taxonomy of 'Canthon sensu lato', especially in the second half of the $20^{\text {th }}$ century, has been the division of the former concept of the genus Canthon into several small, peripherical subgenera and genera, a classification that, in principle, attempts to 

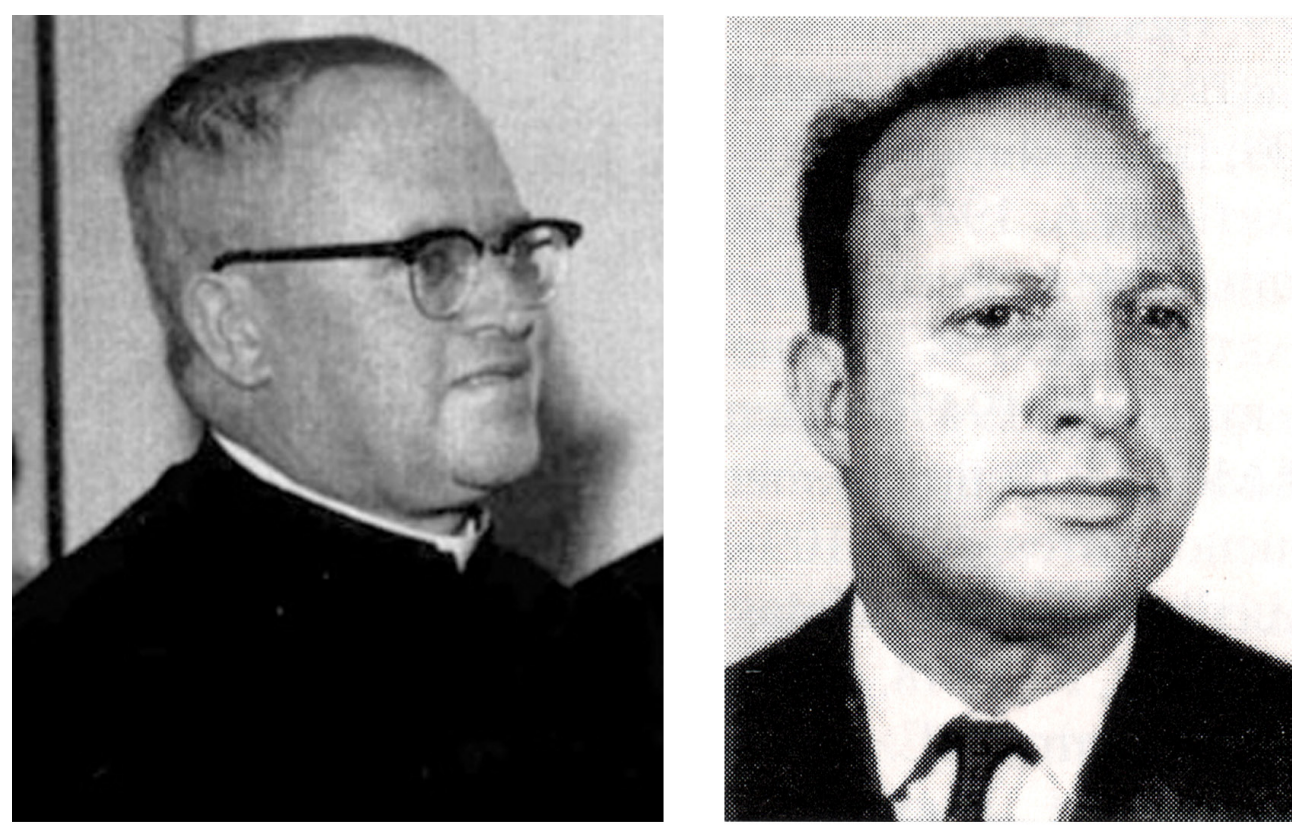

A

B

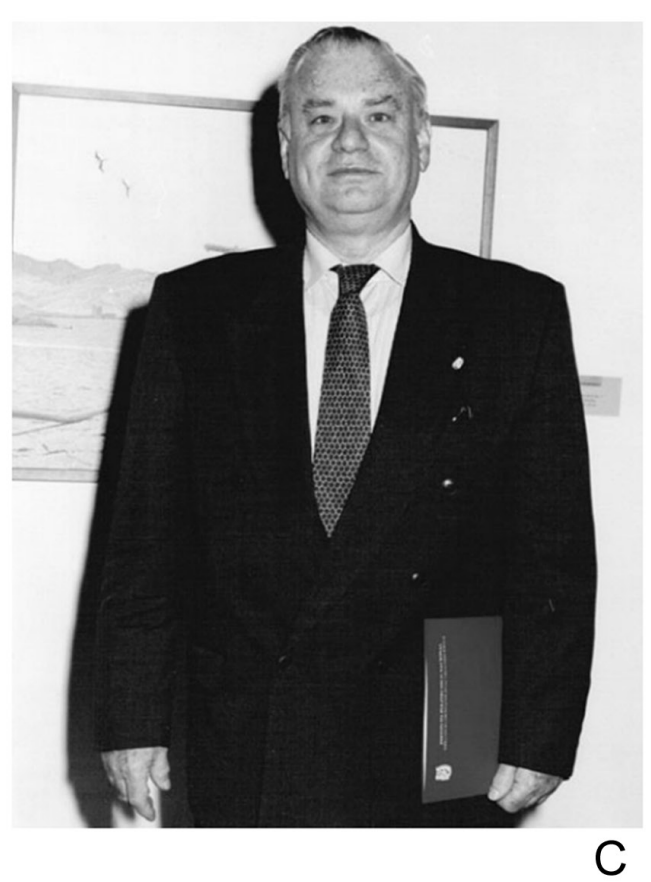

Fig. 4. The three scarab beetle specialists responsible for the intense period of taxonomic activity that 'Canthon sensu lato' passed through during the 1940s-1970s. Throughout that period and through tens of papers, the former concept of the genus Canthon Hoffmannsegg, 1817 was divided into several genera and subgenera, including Sylvicanthon Halffter \& Martínez, 1977, published in the last work of that series. A. The Brazilian cleric, Padre Francisco Silvério Pereira, CMF (1913-1991) (image courtesy of Everardo Grossi and Brett Ratcliffe). B. The Argentinian entomologist Antonio Martínez (19221993) (modified from Fritz 1994). C. The Mexican entomologist Gonzalo Halffter (b. 1932) (modified from Morrone 2015a). 
reflect the phylogeny of the group. Nevertheless, as argued by Solís \& Kohlmann $(2002,2012)$ and Medina et al. (2003), that goal, in reality, has not been fully met, something recognized even by both Martínez (1987), who considered Canthon an "omnibus genus", and Halffter (2003). As shown by Solís \& Kohlmann $(2002,2012)$ and Medina et al. (2003), several of the characteristics used to define supraspecific taxa do not have an adequate phylogenetic signal as to indicate old relationships. These features (e.g., shape of meso- and metatarsi, eyes and clypeus) have apparently been subject to strong action from directional natural and sexual selection and, hence, are in constant change, passing through convergences, parallelisms and reversions throughout the evolutionary history of the group. Having been based on such plastic characteristics, the classification proposed by Halffter \& Martínez (1977) is largely artificial ${ }^{12}$.

In an exploratory cladistic analysis of 'Canthon sensu lato' based on 39 species and 83 characters, Medina et al. (2003) found that Canthon, as defined by Halffter \& Martínez (1977), is highly artificial, with several other genera such as Sylvicanthon, Scybalocanthon Martínez, 1948, Anisocanthon Martínez \& Pereira, 1956 and Melanocanthon Halffter, 1958, nested within it. Based on those results, Solís \& Kohlmann $(2002,2012)$ proposed the rejection, at least temporarily, of a large part of the generic and subgeneric names and that their species be referred to Canthon. This latter name would then represent only a miscellany of not-particularly-closely-related species waiting for a revision that could form natural groups (i.e., monophyletic sensu Hennig, 1966) based on more robust and stable suite of characters having stronger phylogenetic information.

Although we certainly agree with the diagnosis presented by Solís \& Kohlmann (2002, 2012), we disagree on the temporary solution put forward by them. At the moment, the most urgent concern about 'Canthon sensu lato' is, in our view, the alpha taxonomy, since it is crystal clear that we still have a very limited knowledge of its species diversity. Three revealing examples are the revision of the Mexican Glaphyrocanthon by Rivera-Cervantes \& Halffter (1999), which described 10 new species and hence doubled the number of known representatives of this group in that country, the revision of Hansreia Halffter \& Martínez, 1977 by Valois et al. (2015), which added five species to a genus considered monotypic for almost 40 years, and the present work, which triples the number of species in Sylvicanthon (including the description of six new species).

If we gather again under the same name 'Canthon' the cohesive and easily identifiable groups of species (i.e., genera and subgnera) delimited during the second half of the $20^{\text {th }}$ century (such as Sylvicanthon), we would have once more an overly inflated and heterogeneous genus. Naturally, this situation would inhibit the start of any taxonomic revision with the group, as it had already occurred during the $19^{\text {th }}$ and the early $20^{\text {th }}$ centuries and, in fact, still occurs with Canthon s. str. Moreover, contrary to what was written by Solís \& Kohlmann (2002), the results obtained by Medina et al. (2003) do not tell us that the genera peripheral to Canthon (e.g., Sylvicanthon) are artificial (i.e., whether they are polyphyletic or paraphyletic). In fact, for the most part, this would be impossible to ascertain, since only a single species of each group was included in the analysis (Medina et al. (2003: 59) indeed recognized that: "[...] only a few species from the other genera were included in the analysis [...], so we cannot speculate as to whether genera such as Anisocanthon, Melanocanthon, or Sylvicanthon are natural species groups"). On the other hand, except for the genus Canthon as a whole and Glaphyrocanthon in particular, the other two groups of genus/subgenus rank that had more than one species included in the analysis, Francmonrosia Pereira \& Martínez, 1959 and Scybalocanthon, appeared monophyletic.

The major problem, thus, seems to be the delimitation of Canthon (especially Canthon s. str. and Glaphyrocanthon) and not necessarily that of its closely related taxa. Therefore, the synonymy of Sylvicanthon and other genera and subgenera with Canthon as proposed by Solís \& Kohlmann (2012) and Ratcliffe (2002) seems to be overly conservative and would only bring more uncertainty to our 
understanding of the diversity of "Canthon sensu lato". Future phylogenetic analyses based on both morphological and molecular data will lead us closer to a natural classification, but this will only be possible with a deep understanding of the species and morphological diversity of "Canthon sensu lato". For now, we should follow a bottom-up approach; i.e., from the delimitation of closely related species to the recognition of their slightly more distant phylogenetic affinities (something already suggested by Solís \& Kohlmann, 2002: 3). Hence, the formation of easily identifiable sets of species with similar morphology is of great utility and practicality, even if these groups are not monophyletic. The next step, at last, will be of unravelling the deeper and older relationships between those species. When we finally have a sound understanding of their phylogeny, it will be time to propose a new classification reflecting it, one that will leave no room for non-monophyletic groups.

Accordingly, here we follow Halffter \& Martínez (1977) and consider valid Sylvicanthon and all the other names categorized by them as genera and subgenera. Despite that, we do believe that the taxa considered by them as subgenera of Canthon will eventually turn out to be independent genera, since there is no synapomorphy nor clear diagnostic characteristic bringing them together, and there are evident affinities between some of the subgenera of Canthon with other genera of "Canthon sensu lato" (e.g., between Sylvicanthon and at least some groups of Glaphyrocanthon Martínez, 1948). See Table 1 for information on the genus-group names proposed throughout the taxonomic history of 'Canthon sensu lato'.

Genus Sylvicanthon Halffter \& Martínez, 1977

Sylvicanthon Halffter \& Martínez, 1977: 36, 45, 61-63.

Sylvicanthon - Halffter \& Edmonds 1982: 139. — Martínez 1987: 47. — Kohlmann \& Halffter 1990: 8. Hanski \& Cambefort 1991: 472. - Medina \& Lopera-Toro 2000: 301, 311. — Vaz-de-Mello 2000: 186, 195. - Escobar 2000a: 200, 210. — Medina et al. 2001: 133. — Solís \& Kohlmann 2002: 2. Halffter 2003: 31. — Medina et al. 2003: 25, 29-30, 36, 38-41, 45, 59, 62. — Durães et al. 2005: 724. - Scheffler 2005: 14. - Hamel-Leigue et al. 2006: 3. — Medina \& Pulido 2009: 56. Scholtz et al. 2009: 567. - Carvajal et al. 2011: 99, 117, 316. — Vaz-de-Mello et al. 2011a: 6, 11, 19, 26, 33, 41. - Krajcik 2012: 63 (as junior synonym of Canthon). - Solís \& Kohlmann 2012: 3 (as junior synonym of Canthon). - Boilly \& Vaz-de-Mello 2013: 107. — Medina et al. 2013: 468, 473. — Noriega et al. 2015: 101. — Feer 2015: 8. — Pacheco et al. 2016: 145. — Tarasov \&

Dimitrov 2016: 15. — Chamorro et al. 2018: 76, 98. — Espinoza \& Noriega 2018: 147, fig. 2. Silvicanthon [sic] - Noriega 2004: 39.

\section{Type species}

Canthon candezei Harold, 1869, by original designation (Halffter \& Martínez 1977: 62).

\section{Diagnosis}

The following combination of characters is found uniquely in Sylvicanthon: small- to medium-sized species usually with dark colouration (black, dark blue, dark green or purple, but also light green and coppery) and, sometimes, with metallic sheen, and general body shape oval, flat and compact; clypeus with two small, contiguous at base or only slightly separated apical teeth, never with emargination between them (group candezei, 14 species, Fig. 6B-G), or clypeus with four large teeth, but also without emargination between them (group enkerlini, a single species, Fig. 14); external margin of genae with an evident denticle adjacent to the junction with clypeus; dorsal surface of eyes large (width about one fifth of that of interocular space); pronotum with lateral edges forming a strong medial angle and without prescutellar depression; anterior region of hypomera strongly excavated and delimited posteriorly by a complete hypomeral carina (Fig. 35); external margin of anterior region of hypomera with a very small tubercle or simple, without tubercle; mesoventrite horizontal and very short (Fig. 54); mesocoxae with 
Table 1 (continued on next two pages). Genus-group names proposed for 'Canthon sensu lato'. Validity status follows Halffter \& Martínez (1977) and Vaz-de-Mello et al. (2011). Abbreviation 'sg' indicates names originally described in the genus category, but considered as subgenera of Canthon by Halffter \& Martínez (1977).

\begin{tabular}{|c|c|c|c|c|}
\hline Year & Genus & Authorship & $\begin{array}{c}\text { Current status (number of } \\
\text { valid species) }\end{array}$ & Type species \\
\hline 1817 & Canthon & Hoffmannsegg & $\begin{array}{l}\text { Valid ( } 155 \mathrm{spp} \text {. in the genus, } \\
48 \mathrm{spp} \text {. in the nominotypical } \\
\text { subgenus and } 22 \text { in incertae } \\
\text { sedis }^{3,15,16,17} \text { ) }\end{array}$ & $\begin{array}{c}\text { Scarabaeus pilularius Linnaeus, } \\
\text { 1758, by subsequent designation } \\
\text { of Paulian (1939) }\end{array}$ \\
\hline 1829 & Coprobius & Latreille & $\begin{array}{l}\text { Junior subject synonym of } \\
\text { Canthon Synonymy firstly } \\
\text { recognized by Sturm (1843) }\end{array}$ & $\begin{array}{c}\text { Scarabaeus volvens Fabricius, } \\
\text { 1792, by subsequent designation } \\
\text { of Reiche }(1841)\end{array}$ \\
\hline 1841 & Coeloscelis & Reiche & $\begin{array}{l}\text { Junior subject synonym of } \\
\text { Canthon Synonymy firstly } \\
\text { recognized by Erichson (1847) }\end{array}$ & $\begin{array}{c}\text { Coeloscelis coriaceus Reiche, } \\
\text { 1841, nomen dubium, by } \\
\text { original designation }\end{array}$ \\
\hline 1846 & Tetraechma & Blanchard & Valid (2 spp. $\left.{ }^{2}\right)$ & $\begin{array}{c}\text { Tetraechma sanguineomaculata } \\
\text { Blanchard, 1846, by original } \\
\text { monotypy }\end{array}$ \\
\hline \multirow[t]{2}{*}{1887} & Agamopus & Bates & Valid (6 spp. $\left.{ }^{3}\right)$ & $\begin{array}{c}\text { Agamopus lampros Bates, } 1887 \text {, } \\
\text { by original monotypy }\end{array}$ \\
\hline & Pseudocanthon & Bates & Valid (9 spp., $\left.{ }^{2,3}\right)$ & $\begin{array}{l}\text { Canthon perplexus LeConte, } \\
1847 \text {, by original monotypy }\end{array}$ \\
\hline 1893 & Paedohyboma & Kolbe & $\begin{array}{c}\text { Junior subjective synonym of } \\
\text { Canthon (Halffter \& Martínez, } \\
\text { 1977) }\end{array}$ & $\begin{array}{c}\text { Canthon aberrans Harold, } 1868 \\
\text { by original monotypy }\end{array}$ \\
\hline 1928 & Sinapisoma & Boucomont & Valid (1 sp. $\left.{ }^{2,4}\right)$ & $\begin{array}{l}\text { Sinapisoma minuta Boucomont, } \\
1928 \text {, by original monotypy }\end{array}$ \\
\hline 1930 & Canthonella & Chapin & Valid (18 spp..$\left.^{3,5,6}\right)$ & $\begin{array}{c}\text { Canthonella parva Chapin, } 1930 \\
\text { by original designation }\end{array}$ \\
\hline 1932 & Zonocopris & Arrow & Valid (2 spp., $\left.{ }^{3,7}\right)$ & $\begin{array}{c}\text { Zonocopris bucki Arrow, } 1932 \\
\text { by original monotypy }\end{array}$ \\
\hline 1933 & Plesiocanthon & Gillet & $\begin{array}{c}\text { Junior subjective synonym of } \\
\text { Zonocopris (Pereira, 1946) }\end{array}$ & $\begin{array}{c}\text { Canthon gibbicollis Harold, } 1868, \\
\text { by original monotypy }\end{array}$ \\
\hline 1934 & Canthochilum & Chapin & Valid (23 spp. $\left.{ }^{3,8}\right)$ & $\begin{array}{l}\text { Canthochilum oakleyi Chapin, } \\
1934 \text {, by original designation }\end{array}$ \\
\hline 1935 & Ipselissus & d'Olsoufieff & $\begin{array}{c}\text { Junior subjective synonym } \\
\text { of Canthochilum (Halffter } \\
\& \text { Martínez, 1977). Senior } \\
\text { objective synonym of } \\
\text { Ipsepilissus }\end{array}$ & $\begin{array}{l}\text { Epilissus silphoides Harold, 1867, } \\
\text { by original monotypy }\end{array}$ \\
\hline 1938 & Paracanthon & Balthasar & Valid (4 spp..$\left.^{2,3}\right)$ & $\begin{array}{c}\text { Paracanthon trichonotulus } \\
\text { Balthasar, 1938, by original } \\
\text { monotypy }\end{array}$ \\
\hline \multirow[t]{3}{*}{$1939^{1}$} & Canthonidia & Paulian & Valid (2 spp. $\left.{ }^{2,3}\right)$ & $\begin{array}{l}\text { Canthonidia hirsuta Paulian, } \\
\text { 1939, by original designation }\end{array}$ \\
\hline & Canthotrypes & Paulian & Valid (1 sp. $\left.{ }^{3,4}\right)$ & $\begin{array}{l}\text { Canthotrypes oberthuri Paulian, } \\
1939 \text {, by original designation }\end{array}$ \\
\hline & Ipsepilissus & Paulian & $\begin{array}{c}\text { Junior objetive synonym of } \\
\text { Ipselissus }\end{array}$ & $\begin{array}{c}\text { Epilissus silphoides Harold, 1867, } \\
\text { by original designation }\end{array}$ \\
\hline
\end{tabular}


Table 1 (continued).

\begin{tabular}{|c|c|c|c|c|}
\hline Year & Genus & Authorship & $\begin{array}{c}\text { Current status (number of } \\
\text { valid species) }\end{array}$ & Type species \\
\hline & Paracanthon & Paulian & $\begin{array}{c}\text { Junior subjetive synonym } \\
\text { (Balthasar, 1942) and junior } \\
\text { homonym of Paracanthon } \\
\text { Balthasar }\end{array}$ & $\begin{array}{c}\text { Paracanthon hirsutus Paulian, } \\
\text { 1939, by original designation }\end{array}$ \\
\hline 1942 & Cryptocanthon & Balthasar & Valid (38 spp. ${ }^{3,9,10}$ ) & $\begin{array}{c}\text { Cryptocanthon paradoxos } \\
\text { Balthasar, 1942, by original } \\
\text { designation }\end{array}$ \\
\hline 1947 & Opiocanthon & Paulian & $\begin{array}{c}\text { Junior subjective synonym of } \\
\text { Pseudocanthon (Matthews, } \\
\text { 1966) }\end{array}$ & $\begin{array}{l}\text { Canthon vitraci Fleutiaux } \\
\& \text { Sallé, } 1889 \text {, by original } \\
\text { designation }\end{array}$ \\
\hline \multirow[t]{2}{*}{1948} & Glaphyrocanthon & Martínez & Valid $^{\text {sg }}$ (50 spp. $\left.{ }^{3}\right)$ & $\begin{array}{c}\text { Glaphyrocanthon variabilis } \\
\text { Martínez, 1948, by original } \\
\text { designation }\end{array}$ \\
\hline & Scybalocanthon & Martínez & Valid (19 spp. ${ }^{14}$ ) & $\begin{array}{c}\text { Canthon moniliatus Bates, } 1887, \\
\text { by original designation }\end{array}$ \\
\hline 1949 & Deltepilissus & Pereira & Valid (2 spp. ${ }^{2,3}$ ) & $\begin{array}{l}\text { Deltepilissus travassosi Pereira, } \\
\text { 1949, by original designation }\end{array}$ \\
\hline 1950 & Coprocanthon & Martínez & $\begin{array}{c}\text { Junior subjetive synonym of } \\
\text { Glaphyrocanthon (Halffter \& } \\
\text { Martínez, 1977) }\end{array}$ & $\begin{array}{c}\text { Glaphyrocanthon rufocoeruleus } \\
\text { Martínez, 1948, by original } \\
\text { designation }\end{array}$ \\
\hline 1952 & Xenocanthon & Martínez & Valid (1 sp. $\left.{ }^{2,3}\right)$ & $\begin{array}{l}\text { Xenocanthon vianai Martínez, } \\
\text { 1952, by original designation }\end{array}$ \\
\hline \multirow[t]{2}{*}{1953} & Peltecanthon & Pereira & Valid $^{\text {sg }}\left(3\right.$ spp. $\left.^{2,3,16}\right)$ & $\begin{array}{c}\text { Peltecanthon staigi Pereira, } 1953, \\
\text { by original designation }\end{array}$ \\
\hline & Scybalophagus & Martínez & Valid (5 spp. $\left.{ }^{3,11}\right)$ & $\begin{array}{c}\text { Scybalophagus patagonichus } \\
\text { Martínez, 1953, by original } \\
\text { designation }\end{array}$ \\
\hline 1954 & Pseudepilissus & Martínez & Valid $^{\mathrm{sg}}\left(5 \mathrm{spp} .^{2,3}\right)$ & $\begin{array}{c}\text { Canthon lunatus Schmidt, } 1922, \\
\text { by original designation }\end{array}$ \\
\hline \multirow[t]{5}{*}{1956} & Anisocanthon & $\begin{array}{l}\text { Martínez \& } \\
\text { Pereira }\end{array}$ & Valid (4 spp. ${ }^{2,3}$ ) & $\begin{array}{l}\text { Deltochilum pygmaeum Gillet, } \\
\text { 1911, by original designation }\end{array}$ \\
\hline & Holocanthon & $\begin{array}{l}\text { Martínez \& } \\
\text { Pereira }\end{array}$ & Valid (1 sp. $\left.{ }^{2,3}\right)$ & $\begin{array}{l}\text { Holocanthon mateui Martínez } \\
\text { \& Pereira, 1956, by original } \\
\text { designation }\end{array}$ \\
\hline & Nesocanthon & $\begin{array}{l}\text { Pereira \& } \\
\text { Martínez }\end{array}$ & Valid $^{\mathrm{sg}}\left(3\right.$ spp. $\left.^{2,3}\right)$ & $\begin{array}{c}\text { Canthon callosus Harold, } 1868, \\
\text { by original designation }\end{array}$ \\
\hline & Goniocanthon & $\begin{array}{l}\text { Pereira \& } \\
\text { Martínez }\end{array}$ & Valid ${ }^{\mathrm{sg}}\left(3 \mathrm{spp} .{ }^{15}\right)$ & $\begin{array}{c}\text { Scarabaeus smaragdulus } \\
\text { Fabricius, 1781, by original } \\
\text { designation }\end{array}$ \\
\hline & Geocanthon & $\begin{array}{l}\text { Pereira \& } \\
\text { Martínez }\end{array}$ & $\begin{array}{c}\text { Junior subjective synonym of } \\
\text { Glaphyrocanthon (Halffter \& } \\
\text { Martínez, 1977) }\end{array}$ & $\begin{array}{l}\text { Canthon rubrescens Blanchard, } \\
1846, \text { by original designation }\end{array}$ \\
\hline \multirow[t]{2}{*}{1958} & Boreocanthon & Halffter & Valid $^{\mathrm{sg}}\left(15\right.$ spp. $\left.^{2,3}\right)$ & $\begin{array}{c}\text { Ateuchus ebenus Say, } 1823 \text {, by } \\
\text { original designation }\end{array}$ \\
\hline & Melanocanthon & Halffter & Valid (4 spp. ${ }^{2,3}$ ) & $\begin{array}{l}\text { Canthon bisp.inatus Robinson, } \\
\text { 1941, by original designation }\end{array}$ \\
\hline
\end{tabular}


Table 1 (continued).

\begin{tabular}{|c|c|c|c|c|}
\hline Year & Genus & Authorship & $\begin{array}{l}\text { Current status (number of } \\
\text { valid species) }\end{array}$ & Type species \\
\hline \multirow[t]{3}{*}{1959} & Canthomoechus & $\begin{array}{l}\text { Pereira \& } \\
\text { Martínez }\end{array}$ & $\begin{array}{c}\text { Junior subjective synonym of } \\
\text { Canthon (Halffter \& Martínez, } \\
\text { 1977) }\end{array}$ & $\begin{array}{l}\text { Canthon quadratus Blanchard, } \\
1846 \text {, by original designation }\end{array}$ \\
\hline & Trichocanthon & $\begin{array}{l}\text { Pereira \& } \\
\text { Martínez }\end{array}$ & Valid sg $\left(1 \mathrm{sp}^{2,3}\right)$ & $\begin{array}{c}\text { Canthon sordidus Harold, } 1868, \\
\text { by original designation }\end{array}$ \\
\hline & Francmonrosia & $\begin{array}{l}\text { Pereira \& } \\
\text { Martínez }\end{array}$ & Valid $^{\text {sg }}$ (6 spp..$\left.^{2,3,16,17}\right)$ & $\begin{array}{l}\text { Canthon rutilans Castelnau, } \\
1840 \text {, by original designation }\end{array}$ \\
\hline 1960 & Vulcanocanthon & $\begin{array}{l}\text { Pereira \& } \\
\text { Martínez }\end{array}$ & Valid (1 sp. $\left.{ }^{2,3}\right)$ & $\begin{array}{l}\text { Canthon seminulum Harold, } \\
1867 \text {, by original designation }\end{array}$ \\
\hline 1964 & Pseudoepirinus & Ferreira & $\begin{array}{c}\text { Junior subjetive synonym of } \\
\text { Scybalophagus (Scholtz \& } \\
\text { Howden, 1987) }\end{array}$ & $\begin{array}{l}\text { Epirinus zumpti Frey, 1963, by } \\
\text { original monotypy }\end{array}$ \\
\hline \multirow[t]{2}{*}{1966} & Antillacanthon & Vulcano \& Pereira & $\begin{array}{l}\text { Junior subjective synonym } \\
\text { of Canthochilum } \\
\text { (Matthews, 1969) }\end{array}$ & $\begin{array}{l}\text { Canthon histeroides Harold, } \\
1868, \text { by original designation }\end{array}$ \\
\hline & Chapincanthon & Vulcano \& Pereira & $\begin{array}{l}\text { Junior subjective synonym } \\
\text { of Canthochilum } \\
\text { (Matthews, 1969) }\end{array}$ & $\begin{array}{l}\text { Canthochilum hisp.idum Chapin, } \\
\text { 1935, by original designation }\end{array}$ \\
\hline \multirow[t]{2}{*}{1977} & Hansreia & $\begin{array}{l}\text { Halffter \& } \\
\text { Martínez }\end{array}$ & Valid (6 spp. ${ }^{12}$ ) & $\begin{array}{l}\text { Canthon affinis Fabricius, } 1801, \\
\text { by original designation }\end{array}$ \\
\hline & Sylvicanthon & $\begin{array}{l}\text { Halffter \& } \\
\text { Martínez }\end{array}$ & Valid (15 spp. ${ }^{17}$ ) & $\begin{array}{c}\text { Canthon candezei Harold, } 1868, \\
\text { by original designation }\end{array}$ \\
\hline 2002 & Paracryptocanthon & Howden \& Cook & Valid (2 sp. $\left.{ }^{3,13}\right)$ & $\begin{array}{c}\text { Cryptocanthon borgmeieri } \\
\text { Vulcano et al, 1976, by original } \\
\text { designation }\end{array}$ \\
\hline \multicolumn{5}{|c|}{ 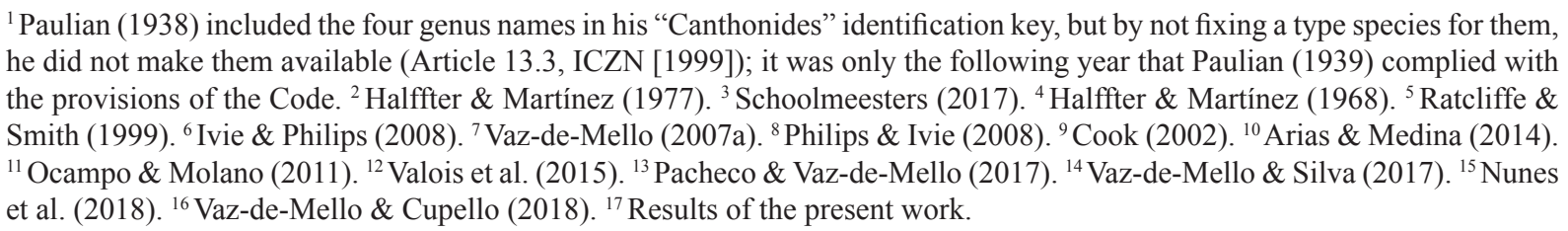 } \\
\hline
\end{tabular}

very broad external margin (Figs 21-22); tarsal claws with a very rudimentary basal angle (Fig. 10); protibiae with two or three teeth and with internal margin expanded or straight (Figs 33-42); second metatarsomere equal to or longer than basal tarsomere; metafemur margined anteriorly on its ventral face (posterior margin present or not) (Figs 46-53, 114-115); elytra without scutellar depression and with very narrow, usually ill-delimited striae of variable number; pygidium and propygidium separated by a very fine, medially angulate carina.

\section{Etymology}

Masculine, from the Latin word 'silva', meaning forest (Brown 1956), and the Greek 'canthon', an insect name (Harold 1869b; Pereira \& Martínez 1959). Although this was not explicitly stated by them, it is likely that Halffter \& Martínez (1977) chose this name inspired by the fact that species of Sylvicanthon are typical inhabitants of New World tropical rainforests. 


\section{Redescription}

HEAD. Clypeus with two tiny apical, obtuse or slightly acute teeth without emargination between them (Fig. 6B-G; group candezei) or with four large, acute teeth also without emargination between them (Fig. 6A; group enkerlini); a single row of setae covering teeth's base (except in S. securus, which has an individual row of setae for each tooth); apical margin of clypeus clearly or only slightly bent upwards. Genae with strong or rudimentary tooth after junction with clypeus (Fig. 6). Clypeo-genal suture complete, fine and well impressed; fronto-clypeal suture indistinct in the middle and present only on the sides. Dorsal portion of eyes large - interocular distance four times the largest width of eyes - and without internal margin. Posterior edge of head with or without a margin between the eyes. Tegument of dorsal region of head varying from smooth or with evident micropunctation to strong three-dimensional alveolar microsculpture obliterating micropunctation. Maxilary and labial palps with three palpomeres.
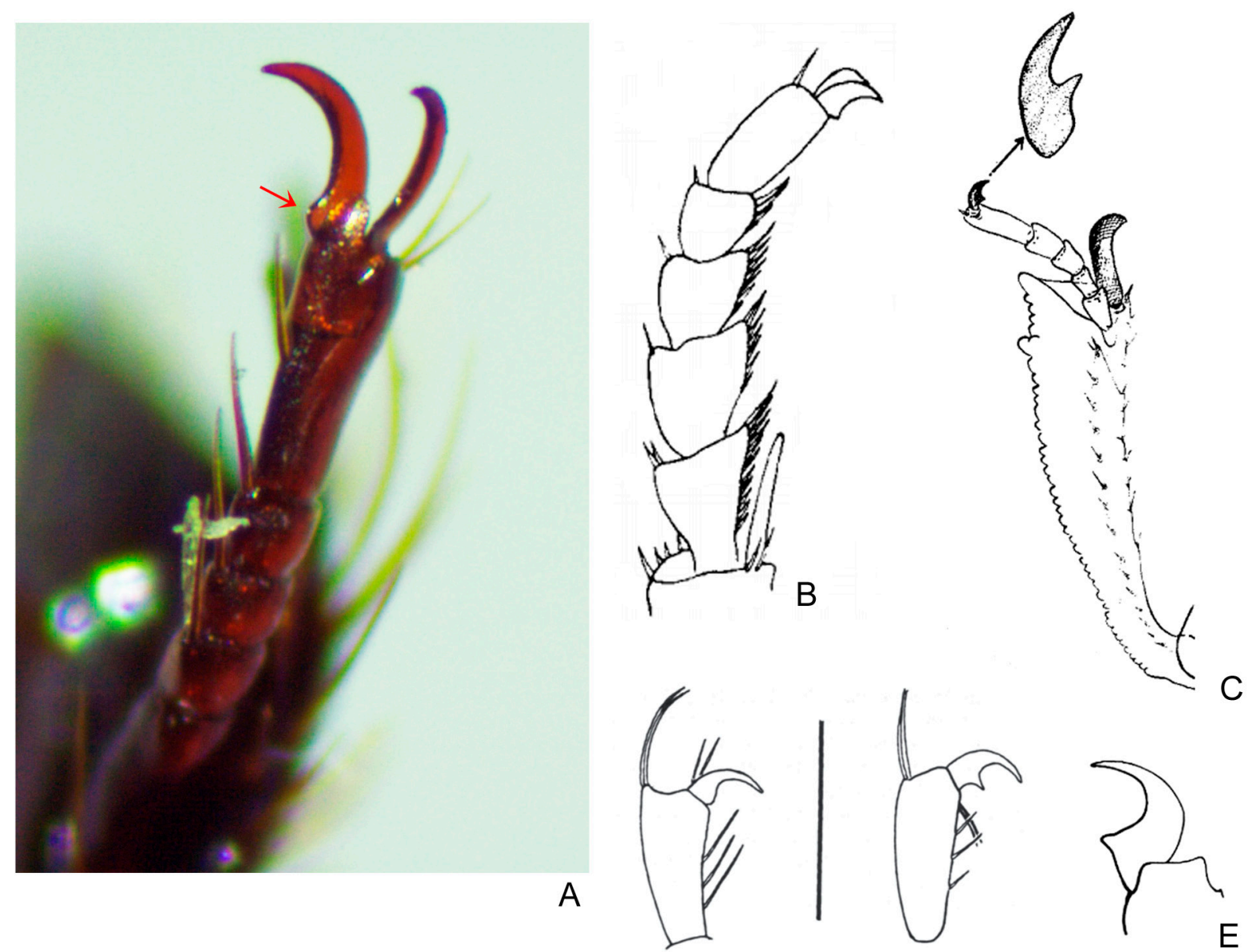

Fig. 5. Subdentate tarsal claws in different groups of dung beetles. The presence of this form of tarsal claw was seen as evidence for a close phylogenetic relationship between several groups of Scarabaeinae distributed over the continents of former Gondwana. A. Protarsal claws of Sylvicanthon proseni (Martínez, 1949) stat. et comb. nov. Red arrow indicates the basal agularity of the claw. B. Pseudocanthon vitraci (Fleutiaux \& Sallé, 1889) (modified from Matthews 1966). C. Canthonella parva (Chapin, 1930) (modified from Halffter \& Martínez 1967). D. Lepanus penelopae Matthews \& Weir, 2002 (left) and L. loftyensis Matthews \& Weir, 2002 (right) (modified from Matthews \& Weir 2002). E. Oficanthon mirabilis Paulian, 1985 (modified from Paulian 1985). 

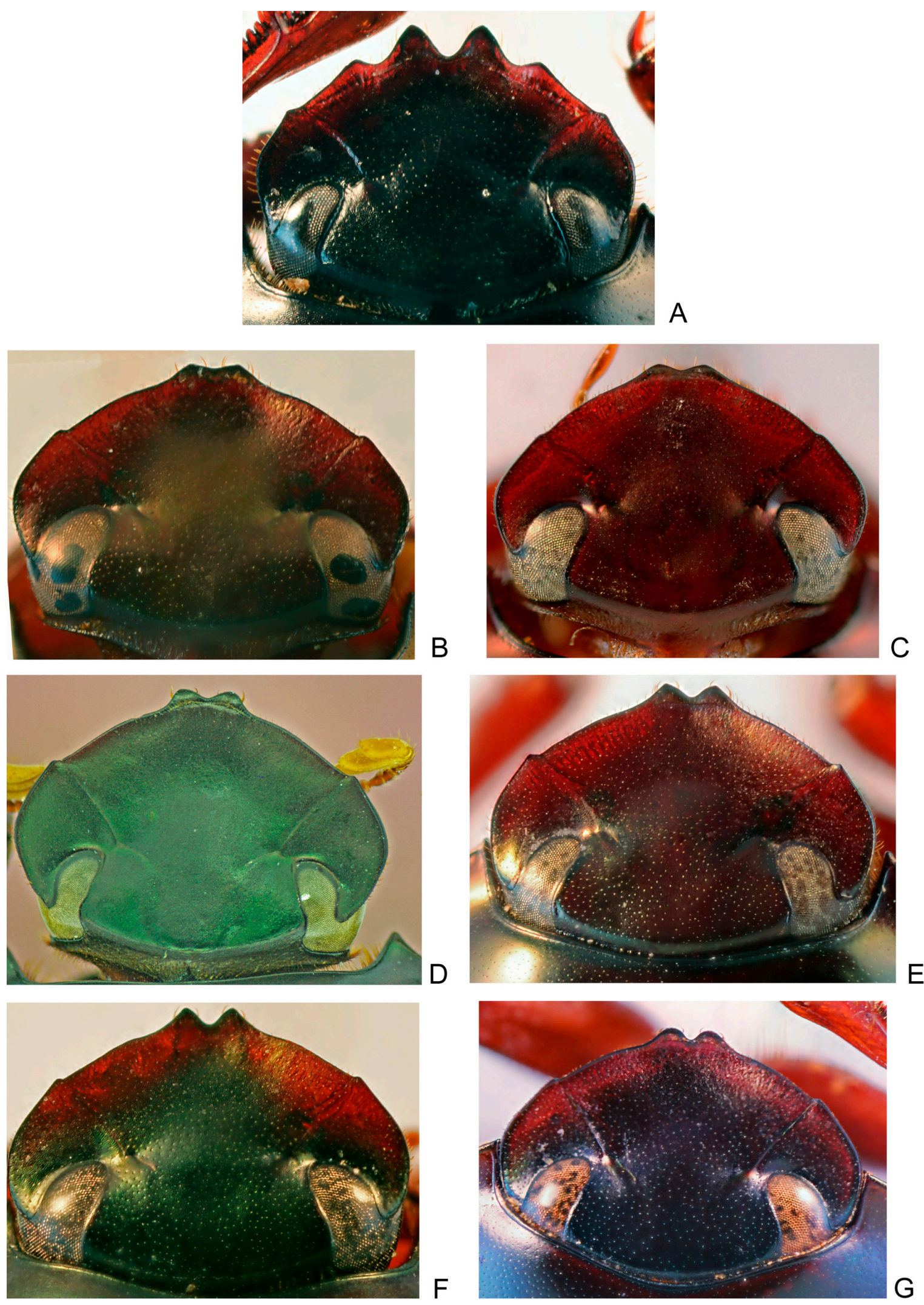

Fig. 6. Head, dorsal view. A. Sylvicanthon enkerlini (Martínez et al., 1964) comb. nov. B. S. candezei (Harold, 1869). C. S. genieri sp. nov. D. S. proseni (Martínez, 1949) stat. et comb. nov. E. S. seag sp. nov. F. S. securus (Schmidt, 1920) comb. nov. G. S. furvus (Schmidt, 1920). 

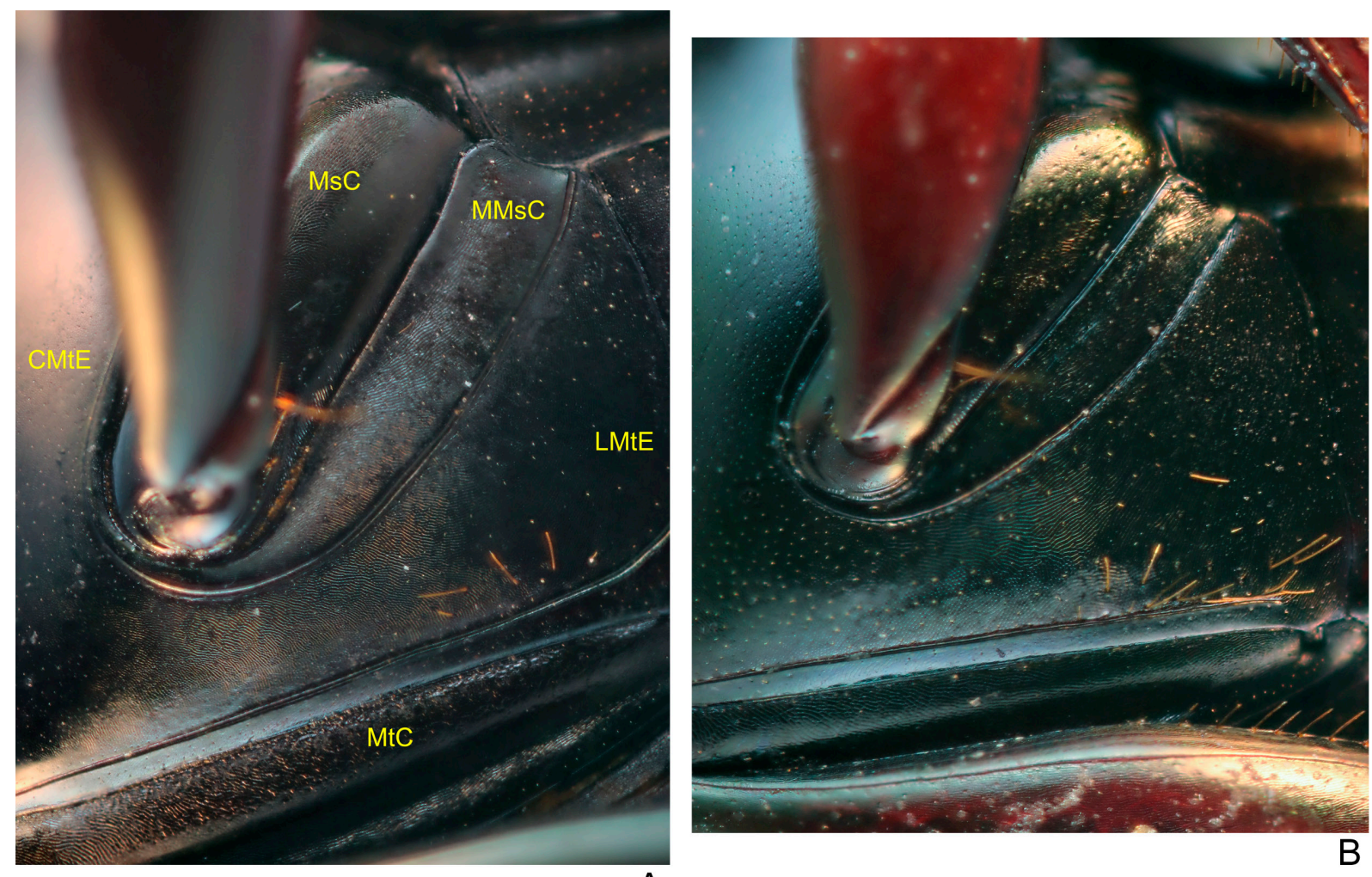

A

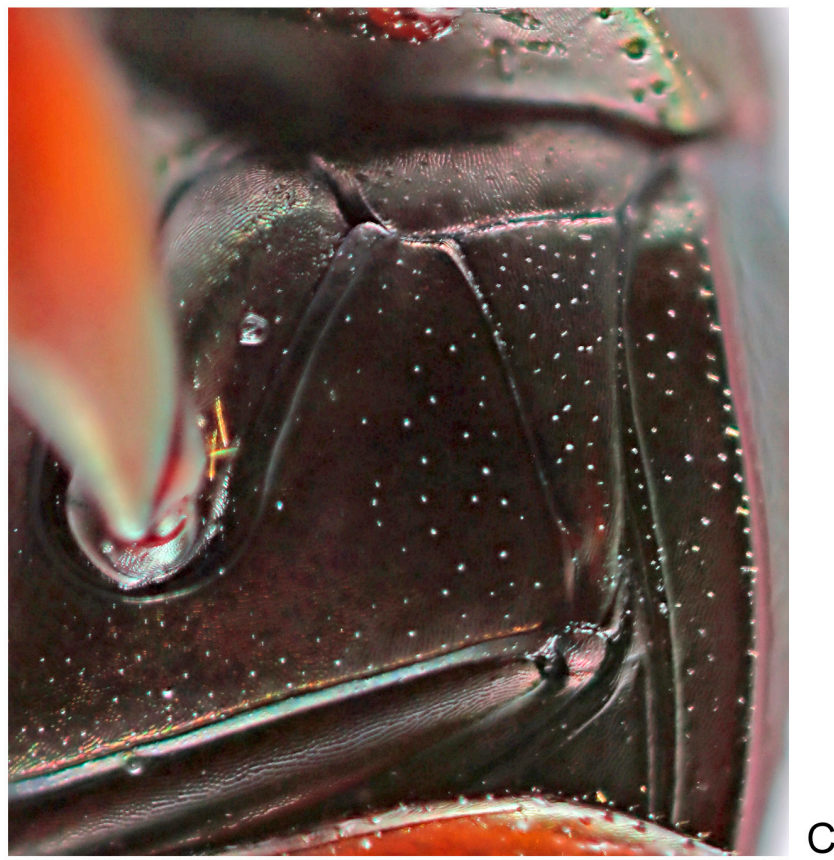

Fig. 7. Pterothorax, ventrolateral views. A. Sylvicanthon aequinoctialis (Harold, 1868) comb. nov. B. S. obscurus (Schmidt, 1920). C. Canthon xanthopus Blanchard, 1846. Abbreviations: $\mathrm{MsC}=$ mesocoxa; $\mathrm{MMsC}=$ external margin of mesocoxa; $\mathrm{CMtE}=$ centre of metaventrite; $\mathrm{LMtE}=$ lateral region of metaventrite; $\mathrm{MtC}=$ metacoxa. 

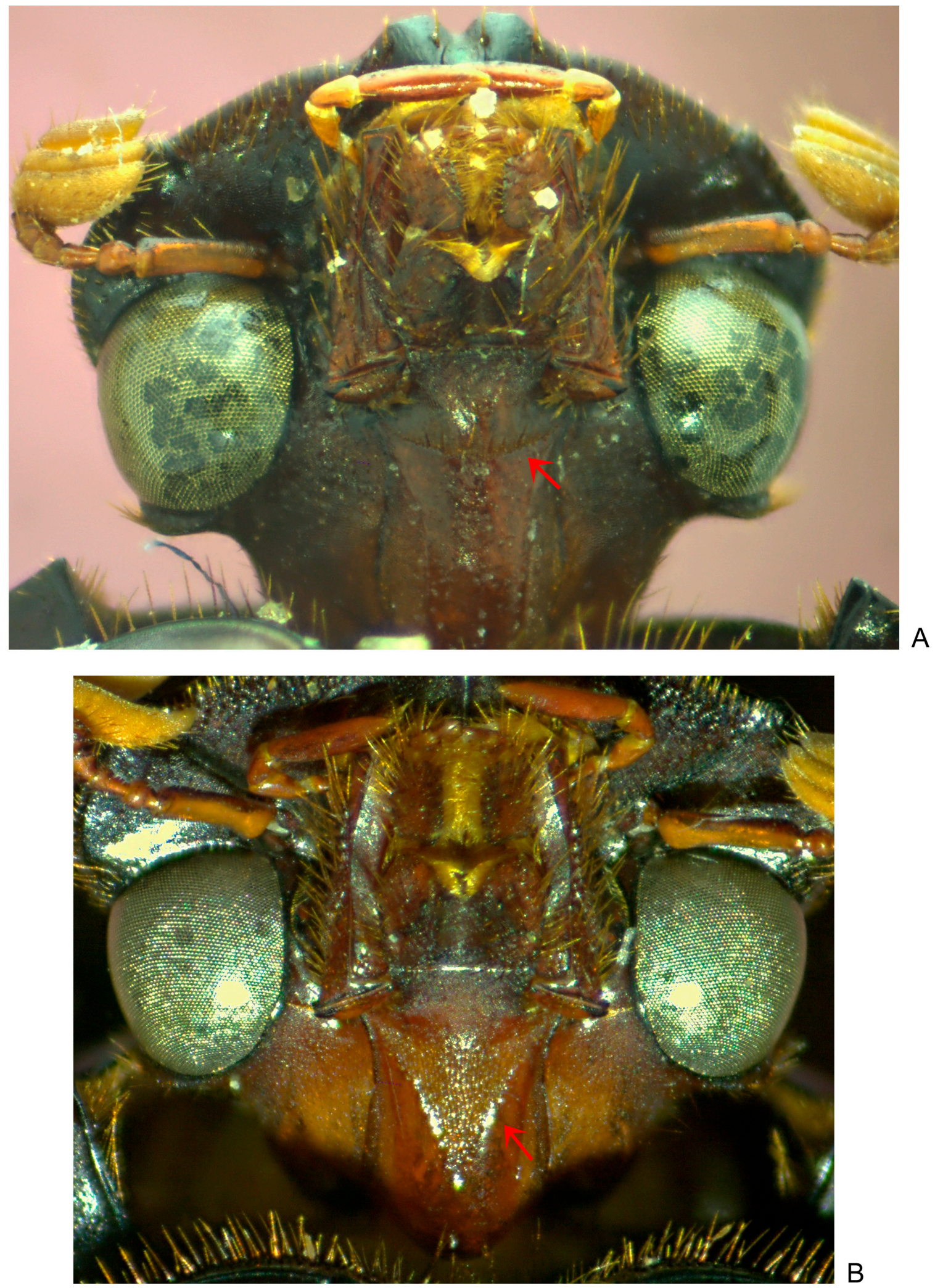

Fig. 8. Head, ventral view. A. Sylvicanthon bridarollii (Martínez, 1949). B. S. proseni (Martínez, 1949) stat. et comb. nov. See the differences in the shape of the suture between submentum and gula in these two species (red arrows), which is rounded in S. bridarollii and most of the other species of Sylvicanthon, while it has a ' $\mathrm{Y}$ '-shape in the two representants of the aequinoctialis subgroup. 
Labium distinctly ' $U$ '-emarginate on its anterior edge (Fig. 8). Suture between mentum and submentum rounded (Fig. 8b) or in a deep ' $Y$ ' shape (Fig. 8a).

Thorax. Pronotum margined only anteriorly and laterally, with lateral edges strongly angulated in the middle; posterior edge unmargined and, in most of the species, with a fine transverse line at the centre (usually, extending up to second elytral stria); tegument ranging from smooth, bright and with strong micropunctation to with strong three-dimensional alveolar microsculpture, diffuse shinning and obliterate micropunctation; lateral fossae and prescutellar depression absent. Hypomera divised into two parts by a complete transversal hypomeral carina; anterior part strongly excavated and delimited posteriorly by a low vertical wall; tegument with strong rivose microsculpture, glabrous at centre (Fig. 35A-B) or covered by long and dense erect yellow setae (Fig. 35C-D); external edge, in general, with a tiny tubercle or, sometimes, simple, without tubercle; posterior part with tegument strongly microsculptured; entirely glabrous (group candezei) or with a few long, individual setae aligned longitudinally close to external edge (Fig. 9D; group enkerlini). Mesepimeron, metepisternum and prosternum glabrous and with microsculptured tegument. Mesoventrite very short and horizontal (Fig. 14A); in the middle, with a triangular projection towards body's anterior region which has a very shallow fovea in its centre (in
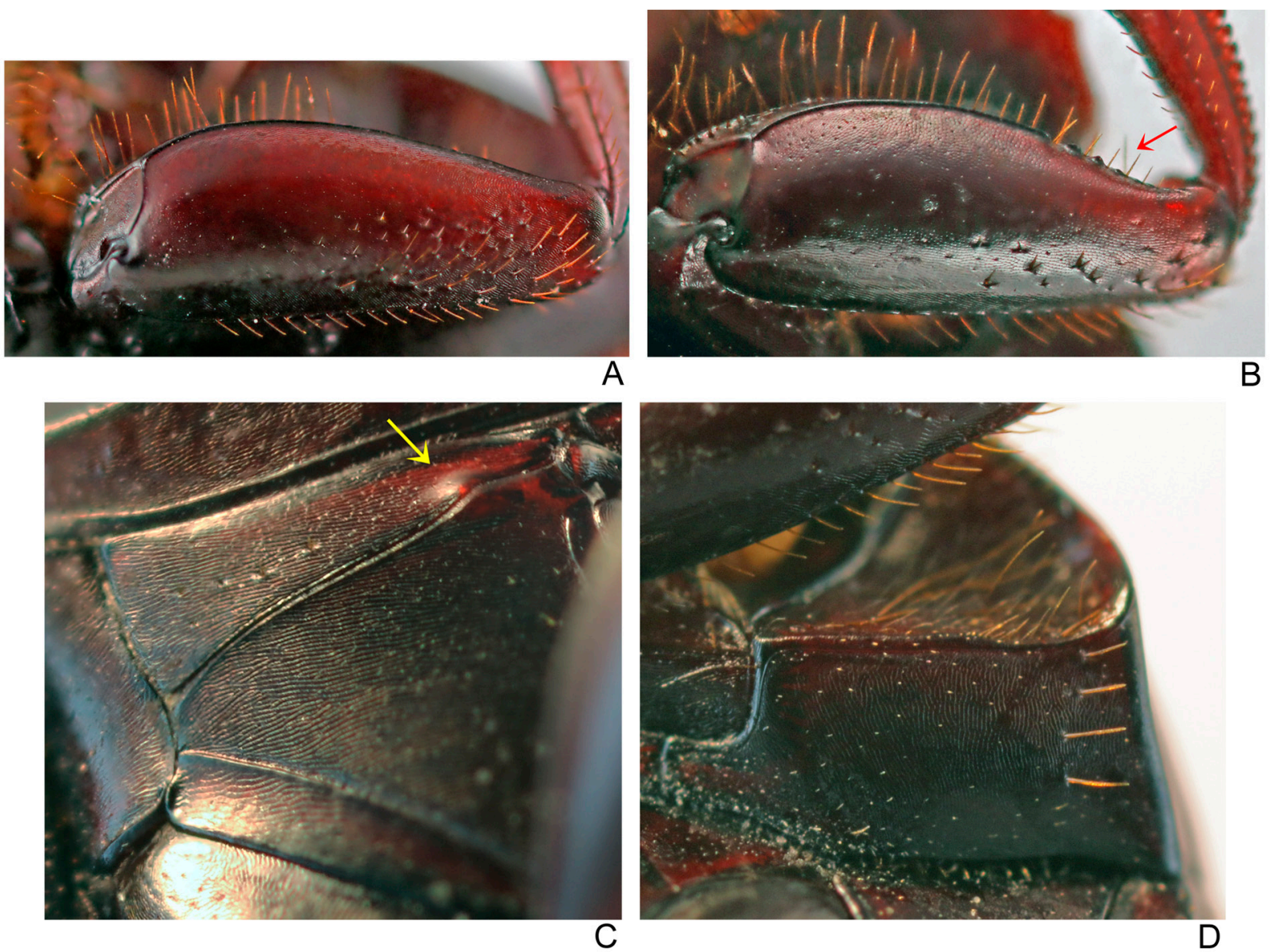

Fig. 9. A. Sylvicanthon bridarollii (Martínez, 1949), profemur. Note that, as occurs in the other species of the candezei group, there is no denticulation on the anterior edge, which is, by contrast, completely smooth. B. S. enkerlini (Martínez et al., 1964) comb. nov., profemur. Arrow indicates the denticulation of anterior edge, a condition present in both sexes and unique in the genus. C. S. enkerlini, metepisternum. Arrow indicates the small tubercle at the suture between metepisternum and the lateral region of metaventrite. D. S. enkerlini, hypomeron. Notice the row of long setae present on the lateral of posterior region, a condition seen uniquely in this species in Sylvicanthon. 

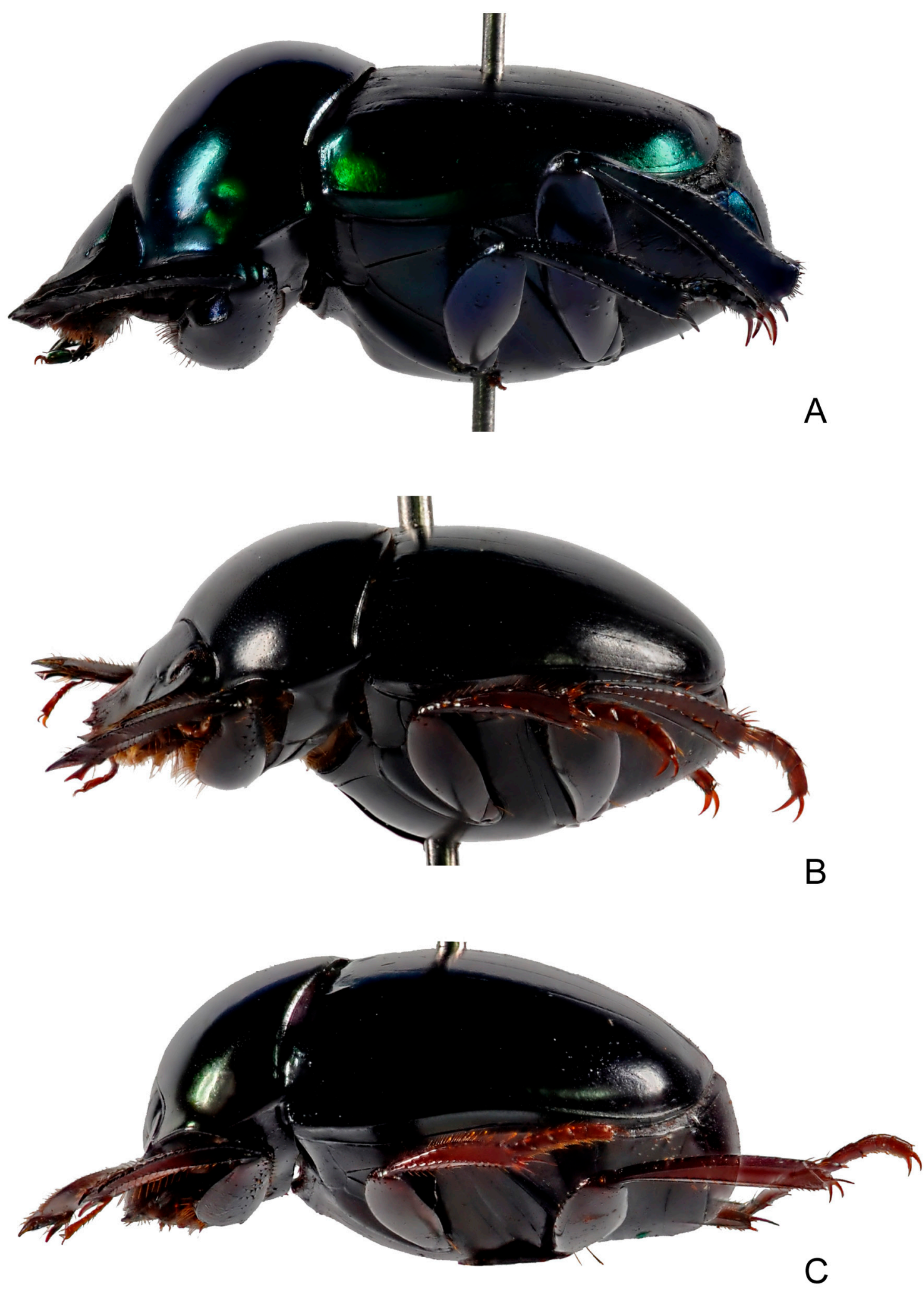

Fig. 10. Lateral view. A. Canthon (Francmonrosia) sp. B. Sylvicanthon enkerlini (Martínez et al., 1964) comb. nov. C. S. candezei (Harold, 1869). 
general, projection covered by prosternum in pinned specimens); tegument with micropunctation and with a transverse row of very short setae. Meso-metaventrite margin very fine and straight. Metaventrite very wide between mesocoxae and slightly convex; tegument with strong rivose microsculpture on the sides and on anterior region between mesocoxae; at centre, tegument ranging from microsculpture absent to well-marked micropunctation to strong three-dimensional alveolar microsculpture with discrete micropunctation.

Legs. Tarsal claws of all legs slightly angulate at base (more clearly so in protarsi, Fig. 5A). Profemora with tegument always covered by microsculpture (rivose or alveolar); anterior margin, at apex of

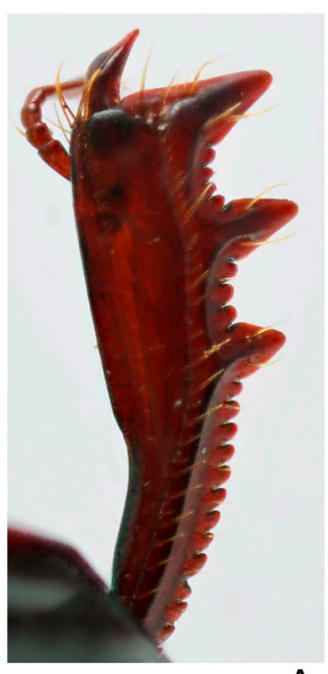

A

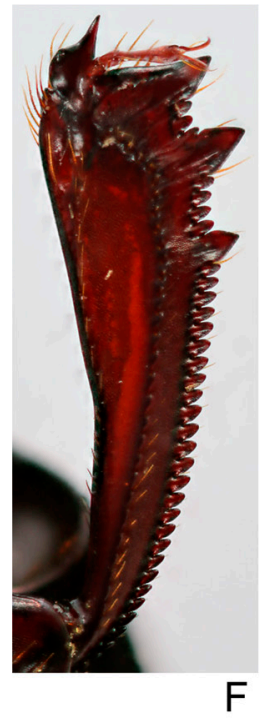

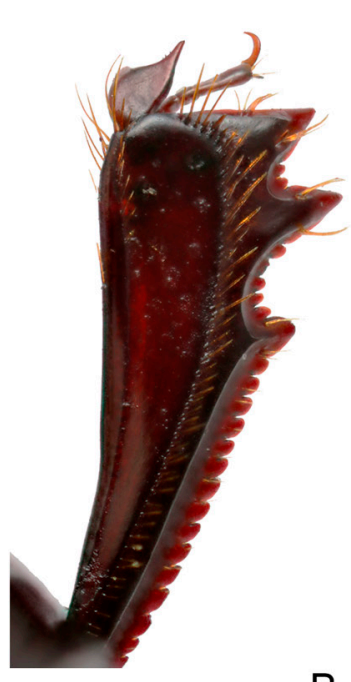

B

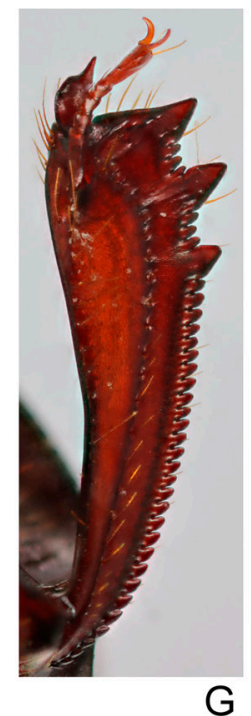

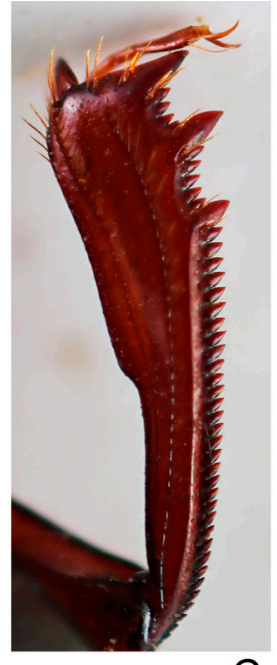

C

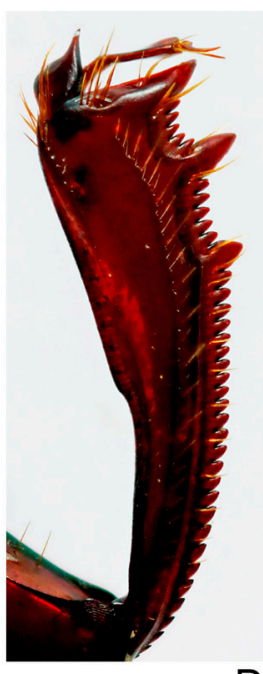

$\mathrm{D}$

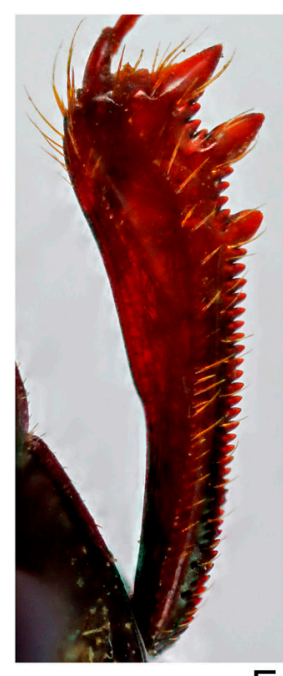

$E$
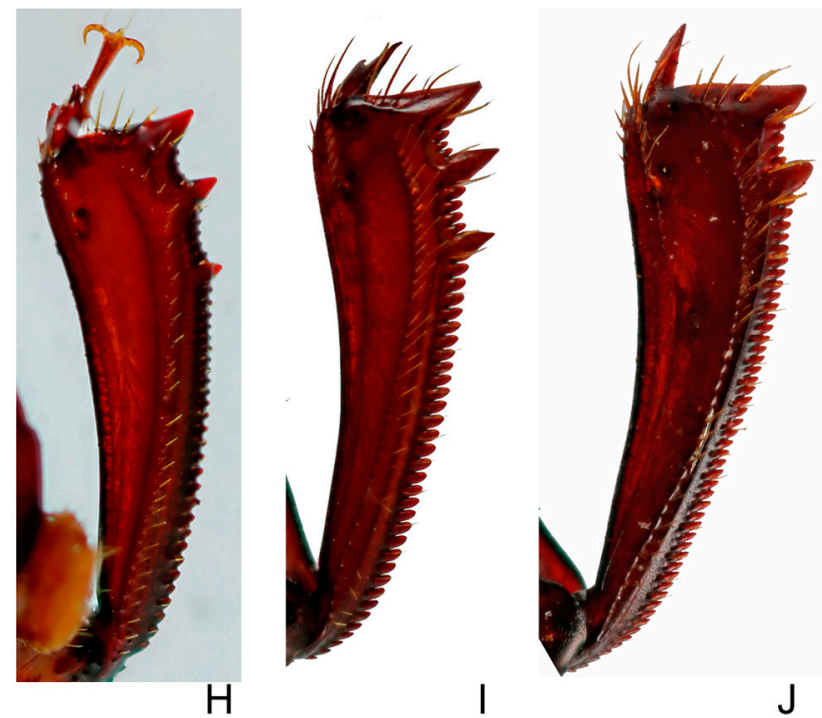

$J$

Fig. 11. Morphological diversity in the protibiae of Sylvicanthon Halffter \& Martínez, 1977. A. S. enkerlini (Martínez et al., 1964) comb. nov. B. S. aequinoctialis (Harold, 1869) comb. nov. C. S. securus (Schmidt, 1920) comb. nov. D. S. obscurus (Schmidt, 1920). E. S. furvus (Schmidt, 1920). F. S. bridarollii (Martínez, 1949) (southern populations). G. S. bridarollii (northern populations). H. S. attenboroughi sp. nov. I. S. edmondsi sp. nov. J. S. candezei (Harold, 1869). Note the variation related to the presence and degree of development of an expansion on the internal edge of protibiae and to the number, size and position of the external teeth. 
profemora, smooth (Fig. 9A; group candezei) or with a row of denticules in both sexes (Fig. 9B; group enkerlini). Protibiae truncate at apex, narrow or wide, and with internal margin straight or strongly expanded at its apical half; with two or three teeth on external margin varying in size from large, wide, and well separated from one another to small, narrow, and restricted to apical third of protibiae; external edge of protibiae covered by smaller denticules, including area between larger teeth (Fig. 11). Dorsal face of protibiae with four longitudinal lines: the most external one very fine, entirely glabrous and, in general, indistinct at the apical expansion; the second most internal one covered by a row of short setae only at its apex; the third one covered by longer setae from its base to apex; the fourth line (the most external one) strongly carinate, entirely glabrous and interrupted at the basal lateral teeth. Ventral surface of protibiae with two longitudinal lines, one parallel to the internal edge and the other at the middle, both interrupted by setae; the latter line keeled at its basal half. Protarsi with five tarsomeres; basal and apical tarsomeres at least as long as tarsomeres II-IV combined. Mesocoxal cavities with wide external margin (Fig. 7A-B) and narrow internal margin. Meso- and metatrochanters with a fine tuft of long yellowish setae turned back at their posterior edges. Meso- and metafemora very flattened. Mesofemora margined
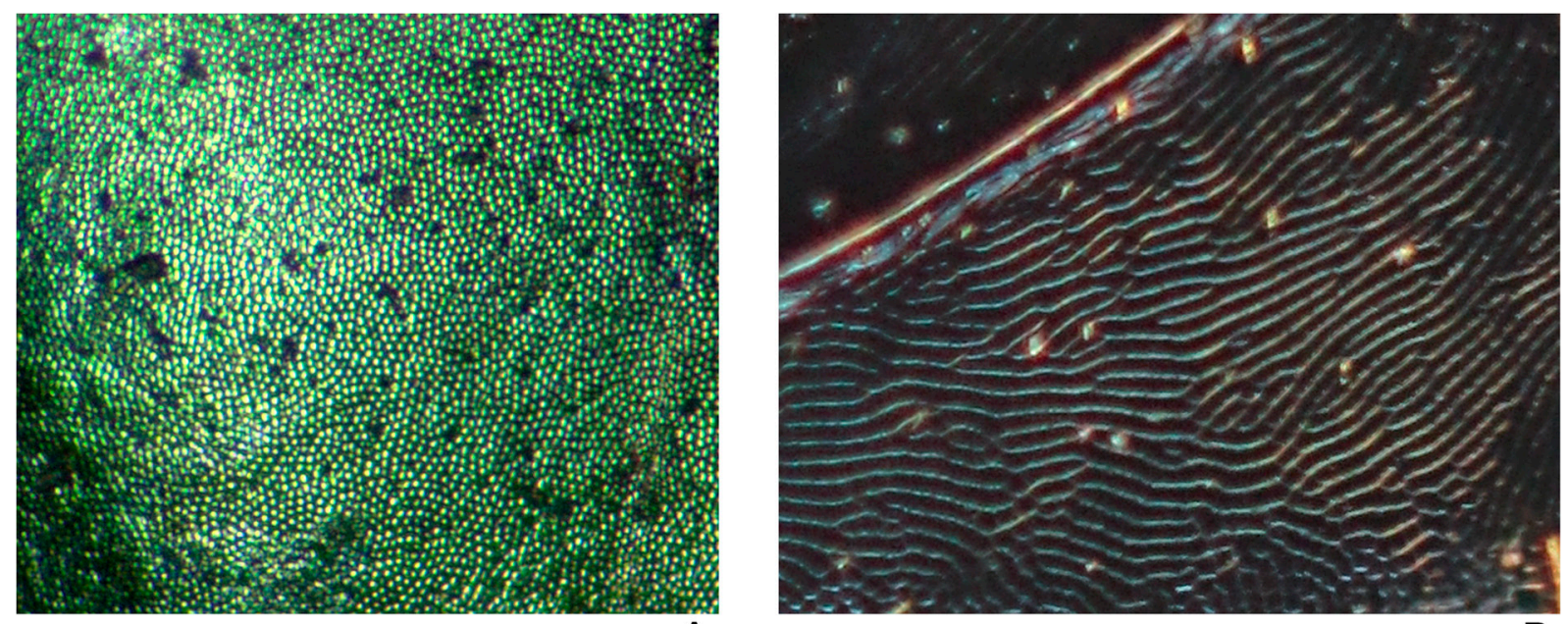

A

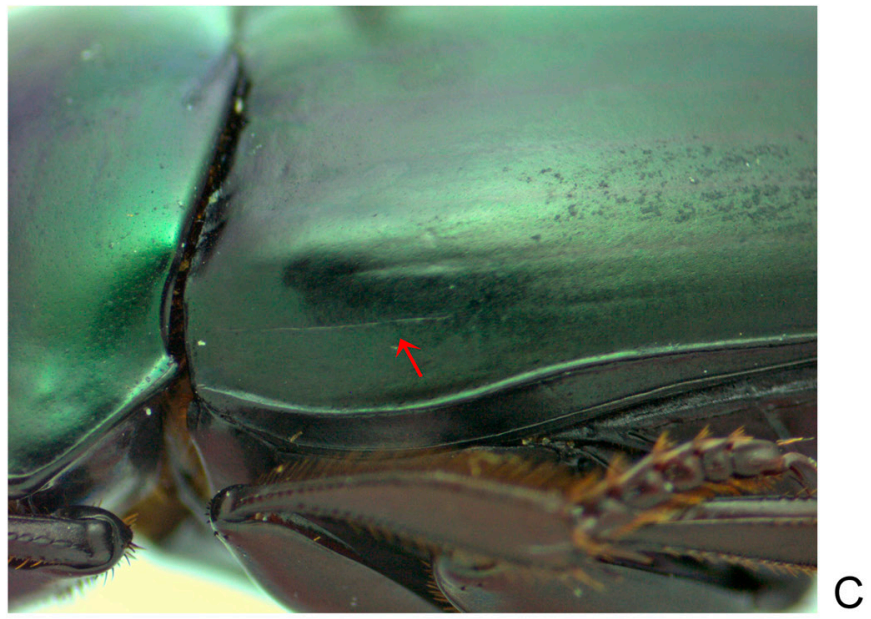

Fig. 12. Tegument variation in Sylvicanthon Halffter \& Martínez, 1977. A. Tridimensional alveolar microsculpture of the elytra in S. proseni (Martínez, 1949) stat. et comb. nov.. B. Rivose microsculpture on the external side of metaventrite in S. obscurus (Schmidt, 1920). C. S. proseni stat. et comb. nov., humeral carina, feature present also in $S$. aequinoctialis (Harold, 1869) and in about two-fifths of the studied specimens of S. obscurus (Schmidt, 1920). 
anteriorly at its basal two thirds; non-margined area with a row of very short setae; posterior margin absent. Metafemora with ventral face always margined anteriorly (Fig. 13), posterior margin present only in the aequinoctialis subgroup (Fig. 114-115); apical half of anterior edge covered by row of setae; micropunctation present throughout the tegument; at base, with or without coarse elongate punctation. Metatibiae curved, metatibial spur straight. Meso- and metatarsi flattened. Metatarsomeres II and V subequal in length and longer than the other tarsomeres; metatarsomere IV shorter than the others; meso- and metatarsi with a continuous row of setae throughout its internal edge.

ELYTRA. Scutellar depression absent. With nine to seven visible striae; from elytral suture, striae progressively more effaced; humeral carina present (Fig. 12C) or not. Tegument of interstriae ranging from smooth with evident micropunctation to with strong three-dimensional alveolar microsculpture
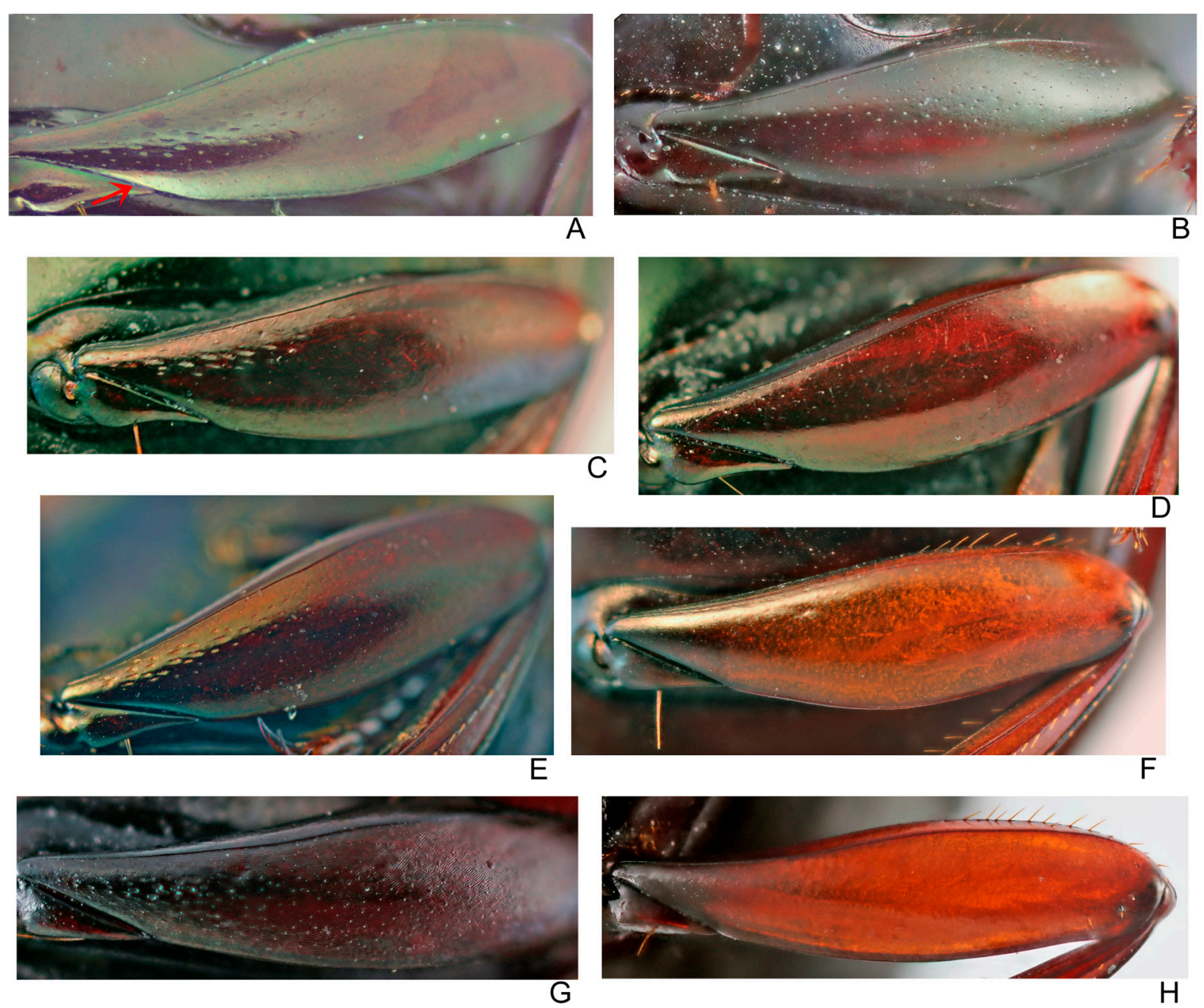

Fig. 13. Morphological variation in the metafemora of Sylvicanthon Halffter \& Martínez, 1977. A. S. foveiventris (Schmidt, 1920). Note the presence of coarse elongate punctures at the base of the metafemur (arrow) and the tegument without microsculpture. B. S. obscurus (Schmidt, 1920). Observe the tegument entirely covered by coarse non-elongate punctures. C. S. monnei sp. nov. D. S. mayri sp. nov. E. S. furvus (Schmidt, 1920). F. S. edmondsi sp. nov. G. S. bridarollii (Martínez, 1949) (southern populations). H. S. bridarollii (Martínez, 1949) (northern populations). Note the differences in colouration and in the presence of coarse punctation at the base of metafemur in the two ends of the clinal variation observed in $S$. bridarollii. 
obliterating micropunctation. Epipleural carina well marked; epipleura slightly sinuous, almost straight, in lateral view, and with tegument with strong rivose microsculpture.

AвDOMEN. Six visible abdominal segments (ventrites); tegument of ventrites $\mathrm{I}-\mathrm{V}$ with strong rivose microsculpture; ventrite VI with very diffuse rivose microsculpture at middle and more clearly marked on the sides; micropunctation absent or very subtle. Pygidium curvilinear, subtriangular and at least slightly convex in both sexes; entirely margined, apical margin much wider than lateral margin in both sexes (usually wider in males); margin between pygidium and propygidium arched; tegument with alveolar microsculpture always present, but ranging from strong to diffuse.

Aedeagus. Parameres shorter or as long as phallobase and very variable in shape, with external faces symmetrical or asymmetrical; when asymmetrical, external face of right paramere flat and external face of left paramere concave. In lateral view, parameres with or without ventral keel or notch and with simple or bifurcate apices. Basal piece of phallobase always with depressed dorsal area.

SeXUAL DIMORPHism. Males: Protibial spur (Fig. 15) narrow or wide, apex with a profound notch or straight with two lateral spines of unequal length. Ventrite VI strongly narrowed at middle by emargination on its posterior edge (Fig. 14D); anterior margin covered by weak medial expansion of ventrite $\mathrm{V}$, or ventrite $\mathrm{V}$ without medial expansion. Abdomen without lateral foveae. Females: Protibial spur spiniform (Fig. 15F) (except in S. proseni, whose spur is bifid, Fig. 15H). Ventrite VI very wide at middle, posterior edge straight, without emargination (Fig. 14B-C, E); anterior margin distinctly covered by medial expansion on the posterior margin of ventrite $\mathrm{V}$, or ventrite $\mathrm{V}$ without medial expansion. Abdomen with or without three pairs of lateral foveae between ventrites I-II, II-III and III-IV (Fig. 74-77).

\section{Taxonomic history of Sylvicanthon}

The first species of what was to become Sylvicanthon was described by Harold (1868a) in his landmark revision of the genus Canthon, namely C. aequinoctialis Harold, 1868, from "Columbien, Neu-Granada". In the following year, Harold (1869a) described two other new species for the genus, including Canthon candezei Harold, 1869, from "Tapajos", Pará, Brazil, another species currently included in Sylvicanthon.

The next author to describe species of Sylvicanthon was Schmidt (1920), in his first paper on Canthon. There, he presented Canthon furvus, from "Peru, Bolivien"; C. securus, from "Surinam"; and C. obscurus and C. foveiventris, both from "Espirito Santo". After having described them, Schmidt (1920) asserted that they were close to $C$. candezei and that, besides colour, those five species were similar in their oval body shape and by the presence of protibiae with a truncate apex and small, apical lateral teeth, clypeus with only two tiny teeth, large eyes, hypomeron with a transverse carina (wrongly cited as "Prosternum", common misunderstanding among old works on Scarabaeinae, as firstly noted by Halffter 1958, 1961, but who, in turn, misinterpreted them as being the propleura) and metafemora with anterior margin. Finally, Schmidt (1920) proposed a key to differentiate those five species. It is worth noting that this group and its unique character combination was an early draft of what would eventually be proposed as the genus Sylvicanthon.

As explained above, in his second work on the genus, Schmidt (1922) updated Harold's key to the species of Canthon and, there, he grouped $C$. aequinoctialis with $C$. candezei and the four species he had described in 1920 under the following steps: 2. Metatibiae with a single spur; 3. Clypeus with teeth; 10. Dorsum, excepting scutellar impression, without elevations or depressions; 26. Large eyes, i.e., space between eyes only five times larger than the diameter of each eye; 27 . Clypeus with two teeth; 30 . Pygidium with an angulate margin; 31. Protibiae with truncate apex, prosternum [sic] with a complete transverse carina and with external margin with a nodule or a very weak tooth. In the following couplet, he grouped C. obscurus and C. aequinoctialis by the presence of a humeral carina, on the one side, and 

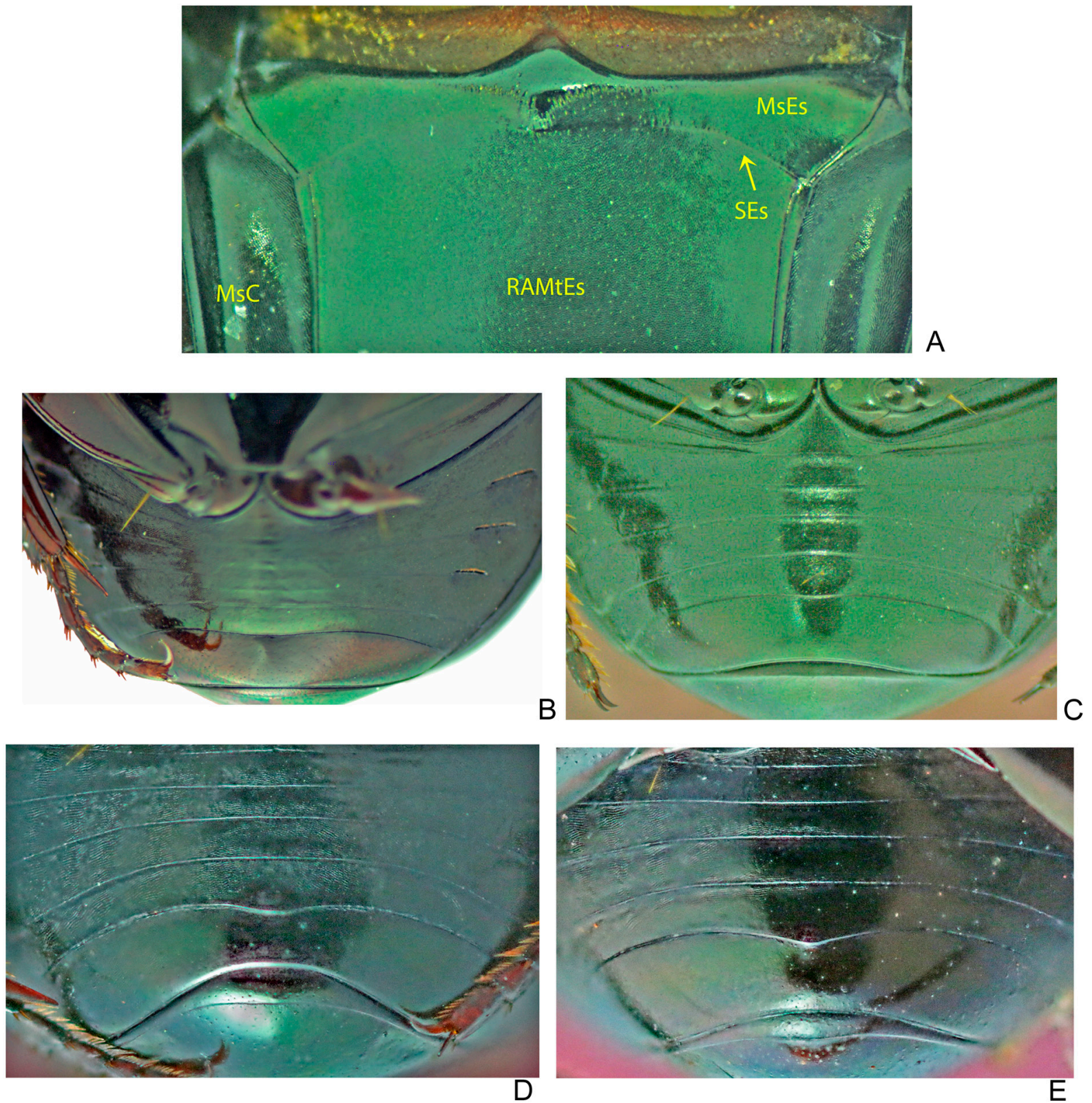

Fig. 14. A. Ventral view of the anterior region of the pterothorax of S. proseni (Martínez, 1949) stat. et comb. nov. Abbreviations: MsEs = mesoventrite; $\mathrm{SEs}=$ meso-metaventrite suture; $\mathrm{MsC}=$ mesocoxa; RAMtEs = anterior region of metaventrite. B-E. Sexual dimorphism in the abdominal ventrites of Sylvicanthon Halffter \& Martínez, 1977. B. S. foveiventris (Schmidt, 1920), ‥ Note the three lateral foveae between ventrites I-II, II-III, and III-IV and the broad ventrite VI at the middle, without emargination on its posterior edge and without its anterior edge covered by a medial flange of ventrite $\mathrm{V}$. C. S. proseni stat. et comb. nov., + , ventrite VI broad. D. S. candezei (Harold, 1869), O. Note how the ventrite VI is narrow at the middle due to the emargination on its porterior edge and to the medial flage of the posterior edge of the ventrite V. E. S. candezei (Harold, 1869), ․ . Despite its posterior edge not being emarginate, its anterior edge is covered by a well-developed medial flange of ventrite $\mathrm{V}$, which gives a narrowed aspect to the centre of ventrite VI. 


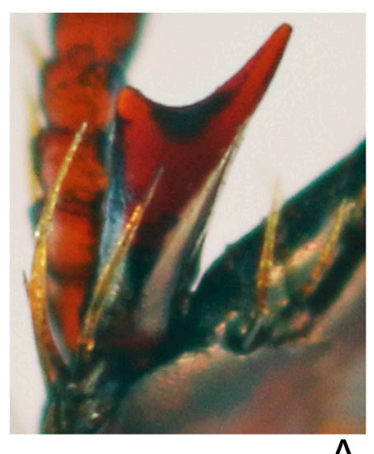

A
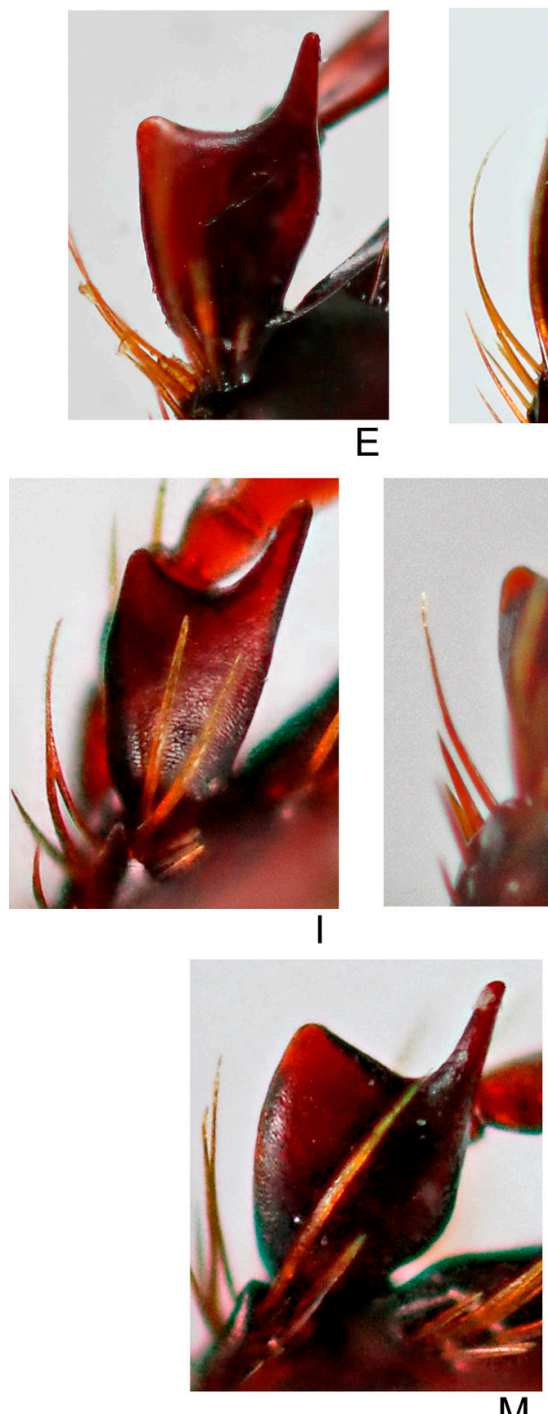
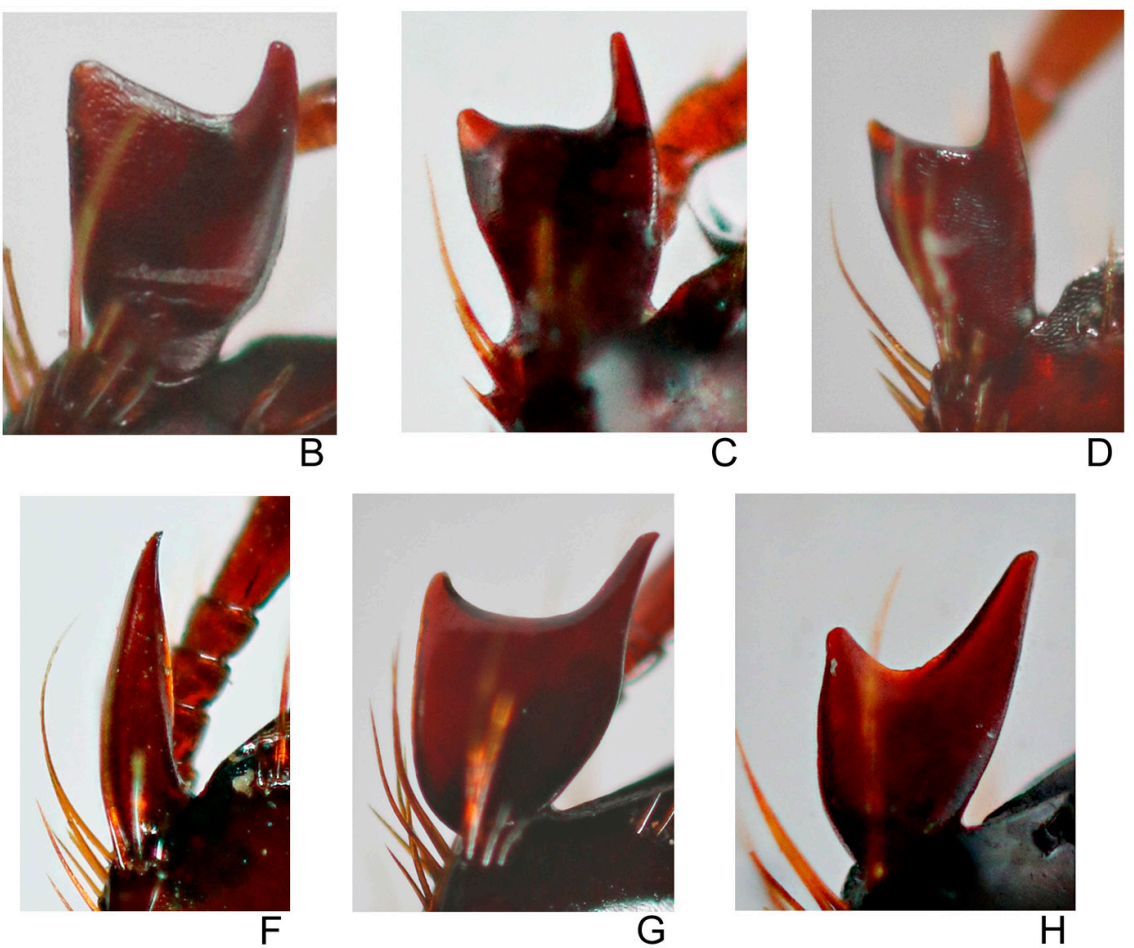

G
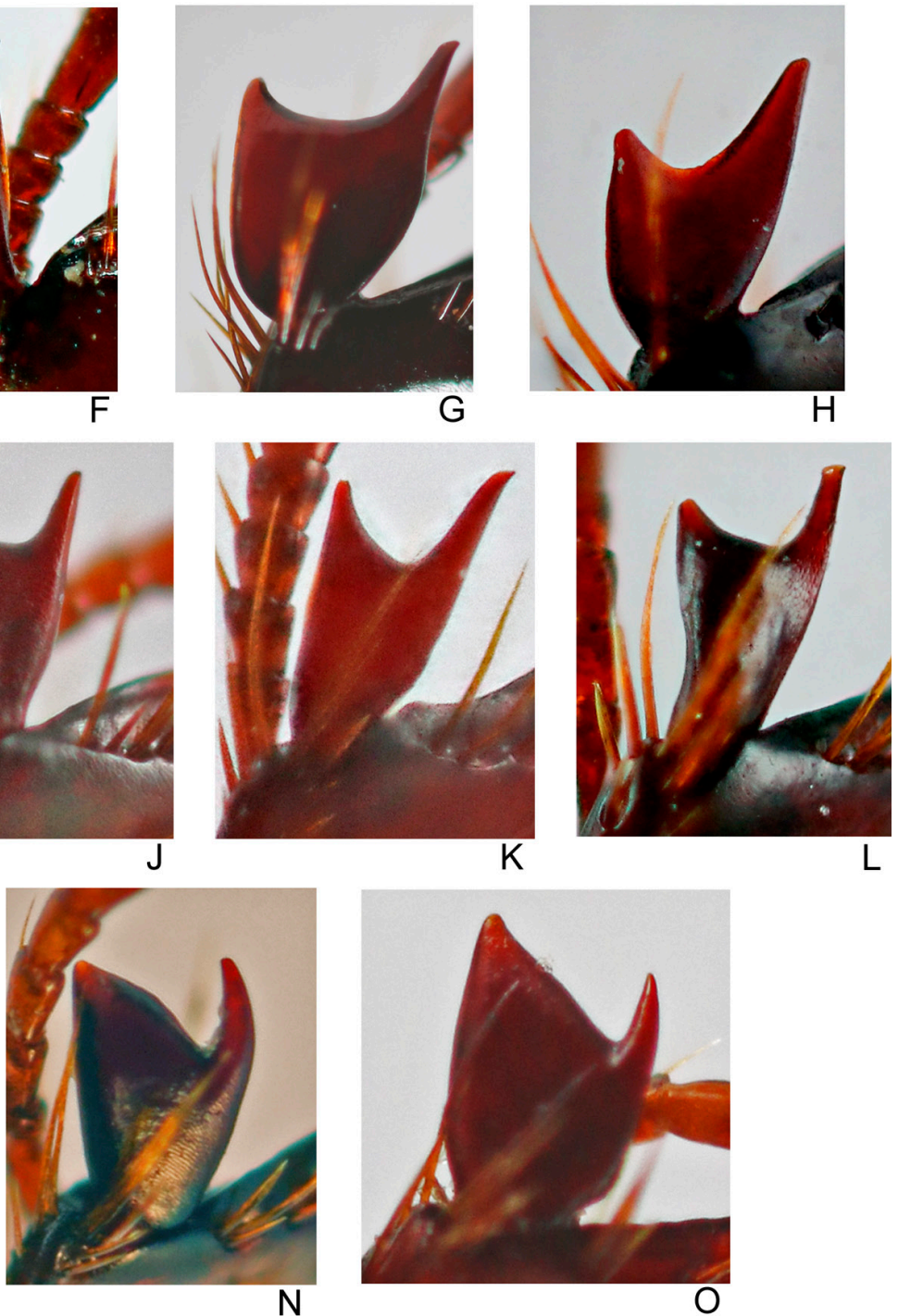

Fig. 15. Morphological variation and sexual dimorphism in the protibial spur of Sylvicanthon. A. S. enkerlini (Martínez et al., 1964) comb. nov., ô. B. S. foveiventris (Schmidt, 1920), ô. C. S. candezei

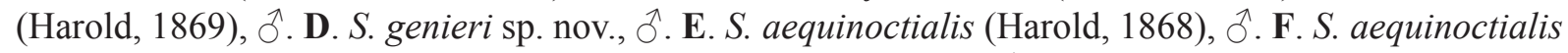
comb. nov., o. G. S. proseni (Martínez, 1949) stat. et comb. nov., ô. H. S. proseni stat. et comb. nov., + . I. S. bridarollii (Martínez, 1949), đ̃. J. S. seag sp. nov., đ̂. K. S. edmondsi sp. nov., đ. L. S. attenboroughi

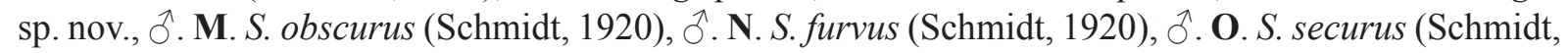
1920) comb. nov., ô. 
C. furvus, C. securus, C. foveiventris and C. candezei by its absence, on the other; next, the presence of a protibial internal expansion joins $C$. furvus with $C$. securus, while its absence groups $C$. candezei and $C$. foveiventris. The steps leading to the group of five species that was to form Sylvicanthon, as well as those differentiating them, remained almost unchanged in the updated version of Schmidt's key by Balthasar (1939).

Already during that 'Latin-American phase' of taxonomic activity on 'Canthon sensu lato' exposed above, Glaphyrocanthon, a taxon described as an independent genus, but lowered to subgenus of Canthon by Halffter \& Martínez (1977), shares much of its taxonomic history with Sylvicanthon. Martínez (1948a) described the genus to accommodate only two Venezuelan species, but the following year (Martínez 1949a), he added two new species from Bolivia: G. bridarollii Martínez, 1949, from the province of Chapare, department of Cochabamba, and G. proseni Martínez, 1949, from the province of Nor Yungas, department of La Paz. Regarding the first species, Martínez (1949a) stated it appeared to be closely related to Canthon foveiventris, a species that he believed should be transferred to Glaphyrocanthon ("creo que deberá ser incluida en Glaphyrocanthon"), while he asserted that G. proseni was close to Canthon aequinoctialis, another species that he supposed to be assignable to Glaphyrocanthon. Those transfers were formally proposed by Pereira \& Martínez (1956), who, among several other transfers, positioned in Glaphyrocanthon the four species that Schmidt $(1920,1922)$ had grouped with $C$. foveiventris and C. aequinoctialis (i.e., C. candezei, C. obscurus, C. furvus, and C. securus) and presented an identification key to them. Soon after, Pereira \& Martínez (1960) described Glaphyrocanthon cobosi, from the Cordillera province, Santa Cruz department, Bolivia, a species that was thought to be related to G. obscurus.

Martínez et al. (1964), in a review of Glaphyrocanthon, recognized four species assemblages in the genus: the variabilis, juvencus and aequinoctialis species groups, of the nominotypical subgenus, and the subgenus Coprocanthon Martínez, 1950. The aequinoctialis group corresponded to the assemblage composed of C. candezei and allied species proposed by Schmidt $(1920,1922)$, and differed from other Glaphyrocanthon in having the unique combination of large eyes and ventral surface of metafemora with a fine anterior margin. According to Martínez et al. (1964), that group was composed of G. aequinoctialis, G. proseni, G. candezei, G. obscurus, G. foveiventris, G. securus, G. furvus, G. bridarollii, G. cobosi and their new species G. enkerlini, from São Luis, Maranhão, Brazil. Three years later, Martínez \& Pereira (1967) described a last species for the group, G. machadoi, an inhabitant of the 'brejos de altitude' (Caatinga moist-forest enclaves) of Serra Negra, Pernambuco, Brazil, and which was said to be closely related to G. foveiventris and G. bridarollii.

Halffter \& Martínez (1977) then made major changes in the classification of 'Canthon sensu lato'. In their work, Glaphyrocanthon, Coprocanthon, and Geocanthon Pereira \& Martínez, 1956 were synonymized (the first name remaining valid) and the taxon was lowered to subgenus status under Canthon. The former aequinoctialis group, in particular, was totally dismembered and none of its species remained in Glaphyrocanthon: G. enkerlini was transferred to the Canthon subgenus Francmonrosia mainly because of its denticulate anterior edge of profemora (Fig. 9B) and protibiae with strong internal expansion (Fig. 11A), while G. aequinoctialis and G. proseni were synonymized and the species transferred to Canthon s. str. (both acts without any formal justification), where it remained isolated as the single member of the aequinoctialis lineage ("linea aequinoctialis").

Five species of the former aequinoctialis group, however, G. candezei, G. furvus, G. bridarollii, G. machadoi and G. cobosi (the latter considered by them a junior synonym of Canthon xanthopus Blanchard, 1846, name of unknown application by entomologists for more than a hundred years; see discussion below), remained grouped and were transferred to the new genus Sylvicanthon. This latter genus was said by Halffter \& Martínez (1977) to be related to Pseudocanthon and Vulcanocanthon Pereira \& Martínez, 1960, 
sharing with them the presumed absence of a fine margin on the posterior edge of their head. Those authors also presented a discussion on the differences between Sylvicanthon and C. aequinoctialis and the reason why, according to them, this species should not be part of that genus. Lastly, Halffter \& Martínez (1977) also judged that the remaining three species of the former aequinoctialis group (C. obscurus, C. foveiventris and $C$. securus), judging from Schmidt's descriptions, would "very likely" be close to the species included by them in Sylvicanthon, but no formal transfer was proposed.

As the main goal of Halffter \& Martínez (1997) was to reevaluate the supraspecific classification of 'Canthon sensu lato', and not to make a detailed study of its alpha taxonomy, questions such as species redescriptions and distributions, as well as a new identification key, were not addressed by them. Therefore, as no other work has so far reevaluated the taxonomy of Sylvicanthon, our knowledge about its species was extremely fragmentary and sometimes simply incorrect.

As addressed several times throughout this work, the geographical distribution attributed to some species of Sylvicanthon was largely wrong ( $S$. candezei is the best example), while the majority of the species were known only from their type locality (e.g., S. securus, S. obscurus, S. furvus and S. enkerlini). Besides, the species delimitation and identification were problematic, with as many as six different species identified in publications and collections under the same name (e.g., S. bridarollii, S. edmondsi sp. nov., S. attenboroughi sp. nov., S. genieri sp. nov., S. seag sp. nov. and $S$. candezei, all of them mingled under the name $S$. bridarollii or $S$. candezei) and with wrong synonymies (between the species now known as Canthon xanthopus and C. cobosi, and S. aequinoctialis and S. proseni). Finally, even the definition of Sylvicanthon had serious flaws as a consequence of character states believed to be universal in the genus not being found in some of its species (the most obvious being the absence of a fine margin on the posterior edge of the head), the inclusion of some species that clearly do not belong to the genus (C. xanthopus, C. machadoi and C. cobosi) and, at the same time, the exclusion of some species that are close to those belonging to Sylvicanthon (S. aequinoctialis comb. nov., S. proseni and S. enkerlini). The only modifications proposed to the taxonomy of Sylvicanthon since Halffter \& Martínez (1977) were the "informal transfers" (or, as put by Sikes \& Barclay 2017, "accidental" transfers; i.e., species cited in Sylvicanthon for the first time without the status of new combinations explicitly recognized) of Canthon foveiventris (by Vaz-de-Mello \& Louzada 1997) and C. obscurus (by Vaz-de-Mello 2000), following the conjectures of Halffter \& Martínez (1977) that those species belonged to Sylvicanthon.

\section{Phylogenetic relationships of Sylvicanthon}

Halffter \& Martínez (1977) included Sylvicanthon among the Canthonina, considered by them as one of the six subtribes of Scarabaeini (see Halffter \& Martínez (1966) for a deeper discussion about the positioning of Canthonina). In more modern classifications (e.g., Smith 2006; Scholtz et al. 2009; Bouchard et al. 2011; Tarasov \& Génier 2015; Tarasov \& Dimitrov 2016), this taxon is raised to the tribe category and renamed to its senior synonym Deltochilini (see Bouchard et al. 2011). Scarabaeini, in turn, is now composed of only a handful of African genera (see Forgie et al. 2005, 2006; Scholtz et al. 2009). Until very recently, Deltochilini comprised over 120 genera and 800 species that despite being distributed all over the world had their global distribution largely centred in the Gondwanian continents (Scholtz 2009; cited as Canthonini). Nevertheless, despite being widely considered as valid, successive phylogenetic analyses -being based either on morphological (e.g., Philips et al. 2004; Vaz-de-Mello 2007b; Tarasov \& Génier 2015) or on molecular evidence (e.g., Ocampo \& Hawks 2006; Monaghan et al. 2007; Sole \& Scholtz 2010; Mlambo et al. 2013; Tarasov \& Dimitrov 2016) - have shown that the tribe Deltochilini is not monophyletic, being instead composed of a large number of non-closely related lineages (Tarasov \& Génier 2015; Tarasov \& Dimitrov 2016; see also the extensive discussion about the phylogeny of Canthonini presented by Scholtz 2009). However, several of the New World taxa of Deltochilini, including the type genus Deltochilum, form together a recurring monophyletic group in most of those analyses. 
In the studies of both Ocampo \& Hawks (2006) and Monaghan et al. (2007), all the New World Deltochlini included in their analyses formed a single clade (species of the genera Deltochilum, Scybalophagus Martínez, 1953, Malagoniella Martínez, 1961, Megathopa Eschscholtz, 1822, Eudinopus Burmeister, 1840 and Canthon, in Ocampo \& Hawks (2006), and of Canthon, Scybalocanthon, Scybalophagus, Hansreia, Deltochilum, Eudinopus and Megathoposoma Balthasar, 1939, in Monaghan et al. (2007)). Tarasov \& Génier (2015), who included a much broader sample of genera, also recovered an exclusive New World Deltochilini clade, which had as members the genera Anomiopus Westwood, 1842, Scatonomus, Scybalocanthon, Tetraechma, Hansreia, Canthon, Scybalophagus, Deltochilum, Malagoniella, Megathoposoma and Sylvicanthon, and was referred to as Deltochilini sensu stricto by the authors. Other American genera of Deltochilini, however, appeared very distant from this clade, such as Paracanthon, Zonocopris, Canthochilum and Cryptocanthon. Previously, with a smaller number of genera, Vaz-de-Mello (2007b) had already obtained a very similar result to that of Tarasov \& Génier (2015) concerning the American Deltochilini, with a clade composed of Canthon, Sylvicanthon, Scatonomus and Anomiopus, while genera like Zonocopris, Canthonella, Paracryptocanthon and Cryptocanthon appeared scattered among different branches of the tree. Finally, the molecular phylogeny of Tarasov \& Dimitrov (2016) also recovered a monophyletic group composed exclusively of New Wold Deltochilini genera. Based both on the topology of the molecular (Tarasov \& Dimitrov 2016) and morphological (Tarasov \& Génier 2015) trees and on some diagnostic apormorphies found by Tarasov \& Génier (2015), Tarasov \& Dimitrov (2016) formally redefined Deltochilini to include only 22 American dung beetle genera, Sylvicanthon included among them; the other groups previously included in Deltochilini were regarded as incertae sedis in Scarabaeinae.

Despite the previously described similarities, the four analyses that included species of Sylvicanthon have found very distinct relationships for the genus among the Deltochilini. In the tree conceived by Medina et al. (2003), which had the goal of studying the phylogenetic relationships of what we are denominating as the 'Canthon sensu lato', 'Sylvicanthon bridarollii' ${ }^{13}$ appeared forming a clade with Canthon (Glaphyrocanthon) politus Harold, 1868, species widely distributed in Central America and northern South America (Vulcano \& Pereira 1964). That clade, in turn, appeared as a sister to the topology (Anisocanthon villosus $(C$. $(G$.) luteicollis $(C$. $(G$.) femoralis $(C$. $(G$.) rubrescens $+C .(G$.) angustatus)))), of which all the analysed Glaphyrocanthon and Anisocanthon were part. That group as a whole, called "node I" by Medina et al. (2003), was supported by three synapomorphies: anterior part of hypomeron (erroneously cited as "proepimeron") deeply excavated and glabrous, and posterior part of hypomeron (erroneously cited as "prosternon") glabrous in the area close to the border with pronotum. Interestingly enough, two of those three character states are variable among species of Sylvicanthon: the pilosity of the anterior part of hypomeron varies extensively in density from almost totally absent (e.g., S. candezei and S. seag sp. nov., Fig. 35A) to present with long and dense setae (e.g., S. bridarollii, Fig. 35C-D), while the posterior part of hypomeron is indeed glabrous in the candezei group, but has an ill-delimited row of setae parallel to the margin with the dorsal portion of pronotum in S. enkerlini, the single species of its group (Fig. 9D).

The other two phylogenetic analyses that included Sylvicanthon species - Vaz-de-Mello (2007b) and Tarasov \& Génier (2015) - were not aimed at studying the particular relationships between the genera of 'Canthon sensu lato' nor even that of the American Deltochilini, but, rather, they studied the phylogeny of the Ateuchini (Vaz-de-Mello 2007b) and the evolutionary history of the major lineages in Scarabaeinae (Tarasov \& Génier 2015). As a natural consequence, their results are less informative as to the Sylvicanthon relationships than those of Medina et al. (2003).

As we have seen, much remains to be studied about the relationships between Sylvicanthon and the other groups of 'Canthon sensu lato'. To reach a sound understanding of this issue, a greater number of species of Sylvicanthon, of different groups and subgroups, should be included in future phylogenetic analyses, 
as well as different representatives of Deltochilini, especially those taxa more similar in morphology to Sylvicanthon. Based on the comparative studies performed for this work (including several species still undescribed), the tentative hypothesis that we propose for testing by formal phylogenetic analyses is the following: among the Deltochilini sensu Tarasov \& Dimitrov (2016), Glaphyrocanthon as considered today (i.e., sensu Halffter \& Martínez 1977) should represent a large paraphylum composed of non-closely related lineages ${ }^{14}$. Within that paraphylum, a number of smaller genera with a uniform morphology - e.g., Sylvicanthon and Pseudocanthon - should be nested. These genera could form either a single clade within Glaphyrocanthon, or (which we believe is most likely) represent distinct lineages with independent origins within 'Glaphyrocanthon'. If this latter hypothesis is retrieved in phylogenetic analyses, Glaphyrocanthon will need to be divided once again into different genera as it was in the past (Coprocanthon and Geocanthon, former genus/subgenus, were synonymized with Glaphyrocanthon by Halffter \& Martínez 1977). Then, its limits will possibly be restricted to those of what Martínez et al. (1964) considered to be the variabilis species group of Glaphyrocanthon. In fact, this hypothesis has several similarities to the results of Medina et al. (2003), who obtained Glaphyrocanthon paraphyletic with one species of both Sylvicanthon and Anisocanthon nested within it; the major difference is that we do not include Anisocanthon among the possible members of this great 'clade Glaphyrocanthon'. It is also interesting to point out that in the phenogram presented by Kohlmann \& Halffter (1990) for the American 'Canthonina', Sylvicanthon and Glaphyrocanthon appeared grouped by about $50 \%$ of similitude and isolated from the remainder 'Canthon sensu lato', so revealing a close morphological connection between these two taxa.

A second hypothesis that has already been raised (FZVM, personal observations; Olivier Montreuil, personal communication to MC in June 2014) says that Sylvicanthon and some other 'Canthon sensu lato' genera (especially Pseudocanthon and Canthonella) would be close to a group of genera of Gondwanian distribution formally placed in Deltochilini that are sometimes separated in a tribe by their own, Epilissini (e.g., d'Olsoufieff 1947; Lebis 1953; Montreuil 2008, 2010, 2011; Montreuil \& Thery 2011, 2016; Montreuil \& Viljanen 2011; Montreuil et al. 2014; Vaz-de-Mello et al. 2011b). Montreuil (2010) revalidated Epilissini from the synonymy with Canthonini (which, in turn, is today a junior synonym of Deltochilini) based on two main morphological features presented by those genera: protibiae truncate at apex and hypomeron strongly excavated anteriorly. These two characteristics, in fact, are seen in Sylvicanthon and in several other Neotropical deltochiline genera, including Pseudocanthon and some Glaphyrocanthon, hence indicating a possible close relationship between them and the Epilissini sensu Montreuil (2010). The overall shape of the meso- and metatarsi, which are strongly flattened ("foliaceous") and with tarsomeri slightly rectangular, is also very similar between Sylvicanthon and the Epilissini.

Although both hypotheses are not mutually exclusive - the 'clade Glaphyrocanthon' could be part of Epilissini, which would make Deltochilini sensu stricto as defined by Tarasov \& Dimitrov (2016) polyphyletic - none of the phylogenetic analyses published so far supports a close relationship between either Sylvicanthon or Glaphyrocanthon with Epilissini nor that this tribe is monophyletic. In Tarasov \& Génier (2015), for example, genera of Epilissini appeared scattered throughout the phylogeny. In that analysis, Canthonella, Ochicanthon Vaz-de-Mello, 1999 and Epactoides d'Olsoufieff, 1947 (all of them included in Epilissini) were clustered with Tanzanolus Scholtz \& Howden, 1987 from Africa and which was not included among the Epilissini by Montreuil (2010), forming the sister clade of almost all the remainder Scarabaeinae. Bohepilissus Paulian, 1975 and Tesserodoniella Vaz-de-Mello \& Halffter, 2006, in turn, the other two genera of Epilissini sensu Montreuil (2010) included in the analysis, were separated one from the other in distinct branches of the tree. In the molecular analysis of Monaghan et al. (2007) the scenario was no different: genera included in Epilissini such as Arachnodes Westwood, 1847, Aleiantus d'Olsoufieff, 1947 and Paronthobium Paulian, 1984 did not show any close relationship ${ }^{15}$. This panorama is repeated in every single phylogenetic analysis so far published. 
Lastly, a third phylogenetic hypothesis also involving Sylvicanthon - which is inconsistent with the "clade Glaphyrocanthon' hypothesis championed by us - is based mainly on the morphology of the tarsal claws. In the taxonomic discussion presented by Halffter \& Martínez (1977) to distinguish Sylvicanthon among the Deltochilini, the authors stated that their new genus differed from Pseudocanthon by the form of their claws, which are simple in Sylvicanthon, while having a distinct basal angle in Pseudocanthon. However, we observed during our studies that this statement is not correct. All the species of Sylvicanthon have, in fact, a small angulosity at the base of their claws (more easily seen on protarsi, even though present in all legs) (Fig. 5A) which, despite the distinct contrast with the strong angulosity of Pseudocanthon (Fig. 5B), we interpret to be homologous to it and different only in size.

It is worth noting that a similar angulosity is present in an even larger size and moved towards the centre of the claw in other former deltochiline genera and, hence, in a more obvious way than in both Pseudocanthon and Sylvicanthon. Those genera are Canthonella (Fig. 5C) and Ipselissus d'Olsoufieff, 1935 from the New World; Temnoplectron Westwood, 1841 and Sauvagesinella Paulian, 1934 from Australasia; Lepanus Balthasar, 1966 (Fig. 5D) from the islands of Java, New Guinea and Australia; Oficanthon Paulian, 1985 (Fig. 5E) from New Guinea; and, to a lesser degree, Nesovinsonia Martínez \& Pereira, 1959 from the island of Mauritius (Martínez \& Pereira 1959; Halffter \& Martínez 1967; Matthews 1974; Paulian 1985). Halffter \& Martínez (1967) raised the hypothesis - which would be later favoured also by Matthews (1974) - that the presence of tarsal claws with a basal angle would be homologous among at least some of these taxa. Therefore, that feature would be evidence for the existence of an ancient lineage of a wide Gondwanian distribution represented nowadays by those relict genera.

Although not included in their discussion, Sylvicanthon and Pseudocanthon share all the main characteristics listed by Halffter \& Martínez (1967) to support that hypothesis. Even though one could argue that the claw angulosity of Sylvicanthon is basal (rather than medial) and much shorter, it is possible to observe a clear, gradual transition between the extreme form seen, for example, in Canthonella (Fig. 5C), passing through the less-developed and closer-to-base forms of Oficanthon (Fig. 5E) and Pseudocanthon (Fig. 5B), and, finally, to Sylvicanthon (Fig. 5A), so indicating the possible homology between these structures. Lepanus alone shows this wide variation, as seen, for instance, in two Australian species described by Matthews \& Weir (2002): L. loftyensis, with a long tooth displaced from the base of the claw, and S. penelopae, with a basal angulosity similar to that of Sylvicanthon (Fig. 5D). Interestingly enough, all these genera with toothed claws have the hypomeron strongly excavated anteriorly, one of the characteristics highlighted by Montreuil (2010) in his definition of the tribe Epilissini. Therefore, within the context of Montreuil's hypothesis, we could see the group proposed by Halffter \& Martínez (1967) and Matthews (1974) as one of the internal branches of Epilissini and, in this way, several different lineages of this tribe would have been spread independently across Gondwana. Matthews (1974), for instance, supposed another Gondwanian lineage represented in the Americas by Cryptocanthon and Canthochilum, and by Tesserodon Hope, 1937 and Ignambia Heller, 1916 in Australasia, a hypothesis that was later expanded and discussed in further detail by Vaz-de-Mello \& Halffter (2006).

Refinement of the phylogenetic placement of Sylvicanthon should be a task for future works. The three hypotheses discussed here - 'clade Glaphyrocanthon', tribe Epilissini, and the 'tarsal claw' hypothesis - are not entirely incompatible, but the scenario endorsed by us is that the first hypothesis is most likely correct and that the 'clade Glaphyrocanthon' is part of the Deltochilini sensu Tarasov \& Dimitrov (2016). As the alpha taxonomy of Glaphyrocanthon is yet largely unknown and several species still await description, it is firstly necessary that this genus undergo a broad taxonomic revision before formal phylogenetic analyses are performed. 


\section{Limits of Sylvicanthon and morphological comparison with allied genera}

As herein delimited, the genus Sylvicanthon is composed of a cohesive and easily identifiable group of species. The diagnosis offered above is very similar to the definition given by Schmidt (1920) to the group formed by Canthon candezei and his four new species (see 'Taxonomic history' above) and to that of the aequinoctialis group of Glaphyrocanthon sensu Martínez et al. (1964). Characteristics such as the presence of large eyes, metafemora with anterior margin, complete hypomeral carina, and excavated hypomeron had already been used by different authors for the delimitation of those groups, as well as by Halffter \& Martínez (1977) in the original description of Sylvicanthon. These latter authors, however, considered the supposed absence of a fine margin on the posterior edge of the head as one of the features that would most readily diagnose Sylvicanthon. Nonetheless, we concluded instead that this character is neither suitable to mark the limits of Sylvicanthon nor to indicate its phylogenetic placement for two main reasons. Firstly, as recognized even by Halffter \& Martínez (1977) themselves, head without posterior margin is a condition seen not only among the Sylvicanthon, but also in a number of other New World deltochiline genera, such as Pseudocanthon, Vulcanocanthon and some species of Cryptocanthon and Anomiopus. On the other hand, contrary to what was said by Halffter \& Martínez (1977), the posterior margin is not absent in not all of the species originally included in Sylvicanthon by them. All the specimens of Canthon machadoi and C. xanthopus possess a complete posterior margin, whereas this characteristic is variable in $S$. furvus and $S$. bridarollii, from completely absent to marked only very finely and being interrupted. Sylvicanthon candezei is the only species originally included in Sylvicanthon by Halffter \& Martínez (1977) of which we have not observed any specimen with at least a vague trace of a margin on the posterior edge of the head. This margin is absent or vestigial also in seven of the nine new species herein described or transferred to Sylvicanthon (S. foveiventris, S. genieri sp. nov., S. seag sp. nov., S. edmondsi sp. nov., S. attenboroughi sp. nov., S. obscurus, and S. monnei sp. nov.), while in two other species (S. enkerlini and S. aequinoctialis) this margin is always present and usually complete. In $S$. proseni, all the variation seen in the genus can be found: in a same population, specimens range from having a complete margin to those with a totally absent margin. Although there is a clear tendency for the posterior margin to be absent or atrophied in Sylvicanthon, this is a variable characteristic with very little taxonomic value or phylogenetic signal.

Genera with which Sylvicanthon can be sometimes confused are Pseudocanthon, Glaphyrocanthon and Canthonella, all of which share the excavated hypomeron, which is transversally divided by a complete hypomeral carina (incomplete in several species of Glaphyrocanthon). With Pseudocanthon, in particular, Sylvicanthon shares large eyes and the absence of prescutellar and scutellar impressions, but they can be easily distinguished from one another by the shape of the pronotum (with lateral edge forming a medial angle in Sylvicanthon, and lateral edges straight and subparallel in Pseudocanthon), shape of protibiae (with three large teeth and distinctly expanded at middle in Pseudocanthon, and with internal expansion or not and with two or three small apical teeth (candezei group) or three large teeth distributed through the apical half of protibiae (enkerlini group) in Sylvicanthon), and elytral pilosity (glabrous in Sylvicanthon, and covered by minute setae in Pseudocanthon), as well as the overall body shape, which is much shorter and flatter in Sylvicanthon than in Pseudocanthon. Number and shape of clypeal teeth also vary between the two taxa: in Pseudocanthon, there are always four acute teeth, the middle two larger than the lateral ones, and with base covered by a single row of short setae extending almost to genae. In Sylvicanthon, in turn, these characters vary widely between the two species groups. In the candezei group, there are two small teeth and the row of setae (which can be single or divided into two smaller fragments at the base of each tooth) hardly extends beyond the base of the teeth (Fig. 6BG). In S. enkerlini, the single species of its group, an intermediate condition is seen: there are four large teeth similar to those of Pseudocanthon, but the row of setae is limited to the base of the teeth as in the other species of Sylvicanthon (Fig. 6A). 
Canthonella, in turn, is readily differentiated from Sylvicanthon by tarsal claws with a strong basal tooth (while this tooth is very small in Sylvicanthon), shape of clypeal teeth and presence of a trochantofemoral pit on the front legs, while this latter feature is absent in Sylvicanthon (Vaz-de-Mello et al. 2011). Glaphyrocanthon, as already discussed, is probably paraphyletic and, hence, some of its species are more closely related to Sylvicanthon (and, consequently, share some apomorphies with this genus) than to other of their congeneric species. The set of species that today forms Glaphyrocanthon is similar to Sylvicanthon, among other characteristics cited throughout this work, by the shape of pronotum, whose lateral edges have a medial angulosity. Even so, Glaphyrocanthon can be easily differentiated from Sylvicanthon by having profemora lacking both the anterior and the posterior margins on its ventral surface (anterior margin always present in Sylvicanthon, posterior margin present or not), eyes with a very narrow dorsal portion (wide in Sylvicanthon) and protibiae obliquely truncate at apex (rectly truncate in Sylvicanthon, Fig. 11).

\section{Species composition}

As defined in the present work, Sylvicanthon has 15 species divided into two groups: the enkerlini group, with a single species, $S$. enkerlini, and the candezei group, with five subgroups: the candezei subgroup, with $S$. candezei, $S$. foveiventris and $S$. genieri sp. nov.; the aequinoctialis subgroup, with S. aequinoctialis and S. proseni; the furvus subgroup, with $S$. obscurus, S. furvus, $S$. monnei sp. nov. and S. mayri sp. nov.; the bridarollii subgroup, with $S$. bridarollii, S. attenboroughi sp. nov., S. edmondsi sp. nov. and $S$. seag sp. nov.; and the securus subgroup, with the sole $S$. securus. This new composition differs from that of Halffter \& Martínez (1977) in three main aspects: 1) two species originally included in Sylvicanthon (the former S. machadoi and S. xanthopus, along with a former junior synonym of the latter, Glaphyrocanthon cobosi, here revalidated) are removed from Sylvicanthon and transferred to Canthon; 2) six species previously placed in Canthon are transferred to Sylvicanthon: C. aequinoctialis, positioned in Canthon s. str. by Halffter \& Martínez (1977), and its former junior synonym, Glaphyrocanthon proseni, which is here revalidated; Glaphyrocanthon enkerlini, placed in Canthon (Francmonrosia) by Halffter \& Martínez (1977); and C. securus, C. foveiventris, and C. obscurus, species mentioned as possible Sylvicanthon by Halffter \& Martínez (1977), but never formally transferred (but see 'Taxonomic history' above for more details about previous informal transfers of the latter two species); and 3) six new species are herein delimitated, described, and named for the genus. Furthermore, the recognition of two groups and five subgroups of species in Sylvicanthon is also new. In the following paragraphs, we discuss the proposed changes.

Although the results of this work undoubtedly show that Canthon xanthopus, Glaphyrocanthon cobosi and G. machadoi (hereafter cited in their original combinations) do not belong to Sylvicanthon, the genus to which they should be transferred is not as clear. The transfer of $C$. xanthopus is the least problematic and made with the most confidence. Among the evidence indicanting that this species does not belong to Sylvicanthon are a) shape of clypeal teeth (large, acute and very apart from each other in C. xanthopus (Fig. 45), and small, usually obtuse and contiguous or very close in Sylvicanthon, Fig. 6B$\mathrm{G})$; b) size of eyes (small eyes of about one-eighth of the width of the interocular space in C. xanthopus, and large eyes of about one-fifth of the width of the interocular space in Sylvicanthon); c) shape of protibiae (with large teeth and apex occupied by the apical tooth in C. xanthopus, and small teeth and truncate apex in Sylvicanthon, Fig. 11); d) shape of hypomeron (only slightly depressed anteriorly and with hypomeral carina incomplete in C.xanthopus, and deeply excavated and with complete hypomeral carina in Sylvicanthon, Fig. 35); and e) external margin of mesocoxae (narrow in C. xanthopus, see Fig. 7C, but very wide in Sylvicanthon, see Fig. 7A-B), among several other characters. At the same time, this species conforms with the definition (certainly artificial) of Canthon given by Halffter \& Martínez (1977). Therefore, we propose that C. xanthopus be returned to its original combination (see below for more details on the relationship of this species with other Canthon). 
Finding a proper generic placement for Glaphyrocanthon machadoi and G. cobosi is a more complicated task given the peculiar combination of characters that these two closely related species possess. Among the main differences with Sylvicanthon are a) clypeal teeth very separated from one another (teeth contiguous or very close in Sylvicanthon); b) dorsal portion of eyes narrow and with a fine internal margin (large unmargined eyes in Sylvicanthon); and c) external margin of anterior part of hypomeron strongly sinuous and with a strong tooth (straight or only slightly sinuous and usually with a very tiny tubercle in place of the tooth in Sylvicanthon). On the other hand, these two species have their general morphology very similar to that of Glaphyrocanthon, especially concerning the shape of the head (clypeus and eyes) and the excavated hypomeron. Even so, the presence of an anterior margin on the metafemora of these two species differentiates them from Glaphyrocanthon, whose species (at least the described ones) have unmargined metafemora ${ }^{16}$. Using the keys of Halffter \& Martínez (1977) and Vazde-Mello et al. (2011), these species would be identified as Canthon. Based on that, and knowing that Canthon is highly artificial and comprises a large number of incertae sedis species of 'Canthon sensu lato' (i.e., it is a 'wastebasket' taxon), we propose the temporary transfer of G. cobosi and G. machadoi to this genus. We believe, however, that when future works will have dedicated themselves to revise both Glaphyrocanthon and Canthon and given a new definition to these genera, those two species should be repositioned in some genus other than Canthon; possibly, a new one (see discussion on the revalidation of Canthon cobosi from the synonymy with C. xanthopus in the section dedicated to the former species).

Six other species formely positioned in Canthon by Halffter \& Martínez (1977) are here incorporated into Sylvicanthon. As previously mentioned, Halffter \& Martínez (1977) synonymized Canthon aequinoctialis and Glaphyrocanthon proseni, stating that the species, which was considered by previous authors to be close to those that today form Sylvicanthon (e.g., Schmidt 1922; Balthasar 1939; Martínez et al. 1964), would be isolated in its own lineage among the Canthon s. str. and, hence, had no intimate relationship with Sylvicanthon. In the discussion of the latter genus, Halffter \& Martínez (1977) stated that Canthon aequinoctialis indeed had several similarities with Sylvicanthon, but they were nevertheless different in the following characters present allegedly only in the former species: a) posterior edge of head margined between eyes; b) mentum with anterior edge emarginate in ' $U$ '; c) suture between submentum and gula ' $Y$ '-shaped; d) protibial teeth of medium size; e) meso- and metatarsomeri I of length subequal to that of meso- and metatarsomeri II; and f) mesocoxae with very narrow external margin.

Save the one concerning character (c), all the other arguments are refuted in the present work and, based on the description and diagnosis given above, Canthon aequinoctialis and Glaphyrocanthon proseni are transferred to Sylvicanthon. Characteristic (a) was discussed above and we saw that, contrary to what was written by Halffter \& Martínez (1977), the presence or absence of a margin on the posterior edge of head is highly variable among the Sylvicanthon (and presumably also among other genera such as Pseudocanthon), both intra- and interspecifically, and, hence, it is not a good indicator of generic limits. Besides, several specimens of the now Sylvicanthon proseni lack this margin, although the majority of the specimens show at least some vague traces of it.

Regarding character (b), it was seen that the so-called 'U'-emarginate mentum in S. aequinoctialis and S. proseni is at most only slightly different from the shape seen in the other Sylvicanthon (Fig. 8), the same occurring to character (f) (Fig. 7B-C). As for characteristic (d), the protibial teeth in those two species are indeed different from the remaining Sylvicanthon of the candezei group (Fig. 11B), but it seems to be an intermediate condition between that seen in S. enkerlini (Fig. 11A) and other related groups such as Glaphyrocanthon and the other species of the candezei group. Therefore, we can see these differences as a transformation series from the more general condition observed in Glaphyrocanthon and S. enkerlini, where the protibial teeth are large and well separated from one another, passing through the state present in S. aequinoctialis and S. proseni, whose teeth are of medium size, to the pattern found among the remaining Sylvicanthon, which have small teeth limited to the apical region of the protibiae 
(members of the candezei subgroup took a further step in this sequence and lost the basal tooth, keeping only the two apical ones).

Finally, characteristic (c) is indeed unique to the aequinoctialis subgroup: while the suture between the submentum and gula has a ' $\mathrm{Y}$ ' shape (shape highlighted by a row of long setae covering it, Fig. 8B) in the members of this subgroup, in all the other species of Sylvicanthon this suture is rounded and may or may not be covered by a row of setae (Fig. 8A). Nonetheless, as previously noted by Halffter \& Martínez (1977), the shape of this suture is extremely variable in Canthon and, therefore, it should not be taken as evidence of phylogenetic affinity between its species and the aequinoctialis subgroup. In this way, the ' $\mathrm{Y}$ '-shaped suture is here interpreted as a synapomorphy of the aequinoctialis subgroup, a modification of the rounded shape found among the other Sylvicanthon and supposedly present in the ancestor of this genus.

In addition, Canthon securus, C. foveiventris and C. obscurus - all species that were considered to be closely related to today's Sylvicanthon by previous authors (e.g., Schmidt 1920, 1922; Balthasar 1939; Martínez et al. 1964; Halffter \& Martínez 1977) - are here at last transferred to the latter genus. These three species show all the characteristics present in the description and diagnosis given above and are intimately related to the other members of the candezei group, with which they are commonly confused both in collections and in publications. Halffter \& Martínez (1977) stated that, very likely, these three species would have to be transferred to Sylvicanthon, but they did not argue why they themselves did not make these transfers (probably because they had not seen the type specimens, though). Although those transfers had never been proposed in a formal manner until now (i.e., explicitly stating they were new combinations and giving the arguments for the new taxonomic acts), subsequent authors started citing two of them - S. foveiventris and S. obscurus - in combination with Sylvicanthon (e.g., Vaz-deMello \& Louzada 1997; Vaz-de-Mello 2000; Hernández 2002; Durães et al. 2005; Falqueto et al. 2005; Almeida \& Louzada 2009; Hernández \& Vaz-de-Mello 2009; Hernández et al. 2011; Larsen 2012; Culot et al. 2013), including important online biodiversity databases such as the Encyclopedia of Life and the Catalogue of Life.

Finally, the last transfer to Sylvicanthon presented herein is that of Glaphyrocanthon enkerlini, considered part of the aequinoctialis species group of Glaphyrocanthon by Martínez et al. (1964) - and thus close to today's Sylvicanthon - but placed in Canthon (Francmonrosia) by Halffter \& Martínez (1977). These latter authors justified their transfer of G. enkerlini to Francmonrosia with the following characteristics: a) profemora with denticulation on its anterior margin; b) protibiae with internal expansion and c) with truncate apex. The latter two characteristics are, in fact, also present in Sylvicanthon and, thus, can be equally used as an argument to place G. enkerlini in this latter genus (protibiae with internal expansion is also seen in Glaphyrocanthon). Profemora with denticulation on its anterior margin, however, are not seen in any other Sylvicanthon and are indeed a characteristic present in all Francmonrosia (as currently defined, at least), which could be seen to support Halffter \& Martínez's hypothesis. However, the denticulation in G. enkerlini is very distinct from the one shown by the great majority of the Francmonrosia: in species of the latter subgenus, teeth tend to be large, few in number, and present only in males, while they are small and, together, give a serrate appearance to the profemora of both sexes in G. enkerlini (Fig. 9B). Canthon (F.) carbonarius Harold, 1868, however, is unique in its subgenus in being similar to G. enkerlini concerning this characteristic and, indeed, it was cited by Halffter \& Martínez (1977) as the closest relative of G. enkerlini.

Despite the similarities between G. enkerlini and C. carbonarius, in particular, and the putative affinity of G. enkerlini with Francmonrosia, in general, several observations were made in the present work that, in our opinion, refute Halffter and Martínez's classification and simultaneously give support to the proposed placement of G. enkerlini in Sylvicanthon: 1) shape of metaventrite, which is swollen on 
its anteromedial region and has a strong transverse depression on its anterior region in Francmonrosia, while it is entirely flat and has an area of rivose microsculpture typical of Sylvicanthon on its anterior part in G. enkerlini; 2) size of dorsal portion of eyes, which is wide in G. enkerlini and Sylvicanthon (Fig. 6), while it is narrow in Francmonrosia; 3) external margin of mesocoxae, which is broad in G. enkerlini and Sylvicanthon (Fig. 7A-B), but narrow in Francmonrosia (Fig. 7C); 4) presence of scutellar depression in Francmonrosia, while it is absent both in G. enkerlini and in Sylvicanthon; 5) the relative width between pronotum and elytra, the former being wider than, or subequal to, the latter in Francmonrosia, while elytra are distinctly wider than pronotum in Sylvicanthon and G. enkerlini; and 6) shape of pronotum, which is swollen, strongly convex and, in lateral view, much higher than the elytra in Francmonrosia (Fig. 10A), while it is flat and at the same level as the elytra both in Sylvicanthon and in G. enkerlini (Fig. 10B-C). Other characteristics differing G. enkerlini from Francmonrosia, on the one hand, and approximating it to Sylvicanthon, on the other, are size and overall body shape (Francmonrosia includes species much larger and more robust than Sylvicanthon). The margin of the posterior edge of head, notwithstanding the problems discussed above, also gives some indications of a closer relationship between G. enkerlini and Sylvicanthon than of that species with Francmonrosia. In this latter subgenus, this margin is always complete and well marked, while in G. enkerlini it is fine and, sometimes, almost imperceptible, in the same way as seen in the majority of the Sylvicanthon. Due to all these arguments, G. enkerlini is herein transferred from Canthon (Francmonrosia) to Sylvicanthon.

However, there are clear differences between S. enkerlini and the other Sylvicanthon. The most obvious of them is the shape of clypeus, structure that in S. enkerlini possesses four large, acute teeth (Fig. 6A), while all the remaining species have only one pair of small, obtuse or slightly acute teeth (Fig. 6B-G). Furthermore, the shape of protibiae, as already discussed, is very different between $S$. enkerlini and the other Sylvicanthon; the condition seen in that species is very similar, however, to that found in many Glaphyrocanthon (see drawings in Rivera-Cervantes \& Halffter (1999), for example). Presence of denticulation on the anterior margin of profemora (Fig. 9B) and pilosity on the posterior part of hypomeron (Fig. 9D) are also conditions seen in Sylvicanthon exclusively in S. enkerlini. Therefore, together with characteristics in habitat preferences (see details further in the text in the sections 'Biogeography' and 'Natural history'), the differences between S. enkerlini and the remaining Sylvicanthon are used here to divide the genus into two species groups: the enkerlini group, with the single $S$. enkerlini, and the candezei group, with all the other 14 species of the genus.

It is interesting to note that $S$. enkerlini has an 'intermediate' overall morphology between the Sylvicanthon of the candezei group and Glaphyrocanthon, presenting characteristics interpreted here as either apomorphies of Sylvicantahon (such as metafemora with anterior margin (Fig. 21B), eyes with wide dorsal portion (Fig. 6A), mesocoxae with wide external margin (Fig. 7A-B), hypomeron strongly excavated anteriorly strongly excavated (Fig. 9D), protibiae truncate at apex (Fig. 11A) and absence of scutellar and prescutellar depressions) or plesiomorphies shared with Glaphyrocanthon that are not present in other Sylvicanthon (e.g., the overall shape of protibiae (Fig. 11A), including large teeth and the expansion on their internal margin, and pilosity on the posterior part of hypomeron (Fig. 9D)). Besides, S. enkerlini shows some unique apomorphies within the genus, such as denticulate profemora (Fig. 9B). Therefore, this new vision of Sylvicanthon presented herein brings with it intrinsic hypotheses about the morphological evolution and evolutionary relationships within the genus that should be tested in future phylogenetic analyses.

The candezei group, in turn, has as unique, easily observable features protibial teeth of smaller size (Fig. 11B-J) and, especially, a clypeus with only two small apical teeth (Fig. 6B-G). The 14 species are divided into five cohesive subgroups of species. The candezei subgroup, with three species, is immediately separated from the remaining Sylvicanthon by the presence of only two protibial teeth (Fig. 11J), while all the other members of the genus have three (Fig. 11A-I). The aequinoctialis subgroup, 
with only two species, is distinct from the remaining species in the shape of its protibiae (wider and with more robust teeth than the other Sylvicanthon of the candezei group, Fig. 11B), presence of metafemora with posterior margin (Fig. 31), suture between submentum and gula ' $Y$ '-shaped (Fig. 8B), and constant presence of humeral carina (Fig. 12C; in S. obscurus, this carina is only present in some specimens). The four members of the furvus subgroup are differentiated from the other Sylvicanthon in having, in combination, protibiae with a clear internal expansion (Fig. 11D-E), abdomen with three pairs of lateral foveae in females (Fig. 16A-C; see discussion in the next section) and parameres bifurcate at the apex (Fig. 19B-E), while the four members of the bridarollii subgroup possess protibiae with straight
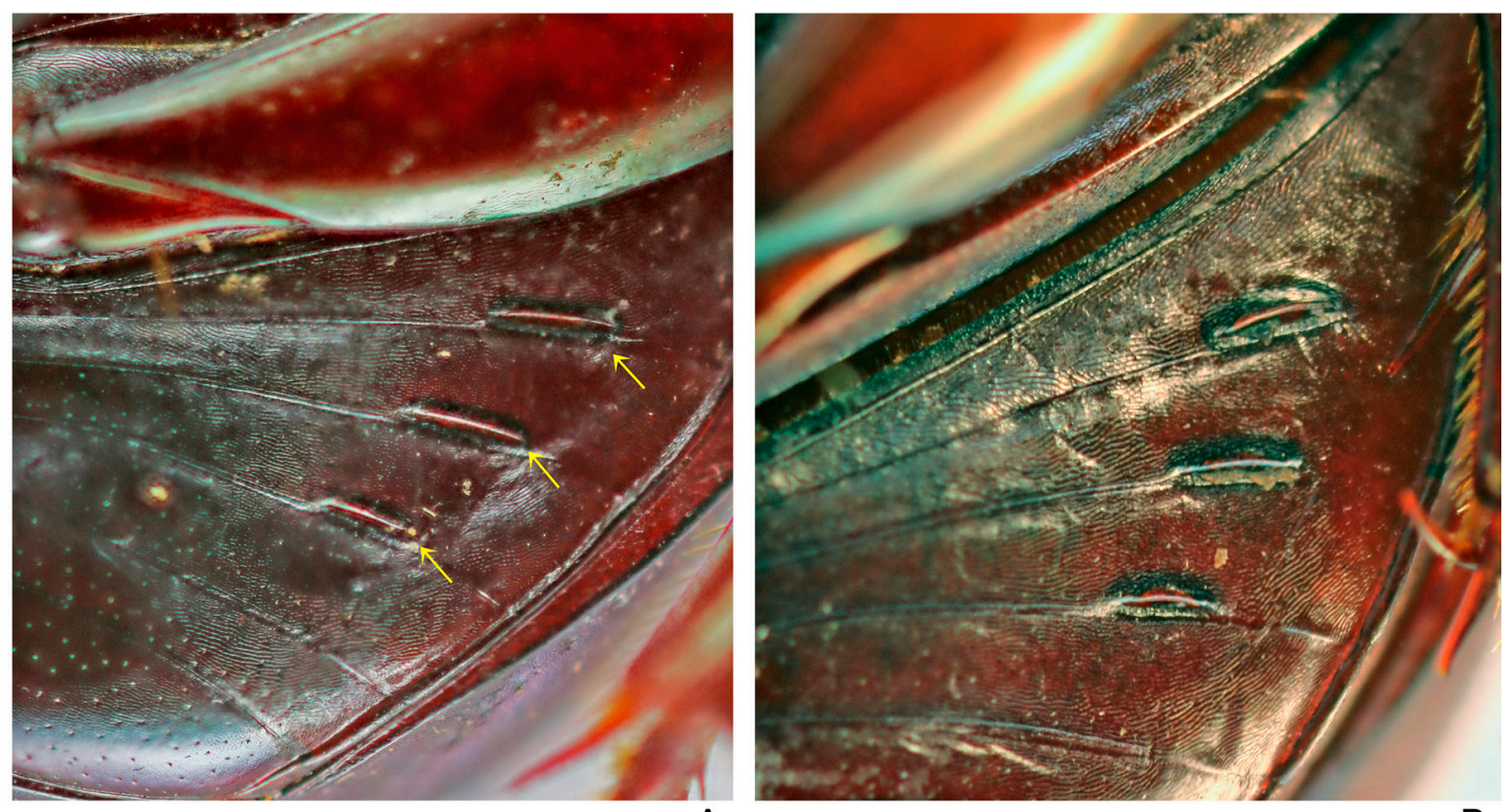

A

B
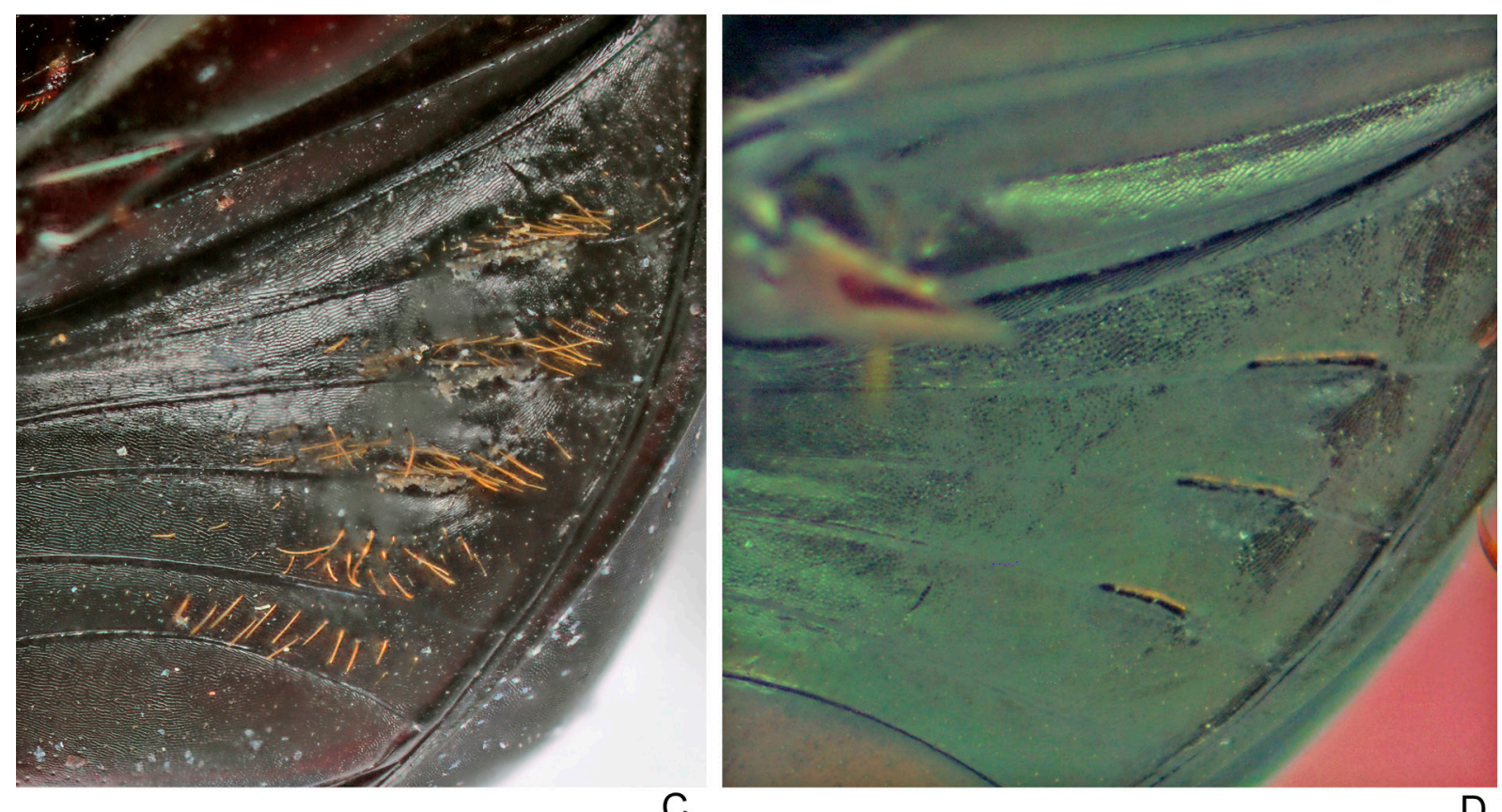

C

$\mathrm{D}$

Fig. 16. Abdominal lateral foveae of females (arrows). A. Sylvicanthon furvus (Schmidt, 1920). B. S. mayri sp. nov. C. S. obscurus (Schmidt, 1920). D. S. foveiventris (Schmidt, 1920). 
internal margin (Fig. 11H-I) (except S. bridarollii, Fig. 11F-G) and abdomen lacking lateral foveae in both sexes. The remaining subgroup only includes $S$. securus, a species that has ambiguous relationships with two of the other four subgroups. On the one hand, S. securus is close to the furvus subgroup in view of the strong internal expansion on its protibiae (the strongest protibial expansion in any species of the candezei group, Fig. 11C), but it is distinct from its species in having simple parameres (Fig. 19A) and because its females do not bear abdominal foveae, characters that, in turn, are typical of the species of the bridarollii subgroup.

Although this classification in subgroups has the aim of representing monophyletic groups, future formal phylogenetic analyses should test this scheme, present a clearer positioning for $S$. securus, and evaluate with more robust data the complex evolution of the characters used to delimit the subgroups (especially the evolution of the abdominal foveae, which, apparently, had multiple origins in different subgroups; see discussion below). Table 2 summarizes the characteristics used in this classification of the species of Sylvicanthon.

\section{Comparative morphology of species of Sylvicanthon}

The differences between the species of Sylvicanthon, especially among members of a same subgroup, are usually very subtle and lie in a combination of characters related to colour, microsculpture of the tegument and shape of parameres. In this section, we present a detailed comparison between the species of Sylvicanthon in relation to key structures both to the delimitation and to the identification of its species.

Dorsal Colouration. Excluding S. genieri sp. nov., which has a coppery colouration throughout the body, the other species of Sylvicanthon possess darker shades such as green (S. securus, S. candezei, $S$. mayri sp. nov., S. monnei sp. nov. and some specimens of $S$. seag sp. nov.), dark blue (some specimens of $S$. seag sp. nov. and in $S$. edmondsi sp. nov.) or black with bluish or violet reflexes (S. aequinoctialis, S. proseni and S. enkerlini). The more common pattern, however, is the bicolour one, in which pronotum and head are purple and elytra are black, dark blue or dark green, as seen in S. foveiventris, S. bridarollii, S. attenborough sp. nov., S. obscurus and some specimens of S. furvus and S. seag sp. nov. In S. obscurus and $S$. seag sp. nov., the colouration pattern varies geographically: in S. obscurus, populations in Espírito Santo (Brazil) show a gradient where individuals may have head and pronotum green or yellow, at the one extreme, or purple, at the other, while elytra are always dark green or dark blue. In the Brazilian northeast, however, only specimens close to the 'purple-head-and-pronotum extreme' were observed (see more details in the discussion of this species). In $S$. seag sp. nov., the colouration also varies in a north-south axis: populations close to the banks of the Amazon river (e.g., Manaus and Belém) and those in the state of Maranhão show the bicolour pattern described above, while individuals from the Guianas, Venezuela and Trinidad possess a purple head, and green or blue pronotum and elytra (see detailed description in the discussion of this species).

Teneral specimens of all the species possess colouration distinct from the one described above. They are clearer and, most of the time, brownish with weak bluish and greenish reflexions. As this pattern is common to all the species, only the mature colouration is described and discussed throughout this work. Therefore, it is important to keep always in mind that occasional teneral specimens will not fit what is presented in each species' description.

SCULPTURE OF THE TEGUMENT. The pattern of the tegument sculpturing on head, pronotum, elytra, and metaventrite was one of the main sources of evidence for the species delimitation in Sylvicanthon. The terminology for the description of the microsculpture has been employed in a very inconsistent and imprecise way in the literature concerning 'Canthon sensu lato'. Therefore, it is necessary to clarify the meaning of the terms used throughout this work. 


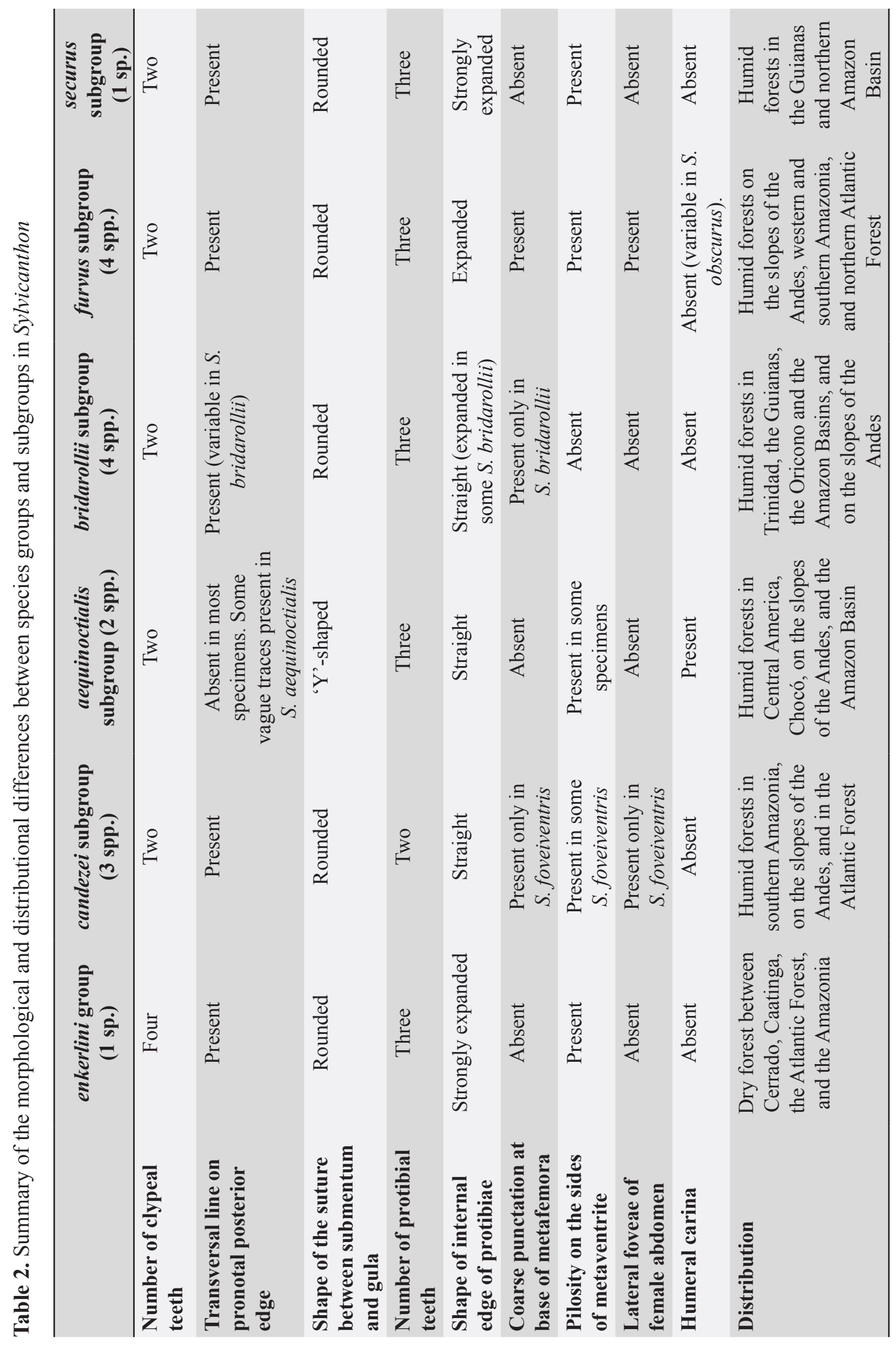


When the surface of the tegument does not show any visible microsculpture, it is denominated smooth, even though micropunctation (i.e., small, individual non-sericeous perforations of the tegument) may be present. Microsculpture (i.e., the pattern of impressions or elevations on the surface of the body seen under microscopic lens; modified from the definition of 'sculpture' by Torre-Bueno 1989), in turn, can be present among Sylvicanthon in two general ways: the first one, when the tegument surface is covered by a net of tiny, well-delimited polygons ${ }^{17}$ contiguous to one another, is denominated alveolar microsculpture (following Krell 1994 and Harris 1979) (Fig. 12A). The second one, where microsculpture does not show a well-defined regular pattern and is, instead, formed of a conjunct of tiny lines running in a nonparallel way, is denominated rivose microsculpture (following Harris 1979) (Fig. 12B). The alveolar pattern may have a three-dimensional appearance, being clearly present in the tegument's most external layer, or may have a flatter aspect, when it seems to be internal to the tegument, and more externally covered by a translucid, smooth layer (i.e., an external layer without microsculpture). In the second case, the alveolar microsculpture is always more difficult to observe and, in some occasions, only some vague traces can be seen, when they are called 'diffuse microsculpture'. Krell (1994) discussed in detail several aspects of the evolution, physiology and structure of the insect alveolar microsculpture and how this feature can serve to delimitate species.

All the species of Sylvicanthon have a very complex microsculpture pattern, which can show either only a little variation among conspecific individuals (e.g., in the four species of the furvus subgroup) or a remarkable intrapopulational (e.g., S. proseni) or geographical (e.g., S. seag sp. nov. and S. candezei) variation. The meaning of those different levels of intraspecific variation is, for now, unknown to us. Some areas of the tegument, however, have a similar sculpturing in all the individuals of Sylvicanthon: hypomeron (both the anterior and the posterior parts), mesepimera, metepisterna, prosternum, epipleura, and the external sides and antero-medial region of metaventrite are always covered by strong rivose microsculpture (Fig. 12B). It is actually on the tegument of the centre of the pronotum and elytra where lies the greater part of the variation.

The pronotum of $S$. enkerlini, S. foveiventris, S. edmondsi sp. nov., S. securus and the species of the furvus subgroup, as well as in the northern populations of $S$. candezei, is smooth and has evident micropunctation; in S. aequinoctialis, S. bridarollii, S. seag sp. nov., S. attenboroughi sp. nov. and in the southern populations of $S$. candezei, the alveolar microsculpture on the pronotum may be present, but it is always flat and micropunctation is evident; S. genieri sp. nov. is the only species where the pronotum always presents a strong alveolar microsculpture at the centre with the micropunctation obliterated by it, while $S$. proseni shows all the variation discussed above. In turn, elytra of S. foveiventris, S. securus, S. monnei sp. nov. and individuals from northern populations of S. candezei and S. seag sp. nov. are smooth and have dense micropunctation; those of $S$. aequinoctialis have a very subtle alveolar microsculpture, while those of $S$. mayri sp. nov. have a diffuse microsculpture, being the micropunctation evident in both species; and the elytra of the southern populations of $S$. candezei and $S$. seag sp. nov. and those of S. genieri sp. nov., S. proseni, S. bridarollii, S. edmondsi sp. nov., S. attenboroughi sp. nov. (majority of the specimens) and $S$. furvus show an evident alveolar microsculpture obliterating the micropunctation. Finally, a unique pattern is seen on the elytra of S. obscurus and S. enkerlini: the tegument of the centre of the elytra is smooth and has a dense micropunctation, while that of the sides and apex has a strong alveolar microsculpture obliterating micropunctation.

TRANSVERSE LINE ON THE POSTERIOR EDGE OF PRONOTUM. Schmidt $(1920,1922)$ assigned the presence of a fine transverse line at the centre of the posterior edge of the pronotum only to $S$. furvus, which is one of the features used by him to differentiate this species from $S$. obscurus in his key. In fact, this fine, sulcate line is absent in $S$. obscurus, as well as in S. foveiventris, but it is present in $S$. candezei, S. securus and $S$. aequinoctialis, species studied by Schmidt (1920,1922), as well as in S. enkerlini, S. genieri sp. nov., S. proseni, S. seag sp. nov., S. edmondsi sp. nov., S. attenboroughi sp. nov., S. monnei sp. nov., 
S. mayri sp. nov. and the majority of the specimens of S. bridarollii (see discussion on the geographical variation on this character in S. bridarollii in this species' section). Therefore, in the same way as for other characteristics thought earlier to be exclusive to only one species in the genus (see below the discussion about the coarse punctation on metafemora and the three pairs of female abdominal foveae), the transverse line of pronotum is actually a feature widely present among the Sylvicanthon.

Coarse punctation at the base of metafemora. In four species of Sylvicanthon, S. foveiventris (Fig. 13A), S. furvus (Fig. 13E), S. monnei sp. nov. (Fig. 13C) and individuals from southern populations of $S$. bridarollii (Fig. 13G), the ventral surface at the base of metafemora has a group of elongate and narrow impressions that is here denominated coarse punctation of the base of metafemora. Schmidt $(1920,1922)$ was the first author to observe this characteristic, saying it was present in S. foveiventris. Martínez (1949a), in the original description of S. bridarollii, observed the same coarse marks in this species and, indeed, he said his new taxon was close to $S$. foveiventris. In the present work, besides having observed for the first time this feature in S. furvus and S. obscurus, and describing it for the new species $S$. monnei sp. nov., we also noticed a curious geographical variation in S. bridarollii (Fig. 36): individuals from populations from central Bolivia, in places such as Cochabamba and Santa Cruz, have a very evident coarse punctation, whereas farther north in Bolivia and in southern Peru, this punctation is sparser and ill marked. Northwards in Peru and in Ecuador and Colombia, this punctation becomes increasingly thinner (almost undistinguishable from the micropunctation of the rest of the tegument) and, in the northernmost populations, it is completely absent. This clinal variation is very interesting because it shows that the coarse punctation is likely to be homologous to the micropunctation of the remainder of the tegument (which is present in all the other Sylvicanthon). Since species in three different subgroups show this kind of punctation, it is possible that it has evolved at least three times in Sylvicanthon. A final species, $S$. obscurus, is noteworthy in presenting, apparently, an intermediate condition: in the entire surface of its metafemora, the punctation is thicker and more evident than the micropunctation seen in other species (e.g., S. securus, $S$. edmondsi sp. nov., etc; or in the apical region of $S$. foveiventris, $S$. furvus, $S$. monnei sp. nov. and $S$. bridarollii), but they are not as elongated and deep as in the species with coarse punctation (Fig. 13B).

In the same way as for the abdominal foveae (see below), it is reasonable to suppose that the coarse punctation of the mefemora has a role in the chemical communication (through pheromones) between individuals of a same species. In the four species that possess it, the density of this punctation can vary intrapopulationally, but, with the sole exception of a specimen of $S$. foveiventris collected in Itamonte (Minas Gerais, Brazil), which has only vague vestiges of it, all the remaining specimens studied clearly show the coarse marks at the base of their metafemora. Other members of 'Canthon sensu lato' that have similar coarse punctuation are two of the species of Canthon (Peltecanthon) Pereira, 1953, namely C. staigi (Pereira, 1953) and C. sulcatus Castelnau, 1840 (see Halffter \& Martínez 1967: figs 9-10).

Elytral striae. Halffter \& Martínez (1977) and Tarasov \& Génier (2015) stated that Sylvicanthon have nine elytral striae and, indeed, this is probably the ancestral condition in the genus. In all the species, counting the number of striae is usually a difficult task, since, save the three or four more internal ones, they are very effaced, fine and discontinuous. As an effect, the maximum number of observable striae vary among the species: in $S$. proseni, S. obscurus and the members of the bridarollii subgroup the maximum number is nine; in $S$. candezei, $S$. genieri sp. nov. and $S$. aequinoctialis it is eight; and in $S$. foveiventris, $S$. securus, $S$. furvus, $S$. monnei sp. nov. and $S$. mayri sp. nov., seven. Another important feature to stress related to the elytral striae is the presence of a fine carina on the humeral region of the eighth stria; because of its position, this carina is hereafter called the humeral carina (Fig. 12C). Three species of Sylvicanthon possess it: S. aequinoctialis, S. proseni and S. obscurus. In the latter species, only two-fifths of the individuals studied show the humeral carina; in the other specimens, the eighth stria is flat and very fine in the same way as the other internal striae (see more details in the discussion of 
this species). On the other hand, all the specimens of S. aequinoctialis and S. proseni evidently show this carina, although in the first species it tends to be longer than in the second. Other groups of Neotropical Deltochilini also show a humeral carina, including species of Canthon and Scybalocanthon (e.g., see the discussion on Canthon xanthopus below).

SeXual DIMORPHISM. As commonly observed in Deltochilini, few secondary sexual characteristics are evident among the species of Sylvicanthon, a fact that turns the sexing of specimens into a difficult task. Being telecoprids, they have not developed the horns and other armaments that evolved among paracoprid dung beetles and which are used in combats between males inside tunnels and other closed spaces (see Emlen \& Philips (2006) for a detailed discussion on the relation between horns and paracoprid behaviour). In this way, sexual dimorphism is limited in Sylvicanthon to more discreet features, such as the shape of the sixth ventrite (Fig. 14B-E) and that of the protibial spur (Fig. 15).

In all Sylvicanthon, the fit between the apex of the pygidium and the sixth ventrite is distinct between males and females: in males, ventrite six has an emargination on its posterior edge that allows the pygidium to extend itself further into the ventral side of the abdomen (Fig. 14D); in females, there is no evident emargination and the pygidium does not extend towards the ventral side of the abdomen (Fig. 14B-C, E). Thus, it is possible to differentiate both sexes observing that the sixth ventrite of males is narrowed at the middle, whereas it is wide in females. Some species, however, exhibit modifications on the posterior edge of ventrite five that makes the observation of this difference difficult. Mainly in females of S. candezei, S. seag sp. nov., S. edmondsi sp. nov., S. attenboroughi sp. nov.and both sexes of S. securus, ventrite five has a weak medial expansion on its posterior edge covering the anterior region of ventrite six and thus giving a narrowed appearance to the latter (Fig. 14E). In males of those species, ventrite five also presents this medial flange and, in general (except in $S$. securus), it can be as or even more developed than in females (Fig. 14D).

Another sexual dimorphism found among the species of Sylvicanthon lies in the shape of the protibial spur: in females, this spur is spiniform and simple, without any bifurcation or apical expansion (Fig. 15F); the only exceptions are the females of $S$. proseni, whose spur is apically bifurcate (Fig. 15H). In sharp contrast to this uniform female shape, males of Sylvicanthon show wide interspecific variation in the morphology of their protibial spurs, with a unique pattern found in each species (excepting the group formed by $S$. furvus, $S$. monnei sp. nov. and $S$. mayri sp. nov., which shows the same shape in all the three species). In S. enkerlini, the spur is long, narrow and bifurcate at the apex, with the external branch longer than the internal (Fig. 15A). In the candezei subgroup, the spur is broad and bifid, with the external branch always longer than the internal one: in S. foveiventris, the internal branch is very broad and only slightly shorter than the external one, which is spiniform (Fig. 15B); in S. candezei, the internal branch is only slightly indicated and the separation between it and the external branch is horizontal (Fig. 15C); in S. genieri sp. nov., an intermediate condition is seen (Fig. 15D). In the aequinoctialis subgroup, the spur is also broad and bifid: in S. aequinoctialis, the internal branch is only slightly indicated (Fig. 15E), while it is much more developed in S. proseni (Fig. 15G); the female spur of S. proseni differs from males in being more narrowed and having the separation between external and internal branches in a closer angle (in ' $\mathrm{V}$ ', Fig. 15H), whereas in males it is much broader (in 'U'). In the bridarollii subgroup we see the highest level of interspecific variation: in S. bridarollii (Fig. 15I), the spur is narrowed and the internal branch is only slightly developed; in $S$. seag sp. nov., the spur is broad and the internal branch is also short (Fig. 15J) (in a single specimen from French Guiana, one of the spurs has a small tubercle in the space between the two branches); in $S$. edmondsi sp. nov., the two branches are very developed (the external one slightly longer) (Fig. 15K); and, lastly, in S. attenboroughi sp. nov., the spur has a narrow base, the apical region is broad and the internal branch is only slightly developed, clearly shorter than the external one (Fig. 15L). In the furvus subgroup, a shape is observed in S. obscurus, whose internal branch is broad and much shorter than the external one, from which it is separated by an open angle 
(Fig. 15M), and the one observed in the other three species, where the external and the internal branches are subequal in length and separated by a very close angle (Fig. 15N). Finally, the spur of S. securus differs from all the other species in having the internal branch, which is very broad, longer than the external one, which is spiniform (Fig. 15O). Such sheer diversity in the shape of the male protibial spur must have been the fruit of an intense pressure from sexual selection, although the role played by the protibial spurs in the life of the Sylvicanthon is still unknown.

A third sexually dimorphic characteristic is restricted to only five species in the genus: S. foveiventris and members of the furvus subgroup. Females of these five species possess three pairs of foveae located on the sides of the abdomen at the sutures between ventrites I-II, II-III and III-IV (Fig. 16). It is interesting to note that the presence of these foveae among the species and sexes in Sylvicanthon was matter of a wide confusion in the literature.

Schmidt (1920) included this characteristic in the description of $S$. foveiventris (and, probably, it was thanks to this feature that the species was named as such), but he did not make any mention whether these foveae were present in both sexes or whether they were unique to just one of them. It is curious to note, actually, that this was the only one of the four species of Sylvicanthon described by Schmidt (1920) without the sexual dimorphism discussed by him. For S. obscurus and S. furvus, although he had described sexual dimorphism related to the protibial spur, Schmidt (1920) did not mention the presence of abdominal foveae. Two years later, Schmidt (1922) erred again by assigning the presence of abdominal foveae to both sexes of $S$. foveiventris, an opinion that was repeated by most of the subsequent authors (Pereira \& Martínez 1956; Martínez et al. 1964). The exception was Balthasar (1939), who, in turn, was also wrong in suggesting that foveae might be a male characteristic in $S$. foveiventris ("nur beim ${ }^{\lambda}$ ?", $\mathrm{p}$. 189); once more, nothing was mentioned about the presence of this characteristic in both S. furvus and S. obscurus. As demonstrated in the present work, not only are the abdominal foveae present in other species than S. foveiventris, but in all these species they are restricted to females, being the easiest and the most reliable way to separate the sexes.

Little variation exists between the abdominal foveae of $S$. foveiventris (Fig. 13E, 16D), S. furvus (Fig. 16A) and S. monnei sp. nov. In S. obscurus, there is a row of long setae covering the anterior margin of each fovea, which, therefore, stand out from the remaining tegument of the abdomen (Fig. 16C). In the two females of S. mayri sp. nov. studied, in contrast, the abdominal foveae are clearly more narrowed and superficial than those seen in the other four species (Fig. 16B; see more details in the discussion of S. mayri sp. nov.).

In the same way as for the coarse punctation at the base of metafemora, it is here hypothesized that the abdominal foveae should also play a role in the intraspecific chemical communication, and, in this particular case, as they are secondary sexual characteristics, probably related to the sexual behaviour. The presence of tegumentary exocrine glands secreting semiochemicals is known for several groups of Scarabaeinae (e.g., Tribe 1975; Pluot-Sigwalt 1982; Houston 1986; Burger et al. 1990, 1995a, 1995b, 2002, 2008). Pluot-Sigwalt (1982), having studied several dung beetle genera, found an intricate distribution pattern of exocrine glands in the abdominal ventrites. In some cases, both males and females had these glands (although there was a remarkable sexual dimorphism in their numbers and dispositions), while in other cases they were restricted to just one sex. Interestingly enough, there was a clear distinction between telecoprid and paracoprid groups, with a much larger number of genera of the first group - to which Sylvicanthon belongs - presenting glands than of the second (Pluot-Sigwalt 1982).

The row of setae seen exclusively in the foveae of S. obscurus (Fig. 16C) may work as a kind of net to capture and concentrate close to the female's body the pheromones released into the air by the abdominal glands. Houston (1986), for instance, described two exocrine gland complexes associated to a tuft of 
setae present in the front legs of some species of Onitis Fabricius, 1789. Following his hypothesis, the pheromone secreted by one group of glands present only in males could work as a trail marker and, in this way, it could indicate to females the path to the dung mass or to the nest entrance. Therefore, the tuft of setae associated to exocrine glands would serve to deposit the pheromone to the substrate while the path is being marked. Although in S. obscurus these glands and associated setae are exclusive to females, not males, it is still possible that some similar behaviour occurs in this species. Studies on the reproductive habits of the Sylvicanthon species are necessary in order to know the actual function of the abdominal foveae in this group.

Aedeagus. As discussed above, males of Sylvicanthon do not differ from the majority of the other telecoprid dung beetles in not having horns or any other kinds of armaments. In these groups, it is in the shape of the parameres and pieces of the internal sac and their counterpart in the female sexual organ that the sexual selection should act in a more intense way (see for a discussion on the evolution and anatomy of the copulatory organs of a model species of dung beetle: Werner \& Simmons 2008; House \& Simmons 2003; Tarasov \& Solodovnikov 2011). This fact is reflected in the large variety of forms of aedeagi seen in Sylvicanthon, where even closely related species with a very similar external morphology may have entirely distinct parameres. The morphology of the female genitalia was not studied for this work, but, as seen in other groups of Scarabaeinae that had it examined (e.g., Zunino 1971, 1972, 1975, 1976, 1978, 2012; Zunino \& Halffter 1988; Marchisio \& Zunino 2012), it probably varies in a similar degree as the aedeagus. As emphasized by Zunino (1987), Méndez \& Córdoba-Aguilar (2004) and Ah-King et al. (2014), among several other authors, there is no reason to suppose that there is a higher morphological diversity among the male genitalia than among the female ones, since these structures evolve jointly in a complex interaction of evolutionary pressures derived from female choice and intra- and intersexual conflicts (see also Simmons 2014).

It is in the candezei and bridarollii subgroups where we can find the greatest diversity in paramere shapes. In the first subgroup, the parameres may be straight and simple (i.e., without any notch or keel in the ventral region; S. foveiventris, Fig. 17B), may have a strong ventral keel and a short notch on its posterior region (S. genieri sp. nov., Fig. 17D), or may bear a deep ventral notch without any keel (S. candezei, Fig. 17C). In the bridarollii subgroup, in turn, the parameres may be simple (S. bridarollii, Fig. 18A), with a short ventral keel (S. edmondsi sp. nov., Fig. 18C and S. attenboroughi sp. nov., Fig. 18D) or be highly modified with a ventral keel so deep that almost divide the parameres into two halves (S. seag sp. nov., Fig. 18B). With the exception of S. foveiventris and S. bridarollii, all the other species have sharply asymmetric parameres, with external faces differing from one another by being either concave or flat.

In the furvus subgroup, whose parameres are apically bifurcate and have no ventral keels or notches, the difference between the species is subtler in three of the four species. In S. furvus (Fig. 19C) and S. mayri sp. nov. (Figs 19E, 44A-B), the inferior branch of the bifurcation is distinctly projected and divergent from the superior branch, whereas in S. monnei sp. nov. (Figs 19D, 44C-D) the inferior branch is only slightly projected and is parallel to the superior branch. In those three species, both branches are connected by a fine membrane, but in the fourth member of their subgroup, S. obscurus, both branches are free and the superior branch projects itself much stronger than the inferior one, which has an acuminate apex (Fig. 19B). In the aequinoctialis subgroup, different from the other subgroups discussed before, there is no difference between the species (Fig. 17E-F); in both, the parameres are simple and have a broad depressed area at the apex which extends posteriorly farther in the left paramere than in the right. Finally, S. securus (Fig. 19A) and S. enkerlini (Fig. 17A) have elongate and simple parameres, without any ventral keel or notch. 


\section{Biogeography}

Sylvicanthon are largely distributed in the Neotropical region as defined by Morrone (2014, 2015b), occurring from Honduras to the Amazon Basin, the Atlantic Forest in NE and SE Brazil, and in the transition zone between the latter two biomes and the Brazilian Cerrado and Caatinga (Figs 20, 22). Among the areas into which Morrone (2014) divided the Neotropical region, Sylvicanthon is present in two of the three subregions (Brazilian and Chacoan), in all of the six dominions and in 24 of the 53 provinces. Four species (S. genieri sp. nov., S. bridarollii, S. edmondsi sp. nov. and S. furvus) are also present in the province of Paramo, in the South American Transitional Zone between the Neotropical and the Andean regions.

The candezei species group and S. enkerlini are very distinct with respect to the environments in which they live (Fig. 20). Species of the first group are distributed in the four great areas of tropical rainforests in the Neotropical region - the Central American tropical forests, the Choco, the Amazon forest and the Atlantic Forest -, where temperature and humidity are high, there is a dense and continuous canopy and the sunlight incidence on the surface of the soil, in the leaf litter in the understory and in the lower tree layers is very low. Thanks to these factors, mammalian dung, upon which Sylvicanthon feed, remains fresh and available for consumption and nidification for a longer time in those habitats. In contrast, S. enkerlini occurs in the transitional zones between Amazonia, Cerrado, Caatinga and the Atlantic
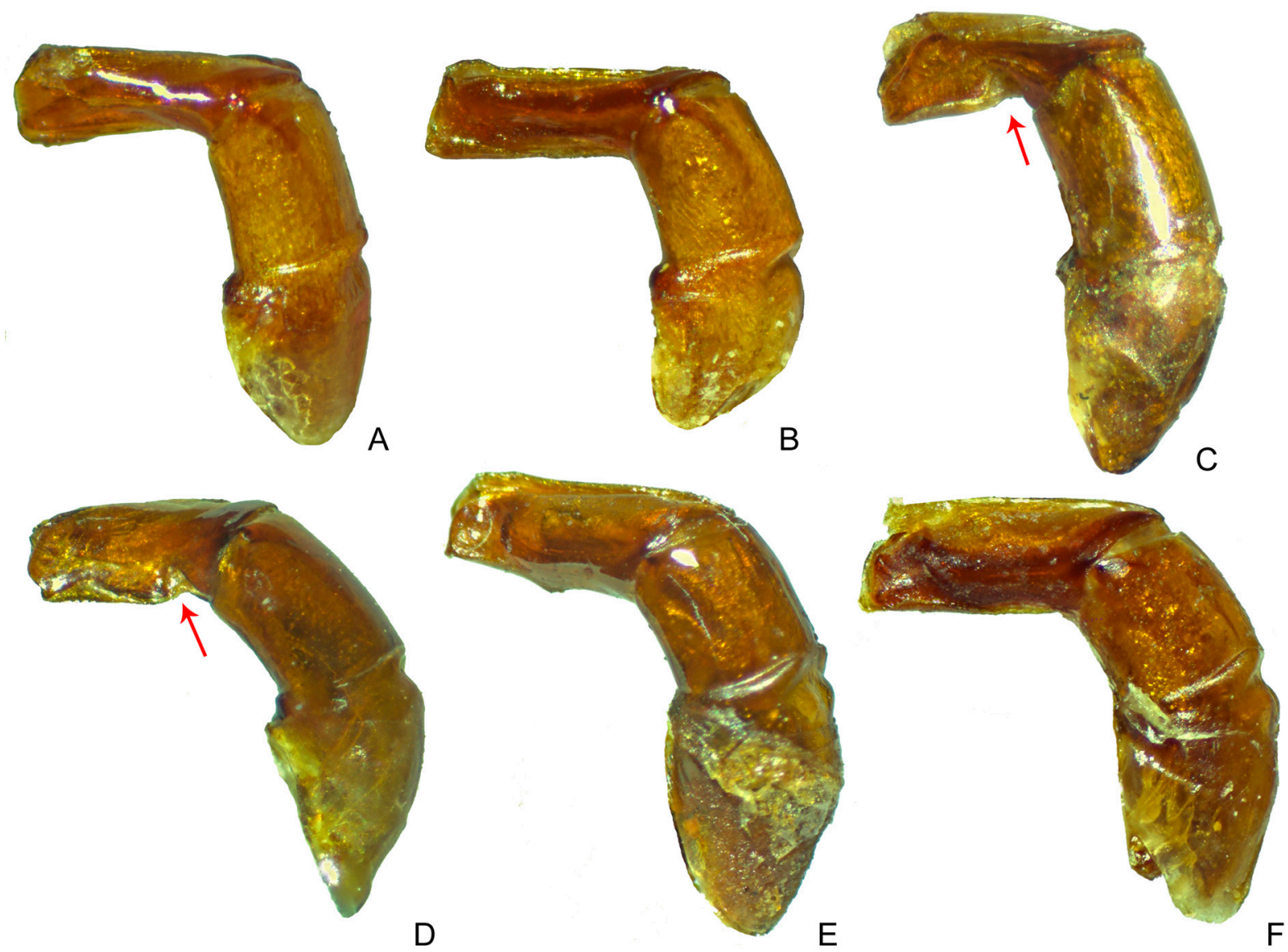

Fig. 17. Aedeagus morphological diversity in Sylvicanthon. A. S. enkerlini (Martínez et al., 1964) comb. nov. B. S. foveiventris (Schmidt, 1920). C. S. candezei (Harold, 1869) (arrows points to the ventral notch). D. S. genieri sp. nov. (idem). E. S. aequinoctialis (Harold, 1868). F. S. proseni (Martínez, 1949) stat. et comb. nov. 
Forest, in more open, shorter and drier semidecidual forests, such as the Mata dos Cocais, in Maranhão, the tableland forests (from the Portuguese 'matas de tabuleiro') in the coast of Ceará, and dryer forested areas typical of Cerrado and Caatinga in the interior of the Brazilian states of Piauí, Bahia, and Minas Gerais (Figs 20, 22; see more details on the distribution of S. enkerlini in the 'Natural history' section for this species).

Martínez et al. (1964) raised the hypothesis that Sylvicanthon (cited as "grupo aequinoctialis" of Glaphyrocanthon) originated in Amazonia and, from there, it dispersed to the other areas where it is present today. The greatest species diversity in the genus is indeed located in the Western Amazonia, in cloud forest areas close to the slopes of the Andes in Bolivia, Peru, Ecuador and Colombia, where S. genieri sp. nov., S. proseni, S. bridarollii, S. edmondsi sp. nov., S. attenboroughi sp. nov., S. furvus and $S$. mayri sp. nov. occur. The distribution of three of these species - S. proseni (Fig. 30), S. bridarollii
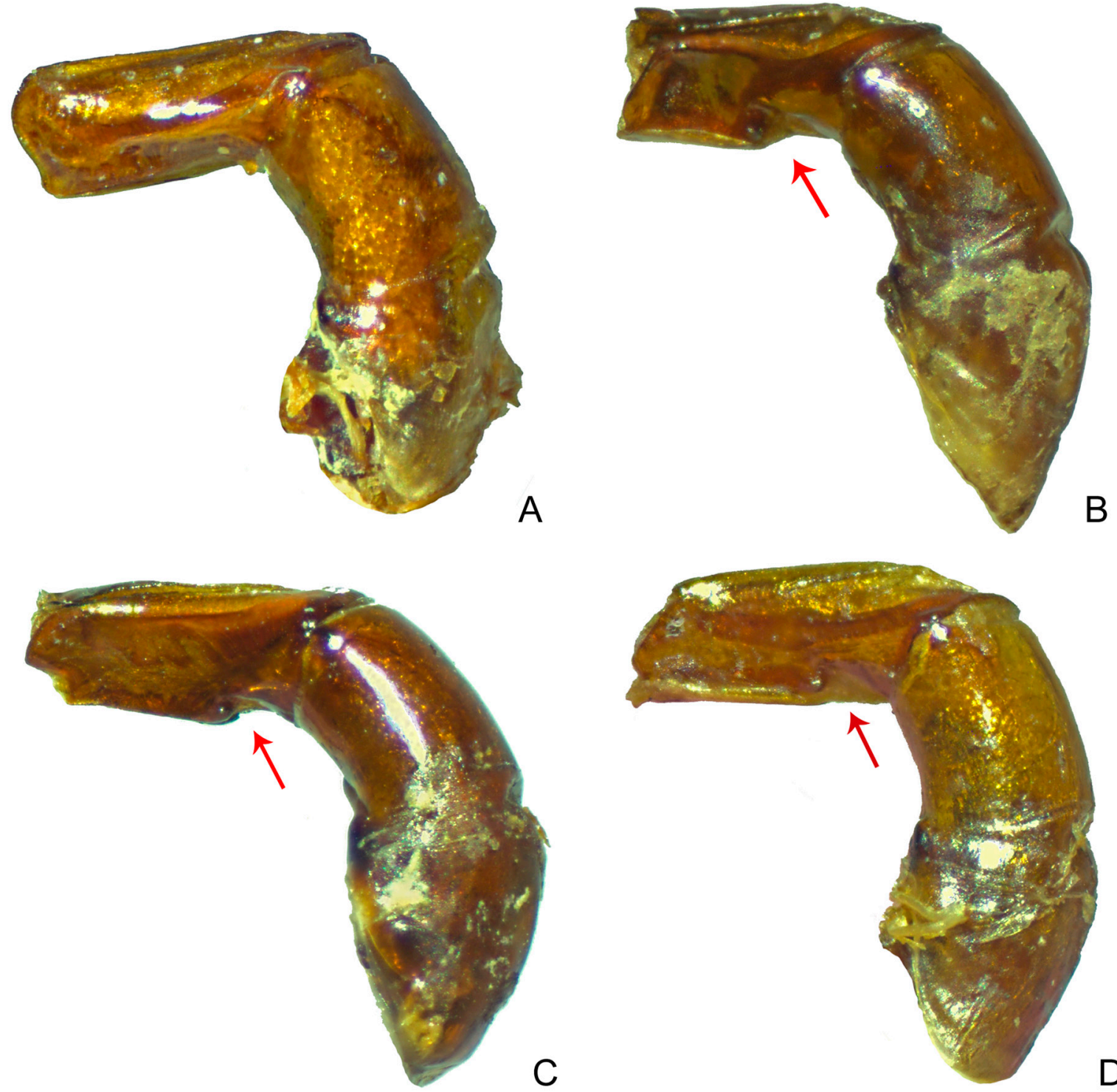

Fig. 18. Aedeagus morphological diversity in the bridarollii subgroup. A. S. bridarollii (Martínez, 1949). B. S. seag sp. nov. (arrow points to the ventral notch). C. S. edmondsi sp. nov. (idem). D. S. attenboroughi sp. nov. (idem). 
and S. attenboroughi sp. nov. (Fig. 34) - extends eastwards into the Amazon Basin, but the latter two are absent on the left banks of the Amazon river. In the latter region, it occurs $S$. securus (Fig. 41) and S. seag sp. nov. (Fig. 34), whose distribution extends farther north into the Guianas and, in the case of the latter species, also towards Venezuela and the island of Trinidad, the only insular record for the genus. Two further species occur in the Amazon region: S. monnei sp. nov., which is distributed throughout the forests of northern Mato Grosso and southern Pará, a dryer Amazon area with a more pronounced seasonality where rainy and dry seasons are sharply demarcated (Fig. 41), and S. candezei, which exhibits a very peculiar bow-shaped distribution from the mouth of the Tapajós River through the dry forests of the transitional region bordering the Cerrado in southeastern Pará and goes southwards into southern Amazon and its transition zone with the Pantanal region (Fig. 24). Together, therefore, eleven of the fifteen species of Sylvicanthon are typical elements of the Amazon forest. Following the hypothesis of Martínez et al. (1964), which is championed here, at least three distinct dispersal waves departed from the Amazonian centre of origin: the ancestors of $S$. foveiventris (candezei subgroup) and S. obscurus (furvus subgroup) towards the Atlantic forest, and those of $S$. aequinoctialis into Central America (Fig. 20).

The dispersal of Sylvicanthon aequinoctialis into the forests of Central America probably occurred only after the uplift of the Isthmus of Panama. The chronology about when this landbridge connecting North and South Americas was formed enough to allow the passage of fauna is yet a matter of great debate. Some authors argue for an older formation, where the vast marine passage connecting the Caribbean Sea
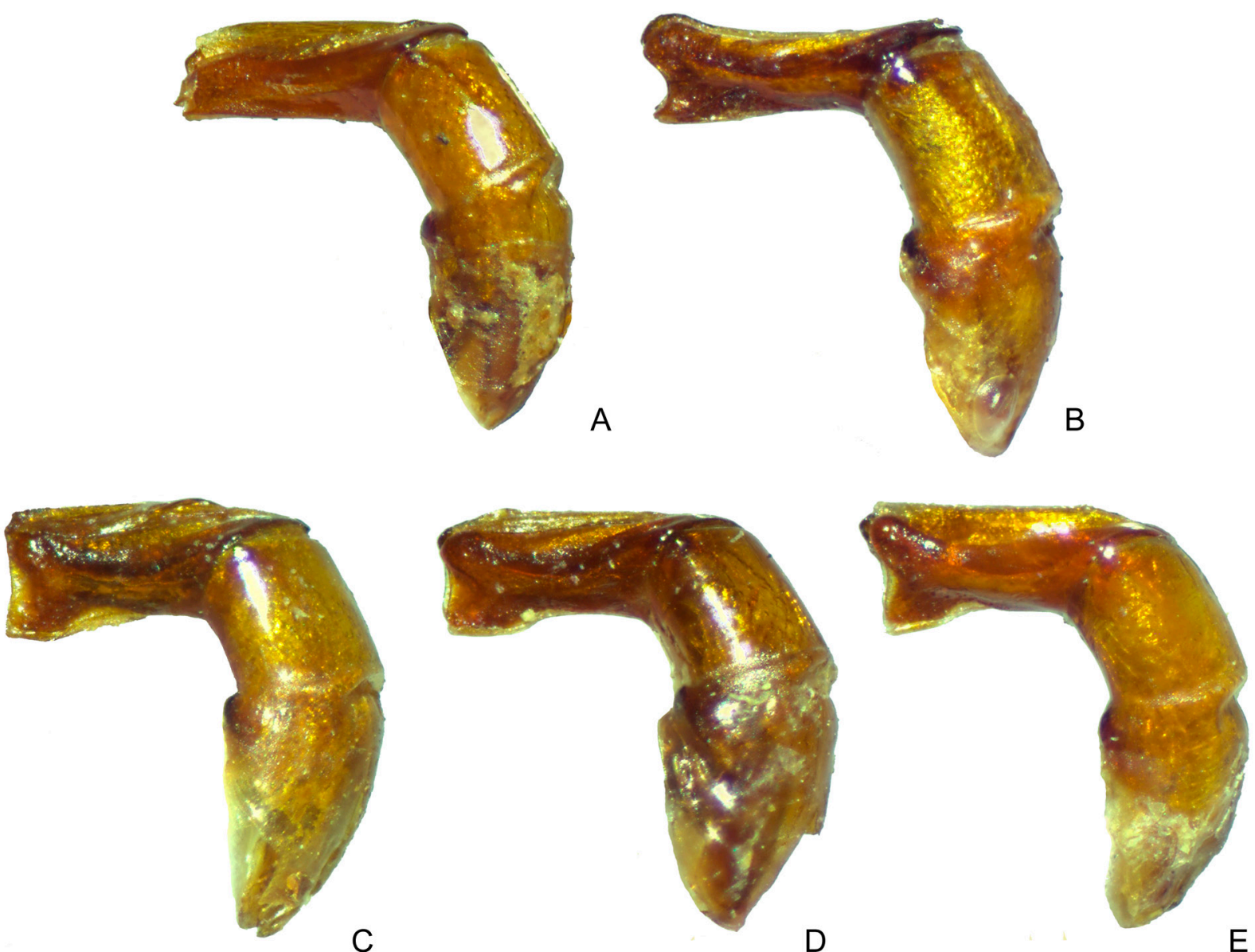

Fig. 19. Aedeagus morphological diversity in Sylvicanthon. A. S. securus (Schmidt, 1920) comb. nov. B. S. obscurus (Schmidt, 1920). C. S. furvus (Schmidt, 1920). D. S. monnei sp. nov. E. S. mayri sp. nov. 
and the Pacific Ocean, the so-called Central American Seaway, was closed in the Miocene, some 15 million years ago, and, thereafter, the right conditions allowing the biotic movement between the Americas were fully present (e.g., Montes et al. 2012a, 2012b, 2015; Jaramillo et al. 2017). Other authors, instead, argue that, between 15 million and about three or four million years ago, Central America and the northwest coast of South America were indeed close (about $200 \mathrm{~km}$ away from one another), but yet separated by a very deep sea, which prevented faunistic interchange until the final completion of the Isthmus of Panama

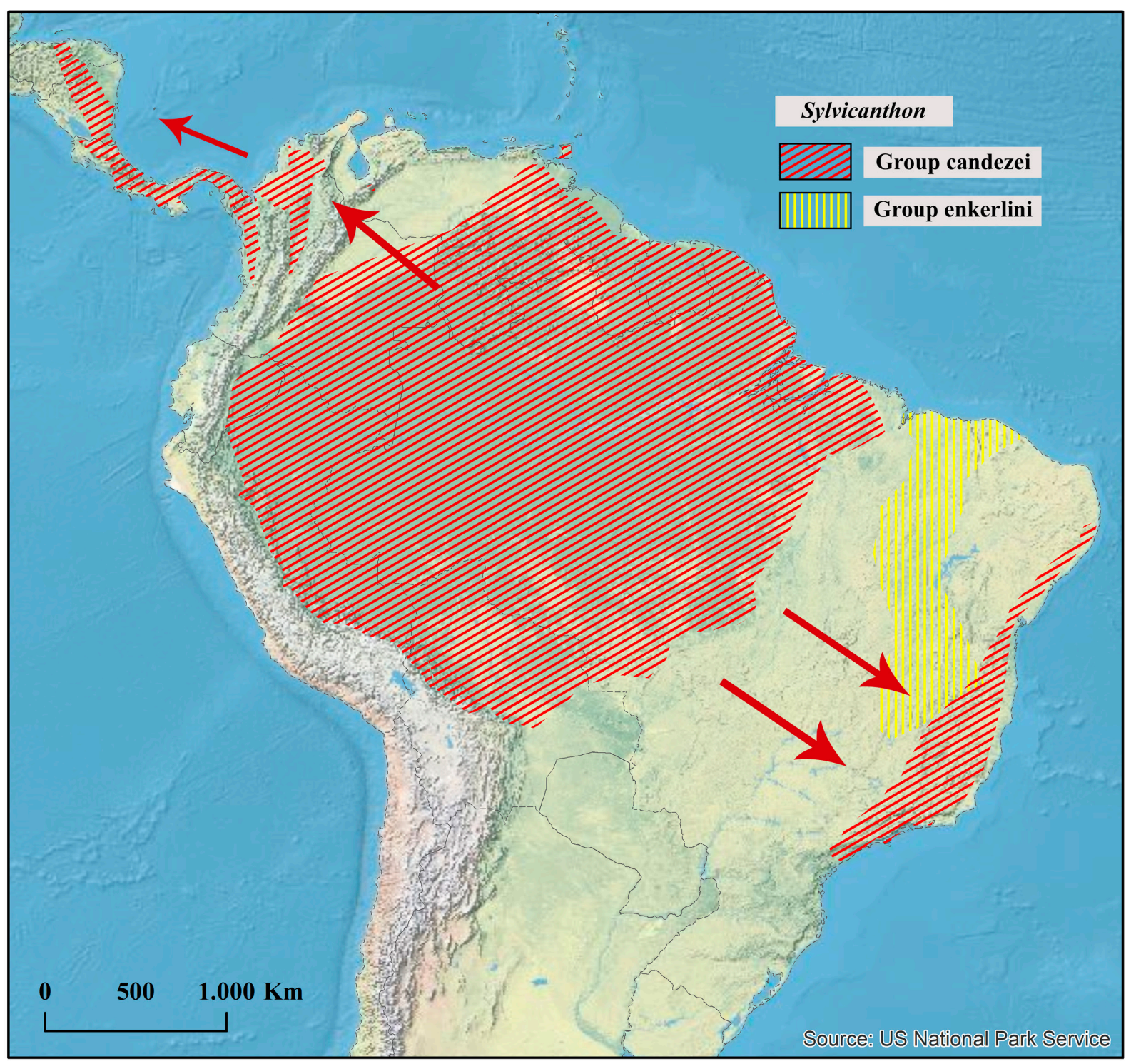

Fig. 20. Combined distribution of the species of Sylvicanthon in the Neotropical region. Note that the genus occupies the four great areas of tropical humid forest of the American continent: Central American forests, the Choco of the South American northwest, the Amazon Rainforest and the Atlantic Forest. Following the hypothesis of Martínez et al. (1964) that the Amazon Basin was the ancestral area of the Sylvicanthon of the candezei group, three lineages have independently dispersed from there (arrows): that of the ancestors of S. aequinoctialis (Harold, 1868), which, from the Choco, invaded Central America at the pace of the tropical forests' gradual northwards advance, occurred during the Plio-Pleistocene, and those of the ancestors of respectively S. obscurus (Schmidt, 1920) and S. foveiventris (Schmidt, 1920), which reached the Atlantic Forest through the corridors of humid forests that bridged that biome to the Amazon forest during the wettest periods of the Neogene (see a more detailed discussion in the text). 
about 3 million years ago (e.g., Coates \& Stallard 2013; O'Dea et al. 2016). This latter case would be an analogous situation to the current Wallace and Lydekker lines, on the limits, respectively, of the Sunda and Sahul continental shelves, in Indonesia, which mark the separation between the faunas of the Oriental and Australasian biogeographical regions (Coates \& Stallard 2013).

Curiously enough, studies on the dung beetle dispersal from South to North America argue that this movement occurred in two independent waves, one during the Miocene and another during the PlioPleistocene (Kohlmann \& Halffter 1988, 1990; Edmonds 1994; Price 2009; Halffter \& Morrone 2017). Not coincidently, these two migratory waves correspond exactly to those two distinct phases in the geological history of the Isthmus of Panama as theorized by Coates \& Stallard (2013) and O'Dea et al. (2016) (but see the replies by Jaramillo et al. 2017 and Molnar 2017). The first migratory wave would have advanced through a chain of several small islands in the then-existing strait between Central America and South America's northwest coast, while the second wave would have occurred during the gradual advance of the South American tropical forest into Central America after the uplift of the Isthmus of Panama was completed. Being a tropical forest dweller, S. aequinoctialis should have invaded Central America from the Choco forest in northern South America during this second migratory wave (Fig. 20), in the same way as done by Glaphyrocanthon and allied groups (Kohlmann \& Halffter 1990).

Together, those migratory waves were part of the so-called Great American Biotic Interchange of the Neogene. Several groups of dung beetles of a clear South American origin, such as Phanaeus MacLeay, 1819, Coprophanaeus d'Olsoufieff, 1924, Dichotomius Hope, 1838, Ontherus Erichson, 1847, Canthidium, Ateuchus, Uroxys, Deltochilum, Canthon and Scybalocanthon, trod this very same path from the southern continent towards Central America and, in the most successful cases, to North America, places where some of these groups have undergone a remarkable adaptive radiation. The reverse path, that is, from North to South America, was traveled by a much smaller number of lineages, including Onthophagus Latreille, 1802 and Copris Geoffroy, 1762. It is interesting to note that this was exactly the opposite migration pattern of the mammals, whose primary direction was southwards and which were the focus of much of the studies on the Great American Interchange (e.g., Simpson 1980); in this context, it is especially important to remember that mammals are the main group of vertebrates which dung beetles depend on for food. Birds, on the other hand, migrated mainly from south to the north (Weir et al. 2009), in the same way as it seems to have occurred with some scarab groups (e.g., Dynastes Kirby, 1825; Huang 2016) and dung beetles (personal observations ${ }^{18}$ ). We agree that future studies on the participation of the dung beetles and other insect taxa in the Great American Interchange will shed light on the ecological factors driving the distinct patterns seen in different groups of organisms. But most importantly, the dung beetle northwards migration pattern shows that simplistic hypotheses championing a 'more competitive nature' of North American elements fail to explain the whole biotic movement, to say the least.

The other two species of the candezei group, occuring outside Amazonia, are S. foveiventris and S. obscurus, both inhabitants of the Atlantic Forest (Figs 24, 41). Although the South American Dry Diagonal formed by the Caatinga, Cerrado and Chaco separates the humid forests of Amazonia and the Atlantic Forest, both biomes have never been completely isolated from one another and, in fact, they have a long and complex history of interactions throughout the Cenozoic (Costa 2003; Batalha-Filho et al. 2013; Daniel \& Vaz-de-Mello 2016; Ledo \& Colli 2017; and references cited therein). Studies based mainly on the distribution and phylogeny of land vertebrates showed that there was a great mixture of fauna between those two areas, especially during intervals of more humid climate, when gallery forests and patches of humid forests penetrated more strongly into the interior of the dry regions of central South America and in this way served as bridges connecting the two biomes. Batalha-Filho et al. (2013), for example, found that there were two great bird interchange movements between Amazonia and the Atlantic Forest during the Neogene, the oldest having occurred between southwestern Amazonia and 
southern Atlantic Forest during the Miocene (24 to 5 million years ago) and the most recent one during the Plio-Pleistocene (the last 5 million years) between northeastern Amazonia and the northern portion of the Atlantic Forest. In this way, the phylogeny of South American animals shows several cases where sister species or sister groups occur separately, one in the Amazon, the other in the Atlantic Forest.

If Sylvicanthon and other Deltochilini took part in episodic migratory waves as those of the example discussed above, or if they had a history of a continuous communication between the Amazonia and the Atlantic Forest, is still a question for further research. What is clear, nonetheless, is that at least two lineages - the one which gave origin to $S$. obscurus and the other which originated S. foveiventris - arrived independently at the Atlantic Forest from the Amazon region. As argued by Costa (2003), the dispersal history of any animal group between these two biomes should have been extremely complex and deeply influenced by local events that varied over time, scale and mainly in the effect that they had in different groups of organisms, as shifts in river courses, climate changes or refuge formations. Therefore, hardly a single phenomenon or pattern will be found to explain the whole movement of fauna between the Atlantic Forest and the Amazon which Sylvicanthon species could fit in. In order to understand in deep detail the biogeography of Sylvicanthon, it is necessary that we first study empirically the phylogenetic relationships between its species.

It is also interesting to note here that each of the polytypic subgroups of Sylvicanthon show both a distribution and a phylogenetic pattern that could lead an evolutionary biologist to classify them as superspecies, that is "monophyletic group[s] of allopatric or nearly allopatric taxa that are known or believed to have evolved to the species level" (Amadon 1966, 1968; see also Mayr 1931, 1942, 1963, 1970; Mayr \& Diamond 2001; Mayr et al. 1953; Haffer 1986; Mallet 2007). This observation may indicate that the species of at least some of the subgroups represent very recent events of allopatric speciation, since even in cases where the former geographic barrier seems to have already collapsed, the allospecies (i.e., each constituent species of a superspecies) remain largely allopatric or parapatric in relation to its sister or other closely-related species.

For instance, in the bridarollii subgroup, the distribution of S. bridarollii and S. attenboroughi sp. nov. are parapatric, with a clear overlap in southern Peru and northwestern Brazil, but neither penetrates completely into the range of the other, with $S$. bridarollii being the only species occurring both south to Bolivia and north to Colombia, while $S$. attenboroughi sp. nov. is the only one to occur farther east in Brazil (Fig. 34). Sylvicanthon edmondsi sp. nov., on the other hand, is found in sympatry with S. bridarollii throughout its distribution range, although no possible case of hybridization has been found, indicating thereby that a complete reproductive isolation must already have been developed, which in turn made sympatry possible without the merging of both species. The fourth member of this subgroup/superspecies, S. seag sp. nov., is the only one completely allopatric in relation to the other three species, being separated from them by the Amazon River.

The case of the candezei subgroup is probably distinct, since the three allospecies are distributed very apart from each other, one in the Atlantic Forest (S. foveiventris), the second in the southeastern Amazonia (S. candezei), and the third on the slopes of the Andes (S. genieri sp. nov.) (Fig. 24). This may indicate instead a relict distribution pattern of a subgroup that was once widely distributed in the Amazon Basin and, perhaps, even in the Atlantic Forest. The distribution of the species in the furvus subgroup (Fig 41), in turn, is so poorly known that it is difficult to make any generalization. Given the very suble morphological differences between its three Amazonian allospecies (S. furvus, S. monnei sp. nov. and S. mayri sp. nov.), however, we believe this subgroup, in the same way as discussed above for the bridarollii subgroup, should have experienced a series of recent speciation events. As for the aequinoctialis subgroup, the continuing uplift of the Colombian Andes, with the subsequent isolation of two independent demes on 
either side of the mountain range, should have been the vicariance event responsible for the division of the ancestral species that gave origin to $S$. aequinoctialis and S. proseni (Fig. 30).

Although the concept of superspecies has been mostly applied to vertebrate taxa (particularly birds), some authors such as Huang (2017), dealing with the genus Dynastes, and Mayr (1963: 501), referring to the Mycotrupes LeConte, 1866 studied by Olson et al. (1954), have already used it to refer to monophyletic groups of allopatric species in Scarabaeoidea. Although one could argue that the adoption of this term would only add more uncertainty to an already rather turbulent epistemological context (see the discussion on the species concept above), the first author of this monograph believes that its synthesis of both biogeographical (allopatry) and phylogenetic (monophyly) information is of great value for evolutionary studies, particularly for those dealing with allopatric speciation processes (i.e., the formation of geographic barriers to the gene flow, the development of reproductive isolation and the multiplication of species). Therefore, he encourages a more widespread application of the superspecies concept in biogeographical and taxonomic works dealing with scarab beetles. See Amadon $(1966,1968)$ for a more detailed defence of the value of the term superspecies.

\section{Natural history}

Literature and label information make it clear that Sylvicanthon species are primarily coprophagous, consuming human faeces and other primate, pig and cow dung, although there are also some records of specimens feeding on carcases. All the species are nocturnal, as can be inferred from their large eyes with smooth corneas (Caveney \& McIntyre 1981; McIntyre \& Caveney 1998) and from their usual dark colouration (Hernández 2002; Feer \& Pincebourde 2005). It is curious to note that, in this genus context, some species can be classified as eurytopic, such as S. proseni, S. aequinoctialis, S. bridarollii and S. seag sp. nov., as they live in a wide altitudinal gradient, have a vast distribution and are very abundant (usually, they are among the most abundant species in the dung beetle communities of which they are part), while other species, thanks to their rarity or environmental specificity (or both factors), are clearly stenotopic, like S. securus, S. foveiventris and, especially, S. furvus, S. monnei sp. nov. and S. mayri sp. nov. Sylvicanthon foveiventris, for instance, although not rare, is found only in forest areas higher than $600 \mathrm{~m}$, whereas $S$. securus, despite having a wide distribution in the north of the Amazon region, is a very rare species. In fact, this relationship between specialist and less-abundant species in contraposition to more generalist and more abundant ones is clear when we compare the relative abundance of $S$. seag sp. nov. and $S$. securus in places where those two species occur in sympatry: the relation can vary from three up to $65 S$. seag sp. nov. for each $S$. securus in the same area, according to the data gathered for the present work (see more details in the discussion of $S$. securus). Nothing is known about the nesting behaviour of Sylvicanthon, although it is reasonable to assume they belong to Pattern IV as defined by Halffter \& Edmonds (1982), where most of the American Deltochilini are classified to.

\section{Identification key to the species of Sylvicanthon Halffter \& Martínez, 1977}

1. Clypeus with four teeth (Fig. 6A). Anterior margin of profemora with denticulation at its apical half (Fig. 9B). Protibiae with three large and widely separated teeth and with a strong expansion on its internal edge (Fig. 11A). Hypomera with posterior part with about 5 long setae forming a longitudinal row close to external edge (Fig. 9D). Ecotone between the Amazon rainforest, Cerrado, and the Atlantic Forest in Brazil (Maranhão, Piauí, Ceará, Bahia, and Minas Gerais) enkerlini group: Sylvicanthon enkerlini (Martínez et al., 1964) comb. nov.

- Clypeus with only two small apical teeth (Fig. 6B-G). Anterior margin of profemora without denticulation (Fig. 9A). Protibiae with two or three small or medium-sized teeth; if teeth are large, internal edge always straight; if small, internal edge straight or expanded (Figs 11C-J). Hypomera with posterior part glabrous. Humid tropical forest in Central America, Amazonia and Atlantic Forest 
2. Protibiae with two small teeth and internal edge always straight (Fig. 11J) ... candezei subgroup: 3 .

- Protibiae with three small or large teeth and internal edge straight or expanded (Fig. 11C-I) ........ 5

3. Head and pronotum purplish and elytra green or dark blue (Fig. 23A). Pronotum and elytra with no microsculpture at centre. Metafemora with coarse elongate punctation at base (Fig. 13A). Females with three pairs of lateral foveae on abdomen between ventrites I-II, II-III, and III-IV (Fig. 14B, 16D). Parameres simple, without ventral keel or notch (Fig. 17B). Forests above $600 \mathrm{~m}$ in southeastern Brazil Sylvicanthon foveiventris (Schmidt, 1920).

- Different colour pattern. Centre of pronotum and elytra with strong microsculpture (S. genieri sp. nov.) or with smooth or even absent microsculpture (S. candezei). Metafemora without coarse punctation at base. Abdomen of both sexes without lateral foveae. Parameres with ventral keel and/ or notch (Fig. 17C-D). Amazonia

4. Dorsal colouration of the body dark green (Fig. 25A). Centre of pronotum, elytra, and pygidium without microsculpture (northern populations) or with flat alveolar microsculpture weakly marked (southern populations); in both cases, micropunctation abundant (denser on pronotum than on elytra). Posterior edge of ventrite $\mathrm{V}$, in males, with a weak flange covering anterior edge of ventrite VI (Fig. 14D); in females, posterior edge of ventrite $\mathrm{V}$ with a strong medial expansion over ventrite VI (Fig. 14E). Parameres with strong ventral notch and without ventral keel (Fig. 17C). Humid tropical forests from the mouth of the Tapajós River down to the semideciduous forests of southern and southeastern Amazonia in Brazil (Pará and Mato Grosso)

Sylvicanthon candezei (Harold, 1869).

- Dorsal colouration bright coppery (occasionally, with greenish reflections on head and on the sides of elytra) (Fig. 27A). Centre of pronotum, elytra, and pygidium with strong alveolar microsculpture obliterating micropunctation. Posterior edge of ventrite V, in males, without medial flange (rarely, with a very weak trace of flange over anterior edge of ventrite VI); in females, posterior edge of ventrite $\mathrm{V}$ with weak medial flange over ventrite VI. Parameres with short ventral notch and strong ventral keel (Fig. 17D). Cloud forests of western Amazonia and slopes of the Andes in Ecuador and Peru

Sylvicanthon genieri sp. nov.

5. Suture between submentum and gula Y-shaped (Fig. 8B). Protibiae with internal edge straight and medium- or large-sized teeth at their apical half (Fig. 11B). Ventral face of metafemora with posterior margin (Fig. 31). Humeral carina always presente (Fig. 12C). Parameres with depressed apical area (Fig. 17E-F); without ventral keel or notch. Central America and Amazon Basin aequinoctialis subgroup: 6 .

- Suture between submentum and gula rounded (Fig. 8A). Protibiae with internal edge straight or expanded and with small and narrow teeth at their apical third (Fig. 11C-I). Ventral face of metafemora without posterior margin (Fig. 13). Humeral carina usually absent (present only in some specimens of S. obscurus). Parameres without depressed apical area; with or without ventral keel and notch. Amazon Basin and Atlantic Forest 7

6. Dorsum, ventral surface of metafemora, and pygidium with bright and lustrous appearance. Centre of pronotum and elytra without microsculpture or with very subtle flat alveolar microsculpture. Ventral surface of metafemora and pygidium with very fine three-dimensional alveolar microsculpture (i.e., with tiny alveoli). Posterior edge of head with margin between eyes always complete. Posterior margin of metafemora extending from apex to at least the height of trochanter (usually going beyond it) (Fig. 31A). Protibial spur of females spiniform (Fig. 15G). From Honduras to northern Colombia Sylvicanthon aequinoctialis (Harold, 1868) comb. nov.

- Dorsum, ventral surface of metafemora, and pygidium with diffuse shine and with a more matte appearance. Centre of pronotum, ventral surface of metafemora and pygidium with very strong 
three-dimensional alveolar microsculpture; micropunctation ranging from very dense to absent. Posterior edge of head with margin between eyes complete, incomplete, or absent. Posterior margin of metafemora not reaching trochanter (usually extending little beyond the apical half of metafemur) (Fig. 31B). Protibial spur of female bifid (Fig. 15H). Amazonia (Colombia, Ecuador, Brazil, Peru, and Bolivia) Sylvicanthon proseni (Martínez, 1949) stat. et comb. nov.

7. Protibiae with internal margin straight (Fig. 11H-I) (moderately expanded in northern populations of S. bridarollii (Fig. 11G) and only slightly expanded in southern populations of this species (Fig. 11F); in these cases, pronotum with alveolar microsculpture). Lateral portions of metaventrite completely glabrous. Abdomen of both sexes without lateral fovea. Amazonia ................bridarollii subgroup: 8

- Protibiae with internal edge clearly expanded (Fig. 11C-E). Pronotum without alveolar microsculpture. Sides of metaventrite with some few setae near metacoxae (Fig. 7B). Abdomen of females with (Fig. 16A-C) or without lateral foveae (absent only in S. securus) Amazonia and Atlantic Forest

8. Hypomeral cavity covered at centre by long yellowish erect setae (Fig. 25C-D). Protibiae with internal edge moderately (Fig. 11G; northern populations) or only slightly (Fig. 11F; southern populations) expanded. Metafemora with (Fig. 13G) or without (Fig. 13H) coarse elongate punctation at base. Metaventrite covered at centre by strong three-dimensional alveolar microsculpture. Pygidium with three-dimensional alveolar microsculpture strongly marked and with very subtle, almost imperceptible punctation. Parameres symmetrical (both with external face flat) and simple, without ventral keel or notch (Fig. 18A). Western Amazonia in Colombia, Ecuador, Brazil (Acre, Rondônia), Peru and Bolivia ........................................ Sylvicanthon bridarollii (Martínez, 1949).

- Hypomeral cavity glabrous at centre (Fig. 35A-B; rarely with one or two very short setae); setae, if present, restricted to anterior and posterior regions of the cavity. Protibiae with internal edge straight (Fig. 11H-I). Metafemora without coarse elongate punctation at base (except in rare especimens of $S$. attenboroughi sp. nov.) (Fig. 13F). Metaventrite with very fine alveolar microsculpture at centre and progressively more diffuse towards posterior region. Pygidium with or without alveolar microsculpture strongly marked and with micropunctation of variable density, but always evident. Parameres asymmetrical (external face of left paramere excavated and external face of right paramere flat) and with ventral keel (Fig. 18B-D). Amazonia

9. Anterior edge of ventrite VI of females distinctly covered by medial flange of posterior edge of ventrite $\mathrm{V}$. Parameres with strong ventral notch and with ventral carina strongly projected; apical half of parameres squared (Fig. 18B). Northern Amazonia, in Trinidad, Venezuela, Guyana, Suriname, French Guiana and Brazil; except the region east of its mouth, always limited to the left banks of the Amazon River Sylvicanthon seag sp. nov.

- Anterior edge of ventrite VI of females only subtly covered by weak medial expansion of posterior edge of ventrite V. Parameres with elongate appearance and shorter ventral keel (Fig. 18C-D). Western and southern Amazonia

10. Head dark purple, pronotum with strong greenish or bluish shine at centre and purplish on sides, elytra dark blue or purple, and meso- and metafemora orangish-brown or yellowish (Fig. 38A-B). Dorsal surface of head with very subtle, almost imperceptible micropunctation. Northwestern Amazonia, mainly in Sub-Andean areas in Colombia, Ecuador and Peru ..........Sylvicanthon edmondsi sp. nov.

- Head and pronotum entirely very dark purple (almost black), without central greenish or bluish central spot on pronotum; elytra dark green or dark blue; meso- and metafemora orangish-brown, reddish-brown or dark brown (Fig. 38C-D). Dorsal surface of head with micropunctation evident on posterior region of clypeus and mainly on frons. Southern Amazonia, on the right margin of the Amazon River, in Brazil and Peru 
11. Each clypeal tooth with base covered by a separate row of setae. Elytra with dense micropunctation and without trace of alveolar microsculpture. Internal edge of protibiae strongly expanded (Fig. 11C). Abdomen of both sexes without lateral foveae. Parameres simple, without apical bifurcation (Fig. 88). Northern Amazonia, in Suriname, French Guiana and Brazil Sylvicanthon securus (Schmidt, 1920) comb. nov.

- Pair of clypeal teeth with base covered by a single row of setae. Elytral sculpture variable, alveolar microsculpture present or not. Internal margin of protibiae not as strongly expanded as in S. securus (Fig. 11D-E). Females with three pairs of foveae at the sides of the abdomen between ventrites I-II, II-III, and III-IV (Fig. 16A-C). Parameres bifurcate at apex (Fig. 19B-E). Southern and western Amazon and the Atlantic Forest

furvus subgroup: 12

12. Elytra with strong micropunctation and without microsculpture at centre and with strong threedimensional alveolar microsculpture on sides and apex. Humeral carina present in about two-fifths of the specimens (Fig. 12C). Metafemora without coarse elongate punctation at base (Fig. 13B). Lateral foveae of abdomen of females covered by row of long setae (Fig. 16C). Parameres with branches of apical bifurcation free, with no membrane connecting them (Fig. 19B). Northern Atlantic Forest, from Alagoas to Espírito Santo (Brazil) Sylvicanthon obscurus (Schmidt, 1920).

- Elytra with different sculpture pattern; either entirely microsculptured or entirely smooth. Humeral carina always absent. Metafemora with coarse elongate punctation (Fig. 13C, E) (except S. mayri sp. nov., Fig. 13D; see comments above). Lateral foveae of female abdomen glabrous (Fig. 16AB). Parameres with branches of apical bifurcation connected by a fine membrane (Fig. 19C-E). Amazonia 13

13. Head with diffuse shine and strong alveolar microsculpture covering the entire tegument. Meso- and metafemora with ventral surface completely covered by rivose microsculpture, with no smooth areas and with strong three-dimensional alveolar microsculpture. Elytra with diffuse shine and entirely covered by strong three-dimensional alveolar microsculpture. Pygidium with diffuse alveolar microsculpture at centre and apex, and with strong rivose microsculpture at base. Eastern slopes of the Andes in Peru and Bolivia Sylvicanthon furvus (Schmidt, 1920).

- Head shiny and with weak alveolar microsculpture, which, in some areas, is totally absent. Mesoand metafemora with ventral surface almost entirely smooth and with evident micropunctation, except on anterior apical area with rivose microsculpture. Elytra shiny, entirely smooth or with very diffuse microsculpture and ill-delimited alveoli. Pygidium completely smooth at centre and with rivose microsculpture occasionally present on sides of base. In general, in lower Amazon areas; with no records from the Peruvian and Bolivian Andes

14. Elytra smooth, with no trace of microsculpture throughout its surface. Metafemora with coarse elongate punctation at base (Fig. 13C). Abdominal foveae of females always well marked and deep (Fig. 16A). Parameres with inferior branch of apical bifurcation weakly projected or straight, without posterior excavation (Fig. 44C). Southern Brazilian Amazonia (Pará and Mato Grosso)

Sylvicanthon monnei sp. nov.

- Elytra with diffuse microsculpture, which is difficult to see and has ill-defined alveoli. Metafemora with coarse punctation modified in fine, simple points at centre of base (Fig. 13D; but see discussion above). Abdominal foveae of females very shallow (especially between ventrites III-IV) (Fig. 16B). Parameres with inferior branch of apical bifurcation well projected and largely divergent from superior branch, with strong posterior excavation (Fig. 44A). Western Amazonia in Colombia, Brazil (Amazonas and Acre) and Peru

Sylvicanthon mayri sp. nov. 


\section{The enkerlini group}

Sylvicanthon enkerlini (Martínez et al., 1964) comb. nov.

Figs 6A, 9B-D, 10B, 11A, 15A, 17A, 20-22

Glaphyrocanthon (Glaphyrocanthon) enkerlini Martínez et al., 1964: 5, 8, 13, 17-21, figs 1-2.

Canthon (Francmonrosia) enkerlini - Halffter \& Martínez 1977: 86.

Canthon enkerlini - Krajcik 2012: 63.

Sylvicanthon sp. - Lima et al. 2013: 91-93.

\section{Etymology}

Eponym after the Mexican entomologist Dieter Enkerlin Schallenmüller (1926-1995) (Martínez et al. 1964).

\section{Material examined}

Holotype

BRAZIL: フ̃, Maranhão, São Luís (“BRASIL / Eo Maranhao / São Luiz / Coll. Martínez / Sep. 955”, "HOLOTYPUS", "Glaphyrocanthon / enkerlini / ô / sp. nov. / M. H. y H. / A. Martínez det 1963", "FICHADO", "MACN-En / 1050"), genital capsule removed and glued in a triangular label (MACN-En / 1050) (Fig. 21C).

Additinal material $(47 \hat{\partial} \widehat{\partial}, 44$ 우)

BRAZIL: Bahia: 1 , Barreiras, Oct. 1991, light trap, without collector (CEMT); 1 , Barreiras, Nov. 1991, without collector (CEMT); 2 đ̊̄, 1 q, Barreiras, Jan. 2003, P. Schmidt leg. (CEMT); 2 q $q$, Pilão Arcado, Barra do Brejo, $10^{\circ} 06.677^{\prime}$ S, 4253.678' W, 416 m, 5 Dec. 2005, P.P. Lopes leg. (CEMT); 2 우, Pilão Arcado, Barra do Brejo, 1006.677' S, 4253,678' W, 416 m, 27 Mar. 2006, V. Mendes leg. (MZFS). - Maranhão: $2 \hat{\jmath}, 4$ 우, Mirador, Parque Estadual do Mirador, Povoado Pindaíba (Mel), $06^{\circ} 41^{\prime} 06^{\prime \prime}$ S, 450 $00^{\prime} 26^{\prime \prime} \mathrm{W}, 1-5$ Jun. 2010, pitfall with human faeces, F. Limeira-de-Oliveira, M.M. Abreu and J.S. Pinto leg. (CEMT). - Minas Gerais: 1 q, Bandeira ("R. Bandeira"), Jan. 1932, José Blaser

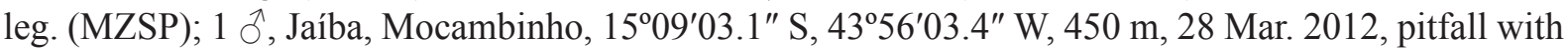
human faeces, A. Fialho leg. (CEMT); 1 ㅇ, Três Marias, 17 Mar. 1992, without collector (CEMT). -

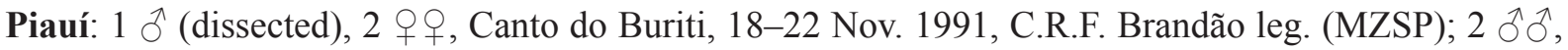

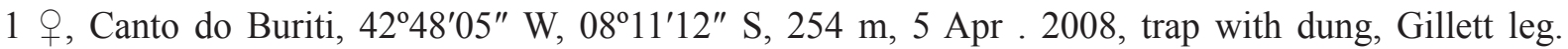
(CEMT); 1 §, Corrente ("10 km N Corrente"), Fazenda Maracujá, 23-27 Nov. 1991, E.M. Cancello and M.T. Ponte leg. (MZSP); 1 §ิ, Corrente ("10 km N Corrente"), Fazenda Maracujá, 23-27 Nov. 1991, S.T.P. Amarante and C.F. Martins leg. (MZSP); 1 đ̃, Floriano, Fazenda Buriti Sol, 5-12 Oct. 1991, S.T.P. Amarante leg. (MZSP); $6 \widehat{\partial} \hat{\jmath}, 3$ q $q$, Oeiras (“5 km E Oeiras"), Fazenda Talhada, 13-17 Nov.

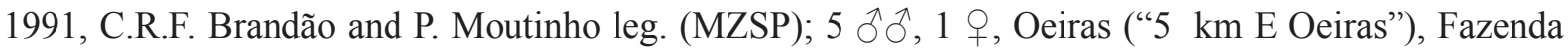
Talhada, 13-17 Nov. 1991, E.M. Cancello and M.T. Ponte leg. (MZSP); 1 ㅇ, Oeiras ("5 km E Oeiras"), Fazenda Talhada, 13-17 Nov. 1991, S.T.P. Amarente leg. (MZSP); 1 ㅇ, Piripiri, Parque Nacional de Sete Cidades, $04^{\circ} 05^{\prime} 51^{\prime \prime} \mathrm{S}, 41^{\circ} 42^{\prime} 30^{\prime \prime} \mathrm{W}, 170 \mathrm{~m}, 7-12 \mathrm{Feb} .2013$, pitfall with human faeces, Vaz-de-Mello

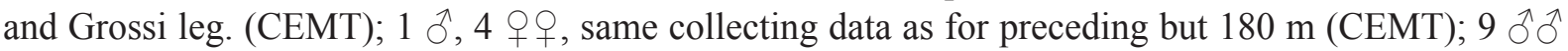

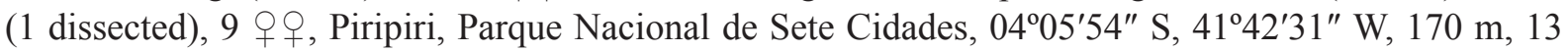

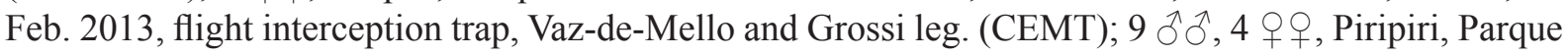

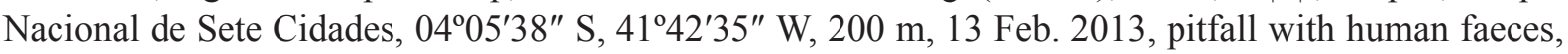
Vaz-de-Mello and Grossi leg. (CEMT); 1 + , Piripiri, Parque Nacional de Sete Cidades, $04^{\circ} 06^{\prime} 38^{\prime \prime}$ S, 41 44'48" W, 180 m, 12 Feb. 2013, flight interception trap, Vaz-de-Mello and Grossi leg. (CEMT); 1 ,

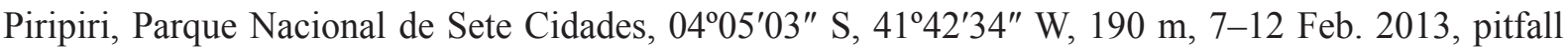
with human faeces, Vaz-de-Mello and Grossi leg. (CEMT); 1 §̂, Ribeiro Gonçalves, Estação Ecológica 

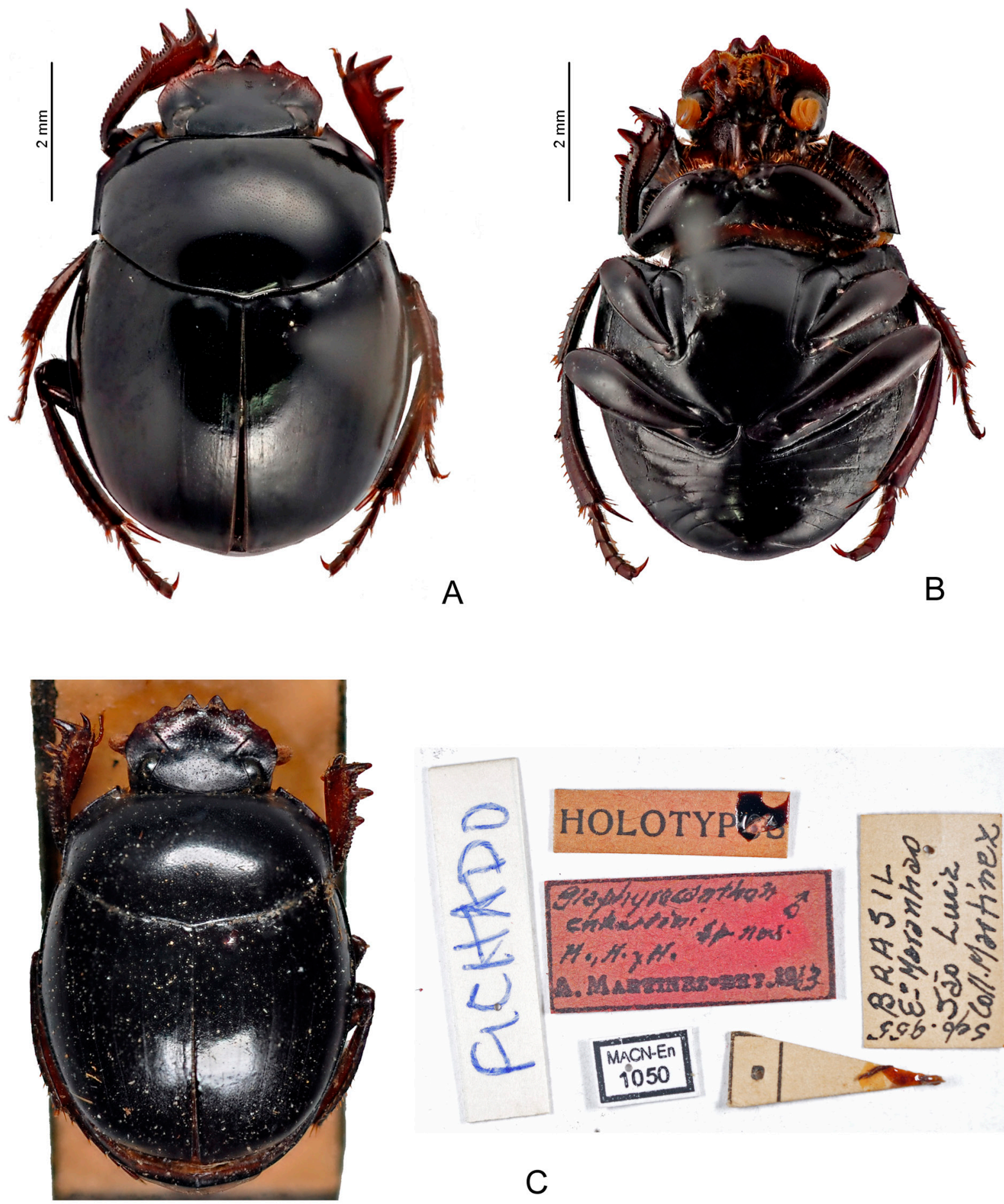

Fig. 21. Sylvicanthon enkerlini (Martínez et al., 1964) comb. nov. A. Dorsal view. B. Ventral view. C. Holotype and its labels. 


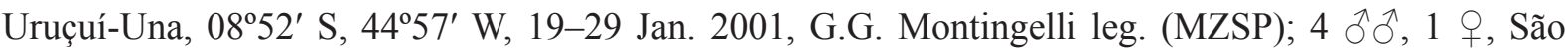
Raimundo Nonato, Parque Nacional da Serra da Capivara, Jan. 1999, C.A. Matrangolo leg. (CEMT); 2 우, São Raimundo Nonato, Parque Nacional da Serra da Capivara, Zabelê, 12 Apr. 2001, A.C.A. Moura leg. (CEMT); 2 $\widehat{\jmath}$, Teresina, Jan. 1953, Oliveira leg. (CMNC).

\section{Redescription}

Colouration. Dorsum, metaventrite and pygidium entirely black, without metallic reflections; external edge of clypeus occasionally dark brown. Ventral face of legs ranging from black to dark brown; dorsal face of protibiae reddish-brown.

HEAD. Tegument with diffuse shine and strong alveolar microsculpture, which is usually more marked on frons and genae than on clypeus, which can present diffuse microsculpture; micropunctation always evident throughout dorsal surface, more impressed in areas with sparser microsculpture. Clypeus with four large, acute teeth well separated from one another (Fig. 6A; in worn specimens, teeth obtuse); external edge (including teeth) clearly folded up; with a single row of setae covering the base of the four teeth. Genae with strong tooth immediately behind clypeal-genal juncture. Posterior edge of head with a fine margin between eyes; occasionally, margin lacking only at the area adjacent to eyes.

THORAX. Pronotum with shiny and lustrous tegument; alveolar microsculpture usually restricted to sides, where it is very dense; centre with strong micropunctation and without microsculpture, or with very diffuse microsculpture. Posterior edge with fine transverse line at centre (usually extending up to the second elytral stria). Hypomeral cavity with tegument densely covered by long yellowish setae and with depressed area close to external margin, the latter with a weak tubercle; posterior part of hypomeron with long, individual setae (around five) aligned longitudinally close to its external edge (Fig. 9D). Metepisternum with posterior region, at the suture with metaventrite, with an evident tubercle (Fig. 9C). Metaventrite entirely glabrous; tegument with strong rivose microsculpture at lateral and anterior regions; at centre, alveolar microsculpture very fine and diffuse, slightly more delimited at posterior region; micropunctation very fine, but distinct at centre.

Legs. Profemora with tegument with strong alveolar microsculpture at anterior region, and alveolar microsculpture at posterior region; without micropunctation; anterior margin, at apex of profemur, interrupted by row of denticles (Fig. 9B). Protibiae wide and with internal margin strongly expanded at their apical half(Fig. 11A); in its apical half, external margin with three large, acute teeth widely separated from one another, the apical two of subequal length and longer than the basal. Mesofemora margined anteriorly only at their basal two-thirds; unmargined portion with a row of very short setae; tegument with strong alveolar microsculpture at anterior region and gradually with more diffuse microsculpture towards posterior and basal regions, where micropunctation is strong. Metafemora margined only anteriorly, posterior margin absent; tegument with strong rivose microsculpture at apical and anterior regions, with microsculpture gradually more diffuse towards posterior region and base; micropunctation present throughout the tegument, more marked in areas of diffuse microsculpture, especially at base, where it can be very dense. Metatarsomeres II and V subequal in length and longer than the others; metatarsomere IV shorter than the others; the entire meso- and metatarsi with a single continuous row of setae throughout its internal margin.

ELYTRA. With nine very narrow visible striae; in general, first six to seven striae well marked, but never carinulate; from them, striae progressively more effaced and interrupted; humeral carina absent. Tegument of interstriae at centre of elytral disc lustrous and without microsculpture (or with very diffuse microsculpture); lateral and apical regions with strong alveolar microsculpture and diffuse shine; micropunctation present throughout tegument, but more distinguishable in areas without microsculpture. 
AвDOMEN. Ventrite VI with diffuse rivose microsculpture at middle and more clearly marked on the sides; micropunctation absent or very subtle; both sexes without lateral foveae. Pygidium with tegument with diffuse shine and covered by strong alveolar or rivose microsculpture; in some specimens, microsculpture weaker or even absent at apex; micropunctation obliterated by microsculpture and usually indistinct.

Aedeagus. Parameres almost as long as phallobase and symmetrical, both faces flat. In lateral view, parameres simple, without any ventral keel or notch (Fig. 17A).

Sexual dimorphism. Males: Protibial spur narrow and bifid at apex, with spiniform projections, the external project longer than the internal one (Fig. 15A). Ventrite VI strongly narrowed at middle; anterior margin covered only slightly by weak medial expansion of posterior edge of ventrite V. Pygidium very long (length between 1.2 and $0.9 \mathrm{~mm}$ ). Females: Protibial spur spiniform, simple, and distinctly bent towards external side. Ventrite VI very wide at middle; anterior margin covered by medial flange of posterior edge of ventrite V. Pygidium shorter (between 1.0 and $0.7 \mathrm{~mm}$ ).

\section{Measurements}

Males (N = 14). TL: AV: $6.6 \pm 0.64$; MX: 8; MN: 5.8. EW: AV: $4.6 \pm 0.38$; MX: 5,5; MN: 4.1. PL: ME: $2.1 \pm 0.2$; MX: 2.5; MN: 1.8. PW: AV: $4.0 \pm 0.35$; MX: 4.8; MN: 3.5. PgL: AV: $1.0 \pm 0.09$; MX: 1.2; MN: 0.9. PgW: AV: $1.7 \pm 0.23$; MX: 2.2; MN: 1.3 .

Females $(\mathrm{N}=15)$. TL: AV: $6.4 \pm 0.58$; MX: 7.3; MN: 5.7. EW: AV: $4.5 \pm 0.39$; MX: 5.2; MN: 3.9. PL: AV: $2.0 \pm 0.18$; MX: 2.3; MN: 1.7. PW: AV: $3.8 \pm 0.31$; MX: 4.4; MN: 3.3. PgL: AV: $0.9 \pm 0.08$; MX: 1; MN: 0.7. PgW: AV: $1.7 \pm 0.11 ;$ MX: 1.9; MN: 1.5.

\section{Geographical distribution}

Dry forests between Cerrado, Caatinga, Amazonia and the Atlantic Forest in the Brazilian north- and southeast.

\section{Ecoregions}

Maranhão Babaçu Forests, Cerrado, Caatinga, Bahia Interior Forests.

\section{Collecting sites (Fig. 22)}

BRAZIL. Maranhão: São Luís, Mirador (Parque Estadual do Mirador). Piauí: Canto do Buriti, Corrente, Floriano, Oeiras, Parnaíba, Piripiri (Parque Nacional de Sete Cidades), Ribeiro Gonçalves (Estação Ecológica de Uruçuí-Una), São Raimundo Nonato (Parque Nacional da Serra da Capivara), Teresina. Ceará: Caucaia. Bahia: Barreiras, Pilão Arcado. Minas Gerais: Bandeira, Jaíba, Três Marias.

\section{Intraspecific variation and taxonomic discussion}

If, on the one side, S. enkerlini comb. nov. seems to be the most isolated species in the genus and with no close relationships to any known Deltochilini, on the other side, the studied populations form a cohesive entity without any noticeable geographical variation. In the same way, little intrapopulational variation was observed. The exceptions are the specimens (two males and one female) collected in 2003 by P. Schmidt in Barreiras (Bahia): the alveolar microsculpture of the entire tegument is much stronger on them than on the other individuals, being evident even at the centre of the pronotum (where it is diffuse in the other specimens). The two females collected at the same place in 1991, on the other hand, have microsculpture typical of the rest of the distribution of S. enkerlini, as well as the four females collected between 2005 and 2006 in the municipality of Pilão Arcado, distant only about $300 \mathrm{~km}$ from Barreiras. The reason for that difference is unknown to us. 


\section{Natural history}

Martínez et al. (1964) described S. enkerlini based solely on the male holotype collected in a humid forest surrounding a water reservoir in the outskirts of the city of São Luís, Maranhão, Brazil ("el ejemplar holotipo y único [...] fue capturado en las afueras de la ciudad de Sao Luiz, dentro del bosque tropical y húmedo que rodea la reserva de agua potable de esa población"). As they were aware of only this single geographical record, those authors considered S. enkerlini as being a typical Amazonian species. Nonetheless, over the past 25 years, several collections in transitional regions between the Cerrado, Caatinga and Amazonia, in the Brazilian states of Piauí, Bahia, Ceará and Minas Gerais, have revealed the presence of $S$. enkerlini in that vast area, whereas other collections in regions farther west in the Amazon forest, such as in the state of Pará, have not yielded the species. Therefore, it seems

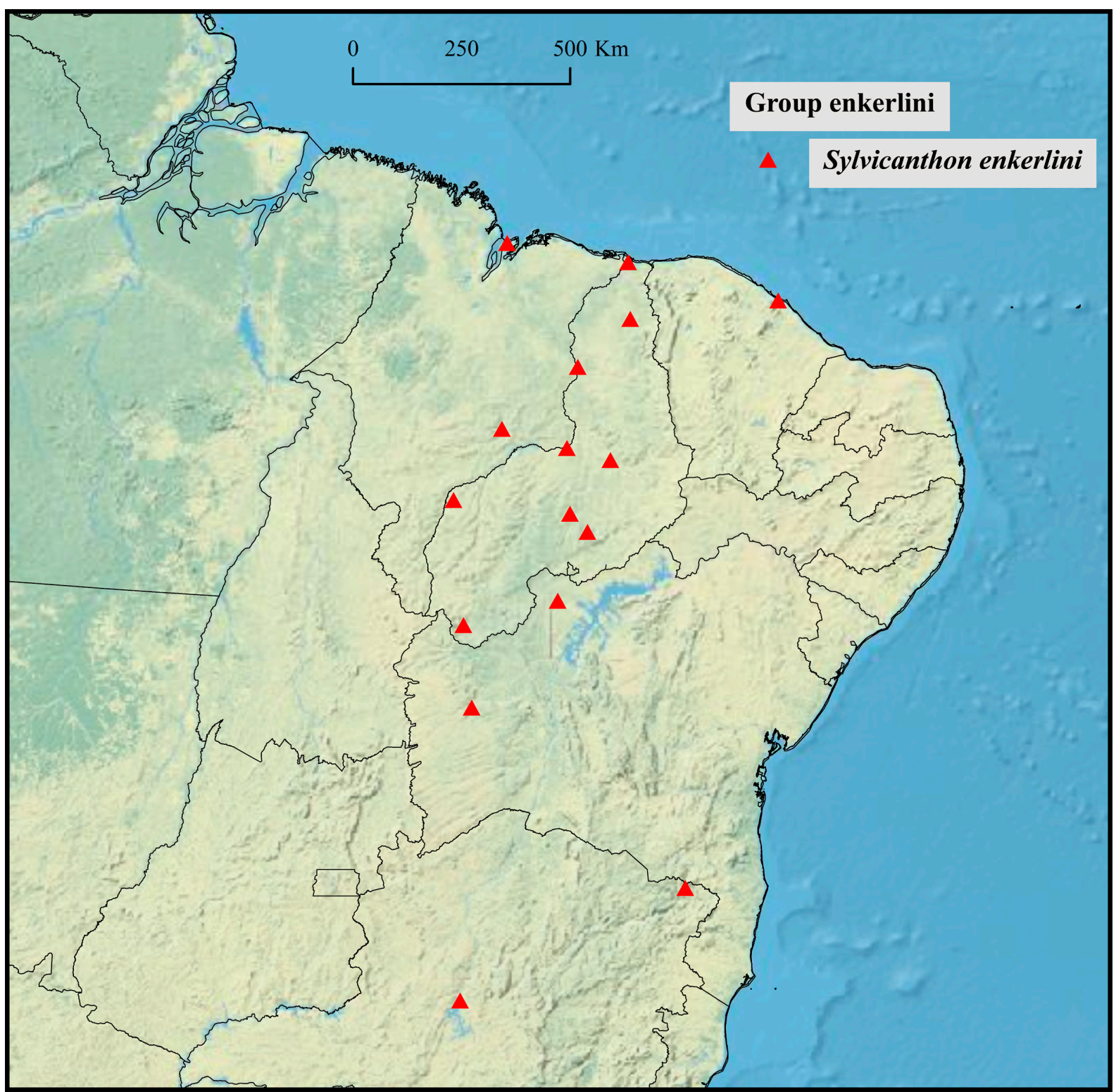

Fig. 22. Distribution of Sylvicanthon enkerlini (Martínez et al., 1964) comb. nov. Note that the species occupies transition zones between the Amazonia, Cerrado, Caatinga and Atlantic Forest biomes, regions much dryer and more open than the humid forests occupied by the species of the candezei group. 
that $S$. enkerlini is actually an inhabitant of open and dry lowland forests typical of the transitional zone between those three biomes, including the Mata dos Cocais, in the transitional zone between the Amazon rainforest and the Caatinga, where the babaçu palm (Attalea speciosa Mart.) predominates. One specimen was collected in 1932 in the municipality of Bandeira, Minas Gerais, an area originally covered by the Atlantic rainforest (ecoregion of Bahia Interior Forests). However, due to the intense anthropogenic activity across this entire ecoregion converting the former humid forest into open areas for agriculture and pasture, it was given the right conditions for the immigration of a fauna typical of Cerrado into that region, $S$. enkerlini included.

Based on the specimen labels, it is possible to know that S. enkerlini occurs in altitudes between 170 and $416 \mathrm{~m}$ and is collected between October and June (no records for May) using pitfall traps baited with human faeces as well as flight interception traps and light traps. The only record of flight activity time is that of Martínez et al. (1964), who said the holotype was collected during the first hours of the evening.

\section{The candezei group}

\section{The candezei subgroup}

Sylvicanthon foveiventris (Schmidt, 1920)

Figs 13A, 14B, 15B, 16D, 17B, 20, 23-24

Canthon foveiventris Schmidt, 1920: 132-133.

Canthon foveiventris - Schmidt 1922: 64, 75. — Balthasar 1939: 188-189. — Martínez 1949a: 287. — Halffter \& Martínez 1977: 63. - Krajcik 2012: 63.

Canthon foveiventre - Blackwelder 1944: 199.

Glaphyrocanthon (Glaphyrocanthon) foveiventris - Pereira \& Martínez 1956: 126, 128. — Martínez et al. 1964: 5, 8, 10, 14. - Vulcano \& Pereira 1964: 662. — Martínez \& Pereira 1967: 53.

Sylvicanthon foveiventre - Vaz-de-Mello \& Louzada 1997: 57. — Vaz-de-Mello 2000: 195. — Hernández 2002: 598. — Falqueto et al. 2005: 20. — Hernández \& Vaz-de-Mello 2009: 610-611. — Hernández et al. 2011: 7-8, fig. 3.

Sylvicanthon foveiventris - Durães et al. 2005: 725. — Almeida \& Louzada 2009: 37-39. — Culot et al. 2013: $85,87$.

\section{Etymology}

From the Latin words 'fovea' and 'ventris', a likely reference to the three pairs of foveae present on the sides of the abdomen of females of this species.

\section{Material examined}

Lectotype (here designated)

BRAZIL: गे, Espírito Santo ("9652 / E92 +", "24 / 56", "LECTOTYPE o / Canthon / foveiventris / Schmidt / des. F. Z. Vaz-de-Mello, 2013", "Glaphyrocanthon / foveiventris / (Schm.) / P. Pereira det. 66", "foveiventr.", "Esp. Santo") (NHRS) (Fig. 23Ca, b).

\section{Paralectotypes}

BRAZIL: 1 +, ("foveiventris / Schm.", "9653 / E92 +", "Espir. / Santo", "foveiventr", "foveiventris / A. Schm.", "PARALECTOTYPE / 9 / Canthon / foveiventris / Schmidt / des. F. Z. Vaz-de-Mello, 2013") (NHRS) (Fig. 23Cc); 1 ठิ ("PARALECTOTYPE / ठ̊ / Canthon / foveiventris / Schmidt / des. F. Z. Vazde-Mello, 2014", "Coll. C. Felsche / Kauf 20, 1918”, "Esp. Santo") (SMTD); 1 ô, ("PARALECTOTYPE / đ / Canthon / foveiventris / Schmidt / des. F. Z. Vaz-de-Mello, 2014", "Coll. C. Felsche / Kauf 20, 1918”, "Esp. Santo") (SMTD); 1 ô, ("PARALECTOTYPE / § / Canthon / foveiventris / Schmidt 
/ des. F. Z. Vaz-de-Mello, 2014”, “Coll. C. Felsche / Kauf 20, 1918”, "Esp. Santo”) (SMTD); 1 ㅇ, ("PARALECTOTYPE / o / Canthon / foveiventris / Schmidt / des. F. Z. Vaz-de-Mello, 2014", "Coll. C. Felsche / Kauf 20, 1918”, "Esp. Santo") (SMTD); 1 q, (“Typus", "Esp. Santo", "Coll. C. Felsche / Kauf 20, 1918", "Canthon / foveiventris / A. Schmidt", "PARALECTOTYPE / o / Canthon / foveiventris / Schmidt / des. F. Z. Vaz-de-Mello, 2014") (SMTD) (Fig. 23Cd).

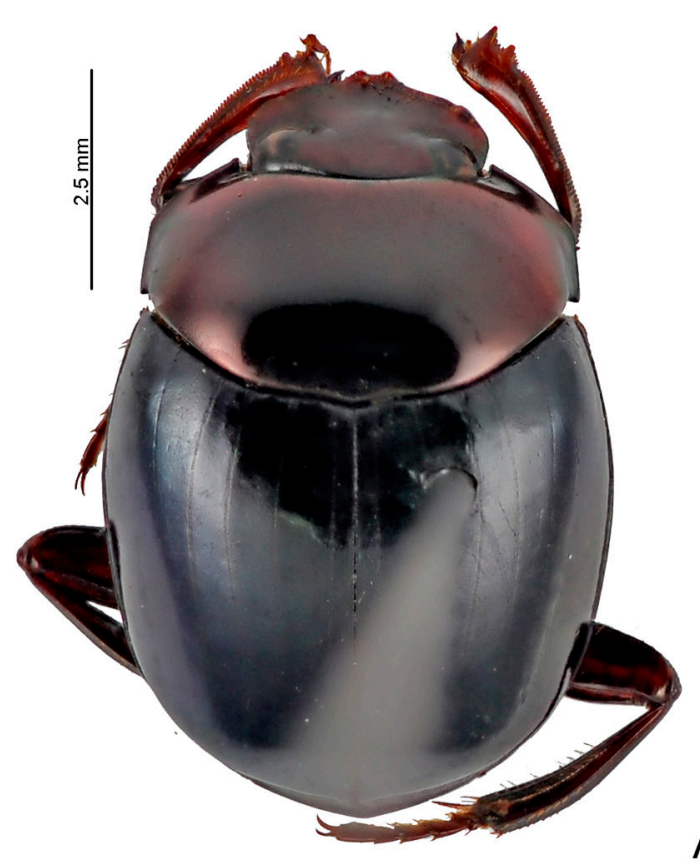

A

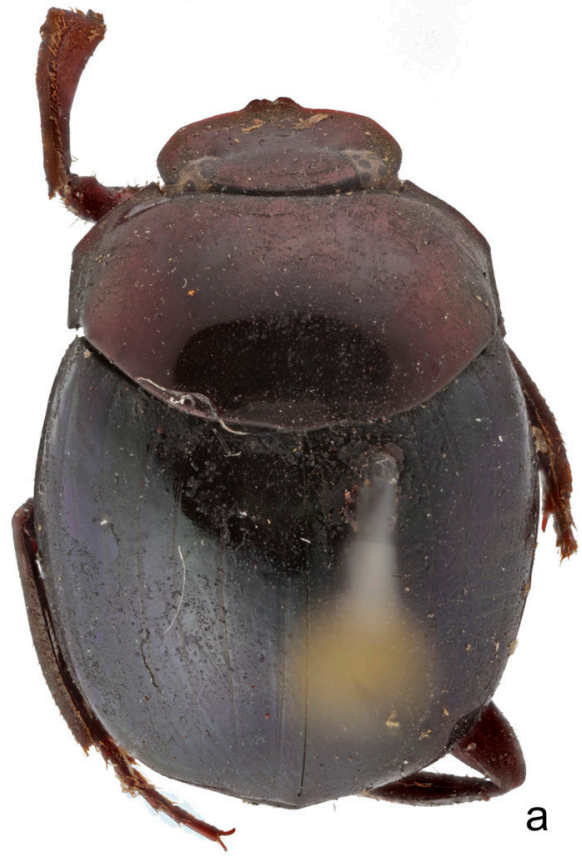

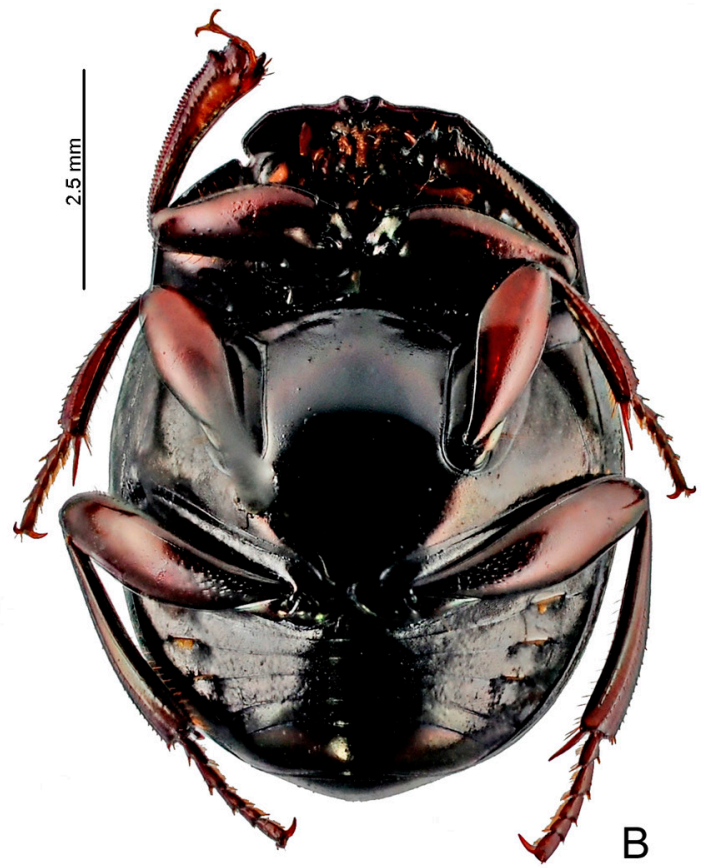
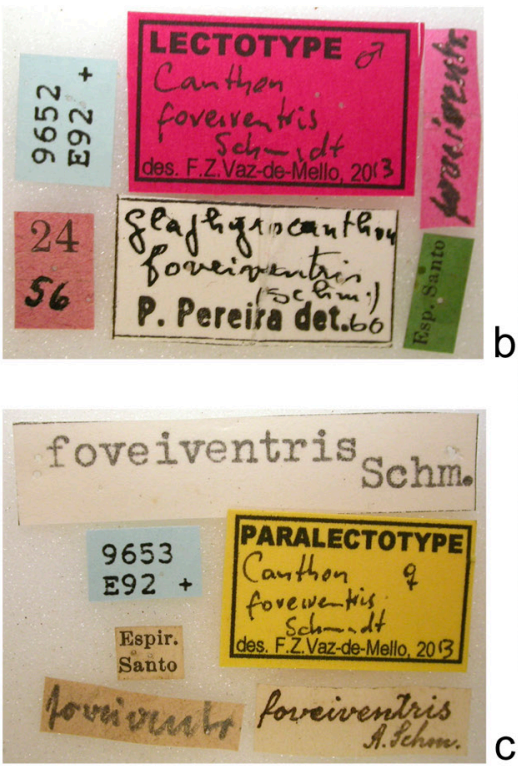

C

Fig. 23. Sylvicanthon foveiventris (Schmidt, 1920). A. Dorsal view. B. Ventral view. C. S. foveiventris type material: a. Lectotype. b. Lectotype's labels. c. Paralectotype 1's label. d. Paralectotype 6's labels. 
Additional material (140 $\hat{\partial} \hat{\partial}, 144 q q$ )

BRAZIL: 1 , no further data, B. Schwarzer leg.,ex. coll. Balthasar (NMPC). - Bahia: 1 o , no other data ["homeótipo"] ("F. Ohaus S.") (MZSP); 1 (NMPC). - Espírito Santo: 1 o, 1 \%, no other data (BMNH); 5 우 (NMPC); 1 ○े (ZMHB); 1 , Jean-Theodore Descourtilz ("Descourtils") leg. (BMNH);

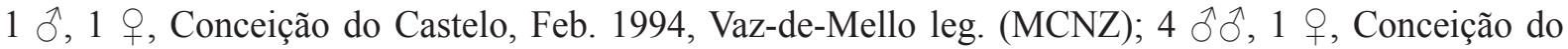
Castelo, $20^{\circ} 22^{\prime}$ S, $41^{\circ} 15^{\prime}$ W, Feb. 1994, human faeces, Arnaud, Grossi and Vaz-de-Mello leg. (CEMT);

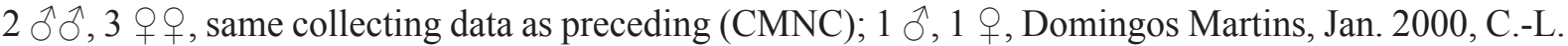
Andrade leg. (NMPC); 3 $\widehat{\jmath}, 1$ \&, Domingos Martins, Parque Estadual da Serra Azul, 1500 m, Jan. 2000, Lopes-Andrade and Vaz-de-Mello leg. (CEMT); 1 \&, Santa Teresa, Estação Biológica de Santa Lúcia, Trilha Indaia-Açu, 1958'13" S, 40³2'06" W, 779 m, 29 Jan. 2015, pitfall trap baited with human faeces, T. Vargas leg. (CEMT); 1 क, Vargem Alta, Jan. 2000, Louzada and Louzada leg. (CEMT); 1 , Vargem Alta, 680 m, 15 Sep. 1995, J.N.C. Louzada leg. (CEMT); 1 , Venda Nova do Imigrante, Lavrinhas, 20 $12^{\prime} 29^{\prime \prime} \mathrm{S}, 41^{\circ} 07^{\prime} 23^{\prime \prime} \mathrm{W}$, Jan. 2013, L.F. Vaz-de-Mello leg. (CEMT); 1 , , Venda Nova do Imigrante, Lavrinhas, $20^{\circ} 12^{\prime} 29^{\prime \prime} \mathrm{S}, 41^{\circ} 07^{\prime} 23^{\prime \prime} \mathrm{W}, 850 \mathrm{~m}, 10-14 \mathrm{Jan} .2011$, human faeces, F.Z. Vaz-deMello leg. (CEMT); 1 , , Venda Nova do Imigrante, Vila Santa Cruz, $20^{\circ} 20^{\prime} 02^{\prime \prime} \mathrm{S}, 41^{\circ} 08^{\prime} 18^{\prime \prime} \mathrm{W}, 800 \mathrm{~m}$, 10-14 Jan. 2011, human faeces, F.Z. Vaz-de-Mello leg. (CEMT); 1 q, Venda Nova do Imigrante,

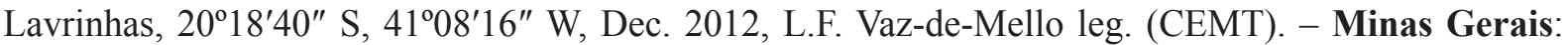

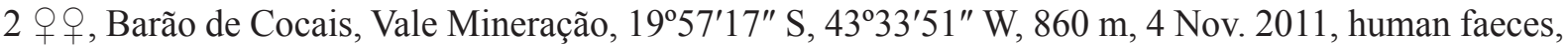
R.N. Mota leg. (CEMT); 1 đૈ, Conceição dos Ouros, Rio Sapucaí, 19 Feb. 2003, without collector (CEMT); 1 §, 1 , Carrancas, Intituto de Permacultura Cerrado-Pantanal ("Inst. Perm. Cer. Pantanal"), 1217 m., -21.4556' S, -44.6203' W, 21 Oct. 2008, pitfall with human faeces, Clever Pinto col. (CEMT);

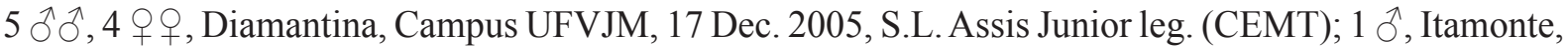
$22^{\circ} 21^{\prime} \mathrm{S}, 4^{\circ} 48^{\prime} \mathrm{W}, 1737 \mathrm{~m}, 12$ Oct. 2009, T. Vidaurre et al. leg. (CEMT); 1 ô, Lavras, May 1997,

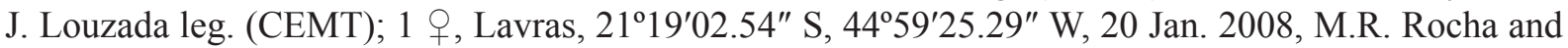
D.H.T. Takahashi leg. (CEMT); 1 †, Lavras, Serrinha da Bocaina, 27 Apr. 2012, pig dung, A. DíazRojas leg. (CEMT); 2 우, Lima Duarte, Parque Estadual do Ibitipoca, Dec. 1997, Souza et al. leg.

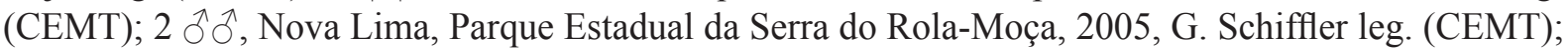
1 ㅇ, Prados, $21^{\circ} 04^{\prime} 40^{\prime \prime} \mathrm{S}, 44^{\circ} 08^{\prime} 06.1^{\prime \prime} \mathrm{W}, 1090 \mathrm{~m}, 17 \mathrm{Feb} .2012$, pitfall with human faeces, Letícia

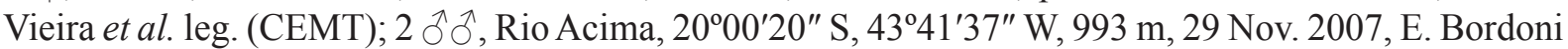

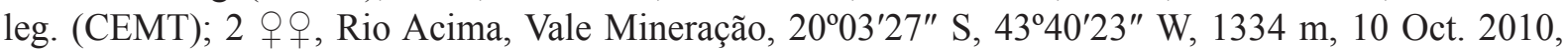
human faeces, R.N. Mota leg. (CEMT); $2 \hat{\jmath} \hat{\jmath}, 1$ †, São Gonçalo do Rio Abaixo, Estação Ambiental

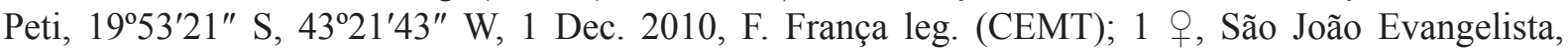

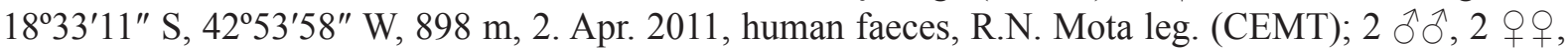

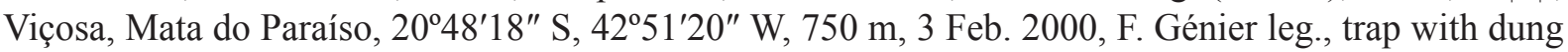

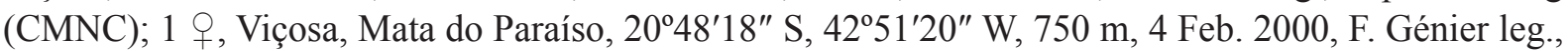
trap with dung (CMNC). - Rio de Janeiro: 1 ภ, no more data (ISNB); 1 ภ, 1 \%, Itatiaia, Jan. 1961,

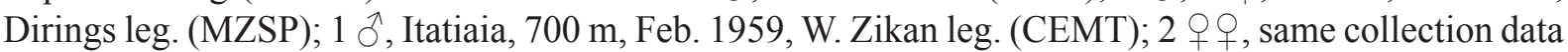
as preceding (MNRJ); 1 , Itatiaia, Mar. 1992, C. Godinho Junior leg. (CEMT); 1 , , Nova Friburgo,

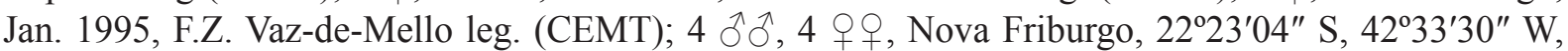

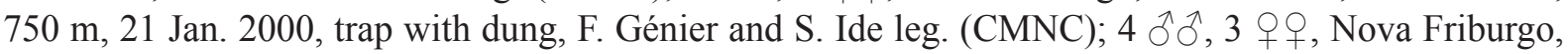
$22^{\circ} 23^{\prime} 04^{\prime \prime}$ S, 42 $33^{\prime} 30^{\prime \prime}$ W, 750 m, 23 Jan. 2000, trap with dung, F. Génier and S. Ide leg. (CMNC); 1 , Nova Friburgo, Macaé de Cima, Jan. 2006, B. Miller leg. (AMBC); 1 ô, 1 q, Nova Friburgo, Macaé de Cima, 1500 m, Mar. 2000, Lopes-Andrade, Gumier and Vaz-de-Mello leg. (CEMT); 1 , , Nova Friburgo,

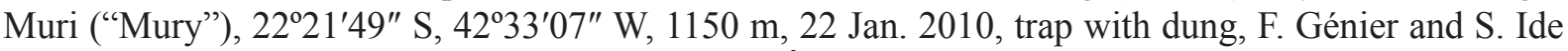
leg. (CMNC); 2 ㅇ , Parque Nacional da Serra dos Órgãos (PARNASO), 850 m, Dec. 2014, pitfall with human faeces, Cristina Araújo and Raissa Drufrayer leg. (CLEI); 1 ð̃, PARNASO, 950 m, Dec. 2014, pitfall with human faeces, Cristina Araújo and Raissa Drufrayer leg. (CLEI); 1 क , PARNASO, 1030 m, Jan. 2014, pitfall with human faeces, Cristina Araújo and Raissa Drufrayer leg. (CLEI); 1 , , PARNASO, 1080 m, Jan. 2014, pitfall with human faeces, Cristina Araújo and Raissa Drufrayer leg. (CLEI); 1 , PARNASO, 1130 m, Jan. 2014, pitfall with human faeces, Cristina Araújo and Raissa Drufrayer leg. 
(CLEI); 1 ภ, PARNASO, 1150 m, Dec. 2014, pitfall with human faeces, Cristina Araújo and Raissa Drufrayer leg. (CLEI); 1 ô, PARNASO, 1230 m, Jan. 2014, pitfall with human faeces, Cristina Araújo and Raissa Drufrayer leg. (CLEI); 1 o, PARNASO, 1230 m, 28-30 Jan. 2014, pitfall trap, Cristina Araújo and Raissa Andrade leg. (CEMT); 1 \%, PARNASO, 1280 m, Jan. 2014, pitfall with human

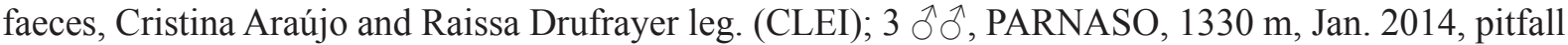
with human faeces, Cristina Araújo and Raissa Drufrayer leg. (CLEI); 1 , PARNASO, 1400 m, Dec. 2014, pitfall with human faeces, Cristina Araújo and Raissa Drufrayer leg. (CLEI); 1 o, 1 \&, Parque Nacional do Itatiaia (PNI), 700 m, Jan. 2012, pitfall with human faeces, Cristina Araújo and Raissa

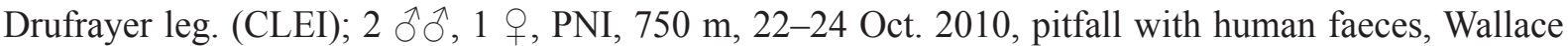
Beiroz and Mario Cupello leg. (MNRJ); 1 §., PNI, Casa do Pesquisador, $750 \mathrm{~m}$ [sic], 11-13 Nov. 2011, pitfall, Mario Cupello leg. (MNRJ); 1 §, PNI, 750 m, Jan. 2012, Cristina Araújo and Raissa Drufrayer leg. (CLEI); 1 đ, PNI, 800 m, Dec. 2011, pitfall with human faeces, Cristina Araújo and Raissa Drufrayer leg. (CLEI); 1 क , PNI, Casa do Pesquisador, 810 m, 22-25 Feb. 2013, pitfall with human faeces, Mario Cupello leg. (CEMT); $6 \hat{\jmath} \hat{\delta}, 1$ क , same sollecting data as for preceding (MNRJ); 1 क, PNI, Casa do Pesquisador, 850 m, 03-06 Oct. 2013, A. Carelli and J.P. Botero leg. (MNRJ); 1 ô, PNI, 900 m, dec. 2011, pitfall with human faeces, Cristina Araújo and Raissa Drufrayer leg. (CLEI); 2 우, PNI, 900 m,

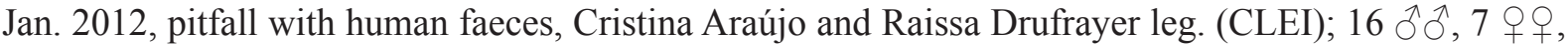
PNI, 1000 m, Jan. 2012, pitfall with human faeces, Cristina Araújo and Raissa Drufrayer leg. (CLEI); 1 , PNI, 1050 m, Dec. 2011, pitfall with human faeces, Cristina Araújo and Raissa Drufrayer leg. (CLEI); 3 ๙ $\delta^{\lambda}, 6$ 우, PNI, 1050 m, Jan. 2012, pitfall with human faeces, Cristina Araújo and Raissa Drufrayer leg. (CLEI); 1 ô, PNI, 1050 m, Aug. 2012, pitfall with human faeces, Cristina Araújo and Raissa Drufrayer leg. (CLEI); 1 ô, PNI, 1100 m, Jan. 2012, pitfall with human faeces, Cristina Araújo and Raissa Drufrayer leg. CLEI); 1 o, PNI, $1200 \mathrm{~m}$, Dec. 2011, pitfall with human faeces, Cristina

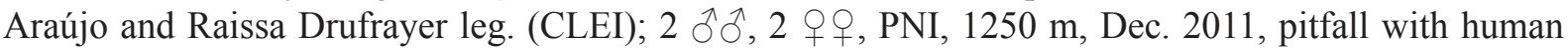
faeces, Cristina Araújo and Raissa Drufrayer leg. (CLEI); 2 ऽิ $\sigma^{\lambda} 1$ ㅇ, PNI, 1250 m, Jan. 2012, pitfall with human faeces, Cristina Araújo and Raissa Drufrayer leg. (CLEI); 5 ô $\widehat{0}, 6$ 우, PNI, 1300 m, Jan. 2012, pitfall with human faeces, Cristina Araújo and Raissa Drufrayer leg. (CLEI); 1 o, 1 क, PNI, 1350 m, Jan. 2012, pitfall with human faeces, Cristina Araújo and Raissa Drufrayer leg. (CLEI); 2 $\widehat{\partial}$, PNI, 1400 m, Dec. 2011, pitfall with human faeces, Cristina Araújo and Raissa Drufrayer leg. (CLEI); 1 ऽ, 1 क , PNI, 1400 m, Jan. 2012, pitfall with human faeces, Cristina Araújo and Raissa Drufrayer leg. (CLEI); 1 ô, 1 क, PNI, 1450 m, Dec. 2011, pitfall with human faeces, Cristina Araújo and Raissa Drufrayer leg. (CLEI); 2 $\widehat{\partial}$, PNI, $1450 \mathrm{~m}$, Jan. 2012, pitfall with human faeces, Cristina Araújo and Raissa Drufrayer leg. (CLEI); 1 ô, 2 q, , PNI, 1500 m, Dec. 2011, pitfall with human faeces, Cristina Araújo and Raissa Drufrayer leg. (CLEI); 1 \%, PNI, 1550 m, Aug. 2012, pitfall with human faeces, Cristina Araújo and Raissa Drufrayer leg. (CLEI); 1 đે, PNI, 1600 m, Jan. 2012, pitfall with human faeces, Cristina Araújo and Raissa Drufrayer leg. (CLEI); 2 우, PNI, 1750 m, Jan. 2012, pitfall with human faeces, Cristina Araújo and Raissa Drufrayer leg. (CLEI); $1 \hat{\jmath}$, Rio de Janeiro, Grajau, Nov. 1965, H.S. Lopes leg. (CEMT). - São Paulo: 1 + , Mogi das Cruzes, Parque das Neblinas, 234 $47^{\prime 2} 28^{\prime \prime}$ S, 46 $11^{\prime} 48^{\prime \prime}$ W, 810 m, Nov. 2015, pitfall trap baited with human faeces, R.V. Nunes leg. (CEMT); 2 우,

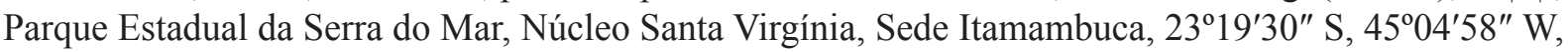
18 Jan. 2012, pitfall trap baited with human faeces, E. Bovy leg. (CEMT); 7 ๙ $\sigma^{\circ}, 12$ 우, Parque

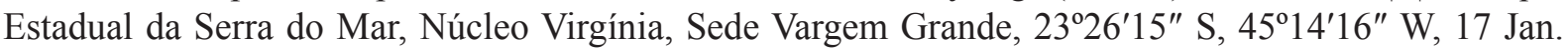

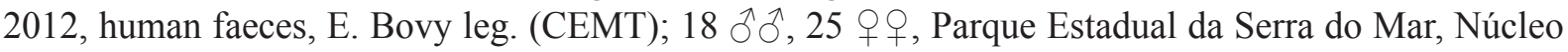

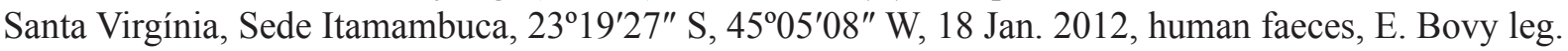

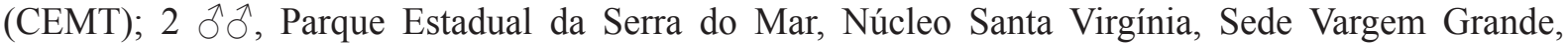

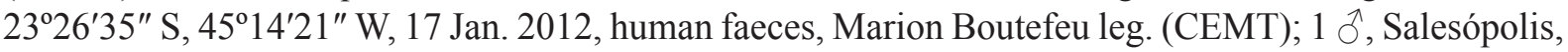
Estação Biológica de Boracéia, Jan. 2006, M. Uehara leg. (CEMT); 1 đ, Salesópolis, Estação Biológica de Boracéia, Feb. 2006, M. Uehara leg. (AMBC); 1 đ̃, São Luiz do Paraitinga, Parque Estadual da Serra do Mar, Núcleo Santa Virgínia, Mar. 2005, M. Uehara leg. (CEMT); 2 ふ઼, 1 ㅇ, São Miguel Arcanjo,

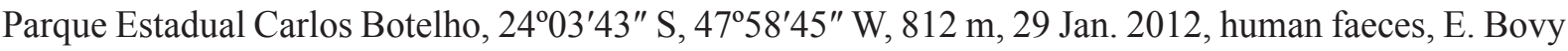




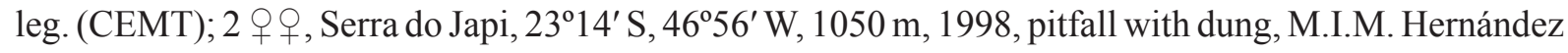
leg. (CEMT).

\section{Redescription}

Colouration. Dorsum lustrous and shiny. Head, pronotum, pygidium and ventrite VI dark purple. Elytra dark green or dark blue. Meso- and metafemora reddish-brown. Venter with purplish reflections.

HEAD. Tegument shiny and covered by dense micropunctation and very fine alveolar microsculpture; sometimes, microsculpture lacking at the posterior region of frons. Clypeus with two apical teeth obtuse and contiguous at base; with a single transverse row of very short setae covering the base of both teeth. Genae with a weak tooth immediately behind clypeal-genal juncture. Posterior edge of head unmargined between eyes (some few specimens with traces of a fine line between eyes).

Thorax. Pronotum with shiny tegument; alveolar microsculpture restrict to a very narrow strip above lateral margins; rest of tegument smooth, with dense micropunctation, almost as dense as on head. Posterior edge with a fine transverse line at middle (extending just beyond the second elytral stria) Hypomeral cavity with tegument with some long yellowish setae at centre; external margin with a minute tubercle. Metaventrite with some few setae close to metacoxae on the sides, and entirely glabrous at centre; anterior region with tegument with strong rivose microsculpture; centre and posterior region with dense micropunctation.

LeGs. Protibiae very narrow and without expansion on its internal margin; at their apical seventh, with two tiny, acute teeth of unequal length. Mesofemora margined anteriorly only at its basal half or third; tegument with sparse, almost imperceptible micropunctation. Metafemora margined only anteriorly; with strong coarse elongate punctation at base and with sparse micropunctation at the rest of tegument (Fig. 13A). Metatarsomeres II and V subequal in length and longer than the others; metatarsomere IV shorter than the others.

ELYTRA. With only eight visible striae: first four to five striae strongly marked, finely carinulate and widened at base; sixth to eighth striae very effaced and discontinuous; seventh stria absent at humerus; all striae lack their carinulae at the apex of elytra, being either marked only by microsculpture or completely indistinct; humeral carina absent. Tegument of interstriae shiny, without microsculpture and with shallow, but evident micropunctation.

AвDomen. Ventrite VI smooth at centre and with diffuse microsculpture on the sides (Fig. 14B). Pygidium slightly convex in both sexes and with shiny tegument, without microsculpture and with evident micropunctation.

Aedeagus. Parameres almost as long as phallobase and symmetrical, with both external faces flat. In lateral view, simple, without any ventral notch or keel and with truncate apex (Fig. 17B).

SEXUAL_dimorPhism. Males: protibial spur wide and bifid, with external projection long, straight, and fine, and internal projection shorter, bent, and widened (Fig. 15B). Pygidium very long (length between 1.1 and $1.4 \mathrm{~mm}$ ). Ventrite VI strongly narrowed at middle; ventrite V without medial expansion on its posterior edge. Females: protibial spur fine and spiniform. Abdomen with three pairs of transverse foveae located in the suture between ventrites I-II, II-III and III-IV, respectively; foveae not margined by row of long setae (Figs 14B, 16D). Pygidium shorter (between 0.9 and $1.1 \mathrm{~mm}$ ). Ventrite VI wide at middle, only slightly narrowed by medial expansion on the posterior edge of ventrite V (Fig. 14B). 


\section{Measurements}

Males (N = 16). TL: AV: $7 \pm 0.53$; MX: 7.9; MN: 6.2. EW: AV: $5.2 \pm 0.29$; MX: 5.8; MN: 4.7. PL: AV: $2.4 \pm 0.13$; MX: 2.6; MN: 2.2. PW: AV: $4.4 \pm 0.21$; MX: 4.8; MN: 4.1. PgL: AV: $1.2 \pm 0.07$; MX: 1.4 ; MN: 1.1. PgW: AV: $2.2 \pm 0.12 ;$ MX: $2.4 ;$ MN: 2 .

Females (N = 21). TL: AV: $6.3 \pm 0.38$; MX: 7.5; MN: 6.36. EW: ME: $5.3 \pm 0.39$; MX: 6; MN: 4.5. PL: AV: $2.4 \pm 0.16$; MX: 2.6; MN: 2.1. PW: AV: $4.5 \pm 0.3$; MX: 5; MN: 3.9. PgL: AV: $1 \pm 0.09$; MX: 1.1; MN: 0.9. PgW: ME: $2.3 \pm 0.12$; MX: 2.5 ; MN: 2 .

\section{Geographical distribution}

Atlantic Forest above $600 \mathrm{~m}$ in the Brazilian southeast.

\section{Ecoregions}

Bahia Interior Forests, Bahia Coastal Forest, Alto Paraná Atlantic Forest, Serra do Mar Coastal Forests.

\section{Collecting sites (Fig. 24)}

BRAZIL. Bahia (?). Minas Gerais: Barão de Cocais, Belo Horizonte (Parque Estadual da Serra do Rola-Moça), Carrancas (Chapada das Perdizes), Conceição dos Ouros, Diamantina, Itamonte, Lavras, Lima Duarte (Parque Estadual do Ibitipoca), Nova Lima (Parque Estadual da Serra do Rola-Moça), Prados, Rio Acima, São João Evangelista, Viçosa. Espírito Santo: Conceição do Castelo, Domingos Martins (Parque Estadual da Pedra Azul), Santa Teresa (Estação Biológica Santa Lúcia), Vargem Alta, Venda Nova do Imigrante. Rio de Janeiro: Itatiaia (Parque Nacional do Itatiaia), Nova Friburgo, Parque Nacional da Serra dos Órgãos, Rio de Janeiro. São Paulo: Mogi das Cruzes (Parque das Neblinas), Parque Estadual da Serra do Mar (Núcleo Santa Virgínia), Salesópolis (Estação Biológica de Boracéia), São Luiz do Paraitinga, São Miguel Arcanjo (Parque Estadual Carlos Botelho), Serra do Japi.

\section{Intraspecific variation and taxonomic discussion}

Apart from the colouration of the teneral specimens, little intraspecific variation was observed in S. foveiventris. Although the majority of the specimens do not show any trace of a margin between the eyes, a few individuals have a very short, tenuous line at the centre of the posterior edge of the head. Another noticeable variation refers to the density of coarse punctation at the base of metafemora: at one extreme, this punctation is deep and dense, being easily observed (Fig. 13A). At the other extreme, there are a few short points - in the male from Itamonte (Minas Gerais), especially, these points are almost absent, only weakly marked on the left metafemur. Between those extremes, a complete gradual variation exists. Finally, variation is also seen in the elytral striae, with some specimens showing all the first five striae well marked and carelunate, while others have only the first four striae in that way, whereas the fifth stria is as effaced and discontinuous as the more external striae.

Being a member of the candezei subgroup, S. foveiventris is closely related to $S$. candezei and $S$. genieri sp. nov. It differs from both species by the dorsal colouration pattern (Fig. 23A), the presence of a coarse punctation at the base of the metafemora (Fig. 13A), the presence of three pairs of abdominal foveae in females (Figs 14B, 16D), the shape of the parameres (Fig. 17B), and the distribution (Fig. 24). From S. candezei, in particular, S. foveiventris is distinct also in the shape of the posterior edge of ventrite $\mathrm{V}$ (Fig. 14B) and from S. genieri sp. nov. in the microsculpture of the surface of the pronotum, elytra and pygidium. Table 3 summarizes the differences between these three species.

Since they are found in sympatry in at least some localities in Espírito Santo, specimens of S. obscurus have been misidentified as $S$. foveiventris in several collections. Nonetheless, it is possible to readily separate the two species by the number of protibial teeth (two in S. foveinvetris, Fig. 11J, and three 
Table 3. Summary of the morphological and distributional differences between the three species of the candezei subgroup.

\begin{tabular}{|c|c|c|c|}
\hline & $\begin{array}{c}\text { S. candezei } \\
\text { (Harold, 1868) }\end{array}$ & S. genieri sp. nov. & $\begin{array}{c}\text { S. foveiventris } \\
\text { (Schmidt, 1920) }\end{array}$ \\
\hline Dorsal colouration & Dark green & Shiny copper & $\begin{array}{l}\text { Head and pronotum dark } \\
\text { purple, elytra green or dark } \\
\text { blue }\end{array}$ \\
\hline $\begin{array}{c}\text { Tegument at centre of } \\
\text { pronotum }\end{array}$ & $\begin{array}{l}\text { Alveolar microsculpture } \\
\text { absent or weakly impressed; } \\
\text { micropunctation dense }\end{array}$ & $\begin{array}{l}\text { Alveolar microsculpture } \\
\text { very strong obliterating } \\
\text { micropunctation }\end{array}$ & $\begin{array}{l}\text { Alveolar microsculpture } \\
\text { absent and micropunctation } \\
\text { very strong }\end{array}$ \\
\hline $\begin{array}{c}\text { Pilosity on the sides of } \\
\text { metaventrite }\end{array}$ & Absent & Absent & Present in a few specimens \\
\hline $\begin{array}{l}\text { Coarse punctation at } \\
\text { the base of metafemora }\end{array}$ & Absent & Absent & Present \\
\hline $\begin{array}{c}\text { Tegument of elytra and } \\
\text { pygidium }\end{array}$ & $\begin{array}{l}\text { Microsculpture absent and } \\
\text { micropunctation strong }\end{array}$ & $\begin{array}{l}\text { Alveolar microsculpture } \\
\text { very strongly } \\
\text { impressed obliterating } \\
\text { micropunctation }\end{array}$ & $\begin{array}{l}\text { Microsculpture absent and } \\
\text { micropunctation dense }\end{array}$ \\
\hline $\begin{array}{l}\text { Lateral foveae of } \\
\text { female abdomen }\end{array}$ & Absent & Absent & $\begin{array}{l}\text { Present at suture between } \\
\text { ventrites I-II, II-III, and } \\
\text { III-IV }\end{array}$ \\
\hline $\begin{array}{c}\text { Shape of posterior edge } \\
\text { of female ventrite } V\end{array}$ & $\begin{array}{l}\text { With strong medial flange } \\
\text { covering anterior edge of } \\
\text { ventrite VI }\end{array}$ & $\begin{array}{l}\text { With very subtle medial } \\
\text { flange covering anterior } \\
\text { edge of ventrite VI }\end{array}$ & $\begin{array}{l}\text { With very subtle medial } \\
\text { flange covering anterior } \\
\text { edge of ventrite VI }\end{array}$ \\
\hline $\begin{array}{c}\text { Parameres (lateral } \\
\text { view) }\end{array}$ & $\begin{array}{l}\text { With a strong notch on } \\
\text { its ventral region, which } \\
\text { divides the parameres at } \\
\text { middle; without ventral keel }\end{array}$ & $\begin{array}{l}\text { With a short notch on its } \\
\text { ventral region and with a } \\
\text { strong ventral keel }\end{array}$ & $\begin{array}{l}\text { Elongated and simple, } \\
\text { without both ventral keel } \\
\text { and notch }\end{array}$ \\
\hline Distribution & $\begin{array}{c}\text { Eastern and southern } \\
\text { Brazilian Amazon (Pará and } \\
\text { Mato Grosso) }\end{array}$ & $\begin{array}{l}\text { Slopes of the Andes in } \\
\text { Peru and Ecuador }\end{array}$ & $\begin{array}{l}\text { Atlantic Forest in } \\
\text { southeastern Brazil }\end{array}$ \\
\hline
\end{tabular}

in S. obscurus, Fig. 11D), shape of the internal margin of the protibiae (straight in S. foveiventris and strongly expanded in the apical half in $S$. obscurus), by the coarse punctation at the base of the metafemora (present in S. foveiventris, Fig. 13A, and absent in S. obscures, Fig. 13B), pilosity on the female abdominal foveae (glabrous in $S$. foveiventris, Figs 14B, 16D, and with a row of long setae on the anterior margin in S. obscurus, Fig. 16C), among other features. Besides, the distribution of both species does not entirely overlap: $S$. obscurus occurs throughout the Atlantic Forest from Alagoas to Espírito Santo (Fig. 41), while S. foveiventris is present in the mountain ranges of southeastern Brazil (Minas Gerais, Espírito Santo, Rio de Janeiro and São Paulo) (Fig. 24); sympatry was observed only in the municipalities of Santa Teresa and Venda Nova do Imigrante, in Espírito Santo state.

\section{Comments}

In a very vague way, without specifying either an exact locality or the source for the new record, Martínez et al. (1964) cited S. foveiventris as being present in Paraguay. Although we have studied the specimens deposited in the Martínez collection (now at the CMNC) and in the MACN, institution where Martínez worked, we could not find any specimens of S. foveiventris from that country or from Brazilian localities bordering Paraguay. Thus, we consider the Paraguayan record for $S$. foveiventris erroneous and possibly fruit of a misidentification of specimens of Canthon cobosi (e.g., Pereira \& Martínez (1960) considered C. cobosi close to $S$. foveiventris). In reality, based on the material gathered for this work, S. foveiventris 
seems to be a species restricted to the mountain ranges of southeastern Brazil; the only other records outside that region are two specimens labelled "Bahia" deposited in the MZSP and NMCP, which we consider a doubtful record.

\section{Natural history}

In the same way as for the other species in the genus, S. foveiventris seems to be strictly coprophagous, having been attracted to human faeces (Vaz-de-Mello \& Louzada 1997; Hernández 2002; Falqueto et al. 2005; Almeida \& Louzada 2009; Hernández \& Vaz-de-Mello 2009; Hernández et al. 2011; MC, personal observation; and information from specimen labels) and to a mixture of maned wolf (Chrysocyon brachyurus (Illiger, 1815)), capuchin monkey (Sapajus apella (Linnaeus, 1758)) and coati (Nasua nasua (Linnaeus, 1766)) dung (Duraes et al. 2005). Other baits offered apart from dung, such as cow spleen (Vaz-de-Mello \& Louzada 1997; Falqueto et al. 2005; Almeida \& Louzada 2009) and rotten bananas and fungi (Falqueto et al. 2005), did not attract individuals of S. foveiventris. The time of foraging activity is also the one expected for the genus, i.e., nocturnal. In Serra do Japi (São Paulo), Hernández (2002) collected eight specimens at night, four at sunset, and only one at sunrise, having found no specimens during the day.

Sylvicanthon foveiventris seems to be a seasonal species, with adults active mainly during the rainiest and hottest season of the year, which, in the Brazilian southeast, occurs during spring and summer. This is corroborated both by label data (one specimen recorded for September, five for October, 29 for December, 110 for January and 14 for February, and only two specimens in August, in the second half of the winter) and by the results obtained by Hernández \& Vaz-de-Mello (2009) during a year of

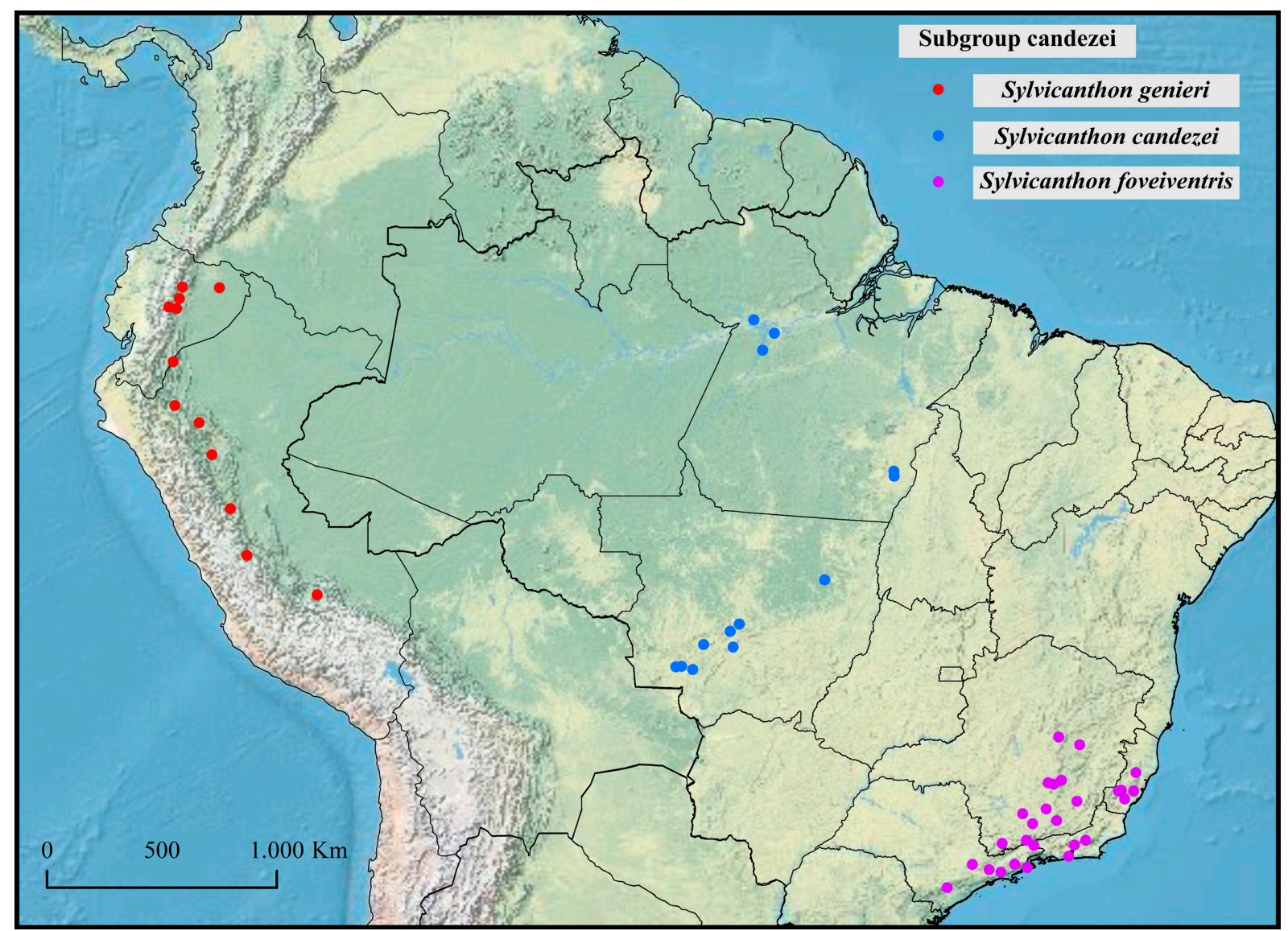

Fig. 24. Distribution of the three species of the candezei subgroup. 
monthly collecting in Serra do Japi. The species was reported exclusively in altitudes between 680 and 1727 m (data compiled from Vaz-de-Mello \& Louzada 1997; Duraes et al. 2005; Almeida \& Louzada 2009; and specimen labels). Indeed, S. foveiventris is present in several mountain ranges in southeastern Brazil, such as Serra Capixaba, Serra da Mantiqueira, Serra dos Órgãos and Serra do Mar, areas covered predominantly by ombrophilous and dense or semidecidual Atlantic Forest.

The strategy of arboreal foraging, a notable behavioural characteristic of $S$. foveiventris, was reported for this species by Vaz-de-Mello \& Louzada (1997). In forest fragments in Viçosa (Minas Gerais), those authors hoisted some traps baited with human faeces $10 \mathrm{~m}$ from the ground and 22 specimens of $S$. foveiventris were collected as a result. As discussed by Vaz-de-Mello \& Louzada (1997) (and, before them, by Howden \& Young 1981), arboreal mammal and bird dung can usually attach to leaves and branches high in the trees. Consequently, dung beetles that developed a special capacity of threedimensional foraging (i.e., the ability of searching for food in several different strata in the forest, in contrast to searching only horizontally above the ground) had access to an alternative food source to the dung deposited in the forest floor, which is heavily disputed by a rich guild of coprophagous arthropods. For Vaz-de-Mello \& Louzada (1997), perching on leaves, a behaviour displayed by many tropical dung beetles, was a preadaptation to the evolution of arboreal foraging - indeed, one of the specimens of $S$. foveiventris collected in the Parque Nacional do Itatiaia (Rio de Janeiro) was caught perching on a leaf on the understory (Juan Pablo Botero, 2014, personal communication to MC).

Sylvicanthon candezei (Harold, 1869)

Figs 6B, 10C, 11J, 14D-E, 15C, 17C, 20, 24, 25-26A-B

Canthon candezei Harold, 1869a: 96.

Canthon candezei - Harold 1869b: 990. — Gillet 1911: 28. — Schmidt 1920: 133; 1922: 64, 73. Balthasar 1939: 188. — Blackwelder 1944: 198. — Halffter \& Martínez 1977: 62-63. — Krajcik 2012: 63.

Glaphyrocanthon (Glaphyrocanthon) candezei - Pereira \& Martínez 1956: 126, 129. — Martínez et al. 1964: 5, 8-9, 14, 20. - Vulcano \& Pereira 1967: 561.

Glaphyrocanthon (Glaphyrocanthon) candèzei - Vulcano \& Pereira 1964: 661.

Sylvicanthon candezei - Halffter \& Martínez 1977: 63. - Feer 2000: 32 (error: refers to S. seag sp. nov.); 2008: 62 (error: refers to S. seag sp nov.). — Vaz-de-Mello 2000: 195. — Escobar 2000a: 210 (error: probably refers to $S$. genieri sp. nov. or S. mayri sp. nov.). — Medina et al. 2001 : 137 (idem). Feer \& Pincebourde 2005: 30 (error: refers to S. seag sp nov.). — Scheffler 2005: 19. — Medina \& Pulido 2009: 59 (error: probably refers to $S$. genieri sp. nov. or S. mayri sp. nov.). - Carvajal et al. 2011: 117, 316 (error: refers to S. genieri sp. nov.).

\section{Etymology}

Eponym after the Belgian entomologist Ernest Candèze (1827-1898). One of the specimens studied by Harold (1869a) belonged to the Candèze collection - nowadays largely housed at the ISNB (Horn \& Kahle 1935) - and this may have been the reason for the homage.

\section{Material examined}

Lectotype (here designated, Fig. 26)

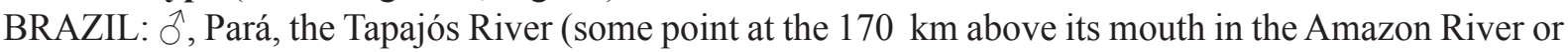
across the banks of the Cupari River (Fig. 26B); see more details below), type locality cited by Harold (1869): "Tapajos". Labels: (“Candezei / Harold. Hefte V.", "Muséum Paris / 1952 / Coll. R. Oberthur", "Tapajos", "Ex-Musæo / H. W. Bates / 1892", "LECTOTYPE ô / Canthon / candezei / Harold / des. F. Z. Vaz-de-Mello, 2014") (MNHN). 
Paralectotypes $(4 \hat{\jmath}, 4$ 車)

BRAZIL: 1 đ, (“Tapajós", "Ex-Musæo / H. W. Bates / 1892", "Muséum Paris / 1952 / coll. R. Oberthür", "PARALECTOTYPE / ô / Canthon / candezei / Harold / des. F. Z. Vaz-de-Mello, 2014") (MNHN); 1 ô, ("Tapajos", "Candezei / Harold", "Ex-Musæo / E. Harold", "Sylvicanthon / candezei / Harold / G. H. y A. M. det. 76", "PARALETOTYPE / Canthon candezei / Harold, 1869 § / des. Cupello \& Vaz-de-Mello, 2015") (MNHN); 1 § (dissected) ("Tapajos", "Candezei / Harold”, "Ex-Musæo / E. Harold", "Sylvicanthon / candezei / Harold / G. H. y A. M. det. 76", "PARALECTOTYPE / O / Canthon / candezei / Harold / des. F. Z. Vaz-de-Mello, 2015") (MNHN); 1 \& ("Tapajos", "Ex-Musæo / H. W. Bates / 1892", "candezei / Harold / [ilegível] Har. [illegible]", "Muséum Paris / 1952 / coll. R. Oberthür" "PARALECTOTYPE / o / Canthon / candezei / Harold / des. F. Z. Vaz-de-Mello, 2014") (MNHN) (Fig. 26); 1 ㅇ, ("Tapajos", "Ex-Musæo / H. W. Bates / 1892", "PARALECTOTYPE / q / Canthon / candezei / Harold / des. F. Z. Vaz-de-Mello, 2014") (MNHN); 1 q ("Tapajos", "Ex-Musæo / H.W. Bates / 1892", "Muséum Paris / 1952 / coll. R. Oberthür" "PARALECTOTYPE / q / Canthon / candezei / Harold / des. F.Z. Vaz-de-Mello, 2014") (MNHN); 1 + , ("Tapajos" "Candezei / Harold", "Type", "Collection / E. CANDÈZE", "PARALECTOTYPE / 9 / Canthon / candezei / Harold / des. F.Z. Vazde-Mello, 2014") (ISNB); 1 đ ("Tapajos", "PARALECTOTYPE / ठ̊ / Canthon / candezei / Harold / des. F. Z. Vaz-de-Mello, 2014”) (CEMT, ex MNHN).

Additional material (103 $\hat{\jmath}, 54 q q)$

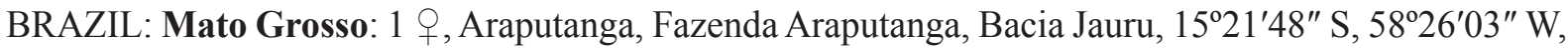

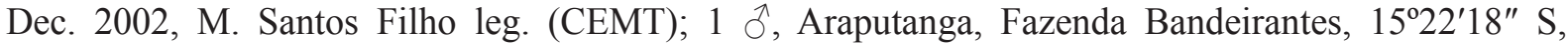
58 26'23" W, 297 m, 21-23 Jan. 2013, pitfall with human faeces, R. J. Silva leg. (CEMT); 1 , Araputanga, Fazenda Bandeirantes, 15 $22^{\prime} 14^{\prime \prime}$ S, 58 $26^{\prime} 02^{\prime \prime}$ W, 338 m, 20-22 Jan. 2013, pitfall with human and swine dung, R.J. Silva leg. (CEMT); 1 స̂, Curvelândia, Fazenda Calça Vermelha, Bacia Cabaçal, 153'02" S, 58 00'57" W, Feb. 2004, M. Santos-Filho leg. (CEMT); 1 q, Diamantino, Fazenda São João, $14^{\circ} 14^{\prime} 10^{\prime \prime}$ S, 56 $06^{\prime} 11^{\prime \prime}$ W, 11 Jan. 2001, flight interception trap, Génier and Vaz-

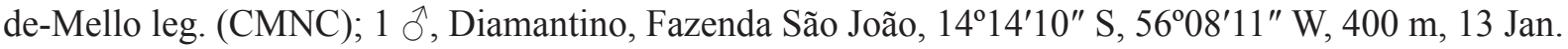
2001, flight interception trap, Génier and Vaz-de-Mello leg. (CMNC); 1 , Diamantino, Fazenda São João, 14²3'49" S, 56 $09^{\prime} 30^{\prime \prime}$ W, 480 m, 13 Jan. 2001, trap with faeces, Génier and Vaz-de-Mello leg.

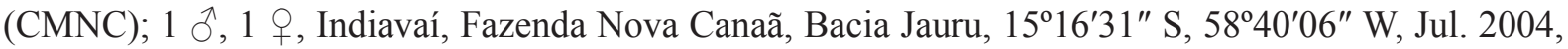
M. Santos-Filho leg. (CEMT); 1 ${ }^{2}, 1$, Nobres, Jan. 2001, A. Bello leg. (AMBC); 1 , , Nova Mutum, $13^{\circ} 48^{\prime} 07^{\prime \prime}$ S, 56 $06^{\circ} 22^{\prime \prime}$ W, 23 Jan. 2011, human faeces, M.F. Souza leg. (CEMT); 2 ô $\widehat{\jmath}$, Nova Mutum, $13^{\circ} 48^{\prime} 07^{\prime \prime}$ S, 56 $05^{\prime} 22^{\prime \prime}$ W, 25 Jan. 2011, human faeces, M.F. Souza leg. (CEMT); 8 $\widehat{\partial}, 4$ q $ᄋ$, Nova

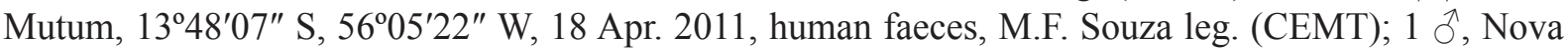

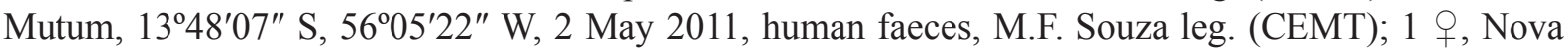
Mutum, Trivelato, 15 Dec. 1995, W.O. Silva-Filho leg. (CEMT); 1 đ̃, 2 q , , Querência, Fazenda São Luiz, $12^{\circ} 39.68^{\prime}$ S, 52²2.14' W, 8 Jul. 2008, flight interception trap, R. Andrade leg. (CEMT); 2 우, Querência, Fazenda São Luiz, 12²39.81' S, 52²2.74' W, 17 Jul. 2008, pitfall, R. Andrade leg. (CEMT); 2 우, Querência, Fazenda São Luiz, $12^{\circ} 39.94^{\prime}$ S, 52²1.85' W, 14- Jul. 2008, pitfall, R. Andrade leg.

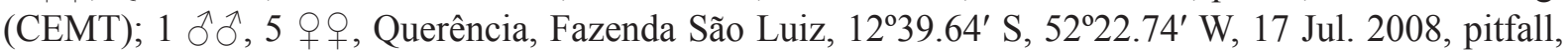

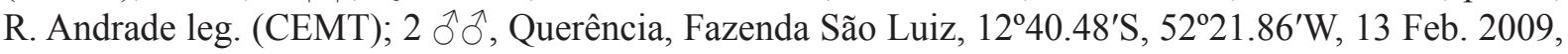
pitfall, R. Andrade leg. (CEMT); 1 § , 3 우, Tangará da Serra, 16 Jul. 2008, pitfall with human faeces,

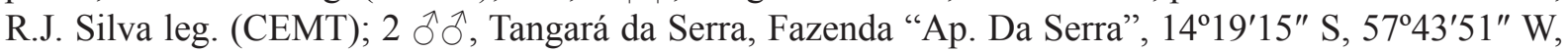

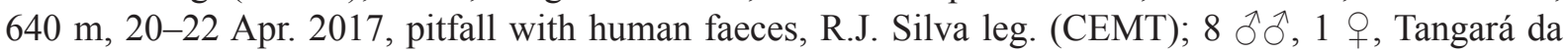

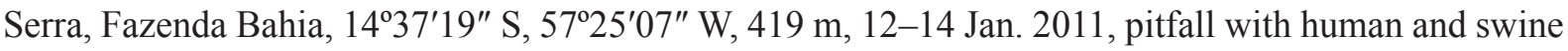

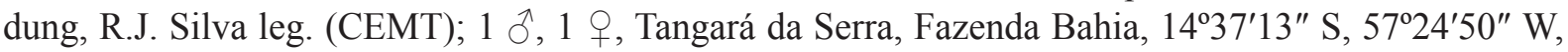
428 m, 26-28 Jan. 2012, pitfall with cow dung, R.J. Silva leg. (CEMT); 1 đ, Tangará da Serra, Fazenda Curitiba, 14 $21^{\prime} 47^{\prime \prime}$ S, 57 $28^{\prime} 17^{\prime \prime}$ W, 345 m, 2-9 Apr. 2012, flight interception trap, R.J. Silva leg.

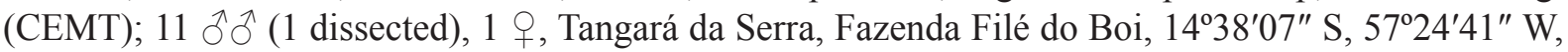
439 m, 25-27 Jan. 2011, pitfall with human and swine dung, R.J. Silva leg. (CEMT); 1 त̂, Tangará da 
Serra, Fazenda Fontosa, 14 35'36" S, 57 50'37" W, 296 m, 6 Feb. 2012, pitfall with human and swine

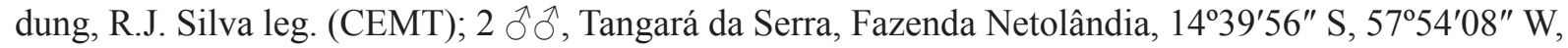
304 m, 20-22 Mar. 2012, pitfall trap baited with human faeces and pig dung, R.J. Silva leg. (CEMT);

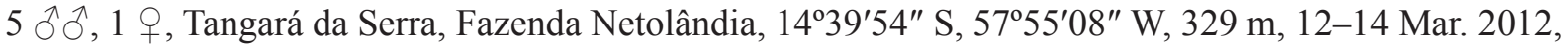

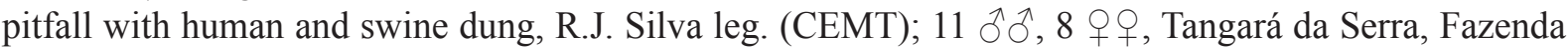

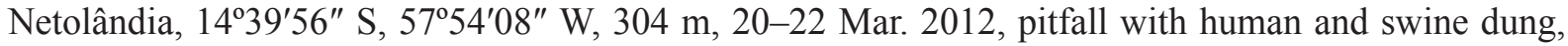

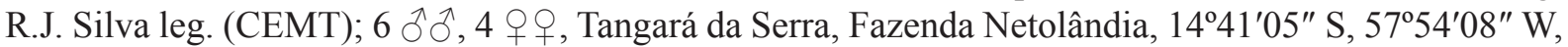
263 m, 25-27 Mar. 2012, pitfall with human and swine dung, R.J. Silva leg. (CEMT); 1 q, Tangará da

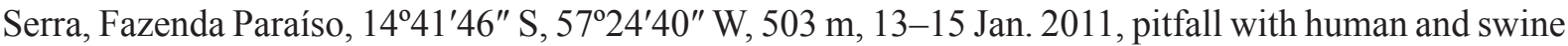

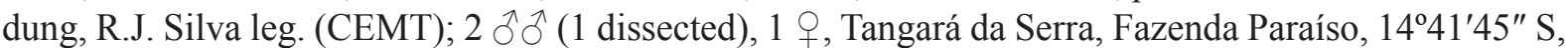
57²4'38" W, 520 m, 15-22 Jan. 2011, flight interception trap, R.J. Silva leg. (CEMT); 4 ổ, Tangará

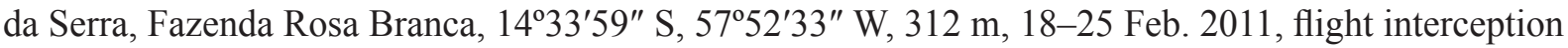

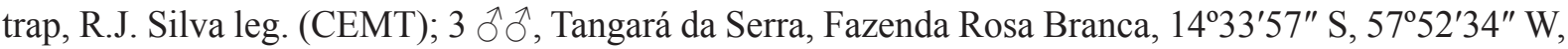
321 m, 20-27 Feb. 2011, flight interception trap, R.J. Silva leg. (CEMT); 2 đð, Tangará da Serra, Fazenda

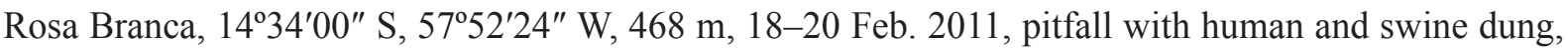

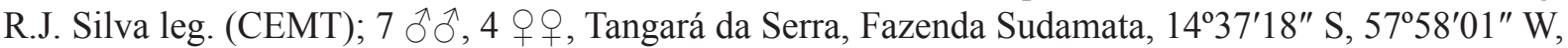
354 m, 10-17 Mar. 2012, flight interception trap, R.J. Silva leg. (CEMT); 3 $\widehat{\partial}, 1$ ㅇ, Tangará da Serra, Fazenda Sudamata, $14^{\circ} 37^{\prime} 18^{\prime \prime}$ S, 57 $58^{\prime} 01^{\prime \prime}$ W, 354 m, 21-23 Feb. 2012, pitfall with human and swine

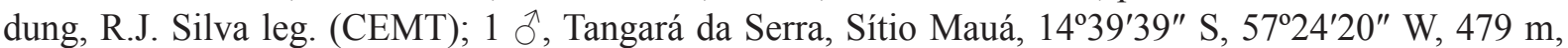
19-26 Jan. 2011, R.J. Silva leg. (CEMT). - Pará: 1 क , Belterra, 5432'36" W, 02³6'50" S, 15 Jul. 2016, human and pig dung, F. França leg. (CEMT); 1 §ิ ([dissected), Óbidos, 4 Mar. 1938, Zellibor-Hauff leg. (MNRJ); 1 § (dissected), Óbidos, Nov. 1955, C.A.C. Seabra leg. (CMNC); 1 §, 1 ㅇ, Pau-d'Arco, Fazenda Marajoara, 07050' S, 50 $16^{\prime}$ W, 13 Oct. 1998, P.Y. Scheffler leg. (CEMT); 1 ô (dissected),

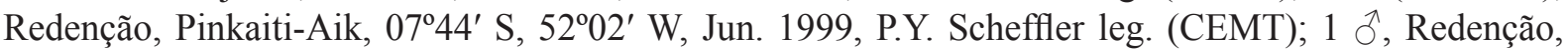
Pinkaiti-Aik, 07 $46^{\prime}$ S, $51^{\circ} 58^{\prime}$ W, Oct. 1999, P.Y. Scheffler leg. (CEMT); 1 q, Redenção, Pinkaiti-Aik, $07^{\circ} 50^{\prime}$ S, 50¹6' W, Nov. 1999, P.Y. Scheffler leg. (CEMT); 3 우우, Tapajós River [1852], H.W. Bates leg. (BMNH); 2 $\widehat{\jmath}, 2$ 우, Santarém, May 2010, V.H. Oliveira leg. (CEMT).

Ambiguous data: 1 đै, “Amazon” (ISNB - Coll. J. Thomson).

\section{Redescription}

Colouration. Surface of the entire body with very dark shades. Head predominantly purple with greenish reflections, especially at centre. Pronotum with green shine at centre and purplish on the sides. Elytra usually dark green with purplish striae; in some specimens, elytra dark blue. Metaventrite very dark, with coppery or purple reflections. Meso- and metafemora dark brown or reddish-brown. Pygidium dark green.

HEAD. Tegument shiny, with strong alveolar microsculpture and covered by dense micropunctation, which is almost imperceptible or even absent only at the external edge of head (Fig. 6B). Clypeus with two apical teeth obtuse and contiguous at base; with a single transverse row of very short setae covering the base of both teeth. Genae with a weak tooth immediately behind clypeal-genal juncture. Posterior edge of head unmargined between eyes.

THORAX. Tegument of pronotum with diffuse shine, dark and with dense micropunctation at centre, denser and more marked than on head; towards the sides, micropunctation less dense and less marked, being completely absent or only very weakly impressed on the lateral margin; tegument with strong microsculpture throughout pronotal surface (southern populations) or with weak or almost absent microsculpture (northern populations). Posterior edge of head with a fine transverse line at centre (usually extending a little beyond the second elytral stria). Hypomeral cavity with tegument entirely glabrous or with only some few long or short yellowish setae at posterior region near to hypomeral carina, but always glabrous at centre; external margin simple, without any trace of tubercle. Metaventrite entirely 
glabrous; anterior region with tegument with distinct rivose microsculpture; centre and posterior region with dense alveolar microsculpture obliterating micropunctation.

Legs. Ventral surface of all femora and tibiae dark (Fig. 25B). Profemora with tegument with strong alveolar microsculpture at their anterior half and with strong rivose microsculpture at posterior half. Protibiae narrow and straight on internal margin; at their apical seventh, with two tiny, acute external teeth - the apical one slightly larger than the second (Fig. 11J). Mesofemora margined anteriorly only at their basal three-fourths; unmargined portion of anterior edge with a row of short setae; tegument with strong rivose microsculpture. Metafemora margined only anteriorly; apical third of anterior edge covered by a row of setae; tegument with strong rivose microsculpture obliterating micropunctation, which is almost imperceptible; without coarse elongate punctation at base. Metatarsomeres II and V subequal in length and longer than the others; metatarsomere IV shorter than the others.

ELYTRA. With only seven narrow visible striae: first four to five striae strongly impressed, very finely carinulate and widened at base; fifth, sixth and seventh striae progressively more effaced and interrupted; all striae lack carenule before reaching apex of elytra, where they are marked only by microsculpture or are completely indistinct; humeral carina absent. Tegument of interstriae either with alveolar microsculpture and very dense micropunctation (southern populations) or with very weak or even absent alveolar microsculpture (northern populations).

ABDOMEN. Ventrite VI smooth at centre and with weaker rivose microsculpture on the sides (Fig. 14DE). Pairs of foveae absent in both sexes. Pygidium with tegument with strong alveolar microsculpture and dense micropunctation; average length equal in both sexes.

AedEAGus. Parameres short, less than half as long as phallobase, and slightly asymmetrical: external face of left paramere flat or concave and external face of right paramere convex (difference more easily seen

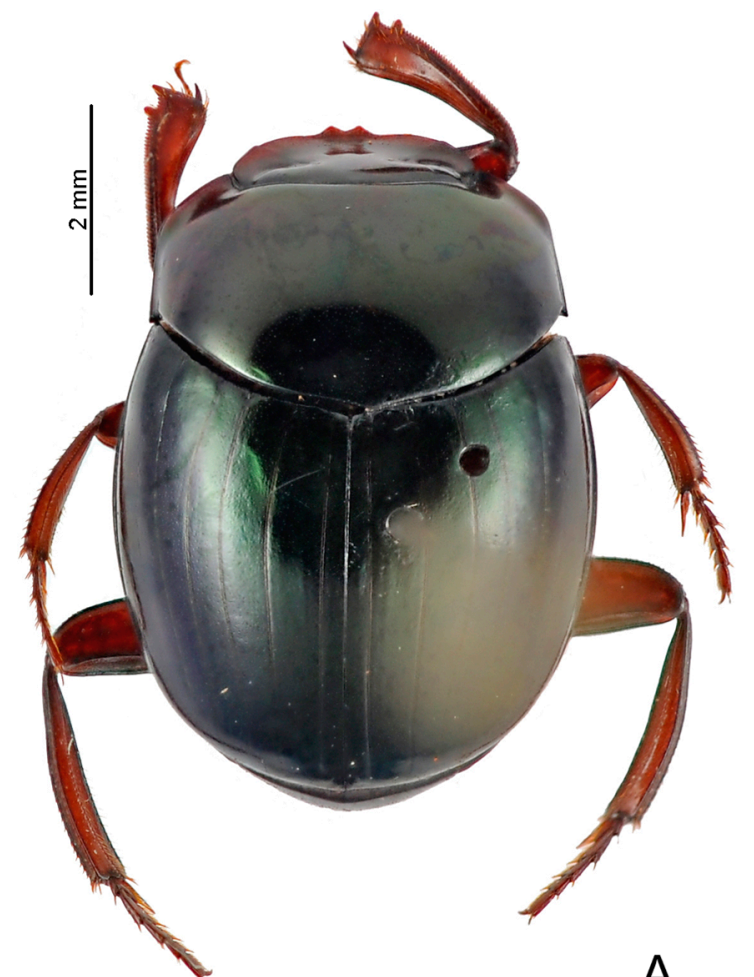

A

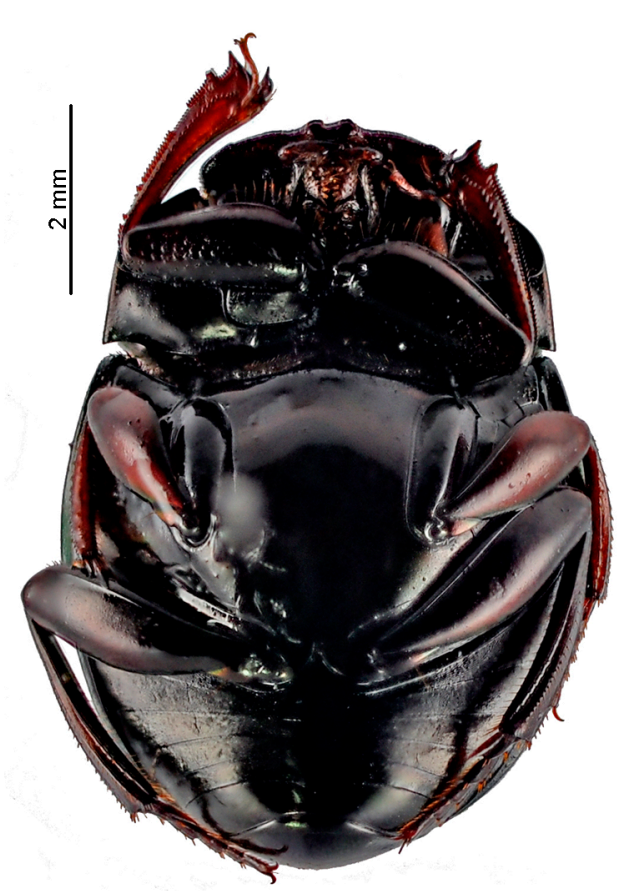

B

Fig. 25. Sylvicanthon candezei (Harold, 1869). A. Dorsal view. B. Ventral view. 

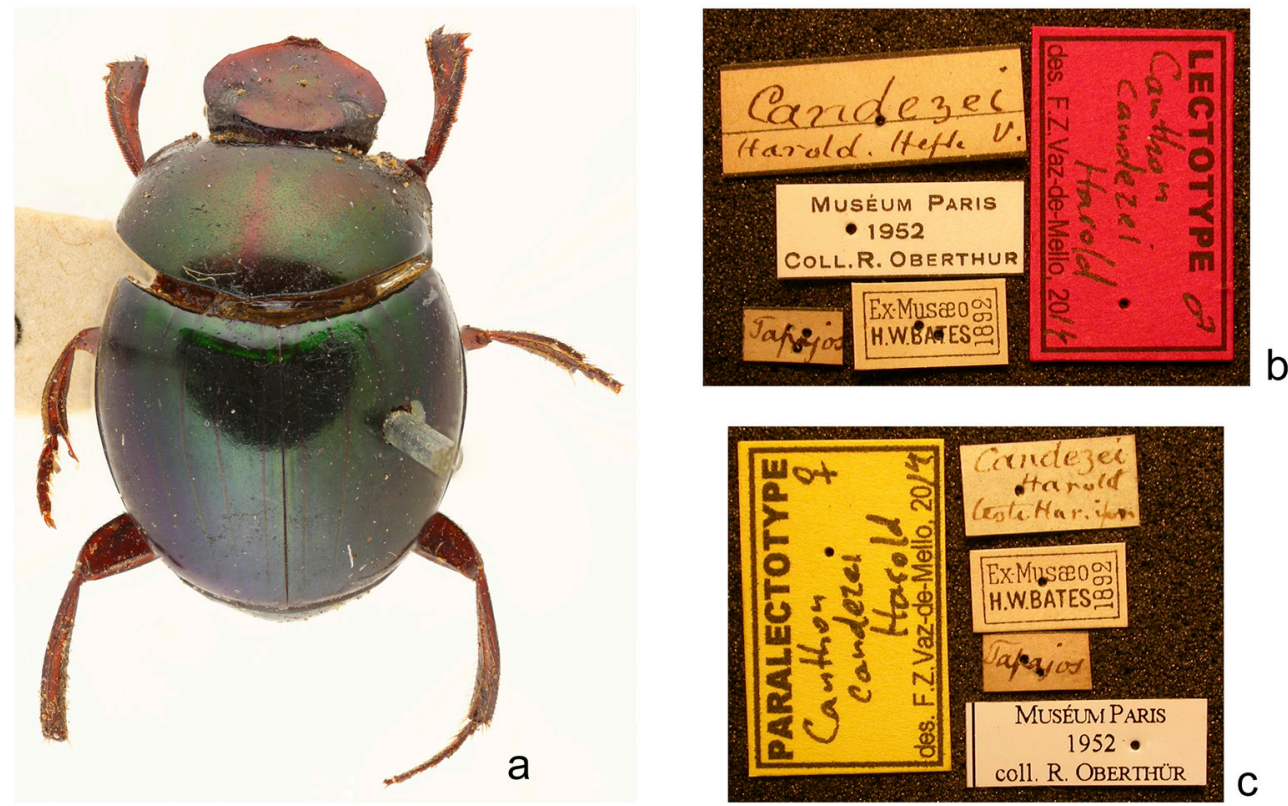

A
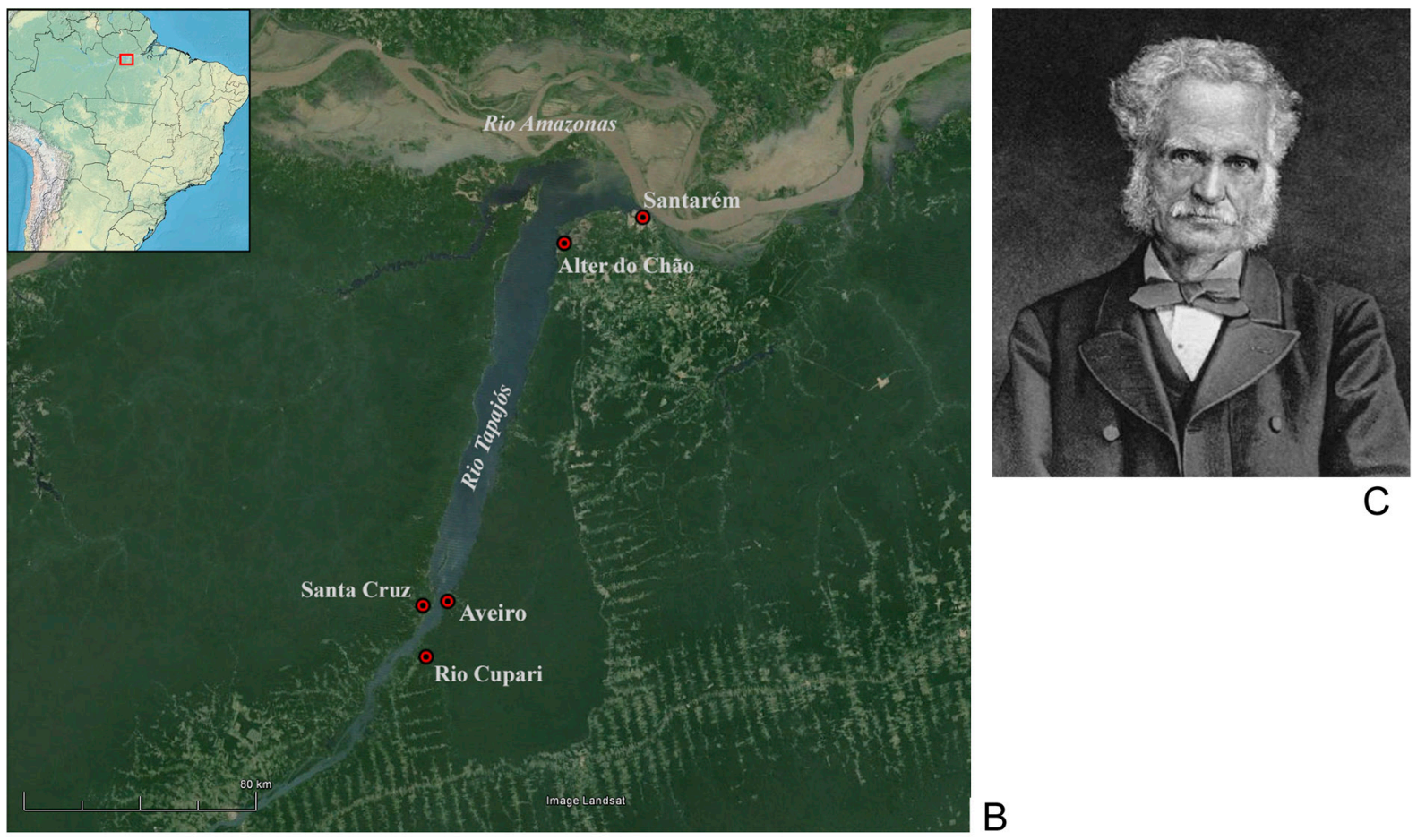

Fig. 26. Sylvicanthon candezei (Harold, 1869) type material. A. a. Lectotype. b. Labels of lectotype. c. Labels of paralectotype 3. B. The four localities where $S$. candezei type series may have been collected by Bates in the lower Tapajós region in 1852 (see discussion in the text). C. The English naturalist Henry Walter Bates (1825-1892), the collector of the S. candezei type series (modified from Bidau 2014). 
in ventral view). In lateral view, parameres without ventral keel and with a profound notch at middle (Fig. 17C).

SEXUAL DIMORPHISM. Males: Protibial spur wide and bifid, with external projection spiniform, straight, and not very long, and internal projection bent and wide (Fig. 15B). Ventrite VI strongly narrowed at middle by emargination of its posterior edge and covered anteriorly by medial projection of ventrite V (Fig. 14D). Females: Protibial spur spiniform, simple. Ventrite VI wide at middle and covered anteriorly by medial projection of ventrite $\mathrm{V}$, which gives a narrowed appearance to it (but never as in male) (Fig. 14E).

\section{Measurements}

Males $(\mathrm{N}=13)$. TL: AV: $6.7 \pm 0.56$; MX: 7.6; MN: 5.8. EW: AV: $4.8 \pm 0.38$; MX: 5.3; MN: 4.1. PL: AV: $2.0 \pm 0.22$; MX: 2.5; MN: 1.8. PW: AV: $4.1 \pm 0.29$; MX: 4.5; MN: 3.6. PgL: AV: $1.4 \pm 0.19$; MX: 1.9; MN: 1.1. PgW: AV: $2.0 \pm 0.17$; MX: 2.3; MN: 1.7 .

Females (N = 14). TL: AV: $6.7 \pm 0.48$; MX: 7.4; MN: 6. EW: AV: $4.8 \pm 0.25$; MX: 5.3; MN: 4.4. PL: AV: $2.26 \pm 0.16$; MX: 2.5; MN: 1.9. PW: ME: 4.2 \pm 0.2 ; MX: 4.6; MN: 3.9. PgL: ME: $1.4 \pm 0.09$; MX: 1.2; MN: 1.5. PgW: AV: $2.1 \pm 0.11 ; \mathrm{MX}: 2.3 ; \mathrm{MN}: 1.9$.

\section{Geographical distribution}

Humid tropical forests from the mouth of the Tapajós River down to the semideciduous forests of southern and southeastern Amazonia in Brazil.

\section{Ecoregions}

Uatuma-Trombetas Moist Forests, Madeira-Tapajós Moist Forests, Tapajós-Xingu Moist Forests, Mato Grosso Tropical Dry Forest, Chiquitiano Dry Forest.

\section{Collecting sites (Fig. 24)}

BRAZIL. Pará: Belterra, Óbidos, Pau-d'Arco, Redenção, Santarém. Mato Grosso: Araputanga, Curvelândia, Diamantino, Indiavaí, Nobres, Nova Mutum, Querência, Tangará da Serra.

\section{Intraspecific variation and taxonomic discussion}

Since the beginning of the $20^{\text {th }}$ century, specimens of Sylvicanthon collected throughout the Amazon region have been misidentified as $S$. candezei, both in collections and in publications. Nevertheless, even individuals from places as distant from that biome as Rio de Janeiro also suffered from that mistake, as a specimen of $S$. foveiventris colleted in Itatiaia in 1959 and now deposited in the MNRJ has shown. Two other species that were largely confused with $S$. candezei are $S$. seag sp. nov. and $S$. genieri sp. nov. The great confusion in the recognition of the true identity of $S$. candezei naturally brought to publication a large amount of incorrect information on the geographical distribution of this species. Schmidt (1922), for example, cited "Amazonas, Surinam, Cayenne, Ecuador" as being the distribution of S. candezei, and that was followed by Martínez et al. (1964), who considered this species was distributed in most parts of the Amazonia, including Venezuela, Suriname, French Guiana, Brazil, and Ecuador.

In the present work, we observed that $S$. candezei has actually a much more restricted distribution than previously thought, being limited to eastern Amazonia, from the mouth of the Tapajós River, in Pará, south to the state of Mato Grosso (Fig. 24). Interestingly enough, in Mato Grosso and southern Pará, specimens of $S$. candezei were found only at sites in the outer limits of the Amazon forest, i.e., places close to the transition between that biome and the Cerrado and Pantanal; no specimens were collected farther inland in this part of the Amazon region despite extensive collections made in places such as Cotriguaçu, Alta Floresta, Carlinda, and Nova Bandeirante, in Mato Grosso, and Novo Progresso, in 
Pará. This information tells us that $S$. candezei has possibly its southern distribution more closely related to the peripherical areas of the Amazon Rainforest, whereas northern populations are present farther inland in that biome.

Apart from this supposed difference in habitat preference, southern and northern populations of S. candezei also exhibit clear morphological distinctions. Specimens collected in Óbidos, Santarém, and in the region of the lower Tapajós River, in Pará, have pronotal and elytral tegument with a more smooth microsculpture, which is sometimes almost absent, so giving a brighter appearance to the entire body and a greater contrast to the elytral striae. Conversely, southern population in southern Pará (Pau d'Arco and Redenção) and in Mato Grosso have a strong microsculpture, with a very dark pronotum and elytra and very subtle elytral striae. Concerning colouration, such a variable feature among other Sylvicanthon, in S. candezei it is much more uniform, with the majority of the specimens of all populations being dark green with a weak metallic sheen.

\section{Comments}

The type series of $S$. candezei was collected by the much-celebrated English naturalist and explorer Henry Walter Bates (1825-1892) (Fig. 26C) during his long and famous collecting period in the Amazon Basin between 1848 and 1859. As the type locality of S. candezei, Harold (1869a) cited "Tapajos" and this information is indeed present on the labels of all the syntypes. Nevertheless, the Tapajós River is one of the largest tributaries of the Amazon, covering almost eight hundred kilometres from its formation in the convergence of the Teles Pires and Juruena Rivers to its mouth situated near the city of Santarém, in Pará. Therefore, where exactly in this vast area would have Bates collected the oldest known specimens of $S$. candezei?

In his journey's narrative, Bates (1863) dedicated a full chapter to his exploration of the Tapajós River. After spending almost six months in Santarém, a city on the banks of the Amazon, Bates decided to explore the lower region of the Tapajós. With that goal in mind, he rented a suitable vessel, hired a small crew and set off on the $8^{\text {th }}$ of June 1852 . For the next four months, he navigated approximately $170 \mathrm{~km}$ upstream in the Tapajós and made collections in four main localities: Alter do Chão and Aveiro, on the right banks of the Tapajós, and Santa Cruz, on the left banks, besides having gone up for a few days the much narrower Cupari River, a tributary on the right banks of the Tapajós (Fig. 26B). At the end of this trip, Bates returned to Santarém, from where he then left to go up the Amazon River towards Ega (nowadays known as Tefé). By reading his accounts, it is not possible to find any mention to dung beetle collections, although it is clear that Bates collected a large number of insects in that region. Therefore, although we do not have the exact locality where Bates caught the type series of $S$. candezei, we do know at least that it was in the lower Tapajós area, very likely either in Alter do Chão, Aveiros, Santa Cruz or at some point along the Cupari River, between June and October 1852.

Apart from the nine specimens listed in the type series above, three other females collected by Bates in the Tapajós were found in the BMNH collection. Two of them bear circular blue labels handwritten "Tapayo", on one side, and "54 / 18", on the other. According to Max Barclay (personal communication to MC, 2015), curator of Coleoptera at the BMNH, this code refers to a lot consisting of 237 beetles collected by Bates in "Amazon (Alta de Chia) 100 miles from Santaren on the Japayos". This lot was bought in 1854 by the BMNH at the J.C. Stevens Auction Rooms, London, an auction house specialized in natural history and antiquities and then property of J.C. Stevens, brother of Samuel Stevens, English naturalist who arranged Bates' travel to the Amazon region and from whom he received material there collected (Anonymous 1899; Carrington 1899). 'Alta de Chia' certainly refers to Alter do Chão, whereas 'Japayos' is a corruption of Tapajós. The third female in the BMNH, differently, has a circular blue label handwritten "Braz / Tapajos", on the one face, and " 53 / 27", on the other, code referring to, according to Barclay, 232 beetles collected by Bates in "Brazil, Banks of the Rio Japayos" and also auctioned by Stevens in 1854. 
As none of those three females bears any label with Edgar von Harold's handwriting, we do not consider them syntypes of $S$. candezei. Nonetheless, two of them have rectangular pinkish identification labels with other names: one was identified as "castanipes Reiche", nomen in litteris that we do not know whether it was cited in the literature before, while the other specimen is labelled "Serrimanus mihi" (mihi, from the Latin, meaning "belonging to me"; Schenk \& McMasters 1956). According to Harold (1868a, 1869b), "serrimanus" was a nomen in litteris used by the French entomologist Auguste Chevrolat (1799-1884) to refer to the species named by Harold as C. chevrolati Harold, 1868, nowadays a subspecies of Canthon indigaceus LeConte, 1886, from North and Central America. Therefore, in principle, Chevrolat should have been the author of that identification label; indeed, although the majority of his Scarabaeinae collection is currently housed in the SMTD (via C. Felsche collection), other Coleoptera groups of his collection, such as Cerambycidae, were deposited at the BMNH (Horn \& Kahle 1935). Even so, as C. indigaceus chevrolati is completely distinct from $S$. candezei in both morphology and distribution, it would be curious that such an experienced entomologist as Chevrolat could have confused them. Alternative explanations are that Harold perhaps confused the actual application of the name "serrimanus" by Chevrolat and that this latter entomologist used that name to refer to the current $S$. candezei, or that, in reality, the label's author was not Chevrolat but, instead, a third unidentified entomologist who used the name 'serrimanus' independently from Chevrolat to refer to $S$. candezei. Although these nomina in litteris are unavailable and, therefore, cannot affect the validity of the name Canthon candezei, tracing their histories is worthy because it allows us to better understand the dynamics of discovering and naming taxa in the $19^{\text {th }}$ century, as well as communication between entomologists during the period.

\section{Natural history}

No information about the biology of $S$. candezei has been published until now. Label data state the species occurs in altitudes between 263 and $520 \mathrm{~m}$ and is attracted to pitfall traps baited with human faeces and cow and pig dung, and that it can also be collected using flight interception traps. Apparently, adults of $S$. candezei are active throughout the year, having been collected between January and May, and in July, October and December. Nonetheless, it is worth noting that it was during the first four months of the year that 115 out of the 157 examined specimens were caught (January: 35 specimens; February: 20; March: 47; April: 13), indicating that, although active throughout the year, S. candezei should be more abundant during the rainiest and hottest months than during the dry season in the middle of the year.

Sylvicanthon genieri sp. nov. urn:lsid:zoobank.org:act:AB21F887-15E7-40CD-BBA8-673CDB21ED37

Figs $6 \mathrm{C}, 15 \mathrm{D}, 17 \mathrm{D}, 20,24,27$

Sylvicanthon sp. 2: Celi et al. 2004: 46.

Sylvicanthon candezei - Carvajal et al. 2011: 117, 316 (error).

\section{Etymology}

The specific name, a noun in the genitive case, is an homage to the Canadian entomologist François Génier, one of the leading specialists in Scarabaeinae and author of some great works on this group, in recognition of his immense help and kindness in loaning more than one thousand specimens of Sylvicanthon (including 131 S. genieri sp. nov.) from the CMNC to us. As far as we know, Génier was the first entomologist to recognize this species as new, having identified since 1998 several specimens in the CMNC collection as "Sylvicanthon sp. nov". 


\section{Material examined}

\section{Holotype}

ECUADOR: ^ึ, Tungurahua, 6 km east from Río Negro, 1500 m (“ECU: Tungurahua / 6 kmE RioNegro 1500m / 13-17.vii.76 S.Peck / for. car. tps. 40-50"), genital capsule removed and glued to a triangular label (CMNC).

\section{Paratypes $(112 \hat{\jmath} \widehat{\partial}, 89$ 우 $)$}

ECUADOR: Morona Santiago: 1 đ, Untsuants, site 4, 1100 m, 20 Jan. 2002, J. Celi and M. Ortega

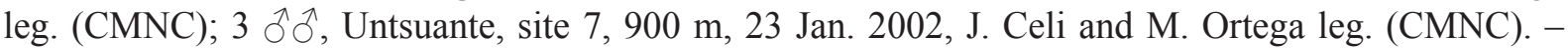

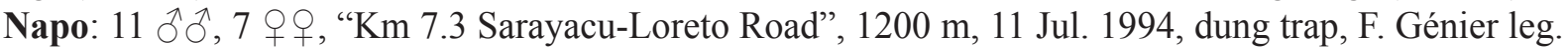

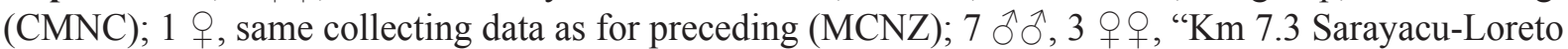
Road", 1200 m, 14 Jul. 1994, dung trap, F. Génier leg. (CMNC); 3 đิ ô, 2 우 , "Km 7.3 Sarayacu-Loreto Road", 1200 m, 20 Jul. 1994, dung trap, F. Génier leg. (CMNC); 1 đ̂, 1 \&, "Km 11.1 Sarayacu-Loreto Road", 1200 m, 20 Jul. 1994, dung trap, F. Génier leg. (CMNC); 1 \%, same collecting data as for

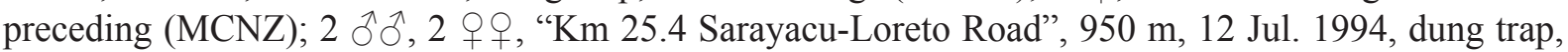

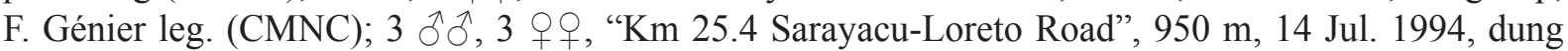
trap, F. Génier leg. (CMNC). - Orellana: 1 + , Onkone Gare Camp, 00 $39^{\prime} 10^{\prime \prime}$ S, 76 $26^{\prime} 00^{\prime \prime} \mathrm{W}, 220 \mathrm{~m}$, 4-12 Oct. 1995, active collecting beneath the leaf litter, T.L. Erwin Ecuador Expedition 1995, G.E. Ball and D. Shpeley leg. (CMNC). - Pastaza: 3 q 4.3 km Rio Negro, 1200 m, 18 Jul. 1994, dung trap, F. Génier leg. (CMNC); 1 đ, "09 km ESE Veracruz", 22-24 Aug. 1975, dung trap, R. Webster leg. (CMNC); 1 Ĵ, 1 q, Pastaza, "22 km SE Puyo", 900 m, 16 Jul. 1976, dung trap, S. Peck leg. (CMNC);

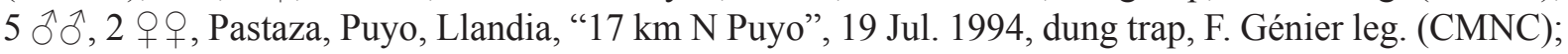

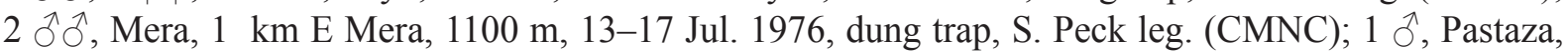
Puyo, Llandia, "17 km N Puyo", 20 Jul. 1994, dung trap, F. Génier leg. (CMNC). - Tungurahua: 1 ð, 3 km W Río Negro, 1200 m, 18 Jul. 1994, dung trap, F. Génier leg. (CMNC); 1 ô, 4.3 km E Río Negro, 1200 m, 18 Jul. 1994, dung trap, F. Génier leg. (CMNC); 1 ㅈ, 3 우우, 4.3 km E Río Negro, 1200 m, 20 Jul. 1994, dung trap, F. Génier leg. (CMNC); 3 đ̊ ô, 6 km E Río Negro, 1500 m, 13-17 Jul. 1976,

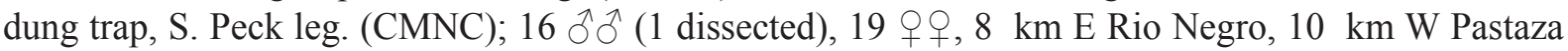
(= Shell), 1400 m, 13-17 Jul. 1976, dung trap, S. Peck leg. (CMNC); 9 đ̂̃ , 6 qㅜ, Baños, "El Topo", $01^{\circ} 23^{\prime} 41^{\prime \prime}$ N, 78 $22^{\prime} 52^{\prime \prime}$ W, 1590 m, 23 Jan. 2011, human faeces, G. Maldonado leg. (CEMT). - Zamora

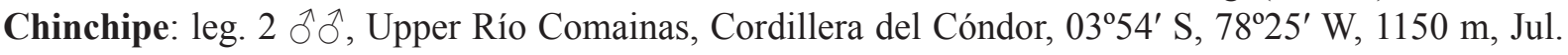
1994, human faeces, A. Forsyth (MUSM).

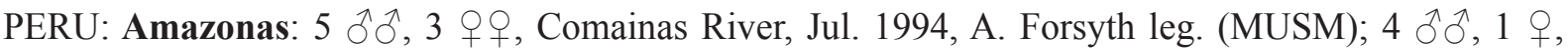
Comainas River, 21 Jul. 1994, A. Forsyth leg. (MUSM); 7 ठิ $\widehat{~}, 12$ 우, Comainas River, 23 Jul. 1994, A.

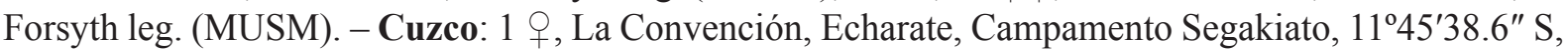
73¹4'57.7" W, 908 m, 2 Mar. 2011, M. Alvarado and E. Rázuri leg. (MUSM); 1 đ, La Convención,

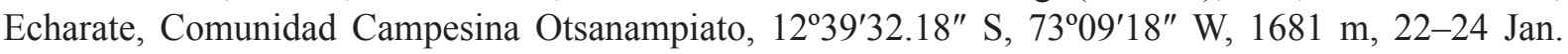
2010, C. Carranza and C. Rossi leg. (MUSM); 1 స, La Convención, Echarate, Comunidad Campesina

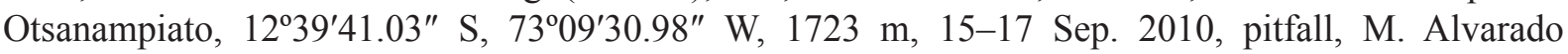
and J. Peralta leg. (MUSM); 1 त, La Convención, Echarate, Comunidad Campesina Santa Rosa, $12^{\circ} 33^{\prime} 54.41^{\prime \prime} \mathrm{S}, 7^{\circ} 05^{\prime} 36.85^{\prime \prime} \mathrm{W}, 1747 \mathrm{~m}, 26-29$ Jan. 2010, C. Carranza and C. Rossi leg. (MUSM); 1 q,

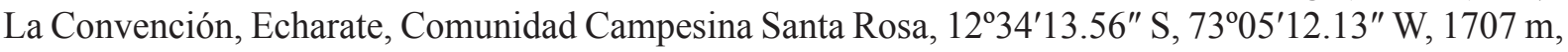
18-21 Sep. 2010, M. Alvarado and J. Peralta leg. (MUSM); 1 đે, La Convención, Echarate, Comunidad Campesina Santa Rosa, 12 ${ }^{\circ} 34^{\prime} 12.73^{\prime \prime}$ S, 7305' $13.73^{\prime \prime}$ W, 1709 m, 18-21 Sep. 2010, M. Alvarado and J. Peralta leg. (MUSM); 1 đ (dissected), 2 q $q$, La Convención, Echarate, Comunidad Campesina Santa

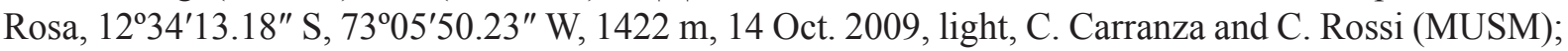
$1 \delta^{\top}$, La Convención, Echarate, Comunidad Campesina Santa Rosa, $12^{\circ} 34^{\prime} 10.12^{\prime \prime}$ S, $73^{\circ} 05^{\prime} 13.85^{\prime \prime}$ W, 1587 m, 18-21 Sep. 2010, M. Alvarado and J. Peralta leg. (MUSM); 1 đ, La Convención, Echarate,

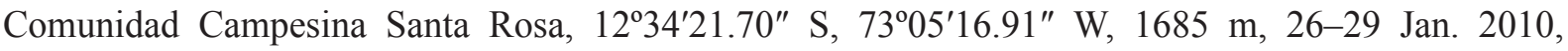


C. Carranza and C. Rossi leg. (MUSM); 1 §, 2 우, La Convención, Echarate, Comunidad Campesina Santa Rosa, 12034'10.72" S, 7305'15.17" W, 1693 m, 18-21 Sep. 2010, pitfall, M. Alvarado and J. Peralta leg. (MUSM). - Huánuco: 1 đ̃, 3 $q$ \%, Leoncio Prado, Rupa-Rupa, Tingo María, Universidad Nacional Agraria de la Selva ("Tingo María Universidad"), Jul. 1974 (CMNC); 10 ठૈ $\widehat{~(1 ~ d i s s e c t e d), ~}$ 5 우, Leoncio Prado, Rupa-Rupa, Tingo María, Universidad Nacional Agraria de la Selva ("Tingo María Universidad"), Dec. 1974 (CMNC). - Junín: 1 +, Chanchamayo, San Ramón, 10 May 2002, F.G. Horgan leg. (MUSM); 2 우, Chanchamayo, San Ramón, Oct. 2002, pitfall with human faeces,

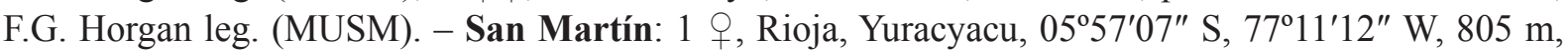
6-7 Sep. 2008, C. Albujar leg. (MUSM); 1 ○ (dissected), Mariscal Cáceres, Juanjuí, Mar. 2010 (CEMT).

Incorrect data: VENEZUELA: Bolívar: 1 đ (dissected), "150 km sur Caicara, R. Suapare”, 3-10 Apr. 1977, Bordón leg. (CMNC).

\section{Description}

Colouration. Head, pronotum, elytra, metaventrite, and pygidium largely coppery; pygidium and, more rarely, centre of head occasionally with greenish reflections. Meso- and metafemora orangish.

HEAD. Tegument shiny, with strong alveolar microsculpture on frons, and more diffuse (yet clearly present) microsculpture on clypeus and genae; micropunctation fine and very subtle, sometimes almost imperceptible throughout most of the head, but often clearly seen on frons (Fig. 6C). Clypeus with two apical teeth obtuse and contiguous at base; with a single transverse row of setae covering the base of both teeth. Genae with a weak tooth immediately behind clypeal-genal juncture. Posterior edge of head unmargined between eyes.

Thorax. Pronotum with shiny tegument and dense micropunctation at centre, denser and with more marked punctures than head (in some specimens, however, punctation can be weaker); towards the sides, micropunctation progressivily less dense and well marked, being completely absent on the lateral margin; tegument with strong alveolar microsculpture throughout its surface. Posterior edge with a fine transverse line at centre (usually extending little beyond the second elytral stria). Hypomeral cavity with variable density of setae, from almost glabrous to with long yellowish setae covering the entire interior of the hypomeral cavity; external margin simple, without any trace of a tubercle. Metaventrite entirely glabrous; anterior region with tegument with distinct alveolar microsculpture; centre and posterior region with dense alveolar microsculpture obliterating weak micropunctation, or micropunctation completely absent.

Legs. Profemora with tegument with strong alveolar microsculpture on their anterior half and with strong rivose microsculpture on their posterior half. Protibiae narrow and straight on their internal edge; at their apical seventh, external edge with two small acute teeth - the apical one slightly longer than the second. Mesofemora margined anteriorly only at their basal half; unmargined portion of anterior edge with row of very short setae; tegument with strong alveolar micosculpture. Metafemora margined only anteriorly, posterior margin absent; apical third of anterior edge covered by row of setae; tegument with strong alveolar microsculpture obliterating micropunctation, which is almost imperceptible; base without coarse elongate punctation. Metatarsomeres II and V subequal in length and longer than the others; metatarsomere IV shorter than the others.

ELYTRA. With only eight visible striae: first four or five striae clearly marked, finely carinulate, and without basal widening; fifth to seventh striae progressivily more effaced and interrupted, the seventh occasionally vestigial; eighth stria vestigial, present only as a weak mark parallel to the apical half of epipleura; all striae lack their carinulae at the apex of elytra, where they are marked only by 
microsculpture or are completely indistinct; humeral carina absent. Tegument of interstriae with strong alveolar microsculpture obliterating micropunctation, which is almost imperceptible.

AвDOMEN. Ventrite VI smooth at centre and with weak rivose microsculpture on the sides. Lateral foveae absent in both sexes. Pygidium with tegument with strong alveolar microsculpture and effaced, frequently imperceptible micropunctation; of equivalent length in both sexes.

AEdeagus. Parameres about half as long as phallobase, and slightly asymmetrical: left paramere laterally flat or concave, right paramere convex (difference more easialy seen from ventral view). In lateral view, parameres with strong ventral keel and with short notch close to base (Fig. 17D).

Sexual dimorphism. Males: Protibial spur broad and bifid, with external projection spiniform, straight, and long, and internal projection bent and widened (Fig. 15D). Ventrite VI strongly narrowed at middle; ventrite $\mathrm{V}$ usually without medial flange on its posterior edge or only slightly indicated over anterior edge of ventrite VI. Females: Protibial spur spiniform. Ventrite VI broad at middle and with anterior edge only slightly covered by weak flange of posterior edge of ventrite $\mathrm{V}$.

\section{Measurements}

Males (N = 16). TL: AV: $7.0 \pm 0.36$; MX: 7.4; MN: 6.5. EL: AV: 4.9 \pm 0.39 ; MX: 5.7; MN: 4.3. PL: AV: $2.1 \pm 0.17$; MX: 2.5; MN: 1.9. PW: AV: $4.1 \pm 0.26$; MX: 4.5; MN: 3.7. PgL: AV: $1.4 \pm 0.09$; MX: 1.5 ; MN: 1.3. PgW: AV: $2.1 \pm 0.13$; MX: 2.3; MN: 1.9.

Females $(\mathrm{N}=21)$. TL: AV: $7.2 \pm 0.50$; MX: 8.2; MN: 6.6. EW: AV: $4.9 \pm 0.23$; MX: 5.3; MN: 4.6. PL: AV: $2.1 \pm 0.14$; MX: 2.3; MN: 1.9. PW: AV: $4.1 \pm 0.19$; MX: 4.5; MN: 3.9. PgL: AV: $1.4 \pm 0.08$; MX: $1.5 ;$ MN: 1.3. PgW: AV: $2.1 \pm 0.11$; MX: 2.3; MN: 1.9 .

\section{Geographical distribution}

Cloud forests of western Amazonia and slopes of the Andes in Ecuador and Peru.

\section{Ecoregions}

Napo Moist Forests, Cordillera Oriental Montane Forest, Marañón Dry Forest, Ucayali Moist Forests, Peruvian Yungas.

\section{Collecting sites (Fig. 24)}

ECUADOR. Orellana: Onkone Gare Camp. Napo. Tungurahua: Baños de Agua Santa, Río Negro. Pastaza: Pastaza (Puyo: Llandia), Mera. Morona Santiago: Untsuante. Zamora Chinchipe: Cordillera del Cóndor.

PERU. Amazonas. San Martín: Rioja (Yuracyacu), Mariscal Cáceres (Juanjuí). Huánuco: Leoncio Prado (Rupa-Rupa: Tingo María). Junín: Chanchamayo (San Ramón). Cuzco: La Convención (Echarate).

\section{Intraspecific variation and taxonomic discussion}

It is interesting to note that many specimens of $S$. genieri sp. nov. studied for this work bear labels identifying them as $S$. candezei. It is not surprising that both species have been confused for such a long time, since they, together with $S$. foveiventris, share several characteristics not found in any other Sylvicanthon. The most obvious of them is the presence of only two protibial teeth (Fig. 11J), while all the other species have three, but we can list also protibiae without internal expansion (absent also in the aequinoctialis subgroup and in the majority of the species of the bridarollii group) and elytral striae very fine and progressively less marked from the elytral suture. Furthermore, among Sylvicanthon, it is only 
in $S$. genieri sp. nov. and $S$. candezei that the hypomeral tubercle is completely absent, fact that leads these two species to key out at the same couplet in all the identification keys published so far (Schmidt 1922; Balthasar 1939; Pereira \& Martínez 1956; Martínez et al. 1964; Vulcano \& Pereira 1967).

Even so, also based on identification labels, it is possible to see that with the increasing accumulation of material collected during the 1990s and 2000s, some entomologists were able to recognize the true identity of S. genieri sp. nov. as a distinct species. From 1998 on, François Génier identified some specimens of this species as 'Sylvicanthon sp. nov.', whereas Trond Tarsen, in 2012, determined others as 'Sylvicanthon sp. $\neq$ candezei'. In fact, even at first sight, S. genieri sp. nov. and S. candezei are easily differentiated by colouration: the former species has a bright coppery colouration (occasionally, with greenish reflexions on head) (Fig. 27A), while S. candezei is entirely dark green (Fig. 25A). The degree of punctation and microsculpture throughout the body also varies between the two species: in $S$. candezei, punctures at the centre of pronotum are strong and easily seen, little obliterated by microsculpture, while punctures are very weak in $S$. genieri sp. nov. and usually almost completely obliterated by the strong microsculpture at the centre of the pronotum. On the elytra and pygidium, the microsculpture is always very strong and punctures are weak or even absent in $S$. genieri sp. nov., whereas, although not as well marked as at the centre of pronotum, they are still completely visible in $S$. candezei.

A difference is also seen on the ventrites: in males of $S$. candezei, ventrite five shows a weak medial flange over the anterior margin of ventrite six (Fig. 14D), while in females this flange is much stronger, giving a false impression of a medial narrowing to ventrite six (characteristic usually associated to males in Sylvicanthon) (Fig. 14E). In S. genieri sp. nov., on the other hand, males usually lack any trace of a flange on ventrite five or, at most, it is very weak, almost imperceptible, while in females this flange is not very strong either, being similar to the one present in males of $S$. candezei, which does not obscure the true broad, typically female nature of ventrite six. Lastly, the clearest morphological difference
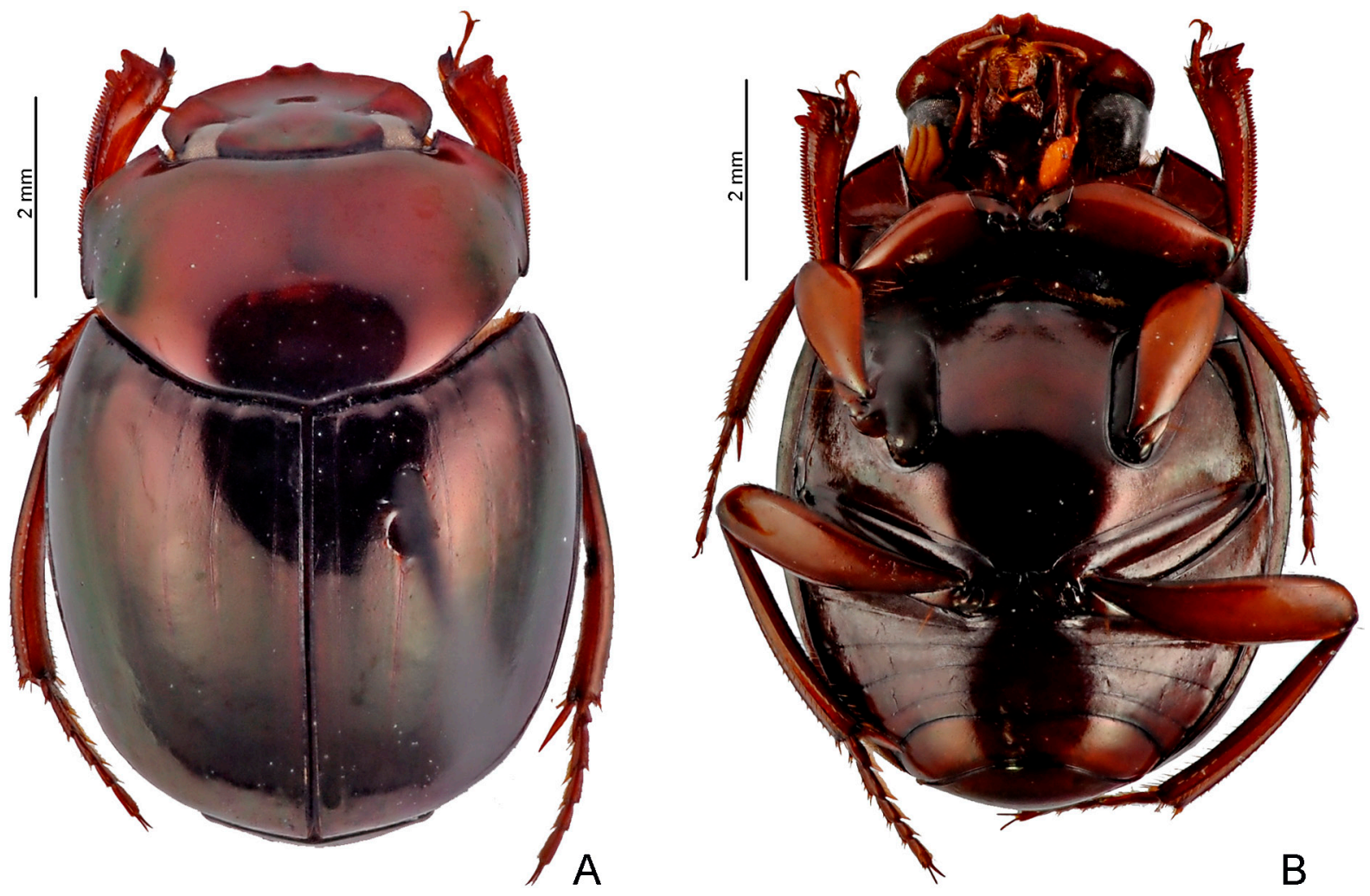

Fig. 27. Sylvicanthon genieri sp. nov. A. Dorsal view. B. Ventral view. 
between these two species lies on the shape of the parameres: in $S$. candezei, they have a deep ventral notch, dividing the parameres into two regions (the anterior one subrectangular) (Fig. 17C), and lack a ventral keel, whereas $S$. genieri sp. nov. presents a much shorter notch (which does not divide the parameres into two distinct parts) and has a strong ventral keel (Fig. 17D).

From $S$. foveiventris, the third species of the candezei subgroup, S. genieri sp. nov. is distinct in presenting a strong alveolar microsculpture on the pronotum, elytra and pygidium, whilst the former species does not possess any sign of microsculpture, with tegument marked only by micropunctation. The absence of paired foveae on the female ventrites (present in three pairs in S. foveiventris, Figs 14B, 16D), the paramere shape (with a ventral keel and a notch in S. genieri sp. nov., Fig. 17D; and simple in S. foveiventris, Fig. 17B), and colouration also distinguish both species. On the other hand, S. genieri sp. nov. and $S$. foveiventris are similar by the presence of a weak (rather than strong) medial flange of ventrite five of females (although this structure is even less developed in S. foveiventris, Fig. 14B, than in $S$. genieri sp. nov.).

Limited morphological variation was observed in $S$. genieri sp. nov., none of it related to distribution. The few variable characteristics are related to the micropunctation of the pronotum and the elytra (which can be clearly present or almost entirely effaced and imperceptible; on the elytra, in particular, sometimes it is completely absent), the pilosity of the hypomeral cavity (which can be entirely glabrous or present several yellowish setae all over its surface), and the colouration (which can vary from a very dark coppery with little sheen to light reddish with greenish reflections on the head, with the majority of the specimens being in an intermediate position between these two extremes, with a bright coppery colouration without any trace of greenish reflexions). The colouration of the meso- and metafemur also varies, with one end of the variation spectrum being light yellow and the other dark brown. Teneral specimens are entirely yellow.

\section{Comments}

Judging from the cited locality, specimens identified as S. candezei by Carvajal et al. (2011) from Ecuador are probably $S$. genieri sp. nov.. In addition, having studied some specimens of the species that Celi et al. (2004) called "Sylvicanthon sp. 2", it was possible to see that this species is actually $S$. genieri sp. nov. (see discussion about this and other identifications by Celi et al. on the comments under $S$. edmondsi sp. nov.).

\section{Natural history}

Based on the label information, it is possible to say that $S$. genieri sp. nov. is mainly collected with pitfall traps baited with human faeces. A male was collected in La Convención (Cuzcu, Peru) with a light trap and a female was found beneath the leaf litter in Onkone Gare Camp (Orellana, Ecuador). Living on the Amazon slopes of the Andes, S. genieri sp. nov. is in the candezei group the species which occurs at the highest elevation, having been recorded mostly in altitudes ranging from 805 to $1685 \mathrm{~m}$; just one specimen was caught at $200 \mathrm{~m}$ in the Onkone Gare Camp. This species was collected throughout the year (January, March, April, May, July, August, September and October), but July (125) and January (22) concentrated the record of the vast majority of the 202 specimens studied.

\section{The aequinoctialis subgroup}

Sylvicanthon aequinoctialis (Harold, 1868) comb. nov. Figs 7A, 11B, 15E-F, 17E, 20, 28A-B, 29A-B, 30, 31A

Canthon aequinoctialis Harold, 1868a: 2, 5, 14, 79, 141. 
“Coprobius aequinoctialis" - Dejean 1833: 136.

"Coprobius aequinoctialis" - Dejean 1836: 151. — Harold 1868a: 79 (as synonym of C. aequinoctialis). Nomen nudum.

Canthon aequinoctialis - Harold 1869b: 989; 1880: 16. — Bates 1887: 33. — Gillet 1911: 27. — Schmidt 1922: 64, 72. — Balthasar 1939: 187; 1941: 341 (error: refers to S. proseni); 1951: 326 (error: refers to S. proseni). — Martínez 1949a: 290. — Vulcano \& Pereira 1967: 561. — Gill 1991: 225-226, 228. - Escobar 2000a: 206 (error: refers to S. proseni); 2000b: 114, 121 (mixed information with $S$. proseni). - Medina et al. 2001: 135 (mixed information with S. proseni); 2003: 27, 51, 57-58, figs 9, 164; 2012: 93, 115, 171, 192. — Ratcliffe 2002: 12. — Solís \& Kohlmann 2002: 1, 4, 6-8, 53-54, 64, figs 1f, 31; 2012: 3, 21. - Halffter 2003: 43. - Celi et al. 2004: 42 (error: refers to $S$. proseni). — Noriega-Alvarado 2004: 40 (idem). — Kohlmann et al. 2007: 9, 28; 2010: 553. - Noriega et al. 2008: 78-79 (error: refers to S. proseni). - Carpio et al. 2009: 462, 464, 469 (idem). - Medina \& Pulido 2009: 58 (error: refers to S. proseni). — Arango \& Montes 2010: 262. — Figueroa \& Alvarado 2011: 210-211, fig. 1c (error: refers to S. proseni). — Solís et al. 2011: 36, 38. - Krajcik 2012: 63. — Noriega 2012: 4 (error: refers to S. proseni). — Ratcliffe et al. 2015: 195 (error: refers to $S$. proseni).

Canthon aequinoctiale - Blackwelder 1944: 198; 1973: 2. — Gacharná 1951: 221. — Howden \& Young 1981: 20, 27-28, 153, 167, figs 36-37. — Vaz-de-Mello \& Louzada 1997: 56. — Vaz-de-Mello 1999: 449-450 (error: refers to S. proseni). - Young 2009: 322.

Canthon cf. aequinoctialis - Noriega et al. 2007b: 81. — Martínez et al. 2010: 24.

Canthon (Canthon) aequinoctialis - Halffter \& Martínez 1977: 62, 90-91. - Noriega et al. 2007a: 54-55 (error: refers to $S$. proseni).

Canthon (Canthon) aequinoctiale - Vaz-de-Mello 2000 (error: refers to S. proseni).

Canthon (Canthon) aequinotialis [sic] - Noriega-Alvarado 2009. - Culot et al. 2011: Supporting information, table S1 (error: refers to S. proseni).

Canthon (Glaphyrocanthon) aequinoctialis - Howden 1966: 730.

Glaphyrocanthon (Glaphyrocanthon) aequinoctialis - Pereira \& Martínez 1956: 126, 128. — Martínez et al. 1964: 3, 5, 8-10, 13. - Vulcano \& Pereira 1967: 561.

Glaphyrocanthon (Glaphyrocanthon) aequinotialis [sic] - Vulcano \& Pereira 1964: 661.

\section{Etymology}

From the Latin 'aequinoctialis', meaning 'equinox' or 'equinoctial'. Probable reference to the type locality, region crossed by the Equator.

\section{Material examined}

Lectotype (here designated)

COLOMBIA: $\widehat{O}$, type locality cited by Harold (1868a) as "Columbien, Neu-Granada", ("cequinoctialis / t. Har", "Nov. Grenade", "Ex-Musæo / E. Harold", "HOLOTYPE", "TIPO / Canthon / (Canthon) / aequinoctialis / Harold / G. H. y A. M. det. 76") (MNHN) (Fig. 29A).

\section{Paralectotype}

COLOMBIA: ㅇ, (“26381”, "Nov Granad. Gom.", "Type", "aequinoctialis / Harold* / Nov. Granada", "PARALECTOTYPE / Canthon aequinoctialis / Harold, 1868 / des. Cupello \& Vaz-de-Mello, 2015") (ZMHB) (Fig. 29B).

Additional material (282 $\hat{\partial}, 210 q q, 81$ unsexed specimens)

COLOMBIA: 1 †, "Lebas" (collector or locality?) (ISNB, Gillet collection); 1 ô, illegible locality,

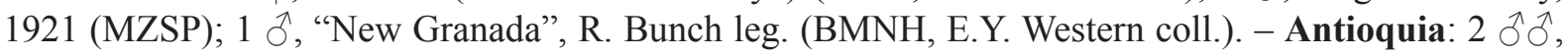
San Luis, Sonsón, Reserva Natural Cañon del Río Claro, 1440 m, 2 Mar. 1994, Harold M. Parra leg. (CEMT); 2 $\widehat{\jmath}$, San Luis, Sonsón, Reserva Natural Cañon del Río Claro, 1440 m, 3 Mar. 1994, H.M. 

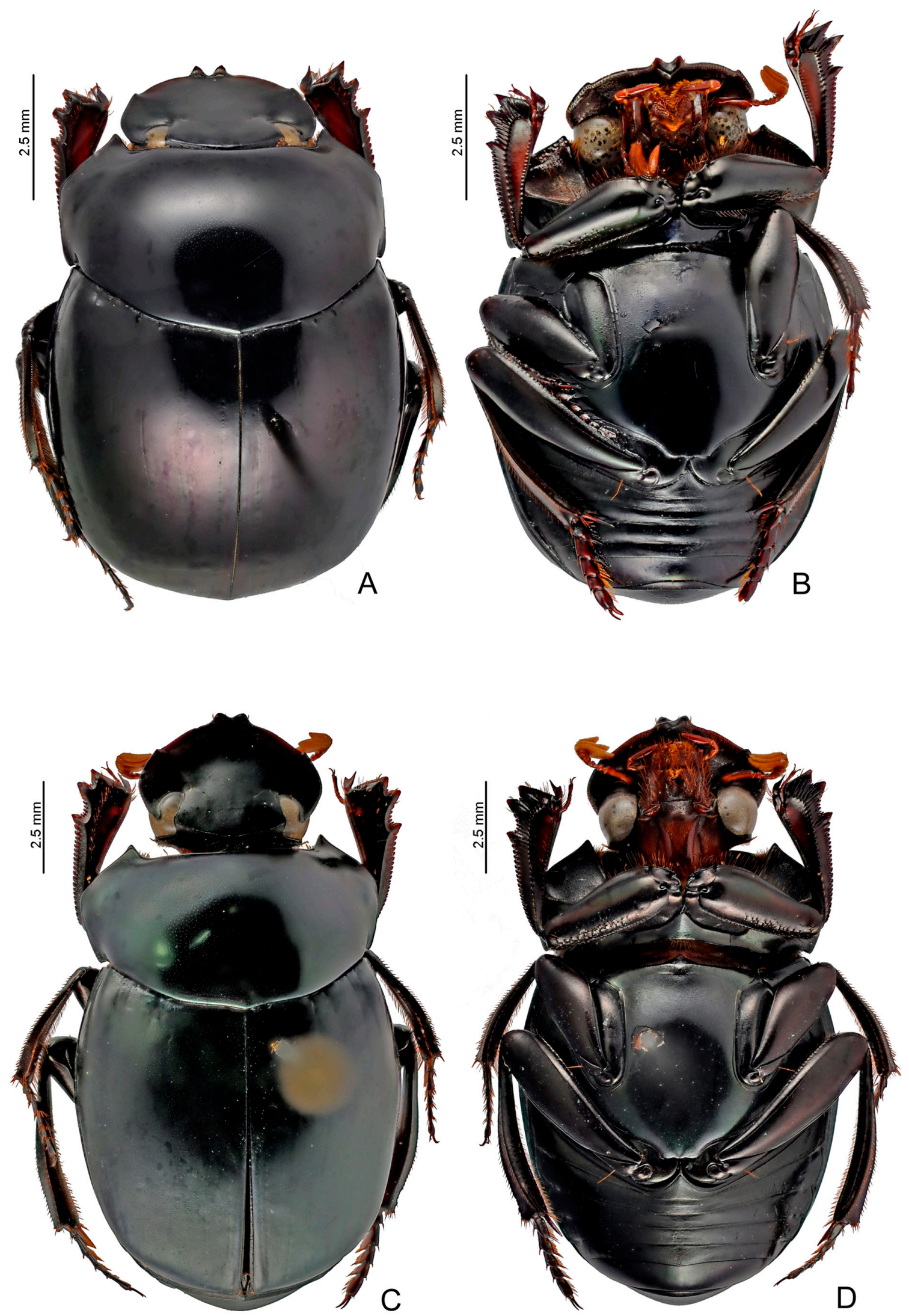

Fig. 28. A-B. Sylvicanthon aequinoctialis (Harold, 1868) comb. nov. A. Dorsal view. B. Ventral view. C-D. S. proseni (Martínez, 1949) stat. et comb. nov. C. Dorsal view. D. Ventral view. 
Parra leg. (CEMT); 1 †, San Luis, Sonsón, Reserva Natural Cañon del Río Claro, 1440 m, 3 Mar. 1994, H.M. Parra leg. (MCNZ). - Cesar: 1 đo, 1 q, Chimichagua, Finca Señor Reyes, 09² 21'9.8" N,

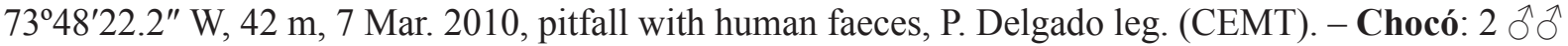
(1 dissected), 1 +, Acandí, Capurganá, “caminho “Al Cielo"”, 10 m, 6 Jan. 1999, A. Vitolo leg. (CEMT);

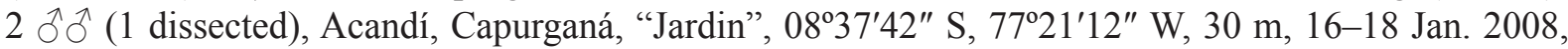

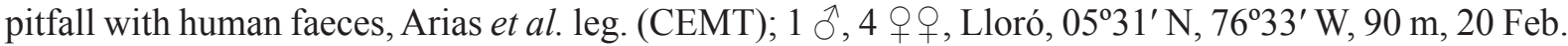
2003, Olaya and Mosquero leg. (TAMU); 1 q, Parque Nacional Natural Ensenada de Utría, 19 Jun. 1997, pitfall with human faeces, Llanos-Jurado leg. (CEMT); 2 ふરે, 1 ㅇ, Quibdó, Tutunendó ("20 km NE Quibdó”), 60 m, 26 Nov. 2001, J.C. Neita leg. (TAMU); 3 ô ô, Quibdó, Estación Ambiental Pandó, $05^{\circ} 42^{\prime} 43^{\prime \prime}$ S, 76 37'59" W, 43 m, 9-11 Jun. 2010, pitfall with human faeces, J. Arias leg. (CEMT);

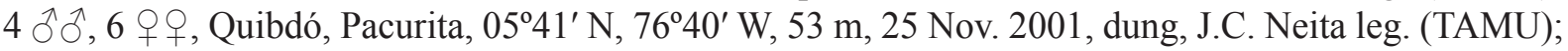

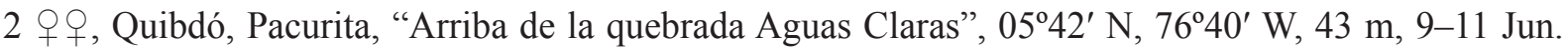

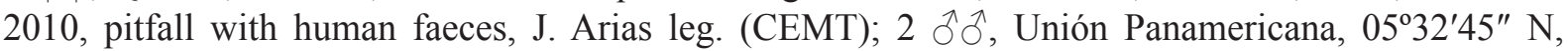

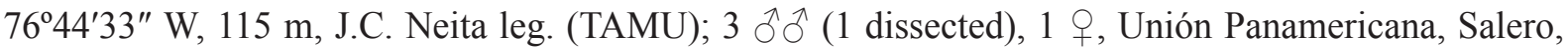
$05^{\circ} 32^{\prime}$ N, 76 $44^{\prime}$ W, 120 m, 3-5 Jun. 2010, pitfall with human faeces, J. Arias leg. (CEMT). - Distrito Capital(?): 1 specimen, Bogotá (BMNH). - Santander: $3 \hat{\jmath}$, 1 + , Serranía de las Quinchas, Reserva El Paujil, Jul. 2006, pitfall with Alouatta seniculus dung, Santos Zarate leg. (CEMT); 1 o, 1 q, Serranía de las Quinchas, Reserva El Paujil, Sep. 2006, pitfall with Alouatta seniculus dung, Santos Zarate leg. (CEMT). - Tolima: 1 J, 300 m, Nov. 1995, human faeces, F. Escobar leg. (CEMT). - Valle Del Cauca: 1 đે, Estación Agro-Forestal Bajo Calima, 50 m, 2 Oct. 1995, A. Lopera leg. (CEMT); 1 đ (dissected), Dagua, Río Escalerete, 31 Mar.-4 Apr. 1991, L.C. Pardo Locarno leg. (CEMT).

COSTA RICA: Guanacaste: Volcán Rincón de la Vieja, Hacienda Guachipelín, 13 Aug. 1999, trap with human faeces, J. L. Moreno \& T. Mestre leg. 1 đ (CEMT). - Limón: Río Reventazón,

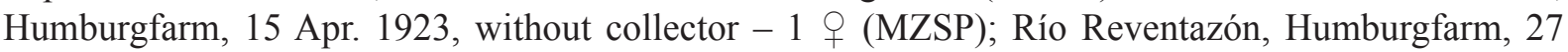
Aug. 1925, F. Nevermann leg. 1 đ (MZSP). - Puntarenas: Osa, 10-15 Aug. 1966 [trap with rotten flesh], S. Peck leg. 1 o (CNCI); 11 specimens, Península de Osa, Corcovado National Park, Sirena Biological Station, 08 $30.259^{\prime}$ N 83³5.958' W, 18 m, 17-20 Jul. 2009, Mehrabi et al. leg. (OUMNH); 20 specimens, Península de Osa, Corcovado National Park, Sirena Biological Station, 08 ${ }^{\circ} 30.502^{\prime}$ N,

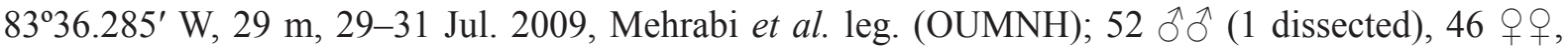
Península de Osa, Sirena Biological Station, 08 $30^{\prime}$ N, 833' W, 30 m, Jul. 2009, swine dung, Mann leg. (CEMT); 7 specimens, Península de Osa, Corcovado National Park, Sirena Biological Station, 08²9.891' N 35999' W, 31 m, 11-14 Jul. 2009, Mehrabi et al. leg. (OUMNH); 9 specimens, Península

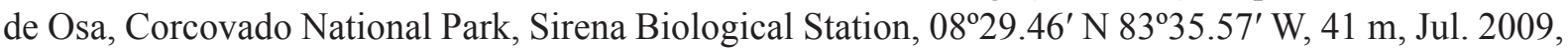
Mehrabi, Coals, Cowburn and Yu leg. (OUMNH); 2 specimens, Península de Osa, Corcovado National

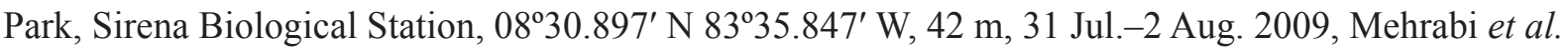
leg. (OUMNH); 2 specimens, Península de Osa, Corcovado National Park, Sirena Biological Station, 08²8.230' N 8335.275' W, 47 m, 26-29 Jul. 2009, Mehrabi et al. leg. (OUMNH); 8 specimens,

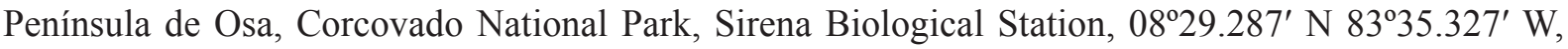
49 m, 19-22 Jul. 2009, Mehrabi et al. leg. (OUMNH); 1 specimen, Península de Osa, Osa Biodiversity

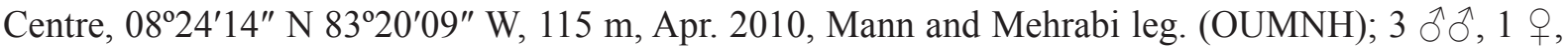
Reserva Biológica Bosque Nuboso Monteverde ("Parque Nacional Monteverde"), 13 Aug. 1999, J.L. Moreno and T. Mestre leg. (CEMT).

HONDURAS: Atlántida: 1 đ (dissected), 2 †+, 15 km W of La Ceiba, 15-19 Jun. 1996, flight interception trap, R. Lehman leg. (TAMU).

NICARAGUA: Chontales: 1 specimen, T. Belt leg. (BMNH, BCA). - Jinotega: 2 q , Reserva Natural Cerro Kilambé, 1000 m, Aug. 2001, M.A. Guatemala leg. (SEAN); 1 ㅇ, Santa Maura, 1215 m, Mar. 2002, L. Pivotti leg. (SEAN). - Matagalpa: 41 ふึ, 17 우, Matiguas, 5-6 Dec. 2003, B. Hernández 

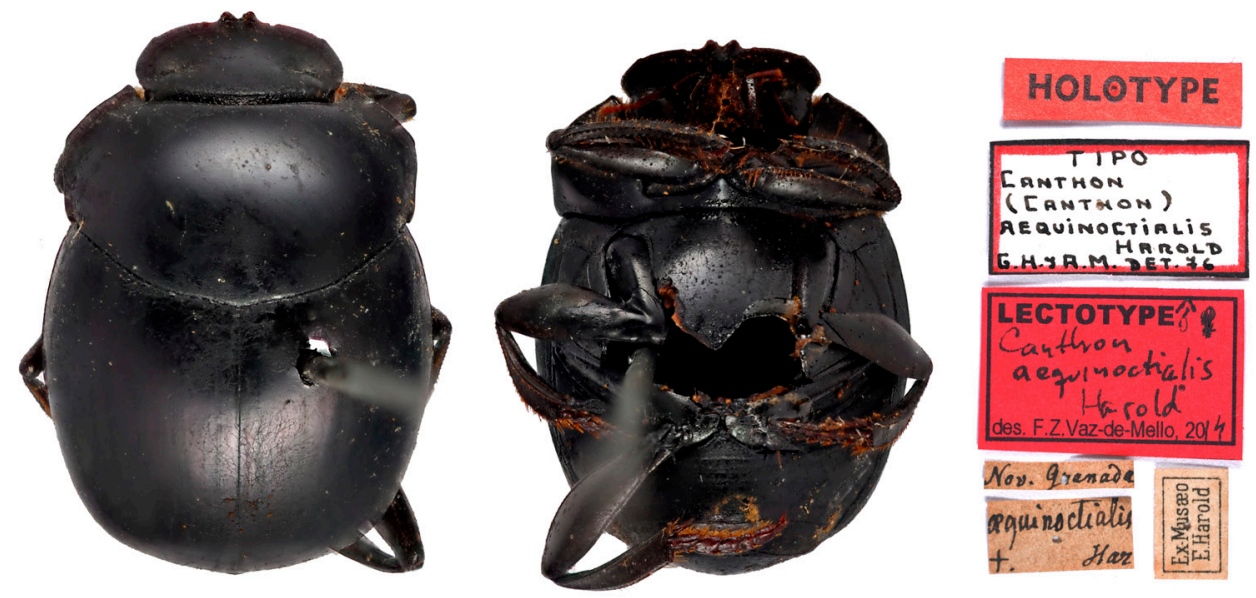

A
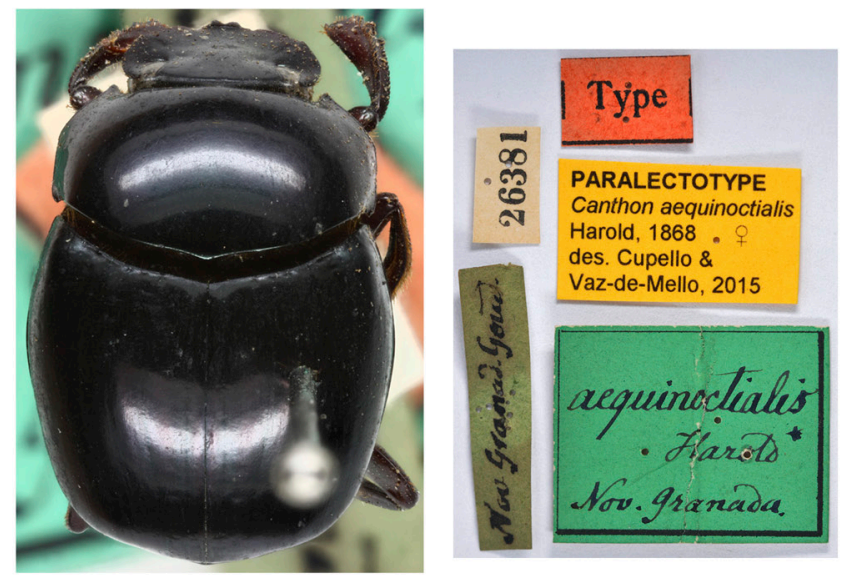

B
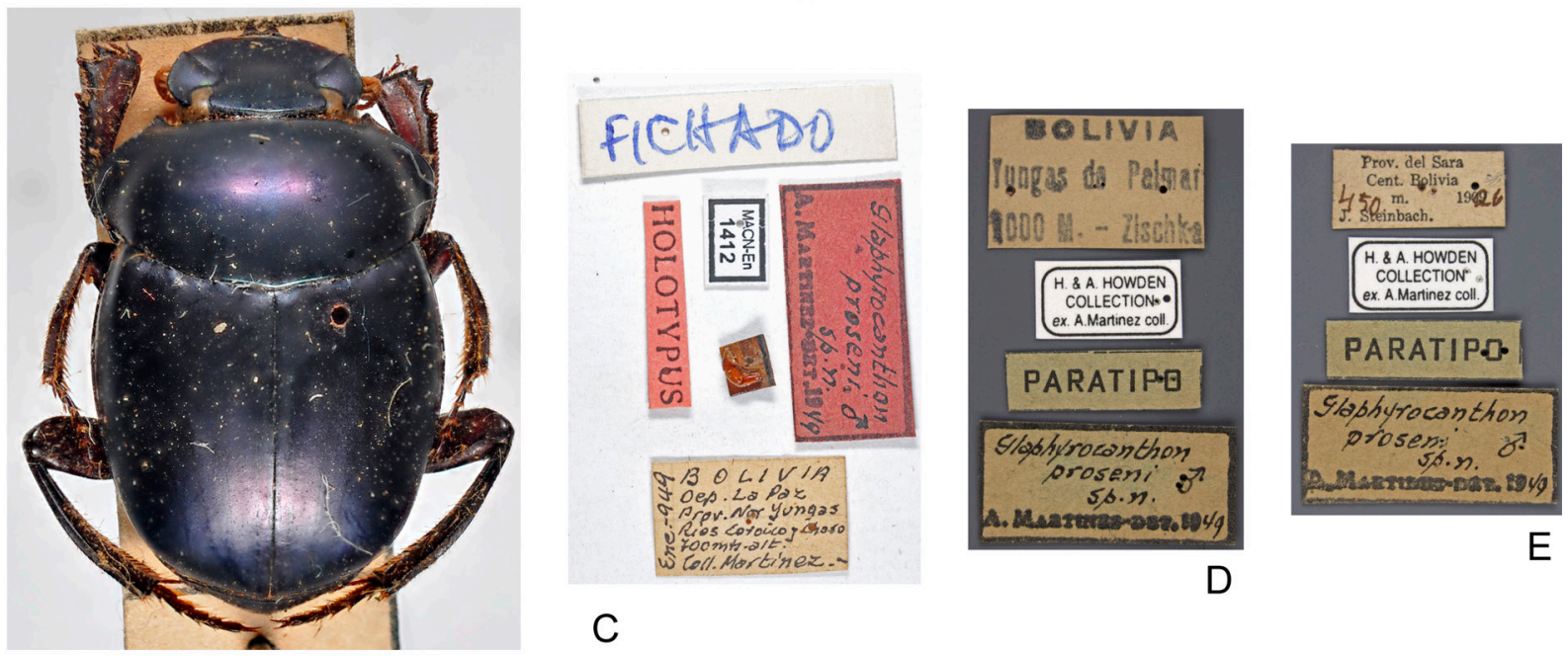

$\mathrm{E}$

Fig. 29. Type material of the aequinoctialis subgroup. A-B. Sylvicanthon aequinoctialis (Harold, 1868) comb. nov., type series. A. Lectotype and its labels. B. Paralectotype and its labels. C-E. S. proseni (Martínez, 1949) stat. et comb. nov., type series. C. Holotype and its labels. D. Paratype 1. E. Paratype 2. 


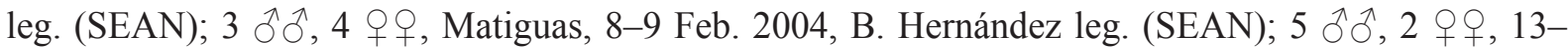
14 Feb. 2004, B. Hernández leg. 5 (SEAN); 18 §ో, 21 q 우, Matiguas, 10-11 Mar. 2004, B. Hernández

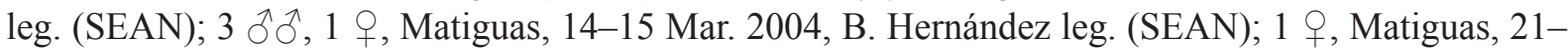

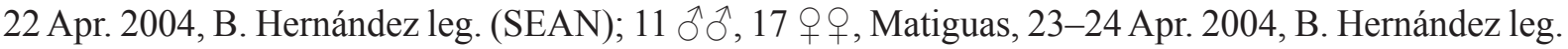

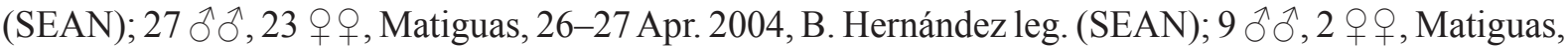
3-4 Jun. 2004, B. Hernández leg. (SEAN); 9 §ึ̄, 5 우우, Matiguas, 19-20 Jun. 2004, B. Hernández

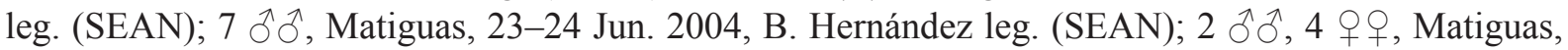
29-30 Jun. 2004, B. Hernández leg. (SEAN); 1 ð, Matiguas, 2-3 Jul. 2004, B. Hernández leg. (SEAN); $2 \widehat{\jmath}$ ô, Reserva Natural Biósfera de Bosawas, Macizo de Peñas Blancas, 29-30 Apr. 2017, B. Hernández

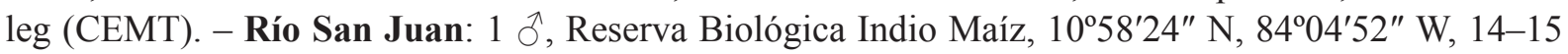
Jun. 2002, P. Schmit and B. Hernández leg. (SEAN).

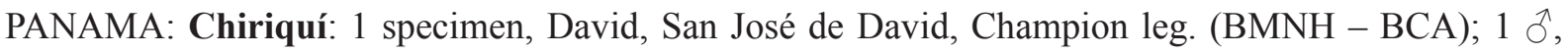
Gualaca, Hornito, Finca La Suiza, 9-15 May 1999, pitfall with human faeces, Wappes and Morris leg. (TAMU). - Colón: 1 + , Chagres, Fort San Lorenzo (“San Lorenzo Forest" sic), 09¹7' N, 7958' W, May

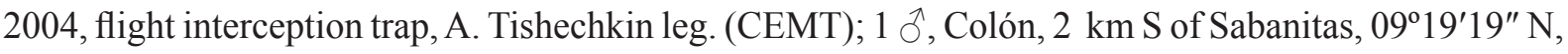
7907'54" W, 25-26 Jun. 1999, UV light, A. Gillogly leg. (TAMU). - Panamá: 3 q + , Canal Zone,

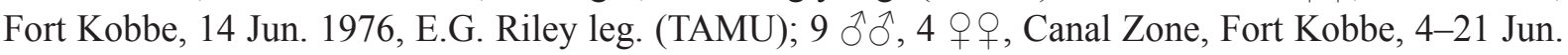
1985, pitfall with human faeces, E.G. Riley leg. (TAMU); 1 specimen, Canal Zone, Lago Gatún, Barro Colorado Island, K.W. Cooper leg. (MNHN); 1 đ̃, Canal Zone, Lago Gatún, Barro Colorado Island, 22 Feb. 1955, R. Freund leg. (CNCI); 1 ㅇ, Canal Zone, Lago Gatún, Barro Colorado Island, 13 Feb.

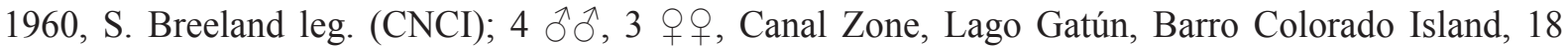
Jul. 1963, L. J. Bottimer leg. (CNCI); 7 specimens, Canal Zone, Gatún Lake, Barro Colorado Island, Mar. 1975, O.P. Young leg. (BMNH); 1 ð’, Canal Zone, Gatún Lake, Barro Colorado Island, Jun. 1978 (CEMT); 2 đ̂̀ 1 क , Canal Zone, Gatún Lake, Barro Colorado Island, 9 Jul. 1978, dung trap, A. Forsyth leg. (TAMU); 1 §̂, Canal Zone, Gatún Lake, Barro Colorado Island, 19 Jul. 1978, dung trap, A. Forsyth leg. (TAMU); 1 đે, Canal Zone, Gatún Lake, Barro Colorado Island, 16 Aug. 1978, dung trap, A. Forsyth leg. (TAMU); 4 specimens, Canal Zone, Gatún Lake, Barro Colorado Island, 12-14 May 1981, B. Gill leg. (BMNH); 1 specimen, Canal Zone, Gatún Lake, Barro Colorado Island, 20-28 May 1981, B. Gill

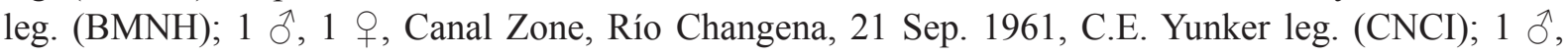
Canal Zone, Skunk Hollow, 13 Jul. 1975, B.C. Ratcliffe leg. (ZMHB); 5 specimens, Canal Zone, Skunk Hollow, 6 mi. NW of Gatún Lake, 17-31 May 1980, B.C. Ratcliffe leg. (BMNH); 4 ふぇ, 1 , same collecting data as for preceding (ZMHB); $2 \widehat{\partial}$, Cerro Azul, 12-13 May 1996, Wappes, Huether and Morris leg. (TAMU); 2 우, Cerro Azul, 21-24 May 1996, Wappes, Huether and Morris leg. (TAMU); 1 , El Llano-Carti Road, Km 7.5, 350 m, 4-6 Jun. 1995, flight interception trap, A.R. Gillogly leg. (TAMU); 1 ô, 1 ㅇ, El Llano-Carti Road, Km 8-13, 21-24 May 1996, Wappes, Huether and Morris leg. (TAMU); 1 q, Nusagandi, Ina Igar (Trail), 18-21 May 1993, pitfall with human faeces, E.G. Riley

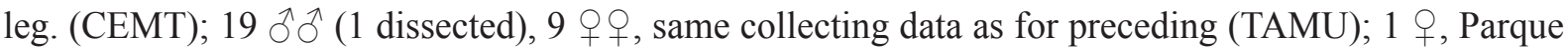
nacional Soberanía, 23-27 May 1996, Wappes, Huether and Morris leg. (TAMU); 1 +, Pipeline Road, Km 01-12, 26-30 Jun. 1997, Wappes and Morris leg. (CEMT); 3 $\lesssim$, 3 웅, same collecting data as for preceding (TAMU); 1 §̂, 1 क, Pipline Road, Km 6.1, "near Gambba", 40 m, 7-21 Jun. 1995, J. Ashe and R. Brooks leg. (MCNZ).

No data: $1 \hat{\jmath}, 1$ (ISNB, Gillet collection), 3 우 (ISNB, J. Thomson collection, pseudotypes).

\section{Redescription}

Colouration. Entire body surface bright and glossy, including the surface of pygidium. Head, pronotum, elytra, and pygidium usually purple, blue, or, occasionally, green. Metaventrite dark green or dark blue. Meso- and metafemora dark brown and, in general, with greenish reflections. 
HEAD. Tegument entirely covered by alveolar microsculpture and without any trace of micropunctation or, occasionally, with very weak, almost imperceptible micropunctures among microsculpture. Clypeus with two apical teeth obtuse and contiguous at base; with a single transverse row of very short setae covering the base of both teeth. Genae with evident tooth immediately behind clypeal-genal juncture. Posterior edge of head with complete margin between eyes.

THorax. Pronotum very shiny and with tegument at centre ranging from completely smooth, with no trace of microsculpture or micropunctation, to with very weak and effaced alveolar microsculpture and micropunctation; on the sides, always with fine alveolar microsculpture. Posterior edge, in general, without transverse line at centre; in some specimens, with traces of fine transverse line at centre. Hypomeral cavity with long setae on posterior region and as long or shorter setae at centre and on external edge; external edge with a turbercle which can be clearly present or almost imperceptible. Metaventrite entirely glabrous (or, occasionally, with few setae at lateral region close to metacoxae, Fig. 7A); with uniform alveolar microsculpture throughout ventral region of metaventrite (i.e., between metacoxae) and with very tenuous micropunctation, which, in general, is only visible under high magnification (higher than $35 \times$ ).

Legs. Ventral surface of all femora bright and with silky appearance. Profemora with tegument completely covered by alveolar microsculpture. Protibiae broad and without internal expansion; at their apical half, external edge with three medium-sized, broad and acute or obstuse teeth - the two apical much larger than basal ones (Fig. 11B). Mesofemora margined anteriorly only at basal half; unmargined portion of anterior edge with row of very short setae; tegument with rivose microsculpture at external (anterior) half and with alveolar microsculpture at internal (posterior) half. Metafemora with both anterior and posterior margins (Fig. 31A); posterior margin extending from the apex of femur until, at most, little beyond the trochanter; tegument as on mesofemora, with no trace of micropunctation or coarse punctation at base. Metatarsomeres II and V subequal in length and longer than the others; metatarsomere IV shorter than the others.

ELYTRA. With only eight very subtly-marked, fine and superficial striae, all of which without carinulae; first seven striae equally marked (only seventh stria, occasionally, more effaced and discontinuous); eighth stria present only on humerus and subtly carinate (humeral carina). Tegument bright with alveolar microsculpture and micropunctation very subtle and effaced, only visible under magnification of at least $30 \times$; microsculpture more evident only on the outer sides.

ABDomen. Ventrite $V$ and, especially, ventrite VI smooth at centre and with weaker rivose microsculpture on the sides. Lateral foveae absent in both sexes. Pygidium with shiny tegument and very diffuse effaced rivose microsculpture; of equivalent length in both sexes.

Aedeagus. Parameres long, slightly shorter than phallobase, and clearly asymmetrical: left paramere laterally with apical depression more profound and wide than depression on left paramere (difference more easily seen in dorsal view). In lateral view, parameres with central angularity and without ventral keel or notch.

Sexual dimorphism. Males: Protibial spur wide and foliaceous, external edge projected into an acute long spine, while internal edge has no prolongation or has a very short spine; area between both spines straight or slightly excavated (Fig. 15E). Ventrite VI strongly narrowed at centre; ventrite V usually without medial flange or only slightly indicated over anterior edge of ventrite VI. Females: Protibial spur spiniform (Fig. 15F). Ventrite VI broad at centre and with anterior edge slightly covered by weak medial flange of ventrite $\mathrm{V}$. 


\section{Measurements}

Males $(\mathrm{N}=20)$. TL: AV: $10.5 \pm 0.93$; MX: 12.3; MN: 9.0. EW: AV: $7.1 \pm 0.66$; MX: 7.8; MN: 5.7 . PL: AV: $3.4 \pm 0.3$; MX: 3.9; MN: 2.7. PW: AV: $6.3 \pm 0.83$; MX: 7.4; MN: 5.3. PgL: AV: $1.9 \pm 0.16$; MX: 2.1; MN: 1.6. PgW: AV: $3.4 \pm 0.29 ;$ MX: 3.7; MN: 2.8 .

Females $(\mathrm{N}=21)$. CT: AV: $10.4 \pm 0.88$; MX: 11.8; MN: 8.7. EW: AV: $7.0 \pm 0.51$; MX: 7.6; MN: 6 . PL: AV: $3.4 \pm 0.29$; MX: 3.9; MN: 2.9. PW: AV: $6.3 \pm 0.47$; MX: 5.3; MN: 6.8. PgL: AV: $1.7 \pm 0.14$; MX: 2.0; MN: 1.5. PgW: AV: $3.3 \pm 0.27$; MX: 3.7; MN: 2.8 .

\section{Geographical distribution}

Widespread throughout the tropical forests from Honduras to northern Colombia.

\section{Ecoregions}

Central American Atlantic Moist Forests, Central American Montane Forests, Isthmian-Atlantic Moist Forests, Talamancan Montane Forests, Costa Rican Seasonal Moist Forests, Isthmian-Pacific Moist Forests, Chocó-Darién Moist Forests, Guajira-Barranquilla Xeric Scrub, Magdalena-Urabá Moist Forests, Magdalena Valley Montane Forests, Magdalena Valley Dry Forests.

Collecting sites (Fig. 30)

HONDURAS. Atlántida: La Ceiba.

NICARAGUA. Jinotega: Reserva Natural Cerro Kilambé, Santa Maura. Matagalpa: Matiguas, Reserva Natural Biósfera de Bosawas (Macizo de Peñas Blancas). Chontales. Río San Juan: Reserva Biológica Indio Maíz.

COSTA RICA. Guanacaste: Cerro El Hacha, Volcán Rincón de la Vieja. Alajuela: Playuelas, San Ramón de dos Ríos, Volcán Tenorio (Colonia Río Celeste). Heredia: Sarapiqui (Estación Biológica La Selva). Puntarenas: Golfitos (Las Torres), Osa (Albergue Ecoturístico Cerro de Oro), Parque Nacional Corcovado (Estación Biológica Sirena), Reserva Biológica Bosque Nuboso Monteverde. San José: Santa Ana (Ciudad Colon), Turrúcares. Limón: Guácimo (Parque Nacional Tortuguero), Limón (Río Blanco), Pococí (Cedrales de la Rita, Cerro Cocorí, Refugio Nacional de Fauna Silvestre Barra del Colorado), Refugio de Vida Silvestre Gandoca-Manzanillo (Manzanillo), Talamanca (Bratsi: Amubri).

PANAMA. Chiriquí: Barú (Progreso), David (San José de David), Gualaca (Hornito), Colón: Chagres (Fort San Lorenzo), Colón. Panamá: Panama Canal (Fort Kobbe; Lago Gatún: Isla Barro Colorado; Skunk Hollow), Cerro Azul, Nusagandi, Parque Nacional Soberanía.

COLOMBIA: Atlántico: Juan de Acosta (Reserva de Tierra Arena). Cesar: Chimichagua. Santander: Serranía de las Quinchas (Reserva El Paujil). Antioquia: San Luis (Sonsón). Chocó: Acandí (Capurganá), Lloró, Parque Nacional Natural Ensenada de Utría, Quibdó (Tutunendó, Estación Ambiental Pandó, Pacurita), Unión Panamericana (Salero). Caldas: Norcasia (Reserva Natural Río Manso). Valle del Cauca: Estación Agro-Forestal Bajo Calima, Dagua. Cundinamarca. Tolima.

\section{Intraspecific variation and taxonomic discussion}

Despite its extensive geographical distribution and the large number of specimens studied for this work, limited morphological variation was observed in S. aequinoctialis apart from colouration and size ${ }^{19}$. The most noticeable variation is related to the sculpture at the centre of the pronotum, which can be almost completely smooth, without any trace of alveolar microsculpture or micropunctation, in some specimens, or have microsculpture and micropunctation present, but very fine and effaced, in others. It is interesting 
to note that in its sister species, S. proseni, the degree to which the pronotal micropunctation is marked varies intrapopulationally at a much stronger intensity. A detailed comparison between $S$. aequinoctialis and $S$. proseni is present in the taxonomic discussion of the latter species.

\section{Comments}

The earliest references found in the literature on the species we now know as $S$. aequinoctialis are the records by Dejean $(1833,1836)$ of the presence of "Coprobius cequinoctialis", from "Carthagena", in his beetle collection. As for other nominal species firstly established in the catalogues of Dejean, this name is unavailable as it was not published along with a description or indication and, therefore, it is out of the availability criteria adopted by the Code (Articles 11 and 12). Only thirty years later, Harold (1868a), in his revision of Canthon, at last described the species, now with the name Canthon aequinoctialis, from "Columbien, Neu-Granada".

There is no doubt that the two specimens here recognized as part of the type series of $S$. aequinoctialis were indeed described by Harold (1868a). The now-lectotype, besides having originated from Harold's personal collection (nowadays deposited at the MNHN), bears a label with the information "cequinoctialis / t. Har" in Harold's own handwriting (Fig. 29A). The paralectotype, in turn, housed at the ZMHB, has an old drawer label written "aequinoctialis / Harold* / Nov. Granada" (Fig. 29B). According to Joachim Willers (personal communication to MC, 2015), curator at ZMHB, the asterisk following the author's name indicates that the collection has at least one type specimen of that nominal species which, in this case, should be the female here recognized as paralectotype (and it is worth noting that Harold (1868a:

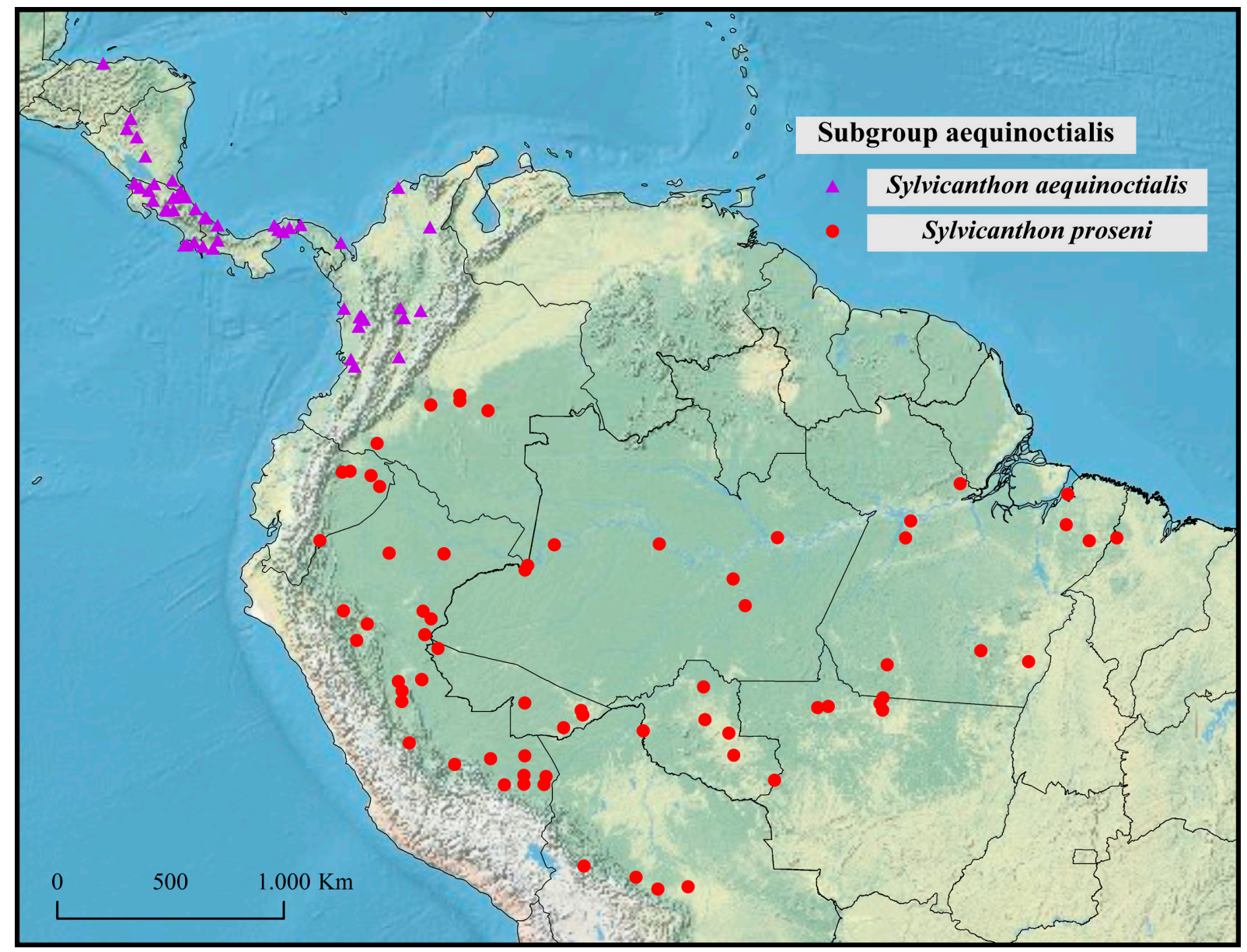

Fig. 30. Distribution of the two species of the aequinoctialis subgroup. 
10) indeed made it clear he had examined specimens from the ZMHB for his revision of Canthon). The choice which of the two known syntypes should be designated as lectotype was not a simple one: while the female is in perfect condition, the male is significantly damaged around the pin, although no known diagnostic characters of the species have been lost. On the other hand, the male belongs to the Edgar von Harold collection, has a label handwritten by the nominal species' author and, the most important fact, it is of the same sex as all the other name-bearing types in Sylvicanthon (i.e., holotypes and lectotypes). Therefore, the male syntype was chosen instead of the female to be here designated as lectotype.

As $S$. aequinoctialis was for a long time confused with $S$. proseni, much of what is published under the former name actually refers to the latter species (see the discussion of $S$. proseni for more details). In particular, the geographical distribution cited in the literature for $S$. aequinoctialis suffered from this problem. In general, the species is cited as occurring in large parts of Central America and throughout the Amazon region, including Brazil, Peru and Bolivia. In reality, however, in South America, S. aequinoctialis is present only in the portion west of the Cordillera Oriental ${ }^{20}$, in the Colombian Andes, specifically on the Caribbean coast (department of Atlántico), in the Chocó biogeographical region (maybe also present in Ecuador, although not recorded from there yet) and in the valleys between the Central and Oriental Cordilleras, in places such as Tolima and Caldas. In Central America, the species occurs at least from Panama northwards to Honduras (Fig. 30). Howden \& Young (1981), Kohlmann \& Solís (2002) and Halffter (2003), without citing their primary sources, said that $S$. aequinoctialis was also present in Belize, but this information is probably incorrect, since we could not find any specimens
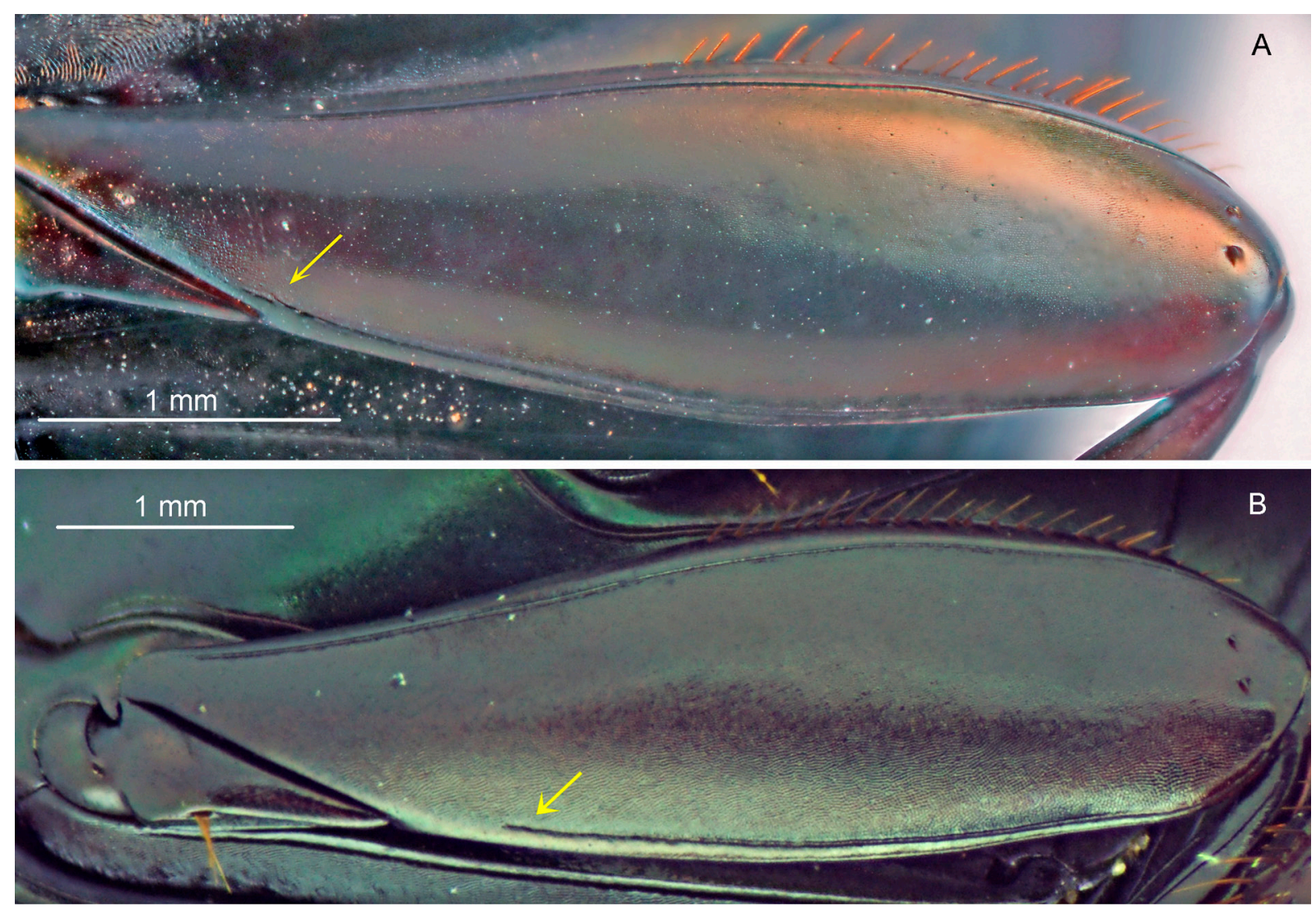

Fig. 31. Metafemora of the two species of the aequinoctialis subgroup. A. Sylvicanthon aequinoctialis (Harold, 1868) comb. nov. B. S. proseni (Martínez, 1949) stat. et comb. nov. Arrow indicates the basal end of the posterior margin of the ventral face of metafemora (note that it is longer in S. aequinoctialis comb. nov. than in S. proseni stat. et comb. nov. and may exceed the trochanter in the first species). 
with this provenance in none of the studied collections (including the former private collection of Henry Howden, today housed at the CMNC; François Génier, personal communication to MC, 2015), nor researchers having recently collected in that country found the species living there (Latha Thomas, University of Belize, personal communication to MC, 2015). Halffter (2003) added that this species occurred in Guatemala and most probably also in southern Mexico, but these records were equally unsupported by more detailed information.

\section{Natural history}

In contrast to the other species of Sylvicanthon, of which only fragmentary biological information has been published, it is possible to find far more detailed data about $S$. aequinoctialis in the literature. Howden \& Young (1981), for example, in their important monograph on the Panamanian dung beetles, described several aspects of the life of this species based on populations from the island of Barro Colorado, in the Gatun Lake of the Panama Canal. According to the authors, S. aequinoctialis breeds throughout the year and is one of the most abundant dung beetle species on the island, not showing any seasonal variation in its population density. During the rainy season (May to December), they feed on both dung and carrion, with the consumption of carcasses of animals such as the agouti [Dasyprocta punctata (Gray, 1842)], collared peccary [Pecari tajacu (Linnaeus, 1758]), and rat, as well as human faeces and coati [Nasua nasua (Linnaeus, 1758)], jaguarundi [Puma yagouaroundi (Geoffroy Saint-Hilaire, 1803)] and tapir [Tapirus bairdii (Gill, 1865)] dung, being reported. During the dry season (December to May), however, when carcasses are scarcer and consumed mainly by vertebrates or specialist necrophagous dung beetles (Young 1978, 1980), S. aequinoctialis is found only on dung. Regarding their circadian cycle, $S$. aequinoctialis, as the other species in the genus, is crepuscular and nocturnal, with an activity period between 5 and 9 pm (Howden \& Young 1980). In Barro Colorado, S. aequinoctialis is the most abundant roller dung beetle, having been responsible for the consumption of at least one-fourth of the total volume of tapir dung utilized in experiments by Young (2009) on the island.

Farther north, we have information about some populations of $S$. aequinoctialis from Costa Rica given by Kohlmann \& Solís (2002). Like in Panama, Costa Rican adults of S. aequinoctialis from both sides of the Continental Divide (i.e., both on the Caribbean and the Pacific coasts of Costa Rica) are active throughout the year and are among the most abundant nocturnal dung beetles of humid lowland forests. There, they live up to $800 \mathrm{~m}$ altitude on the Atlantic side of the Continental Divide, and up to $900 \mathrm{~m}$ on the Pacific side. Specimens were collected on human and equine dung, as well as using flight interception traps and through active collections on the ground or beneath fallen tree trunks.

Lastly, we have data for populations in Colombia. Medina et al. (2012) also highlighted S. aequinoctialis as one of the most common species in the Magdalena River Valley region at an altitude between 180 and $300 \mathrm{~m}$, and stated that the species was collected with traps baited with human faeces and cow dung, mushrooms and, occasionally, with rotten fish. Additionally, Solís et al. (2011) stated that this species was present in the Atlántico department in altitudes between 160 and $500 \mathrm{~m}$.

Several of the specimens examined also have bionomic information on their labels. There are records of specimens collected using traps baited with swine, human and howler monkey [Alouatta seniculus (Linnaeus, 1758)] dung, as well as rotten flesh, and also in flight interception traps and with ultraviolet light. Specimens were collected in all the months of the year, but there is an apparent higher concentration during the rainiest months (March: 49; April: 87; May: 52; June: 76; July: 63), when 327 out of the 573 studied specimens were caught. In relation to the altitudinal amplitude, there are representatives of S. aequinoctialis collected from at approximately the sea level up to areas as elevated as $1000 \mathrm{~m}$ in the Reserva Natural Cerro Kilambé (Jinotega, Nicaragua) and $1440 \mathrm{~m}$ in San Luis (Antioquia, Colombia). Therefore, after combining all the available data, what we see is that $S$. aequinoctialis is, throughout its distribution, an opportunistic species that explores several food sources and habitats and that is resistant 
to the seasonal changes, characteristics that make it one of the most abundant and dominant species among the roller Scarabaeinae of the New World tropical forests.

Sylvicanthon proseni (Martínez, 1949) revalidation and comb. nov.

Figs 5A, 6D, 8B, 12A, 12C, 14A, 14C, 15G-H, 17F, 20, 28C-D, 29C-E, 30, 31B

Glaphyrocanthon proseni Martínez, 1949a: 282, 287-291, fig. 2.

Glaphyrocanthon proseni - Halffter \& Matthews 1966: 43, 293. — Halffter \& Martínez 1977: 90-91 (as synonym of C. aequinoctialis). - Solís \& Kohlmann 2002 (as synonym of C. aequinoctialis).

Glaphyrocanthon (Glaphyrocanthon) proseni - Martínez 1950: 170-171. - Pereira \& Martínez 1956: 92, 126, 128. - Martínez et al. 1964: 3, 5, 8, 10-11, 13. - Vulcano \& Pereira 1964: 663; 1967: 561. Canthon (Canthon) proseni - Vaz-de-Mello et al. 2011b: 82, 86, 93. - Chamorro et al. 2018: 87, 92, fig. 10D, F.

Canthon proseni - Jacobs et al. 2008: 642. — Korasaki et al. 2012: 425, 427. — Silva et al. 2014: 348. — Nunes et al. 2014: 410-411. - Silva et al. 2017: 490.

Canthon aequinoctialis sensu - Balthasar 1941: 341; 1951: 326. - Escobar 2000a: 206; 2000b: 114, 121 (mixed information with S. aequinoctialis comb. nov.). - Medina et al. 2001: 135 (idem). Celi et al. 2004: 42. — Noriega-Alvarado 2004: 40. — Noriega et al. 2008: 78-79. - Carpio et al. 2009: 462, 464, 469. — Medina \& Pulido 2009: 58. — Figueroa \& Alvarado 2011: 210-211, fig. 1c. — Noriega 2012: 4. — Ratcliffe et al. 2015: 195.

Canthon aequinoctiale sensu - Vaz-de-Mello 1999: 449-450.

Canthon (Canthon) aequinoctiale sensu - Vaz-de-Mello 2000.

Canthon (Canthon) aequinoctialis sensu - Noriega et al. 2007a: 54-55.

Canthon (Canthon) aequinotialis [sic] - Culot et al. 2011: Supporting information, table S1.

\section{Etymology}

Eponym after the Argentinian entomologist Alberto F. Prosen (1902-1972).

\section{Material examined}

Holotype

BOLIVIA: $\widehat{O}$, La Paz, Nor Yungas, confluence between the Choro and Coroico Rivers, $700 \mathrm{~m}$ (Martínez 1949), ("BOLIVIA / Dep. La Paz / Prov. Nor Yungas / Ríos Coroico y Choro / 700 mts. alt. / Coll. Martínez / Ene.-949", "HOLOTYPUS", "Glaphyrocanthon / proseni § / sp. nov. / A. Martínez det. 1949", "MACN-En / 1412", "FICHADO"), genital capsule removed and glued on a square label (MACN) (Fig. 29C)

\section{Paratypes}

BOLIVIA: 1 ô, ("BOLIVIA/Yungas de Palmar/1000 M. - Zischka", "H. \& A. Howden / COLLECTION / ex. A. Martinez coll.", "PARATIPO”, "Glaphyrocanthon / proseni / sp. n. / O / A. Martinez - det. 1949") (CMNC) (labels examined by photograph, Fig. 29D); 1 त, ("Prov. del Sara / Cent. Bolivia / 450 m. 190926" / J. Steinbach", "H. \& A. Howden / COLLECTION / ex. A. Martinez coll.", "PARATIPO", "Glaphyrocanthon / proseni / sp. n. / § / A. Martinez - det. 1949") (CMNC) (labels examined by photograph, Fig. 29D).

Additional material (495 $\hat{\partial}, 328 q q, 31$ unsexed specimens)

BOLIVIA: Cochabamba: $3 \partial^{\top} \partial^{\lambda}, 1$, José Carrasco, Valle del Sacta, $17^{\circ} 04^{\prime} 18^{\prime \prime} \mathrm{S}, 64^{\circ} 46^{\prime} 00^{\prime \prime} \mathrm{W}, 250 \mathrm{~m}$, 21-22 Dec. 2004, pitfall with human faeces, Mann, Hamel and Simmons leg. (OUMNH); 2 우, Chapare, Mar. 1994 (CEMT). 
BRAZIL: 1 unsexed specimen, “Amazon”, H.W. Bates leg. (BMNH); 1 §, Rio Purus, Ehrenreich leg. (ZMHB); $1 \AA$, Rio Xingu, Ponte Nova, Feb. (no year) (CEMT). - Acre: $14 \hat{\jmath} \widehat{\jmath}, 20$ q , Mâncio Lima,

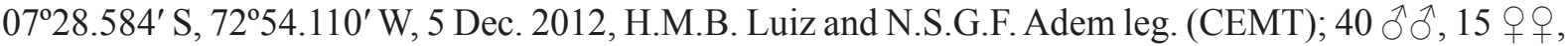

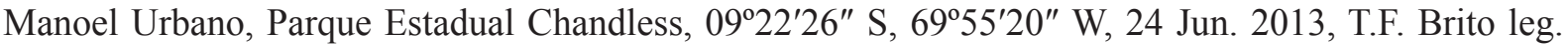

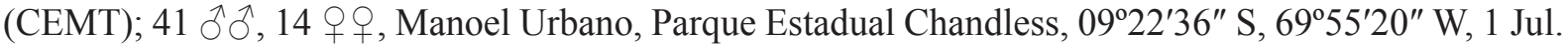
2013, T.F. Brito leg (CEMT); 1 ㅇ, Rio Branco, Jul. 1996, M. Castro leg. (CEMT); 1 đ, 1 ㅇ, Senador Guiomard, 1004' S, 67³7' W, 14 Apr. 2017, human faeces, Bruna S. Bitencourt leg. (CEMT); 1 ô, 1 q, Senador Guiomard ("Rio Branco"), Fazenda [Experimental] Catuaba, Feb. 1997, F.Z. Vaz-de-Mello leg. (CEMT); 1 9, Xapuri, Reserva Chico Mendes, $10^{\circ} 20.975^{\prime}$ S, 68 $40.840^{\prime}$ W, 17 Oct. 2008, pitfall with human faeces, J. Silveira leg. (CEMT); 1 ô,Xapuri, Reserva Chico Mendes, $10^{\circ} 18.930^{\prime}$ S, 68 $40.756^{\prime}$ W, 18 Oct. 2008, pitfall with human faeces, J. Silveira leg. (CEMT). - Amazonas: 1 ô, without specific

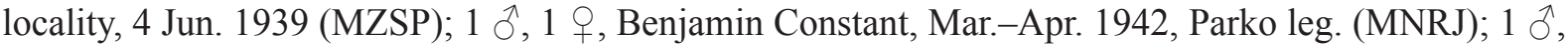
same collecting data as for preceding (MZSP); 1 \& , Benjamin Constant, Dec. 1979, A. Lise leg. (MCNZ); $1 \hat{\partial}$, Benjamin Constant, Rio Javari, Dec. 1960, Dirings leg. (MZSP); 1 o, 1 ㅇ, Beruri, BR-319, Km

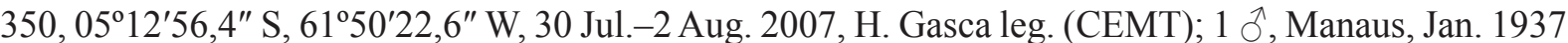
(MZSP); Manaus, II.1941, Parko leg. 1 \& (CEMT); 1 \&, Manaus, Nov. 1941 (MZSP); 1 ô, Manaus, Rio Negro, Dec. 1941, B. Pohl leg. (MNRJ); 1 Ô, 1 क , same collecting data as for preceding (MZSP); 1 o, Manicoré, Rio Madeira, Jun. (no year), J.F. Zikán leg. (FIOC); 1 §̂, São Paulo de Olivença ("Olivenza”) (ZMHB); 1 †, São Paulo de Olivença, Nov. (no year), J.F. Zikán leg. (MZSP); 1 đૈ, São Paulo de Olivença ("Olivenza"), O. Thieme leg. (ZMHB); 1 unsexed specimen, Tefé (Ega), H.W. Bates leg. (BMNH); 1 +, Tefé, 1921, J.F. Zikán leg (FIOC). - Maranhão: 1 q, Centro Novo do Maranhão, Igarapé Gurupi-Uma, Aldeia Araçu, $50 \mathrm{~km}$ E of Canindé, May 1963, Malkin leg. (MZSP). - Mato Grosso: 2

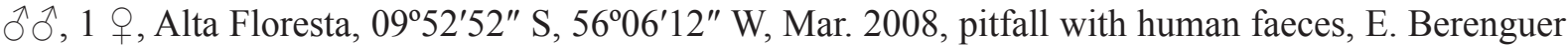

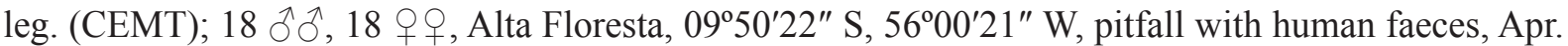

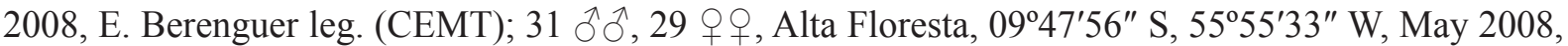

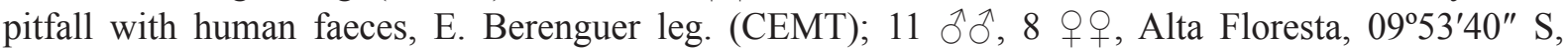

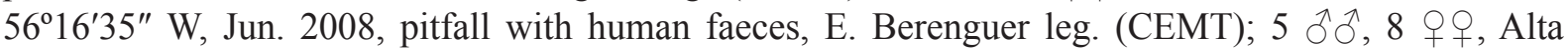
Floresta, CEPLAC, 6 Feb. 2009, pitfall, V. Gonçalves leg. (CEMT); 3 $\widehat{\jmath}, 3$ 우, Alta Floresta, CEPLAC, 24 May 2009, V. Gonçalves leg. (CEMT); 1 +, Alta Floresta, CEPLAC, 4 Dec. 2009, pitfall, V. Gonçalves leg. (CEMT); 1 đ, Alta Floresta, CEPLAC, 1 May 2010, human faeces, V. Gonçalves leg. (CEMT); 2 우, Alta Floresta, CEPLAC, 9 Jan. 2010, pitfall, V. Gonçalves leg. (CEMT); 1 , ,Carlinda, 13 May 2008, C.R. Menezes leg. (CEMT); 1 §, Carlinda, 13 May 2008, J. Ortega leg. (CEMT); 1 ○, Carlinda, 13 May 2008, C. Rosseto leg. (CEMT); 1 o, 1 q, Carlinda, 14 May 2008, M.E. Ortiz leg. (CEMT); 1 ภ, 14 May 2008, J.E. Silva leg. (CEMT); 1 ภ, Carlinda, 15 May 2008, M. Francisco leg. (CEMT); 1 ô, Carlinda 16 May 2008, M.L. Santos leg. (CEMT); 1 \&, Carlinda, 14 Oct. 2008, E. Macena leg. (CEMT); 1 , Carlinda, 21 Oct. 2008, B.C. Kain leg. (CEMT); 2 $\widehat{\partial}$, Carlinda, 22 Oct. 2008, L. Sabino leg. (CEMT); 1 đ̂, Carlinda, 23 Oct. 2008, E.P.P. Cruz leg. (CEMT); $1 \hat{\jmath}$ (dissected), 1 q, Carlinda, 23 Oct. 2008, K. Segatto leg. (CEMT); 1 \&, Carlinda, 10 Oct. 2009, E. Teles leg. (CEMT);

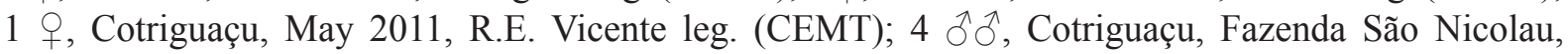

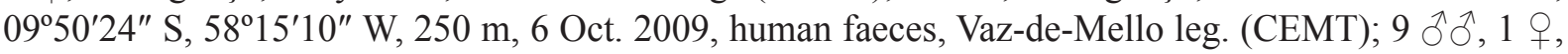
Cotriguaçu, Fazenda São Nicolau, 09 $50^{\prime} 24^{\prime \prime}$ S, 58 $15^{\prime} 10^{\prime \prime}$ W, 250 m, 8 Oct. 2009, human faeces, Vaz-

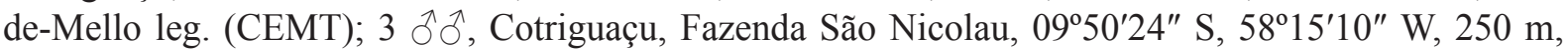
12 Oct. 2009, flight interception trap, Vaz-de-Mello leg. (CEMT); 1 § , Cotriguaçu, Fazenda São Nicolau, 10 Dec. 2009, black light, M.R. Barreto leg. (CEMT); 3 đô, 3 q 우, Cotriguaçu, Fazenda São Nicolau, 0950'53" S, 58¹4'36" W, 11-13 Dec. 2009, human faeces, F.Z. Vaz-de-Mello leg. (CEMT); 1 ô, 1 , Cotriguaçu, Fazenda São Nicolau, Castanheira, 0949'18" S, 58 17'18" W, $12-14$ Dec. 2009, pitfall with

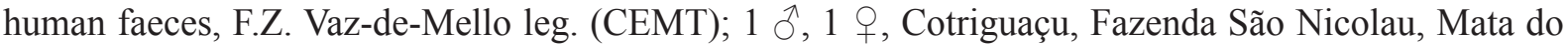
Juruena, 09 52'05" S, 58 13'35" W, 202 m, 15 Dec. 2009, pitfall, F.Z. Vaz-de-Mello leg. (CEMT);

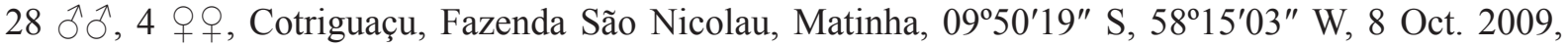
pitfall with human faeces, F.Z. Vaz-de-Mello leg. (CEMT); 2 ổ, 3 우, Cotriguaçu, Fazenda São 


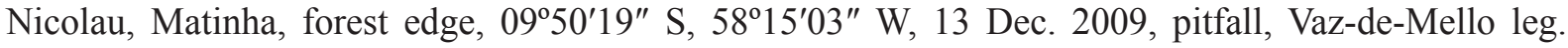

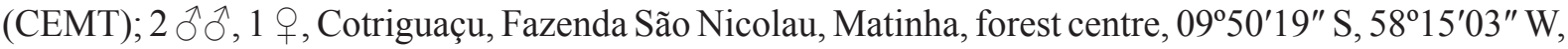
13 Dec. 2009, pitfall, Vaz-de-Mello leg. (CEMT); 5 ふ઼َ, 2 우, Cotriguaçu, Fazenda São Nicolau,

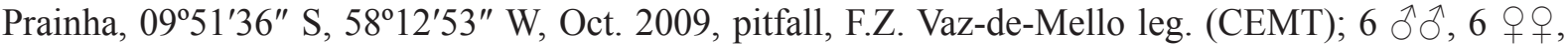
Cotriguaçu, Fazenda São Nicolau, Prainha, 09²51'36" S, 58²12'53" W, 11-13 Dec. 2009, pitfall with human faeces, F.Z. Vaz-de-Mello leg. (CEMT); $2{ }^{\lambda}{ }^{\lambda}$, Cotriguaçu, banks of Juruena river, 09 ${ }^{\circ} 52^{\prime} 47.67^{\prime \prime}$ S, $58^{\circ} 14^{\prime} 07.09^{\prime \prime}$ W, Oct. 2010, pitfall with human faeces, R.V. Nunes and M. Gigliotti leg. (CEMT); 1 , 1 , Nova Bandeirante, banks of Juruena river, 09 $52^{\prime} 47^{\prime \prime}$ S, 58 $8^{\circ} 14^{\prime} 07^{\prime \prime} \mathrm{W}$, Oct. 2010, pitfall with dung, R.V. Nunes and M. Gigliotti leg. (CEMT); 1 , , Novo Mundo, Parque Estadual do Cristalino, May 2013, manual collection, V.S. Corrêa leg. (CEMT). - Pará: 1 đ̂, Almeirim, Monte Dourado, Jan. 1993 (CEMT); 1 § , Alter do Chão, RESEX Tapajós/Arapiuns, 22 Dec. 2008, flight interception trap (CEMT); 10 ふぇ, 6 우, Belém, IPEAN, Oct. 1984 [FIT], N. Degallier leg. (CEMT); 1 đ, Belém, IPEAN, Nov. 1984, N. Degallier leg. (CEMT); 3 $\widehat{\jmath}, 1$ क , Belterra, 15 Jul. 2016, pitfall with human and pig dung, F. França leg. (CEMT); 1 ô, Estrada Belém-Brasília, Km 93, Oct. 1959, E. Lobato leg. (FIOC); 2 o ㅇ, Novo Progresso, Fazenda Florentino, 07 $08^{\prime} 51^{\prime \prime}$ S, 55 $23^{\prime} 38^{\prime \prime}$ W, 230 m, Jan. 2011, pitfall with human

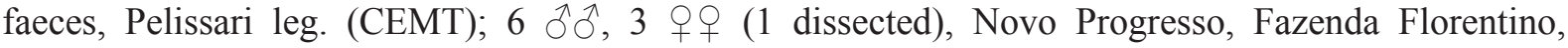
$06^{\circ} 53^{\prime} 18.18^{\prime \prime} \mathrm{S}, 5^{\circ} 30^{\prime} 26.25^{\prime \prime} \mathrm{W}, 2$ Jan. 2011, pitfall with human faeces, T.D. Pelissari leg. (CEMT);

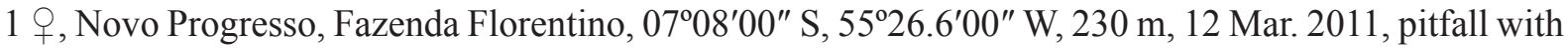
cow dung, Pelissari leg. (CEMT); 3 ồ $\hat{0}, 3$ 우, Paragominas, Jan.- Jul. 2011, Solar et al. leg. (CEMT);

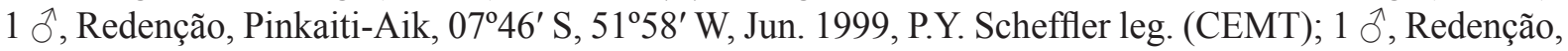

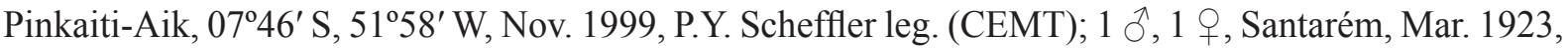

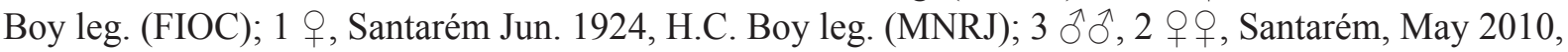

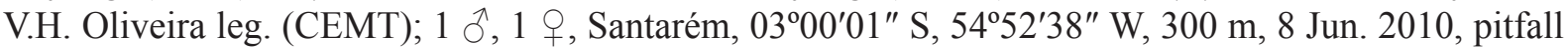

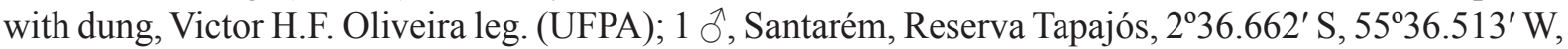
7 Jan. 2009, pitfall with human faeces, R. Andrade leg. (CEMT); 1 ก̃, São Félix do Xingu, Pinkaití Reserve, $07^{\circ} 45^{\prime}$ S, $51^{\circ} 57^{\prime}$ W, 31 Oct. 1998, P.Y. Scheffler leg. (CEMT); 2 đે, 2 q $q$, , Tailândia, "Empresa Agropalma", 9-15 Jul. 2016, F. Silva leg. (CEMT); 3 unsexed specimens, Tapajós, H.W. Bates leg.

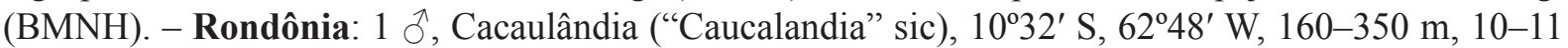
Oct. 1991, John R. Macdonald leg. (CEMT); 2 đે ô, Cacaulândia, Fazenda Rancho Grande, Feb. 1997,

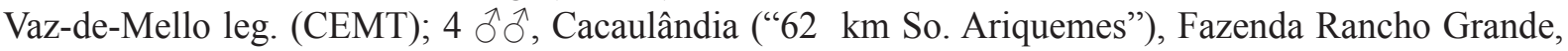

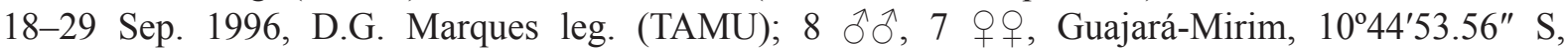
65ำ17'31.1" W, 14-16 Feb. 2010, pitfall with human faeces, Fabricio Coletti leg. (CEMT); 2 ठ

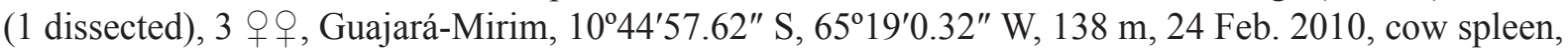

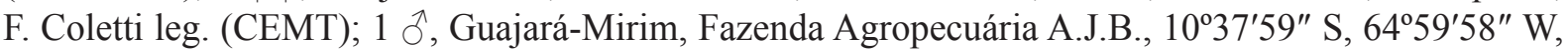
180 m, 15 Jan. 2010, cow spleen, F. Coletti leg. (CEMT); 1 ô, 2 우, Itapuã do Oeste, Floresta Nacional ["FloNa"] do Jamari, 09¹1'25" S, 6306'49" W, 20 Feb. 2013, Mazama gouazoubira dung, J.F. Cerveira

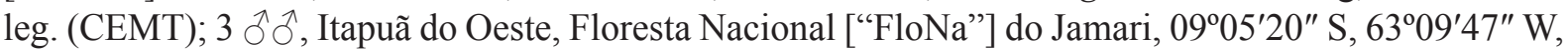
24 Feb. 2013, Mazama nana dung, J.F. Cerveira leg. (CEMT); 1 Ô, Ji-Paraná ("V. Rondônia", or Vila de Rondônia), 25 Jan.-9 Feb. 1961, Pereira and A. Machado leg. (MZSP); 1 đ̃, "Marmelo", Rio Abunã,

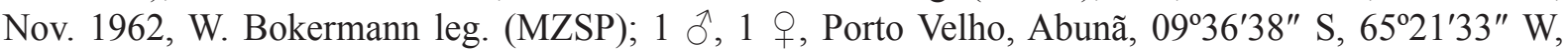
200 m, 19 Nov. 2010, pitfall with human faeces, J.C.F. Falcão leg. (CEMT); 2 $\widehat{\partial}$, Porto Velho, Abunã, 09 ${ }^{\circ} 35^{\prime} 03^{\prime \prime}$ S, 65 22'36" W, 7 Apr. 2011, pitfall with human faeces, L.R. Silva and M.F. Souza leg.

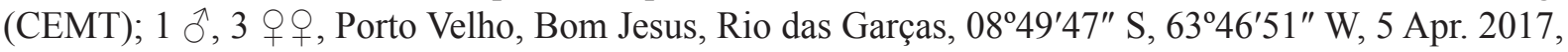
flight interception trap, D.C. Santos and K.K.G. Silva leg. (CEMT); 3 d $\partial^{\lambda}, 3$ q $q$, Porto Velho, Caiçara, 09²6'59" S, 64 48'42" W, 27 Jun. 2010, flight interception trap, J.C.F. Falcão and L.R. Silva leg. (CEMT); 1 ô, Porto Velho, Caiçara, 09 $26^{\prime} 42^{\prime \prime} \mathrm{S}, 64^{\circ} 49^{\prime} 41^{\prime \prime} \mathrm{W}, 20$ Mar. 2011, pitfall with human faeces,

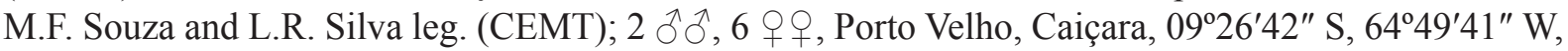
29 Mar. 2011, pitfall with human faeces, M.F. Souza and L.R. Silva leg. (CEMT); 1 § , 1 q, Porto Velho, Caiçara, 09 26'59" S, 64'48'42" W, 30 Mar. 2011, flight interception trap, L.R. Silva and M.F. Souza leg.

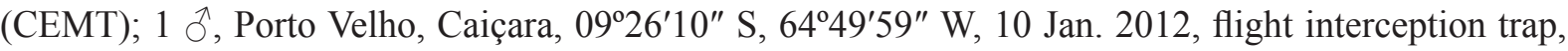




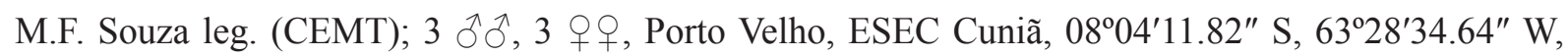
4-6 Dec. 2011, pitfall with bananas, M.A.P.A. Silveira leg. (CEMT); 1 ठૈ, Porto Velho, ESEC Cuniã, 08 04'11.82" S, 6328 $34.64^{\prime \prime}$ W, 4-6 Dec. 2011, pitfall with human faeces, M.A.P.A. Silveira leg.

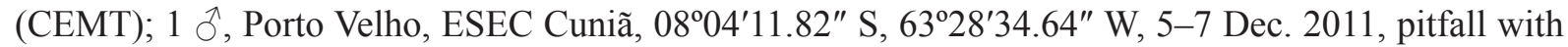

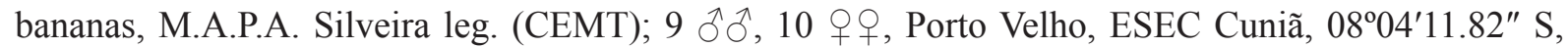

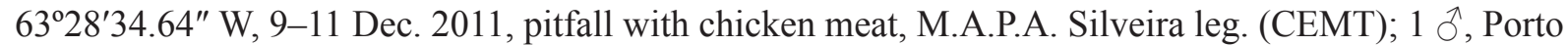
Velho, ESEC Cuniã, 08 $04^{\prime} 11.82^{\prime \prime}$ S, $63^{\circ} 28^{\prime} 34.64^{\prime \prime} \mathrm{W}, 8-12$ Aug. 2012, pitfall with bananas, M.A.P.A.

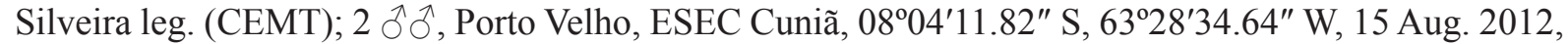
pitfall with human faeces, M.A.P.A. Silveira leg. (CEMT); 1 ô, 1 क, Porto Velho, ESEC Cuniã, $08^{\circ} 04^{\prime} 11.82^{\prime \prime} \mathrm{S}, 63^{\circ} 28^{\prime} 34.64^{\prime \prime} \mathrm{W}, 19$ Oct. 2012, pitfall with human faeces, M.A.P.A. Silveira leg. (CEMT); 1 §, 1 ㅇ, Porto Velho, Mutum-Paraná ["Mutum"], 09³8'36" S, 65²6'54" W, 14 May 2010, pitfall with human faeces, F. Albertoni and L.R. Silva leg. (CEMT); 2 $\widehat{\jmath}, 2$ q $q$, Porto Velho, MutumParaná ["Mutum"], 09 35' S, 6503' W, 250 m, 15-17 Sep. 2010, human faeces, J.C.F. Falcão and L.R.

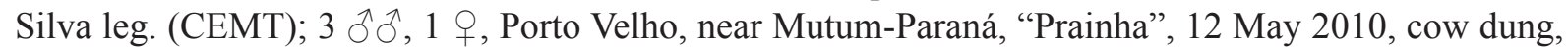
F.F. Albertoni and L.R. Silva leg. (CEMT); 1 q, Porto Velho, Nova Mutum-Paraná, 09 $26^{\prime} 25^{\prime \prime}$ S,

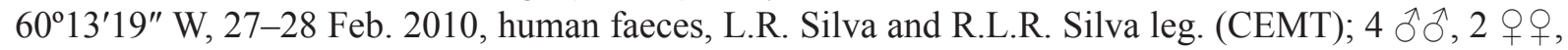
Porto Velho, Nova Mutum-Paraná, $09^{\circ} 26^{\prime} 55^{\prime \prime}$ S, 61 $01^{\circ} 57^{\prime \prime}$ W, 1-2 Mar. 2010, human faeces, L.R. Silva

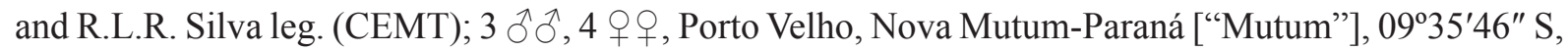
6502'27" W, Jan. 2012, R.V. Nunes leg. (CEMT); 1 §, Porto Velho, Nova Mutum-Paraná ["Mutum"],

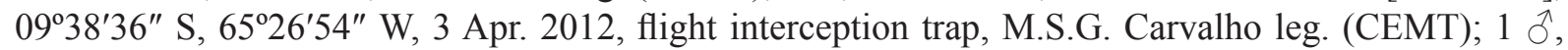
Porto Velho, Nova Mutum-Paraná [“Mutum”], 09³4'49" S, 6503'13" W, 3 Apr. 2012, pitfall with human faeces, M.S.G. Carvalho leg. (CEMT); 7 §ె, 4 q우, Porto Velho, Nova Mutum-Paraná

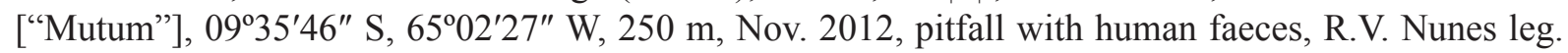

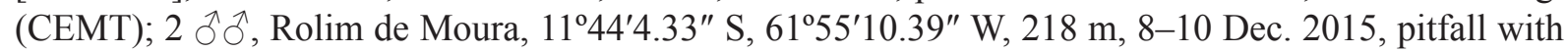

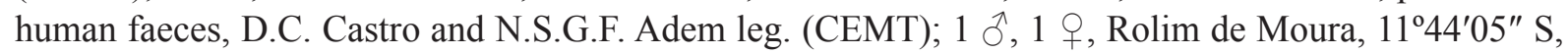
61 ${ }^{\circ} 55^{\prime} 11.62^{\prime \prime} \mathrm{W}, 219 \mathrm{~m}, 8-10$ Dec. 2015, pitfall with human faeces, D.C. Castro and N.S.G.F. Adem leg.

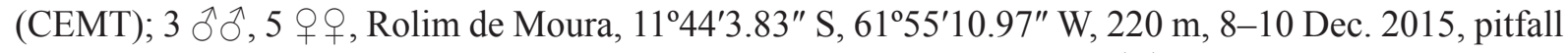
with human faeces, D.C. Castro and N.S.G.F. Adem leg. (CEMT); $4 \hat{\delta} \hat{o}, 2$ 우, Rolim de Moura, $11^{\circ} 44^{\prime} 3.83^{\prime \prime} \mathrm{S}, 61^{\circ} 5510.97^{\prime \prime} \mathrm{W}, 221 \mathrm{~m}, 8-10$ Dec. 2015, pitfall with human faeces, D.C. Castro and

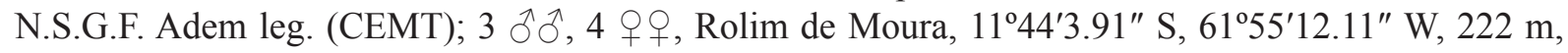
8-10 Dec. 2015, pitfall with human faeces, D.C. Castro and N.S.G.F. Adem leg. (CEMT); 3 $\partial^{\lambda}, 2$ + $q$,

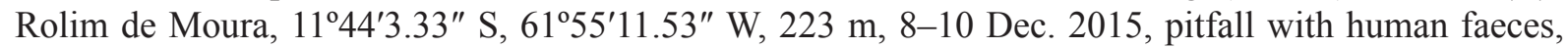
D.C. Castro and N.S.G.F. Adem leg. (CEMT); 2 우, Vilhena, Nov. 1987, O. Roppa and P. Magno leg. (MNRJ).

COLOMBIA: Amazonas: 1 , Leticia, Monilla Amena, 27 Jun. 1997, pitfall with human faeces during

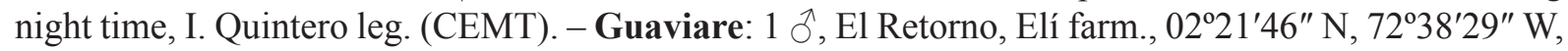
15 Jul. 2007, Lagothrix lagotricha dung, Zárate leg. (CEMT); 1 §, San José del Guaviare, Finca La

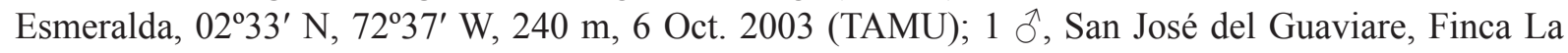

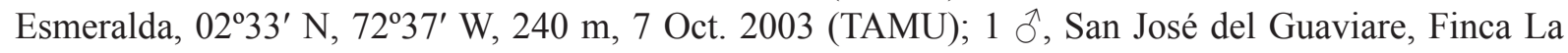

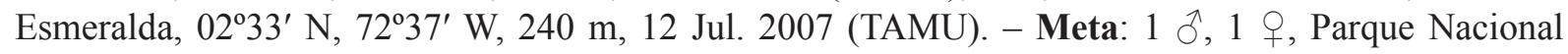
Natural Tinigua, Centro de Investigaciones Ecológicas La Macarena, Rio Duda, $02^{\circ} 40^{\prime} \mathrm{N}, 74^{\circ} 10^{\prime} \mathrm{W}$, 350 m, Jan. 1996, human faeces, I. Jiménez leg. (CEMT).

ECUADOR: Orellana: 1 ก, 1 †, Estación Científica Yasuní, 215 m, 5-10 Sep. 1999, E.G. Riley leg. (CEMT); $19 \hat{\delta} \hat{\delta}, 14$ 우, same collecting data as for preceding (TAMU); $5 \hat{\jmath} \hat{\delta}, 1$ 우, Parque Nacional Yasuní ("Scyasuni”), 200 m, 25-27 Oct. 1997, D. Padilla and I. Tapia leg. (CEMT); 1 q, same collecting data as for preceding (MCNZ); 2 unsexed specimens, Payamino Research Station, $0^{\circ} 29^{\prime} 36^{\prime \prime}$ S,

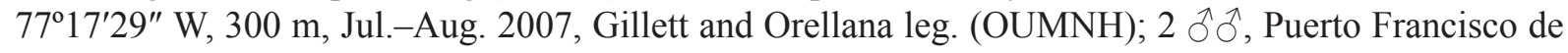

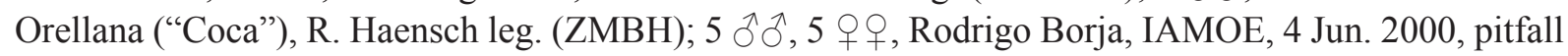


with human faeces, A. Dávalos leg. (CEMT); 5 $\widehat{\jmath}, 3$ 우, 21 unsexed specimens, Tiputini Biodiversity Station, $0^{\circ} 38^{\prime} \mathrm{S} 76^{\circ} 09^{\prime} \mathrm{W}, 220 \mathrm{~m}$, Sep. 2000, pitfall with human faeces, D. Inward leg. (BMNH); 1 \%, 1 q, same collecting data as for preceding (MUSM); 2 § $\widehat{0}, 6$ 우, Yasuni Scientific Research Station, 9-17 Sep. 1999, D.G. Marqua leg. (TAMU).

PERU: 1 unsexed specimen, Río Tambopata, Jan.-Apr. 1995, B.J. Selman leg. (BMNH). - Cuzco:

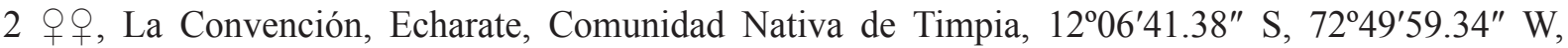
429 m, 22 Oct. 2009, M. Alvarado and E. Rázuri leg. (MUSM); 1 + , La Convención, Echarate,

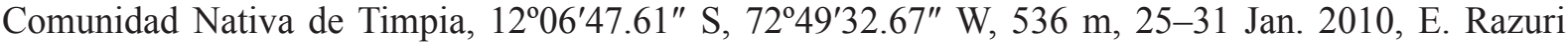
and C. Espinoza leg. (MUSM). - Huánuco: 1 q, Estación Biológica Panguana (Forschungsstation Panguana), Rio Pachitea, Rio Yuyapichis, 09 $37^{\prime}$ S, 74 ${ }^{\circ} 56^{\prime}$ W, 260 m, 28 Aug.-14 Sep. 1986, Listabarth

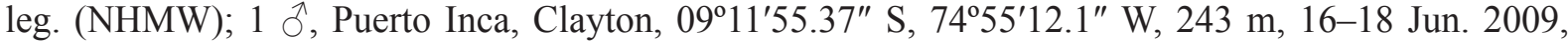

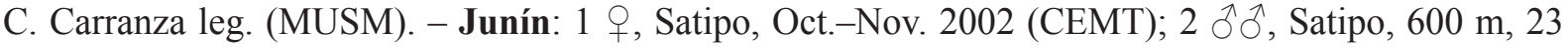
May-3 Jun. 2004, A. Santibañez leg. (TAMU); 2 ふぇ, 2 우우, Satipo, 1100 m, 4-15 Apr. 2003 (CEMT); $2 \widehat{\jmath} \widehat{\jmath}, 1$ q, Satipo, Fundo Santa Teresa, 2 Oct. 2007, M. Alvarado and L. Figueroa leg. (MUSM); 1 ○, Satipo, Rio Tambo, Campamento Kampitiare, Comunidad Nativa Shevoja, $11^{\circ} 42^{\prime}$ S, 73º $01^{\prime}$ W, 250 m, 10 Jan.-7 Feb. 2005, Williams Paredes leg. (MUSM). - Loreto: 1 q, Loreto, Urarinas, right bank of Urituyacu river, 140 m, 18 Nov. 2009, L. Sulca leg. (MUSM); 2 $\widehat{\jmath}$, Loreto, Urarinas, Rio Copalyacu, $03^{\circ} 42^{\prime} 59^{\prime \prime} \mathrm{S}, 75^{\circ} 26^{\prime} 00^{\prime \prime} \mathrm{W}, 161 \mathrm{~m}, 7-8$ Oct. 2009, L. Sulca leg. (MUSM); 1 ô, Maynas, Iquitos, 4 Nov. 2005, L. Culot leg. (MUSM); 1 unsexed specimen, Maynas, Iquitos, 03 ${ }^{\circ} 96^{\prime} 46^{\prime \prime} \mathrm{S} 73^{\circ} 15^{\prime} 49^{\prime \prime} \mathrm{W}$, Dec.

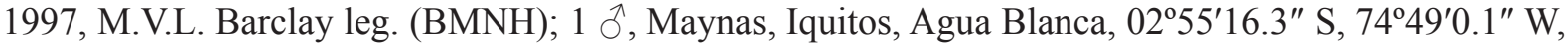

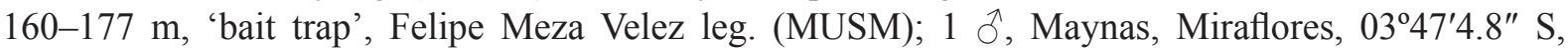
73²41'43" W, 69 m, 10 May 2012, C. Ampudia leg. (MUSM); 1 ô, Maynas, Napo, Rio Curacay, Gaseoducto Barrett, 16-18 Mar. 2008, W. Paredes leg. (MUSM); 1 స, Requena, Masisea, Comunidad Nativa Santa Teresa, 0600 $00^{\prime} 55.07^{\prime \prime}$ S, 7404'59.95" W, 87 m, 12 Aug. 2008, C. Carranza leg. (MUSM); $10^{\lambda}$, Requena, Sierra del Divisor ("a 5 km del Rio Capanagua"), 06 $6^{\circ} 19^{\prime} 30^{\prime \prime}$ S, 7346 $06^{\prime}$ " W, $160 \mathrm{~m}$, 20-21 Oct. 2008, A. García leg. (MUSM); 1 ㅇ, Requena, Sierra del Divisor ("cerca de Rio Punga"),

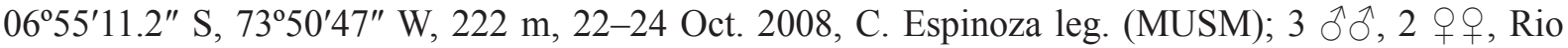

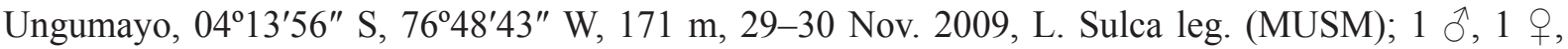
Ucayali, Sierra del Divisor ("cerca de Sarayacu"), 06 $57^{\prime 2} 21.06^{\prime \prime}$ S, 7401'27.4" W, 195 m, 10-11 Oct.

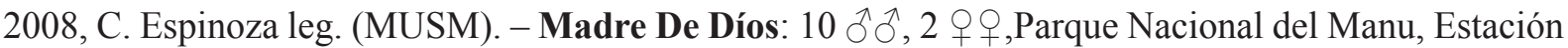
Biológica Cocha Cashu, 11 ${ }^{\circ} 55^{\prime}$ S, $77^{\circ} 18^{\prime}$ W, 380 m, 18 Aug.-5 Sep. 1986, D.C. Darling and A.B. Forsyth leg. (MUSM); 1 \&, Parque Nacional del Manu, Estación Biológica Cocha Cashu, $11^{\circ} 55^{\prime} \mathrm{S}$, $77^{\circ} 18^{\prime}$ W, 380 m, 20-22 Aug. 1986, D.C. Darling leg. (MUSM); 1 ô, Parque Nacional del Manu,

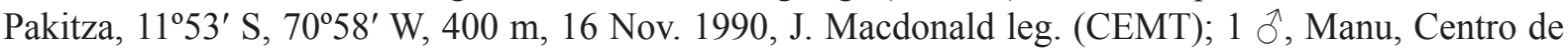
Investigación y Capacitación Río Los Amigos (CICRA), Yugunturo trail, $12^{\circ} 33^{\prime} \mathrm{S}, 70^{\circ} 05^{\prime} \mathrm{W}, 283 \mathrm{~m}, 16$ Nov. 2006, flight interception trap, A. Asenjo leg. (MUSM); 1 ' , Manu, CICRA, $12^{\circ} 34^{\prime} \mathrm{S}, 70^{\circ} 05^{\prime} \mathrm{W}$, 280 m, 10-14 Jul. 2010, C. Chaboo leg. (MUSM); 1 §, Manu, Reserva Comunal Amarakaeri, naciente Qda. Pinquiri, 12 $55^{\prime} 43^{\prime \prime}$ S, 7051'41" W, 421 m, 4 Jun. 2011, M. Vilchez leg. (MUSM); 1 , Reserva Biológica CICRA ["Centro de Investigación y Capacitación Río Los Amigos"], 23 Jan. 2007, flight interception trap, Angelico Asenjo leg. (CEMT); 1 ô, Rio Palma Real Grande, Limon, 12 $2^{\circ} 2^{\prime 2} 2^{\prime \prime}$ S, 68 51'41" W, 400 m, 5-6 Apr. 1999, pitfall with human faeces, T. Larsen leg. (MUSM); 1 q, Rio Palma Real Grande, Limon, 12 $2^{\circ} 32^{\prime 2} 20^{\prime \prime}$ S, 68 $51^{\prime} 40^{\prime \prime}$ W, 220 m, pitfall with human faeces, T. Larsen leg.

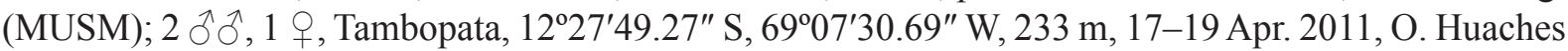
leg. (MUSM); 1 q,Tambopata, 300 m, 18-22 Apr. 1983, E. Perez leg. (MUSM); 1 ô, Tambopata, Inambari, Primavera Baja, 12 ${ }^{\circ} 54^{\prime} \mathrm{S}, 70^{\circ} 05^{\prime} \mathrm{W}, 234 \mathrm{~m}, 4-11$ Nov. 2009, C. Castillo and E. Martinez leg.

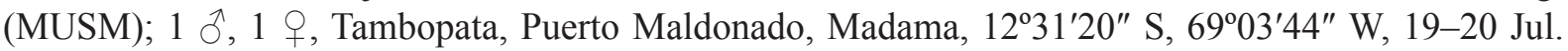
2009, 182 m, M. Alvarado leg. (MUSM); 1 స̃, 1 क , Tambopata, Puerto Maldonado, sector Triunfo,

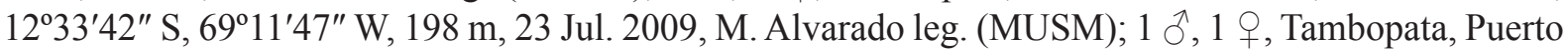
Madonado, Sudadero, 12²1'19" S, 6901'48" W, 221 m, 21-22 Jul. 2009, M. Alvarado leg. (MUSM); 


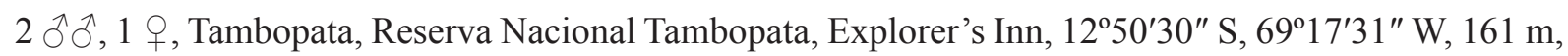
15-18 May 2009, L. Figueroa and M. Alvarado leg. (MUSM); 1 , Tambopata, Rio Tambopata, Colpa

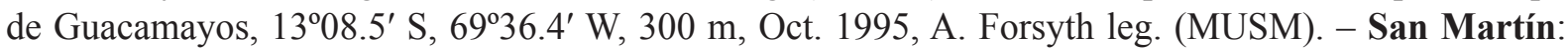
1 §̂, Mariscal Cáceres, Juanjuí, 7 Jul. 2007, P. Melendes leg. (TAMU); 1 ㅇ, San Martín, El Porvenir, Bosque El Pelejo, 06²19'28.3" S, 8150'38.4" W, 161 m, 17-19 May 2010, J. Robledo leg. (MUSM); 1 unsexed specimen, San Pedro de Cumbasa ("Cumbase") (MNHN). - Ucayali: 1 ô, Coronel Portillo, $08^{\circ} 20^{\prime} 40.04^{\prime \prime}$ S, 7342'42.64" W, 212 m, 10-12 Oct. 2012, P. Sanchez leg. (MUSM); 1 \%, Coronel Portillo, Binocura, 08 53'16.9" S, 7400'0.21" W, 140 m, 15-16 Jul. 208, M. Alvarado leg. (MUSM);

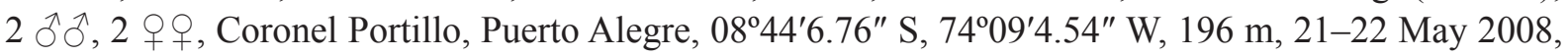
L. Figueroa leg. (MUSM); 1 , Coronel Portillo, Puerto Purin, 08 45'16.7" S, 74¹0'16.8" W, $125 \mathrm{~m}$, 17-18 May 2008, L. Figueroa leg. (MUSM); 2 $\jmath^{\jmath}, 4$ q $q$, Coronel Portillo, Puerto Purin, 08 44'59.2" S,

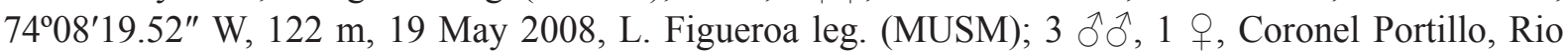

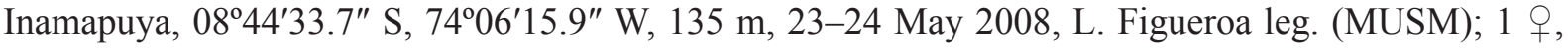

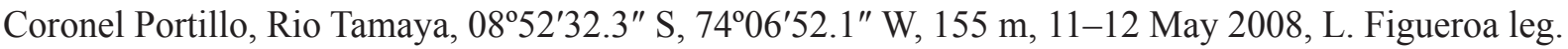

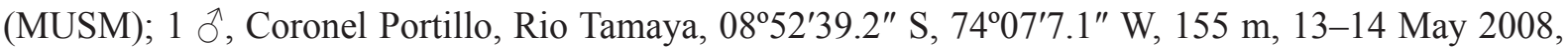
L. Figueroa leg. (MUSM); 1 + , Coronel Portillo, Rio Tamaya, 08 51'41.9" S, 74'04'20.6" W, 150 m, 15-16 May 2008, L. Figueroa leg. (MUSM); 1 đ’, Padre Abad, Alexander von Humboldt, 08 48'46.2" S, 750'ㄷ․" W, 245 m, 10-11 Jun. 2009, C. Carranza leg. (MUSM).

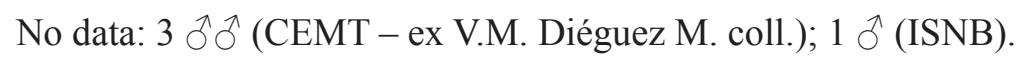

\section{Redescription}

Colouration. Head, pronotum, elytra, pygidium, and underside - including ventral surface of femora - with diffuse shine. Head, pronotum, and pygidium with blue, purple, or greenish reflections; in some specimens, pronotum with strong olive green shine. Elytra dark and with silky aspect; usually dark blue or purple; in some specimens, totally black or with greenish reflections. Meso- and metafemora dark brown and usually with greenish reflections.

HEAD. Tegument with silky aspect and micropunctation almost absent, more evident only on frons (Fig. 6D). Clypeus with two small apical teeth obtuse and contiguous at base; with a single transverse row of short setae covering base of both teeth. Genae with acute tooth immediately behind clypeal-genal juncture. Posterior edge of head usually with a fine line between eyes which can be effaced on the sides, or even totally absent.

Thorax. Pronotum with tegument at centre ranging from bright with dense micropunctation and without microsculpture to with strong alveolar microsculpture obliterating micropunctation; lateral region always without micropunctation, with alveolar microsculpture present and tegument perceptibly more matte than at centre. Posterior edge without fine transverse line at centre. Hypomeral cavity with very short yellowish setae at centre. Metaventrite entirely glabrous (occasionally, with some setae on the sides close to metacoxae); micropunctation indistinct at centre and visible only on region adjacent to apices of metacoxae.

Legs. Ventral surface of all femora and tibiae with diffuse shine of silky aspect. Protibiae with three obstuse or slightly acute teeth at their apical third, the two apical teeth of similar size and larger than the basal one. Mesofemora margined anteriorly only at their basal half; unmargined portion of anterior edge with row of very short setae. Metafemora with both anterior and posterior magins; posterior margin incomplete, always present at apical half and ranging in length at basal half, but never reaching trochanter (Fig. 31B). Metatarsomeres II and V subequal in length and longer than the others; metatarsomere IV shorter than the others. 
Elytra. Nine fine elytral striae only weakly marked, almost imperceptible. Base of striae I-V carinulate and well marked. Tegument of interstriae with a silky shine and with dense three-dimensional alveolar microsculpture obliterating indistinct micropunctation. Fine humeral carina distinct and long, sometimes present throughout basal fourth of elytra (Fig. 12C).

AвDOMEN. Ventrites V-VI smooth, shiny and with micropunctation at centre. Lateral foveae absent in both sexes. Pygidium with diffuse shine, with well-marked alveolar microsculpture and without micropunctation.

Aedeagus. Parameres long, little shorter than phallobase and clearly asymmetrical: left paramere laterally with apical depression much deeper and wider than depression on right paramere (difference more easialy seen in dorsal view). In lateral view, parameres with central angulosity and without ventral keel and notch (Fig. 17F).

SeXual dimorphism. Males: Protibial spur broad and foliaceous, external edge extended into an acute long spine, while internal edge has no prolongation or has much shorter spine; area between both spines straight or slightly excavated (Fig. 15G). Pygidium very long (length between 1.9 and $2.9 \mathrm{~mm}$ ) and convex; apical margin of pygidium much wider than lateral ones. Ventrite VI strongly narrowed at middle. Females: Protibial spur wide and with strong apical incision, with two long spines of uneven length, the internal spine shorter than the external one (Fig. 15H). Pygidium shorter (between 1.5 and 2.2. $\mathrm{mm}$ ) and flat; apical margin only slightly wider than lateral ones. Ventrite VI as wide at middle as on sides.

\section{Measurements}

Males $(\mathrm{N}=40)$. TL: AV: $12.1 \pm 0.78$; MX: 15; MN: 10.5. EW: AV: $8.2 \pm 0.36$; MX: 8.8; MN: 7.4. PL: AV: $4 \pm 0.25$; MX: 4.5; MN: 3.4. PW: AV: $7.5 \pm 0.41$; MX: 8.5; MN: 6.5. PgL: AV: $2.2 \pm 0.18$; MX: 2.9; MN: 1.9. PgW: AV: $3.8 \pm 0.22 ; \mathrm{MX}: 4.3 ; \mathrm{MN}: 3.1$.

Females (N = 20). TL: AV: $11.8 \pm 1$; MX: 14; MN: 9.8. EW: AV: 7.9 \pm 0.6 ; MX: 8.7; MN: 6.1. PL: AV: $3.8 \pm 0.31$; MX: 4.2; MN: 2.9. PW: AV: $7.1 \pm 0.54$; MX: 7.9; MN: 5.7. PgL: AV: $1.9 \pm 0.18$; MX: 2.2; MN: 1.5. PgW: AV: $3.8 \pm 0.28 ; \mathrm{MX}: 4.2 ; \mathrm{MN}: 3$.

\section{Geographical distribution}

Widespread in the Amazon Basin.

\section{Ecoregions}

Negro-Branco Moist Forests, Caquetá Moist Forests, Napo Moist Forests, Cordilleira Oriental Montane Forest, Ucayali Moist Forests, Iquitos Varzea, Southwest Amazon Moist Forests, Purus Varzea, Bolivian Yungas, Purus-Madeira Moist Forests, Monte Alegre Varzea, Madeira-Tapajós Moist Forests, Mato Grosso Tropical Dry Forests, Tapajós-Xingu Moist Forests, Xingu-Tocantins-Araguaia Moist Forests, Tocantis-Pindaré Moist Forests.

\section{Collecting sites (Fig. 30)}

COLOMBIA. Meta: Parque Nacional Natural Tinigua (Centro de Investigaciones Ecológicas La Macarena). Guaviare: El Retorno, Parque Nacional Natural Nukak, San José del Guaviare. Amazonas: Leticia (Monilla Amena).

ECUADOR. Sucumbíos: “Chiruisla Station”. Orellana: Parque Nacional Yasuní, Payamino Research Station, Puerto Francisco Orellana, Tiputini Biodiversity Station. Morona Santiago: Cordillera de Cutucú. 
PERU. Loreto: Loreto (Urarinas), Maynas (Iquitos, Miraflores, Napo), Requena (Masisea: Comunidad Nativa Santa Teresa; Sierra del Divisor), Ucayali (Sierra del Divisor). San Martín: Mariscal Cáceres (Juanjuí), San Martín (El Porvenir), San Pedro de Cumbasa. Huánuco: Estación Biológica Panguana, Puerto Inca (Clayton). Ucayali: Coronel Portillo (Puerto Alegre, Puerto Purin), Padre Abad (Alexander von Humboldt). Junín: Satipo. Cuzco: La Convención (Echarate). Madre de Dios: Manu (Centro de Investigación y Capacitación Río Los Amigos, Reserva Comunal Amarakaeri), Parque Nacional del Manu (Estación Biológica Cocha Cashu), Reserva Biológica "Centro de Investigación y Capacitación Río Los Amigos" (CICRA), Tambopata (Inambari: Primavera Baja; Puerto Maldonado; Reserva Nacional Tambopata).

BRAZIL. Amazonas: Benjamin Constant, Beruri, Manaus, Manicoré, São Paulo de Olivença, Tefé. Acre: Mâncio Lima, Manoel Urbano (Parque Estadual Chandless), Rio Branco, Senador Guiomard, Xapuri (Reserva Extrativista Chico Mendes). Rondônia: Cacaulândia, Guajará-Mirim, Itapuã do Oeste (Floresta Nacional do Jamari), Ji-Paraná, Rolim de Moura, Vilhena. Pará: Almeirim (Monte Dourado), Alter do Chão, Belém, Belterra, Novo Progresso, Paragominas, Redenção, Santarém, São Félix do Xingu, Tailândia. Maranhão: Centro Novo do Maranhão. Mato Grosso: Alta Floresta, Carlinda, Cotriguaçu, Nova Bandeirante, Novo Mundo (Parque Estadual do Cristalino).

BOLIVIA. La Paz: Nor Yungas. Cochabamba: José Carrasco (Valle del Sacta), Chapare. Santa Cruz: Sara.

\section{Intraspecific variation and taxonomic discussion}

Although formally described only in 1949, it is possible to trace back the beginning of the taxonomic history of S. proseni to the late $19^{\text {th }}$ century, when Bates (1887) was the first author to realize that the South American populations of 'Canthon aequinoctialis' differed from the Central American ones in having individuals of considerable different size: "Central-American differ from South-American exemples only in being smaller (11 millim.), the latter varying little from 14 millim" (Bates 1887: 33). Indeed, Henry Walter Bates himself collected some specimens of S. proseni in the Amazon region which were examined for this work. Nonetheless, over the following 60 years, no author noticed those differences or discovered others, treating under the same name $C$. aequinoctialis specimens coming from both Central America and the Amazon Basin, including the revisions of Schmidt (1922) and Balthasar (1939).

Eventually, already in the mid-20 $0^{\text {th }}$ century, Martínez (1949) described Glaphyrocanthon proseni stating his new species was close to $C$. aequinoctialis, but distinct from this latter species by the metafemora with a margin on both edges (while $C$. aequinoctialis would have only the anterior margin) and colouration. It is clear, however, that Martínez did not have on hand specimens of $S$. aequinoctialis, since both species have metafemora with posterior margin and, actually, this margin is even longer in S. aequinoctialis than in S. proseni (Fig. 31) (indeed, Martínez wrote "Según la descripción" when referred to $C$. aequinoctialis).

Later, however, Pereira \& Martínez (1956), in a key to the species then-positioned in Glaphyrocanthon, noted colouration differences between the species, G. proseni being blue-violet and opaque ("azul violeta e opaco") and G. aequinoctialis being black and bright ("preto e brilhante"). Martínez et al. (1964) refined those descriptions writing that G. proseni had indistinct elytral striae, and the elytra, pygidium and ventral surface of femora opaque, while G. aequinoctialis had fine, but perceptible elytra striae and the entire body bright; they were also the first authors to note that $S$. aequinoctialis was restricted to Central and northern South America. But despite these considerations, they also wrote that, the differences between the two taxa being restricted to the microsculpture and elytral striae only, G. proseni would possibly represent a southern subspecies of $G$. aequinoctialis instead of a full species. 
Then, Vulcano \& Pereira (1967), in a key to the dung beetle species of Amazonia, distinguished the two species, apart from their distribution, only by colouration and size (resuming, for the first time and, probably independently, the observation taken by Bates 1887). Lastly, Halffter \& Martínez (1977), after having studied some type specimens of both names (Fig. 29), synonymized C. aequinoctialis and G. proseni without presenting, however, the reasons for that act, although it is reasonable to imagine they did so based on the arguments given by Martínez et al. (1964). In this way, except for some recent faunistic inventories that treated C. proseni as a valid species (e.g., Vaz-de-Mello et al. 2011b; Korasaki et al. 2012; Nunes et al. 2014; Chamorro et al. 2018), these two names have remained in synonymy ever since. Next, we present evidence that, in our view, supports the present revalidation of S. proseni and demonstrates its independence from $S$. aequinoctialis.

As noted by Bates (1887) (despite having considered them different populations of a same species), the average body size of $S$. aequinoctialis and $S$. proseni is truly distinct. The average body length of $S$. proseni is $12 \mathrm{~mm}$, ranging from individuals measuring only $9.8 \mathrm{~mm}$ to those of $15 \mathrm{~mm}$, while S. aequinoctialis has an average length of $10 \mathrm{~mm}$, with the smallest specimens measure $8.7 \mathrm{~mm}$ to the largest ones $12.3 \mathrm{~mm}$. It is interesting to note that the lowest value recorded for S. proseni is only slightly lower than the average of $S$. aequinoctialis, while the largest $S$. aequinoctialis examined is only a little longer than the average of the specimens of $S$. proseni. This pattern is repeated in all the other measurements taken for this work, including the elytral width (average of $8.1 \mathrm{~mm}$ for $S$. proseni, with a maximum of 8.8, a minimum of 5.7 and an average of $7.0 \mathrm{~mm}$ for $S$. aequinoctialis, with a maximum of 7.8 and a minimum of $5.7 \mathrm{~mm}$ ) and the greatest width of the pronotum (an average of $7.3 \mathrm{~mm}$, with a maximum of 8.2. and a minimum of $5.7 \mathrm{~mm}$ for $S$. proseni, and an average of 6.3, with a maximum of 7.4 and a minimum of 5.3 for $S$. aequinoctialis).

Also part of the group of characteristics already used in the past to distinguish both species are the differences in microsculpture and other aspects of the tegument, which form one of the strongest indications for the evolutionary independence of $S$. aequinoctialis and S. proseni. By seeing them with the naked eye, it is possible to realize that the pronotum, ventral surface of femora, pygidium and especially the elytra of $S$. aequinoctialis are very bright and have a smooth surface, while they reflect light in a more diffuse way and, consequently, have a more opaque, silky appearance in S. proseni. This is so thanks to the microsculpture present in the tegument of these two species. In S. aequinoctialis, the microsculpture is absent or very effaced at the centre of the pronotum and on the elytra, and, although clearly present, it is very fine (i.e., the microsculpture's 'alveoli' are very small) on the femora and pygidium. This condition makes the tegument of this species (or gives the appearance of being) much smoother than that of $S$. proseni, which has a strong alveolar microsculpture covering the entire pronotum, femora, elytra and pygidium (Fig. 12A).

The elytral striae are also much more marked and visible in $S$. proseni than in S. aequinoctialis, where they are almost imperceptible; this difference is more easily seen looking at the base of elytra, where the striae are finely marked and expanded in S. proseni and completely indistinct in S. aequinoctialis. Regarding the micropunctation, both species differ in the way the micropunctures are marked. In the majority of the specimens of $S$. proseni (but not all; see below), the pronotum, elytra and pygidium have a very visible micropunctation, which, in general, is not strongly obliterated by the microsculpture. In $S$. aequinoctialis, on the other hand, punctures may be completely absent or, more commonly, they are only weakly marked and are almost imperceptible, having the appearance of being shallower than those of $S$. proseni. Also in relation to the tegument, we see differences between $S$. aequinoctialis and $S$. proseni in the humeral carina (Fig. 12C) (which is longer and more strongly marked in the latter species), on the posterior margin of the metafemora (the margin extends from the apex of metafemur to beyond or immediately before the trochanter in S. aequinoctialis (Fig. 31A), while it never reaches the trochanter and, in general, is present only slightly beyond the middle of metafemur in S. proseni, 
Fig. 31B) and on the posterior margin of the head (which is always present in S. aequinoctialis, and may be incomplete or even completely absent is some specimens of $S$. proseni).

Despite all the differences listed above, the strongest evidence for the isolation between these two species rests on the shape of the female protibial spur. In $S$. aequinoctialis, this spur is spiniform and has an acuminate apex (Fig. 15F), while females of $S$. proseni have a wider and profoundly bifid spur which has the external branch longer than the internal one (separation between both branches ' $V$ '-shaped, Fig. $15 \mathrm{H}$ ). In fact, the presence of this bifid spur distinguishes females of $S$. proseni from all the other females in the genus and is here reported for the first time.

Lastly, the disjunct geographical distribution of $S$. aequinoctialis and S. proseni, separated by the great barrier constituted by the Andes (Fig. 113), adds to the morphological evidence discussed above. Sylvicanthon aequinoctialis is present from Honduras in the north, south to the Choco region on the Pacific coast of South America, and in the great valley between the central and western mountain ranges in Colombia. In turn, S. proseni is distributed throughout most of the Amazon Basin, from Maranhão in the east to the Yungas on the eastern slopes of the Andes in Bolivia, Peru and Ecuador; in Colombia, the latter species was recorded only from the lower areas in the Amazon forest. Ecologically, both species do not seem to be very distinct from one another. Both inhabit a large variety of forest habitats with a very remarkable altitudinal range, living from low and coastal regions (e.g., S. proseni in Belém, on the banks of the Baía de Marajó, Brazil; S. aequinoctialis in La Ceiba on the Caribbean coast of Honduras) to the Andean regions above $1000 \mathrm{~m}$ (e.g., S. proseni in Satipo, Peru, at $1110 \mathrm{~m}$ a.s.l.; S. aequinoctialis in the Reserva Natural Cañon del Río Claro, Colombia, at $1440 \mathrm{~m}$ ). In all those places, S. aequinoctialis and $S$. proseni are among the most abundant dung beetle species, and there they exploit a wide array of food sources (dung, carrion and rotten fruits). Therefore, despite the differences in morphology, both species seem to have little diverged in their life habits.

Being such an abundant and widely-distributed species, Sylvicanthon proseni would be expected to show a great degree of instraspecific variation, and this is indeed what occurs. The variation on the density of pronotal micropunctation is easily seen: even within a single given population it is possible to encounter specimens with a very densely-punctated tegument (and with a very bright pronotum) and others with a very fine, almost imperceptible micropunctation. The most common pattern, however, is the one with fine, but easily visible micropunctation. The size of the dorsal portion of the eyes also varies intraspecifically, the width ranging from approximately one-fifth to one-sixth of the interocular space. Lastly, a very important variation is seen on the posterior edge of the head: in the majority of the specimens a fine line runs across the entire interocular space. In some specimens, however, this line is effaced near the eyes and is marked only at the middle; progressively, this central line disappears, and in some individuals, it is completely absent.

\section{Comments}

Because this species was confused with $S$. aequinoctialis for such a long time, especially after the synonymy proposed by Halffter \& Martínez (1977), most of what is known about S. proseni is published under the name Canthon aequinoctialis. Concerning specifically its geographical distribution, the records of Balthasar $(1941,1951)$ from "Mishujacu, Iquitos" (Peru), Vaz-de-Mello (1999) from Acre (Brazil), Celi et al. (2004) and Carpio et al. (2009) from Ecuador, Noriega-Alvarado (2004), Noriega et al. (2007a) and Noriega (2012) from Meta (Colombia), Noriega et al. (2008) from Amazonas (Colombia), and Figueroa \& Alvarado (2011) from Tambopata (Peru) certainly refer to S. proseni, not to $S$. aequinoctialis as originally mentioned.

The village of San Pedro de Cumbasa, in the department of San Martín, Peru, was included in the distribution of $S$. proseni based on a specimen in MNHN labelled "Cumbase" without any further 
information. Takiya et al. (2003), in their study of the leafhopper genus Hyogonia China, 1927 (Hemiptera, Cicadellidae), also studied a specimen labelled "Cumbase" and, according to them, this word probably refers to San Pedro de Cumbasa. Similarly, the register from Novo Centro do Maranhão, the only known locality of this species in the Brazilian state of Maranhão, was obtained from a single specimen housed at the MZSP labelled "Igarapé Gurupi-Uma, Aldeia Araçu, $50 \mathrm{~km}$ E. de Canindé", information that probably refers to that locality according to Pinto \& Lamas (2011).

\section{Natural history}

Sylvicanthon proseni is widely distributed in the Amazon Basin and seems to be a very common species in all the regions where it lives. In several dung beetle community inventories carried out in the Amazon region, $S$. proseni was one of the most abundant species (e.g., Noriega et al. 2007a: in Meta, Colombia, it corresponded to $4.66 \%$ of the collected specimens; Korasaki et al. 2012: Amazonas, Brazil, 5.6\%; Vaz-de-Mello 1999: Acre, Brazil, 23\%; Noriega et al. 2008: Amazonas, Colombia, 29.9\%; Carpio et al. 2009: Sucumbíos, Ecuador, 55\%). This species seems to be absent only in grasslands and agricultural fields, but, where some small patch of forest is left standing or there is secondary regeneration, S. proseni can be found (Vaz-de-Mello 1999; Noriega et al. 2007a; Korasaki et al. 2012), including river floodplain areas (Escobar 2000b; Nunes et al. 2014). These observations clearly show the species' flexibility and its considerable resistance against anthropic impact.

The individuals studied for this work were collected in all months and within an altitudinal range between 68 and $1100 \mathrm{~m}$ (nonetheless, the greater part of the specimens was collected between 100 and $500 \mathrm{~m}$ ). Although we are aware of just a single time-activity record - which was taken from the label of a specimen from Leticia, Colombia, collected at night -, the information that specimens were collected with a light trap (Vaz-de-Mello et al. 2011) and our knowledge about the other species of Sylvicanthon (especially $S$. aequinoctialis) allows us to confidently believe that $S$. proseni is a nocturnal species.

Sylvicanthon proseni was mainly collected using human faeces as bait and it seems to be preferably coprophagous (Martínez et al. 1949; Vaz-de-Mello 1999; Noriega et al. 2007a, 2008; Figueroa \& Alvarado 2011; Korasaki et al. 2012; Nunes et al. 2015; and information from specimen labels). Some individuals collected in Porto Velho (Rondônia, Brazil), however, were caught using pitfall traps baited with chicken meat and rotten bananas. Furthermore, S. proseni was also collected on dung of the woolly monkey [Lagothrix lagotricha (Humboldt, 1812)] (Noriega 2012) and cows (specimen labels information), with a flight interception trap (Vaz-de-Mello 1999) and a light trap (Vaz-de-Mello et al. 2011).

Pereira \& Martínez (1956) and Martínez et al. (1964) reported a very interesting case of phoretic behaviour between S. proseni and tapirs [Tapirus terrestris (Linnaeus, 1758)]. Nevertheless, neither work stated the primary source for that information (authors' observation?) or any further detail (e.g., place of observation, number of individuals, or whether the tapir was alive or dead when the observation was made, which could rule out the possibility of simple necrophagy). Therefore, whether this information is reliable or not is yet to be resolved. Nevertheless, phoresy has indeed been observed in a great number of other dung beetles, including the relationship between two distinct lineages of Onthophagus and macropod marsupials (wallabies and rat-kangaroos) in Australia (Matthews 1972). In the Neotropical region, phoresy was observed between species of the dung beetle genera Uroxys and Bradypodidium Vaz-de-Mello, 2008 with three-toed sloths [Bradypus Linnaeus, 1758] (Ratcliffe 1980; Howden \& Young 1981; Vaz-de-Mello 2008), and species of Canthidium with the coppery titi monkey, Callicebus cupreus (Spix, 1823) (Herrera et al. 2002). In Deltochilini, Pereira \& Martínez (1956) reported phoretic behaviour of Glaphyrocanthon subhyalinus (Harold, 1867) (cited as "Canthon hyalinus") in the brown titi monkey, Callicebus brunneus (Wagner, 1842), while Jacobs et al. (2008) 
described in detail the relationship between Glaphyrocanthon aff. quadriguttatus (Olivier, 1789) and both Callicebus brunneus and the saki monkey species Pithecia irrorate Gray, 1842.

As hypothesized by Herrera et al. (2002) and Jacobs et al. (2008), this phoretic strategy may be related to the behaviour known as the 'sit and wait' strategy, which is largely beneficial to the dung beetles that employ it because, being mounted on the dung-producing animal itself and positioned around its anus, those beetles can reach the dung as soon as it is released. In doing so, they can start the consumption of the dung before it dries out and before the arrival of competitors. In tropical forest with a low density of large mammals such as those in South America, competition between dung beetles can be intense and, consequently, arriving first at the food source brings a considerable advantage. If the alleged phoresy of $S$. proseni in tapirs is confirmed, it will be the phoretic relationship between the largest host and the largest dung beetle yet discovered. Ratcliffe (1980) and Jacob et al. (2008) give an excellent discussion on the phoretic relationship between Scarabaeinae and mammals.

\section{The bridarollii subgroup}

Sylvicanthon bridarollii (Martínez, 1949)

Figs 8A, 9A, 11F-G, 13G-H, 15I, 18A, 20, 32-34, 35C-D, 36

Glaphyrocanthon bridarollii Martínez, 1949a: 282-287, 290.

Glaphyrocanthon bridarollii - Halffter \& Martínez 1977: 63.

Glaphyrocanthon (Glaphyrocanthon) bridarollii - Martínez 1950: 170-171. — Pereira \& Martínez 1956: 126, 128. - Martínez et al. 1964: 5, 8, 10, 14. — Vulcano \& Pereira 1964: 661; 1967: 561 _ Martínez \& Pereira 1967: 53.

Sylvicanthon bridarollii - Halffter \& Martínez 1977: 63. — Amézquita et al. 1999: 119-120. Medina \& Lopera-Toro 2000: 312, fig. 9d, h. — Vaz-de-Mello 2000: 195. — Escobar 2000a: 210; 2000b: 121. - Medina et al. 2001: 137; 2003: 44, fig. 100; 2013: 464-466, 469, 471, figs 89, 117, 131, 240. - Carpio et al. 2004: 464, 469. — Celi et al. 2004: 46. — Larsen 2004: 261. — Horgan 2006: 364. - Medina \& Pulido 2009: 59. - Carvajal et al. 2011: 117, 316. — Price \& Feer 2012: 327 (error: referring to S. seag sp. nov.) . — Ratcliffe et al. 2015: 196. — Tarasov \& Génier 2015: 21-24, 54, figs 4-7, 29g.

Silvicanthon bridarollii [sic] - Horgan 2005a: 609-610; 2005b: 131; 2009: 3532, 3537. — Chamorro et al. 2018: 98.

Sylvicanthon bridarolli [sic] - Figueroa \& Alvarado 2011: 210-211, fig. 1b. - Chamorro et al. 2018: 86, fig. 9D. - Espinoza \& Noriega 2018: 146, 149.

Sylvicanthon sp. - Kirk 1992: 54 (tentative).

Canthon bridarollii - Krajcik 2012: 63.

\section{Etymology}

Eponym refers to the Argentinian naturalist and Jesuit priest Albino J. Bridarolli (1903-1949) (Martínez 1949).

\section{Material examined}

Holotype

BOLIVIA: Ō, Cochabamba, Chapare, Coni River, 400 m ("BOLIVIA / Dep. Cochabamba / Chapare 400mts. / R. Zischka - leg. / Coll. Martínez", "BOLIVIA / Chapare / 400 M / Zischka", "HOLOTIPO О’”, "Glaphyrocanthon / bridarollii / đ̊ / sp. n. / A. Martínez det. 1949”, "FICHADO", "MACN-En / 937”), genital capsule removed and glued to a triangular card point (MACN) (Fig. 33A). 
Paratypes $(3 \hat{\partial} \widehat{\partial}$ and 4 $q+$ examined)

Two paratypes, male and female, could not be located (they were possibly deposited at the Zischka collection, now housed at the Zoologische Staatssammlung München, Munich, Germany; see comments below).

BOLIVIA: 1 q (allotype) ("CHAPARE / BOLIVIA / ZISCHKA col. / Coll. Martínez / 24-V-48", "ALOTIPO ㅇ", "Glaphyrocanthon / bridarollii / o / sp. n. / A. Martínez det. 1949", "FICHADO", "MACN-En / 938") (MACN) (Fig. 33B); 1 § (dissected) ("BOLIVIA / Dep. Cochabamba / Chapare 400mts. / R. Zischka-leg. / Coll. Martinez", "Bolivia / Region subandina / Prov. Chapare - 400m / ex coll Zischka", "Glaphyrocanthon / bridarollii ô / sp. n. / A. Martínez-det 1949", "PARATYPE", "PARATIPO خ”, "H. \& A. Howden / Collection / ex. A. Martínez coll.", "Canadian Museum of / Musée canadien de la / NATURE / CMNEN 00012714") (CMNC); 1 ○े ("BOLIVIA / Dep. Cochabamba / Chapare 400mts. / R. Zischka-leg. / Coll. Martínez", "Glaphyrocanthon / bridarollii ふ̋ / sp. n. / A. Martínez-det 1949”, "PARATIPO స", "PARATYPE", "H. \& A. Howden / Collection / ex. A. Martínez coll.", "Canadian Museum of / Musée canadien de la / NATURE / CMNEN 00019064") (CMNC), 1 + (“BOLIVIA / Dep. Cochabamba / Chapare 400mts. / R. Zischka-leg. / Coll. Martinez", "Glaphyrocanthon / bridarollii ${ }_{+}$ / sp. n. / A. Martínez-det 1949", "PARATYPE", "PARATIPO क”, "H. \& A. Howden / collection / ex. A. Martínez coll.", "Canadian Museum of / Musée canadien de la / NATURE / CMNEN 00019065")

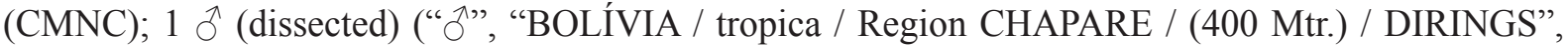
"BOLIVIA / Dep. Cochabamba / Chapare 400mts. / R. Zischka-leg. / Coll. Martínez", "Glaphyrocanthon

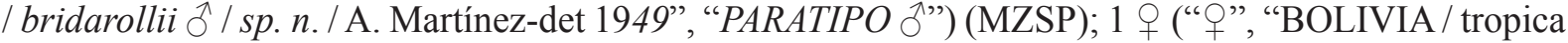
/ Region CHAPARÉ / (400 Mtr.) / DIRINGS", "BOLIVIA / Dep. Cochabamba / Chapare 400 mts. / R. Zischka-legit. / Coll. Martínez", "PARATIPO q", "Glaphyrocanthon / bridarollii + / sp. n. / A. Martínezdet. 1949") (MZSP); 1 ㅇ (“O”, "BOLIVIA / tropica / Region CHAPARÉ / (400 Mtr.) / DIRINGS”, "BOLIVIA / Dep. Cochabamba / Chapare 400 mts. / R. Zischka-legit. / Coll. Martinez", "PARATIPO O", "Glaphyrocanthon / bridarollii 9 / sp. n. / A. Martínez-det. 1949") (MZSP).

Additional material (382 $\hat{\partial}, 256 \propto q)$

BOLIVIA: 1 q, eastern Bolivia ("Ost Bolivien"), Steinbach S.V. leg. (ZMHB, labelled as syntype of

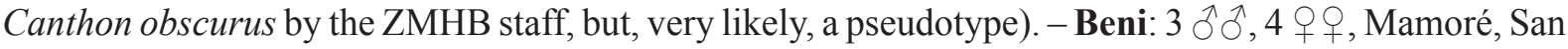

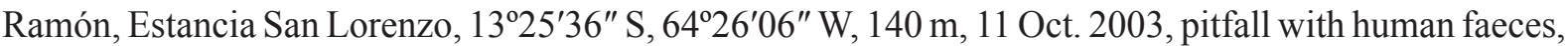
A.C. Hamel and K. Walker leg. (OUMNH); 2 §̃̄, 1 q, Mamoré, San Ramón, Estancia San Lorenzo, $13^{\circ} 25^{\prime} 36^{\prime \prime} \mathrm{S}, 6^{\circ} 26^{\prime} 06^{\prime \prime} \mathrm{W}, 140 \mathrm{~m}, 12$ Oct. 2003, pitfall with human faeces, A.C. Hamel and K. Walker leg.

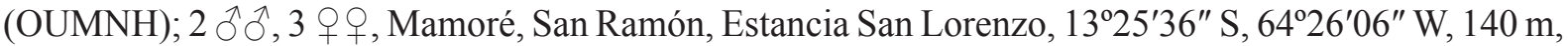
13 Oct. 2003, pitfall with human faeces, A.C. Hamel and K. Walker leg. (OUMNH). - Cochabamba:

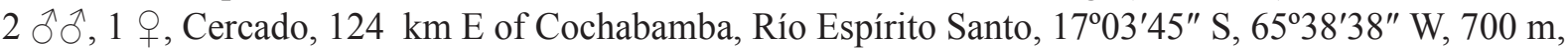
6-8 Feb. 1999, dung trap, F. Génier leg. (CMNC); 2 §ิ ô, 1 ㅇ, Chapare, Villa Tunari, Oct. 1992, Arnagada(?) leg. (CMNC); 21 $\widehat{\partial}$ (1 dissected), 10 우, Estación Biológica Villa Carmen, Universidad San Simon, 67.5 km E of Villa Tunari, 1706'19" S, 6446'57" W, 300 m, 7-9 Feb. 1999, F. Génier leg. (CMNC); 14 วิ $\widehat{\jmath}$ (1 dissected), 7 오, Estación Biológica Villa Carmen, Universidad San Simon, 67.5

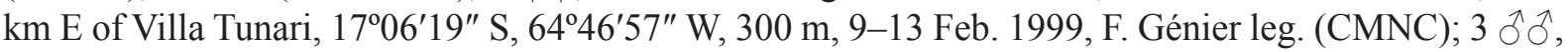
4 우, José Carrasco, Chimoré, 250 m, Jan. 1972, A. Martínez leg. (CMNC); 3 우, "PD Altamachi”, $16^{\circ} 02^{\prime} \mathrm{S}, 66^{\circ} 40^{\prime} \mathrm{W}, 1150 \mathrm{~m}, 25$ Sep. 2004, trap with human faeces, A.C. Hamel leg. (OUMNH); 1 ㅇ, "PD Altamachi", 1602' S, 66 $40^{\circ}$ W, 1150 m, 27 Sep. 2004, trap with human faeces, A.C. Hamel leg. (OUMNH). - La Paz: 1 Ô, 1 \&, Larecaja, Guanay, San José, 17 Oct. 2001, G. Castillo leg. (CEMT); 1 q, Larecaja, Guanay, Uyapi, 15 Oct. 1995, G. Arriágada leg. (CEMT); 1 ภ, 2 q + , Larecaja, Guanay, 10 Nov. 2004, A. U-Peña leg. (CEMT); 1 क , Nor Yungas, Coroico (MZSP); 1 , , Parque Nacional Madidi, 133' S, 68 $44^{\prime}$ W, 260 m, 26 Jul. 2004, trap with human faeces, C. Hamel leg. (OUMNH);

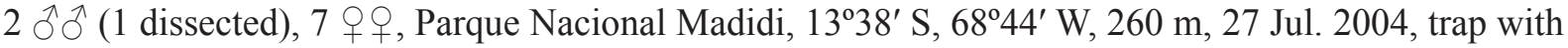
human faeces, C. Hamel leg. (OUMNH). - Santa Cruz: 1 \&, Andrés Ibáñez, El Espejo(?), Feb. 1961, 

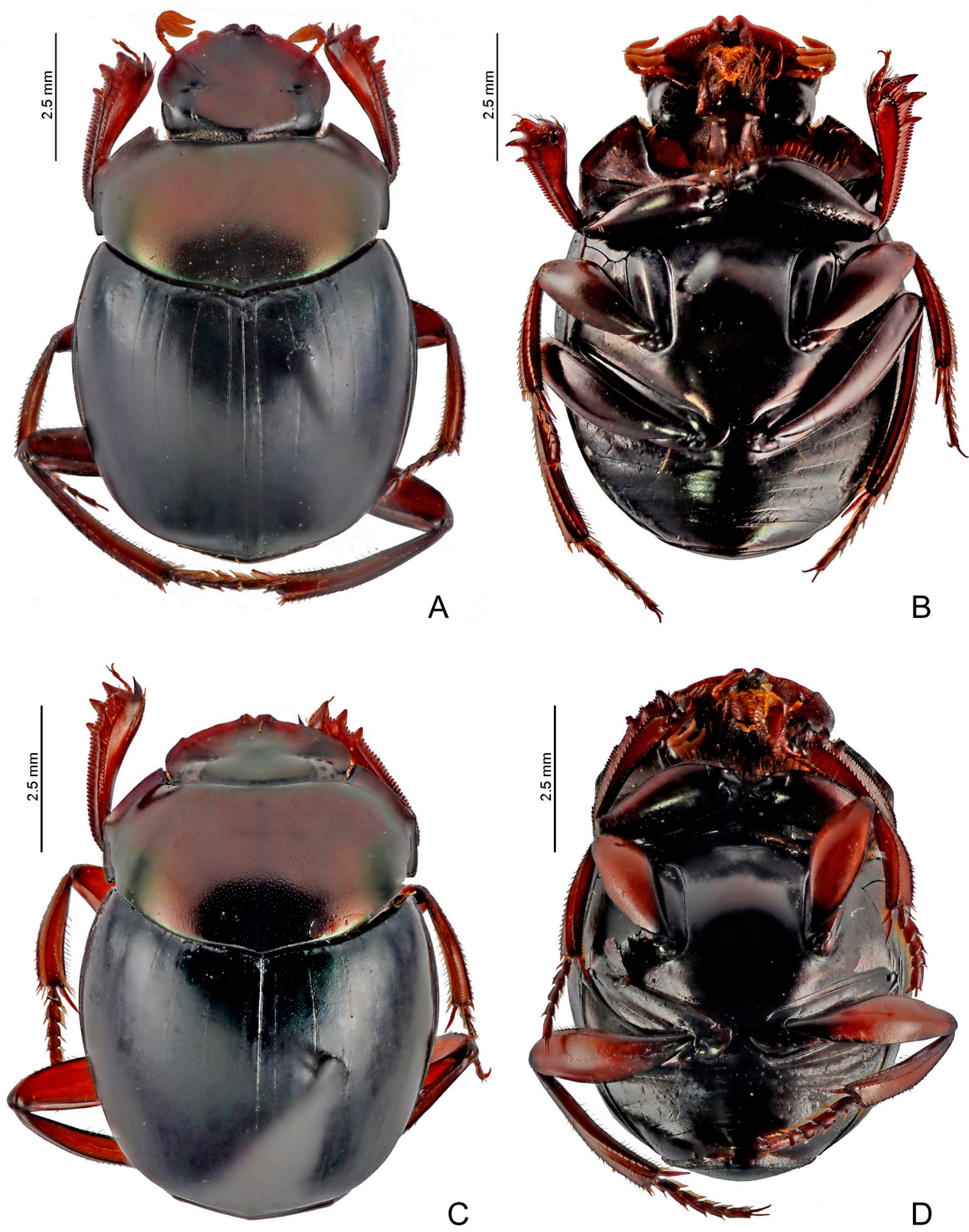

Fig. 32. Sylvicanthon bridarollii (Martínez, 1949). A-B. Individual from southern Bolivia. A. Dorsal view. B. Ventral view. C-D. Individual from Ecuador. C. Dorsal view. D. Ventral view. 
Martínez leg. (CMNC); 2 우, Andrés Ibáñez, Santa Cruz de la Sierra, Jardín Botánico, 29 Sep. 2006,

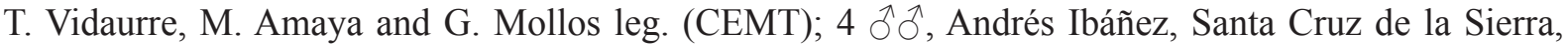

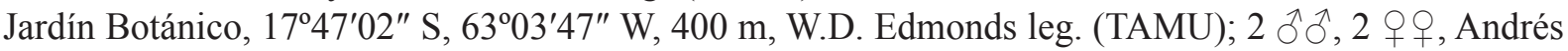

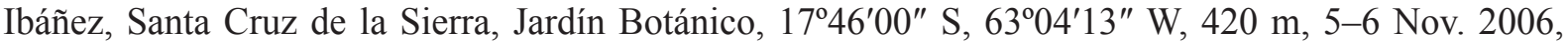
pitfall with human faeces, Mann and Hamel leg. (OUMNH); 3 ภิ (1 dissected), 2 q $ᄋ$, Andrés Ibáñez,

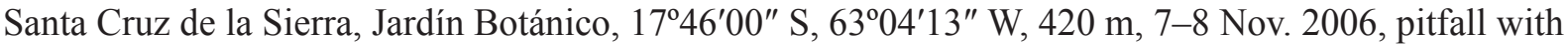
human faeces, Mann and Hamel leg. (OUMNH); 3 $\widehat{\jmath}$, Andrés Ibáñez, Santa Cruz de la Sierra, Jardín Botánico, 17 $46^{\prime} 00^{\prime \prime} \mathrm{S}, 63^{\circ} 04^{\prime} 13^{\prime \prime} \mathrm{W}, 420 \mathrm{~m}, 8-9$ Nov. 2006, pitfall with human faeces, Mann and Hamel leg. (OUMNH); 4 우, Andrés Ibañez, Santa Cruz de la Sierra, Jardín Botánico, "8.5 Km Carretera a Cotoca”, 17045'51.3" S, 6339'30.8" W, 10-12 Nov. 2006, Scarabnet leg. (CEMT); 1 क, Ichilo, Buena Vista ("4-6k SSE Buena Vista"), Hotel Fauna and Flora, 420-450 m, 2-12 Feb. 2000, pitfall with dung/ carrion, J.E. Wappes leg. (TAMU); 1 +, Ichilo, Buena Vista ("3.7 km SSE Buena Vista"), Hotel Fauna

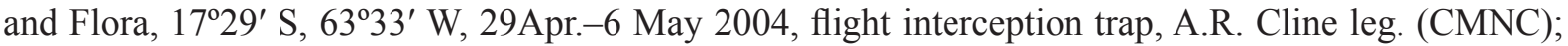
3 우우, Obispo Santistevan, General Saavedra, "CIMCA"(?), 9 Sep. 1988, C.J. Pruetti leg. (CMNC); 1 q, San Pedro(?), 12 Sep. 1997, C. J. Pruetti leg. (CMNC).
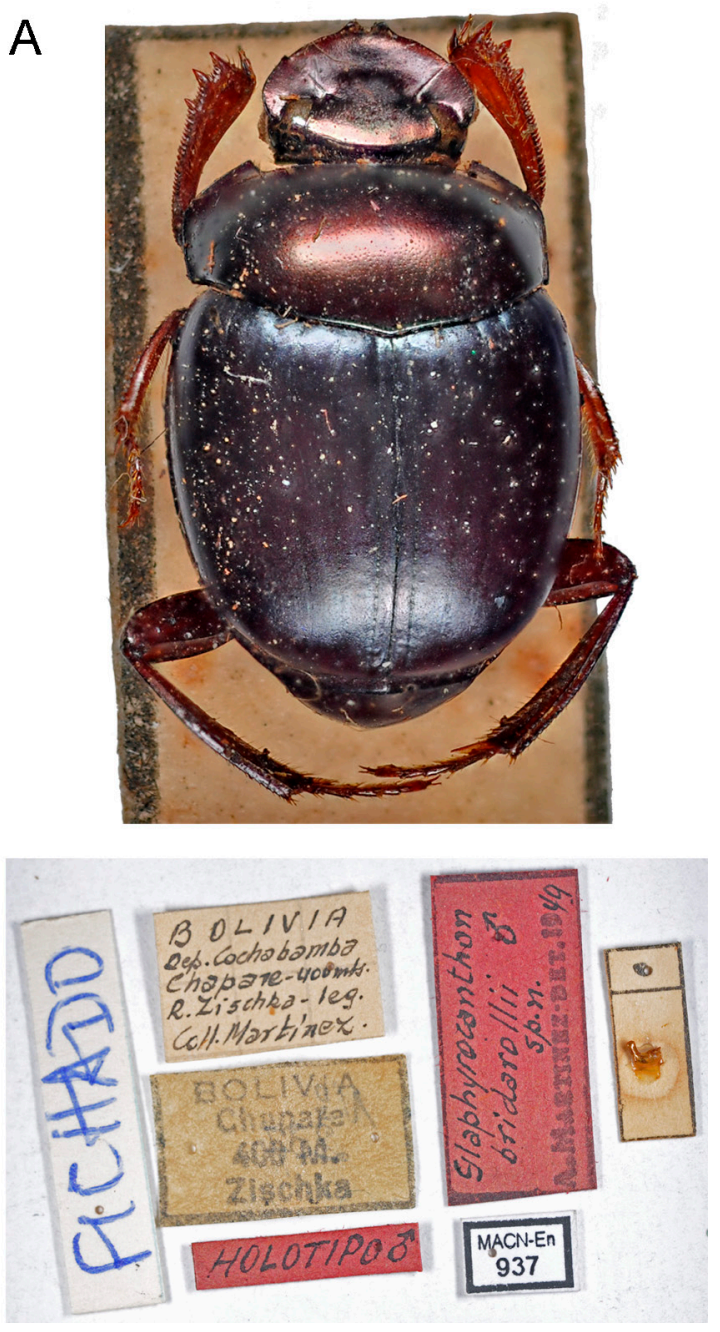
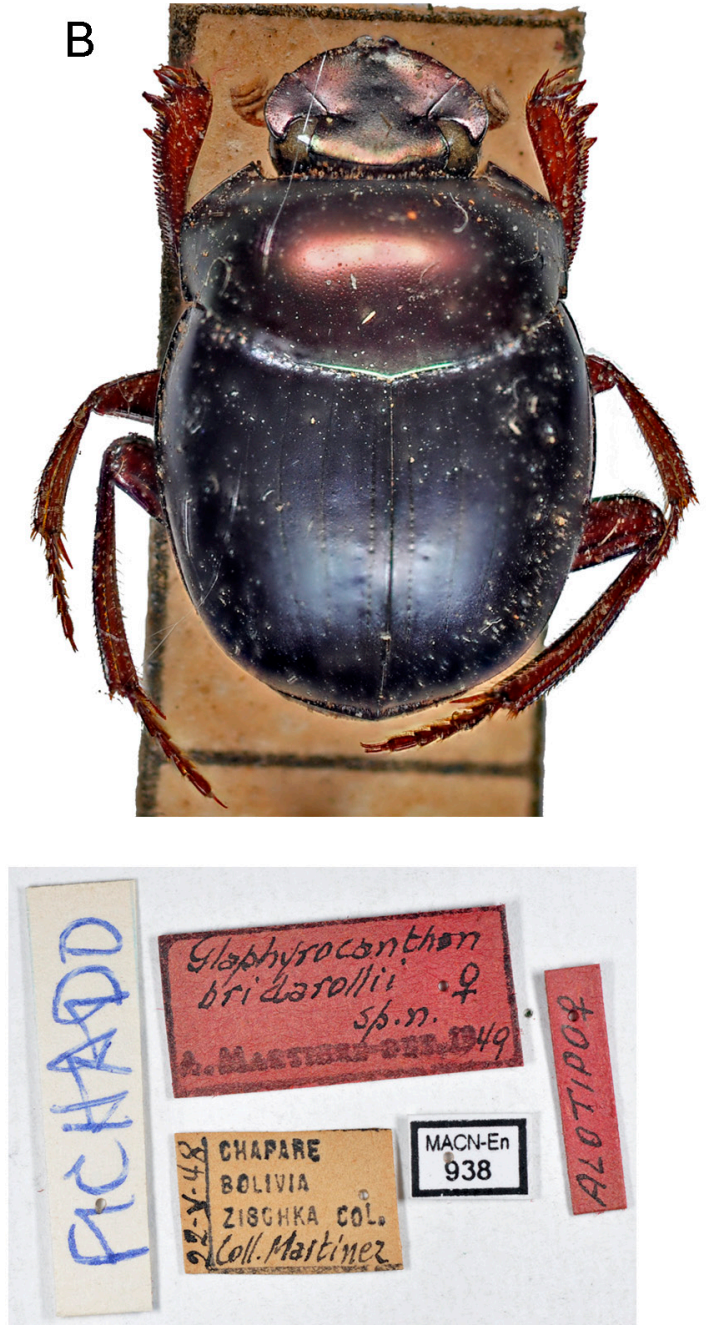

Fig. 33. Sylvicanthon bridarollii (Martínez, 1949) type material. A. Holotype and its labels. B. Allotype and its labels. 


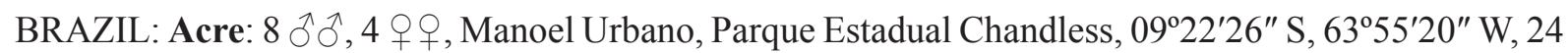

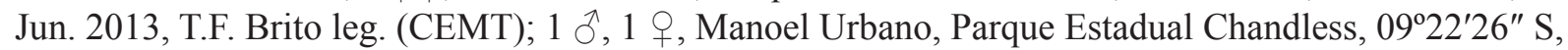

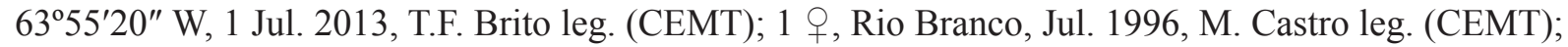
1 ò, 1 q, Senador Guiomard, $67^{\circ} 37^{\prime} \mathrm{W}, 10^{\circ} 04^{\prime} \mathrm{S}, 14$ Apr. 2017, pitfall W ith human faeces, Bruna S.

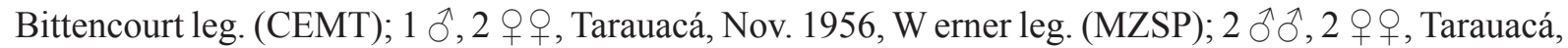
Dec. 1956, Dirings leg. (MZSP); 5 $\widehat{\partial}, 3$ 3 + $q$ (1 dissected), Xapuri, Reserva Chico Mendes, 500 m, 19 Oct. 2008, Rafael Andrade leg. (CEMT); 1 `’, Xapuri, Reserva Chico Mendes, $10^{\circ} 17.607^{\prime} \mathrm{S}, 68^{\circ} 41.638^{\prime} \mathrm{W}$, 500 m, 20 Oct. 2008, pitfall W ith human faeces, J. Silveira leg. (CEMT). - Rondônia: 1 o, 1 ․ Cacoal, Loteamento Pichek, $11^{\circ} 26^{\prime} 26^{\prime \prime} \mathrm{S}, 61^{\circ} 25^{\prime} 22^{\prime \prime} \mathrm{W}, 228 \mathrm{~m}, 14 \mathrm{Jan} .2017$, pitfall W ith human faeces, R. Silva

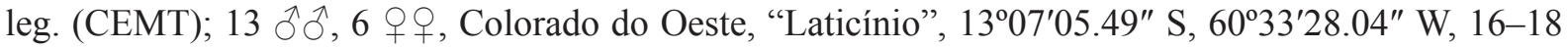
Dec. 2016, pitfall W ith human faeces, C.B.S. Souza leg. (CEMT); $6 \hat{\jmath} \widehat{\lambda}, 3$ q $q$, Colorado do Oeste, "Laticínio", 1307'05.49" S, 60³3'28.04" W, 20-22 Feb. 2017, pitfall W ith human faeces, C.B.S. Souza

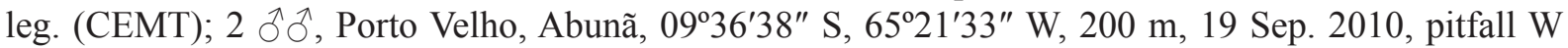
ith human faeces, J.C.F. Falcão leg. (CEMT); 1 đ’, 1 क, Porto Velho, ESEC Cuniã, 08 04'11.82" S, $63^{\circ} 28^{\prime} 34.64^{\prime \prime} \mathrm{W}, 83 \mathrm{~m}, 10-12$ Nov. 2013, pitfall W ith human faeces, M.A.P.A. Silveira leg. (CEMT); 2 우, Porto Velho, Nova Mutum-Paraná ["Mutum”], 09³5'46" S, 6502'27" W, Jan. 2012, R.V. Nunes

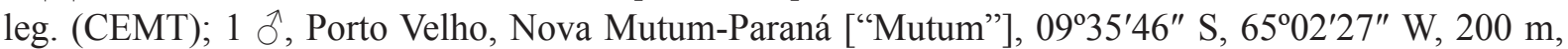

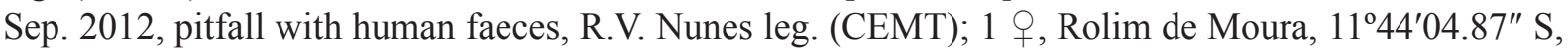
$61^{\circ} 55^{\prime} 08.64^{\prime \prime} \mathrm{W}, 214 \mathrm{~m}, 27-29$ Jul. 2015, pitfall with human faeces, D.C. Castro leg. (CEMT); 1 \%,

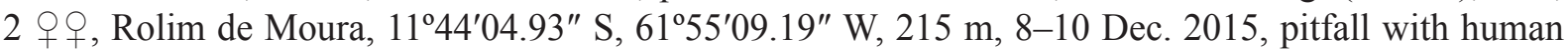

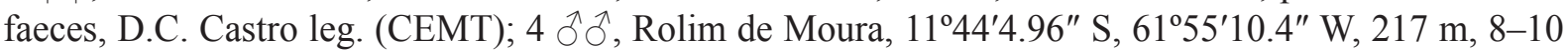

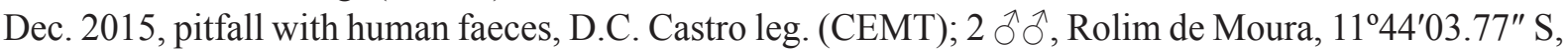
61 ${ }^{\circ} 55^{\prime} 09.74^{\prime \prime} \mathrm{W}, 218 \mathrm{~m}, 27-29 \mathrm{Jul} .2015$, pitfall with human faeces, D.C. Castro leg. (CEMT); 1 ô, 1 q, Rolim de Moura, $11^{\circ} 44^{\prime} 03.77^{\prime \prime}$ S, 61 ${ }^{\circ} 55^{\prime} 09.74^{\prime \prime} \mathrm{W}, 218 \mathrm{~m}, 8-10$ Dec. 2015, pitfall with human faeces,

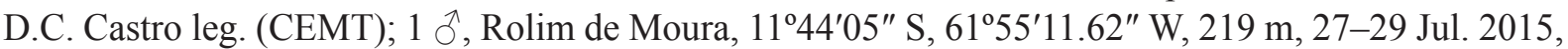

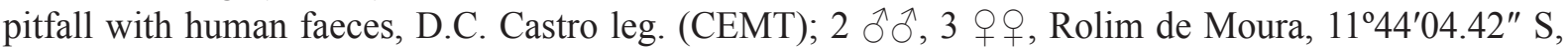
61 $55^{\prime} 11.59^{\prime \prime} \mathrm{W}, 220 \mathrm{~m}, 8-10$ Dec. 2015, pitfall with human faeces, D.C. Castro leg. (CEMT); 1 \%,

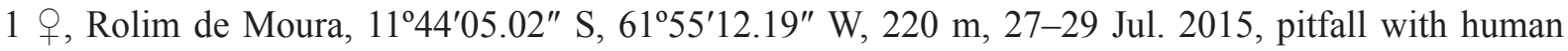

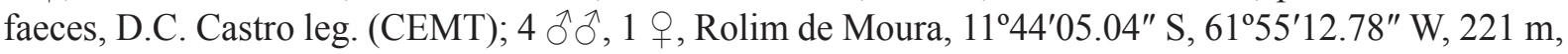

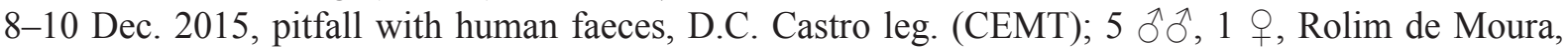
$11^{\circ} 44^{\prime} 04.48^{\prime \prime} \mathrm{S}, 61^{\circ} 55^{\prime} 12.75^{\prime \prime} \mathrm{W}, 222 \mathrm{~m}, 8-10$ Dec. 2015, pitfall with human faeces, D.C. Castro leg.

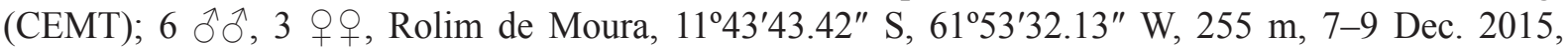

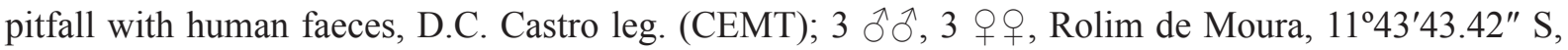
61 ${ }^{\circ} 53^{\prime} 32.13^{\prime \prime} \mathrm{W}, 255$ m, 27-29 Jul. 2015, pitfall with human faeces, D.C. Castro leg. (CEMT); 2 우,

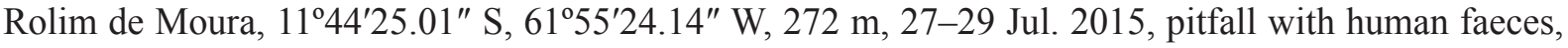

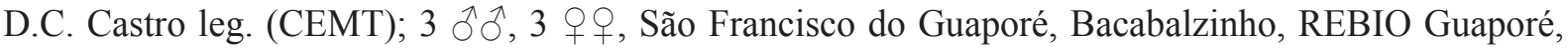

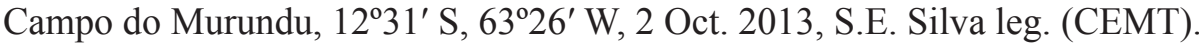

COLOMBIA: Caquetá: 1 đ (dissected), Parque Nacional Natural Sierra de Chiribiquete, $300 \mathrm{~m}$, pitfall with human faeces, Feb. 2000, J. Noriega leg. (CPJN).

ECUADOR: Morona Santiago: $3 \widehat{\partial} \widehat{\partial}$ (1 dissected), Untsuants, Sítio 1, 700 m, 8 Dec. 2001, J. Celi and J. Torres leg. (CMNC); 1 đ, Untsuante, Sítio 3, 700 m, 19 Jan. 2002, pitfall with human faeces, J. Celi and M. Ortega leg. (CMNC); 4 $\widehat{\partial}$, Untsuante, Sítio 5, 600 m, 22 Jan. 2002, J. Celi and M. Ortega leg.

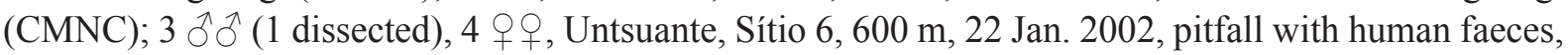
J. Celi and M. Ortega leg. (CMNC). - Napo: 1 , Jatun Sacha Biological Station, $21 \mathrm{~km}$ E of Puerto Napo, 400 m, 8 Jul. 1994, dung trap, F. Génier leg. (CMNC); 2 đ̂̃ 1 क , Puerto Misahualli, Jungle Hotel, 8-20 Sep. 1997, D.G. Marqua leg. (TAMU); 3 $\partial^{\top}, 7$ 우, Tena, 400 m, 15-21 Feb. 1986, human faeces

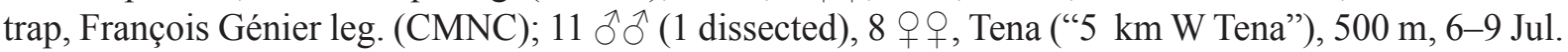

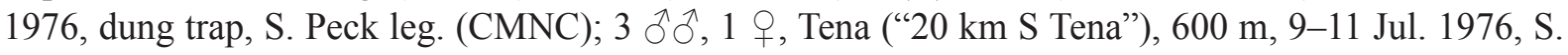


Peck leg. (CMNC). - Orellana: $2{ }^{\lambda}{ }^{\lambda}\left(1\right.$ dissected), 1 ㅇ, Tiputini Biodiversity Station, $0^{\circ} 38^{\prime} \mathrm{S}, 76^{\circ} 09^{\prime} \mathrm{W}$, 220 m, Sep. 2000, carrion trap, D. Inward leg. (BMNH). - Sucumbíos: 1 ð (dissected), Shushufindi, Reserva Biológica Limoncocha ("Limoncocha"), 0²8' S, 76³6' W, 300 m, 31 Mar. 1974, H.P. Stockwell

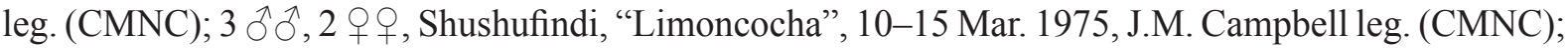
3 ふ઼ે, 5 우, Shushufindi, "Limoncocha”, 250 m, 18-24 Jun. 1976, dung trap, S. Peck leg. (CMNC).

PERU: 1 ô, "Peru mont. / O. Thieme V." (ZMHB, labelled as Syntype of Canthon obscurus by the ZMHB Staff, but, very likely, a pseudotype). - Amazonas: 1 + , Rodríguez de Mendoza, Quebrada Huancabamba, 06 $35^{\prime} 30^{\prime \prime}$ S, 77³3.2' W, 2360 m (“2100m”), 14 Jun.-23 Jul. 2010, D. Chunga leg. (MUSM). - Cuzco: 1 q,La Convención, Echarate, Centro Poblado Tunquio, $12^{\circ} 15^{\prime} 44.30^{\prime \prime} \mathrm{S}$, 72 52'37.08" W, 960 m, 26 Sep.-1 Oct. 2010, C. Carranza and S. Cavero leg. (MUSM); 1 đ, 1 ㅇ, La Convención, Echarate, Comunidad Tupac Amaru, 1206'49.78" S, 7249'35.47" W, 371 m, 22 Oct. 2009, M. Alvarado and E. Rázuri leg. (MUSM); 1 đ, La Convención, Echarate, Comunidad Tupac Amaru, $11^{\circ} 56^{\prime} 52.58^{\prime \prime} \mathrm{S}, 72^{\circ} 54^{\prime} 50.06^{\prime \prime} \mathrm{W}, 536 \mathrm{~m}, 17-19 \mathrm{Jan} .2010$, C. Espinoza and E. Razuri leg. (MUSM); 1 ○,

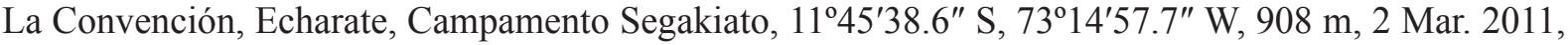
M. Alvarado and E. Rázuri leg. (MUSM); 1 § , 1 †,La Convención, Echarate, Campamento Segakiato,

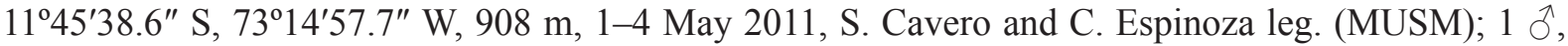

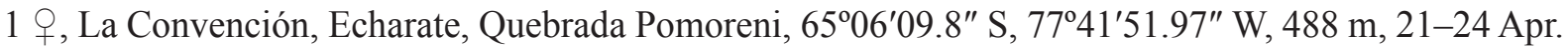
2010, L. Figueroa and D. Chunga leg. (MUSM). - Huánuco: 1 \&, Estación Biológica Panguana (Forschungsstation Panguana), Rio Pachitea, Rio Yuyapichis, 09 $37^{\prime}$ S, 74 $56^{\prime}$ W, 260 m, 28 Aug.-

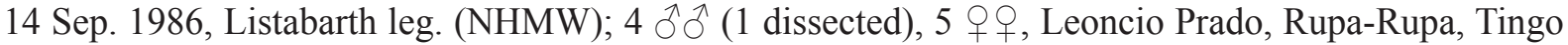
María, Universidad Nacional Agraria de la Selva ("Tingo María Universidad”), Jul. 1974 (CMNC); 1 ठૈ, 2 우, Leoncio Prado, Rupa-Rupa, Tingo María, Universidad Nacional Agraria de la Selva Dec. 1974

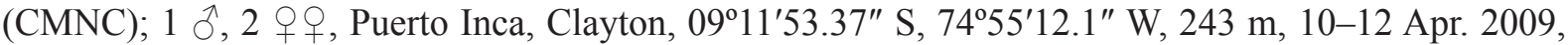

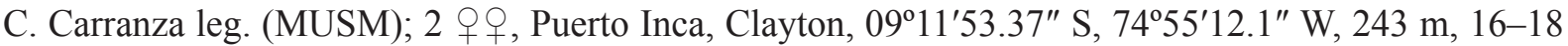

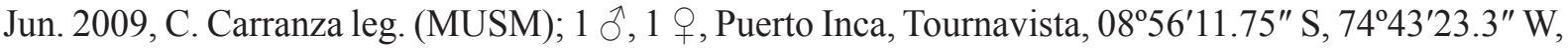

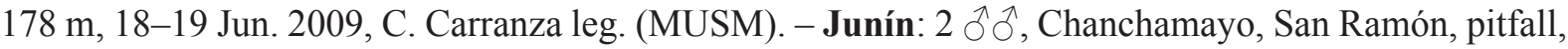
F.G. Horgan leg. (MUSM); 1 §, Chanchamayo, San Ramón, May 2002, human faeces pitfall, F.G. Horgan leg. (MUSM); 1 §, 1 , Chanchamayo, San Ramón, 8 May 2002, human faeces pitfall, F.G. Horgan leg. (MUSM); 1 § , 5 q $q$, Chanchamayo, San Ramón, 17 May 2002, human faeces pitfall, F.G. Horgan leg. (MUSM); 1 (dissected), 2 우, Chanchamayo, San Ramón, Oct. 2002, human faeces pitfall, F.G. Horgan leg. (MUSM); 1 đે, Chanchamayo, San Ramón, Oct. 2002, human faeces pitfall, F.G. Horgan leg. (MUSM); 1 + , Chanchamayo, San Ramón, Catarata El Tirol ("El Tirol”), 820-1000 m, Jul. 2000,

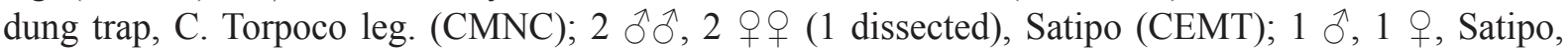

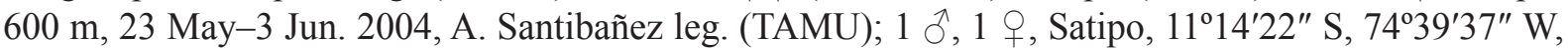
1008 m, 28 Aug.-2 Sep. 2011, I. Medina and L. Figueroa leg. (MUSM). - Loreto: 1 ô, Alto Amazonas, Teniente César López Rojas, 02³5'39.6" S, 7606'55" W, 230-305 m, 18-26 Jul. 1993, flight interception trap, R. Leschen leg. (CMNC); 3 đ̋ ,Reserva Nacional Pacaya Samiria, Rio Samiria, Cocha Shinguito,

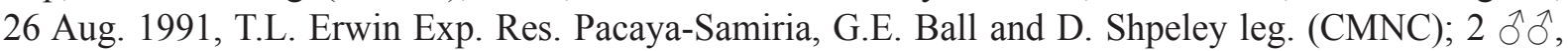
Reserva Nacional Pacaya Samiria, Rio Samiria, Cocha Shinguito, 26-29 Aug. 1991, T.L. Erwin Exp. Res. Pacaya-Samiria, G.E. Ball and D. Shpeley leg. (CMNC); 1 + , Zona Reservada Sierra del Divisor, $07^{\circ} 04^{\prime} 01^{\prime \prime} \mathrm{S}, 74^{\circ} 01^{\prime} 21^{\prime \prime} \mathrm{W}, 213 \mathrm{~m}, 16-19$ Feb. 2009, C. Espinoza leg. (MUSM); 1 ô, 1 क, Zona Reservada Sierra del Divisor, 2 km from Rio Hubuya, 196 m, 13-14 Oct. 2008, C. Carranza leg.

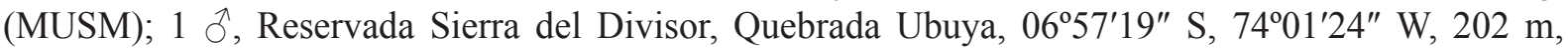
2-3 Mar. 2009, C. Espinoza leg. (MUSM). - Madre De Díos: 2 đิึ, Manu, Manu, Salvación

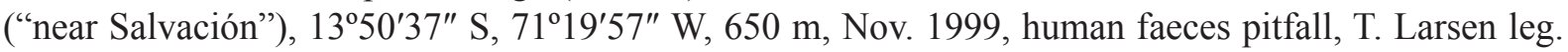
(CMNC); 3 ภำ (1 dissected), 4 우우, Manu, Parque Nacional del Manu ("Manu National Park"), 15-

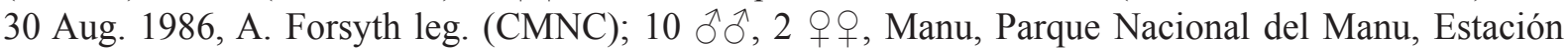
Biológica Cocha Cashu, 11 ${ }^{\circ} 55^{\prime}$ S, $77^{\circ} 18^{\prime}$ W, 380 m, 18 Aug. -5 Sep. 1986, D.C. Darling \& A.B. Forsyth

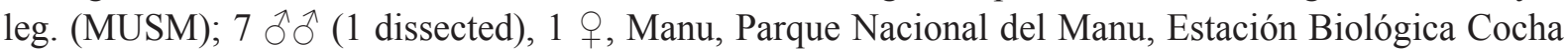




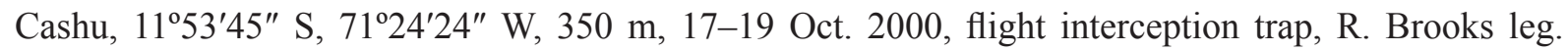

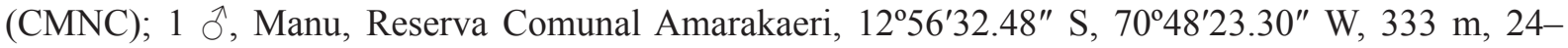
26 Oct. 2010, J. Costa and M. Vilchez leg. (MUSM); 1 , Río Patuyacu, Oculto Camp, 12³9'00" S, 68 55'33" W, 400 m, 25-26 Mar. 1999, human faeces pitfall, T. Larsen leg. (MUSM); 1 +, Tambopata, 290 m, 21 Mar. 1987, pitfall, P. Lozada leg. (MUSM); 1 §, 2 우우, Tambopata, Las Piedras, fundo vivero El Bosque, 12²7'49.27" S, 6907'30.69" W, 17-19 Apr. 2011, O. Huaches leg. (MUSM); 1 + , Tambopata,

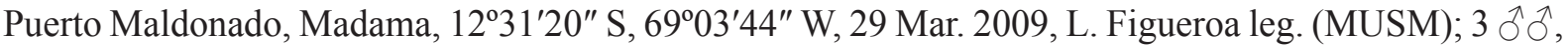

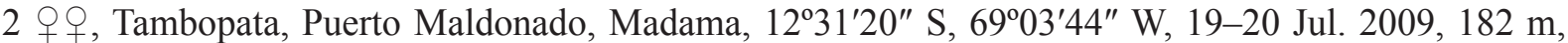

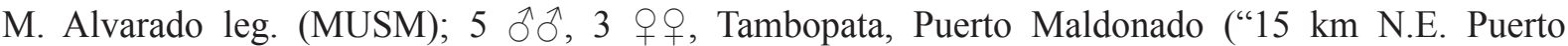
Maldonado"), Reserva Cuzco Amazonica, 12³3' S, 6903' W, 200 m, 13 Jun. 1989, flight interception trap, Ashe and Leschen leg. (CMNC); 1 o, Tambopata, Puerto Maldonado ("15 km N.E. Puerto

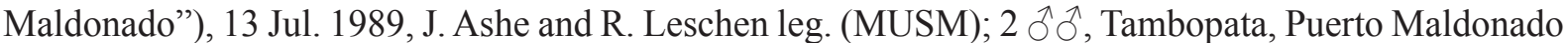
("15 km N.E. Puerto Maldonado"), 200 m, 15 Jul. 1989, J. Ashe and R. Leschen leg. (MUSM); 1 Õ,Tambopata, Puerto Maldonado ("15 km N.E. Puerto Maldonado"), 200 m, Reserva Cuzco

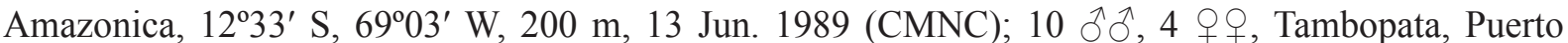
Maldonado, Reserva Cuzco Amazonica, 12³3' S, 6903' W, 200 m, 15 Jun. 1989, flight interception

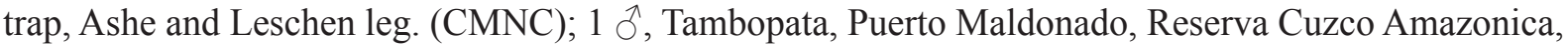
$12^{\circ} 33^{\prime} \mathrm{S}, 69^{\circ} 03^{\prime} \mathrm{W}, 200 \mathrm{~m}, 16$ Jun. 1989, flight interception trap, Ashe and Leschen leg. (CMNC);

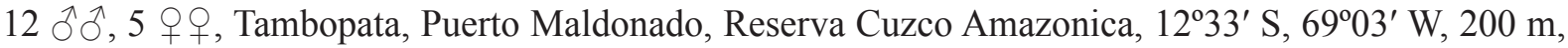

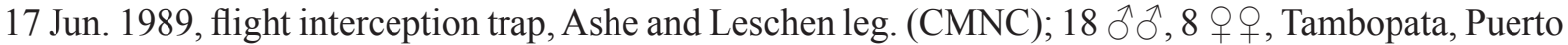
Maldonado, Reserva Cuzco Amazonica, 12³3' S, 6903' W, 200 m, 20 Jun. 1989, flight interception trap, Ashe and Leschen leg. (CMNC); 1 đ, Tambopata, Puerto Maldonado, Reserva Cuzco Amazonica, $12^{\circ} 33^{\prime} \mathrm{S}, 69^{\circ} 03^{\prime} \mathrm{W}, 200 \mathrm{~m}, 22$ Jun. 1989, flight interception trap, Ashe and Leschen leg. (CMNC);

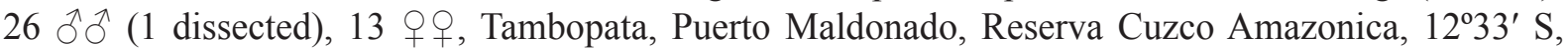

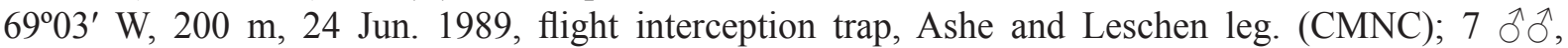
2 우, Tambopata, Puerto Maldonado, Reserva Cuzco Amazonica, 12 $2^{\circ} 33^{\prime} \mathrm{S}, 6^{\circ} 03^{\prime} \mathrm{W}, 200$ m, 26 Jun.

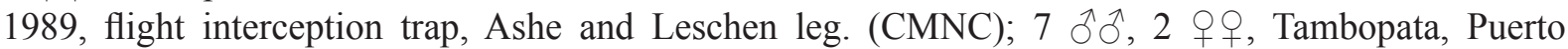

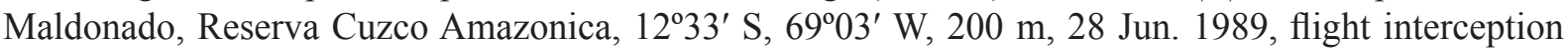

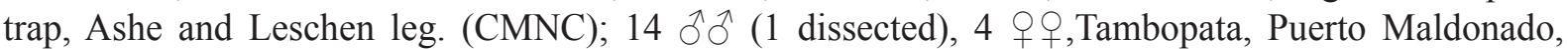

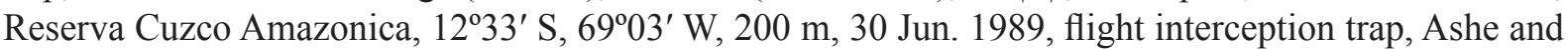

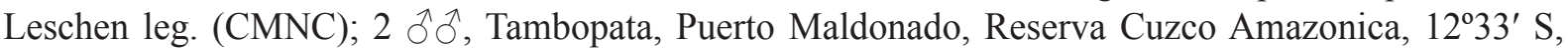

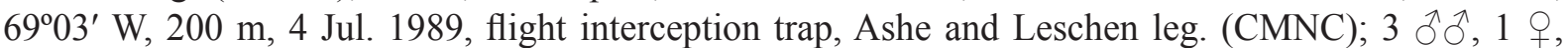
Tambopata, Puerto Maldonado, Reserva Cuzco Amazonica, 12³3' S, 6903' W, 200 m, 7 Jul. 1989, flight interception trap, Ashe and Leschen leg. (CMNC); 1 \%, Tambopata, Puerto Maldonado, Reserva Cuzco Amazonica, 12 $33^{\prime}$ S, 69 $03^{\prime}$ W, 200 m, 16 Jul. 1989, flight interception trap, Ashe and Leschen leg. (CMNC); 1 đ̆, Tambopata, Puerto Maldonado, Reserva Nacional Tambopata, 18-22 Apr. 1983, Enrique Perez leg. (MUSM); 1 o, 1 q, Tambopata, Puerto Maldonado, Reserva Nacional Tambopata ("Rio Tambopata Res. / 30 km (air) Sw. Pto. Malonato"), 1250' S, 69²0' W, 3 Oct. -15 Nov. 1983, 290 m, N.E. Stork leg. (BMNH); 1 ô, Tambopata, Puerto Maldonado, Sector Triunfo, 69º $11^{\prime} 47^{\prime \prime}$ W, $12^{\circ} 33^{\prime} 42^{\prime \prime}$ W, 198 m, 25 Mar. 2009, L. Figueroa leg. (MUSM); 6 ๙ึ, 1 ㅇ, Tambopata, Puerto

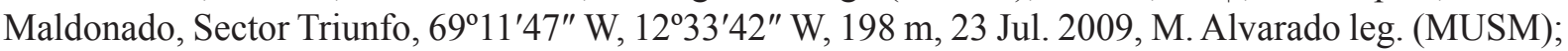

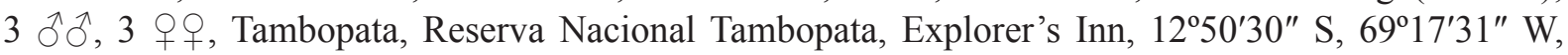
161 m, 15-18 May 2009, L. Figueroa and M. Alvarado leg. (MUSM). - Pasco: 1 $\lambda, 2$ 우, Oxapampa,

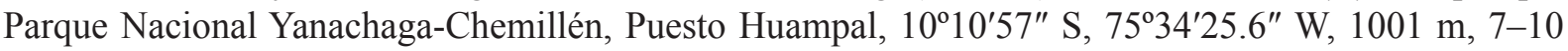
Nov. 2010, C. Carranza and J. Peralta leg. (MUSM). - San Martín: 1 ô, Picota, Pilluana, Fundo Mishquiyacu, 06 04'20.1" S, 76 58'33.8' W, 990 m, 11-12 Dec. 2008, C. Albujar leg. (MUSM). -

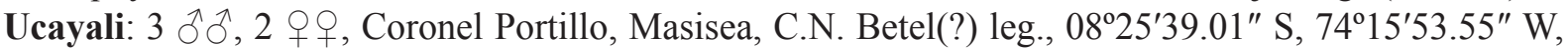
118 m, 8 Aug. 2008, C. Espinoza leg. (MUSM); 1 đ', Coronel Portillo, Puerto Alegre, 08 44'06.76" S, 7409'4.54" W, 196 m, 21-22 May 2008, L. Figueroa leg. (MUSM); 7 §ð, 7 우우, Coronel Portillo, Puerto Purin, 0804'59.2" S, 7408'19.52" W, 122 m, 19 May 2008, L. Figueroa leg. (MUSM); 1 , 
Coronel Portillo, Puerto Purin, 0844'59.2" S, 7408'19.52" W, 196 m, 21-22 May 2008, L. Figueroa

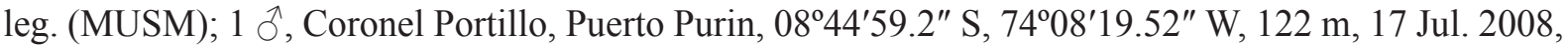
L. Figueroa leg. (MUSM); 1 ô, Coronel Portillo, Río Inamapuya, 08²4'33.7" S, 7406'15.9" W, 135 m, 11-12 Jul. 2008, M. Alvarado leg. (MUSM); 1 స, 1 ㅇ, Padre Abad, Irázola, Alexander von Humboldt,

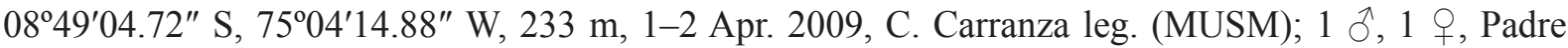

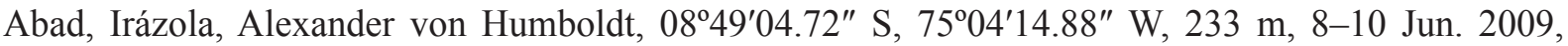
C. Carranza leg. (MUSM).

Ambiguous data: PERU?: 1 ô, “7-8.XI.87 / CUPERJALF” (MUSM).

Erroneous data: BRAZIL: Pará: 1 đ (dissected), Itaituba, Rio Tapajós, Mar. 1964, Dirings leg. (MZSP); 1 q, Redenção, Pinkaiti-Aik, 07046' S, 51ํ5' W, Nov. 1999, P.Y. Scheffler leg. (CEMT).

\section{Redescription}

Colouration. Head and pronotum dark purple or coppery; occasionally, with weak greenish reflections. Elytra dark green or dark blue; when green, striae sometimes with dark blue colouration and slightly more contrasting with elytral tegument. Metaventrite black or coppery; usually with slight greenish reflections. Meso- and metafemora ranging in a north-south cline from dark brown (Bolivia) to reddishbrown (Peru and Brazil) and orangish or yellowish (northern Peru, Ecuador, and Colombia), but base always distinctly darker than at least apical two-thirds. Pygidium, sometimes, with shine predominantly greenish and with some coppery reflections, especially at base.

HEAD. Tegument with little shine, with strong alveolar microsculpture obliterating almost completely micropunctation which is almost imperceptible or even absent across the outer edge of head. Clypeus with two apical teeth obtuse and only slightly separated from one another; with a single transverse row of short setae covering base of both teeth. Genae with strong tooth just behind clypeal-genal juncture. Posterior edge of head without margin between eyes, or margin very fine and tenuous.

THORAX. Pronotum with tegument with diffuse shine and alveolar microsculpture very fine and strongly marked obliterating micropunctation, which is usually very weak at centre and completely absent on sides. Posterior edge may have an evident fine transverse line at centre (generally extending beyond second elytral stria), or transverse line very tenuous and short, or even absent. Hypomeral cavity with long yellowish setae at centre (Fig. 35C); external margin with weak tubercle. Metaventrite glabrous, including lateral region; tegument with strong rivose microsculpture on anterior region and adjacent to internal margin of mesocoxae and with strong alveolar microsculpture and fine micropunctation at centre and on posterior region.

Legs. Ventral surface of all femora and tibiae with diffuse shine. Profemora with tegument with strong rivose microsculpture and without micropunctation (Fig. 9A). Protibiae narrow and with expansion on internal edge, which can be evident (southern populations in Bolivia and Peru, Fig. 11F), or only slightly indicated (especially in Ecuador and Colombia, Fig. $11 \mathrm{G}$ ); at their apical third, external edge with three small acute teeth on external edge, two apical ones of subequal size and longer than the basal. Mesofemora margined anteriorly only at their basal half; unmargined portion of anterior edge with row of very short setae; posterior margin absent; tegument with strong rivose microsculpture. Metafemora margined only anteriorly, posterior margin absent; apical half of anterior edge covered by row of setae; tegument entirely covered by strong rivose microsculpture and with coarse elongate punctation at base geographically variable: individuals from southern populations in Bolivia with coarse punctation evident (Fig. 13G) which becomes progressively finer and imperceptible northwards until being completely absent in populations in Ecuador and Colombia (Fig. 13H). Metatarsomeres II and V subequal in length and longer than the others; metatarsomere IV shorter than the others. 
ELYTRA. With at most nine visible striae: in general, the first two to four striae well marked, finely carinulate, and without basal widening; remaining striae progressively more effaced and interrupted; eighth and ninth striae observable only in specimens with well-marked striae and, in those cases, always very subtle; all striae lack their carinulae before reaching the apex of elytra, where they are completely indistinct; humeral carina absent. Tegument of interstriae with diffuse shine, with strong alveolar microsculpture throughout its surface; micropunctation obliterated by microsculpture and almost imperceptible.

AbDomen. Ventrite VI with rivose microsculpture diffuse at centre and weak on the sides; both sexes without lateral foveae. Pygidium with tegument with diffuse shine and entirely covered by alveolar microsculpture; micropunctation, if present, completely obliterated by microsculpture and difficult to see.

AEDEAGus. Parameres at least half as long as phallobase and symmetrical, both faces flat. In lateral view, parameres simple, with truncate apex and without ventral keel or notch (Fig. 18A).

SeXual dimorphism. Males: Protibial spur narrow and widely bifid at apex, with spiniform projections, the external projection much longer than the internal one (Fig. 15I). Ventrite VI with posterior edge strongly narrowed at middle; anterior edge covered very slightly by weak medial expansion of ventrite $\mathrm{V}$. Females: Protibial spur simple, spiniform. Ventrite VI much wider at middle; anterior edge subtly covered by weak medial expansion of posterior edge of ventrite $\mathrm{V}$.

\section{Measurements}

Males (N =14). TL: AV: $8.1 \pm 0.76$; MX: 9.2; MN: 6.6. EW: AV: $5.7 \pm 0.43$; MX: 6.3; MN: 4.8. PrL: AV: $2.4 \pm 0.27$; MX: 3.0; MN: 1.9. PrW: ME: $4.8 \pm 0.83$; MX: 5.5; MN: 2.2. PgL: ME: $1.4 \pm 0.10$; MX: 1.5; MN: 1.2. PgW: AV: $2.3 \pm 0.24 ; \mathrm{MX}: 2.6 ; \mathrm{MN}: 2.0$.

Females $(\mathrm{N}=12)$. TL: AV: $8.1 \pm 0.54$; MX: 8.9; MN: 7.5. EW: AV: $5.6 \pm 0.48$; MX: 6.4; MN: 4.9 . PrL: ME: $2.4 \pm 0.26$; MX: 2.9; MN: 2.1. PrW: AV: $4.9 \pm 0.43$; MX: 5.6; MN: 4.3. PgL: ME: $1.2 \pm 0.11$; MX: 1.5; MN: 1.1. PgW: AV: $2.3 \pm 0.25 ;$ MX: 3.0; MN: 2.1 .

\section{Geographical distribution}

Western Amazonia in Colombia, Ecuador, Brazil, Peru, and Bolivia.

\section{Ecoregions}

Llanos, Caquetá Moist Forests, Napo Moist Forests, Cordillera Oriental Montane Forests, Iquitos Varzea, Ucayali Moist Forest, Peruvian Yungas, Southwest Amazon Moist Forests, Bolivian Yungas, Bolivian Montane Dry Forest, Chiquitano Dry Forests.

\section{Collecting sites (Fig. 34)}

COLOMBIA. Meta: Puerto Colombia. Caquetá: Parque Nacional Natural Sierra de Chiribiquete. Guaviare: San José del Guaviare (Parque Nacional Natural Nukak).

ECUADOR. Sucumbíos: Shushufindi (Reserva Biológica Limoncocha). Napo: Reserva Biológica Jatun Sacha, Puerto Misahualli, Tena. Orellana: Tiputini Biodiversity Station. Morona Santiago: Cordillera Cutucú, Untsuants.

PERU. Loreto: Alto Amazonas (Teniente César López Rojas), Reserva Nacional Pacaya Samiria, Zona Reservada Sierra del Divisor. Amazonas: Rodríguez de Mendoza (Quebrada Huancabamba). San Martín: Picota (Pilluana: Fundo Mishquiyacu). Ucayali: Coronel Portillo (Puerto Alegre, Puerto Purin), Padre Abad (Irázola: Alexander von Humboldt). Huánuco: Estación Biológica de Panguana, Leoncio Prado (Rupa-Rupa: Tingo María), Puerto Inca. Pasco: Oxapampa (Parque Nacional Yanachaga- 
Chemillén). Junín: Chanchamayo (San Ramón), Satipo. Cuzco: La Convención (Echarate, Santuario Nacional Megantoni). Madre de Díos: Manu (Manu: Salvación; Parque Nacional del Manu: Estación Biológica Cocha Cashu; Reserva Comunal Amarakaeri), Tambopata (Las Piedras; Puerto Maldonado: Madama, Reserva Cuzco Amazonica, Reserva Nacional Tambopata, Sector Triunfo).

BRAZIL. Acre: Manoel Urbano (Parque Estadual Chandless), Rio Branco, Senador Guiomard, Tarauacá, Xapuri (Reserva Extrativista Chico Mendes). Rondônia: Cacoal, Porto Velho, Rolim de Moura, São Francisco do Guaporé.

BOLIVIA. Beni: Mamoré (San Ramón). La Paz: Larecaja (Guanay), Nor Yungas (Coroico), Parque Nacional Madidi. Cochabamba: Cercado (Cochabamba), Chapare (Villa Tunari), Estación Biológica Villa Carmen, José Carrasco (Chimoré). Santa Cruz: Andrés Ibáñez (Santa Cruz de la Sierra), Ichilo (Buena Vista), Obispo Santistevan (General Saavedra).

\section{Intraspecific variation and taxonomic discussion}

Although the four species composing the bridarollii subgroup are very similar to one another, S. bridarollii is precisely the one that we can more readily differentiate from the others. The following characteristics are unique to $S$. bridarollii in its subgroup: pronotum and pygidium with alveolar microsculpture strongly marked and with a very weak micropunctation, which, in general, is indistinct; hypomeral cavity with long setae at centre (Fig. 35C-D); metaventrite with a strong alveolar microsculpture at centre; protibiae with internal margin expanded at their apical half (Fig. 11F-G; see below discussion about the geographical variation of this character); and parameres elongated, simple (i.e., without any ventral keel or notch) and symmetric, both with external faces equally flat (Fig. 18A). Furthermore, the metafemora with a dark brown colour and with well-impressed coarse punctures at base is a characteristic exclusive of the southern populations of $S$. bridarollii (Fig. 13G; see more details below).

As can be seen on the map of Fig. 34, S. bridarollii is distributed parallel to the Andes throughout western Amazonia, in altitudes between 100 and $2360 \mathrm{~m}$. The only representative of the bridarollii subgroup with which it is never found in sympatry is $S$. seag sp. nov., a species exclusive to the northern Amazon region. Apart from the characteristics listed above, these two species are different by the head and pronotal micropunctation, shape of the male protibial spur (Fig. 15I-J), shape of ventrites $\mathrm{V}$ and VI of females, the tegument of pygidium and, especially, the totally distinct shape of the parameres (Fig. 18A-B) (see Table 4). Pronotum and elytra with a bright green or dark blue colouration typical of the northern populations of $S$. seag sp. nov. (Fig. 37B-C) are not seen in S. bridarollii; on the other hand, specimens of S. seag sp. nov. collected on the banks of the Amazon River and in Maranhão have a similar colouration to the one observed in S. bridarollii (Fig. 37A).

The other two species of the bridarollii subgroup, S. edmondsi sp. nov. and S. attenboroughi sp. nov., by contrast, can be found in sympatry with $S$. bridarollii, respectively, in Colombia, Ecuador and Peru, and in Brazil and Peru. From S. edmondsi sp. nov., S. bridarollii can be promptly differentiated by its dorsal colouration (Figs 32A, C, 38A) and the shape of its parameres (Fig. 18A, C), but the populations of both species also differ in the average of the total body length (Table 3). It is worth noting that Celi et al. (2004), having placed pitfall traps across an altitudinal gradient in Morona Santiago (Ecuador), collected twice as many specimens of $S$. edmondsi sp. nov. (116) as of $S$. bridarollii (57) (the former species was collected at altitudes between 600 and $1000 \mathrm{~m}$ and the latter between 500 and $900 \mathrm{~m}$ ); at one point at $700 \mathrm{~m}$ altitude, they collected $114 \mathrm{~S}$. edmondsi sp. nov. vs only $25 \mathrm{~S}$. bridarollii. In order to test whether this result is indeed a real general pattern of relative abundance between these two species, it would be interesting if future ecological works evaluated other sympatric populations of S. bridarollii and $S$. edmondsi sp. nov. Finally, S. attenboroughi sp. nov. is the species most similar to S. bridarollii. Nevertheless, both species are distinguished by the unique characteristics of $S$. bridarollii 
listed above and also by the degree of excavation of the hypomeral cavity (Fig. 35B-C) and by the head micropunctation (Table 3).

Within Sylvicanthon, S. bridarollii is the species that shows the most remarkable form of morphological variation, which is intimately associated with the species' geographical distribution in a clear northsouth cline (Fig. 36). Colouration and presence of coarse punctures on femora, shape of protibiae, and the presence of a fine transverse line on the posterior edge of the pronotum vary along this cline in the following way: individuals from southern populations in the Bolivian provinces of Santa Cruz and Cochabamba have meso- and metafemora black at the base and dark brown on the rest of their surface, metafemora with strong, coarse punctures of irregular shape at their base (Fig. 13G), protibiae with internal margin with an evident expansion at their apical half (Fig. 11F) and pronotum without any trace of a transverse line on its posterior edge. Towards the north of Bolivia, in places like Guanay and the Madidi National Park (province of La Paz) and southern Peru, in the Madre de Díos region, the colouration of meso- and metafemora becomes lighter, being dark brown or reddish-brown; the metafemur punctures are shallower and sparser (in southern Peru, they are almost imperceptible); and the posterior edge of the pronotum starts to show some indications of a medial transverse line; the protibiae, on the other hand, continue to be essentially similar to the shape seen farther south. In central Peru, in the regions of Cuzco, Junín, Pasco, Huánuco, Ucayali, Amazonas and San Martínez, and, in a lesser degree, in the states of Acre and Rondônia, Brazil, individuals have clearly bicolour meso- and metafemora, with a dark brown basal area and the rest of the surface reddish-brown; the punctures at the base of the

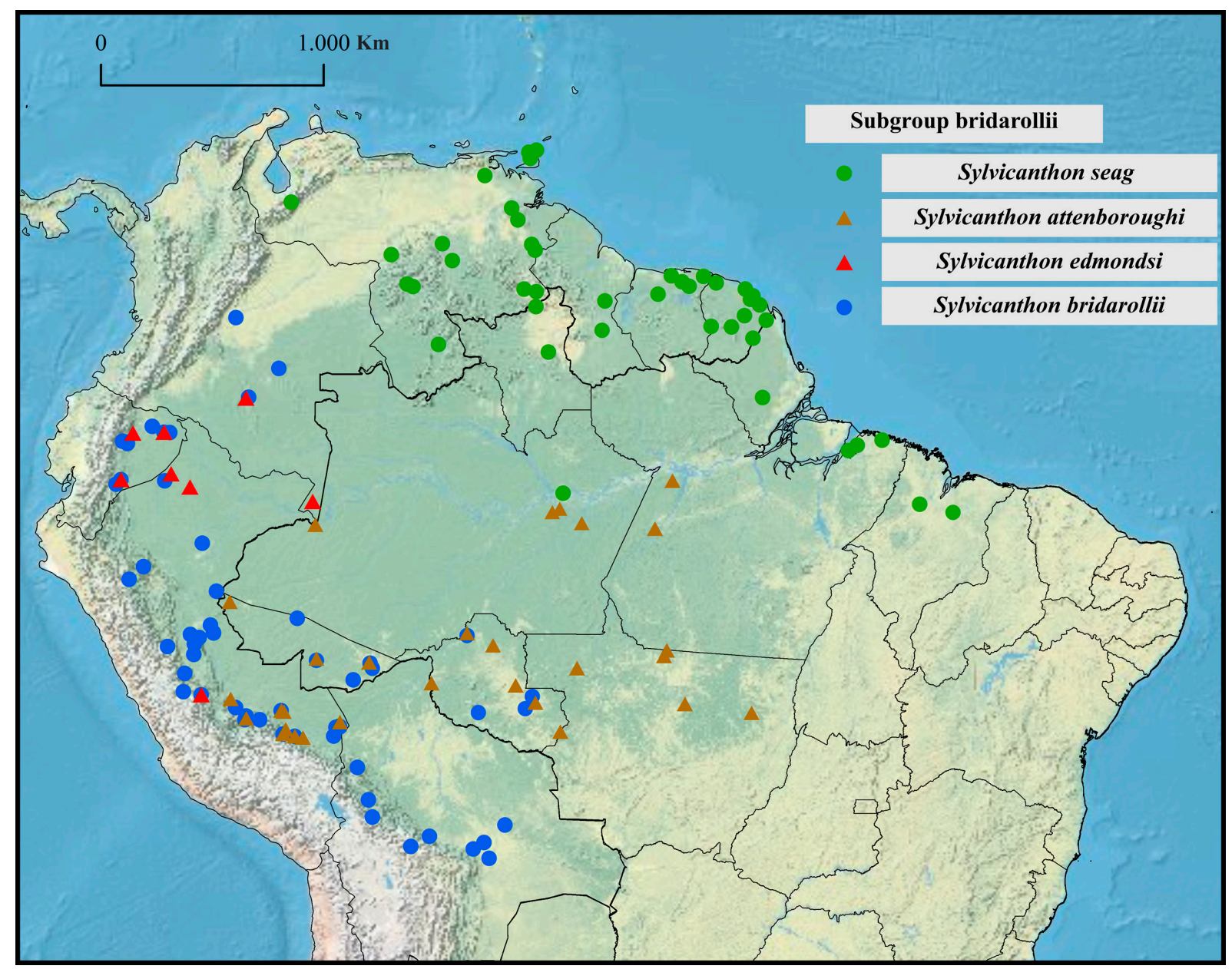

Fig. 34. Distribution of the four species of the bridarollii subgroup. 
metafemora are very tenuous and almost imperceptible; in most of the specimens, the transverse line on the posterior edge of the pronotum is clearly seen; and the internal expansion of the protibiae becomes less pronounced. Then, from Zona Reservada Sierra del Divisor, in the Peruvian region of Loreto, north to Ecuador and Colombia, specimens have meso- and metafemora with a much lighter colouration pattern, the base being dark brown and the rest of the surface orange or yellowish (Fig. $13 \mathrm{H})$; the punctures at the base of the metafemora are extremely tenuous and almost imperceptible (Loreto) or totally absent (Ecuador and Colombia); and all the examined specimens show a clear transverse line on the posterior edge of the pronotum. In those northern populations, the internal expansion of the protibiae is much more tenuous than those in the southern populations (Fig. 11G). If not directly compared with the protibiae of the species that really lack any expansion (i.e., the other members of the bridarollii subgroup and those of the candezei subgroup), one might be misled to think that those populations of S. bridarollii do not possess a protibial expansion either.

Although the previous description was presented by separating the distribution of $S$. bridarollii into four distinct parts, the clinal variation found is completely continuous in that north-south axis (Fig. 36), indicating that this cline is most likely the case of a primary intergradation rather than a secondary intergradation due to secondary contact of formerly allopatric demes, although this possibility should
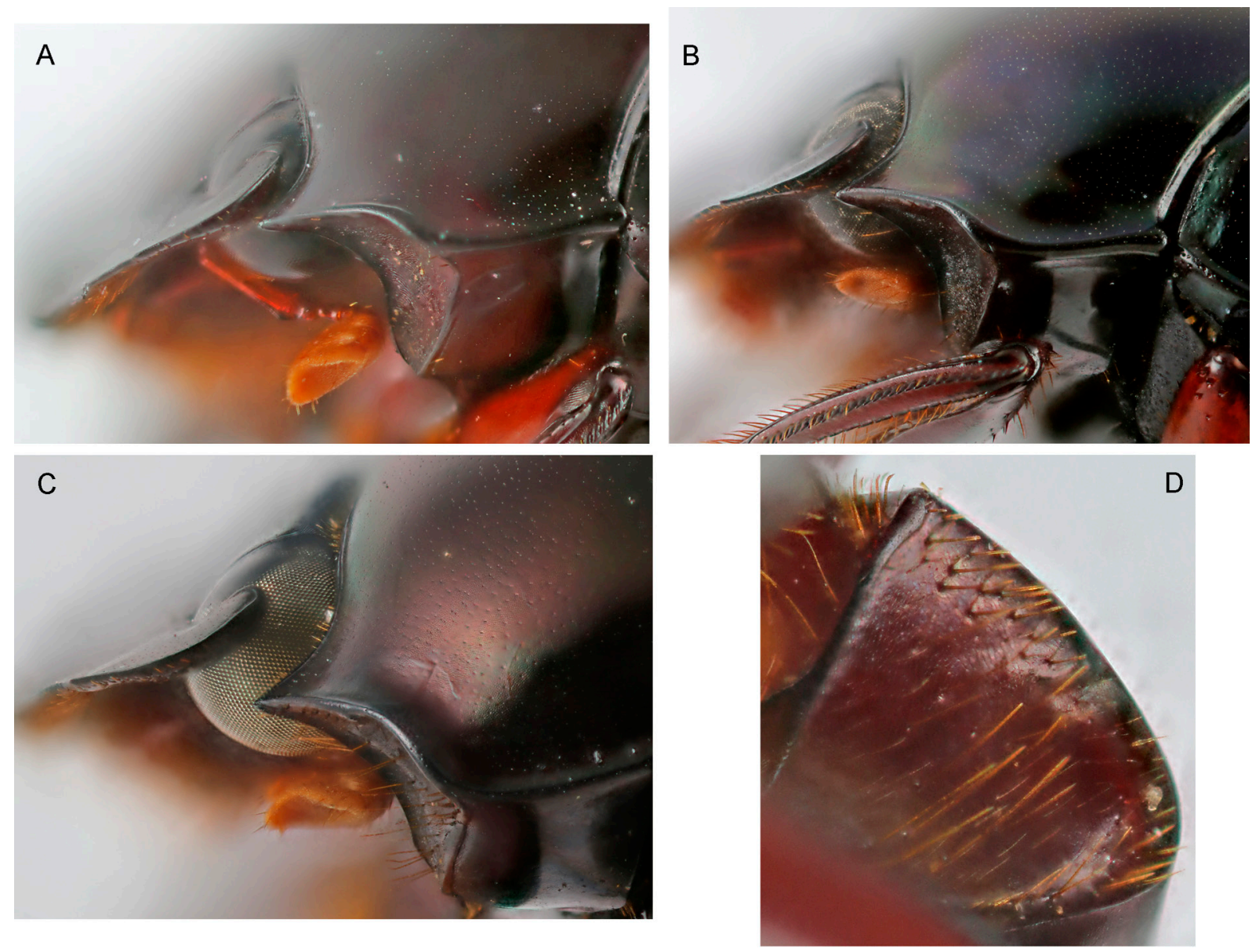

Fig. 35. Variation on the pilosity at the centre of the hypomeral cavity among members of the bridarollii subgroup. A. Sylvicanthon seag sp. nov. B. S. attenboroughi sp. nov. C-D. S. bridarollii (Martínez, 1949). Note the first two species have the hypomeral cavity entirely glabrous or with setae limited to its periphery (centre always glabrous), whereas $S$. bridarollii possesses long and dense setae throughout the tegument of the hypomeral cavity. 
Table 4 (continued on next page). Summary of the morphological and distributional differences between the four species of the bridarollii subgroup.

\begin{tabular}{|c|c|c|c|c|}
\hline & $\begin{array}{c}\text { S. bridarollii } \\
\text { (Martínez, 1949) }\end{array}$ & S. seag sp. nov. & $\begin{array}{l}\text { S. edmondsi } \\
\text { sp. nov. }\end{array}$ & $\begin{array}{l}\text { S. attenboroughi } \\
\text { sp. nov. }\end{array}$ \\
\hline Dorsal colouration & $\begin{array}{l}\text { Head and pronotum } \\
\text { purple or coppery. Elytra } \\
\text { dark green or dark blue }\end{array}$ & $\begin{array}{l}\text { Head and pronotum } \\
\text { purple, and elytra } \\
\text { greenish (southern } \\
\text { populations), or head } \\
\text { purple with greenish } \\
\text { reflexions, and pronotum } \\
\text { and elytra bright green } \\
\text { or dark blue (northern } \\
\text { populations) }\end{array}$ & $\begin{array}{l}\text { Entire body with very } \\
\text { dark tonalities; head dark } \\
\text { purple, pronotum with } \\
\text { greenish sheen at centre } \\
\text { and purplish at sides, and } \\
\text { elytra dark blue or purple }\end{array}$ & $\begin{array}{l}\text { Entire body with dark } \\
\text { tonalities; head and } \\
\text { pronotum dark purple; } \\
\text { elytra dark green or dark } \\
\text { blue }\end{array}$ \\
\hline Tegument of head & $\begin{array}{l}\text { Strong microsculpture; } \\
\text { micropunctation almost } \\
\text { imperceptible }\end{array}$ & $\begin{array}{l}\text { Strong microsculpture; } \\
\text { micropunctation evident } \\
\text { on clypeus posterior } \\
\text { region and mainly on } \\
\text { frons }\end{array}$ & $\begin{array}{l}\text { Strong microsculpture; } \\
\text { micropunctation almost } \\
\text { imperceptible }\end{array}$ & $\begin{array}{l}\text { Strong microsculpture; } \\
\text { micropunctation evident } \\
\text { on clypeus posterior } \\
\text { region and mainly on } \\
\text { frons }\end{array}$ \\
\hline $\begin{array}{l}\text { Tegument at centre } \\
\text { of pronotum }\end{array}$ & $\begin{array}{l}\text { With a diffuse, silky } \\
\text { shine; microsculpture } \\
\text { fine, but always present; } \\
\text { micropunctation, in } \\
\text { general, very weak }\end{array}$ & $\begin{array}{l}\text { Shiny and reflective; } \\
\text { microsculpture, in } \\
\text { general, very diffuse and } \\
\text { effaced or even absent; } \\
\text { micropunctation very } \\
\text { dense and well marked }\end{array}$ & $\begin{array}{l}\text { Slightly shiny and } \\
\text { reflective; microsculpture } \\
\text { fine and sometimes } \\
\text { effaced; micropunctation } \\
\text { dense and well marked }\end{array}$ & $\begin{array}{l}\text { Shiny and reflective; } \\
\text { microsculpture, in } \\
\text { general, very diffuse and } \\
\text { effaced or even absent; } \\
\text { micropunctation very } \\
\text { dense and well marked }\end{array}$ \\
\hline Hypomeral cavity & $\begin{array}{l}\text { Moderately excavated; } \\
\text { with long setae at centre }\end{array}$ & $\begin{array}{l}\text { Very strongly excavated; } \\
\text { centre glabrous or with } \\
\text { sparse very short setae; } \\
\text { long setae, if present, } \\
\text { limited to posterior or } \\
\text { anterior regions }\end{array}$ & $\begin{array}{l}\text { Moderately excavated; } \\
\text { centre glabrous or with } \\
\text { sparse very short setae; } \\
\text { long setae, if present, } \\
\text { limited to posterior or } \\
\text { anterior regions }\end{array}$ & $\begin{array}{c}\text { Very strongly excavated; } \\
\text { centre glabrous or with } \\
\text { sparse very short setae; } \\
\text { long setae, if present, } \\
\text { limited to posterior or } \\
\text { anterior regions }\end{array}$ \\
\hline $\begin{array}{l}\text { Tegument at centre } \\
\text { of metaventrite }\end{array}$ & $\begin{array}{l}\text { Microsculpture strong; } \\
\text { micropunctation evident }\end{array}$ & $\begin{array}{l}\text { Microsculpture very fine } \\
\text { and progressively more } \\
\text { diffuse towards posterior } \\
\text { region; micropunctation } \\
\text { not particularly evident }\end{array}$ & $\begin{array}{l}\text { Microsculpture very fine } \\
\text { and progressively more } \\
\text { diffuse towards posterior } \\
\text { region; micropunctation } \\
\text { very shallow, but always } \\
\text { evident }\end{array}$ & $\begin{array}{l}\text { Microsculpture very fine } \\
\text { and progressively more } \\
\text { diffuse towards posterior } \\
\text { region; micropunctation } \\
\text { very shallow, but, in } \\
\text { general, distinct }\end{array}$ \\
\hline $\begin{array}{l}\text { Shape of internal } \\
\text { margin of } \\
\text { protibiae }\end{array}$ & $\begin{array}{l}\text { Varying from slightly } \\
\text { (Colombia, Ecuador, } \\
\text { Peru) to distinctly } \\
\text { (Peru, Brazil, Bolivia) } \\
\text { expanded }\end{array}$ & $\begin{array}{l}\text { Entirely straight, without } \\
\text { any trace of expansion }\end{array}$ & $\begin{array}{l}\text { Entirely straight, without } \\
\text { any trace of expansion }\end{array}$ & $\begin{array}{c}\text { Entirely straight, without } \\
\text { any trace of expansion } \\
\text { (some few specimens } \\
\text { seem to have a very } \\
\text { slight expansion at apical } \\
\text { half) }\end{array}$ \\
\hline $\begin{array}{l}\text { Shape of protibial } \\
\text { spur of males }\end{array}$ & $\begin{array}{c}\text { Narrow and bifid at apex, } \\
\text { with external projection } \\
\text { longer than the internal } \\
\text { one }\end{array}$ & $\begin{array}{l}\text { Wide at base and with } \\
\text { two apical projections, } \\
\text { the external one longer } \\
\text { than the internal, which, } \\
\text { in general, is only } \\
\text { slightly indicated }\end{array}$ & $\begin{array}{l}\text { Narrow and widely bifid } \\
\text { at apex, with external } \\
\text { projection much longer } \\
\text { than the internal one }\end{array}$ & $\begin{array}{l}\text { Narrow and widely bifid } \\
\text { at apex, with external } \\
\text { projection much longer } \\
\text { than the internal one }\end{array}$ \\
\hline $\begin{array}{l}\text { Colouration } \\
\text { of meso- and } \\
\text { metafemora }\end{array}$ & $\begin{array}{l}\text { Ranging gradually from } \\
\text { yellow and orangish } \\
\text { (northern populations) } \\
\text { to dark brown (southern } \\
\text { populations) }\end{array}$ & $\begin{array}{l}\text { Reddish-brown or dark } \\
\text { brown }\end{array}$ & $\begin{array}{l}\text { Orangish-brown or } \\
\text { yellowish }\end{array}$ & $\begin{array}{l}\text { Orangish-brown, } \\
\text { reddish-brown or dark } \\
\text { brown }\end{array}$ \\
\hline
\end{tabular}


Table 4 (continued).

\begin{tabular}{|c|c|c|c|c|}
\hline & $\begin{array}{c}\text { S. bridarollii } \\
\text { (Martínez, 1949) }\end{array}$ & S. seag sp. nov. & $\begin{array}{l}\text { S. edmondsi } \\
\text { sp. nov. }\end{array}$ & $\begin{array}{c}\text { S. attenboroughi } \\
\text { sp. nov. }\end{array}$ \\
\hline $\begin{array}{l}\text { Coarse punctation } \\
\text { at base of } \\
\text { metafemora }\end{array}$ & $\begin{array}{l}\text { Ranging gradually } \\
\text { from completely absent } \\
\text { (northern populations) to } \\
\text { with well-visible coarse } \\
\text { punctures (southern } \\
\text { populations) }\end{array}$ & Absent & Absent & $\begin{array}{l}\text { Usually absent. In some } \\
\text { few specimens, with } \\
\text { slight traces at base }\end{array}$ \\
\hline $\begin{array}{l}\text { Anterior edge of } \\
\text { female ventrite VI }\end{array}$ & $\begin{array}{c}\text { Subtly covered by a } \\
\text { weak flange of posterior } \\
\text { edge on ventrite } V\end{array}$ & $\begin{array}{l}\text { Distinctly covered } \\
\text { by median flange of } \\
\text { posterior edge on } \\
\text { ventrite } \mathrm{V}\end{array}$ & $\begin{array}{l}\text { Subtly covered by a } \\
\text { weak flange on posterior } \\
\text { edge on ventrite } V\end{array}$ & $\begin{array}{c}\text { Subtly covered by a } \\
\text { weak flange on posterior } \\
\text { edge on ventrite } V\end{array}$ \\
\hline $\begin{array}{l}\text { Tegument of } \\
\text { pygidium }\end{array}$ & $\begin{array}{c}\text { With strong } \\
\text { microsculpture; } \\
\text { micropunctation, if } \\
\text { present, very subtle and } \\
\text { almost imperceptible }\end{array}$ & $\begin{array}{l}\text { Microsculpture ranging } \\
\text { from distinctly marked } \\
\text { (southern population), } \\
\text { diffuse or totally absent } \\
\text { (northern populations) at } \\
\text { centre; on sides, always } \\
\text { present; micropunctation } \\
\text { always clearly marked }\end{array}$ & $\begin{array}{c}\text { With strong } \\
\text { microsculpture; } \\
\text { micropunctation subtle, } \\
\text { but always evidente }\end{array}$ & $\begin{array}{c}\text { With strong } \\
\text { microsculpture; } \\
\text { micropunctation subtle, } \\
\text { but always evident }\end{array}$ \\
\hline $\begin{array}{l}\text { Shape of } \\
\text { parameres }\end{array}$ & $\begin{array}{l}\text { Symmetrical, both } \\
\text { external faces flat; in } \\
\text { lateral view, without } \\
\text { ventral keel or notch; } \\
\text { elongated }\end{array}$ & $\begin{array}{l}\text { Asymmetrical: external } \\
\text { face of left paramere } \\
\text { strongly excavated; in } \\
\text { lateral view, with ventral } \\
\text { keel strongly projected; } \\
\text { apical half of parameres } \\
\text { with squarish appearance }\end{array}$ & $\begin{array}{l}\text { Asymmetrical: external } \\
\text { face of left paramere } \\
\text { excavated; in lateral } \\
\text { view, with projected } \\
\text { ventral keel; elongated }\end{array}$ & $\begin{array}{l}\text { Asymmetrical: external } \\
\text { face of left paramere } \\
\text { excavated; in lateral } \\
\text { view, with projected } \\
\text { ventral keel; elongated }\end{array}$ \\
\hline Body length (mm) & $6.6-9.2(\mathrm{AV}: 8.1 \pm 0.65)$ & $6.8-8.5(\mathrm{AV}: 7.7 \pm 0.44)$ & $6.1-8.0(\mathrm{AV}: 7.1 \pm 0.53)$ & $7.2-9.6(\mathrm{AV}: 8.4 \pm 0.54)$ \\
\hline Distribution & $\begin{array}{l}\text { Western Amazonia: } \\
\text { Colombia, Ecuador, } \\
\text { Peru, Brazil (Acre, } \\
\text { Rondônia), and Bolivia }\end{array}$ & $\begin{array}{l}\text { Northern Amazonia: } \\
\text { Trinidad, Venezuela, } \\
\text { Guianas, and Brazil } \\
\text { (Amazonas, Roraima, } \\
\text { Amapá, Pará, and } \\
\text { Maranhão) }\end{array}$ & $\begin{array}{c}\text { Northwestern Amazonia, } \\
\text { mainly in Sub-Andean } \\
\text { areas in Colombia, } \\
\text { Ecuador, and Peru }\end{array}$ & $\begin{array}{l}\text { Southern Amazonia, to } \\
\text { the right banks of the } \\
\text { Amazon River Brazil } \\
\text { and Peru }\end{array}$ \\
\hline
\end{tabular}

not be ruled out based only on our morphological observations (see the discussion by Mayr 1963 on how complex the history of intergradation gradients can be). Therefore, a question is raised: what were the evolutionary forces that ultimately led to the emergence of this clinal pattern? To give a proper answer to this question, it will be necessary first to acquire further knowledge on the biological roles of the varying features and the environmental factors changing at an equivalent rate along the north-south axis. Other species of Sylvicanthon also show noticeable geographical variations, such as S. seag sp. nov. and S. obscurus (in relation to colouration) and $S$. candezei (the pattern of pronotal microsculpture), which may have some relation to those seen in $S$. bridarollii.

\section{Comments}

The male from MZSP allegedly collected in Itaituba, in the Brazilian state of Pará, is certainly mislabelled, since S. bridarollii does not occur so far east (Fig. 34). This specimen originates from the former collection of the German-Brazilian amateur entomologist Richard von Diringshofen (cited as "Dirings" on specimen labels), which was incorporated in the MZSP collection in 1987 (Costa 1999; Ferreira et al. 2016), and this is not the only specimen housed there with erroneous collecting data. Cupello \& Vaz-de-Mello (2014), for instance, found in that same collection two individuals of Coprophanaeus saphirinus (Sturm, 1826), a species present only in the southern Atlantic Forest, labelled as coming from 


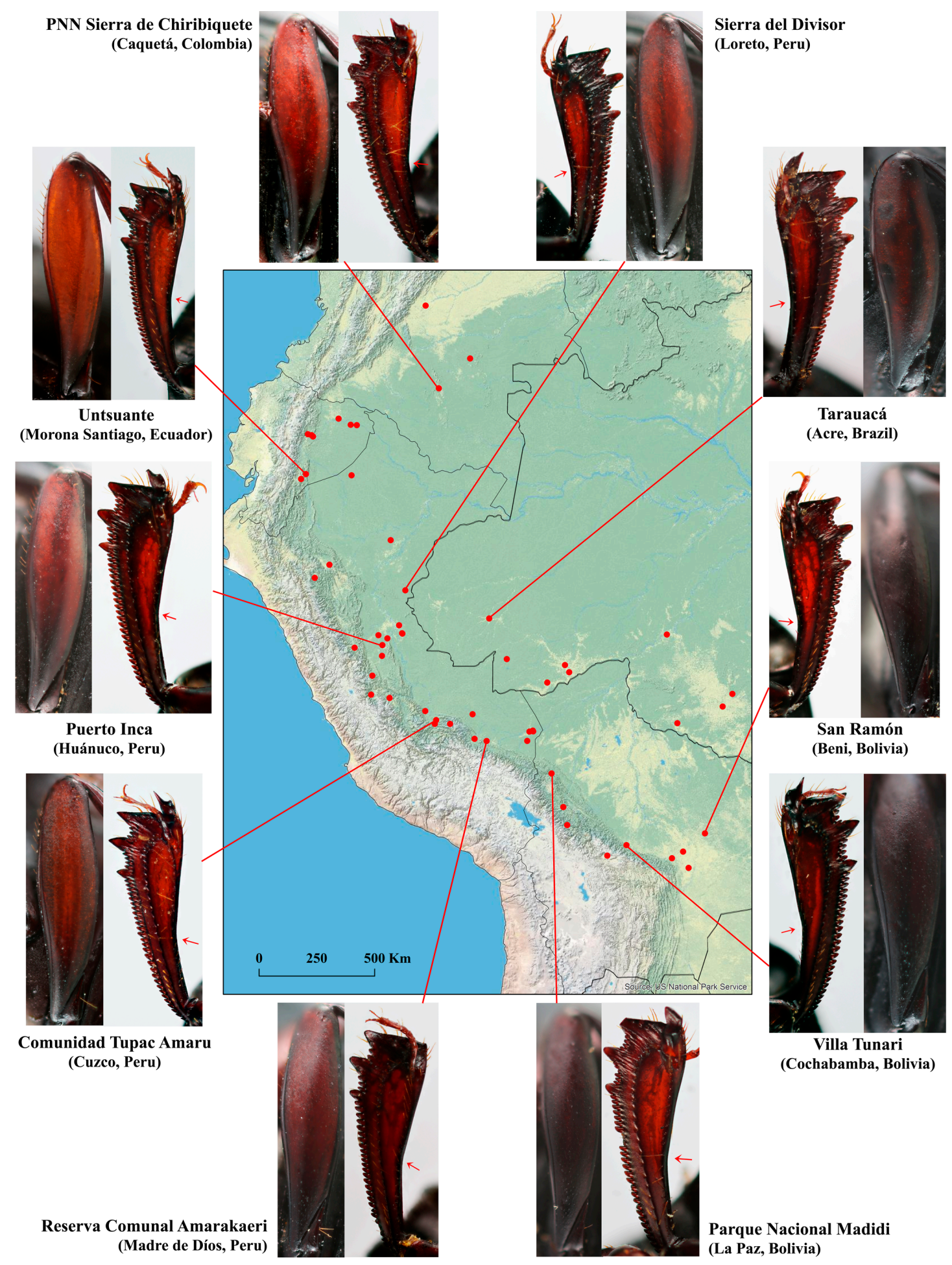

Fig. 36. Clinal morphological variation in S. bridarollii (Martínez, 1949). Note that, from south to north, the colouration of metafemora gradually fades from dark brown to reddish brown and orange with a light-brown base in populations of northern Peru, Ecuador, and Colombia, and that the internal margin of protibiae (indicated by the red arrows) becomes progressively much subtler. Other features varying along this north-south cline are the presence of coarse elongate punctures at the base of metafemora (present in southern populations and absent in the northern ones) and of a fine transverse line on the posterior edge of pronotum (absent in the southern populations). See the text for more details. 
Pará; one of them, curiously enough, also from Itaituba. As a great part of the collection of Diringshofen was bought unprepared (Costa 1999; Ferreira et al. 2016), it is possible that, over time, specimens from different envelopes have been accidentally mixed up, so bringing us to this situation where mislabelling seems not to be such a rare problem.

The type series of Glaphyrocanthon bridarollii is composed of 10 specimens (Martínez 1949): the male holotype (Fig. 33A), the female allotype (Fig. 33B) and eight other paratypes, four males and four females. As expected, both the holotype and the allotype are deposited in the MACN, and, of the paratypes, two males and one female were found in the CMNC, while a male and two females were found in the MZSP, probably deposited there via Padre Francisco Pereira. Therefore, we did not find two of the paratypes, male and female. Martínez (1949) stated he deposited "two couples" of paratypes in the collection of Rodolfo Zischka (1895-1980), from Cochabamba, Bolivia, the type series' collector. Since 1979, Zischka's collection is housed at the Zoologische Staatssammlung München, Munich, Germany (ZSM 2014) and, thus, this museum is probably the place where the missing pair of paratypes (not 'two couples', as said by Martínez) is being conserved.

In their list of the dung beetles occurring in Colombia, Medina et al. (2001) and Medina \& Pulido (2009) cited S. bridarollii for the departments of Casanare, Guainía, Guaviare, Meta and Vichada. For Meta (Amézquita et al 1999) and Guaviare (Escobar 2000b), it was possible to find more precise literature records and, therefore, those departments were included in the geographical distribution given above. On the other hand, for the other three departments, no accurate locality records were found; consequently, we preferred to include them neither in the geographical list above nor on the map.

\section{Natural history}

Following S. aequinoctialis and S. proseni, S. bridarollii has the greatest amount of bionomic information available in the literature and on specimen labels. After compiling all these data, it is possible to say that S. bridarollii does not differ from the genus pattern, having food habits preferentially coprophagous, although the species can occasionally be attracted to carrion, as shown by the specimens collected by D. Inward at the Tiputini Biodiversity Station (Orellana, Ecuador). On the other hand, Figueroa \& Alvarado (2011), collecting at the Reserva Nacional Tambopata (Madre de Díos, Peru), although having used pitfall traps baited with both dung and carrion, caught $S$. bridarollii only with the first kind of bait. A large number of the specimens here studied were collected with flight interception traps.

Having collected during the dry season in Puerto Colombia (Meta, Colombia), Amézquita et al. (1999) found that $S$. bridarollii was the third most abundant species in that region, corresponding to more than $13 \%$ of the collected specimens, following only "Onthophagus haematopus Harold, 1975" and an unidentified species of Uroxys, with $28 \%$. On the other hand, four other inventories - Figueroa \& Alvarado (2011), at the Reserva Nacional Tambopata, in the Peruvian department of Madre de Díos; Larsen (2004), at the Zona Reservada Megantoni, in Cuzcu, Peru; Celi et al. (2004), in the Ecuadorian province of Morona Santiago; and Carpio et al. (2009), in Sucumbíos, also in Ecuador - did not find $S$. bridarollii among the most abundant species. In fact, in the third paper, another species of the same genus, S. proseni (cited as Canthon aequinoctialis), was the most abundant dung beetle in the region.

Regarding habitat preferences, it seems that $S$. bridarollii is restricted to dense rainforests, be it either primary or secondary. Larsen (2004) also collected specimens in a bamboo (Guadua Kunth and Chusquea Kunth) forest. Carpio et al. (2009), in a study on the effect of the opening of a new road at the centre of a pristine forest in Sucumbíos, saw that $S$. bridarollii was among the five dung beetle species that have their abundance progressively increased from the road towards the forest interior. 
As for the altitudinal amplitude, specimens studied for this work were mostly collected between 140 and $1100 \mathrm{~m}$, but one female was caught in Rodríguez de Mendoza (Amazonas, Peru) at about $2300 \mathrm{~m}$ a.s.l. The specimens examined also show that adults of $S$. bridarollii are active throughout the year, although a much higher number of individuals has been collected between May and October.

Sylvicanthon seag sp. nov.

urn:lsid:zoobank.org:act:69A2BE3F-7EDF-439B-8AD3-6ABC98F91125

Figs 6E, 15J, 18B, 20, 34-35A, 37

Sylvicanthon candezei - Feer 2000: 32 (error); 2008: 62 (error). — Feer \& Pincebourde 2005: 30.

Sylvicanthon bridarollii - Price \& Feer 2012: 327 (error).

Sylvicanthon sp. - Larsen et al. 2009: 1294. — Vaz-de-Mello et al. 2011a: 67, figs 164-165 (tentative association). - Boilly \& Vaz-de-Mello 2013: 105, fig. 130.

Sylvicanthon sp. 32 - Feer 2015: 3 (tentative association).

\section{Etymology}

A tribute to the Société entomologique Antilles-Guyane (SEAG), founded in 2007 by a group of amateur entomologists with the aim of facilitating the collection and promoting the study of the entomofauna of the French territories in the Americas. This society was responsible for the collection of 440 of the 1204 S. seag sp. nov. studied in this work, and it was thanks to this enormous volume of specimens that we could see in fine detail the morphological variation - especially the colour variation - shown by this species. The specific name is a noun in apposition.

\section{Material examined}

\section{Holotype}

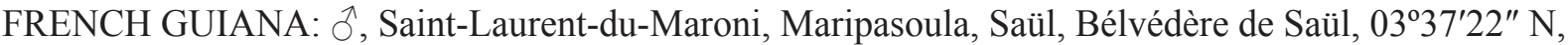

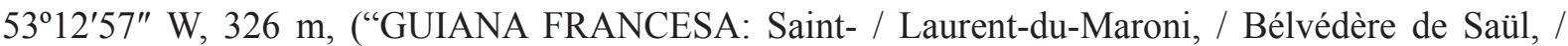
$3^{\circ} 37^{\prime} 22^{\prime \prime} \mathrm{N}, 53^{\circ} 12^{\prime} 57^{\prime \prime} \mathrm{W}, /$ 326m, 15 Sep. 2011 / SEAG col.", "HOLOTYPE O̊ / Sylvicanthon seag / sp. nov. Cupello \& / Vaz-de-Mello des. 2016") (MNHN).

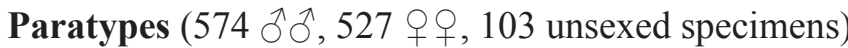

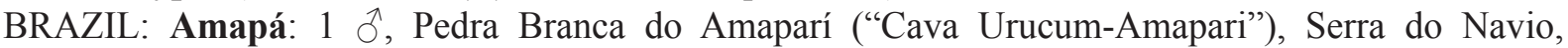
005'06" N, 5152'53" W, Sep. 2000, R. Ribon leg. (CEMT). - Amazonas: 1 + 25 Feb. 1976, I.S.

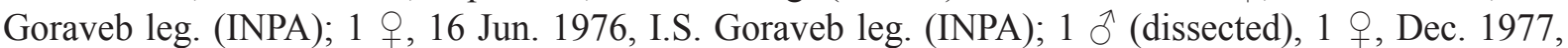

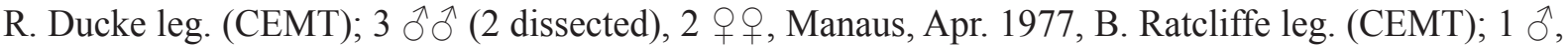

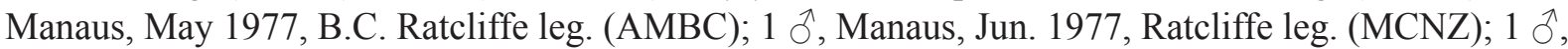
Manaus, 1 Jul. 1977, B.C. Ratcliffe leg. (INPA); 5 unsexed Specimens, Manaus, 11-13 Oct. 1977,

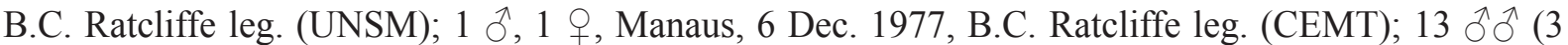
dissected), 12 우, Same collecting data as for preceding (INPA), 16 unsexed specimens, same collecting data as for preceding (UNSM); $12 \hat{\jmath}$ (1 dissected), 11 우, Manaus, 20 Dec. 1977, B.C. Ratcliffe leg. (INPA); 20 unsexed specimens, same collecting data as for preceding (UNSM); 1 , Manaus, 29 Dec. 1977, B.C. Ratcliffe leg. (INPA); 48 unsexed specimens, Manaus, 3 Jan. 1978, B.C. Ratcliffe leg. (UNSM); 13 unsexed specimens, Manaus, 13 Jan. 1978, B.C. Ratcliffe leg. (UNSM); 1 , Manaus, 30 Jan. 1978, L.P. Albuquerque leg. (INPA); 1 \&, Manaus, Campus do INPA, Estrada do Aleixo, Km 4, 6 Mar. 1976, L.F. Albuquerque leg. (INPA); 1 \%, Manaus, INPA, 30 Jan. 1978, L.P. Albuquerque leg. (INPA); 1 \%, Manaus, INPA, Sede Manaus, 18 May 1976, A.P.A. Luna Dias leg. (INPA). - Maranhão: 1 § (dissected), Bom Jardim, Reserva Biológica Gurupi, 1-6 Nov. 2010, light trap, M.M. Abreu,

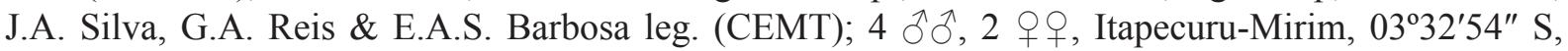

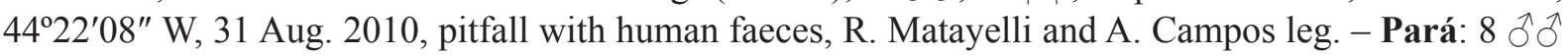


(3 dissected), 1 , Belém, IPEAN, Oct. 1984, flight interception trap, N. Degallier leg. (CEMT); 3 우, Belém, IPEAN, Nov. 1984, N. Degalier leg. (CEMT); 1 đ, Belém, IPEAN, May 1985, N. Degallier

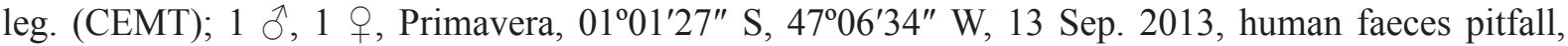

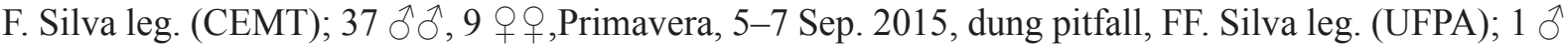

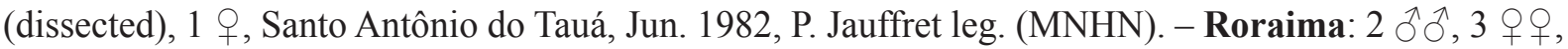
Cantá, Serra Negra, Sep. 1996, Ribeiro and Vaz-de-Mello leg. (CEMT); 8 ồ , 2 우, Pacaraima ("Vila Pacaraima"), 04 $27^{\prime}$ N, 61 ${ }^{\circ} 07^{\prime}$ W, 820 m, Sep. 1996, Ribeiro and Vaz-de-Mello leg. (CEMT).

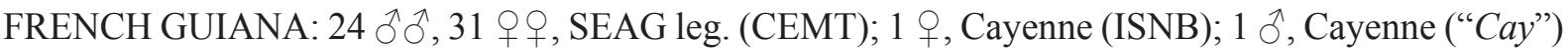

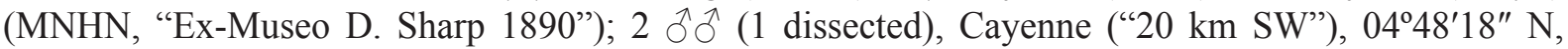
52 $28^{\prime} 41^{\prime \prime}$ W, 30 m, 29 May 9 Jun. 1997, flight interception trap, J. Ashe and R. Brooks leg. (CMNC); 1 q, Cayenne, Camopi, Rio Oyapock, Îlet Massikiri, 17 Nov. 1969, dung, G. Halffter leg. (CMNC); 1 ․ Cayenne, Kourou, Forêt de Wayabo, Dec. 2013, M. Duranton leg. (CEMT); 2 $\widehat{\jmath}, 1$ †, Cayenne, Kourou, Rte. Cayenne-Sinnamary, RN1, PK84, Jan. 2013, flight interception trap, SEAG leg. (CEMT);

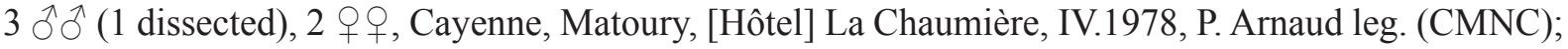
1 §., Cayenne, Matoury, Mont Grand Matoury, dubious date (1995 or 14 Jun. 2011?), M. Trýzna leg.

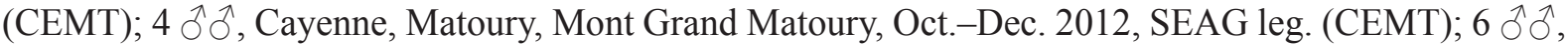
1 ㅇ, Cayenne, Matoury, Réserve Naturelle Nationale du Mont Grand Matoury, 04 $51^{\prime} \mathrm{N}, 52^{\circ} 21^{\prime} \mathrm{W}$, 215 m, 2 Aug. 2012, SEAG leg. (CEMT); 12 ふోَ̂, 22 우, Cayenne, Montsinéry-Tonnegrande,

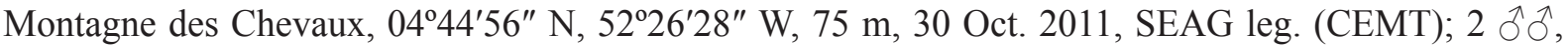
2 우, Cayenne, Montsinéry-Tonnegrande, Montagne des Chevaux, 04 $44^{\prime} 56^{\prime \prime} \mathrm{N}, 52^{\circ} 26^{\prime} 28^{\prime \prime} \mathrm{W}$, 75 m, 27 Jan. 2013, SEAG leg. (CEMT); 2 $\widehat{\partial}, 1$ q, Cayenne, Régina, [Réserve Naturelle Nationale des] Nouragues, $04^{\circ} 05^{\prime} \mathrm{N}, 52^{\circ} 40^{\prime} \mathrm{W}, 155$ m, Mar. 1997, F. Feer leg. (CEMT); 3 우, Cayenne, Régina, [Réserve Naturelle Nationale des] Nouragues, $04^{\circ} 05^{\prime}$ N, $52^{\circ} 40^{\prime}$ W, May 2003, F. Feer leg. (CEMT);

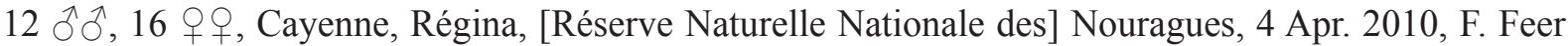

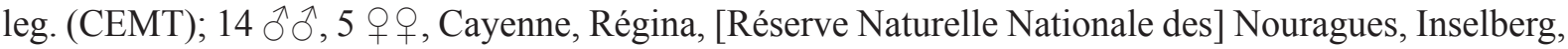
$04^{\circ} 05^{\prime} \mathrm{N}, 52^{\circ} 41^{\prime} \mathrm{W}, 411 \mathrm{~m}, 4$ Apr. 2010, SEAG leg. (CEMT); 2 $\lesssim(1$ dissected), 2 우, Cayenne, Régina, [Réserve Naturelle Nationale des] Nouragues, Saut-Pararé, $04^{\circ} 02^{\prime} 16^{\prime \prime} \mathrm{N}, 52^{\circ} 40^{\prime} 21^{\prime \prime} \mathrm{W}, 30$ Nov.

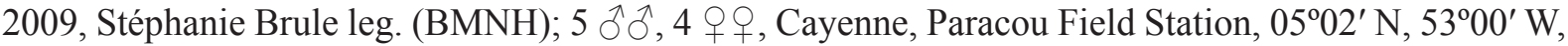
55 m, Oct. 2003, F. Feer leg. (CEMT); 4 ô ô (1 dissected), Cayenne, Roura ("18.4 km SSE"), 04036'38" N, $52^{\circ} 13^{\prime} 25^{\prime \prime} \mathrm{W}, 240 \mathrm{~m}, 22-24$ May 1997, J. Ashe and R. Brooks leg. (CMNC); 3 $\widehat{\jmath}, 1$,, , Cayenne, Roura

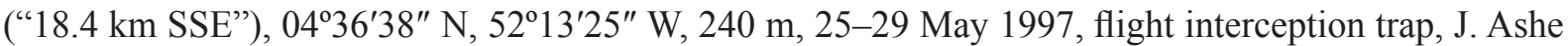

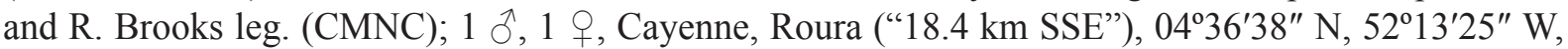
240 m, 10 Jun. 1997, flight interception trap, J. Ashe and R. Brooks leg. (CMNC); 4 $\widehat{\partial}, 2$ $ᄋ$ q , Cayenne,

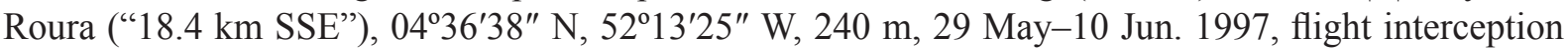
trap, J. Ashe and R. Brooks leg. (CMNC); 1 unsexed Specimen, Cayenne, Roura, Réserve Naturelle Régionale Trésor, $225 \mathrm{~m}, 4^{\circ} 36^{\prime} 38^{\prime \prime} \mathrm{N}, 5^{\circ} 16^{\prime} 45^{\prime \prime} \mathrm{W}$, Dec. 2009, malaise trap (BMNH); 1 ô, 2 우,

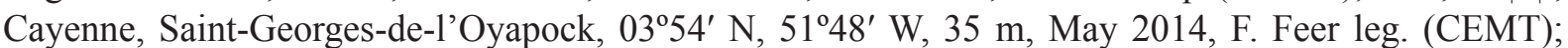
1 § , "Nouveau Chantier", “octobre" (MNHN); 1 q, Régina ("S of Régina"), 30 Dec. 2006, Snižek leg. (NMPC); 1 + , Same collecting data as for preceding (OUMNH); 1 (dissected), Régina, Kaw ("Kaw rd"), PK-38, 23-27 Aug. 1995, J.E. Wappes leg. (CMNC); 1 ð̊, Régina, Route de Kaw ("Caiman Camp env.”), 7 Dec. 2006, M. Snižek leg. (NMPC); 1 q, Régina, Route de Kaw ("Caiman Camp env.”), 20 Dec. 2006, Snižek" (OUMNH); 4 ふึ, 4 q , Saint-Laurent-du-Maroni, Jul. 1975, P. Arnaud leg. (MNHN); 1 đ̆, Saint-Laurent-du-Maroni, Mana, Acarouany, VI.1993, Marek and Seidl leg. (CEMT); 1 q, Saint-Laurent-du-Maroni, Maripasoula ("Maripa"), 27 Nov. 1969, dung, G. Halffter leg. (CEMT); 1 q,Saint-Laurent-du-Maroni, Maripasoula, Route de Belizon, PK 10, 29 Jan. 1990, O. Schmitt leg.

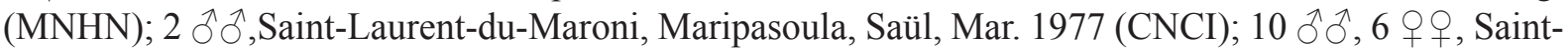

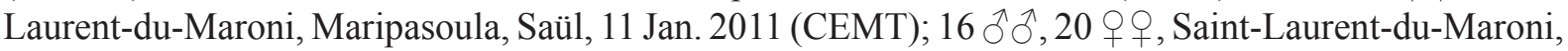
Maripasoula, Saül, 27 May 2011 (CEMT); 1 O, 2 우, Saint-Laurent-du-Maroni, Maripasoula, Saül, 9 Sep. 2011 (CEMT); 14 đิ , 25 우, Saint-Laurent-du-Maroni, Maripasoula, Saül, Bélvédère de Saül, 
033'ㄹ" N, 5312'57" W, 326 m, 11 Jan. 2011, SEAG leg. (CEMT); 1 , Saint-Laurent-du-Maroni, Maripasoula, Saül, Bélvédère de Saül, 0337'22" N, 53¹2'57" W, 326 m, 28 Feb. 2011, SEAG leg.

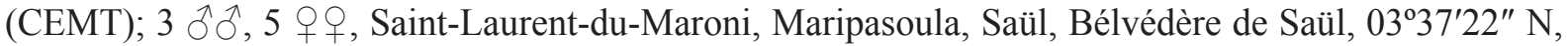

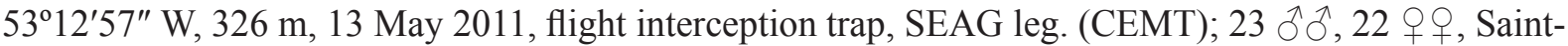

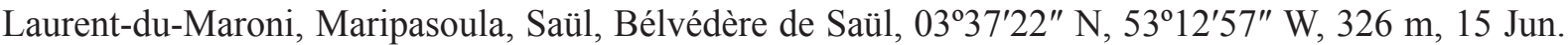
2011, SEAG leg. (CEMT); 33 đิ $\widehat{0}, 32$ 우, Saint-Laurent-du-Maroni, Maripasoula, Saül, Bélvédère

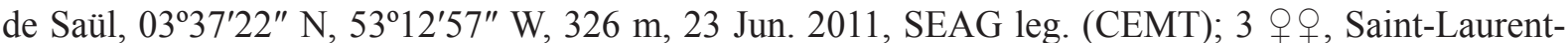

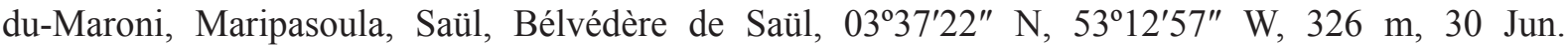

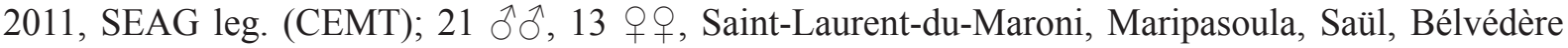

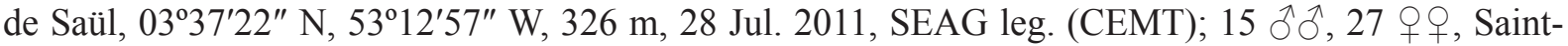

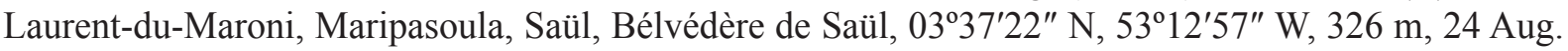
2011, SEAG leg. (CEMT); 11 đో $\widehat{0}, 14$ 우, Saint-Laurent-du-Maroni, Maripasoula, Saül, Bélvédère

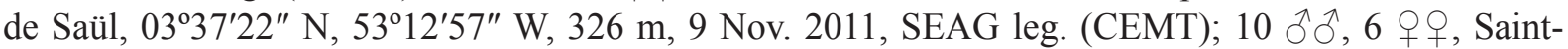
Laurent-du-Maroni, Maripasoula, Saül, Bélvédère de Saül, 15 Sep. 2011, SEAG leg. (CEMT); 13 §ิ ô, 21 우, Saint-Laurent-du-Maroni, Maripasoula, Saül, Bélvédère de Saül, Grand Boeuf Mort, 10 Oct. 2007, SEAG leg. (CEMT); 1 q, Saint-Laurent-du-Maroni, Maripasoula, Saül, Montagne Pelée, 20 May 2011, SEAG leg. (CEMT); 1 ô, Saint-Laurent-du-Maroni, Maripasoula, Saül ("7 km N"), Les Eaux

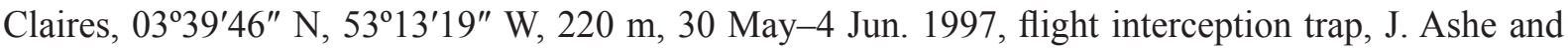
R. Brooks leg. (CMNC); 1 đ, 1 क, Saint-Laurent-du-Maroni, Maripasoula, Saül ("7 km N"), Les Eaux

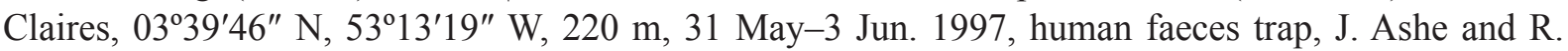

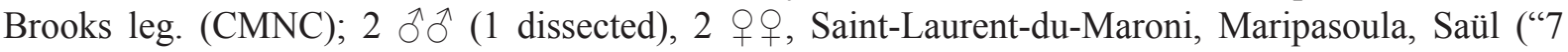
km N"), Les Eaux Claires, 0339'46" N, 53¹3'19" W, 4-8 Jun. 1997, 220 m, malaise, J. Ashe and R. Brooks leg. (CMNC); 1 § (dissected), Saint-Laurent-du-Maroni, Maripasoula, Saül, Mount Galbao,

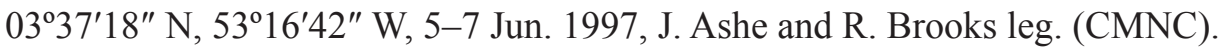

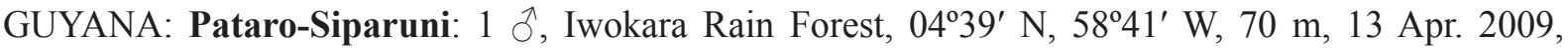

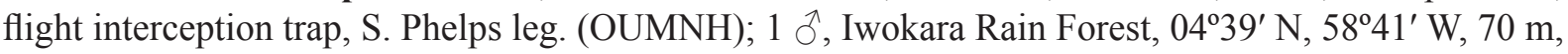
13 Apr.-31 May 2009, baited trap, S. Phelps leg. (OUMNH). - Upper Takutu-Upper Essequibo:

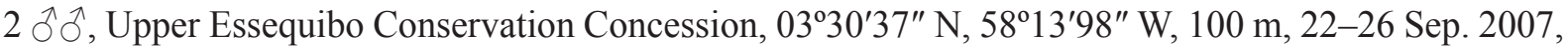
pitfall with human faeces, G.C. McGavin leg. (OUMNH).

SURINAME: $1 \hat{\jmath}, 1$ ( 1 (BMNH); $1 \hat{\delta}$ (dissected) Same collecting data as for preceding (CEMT, "Ex-

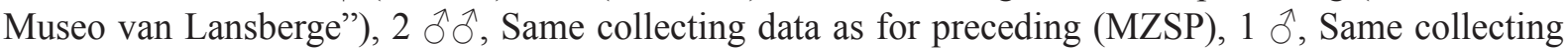
data as for preceding (NMPC, ex. coll. Balthasar). - Brokopondo: $2 \lambda \hat{\partial}, 3$ $q$, , Brownsburg Nature Reserve, 045' $55^{\prime \prime}$ N, 56 $10^{\circ} 53^{\prime \prime}$ W, 450 m, 23 Jun. 1999, flight interception trap, Z. Falin leg. (CMNC);

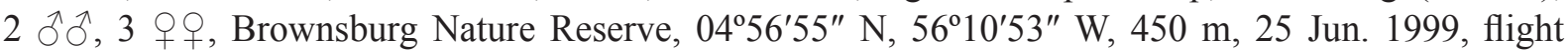
interception trap, Z. Falin leg. (CMNC). - Commewijne: 1 + , Akintosoela, $05^{\circ} 16^{\prime} 17^{\prime \prime} \mathrm{N}, 54^{\circ} 55^{\prime} 15^{\prime \prime} \mathrm{W}$, 40 m, 29 Jun.-3 Jul. 1999, flight interception trap, Z. Falin leg. (CMNC); 1 O, Akintosoela, 05 $16^{\prime} 17^{\prime \prime} \mathrm{N}$, 54 55'15" W, 40 m, 3 Jul. 1999, flight interception trap, Z. Falin leg. (CMNC). - Marowijne: 1 ,

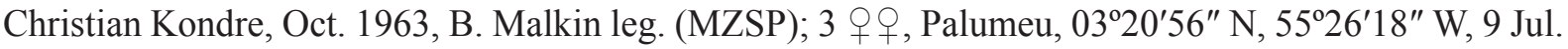
1999, flight interception trap, Z. Falin leg. (CMNC). - Para: 4 ऽ̄ $\delta^{\lambda}, 2$ 우, Zanderij, $11 \mathrm{~km}$ SE of Zanderij Airport, 30 m, 20 Jun. 1999, flight interception trap, Z. Falin leg. (CMNC). - Saramacca: 1 ㅇ, W. Suraname Rd. (East-West Link?), 108 km WSW of Zanderij Airport, 30 m, 05 ${ }^{\circ} 13^{\prime} 37^{\prime \prime}$ N, 5552'54" W, 14 Jun. 1999, Z. Falin leg. (CMNC).

TRINIDAD AND TOBAGO: $3 \hat{\jmath} \widehat{\partial}, 1$, Trinidad, Arima, $16 \mathrm{~km} \mathrm{~N}$ of Arima, Andrews Trace, $620 \mathrm{~m}$,

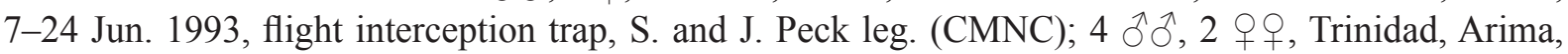
$16 \mathrm{~km} \mathrm{~N}$ of Arima, Andrews Trace, $620 \mathrm{~m}$, 24 Jun.-7 Jul. 1993, flight interception trap, S. and J. Peck leg. (CMNC); 1 §, 1 क , Trinidad, Arima, $19 \mathrm{~km} \mathrm{~N}$ of Arima, Lalaja Trace, $650 \mathrm{~m}, 8-24$ Jun. 1993,

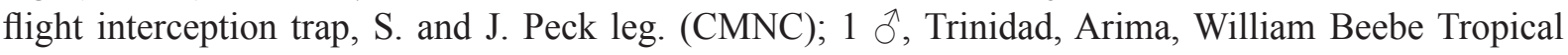


Research Station (“Simla (N. Y. Zool. Soc. Sta.)”), 11 Jun. 1977, pitfall trap With pig dung, R.E. Woodruff

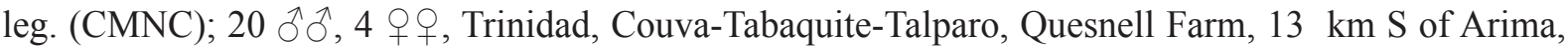

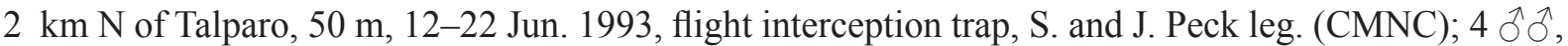
1 q, Trinidad, Couva-Tabaquite-Talparo, Quesnell Farm, $13 \mathrm{~km} \mathrm{~S}$ of Arima, $2 \mathrm{~km} \mathrm{~N}$ of Talparo, $50 \mathrm{~m}$, 22 Jun.-8 Jul. 1993, flight interception trap, S. and J. Peck leg. (CMNC); leg. 1 q, Trinidad, Sangre

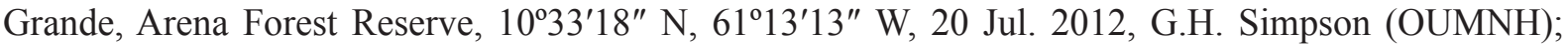

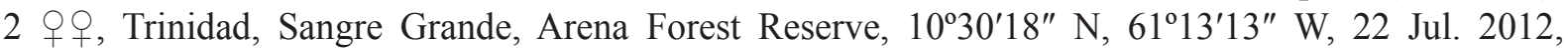
G.H. Simpson leg. (OUMNH); 3 $\hat{\jmath}$, Trinidad, Sangre Grande, Arena Forest Reserve, 80 m, 13-22 Jun.

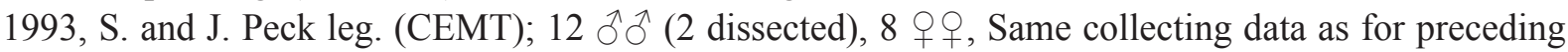

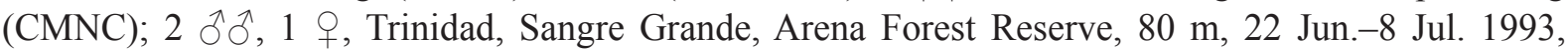
flight interception trap, S. and J. Peck leg. (CMNC); 1 § (dissected), Trinidad, Sangre Grande, Arena Forest Reserve, 10 $33^{\prime} 18^{\prime \prime}$ N, 61 $11^{\circ} 13^{\prime \prime}$ W, 22 Jul. 2012, pitfall with human faeces, G.H. Simpson leg. (OUMNH); 1 §ิ, 2 우, Trinidad, Tunapuna-Piarco, Mount Saint Benedict, 550 m, 5-21 Jun. 1998, flight interception trap, S. and J. Peck leg. (CMNC); 1 ô, Trinidad, Tunapuna-Piarco, Mount Saint Benedict, 550 m, 21 Jun.-8 Jul. 1993, flight interception trap, S. and J. Peck leg. (CMNC); 1 O, Trinidad, William Beebe Tropical Research Station ("Simla, 5mi. N. / Arima"), 19 Aug. 1969, H. and A. Howden leg. (CMNC); 1 đ, 2 우오, Trinidad, William Beebe Tropical Research Station (“Simla Res. Sta."), 8 km N of Arima, 240 m, 6-10 Jun. 1993, flight interception trap, S. and J. Peck leg. (CMNC); 3 के ô (1 dissected), 1 q, Trinidad, William Beebe Tropical Research Station ("Simla Res. Sta."), 8 km N of Arima, 260 m, 6-14 Jun. 1993, flight interception trap, S. and J. Peck leg. (CMNC); 3 ô $\hat{\jmath}, 5$ 우, Trinidad, William Beebe Tropical Research Station ("Simla Res. Sta."), 8 km N of Arima, 260 m, 14-24 Jun. 1993, flight interception trap, S. and J. Peck leg. (CMNC); 1 ${ }^{\lambda}, 5$ 우, Trinidad, William Beebe Tropical Research Station ("Simla Res. Sta."), 8 km N of Arima, 260 m, 24 Jun.-8 Jul. 1993, flight interception

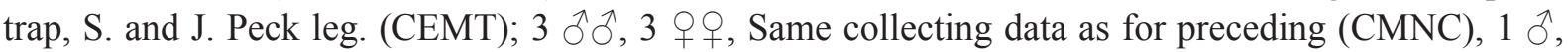
1 q, Same collecting data as for preceding (MCNZ); 1 ${ }^{\lambda}, 1$, , Trinidad, William Beebe Tropical Research Station (“Simla, N Arima”), 21 Jun.-6 Jul. 2007, E.G. Hancock leg. (OUMNH).

VENEZUELA: Amazonas: $3 \widehat{\partial} \widehat{\partial}, 2$ $q$ q, Alto Orinoco (“T.F.A. Atabapo / Alto Orinoco"), Platanal, Jun.

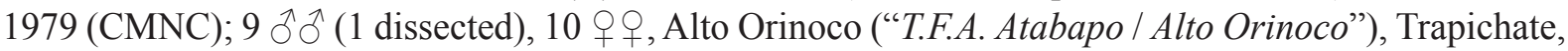
Jun. 1979 (CMNC); 1 ô, 1 \&, Puerto Ayacucho, Atures, Cerro Camani, Jul. 1979 (CMNC); 1 ô (dissected) and 1 , , San Juan de Manapiare, Alto Ventuari (" $1^{\circ}$ Atures / Alto Ventuari / Camani (Aramare)"), Jun. 1979 (CMNC). - Bolívar: 1 9, Gran Sabana, Km 40 Sta. Elena Icabaru Road, 4-6 Aug. 1986, 100 m, B. Gill leg. (CMNC); 1 ㅇ, Gran Sabana, San Francisco Yuruaní (“J. F. Yuruani”), Jan. 1988, illegible collector (CMNC); 1 ô, 1 q, Isla Anacoco, 7 Aug. 2006(CEMT); 1 q, Las Trincheras ("35 km N Las Trincheras", "15 km N Corocito"), 17 Jun. 1987, UV light trap, S. and J. Peck leg. (CMNC); 4 ô ô, Las Trincheras, Río Caura, 10-11 Aug. 1986, B. Gill leg. (CMNC); 1 ô, 5 우, ata de Corocito ("10 km N Corocito"), 18 Jun.-3 Aug. 1987, flight interception trap, S. and J. Peck leg. (CMNC); 1 +, Padre Pedro Chien, 20 km EL Palmar, 18 Jun. 1996, dung, H. and A. Howden leg. (CMNC); 1 q, Río Chicanan,

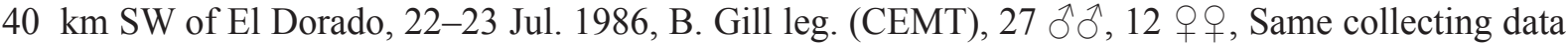
as for preceding (CMNC); $7 \widehat{\jmath}, 9$ q $q$, Río Sipao, $110 \mathrm{~km}$ E of Caicara, 17 Jun.-4 Aug. 1987, flight interception trap, S and J. Peck leg (CMNC); 2 우, Sinfontes, $10 \mathrm{~km} \mathrm{~S} \mathrm{of} \mathrm{El} \mathrm{Dorado,} 200 \mathrm{~m}, 17$ Jul.

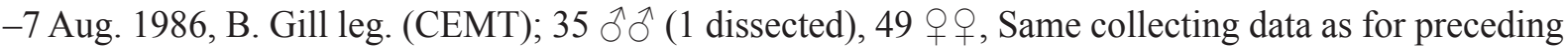
(CMNC); 2 ふ઼, 1 q, Sinfontes, 20 km S. of El Dorado, 220 m, 20-23 Jul. 1986, B. Gill leg. (CMNC); 2

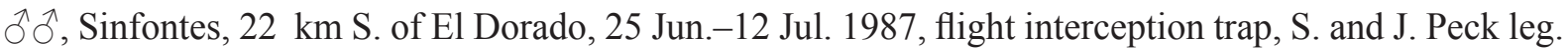

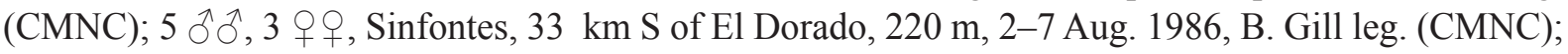

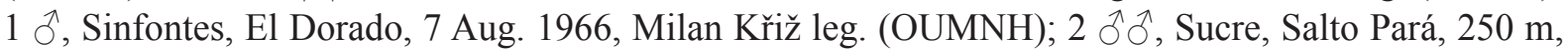
20-22 Nov. 1978, A.H.Chacon leg. (CMNC). - Delta Amacuro: 1 ô, 1 क , Casacoima, $11 \mathrm{~km} \mathrm{~W}$ of Piacoa, 14-31 Jul. 1987, flight interception trap, S. and J. Peck leg. (CMNC). - Mérida: 1 §̊, Libertador, Mérida, Monte Zerpa, Nov. 1987, D. Harraner(?) leg. (CMNC). - Monagas: 2 q , Maturín, 15 km N 
of Maturín, 19-31 Jul. 1987, flight interception trap, S. and J. Peck leg. (CMNC); 1 § (dissected), Teresen (?), 800 m, 12 Jun. 1963, R. Hernandez leg. (CMNC).

Erroneous data: ECUADOR: Napo: 1 +, Lago Agrio, Feb. 1986, illegible collector (CMNC).

PERU: Huánuco: 1 , Leoncio Prado, Rupa-Rupa, Tingo María, Universidad Nacional Agraria de la Selva ("Tingo María Universidad"), Jul. 1974 (CMNC).

No data: 1 (ISNB, “Collection E. Candeze"), $1 \widehat{\jmath}$ (MNHN).

\section{Description}

Colouration. With evident geographical variation on dorsum: in southern populations (specimens examined from Manaus, Belém and Bom Jardim), head and pronotum purple and elytra greenish with contrasting striae (usually of the same colour as, or darker than, pronotum) (Fig. 37A); individuals from northern populations with head purple with greenish reflections and pronotum and elytra bright green (Fig. 37C) or dark blue (Fig. 37B), with elytral striae contrasting; pronotum usually with purplish reflections, especially on the sides. Metaventrite dark, with purplish or coppery reflections (Fig. 37D); specimens from Trinidad and a few others from Venezuela with greenish reflections at centre of disc. Meso- and metafemora reddish-brown or dark brown, base distinctively darker than apical two-thirds. Pygidium ranging from predominantly coppery with greenish shine, to the south, to totally greenish or bluish, on northern populations.

HEAD. Tegument with little shine and strong alveolar microsculpture; micropunctation evident on posterior region of clypeus and especially on frons (Fig. 6E). Clypeus with two apical teeth obtuse and only slightly separated; with a single transverse row of setae covering base of both teeth. Genae with strong tooth immediately behind clypeal-genal juncture. Posterior edge of head completely unmargined.

THORAX. Pronotum with shiny, lustrous tegument, with microsculpture in general very diffuse and effaced or even totally absent at centre; on sides, with stronger alveolar microsculpture; micropunctation denser and more clearly marked at centre and progressively weaker towards the sides. Posterior edge with fine transverse line at centre (usually extending up to the second elytral stria). Hypomeral cavity entirely glabrous or, at most, with some very few short setae at centre; long setae, when present, restricted to posterior region (Fig. 35A); external margin with very short tubercle. Metaventrite entirely glabrous; tegument with evident rivose microsculpture on sides and anterior region, and weaker microsculpture adjacent to internal margin of mesocoxae; at centre, alveolar microsculpture very fine and progressively more diffuse and ill delimited towards posterior region; micropunctation very fine and not evident.

Legs. Ventral surface of all femora and tibiae bright. Profemora with tegument with strong rivose microsculpture and without micropunctation. Protibiae narrow and with internal edge straight and simple, without expansion; at their apical third, with three small acute teeth on external edge, the two most apical ones subequal in length and larger than basal tooth. Mesofemora margined anteriorly only at their basal half; unmargined portion of anterior edge with row of very short setae; posterior margin absent; tegument with effaced rivose microsculpture. Metafemora margined anteriorly, posterior margin absent; apical half of anterior edge covered by a row of setae; tegument covered by effaced rivose microsculpture and without any trace of coarse punctation at base. Metatarsomeres II and V subequal in length and longer than the others; metatarsomere IV shorter than the others.

ELYTRA. In most cases with nine well-visible striae: in general, the first six or seven striae well marked, very finely carinulate and slightly widened at base; seventh stria finer than the others, but always visible; eighth and ninth striae very fine; all striae lack carinulae at apex of elytra, where they are completely indistinct; humeral carina absent. Tegument of interstriae very shiny and lustrous; at centre, 
ranging from weak alveolar microsculpture (populations on the banks of the Amazon River) to diffuse microsculpture or even totally smooth; at apex and on sides, always with strong alveolar microsculpture; micropunctation clearly visible at $20 \times$ magnification.

AвDомen. Ventrite VI with very diffuse rivose microsculpture, or microsculpture absent; in both cases, micropunctation very subtle; in both sexes without lateral foveae. Pygidium with tegument distinctly micropunctated and with variable microsculpture: at centre, alveolar microsculpture distinctly marked

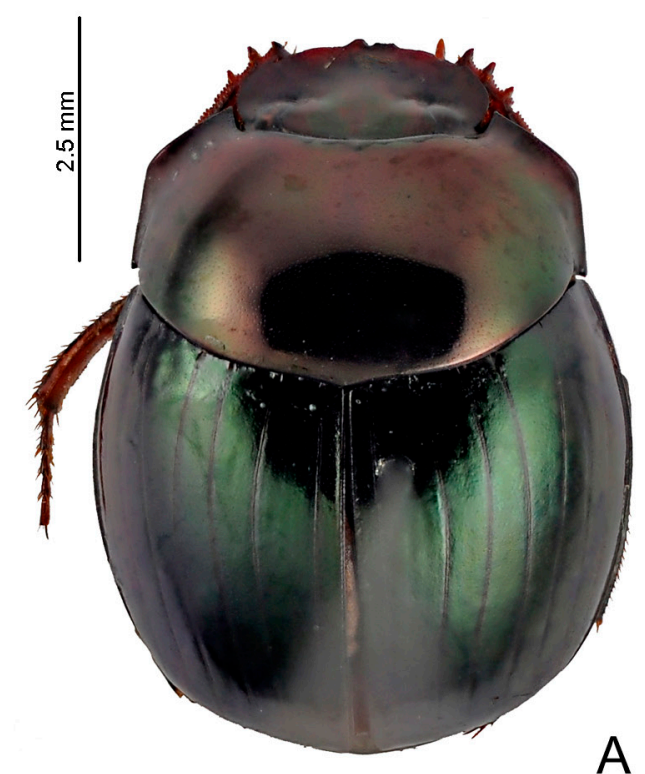

A

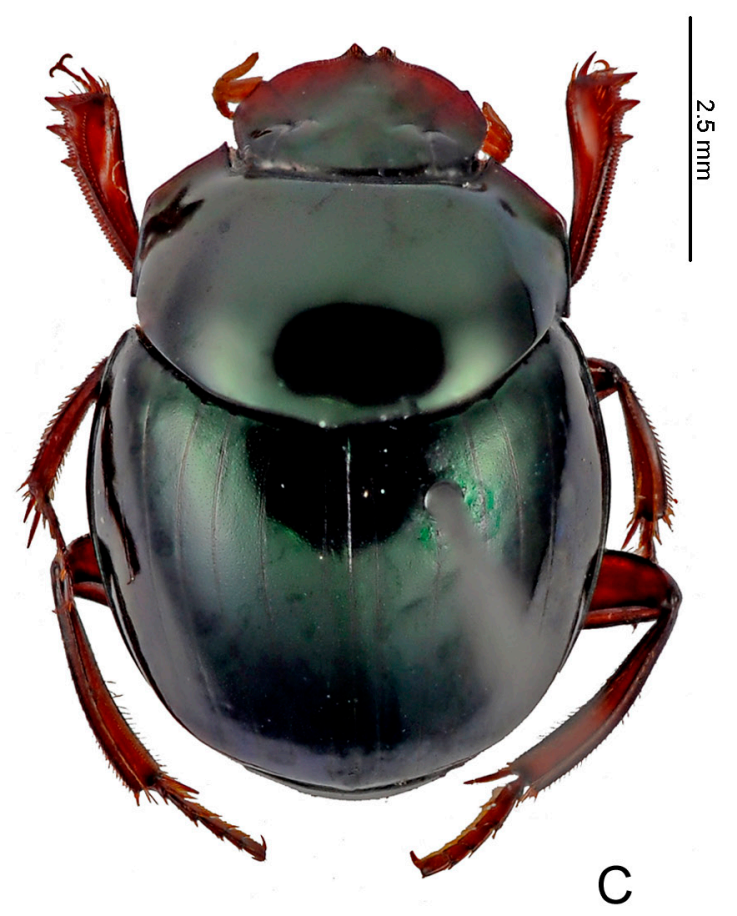

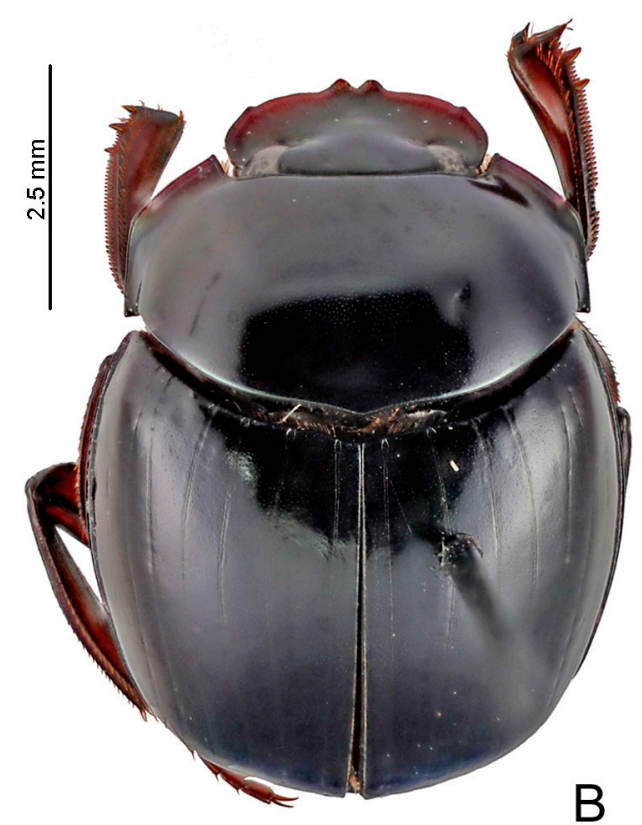

B

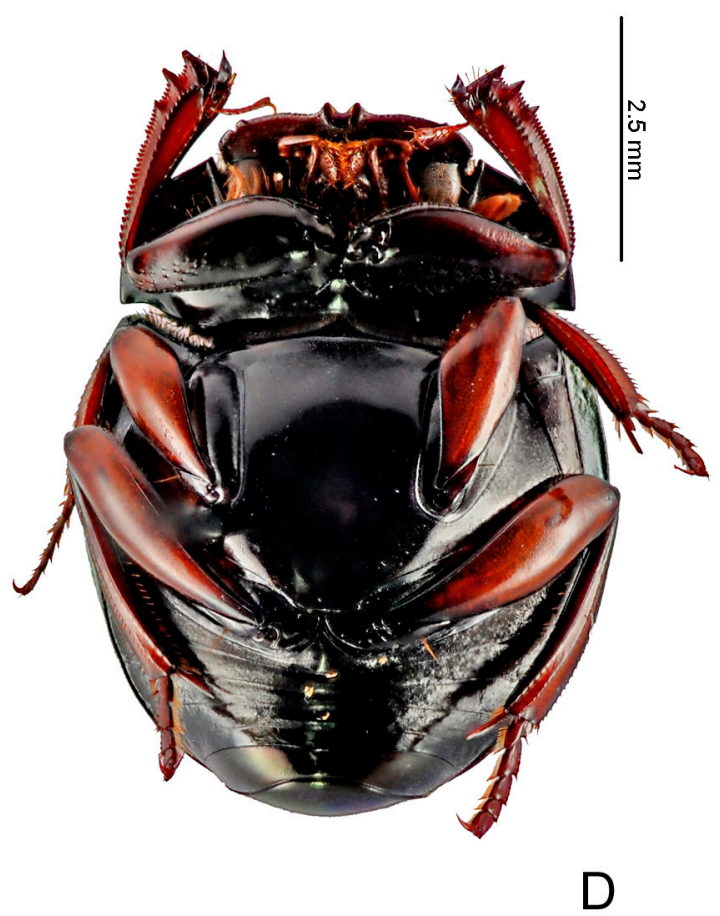

Fig. 37. Sylvicanthon seag sp. nov. A. Dorsal view of a bicolour specimen (present only on the banks of the Amazon River and in the Brazilian state of Maranhão). B. Dorsal view of a bluish specimen. C. Dorsal view of a greenish specimen. D. Ventral view of a greenish specimen. 
(populations on the banks of the Amazon River), diffuse, or even totally absent; on the sides, alveolar microsculpture always present.

Aedeagus. Parameres half as long as phallobase and strongly asymmetrical: external face of right paramere flat and external face of left paramere concave, strongly excavated. In lateral view, parameres with ventral keel strongly projected, giving squarish appearance to apical half of parameres, and with pronounced notch posteriorly to ventral keel (Fig. 18B).

SeXual Dimorphism. Males: Protibial spur wide at base and with two apical projections: external projection spiniform and longer than internal one, usually only slightly indicated (Fig. 15J). Ventrite VI with posterior edge strongly narrowed at centre; anterior edge slightly covered by medial flange of ventrite V. Females: Protibial spur spiniform, simple. Ventrite VI very wide at centre, posterior edge straight, without emargination; anterior edge distinctly covered by medial flange of posterior edge of ventrite $\mathrm{V}$.

\section{Measurements}

Males $(\mathrm{N}=15)$. TL: AV: $7.5 \pm 0.46$; MX: 8.5; MN: 6.8. EW: AV: $5.7 \pm 0.31$; MX: 6.1; MN: 5.2. PrL: AV: $2.3 \pm 0.18$; MX: 2.7; MN: 2.1. PrW: AV: $4.8 \pm 0.28$; MX: 5.3; MN: 4.4. PgL: AV: $1.4 \pm 0.05$; MX: 1.5; MN: 1.3. PgW: AV: $2.3 \pm 0.13$; MX: 2.5; MN: 2.1 .

Females (N = 13). TL: AV: $7.9 \pm 0.31$; MX: 8.4; MN: 7.4. EW: ME: $6.01 \pm 0.24$; MX: 6.3; MN: 5.6. PrL: AV: $2.6 \pm 0.12$; MX: 2.9; MN: 2.5. PrW: AV: $5.0 \pm 0.21$; MX: 5.5; MN: 4.8. PgL: AV: $1.4 \pm 0.08$; MX: 1.5; MN: 1.3. PgW: AV: $2.5 \pm 0.12$; MX: 2.7; MN: 2.2.

\section{Geographical distribution}

Northern Amazonia in Trinidad, Venezuela, Guyana, Suriname, French Guiana and Brazil.

\section{Ecoregions}

Venezuelan Andes Montane Forests, Trinidad and Tobago Moist Forests, Guianan Highlands Moist Forests, Negro-Branco Moist Forests, Guianan Moist Forests, Paramaribo Swamp Forests, Guianan Savanna, Uatuma-Trombetas Moist Forests, Japurá-Solimões-Negro Moist Forests, Tocantins-Pindaré Moist Forests.

\section{Collecting sites (Fig. 34)}

TRINIDAD AND TOBAGO. Arima (William Beebe Tropical Research Station), Couva-TabaquiteTalparo, Sangre Grande (Arena Forest Reserve), Tunapuna-Piarco (Mount Saint Benedict).

VENEZUELA. Mérida: Libertador (Mérida: Monte Zerpa). Monagas: Maturín. Delta Amacuro: Casacoima. Bolívar: Gran Sabana (San Francisco Yuruaní), Isla Anacoco, Las Trincheras, Mata de Corocito, Padre Pedro Chien, Sinfontes, Sucre (Salto Pará). Amazonas: Alto Orinoco, Puerto Ayacucho (Atures: Cerro Camani), San Juan de Manapiare.

GUYANA. Potaro-Siparuni: Iwokrama Forest. Upper Takutu-Upper Essequibo: Upper Essequibo Conservation Concession.

SURINAME. Saramacca. Commewijne: Akintosoela. Marowijne. Para: Zanderij. Brokopondo: Brownsburg Nature Reserve.

FRENCH GUIANA. Cayenne (Camopi; Kourou; Matoury: Réserve naturelle nationale du mont Grand Matoury; Montsinéry-Tonnegrande: Montagne des Chevaux; Régina: Kaw, Réserve naturelle nationale 
des Nouragues; Roura: Réserve naturelle régionale Trésor; Saint-Georges-de-l'Oyapock), Saint-Laurentdu-Maroni (Maripasoula: Saül; Mana: Acarouany).

BRAZIL. Roraima: Cantá (Serra Negra), Pacaraima. Amazonas: Manaus. Amapá: Pedra Branca do Amaparí. Pará: Belém, Primavera, Santo Antônio do Tauá. Maranhão: Bom Jardim (Reserva Biológica Gurupi), Itapecuru-Mirim.

\section{Intraspecific variation and taxonomic discussion}

Sylvicanthon seag sp. nov. is the only representative of the bridarollii subgroup that, as far as we know, is totally allopatric in relation to the other species of its group: it occurs from the Cordillera de Mérida, in western Venezuela, and the island of Trinidad, in the Caribbean Sea, to the Guianas and the northern region of the Brazilian Amazonia (Fig. 34). Throughout most of its extension, the distribution of S. seag sp. nov. is restricted to the left banks of the Amazon River, crossing to the other side only near to its mouth with the Atlantic Ocean, being present in localities such as Belém and Santo Antônio do Tauá in Pará, and at the Reserva Biológica Gurupi in Maranhão. Sylvicanthon attenboroughi sp. nov., the species most closely related to $S$. seag sp. nov., is limited to the right banks of the Amazon. Because the distribution of $S$. attenboroughi sp. nov. does not cross to the right banks of the Tapajós River, this species does not occur so far east to be found in sympatry with the populations of $S$. seag sp. nov. in Pará and Maranhão.

Throughout this vast area, $S$. seag sp. nov. shows a noteworthy geographical variation related to the sculpture of pygidium and colouration. Individuals from southern populations, including those on the banks of the Amazon River (e.g., Manaus and Belém), have a pygidium covered by a distinct alveolar microsculpture and dorsal colouration very similar to that seen in $S$. attenboroughi sp. nov.: head and pronotum purple and greenish elytra (Fig. 37A). To the north, the pygidial microsculpture becomes weaker and, in some specimens, the tegument seems to be completely smooth at the centre. Regarding the colouration, individuals from the Guianas and Venezuela possess a purple head with greenish reflections and pronotum and elytra shiny green or dark blue (the former colour more common than the latter) (Fig. 37B-C). A few specimens from French Guiana, however, have the pronotum mostly covered by a purple colouration, so appearing to be an intermediate phase between the colouration seen farther south and the more typical one seen in this part of the distribution of S. seag sp. nov. Likewise, the two specimens known from Santo Antônio do Tauá also have this intermediate phase between the northern and southern colouration patterns. In Trinidad, finally, the colouration pattern is typically northern, but it differs from the continental populations in having the dark blue as the most frequent colour instead of shiny bright green.

Despite the wide geographical variation discussed above, there is one fundamental characteristic for the identification of $S$. seag sp. nov. that does not seem to vary significantly, either intra- or interpopulationally: the shape of the parameres. In $S$. seag sp. nov., these structures are strongly asymmetric (the external face of the right paramere is flat, while the external face of the left paramere is strongly excavated) and, in lateral view, possess a ventral keel strongly projected, with a squarish appearance (Fig. 18B). No other species of Sylvicanthon has such an elaborate aedeagus. If, externally, individuals of $S$. attenboroughi sp. nov. are extremely similar to specimens from southern populations of S. seag sp. nov. and can be easily confused with them, the examination of the parameres leaves no doubt as to the correct identification of the specimens (Fig. 18D). Other differences between both species rest in the metaventral micropunctation, on the anterior margin of the female ventrite VI and on the pygidial tegument (see Table 4).

From the other two species of the bridarollii subgroup, $S$. seag sp. nov. is different simultaneously in having an evident micropunctation on the head, and by the hypomeral cavity strongly excavated 
(Fig. 35A), the shape of the anterior margin of female ventrite VI, metaventral and pygidial tegument, the shape of parameres (Fig. 18B) and the distribution (Fig. 34). Specifically from S. edmondsi sp. nov., S. seag sp. nov. is different in dorsal colouration (Fig. 37A-C) and size, while it is distinguished from $S$. bridarollii by the tegument of pronotum, the absence of setae at the centre of the hypomeral cavity (Fig. 35A), the shape of the protibiae (Fig. 11H-I), and the absence of coarse punctation at the base of the metafemora (Table 4).

\section{Comments}

Two specimens from the collection of Antonio Martínez are certainly mislabelled: a female supposedly collected at Lago Agrio, in Napo, Ecuador, and another female labelled "Tingo María Universidad", in Huánuco, Peru. From this latter locality, we have examined specimens of $S$. genieri sp. nov. and S. bridarollii, species that indeed occur in Huánuco and, therefore, should be correctly labelled. As they came from the same collection, it is possible the female of S. seag sp. nov. now labelled "Tingo María Universidad" has been accidently mixed up with the material collected in that region and, consequently, received - erroneously - the same provenience label.

\section{Natural history}

Specimen labels show that $S$. seag sp. nov. can be collected with a wide variety of traps: pitfalls baited with human faeces and pig dung, flight interception traps, malaise and light traps, both white and ultraviolet light. This species is collected year-round, but, in the Guianas, Venezuela, and Trinidad, places from where we could examine more material, it is clearly more abundant between May and September. Lastly, labels tell us that S. seag sp. nov. occurs between 30 and $800 \mathrm{~m}$ (but near $2000 \mathrm{~m}$ for the sole specimen collected in Cordillera de Mérida).

Feer \& Pincebourde (2005), studying the flight activity time of dung beetles from a locality in French Guiana, classified S. seag sp. nov. (cited as $S$. candezei) as a diurnal species, a fact that would differentiate it from the other members of Sylvicanthon. Nevertheless, by examining their data more carefully, we see that they collected only two specimens of $S$. seag sp. nov., one at 9:00 and other at 21:00. Therefore, their results are very far from being conclusive for this species. The truth is that the few data we have on the flight time of $S$. seag sp. nov. point to a nocturnal life: as said above, specimens are attracted to light traps, and a female collected in 1969 by Gonzalo Halffter at Îlet Massikiri, on the Oyapock River, also in French Guiana, was caught at night.

Sylvicanthon edmondsi sp. nov. urn:lsid:zoobank.org:act:6C7F8A07-DAB4-4CB9-B0BA-D7CF986C19F5

Figs 11I, 13F, 15K, 18C, 20, 34, 38A-B

Sylvicanthon sp. 1 - Celi et al. 2004: 46.

Sylvicanthon cf. bridarolli [sic] - Noriega et al. 2008: 79 (tentative association).

\section{Etymology}

A tribute to the great American scarabaeidologist W.D. Edmonds, a student of the tribe Phanaeini and author of some of the major classics on the biology and morphology of Scarabaeinae. In recognition of his very kind support and continuous encouragement to MC since their very first contact. The holotype of $S$. edmondsi sp. nov. is deposited in the TAMU collection, the institution where the formerly private Edmonds collection is now housed (Streit 2012). The specific name is a noun in the genitive case. 


\section{Material examined}

\section{Holotype}

ECUADOR: Ō, Orellana, Parque Nacional Yasuní, Estación Científica Yasuní, 215 m ("ECUADOR: Napo Prov. / Estación Cientifica Yasuní / IX-5-10-1999, 215 m / Coll. E. G. Riley”, "TAMU-ENTO / X0668859 / [código de barras]") (TAMU).

Paratypes $(42 \hat{\jmath}, 43 q q)$

COLOMBIA: Amazonas: 1 đ̊, 1 , Leticia, Parque Nacional Natural Amacayacu, Dec. 1998, J. Noriega leg. (CPJN). - Caquetá: 1 q, Parque Nacional Natural Sierra de Chiribiquete, 300 m, Feb. 2000, pitfall with human faeces, J. Noriega leg. (CPJN).

ECUADOR: Morona Santiago: 5 ภ̂̉ (1 dissected), 2 우, Untsuants, sítio 3, 700 m, 13 Jan. 2002,

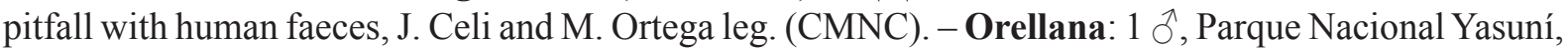
Estación Científica Yasuní, 00³8' S, 76³6' W, 215 m, 27. Jul.-1 Aug. 1998, pitfall with human faeces,

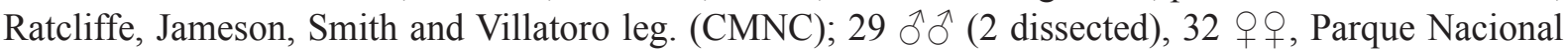
Yasuní, Estación Científica Yasuní, 215 m, 5-10 Sep. 1999, E.G. Riley leg. (TAMU); 1 đ̃, Parque Nacional Yasuní, Estación Científica Yasuní, 9-17 Sep. 1999, D.G. Marqua leg. (TAMU); 1 đ̊, Parque Nacional Yasuní, via Maxus km "Onkone Gare”, 220 m, 14 Nov. 2001, canopy fogging, P. Araujo leg. (CEMT); 2 §ิ, 1 \&, Rodrigo Borja, IAMOE, 4 Jun. 2000, pitfall with human faeces, A. Dávalos leg. (CEMT); 1 ô, Tiputini Biodiversity Station, $0^{\circ} 38^{\prime} \mathrm{S}, 76^{\circ} 09^{\prime} \mathrm{W}, 220 \mathrm{~m}$, sep. 2000, carrion trap, D. Inward leg. (BMNH); 2 우, Tiputini Biodiversity Station, Río Tiputini, 040.5' S, 76² $24^{\prime}$ W, Jul. 1999, flight interception trap, A. Tishechkin leg. (CEMT).

PERU: Junín: 1 đૈ, Satipo, Oct.-Nov. 2002 (CEMT). - Loreto: 3 qq, Campamento San Jacinto, 02 ${ }^{\circ} 8^{\prime} 44.85^{\prime \prime}$ S, 7551'46" W, 175-215 m, 3-12 Jul. 1993, flight interception trap, R. Leschen leg. (CMNC); 1 \&, Río Pucacuro, 203 m, 21 Nov. 2007, dung pitfall, Cesar Moreno leg. (CEMT).

\section{Description}

Colouration. Entire body with very dark tonalities. Head dark purple (in some specimens, frons with greenish reflections). Pronotum with strong greenish or bluish sheen at centre and purplish reflections on sides. Elytra usually dark blue or purple, occasionally with weak greenish reflections; striae with same colouration as the rest of tegument and not contrasting with it. Metaventrite black with very weak greenish or coppery shine. Meso- and metafemora orange-brown or yellowish, with base distinctly darker than at least apical two-thirds. Pygidium usually with predominant greenish shine and some coppery reflections, especially at base.

HEAD. Tegument little shiny, with strong alveolar microsculpture obliterating almost completely micropunctation, which is almost imperceptible or even absent throughout outer edge of head. Clypeus with two apical teeth obtuse and only slightly separated from one another; with single transverse row of setae covering base of both teeth. Genae with strong tooth immediately behind clypeal-genal juncture. Posterior edge of head completely unmargined.

THORAX. Pronotum with tegument slightly bright and lustrous, with very fine microsculpture (sometimes absent at centre), and dense, clearly marked central micropunctation. Posterior edge with fine transverse line at centre (usually extending only up to second elytral stria). Hypomeral cavity entirely glabrous or at most with very few short setae at centre; long setae, if present, restricted to anterior and posterior regions (Fig. 35B); external margin with weak tubercle. Metaventrite entirely glabrous; tegument with strong rivose microsculpture on anterior region and weaker microsculpture adjacent to internal margin of mesocoxae; at centre, alveolar microsculpture very fine and progressively more diffuse and undifferentiated towards posterior region; micropunctation very fine, but always evident. 
Legs. Ventral surface of all femora and tibiae bright. Profemora with tegument with strong rivose microsculpture and without micropunctation. Protibiae narrow and with internal edge straight and simple, without expansion; at apical third, with three acute teeth, two apical ones of subequal length and larger than basal (Fig. 11I). Mesofemora margined anteriorly only at their basal half; unmargined portion of anterior edge with row of very short setae; posterior margin absent; tegument with effaced rivose microsculpture. Metafemora margined anteriorly, posterior margin absent; apical half of anterior edge covered by row of setae; tegument covered by diffuse rivose microsculpture and without any trace of coarse punctation at base (Fig. 13F). Metatarsomeres II and V subequal in length and longer than the others; metatarsomere IV shorter than the others.

ELYTRA. With at most nine very narrow visible striae: in general, first two to four striae well marked, very finely carinulate, and without basal widening; remaining striae progressively more effaced and interrupted; eighth and ninth only seen in specimens with very well-marked striae and, in these cases, always very subtle; all striae lack carinulae before reaching apex of elytra, where they are completely indistinct; humeral carina absent. Tegument of interstriae with diffuse shine and lustrous, with alveolar microsculpture throughout elytra surface; micropunctation, in general, clearly visible at $20 \mathrm{x}$ magnification.

Aвdomen. Tegument of ventrites I-V with rivose microsculpture, in general, diffuse at centre; ventrite VI with rivose microsculpture very diffuse and micropunctation very subtle; both sexes without lateral foveae. Pygidium with shiny tegument and covered by alveolar microsculpture; micropunctation subtle, but always evident among microsculpture.

AEDEAGus. Parameres at least half as long as phallobase and asymmetrical: external face of right paramere flat, external face of left paramere concave, strongly excavated. In lateral view, parameres with ventral keel (Fig. 18C).

Sexual dimorphism. Males: Protibial spur narrow and bifid at apex, with spiniform projections, the external projection much longer than the internal one (Fig. 15K). Ventrite VI with posterior edge strongly narrowed at centre; anterior edge covered only very slightly by weak medial flange of ventrite $\mathrm{V}$. Females: Protibial spur simple, spiniform. Ventrite VI very broad at centre; anterior edge covered by weak medial flange of posterior edge of ventrite $\mathrm{V}$.

\section{Measurements}

Males (N =10). TL: AV: $7.0 \pm 0.70$; MX: 8.0; MN: 6.1. EW: AV: $5.3 \pm 0.42$; MX: 5.7; MN: 4.3. PrL: AV: $2.3 \pm 0.10$; MX: 2.5; MN: 1.8. PrW: AV: $4.5 \pm 0.36$; MX: 4.9; MN: 3.7. PgL: AV: $1.4 \pm 0.12$; MX: 1.5; MN: 1.1. PgW: AV: $2.2 \pm 0.17$; MX: 2.3; MN: 1.8 .

Females (N =12). TL: AV: $7.2 \pm 0.49$; MX: 8.0; MN: 6.4. EW: AV: $5.2 \pm 0.30$; MX: 5.7; MN: 4.7 . PrL: AV: $2.3 \pm 0.19$; MX: 2.6; MN: 2.0. PrW: AV: $4.5 \pm 0.26$; MX: 4.9; MN: 4.1. PgL: AV: $1.3 \pm 0.10$; MX: 1.4; MN: 1.1. PgW: AV: $2.2 \pm 0.17$; MX: 2.5; MN: 1.9 .

\section{Geographical distribution}

Northwestern Amazonia, mainly in Sub-Andean areas in Colombia, Ecuador, and Peru.

\section{Ecoregions}

Napo Moist Forests, Cordillera Oriental Montane Forests, Peruvian Yungas.

Collecting sites (Fig. 34)

COLOMBIA. Caquetá: Parque Nacional Natural Sierra de Chiribiquete. Amazonas: Leticia (Parque Nacional Natural Amacayacu). 

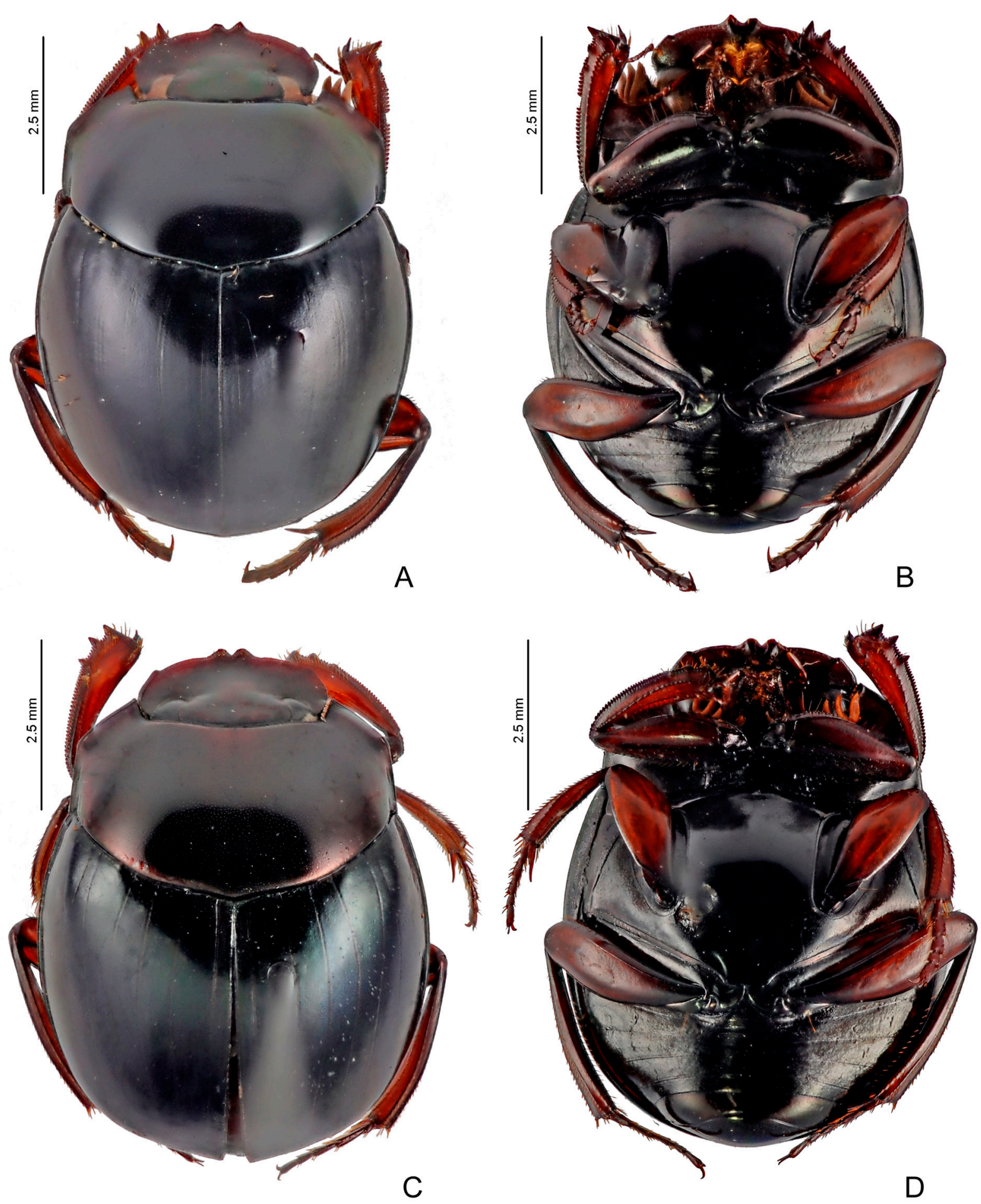

Fig. 38. A-B. Sylvicanthon edmondsi sp. nov. A. Dorsal view. B. Ventral view. C-D. Sylvicanthon attenboroughi sp. nov. C. Dorsal view. D. Ventral view. 
ECUADOR. Orellana: Parque Nacional Yasuní, Tiputini Biodiversity Station. Morona Santiago: Untsuants.

PERU. Loreto: Campamento San Jacinto. Junín: Satipo.

\section{Intraspecific variation and taxonomic discussion}

Sylvicanthon edmondsi sp. nov. is an interesting case of a species easily recognizable at first glance by its darker colouration (Fig. 38A), its very subtle elytral striae, and its smaller size, but that does not have any exclusive morphological character, as the shape of the parameres or a specific micropunctation or microsculpture pattern, that could differentiate it from the other species in a more objective way. Along with $S$. seag sp. nov. and $S$. attenboroughi sp. nov., S. edmondsi sp. nov. is distinguished very easily from $S$. bridarollii by the shape of the parameres: in lateral view, a strong ventral keel is seen in S. edmondsi sp. nov. (Fig. 18C), while the parameres are simple in the latter species (Fig. 18A); besides, the parameres' external faces are asymmetrical in $S$. edmondsi sp. nov. (left paramere with external face excavated and right paramere flat), while they are symmetric (both faces flat) in $S$. bridarollii. Furthermore, S. edmondsi sp. nov. distinguishes itself from S. bridarollii by the tegument at the centre of the pronotum, which shows a fine, sometimes smoothed microsculpture, and a very dense, clearly marked micropunctation; by the absence of long setae at the centre of the hypomeral cavity (Fig. 35AB); metaventrite with a very fine microsculpture at the centre; and the shape of the protibiae (Fig. 11I). From S. attenboroughi sp. nov. and S. seag sp. nov., S. edmondsi sp. nov. differs simultaneously by head with micropunctation almost imperceptible and hypomeral cavity not as strongly excavated as in the first two species; from $S$. seag sp. nov., in particular, S. edmondsi sp. nov. is different mostly because of the shape of the protibial spur (Fig. 15K), the shape of the anterior margin of the female ventrite VI, and the shape of the parameres (Fig. 18C). See Table 4 for a detailed comparison between S. edmondsi sp. nov. and the other species of the bridarollii subgroup.

The distribution of $S$. edmondsi sp. nov. is the most limited in the bridarollii subgroup: this species is present in the humid forests on the slopes of the Andes, in altitudes between 200 and $1110 \mathrm{~m}$, from Colombia in the north to Peru in the south (Fig. 34). We have not seen any geographical variation among the studied populations.

\section{Comments}

It was possible to verify that the morphotype named "Sylvicanthon sp. 1" by Celi et al. (2004) is, in fact, $S$. edmondsi sp. nov. because we examined some of the specimens collected by them (which are now housed at the CMNC) and found the following results: six specimens of $S$. edmondsi sp. nov. from site ("Sítio") $3(700 \mathrm{~m})$; three specimens of S. bridarollii from site $1(700 \mathrm{~m})$, one from site $3(700 \mathrm{~m})$, four from site $5(600 \mathrm{~m})$ and seven from site $6(600 \mathrm{~m})$; and a male $S$. genieri sp. nov. from site $4(1100 \mathrm{~m})$ and three others from site 7 (900 m). Table 3 of Celi et al. (2004) shows that what they called S. bridarollii was collected between 500 and 900 m, "Sylvicanthon sp. 1", between 600 and 1110, and "Sylvicanthon sp. 2", between 600 and $1300 \mathrm{~m}$. Putting all these data together, we conclude that the specimens of S. bridarollii were correctly identified by Celi et al. (2004), while morphotypes "Sylvicanthon sp. 1" and "Sylvicanthon sp. 2" refer, respectively, to $S$. edmondsi sp. nov. and S. genieri sp. nov.

\section{Natural history}

Label information tell us that adults of $S$. edmondsi sp. nov. are active at least between June and January (during that period, no records only from October and December). Specimens were collected mostly in pitfall traps baited with human faeces, but a male from the Tiputini Biodiversity Station (Morona Santiago, Ecuador) was attracted to carrion. Another male was collected at the Parque Nacional Yasuní (Orellana, Ecuador) by the canopy fogging method, but there are no data as to the height of the trees. As for the altitudinal amplitude, studied specimens were collected between 200 and $700 \mathrm{~m}$; in Morona 
Santiago, Celi et al. (2004) collected 116 specimens between 600 and 1110 (cited as "Sylvicanthon sp. 1"; see the discussion of $S$. bridarollii for details on the sympatry between that species and $S$. edmondsi sp. nov.).

Sylvicanthon attenboroughi sp. nov. urn:1sid:zoobank.org:act:2CE9C82F-6618-4579-BA18-D49F3C8BCED7

Figs $11 \mathrm{H}, 15 \mathrm{~L}, 18 \mathrm{D}, 20,34,35 \mathrm{~B}, 38 \mathrm{C}-\mathrm{D}$

Sylvicanthon cf. sp. nov. - Larsen 2004: 261.

Sylvicanthon sp. 1 - Silva et al. 2014: 348.

Sylvicanthon sp. - Pacheco et al. 2016: 143, 147, fig. P.

\section{Etymology}

A tribute to the great British naturalist and broadcaster Sir David Attenborough. In recognition of his profoundly influential work on the public understanding of natural history and evolutionary biology, which, for more than six decades, has been inspiring young people of successive generations (including the first author) to pursue a career as a biologist and the general public to know and preserve the beautiful world in which we live. We paraphrase him: "I did so because I know of no pleasure deeper than that which comes from contemplating the natural world and trying to understand it" (Attenborough 2002). The specific name is a noun in the genitive case.

\section{Material examined}

\section{Holotype}

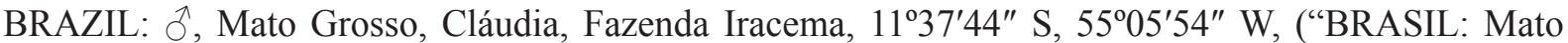

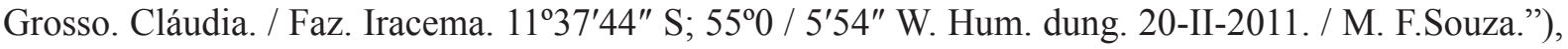
genital capsule extracted and glued to a triangular card (CEMT).

Paratypes $(63 \hat{\jmath}, 67 \uparrow+$ $)$

BRAZIL: Acre: +, Manoel Urbano, Parque Estadual Chandless, 09 $22^{\prime 2} 26^{\prime \prime}$ S, 69 $55^{\prime} 20^{\prime \prime} \mathrm{W}, 24$ Jun.

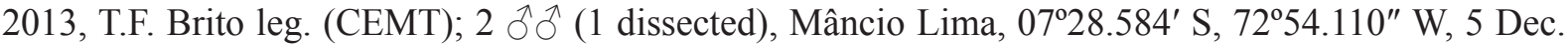
2012, H.M.B. Luiz \& N.S.G.F. Adem leg. (CEMT); 1 + , Senador Guiomard ["Rio Branco"], Fazenda Experimental Catuaba ["Catuaba"], 9 Apr. 1996, A. Bonaldo leg. (MCNZ); 1 đ, 4 우, Senador Guiomard ["Rio Branco"], Fazenda Experimental Catuaba, Feb. 1997, F.Z. Vaz-de-Mello leg. (CEMT).

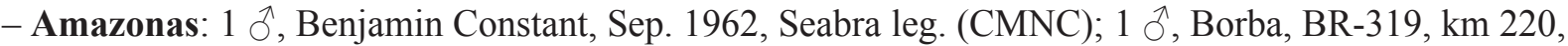
$04^{\circ} 22^{\prime} 55^{\prime \prime}$ S, 6057'19" W, 29 Nov. 2015, pitfall with human faeces, D. Pires leg. (CEMT); ㅇ, Borba,

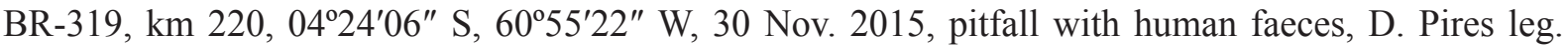

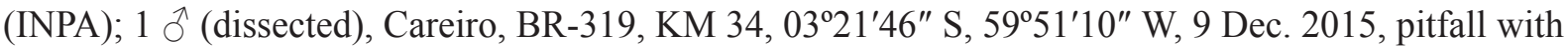

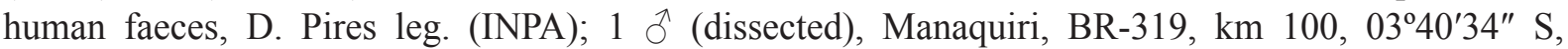
$60^{\circ} 17^{\prime} 46^{\prime \prime} \mathrm{W}, 6$ Dec. 2015, pitfall with human faeces, D. Pires leg. (INPA). - Mato Grosso: 8 우, Alta Floresta, 09 $56^{\prime} 52^{\prime \prime} \mathrm{S}, 5^{\circ} 03^{\prime} 02^{\prime \prime} \mathrm{W}$, May 2008, pitfall with human faeces, E. Berenguer leg.

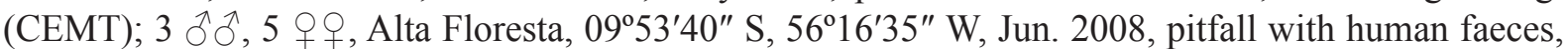
E. Berenguer leg. (CEMT); 1 + , Aripuanã, $10^{\circ} 03^{\prime} 10^{\prime \prime}$ S, 59 $29^{\prime} 42^{\prime \prime}$ W, 320 m, 26 Jan. 2012, H.A.B.

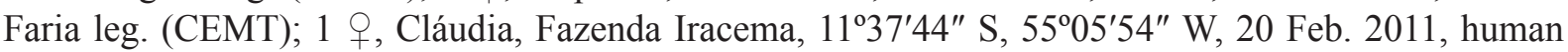
faeces, M.F. Souza leg. (CEMT); 2 우, Novo Mundo, Parque Estadual do Cristalino, 09 $27^{\prime} 53^{\prime \prime}$ S,

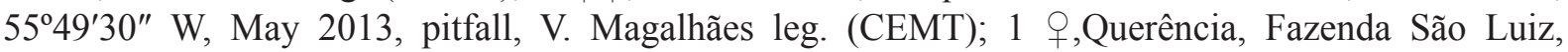
$12^{\circ} 39.85^{\prime} \mathrm{S}, 5^{\circ} 22.18^{\prime} \mathrm{W}, 50 \mathrm{~m}$, Feb. 2009, flight interception trap, R. Andrade leg. (CEMT). - Pará: 1 § (dissected), 1 9, Itaituba, Uruá, $65 \mathrm{~km} \mathrm{SW}$ of Itaituba on BR230 [“BR320”], 12-15 Oct. 1977, B.C. Ratcliffe leg. (CMNC); 1 ㅇ, Santarém, Reserva Extrativista Tapajós-Arapiuns, $03^{\circ} 03^{\prime} \mathrm{S}, 55^{\circ} 30^{\prime} \mathrm{W}$, 22 Dec. 2008, flight interceptation trap (CEMT); 1 (dissected), 1 q, Santarém, Reserva Extrativista 


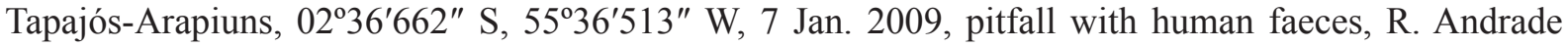
leg. (CEMT). - Rondônia: 1 đ, Itapuã do Oeste, Floresta Nacional ["FloNa"] do Jamari, 0905'21" S,

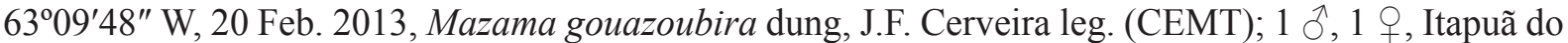
Oeste, Floresta Nacional ["FloNa"] do Jamari, 0905'20" S, 6309'47" W, 24 Feb. 2013, Mazama Nana dung, J.F. Cerveira leg. (CEMT); 2 $\widehat{\jmath}, 2$ 우, Itapuã do Oeste, Floresta Nacional ["FloNa"] do Jamari,

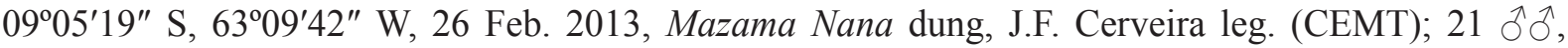
6 우우, Guajará-Mirim, 10 $44^{\prime} 53.56^{\prime \prime} \mathrm{S}, 6^{\circ} 17^{\prime} 31.1^{\prime \prime} \mathrm{W}, 14-16$ Feb. 2010, pitfall with human faeces, Fabricio Coletti leg. (CEMT); 1 ô, Guajará-Mirim, Fazenda Agropecuária A.J.B., 10³7'47.59" S, 6459'52.58" W, 180 m, 15 Jan. 2010, human faeces, F. Coletti leg. (CEMT); 1 +, Guajará-Mirim,

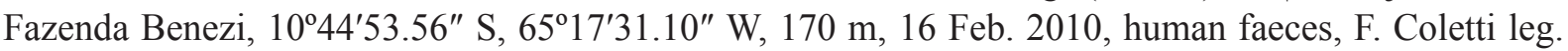
(CEMT); 1 ô, Ji-Paraná ("V. Rondonia (378 km S de P. Velho)"), 25 Jan.-9 Feb. 1961, Pereira and

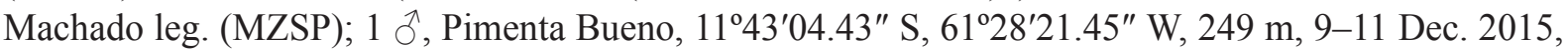
pitfall with human faeces, D.C. Castro leg. (CEMT); 1 o, Porto Velho, Bom Jesus, Rio das Garças, 08 $49^{\prime} 48^{\prime \prime}$ S, 63 $46^{\prime} 45^{\prime \prime}$ W, 20 Apr. 2017, flight interception trap, D.C. Santos and K.K.G. Silva leg.

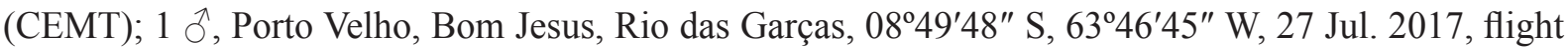
interception trap, D.C. Santos and K.K.G. Silva leg. (CEMT); 1 ${ }^{1}$, Porto Velho, Bom Jesus, Rio das

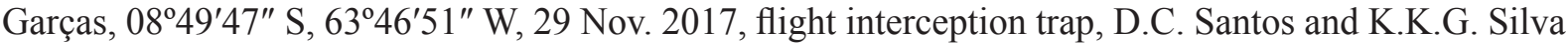

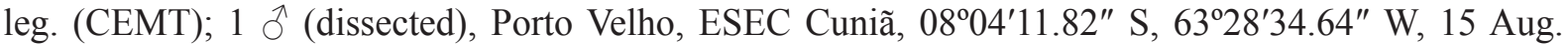
2012, pitfall with human faeces, M.A.P.A. Silveira leg. (CEMT); 1 ô, 1 q, Porto Velho, ESEC Cuniã,

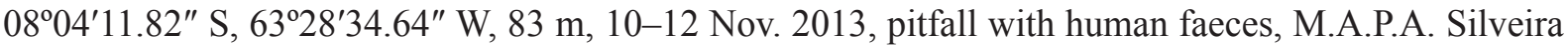

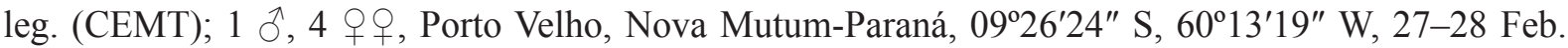
2010, human faeces, L.R. Silva and R.L.R. Silva leg. (CEMT); 1 đ̊, Porto Velho, Nova Mutum-Paraná ["Mutum"], 09'35'46" S, 6502'27" W, Jan. 2012, R.V. Nunes leg. (CEMT); 1 q, Porto Velho, Nova

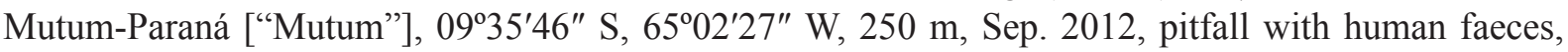
R.V. Nunes leg. (CEMT); 1 क, Vilhena, Nov. 1986, O. Roppa and P. Magno leg. (CEMT); 7 ठð (1 dissected), $7 q q$, Same collection data as for preceding (MNRJ); $1 \stackrel{\lambda}{\alpha}, 2$ q+ , Same collection data as for preceding (BMNH).

PERU: Cuzco: 1 q, La Convención, Echarate, Comunidad Kitaparay, 12²1'47.24" S, 7249'16.12" W, 479 m, 13 Nov. 2009, C. Espinoza and E. Rázuri leg. (MUSM). - Junín: 1 O̊, Satipo, Mashira, Río Tambo,

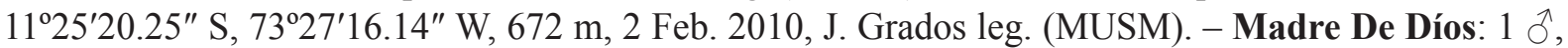
Manu, Huepetuhe ("Huaypetue"), 1259'27.07" S, 70³2'06.74" W, 15-17 Nov. 2010, J. Costa and M. Vilchez leg. (MUSM); 2 ○ึ (1 dissected), 1 ค, Manu, Manu, Salvación ("near Salvación”), 1350'37" S,

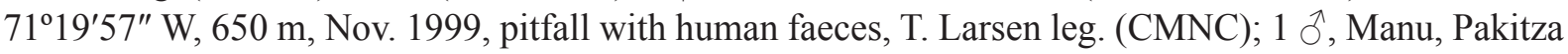
Biological Station, 28 Sep. 1987, B. Trocha leg. (MUSM); 2 우, Manu, Pantiacolla Lodge, 8 km NW

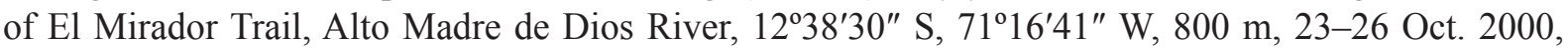
flight interception trap, R. Brooks leg. (CMNC); 1 ô (dissected), 1 ㅇ, Manu, Parque Nacional del Manu ("Manu National Park"), 15-30 Aug. 1986, A. Forsyth leg. (CMNC); 1 + , Manu, Parque Nacional del

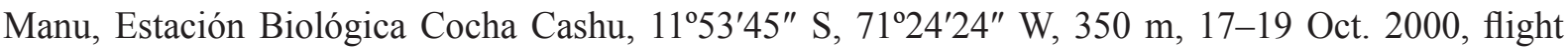
interception trap, R. Brooks leg. (CMNC); 1 + , Manu, Reserva Comunal Amarakaeri, 12 ${ }^{\circ} 59^{\prime} 51.87^{\prime \prime}$ S, 7050'26.05" W, 864 m, 2-4 Nov. 2010, J. Costa and M. Vilchez leg. (MUSM); 2 q $q$, Manu, Reserva Comunal Amarakaeri, 1259'51.87" S, 70 50'26.05" W, 864 m, 10-14 Nov. 2010, J. Costa and M. Vilchez

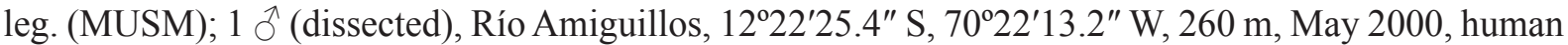
faeces, T. Larsen leg. (MUSM); 1 ㅅ, 2 우, Tambopata, Puerto Madonado, Sudadero, 12⒉ $21^{\prime} 19^{\prime \prime}$ S, 6901'48" W, 221 m, 26-27 Mar. 2009, L. Figueroa leg. (MUSM).

\section{Description}

Colouration. Entire body with very dark tonalities. Head and pronotum dark purple. Elytra dark green or dark blue; when green, striae dark blue and slightly contrasting with the rest of tegument. Metaventrite 
black. Meso- and metafemora orangish-brown, reddish-brown, or dark brown, with base distinctly darker than at least apical two-thirds. Pygidium usually coppery; occasionally, with greenish reflections.

HEAD. Tegument little shiny, with strong alveolar microsculpture; micropunctation evident on posterior region of clypeus and especially on frons. Clypeus with two apical teeth obtuse and only slightly separated; with single transverse row of short setae covering base of both teeth. Genae with strong tooth immediately behind clypeal-genal juncture. Posterior edge of head completely unmargined.

Thorax. Pronotum with slightly shiny and lustrous tegument, with very fine alveolar microsculpture (sometimes effaced at centre), and with dense, clearly marked micropunctation at centre, progressively weaker towards the sides. Posterior edge with fine transverse line at centre (usually extending only up to second elytral stria; sometimes effaced and almost indistinct). Hypomeral cavity entirely glabrous or at most with very few short setae at centre; long setae, if present, restricted to posterior region; external margin with weak tubercle. Metaventrite entirely glabrous; tegument with strong rivose microsculpture on anterior region and weaker adjacent to internal margin of mesocoxae; at centre, alveolar microsculpture very fine and progressively more diffuse and undifferentiated towards posterior region; micropunctation very fine, but usually distinct.

Legs. Ventral surface of all femora and tibiae shiny. Profemora with tegument with strong rivose microsculpture and without micropunctation. Protibiae narrow and with internal edge straight and simple, without expansion; at apical third, with three small acute teeth on external edge, two most apical ones of subequal length and larger than basal (Fig. 11H). Mesofemora margined anteriorly only at basal half; unmargined portion of anterior edge with row of very short setae; posterior margin absent; tegument with effaced rivose microsculpture. Metafemora margined only anteriorly, posterior margin absent; apical half of anterior edge covered by row of setae; tegument covered by effaced rivose microsculpture and, in a few specimens, with traces of coarse elongate punctation at base. Metatarsomeres II and V subequal in length and longer than the others; metatarsomere IV shorter than the others.

ELYTRA. With at most nine very narrow visible striae: in general, first five or six striae well marked, very finely carinulate and slightly widened at base; remaining striae progressively more effaced; eighth and ninth striae seen only in specimens with very well-marked striae and, in these cases, always very subtle; all striae lack carinulae before reaching apex of elytra, where completely indistinct; humeral carina absent. Tegument of interstriae with diffuse shine; at centre, with alveolar microsculpture ranging from clearly marked, in most specimens, to diffuse; at apex, always with strong alveolar microsculpture; micropunctation in general clearly visible at $20 \times$ magnification.

ABdomEn. Tegument of ventrites $\mathrm{I}-\mathrm{V}$ with strong rivose microsculpture at centre; ventrite VI with very diffuse rivose microsculpture and very subtle micropunctation; both sexes without lateral foveae. Pygidium with bright tegument covered by alveolar microsculpture; micropunctation subtle, but always evident among microsculpture.

AedeAgus. Parameres at least half as long as phallobase and asymmetrical: external face of right paramere flat, external face of left paramere concave, strongly excavated. In lateral view, parameres with strong ventral keel (Fig. 18D).

SeXual Dimorphism. Males: Protibial spur narrow and bifid at apex, with spiniform projections, external projection longer than internal one (Fig. 15M). Ventrite VI with posterior margin strongly narrowed at centre; anterior edge covered very slightly by weak medial flange of ventrite V. Females: Protibial spur simple, spiniform. Ventrite VI very broad at centre; anterior edge slightly covered by medial flange of posterior edge of ventrite $\mathrm{V}$. 


\section{Measurements}

Males $(\mathrm{N}=13)$. TL: AV: $8.5 \pm 0.54$; MX: 9.6; MN: 7.5. EW: AV: $6.1 \pm 0.35$; MX: 6.6; MN: 5.5 . PrL: ME: $2.5 \pm 0.14$; MX: 2.9; MN: 2.3. PrW: AV: $5.1 \pm 0.29$; MX: 5.5; MN: 4.6. PgL: AV: $1.6 \pm 0.11$; MX: 1.7; MN: 1.3. PgW: AV: $2.6 \pm 0.18$; MX: 2.9; MN: 2.3 .

Females (N =13). TL: AV: $8.4 \pm 0.55$; MX: 9.4; MN: 7.2. EW: AV: $6.1 \pm 0.29$; MX: 6.8; MN: 4.9. PrL: AV: $2.5 \pm 0.14$; MX: 2.8; MN: 2.4. PrW: AV: $5.2 \pm 0.32$; MX: 5.8; MN: 4.6. PgL: AV: $1.7 \pm 0.15$; MX: 1.9; MN: 1.4. PgW: AV: $2.6 \pm 0.20 ; \mathrm{MX}: 2.9 ; \mathrm{MN}: 2.3$.

\section{Geographical distribution}

Southern Amazonia in Brazil and Peru.

\section{Ecoregions}

Southwest Amazon Moist Forests, Peruvian Yungas, Madeira-Tapajós Moist Forests, Mato Grosso Tropical Dry Forests.

\section{Collecting sites (Fig. 34)}

BRAZIL. Acre: Mâncio Lima, Manoel Urbano (Parque Estadual Chandless), Rio Branco. Amazonas: Benjamin Constant, Borba, Careiro, Manaquiri. Pará: Itaituba (Uruá), Santarém (Reserva Extrativista Tapajós-Arapiuns). Rondônia: Guajará-Mirim, Itapuã do Oeste (Floresta Nacional do Jamari), JiParaná, Pimenta Bueno, Porto Velho, Vilhena. Mato Grosso: Alta Floresta, Aripuanã, Cláudia, Novo Mundo (Parque Estadual do Cristalino), Querência.

PERU. Junín: Satipo (Mashira). Cuzco: La Convención (Echarate). Madre de Díos: Manu (Huepetuhe; Manu: Salvación; Pakitza Biological Station; Pantiacolla Lodge; Parque Nacional del Manu; Reserva Comunal Amarakaeri), Tambopata (Puerto Madonado: Sudadero).

\section{Intraspecific variation and taxonomic discussion}

The distribution of $S$. attenboroughi sp. nov. is very interesting because, based on the data we have on hand, it seems to be clearly delimited by two major rivers in the Amazon Basin: the Amazon, which constrains dispersal towards forests farther north, and the Tapajós, the eastern limit of the distribution of S. attenboroughi sp. nov. in the centre of the Amazon Basin (i.e., excluding the populations in southern Amazonia in the state of Mato Grosso). Beyond those rivers (i.e., to the left banks of the Amazon and to the right banks of the Tapajós) inhabits $S$. seag sp. nov., a species very similar to $S$. attenboroughi sp. nov. and its possible sister species. Southern populations of $S$. seag sp. nov. (i.e., those closer to the range of $S$. attenboroughi sp. nov.) show colouration and pygidial tegument very similar to (if not totally indistinguishable of) those of $S$. attenboroughi sp. nov., but both species are easily separated from one another by the shape of the parameres, which are much simpler in $S$. attenboroughi sp. nov. (Fig. 18D) than the very complex shape seen in S. seag sp. nov. (Fig. 19A). Other differences that do not vary geographically between these two species are the shape of the male protibial spur and the shape of the anterior margin of female ventrite VI (Table 4; see also section on S. seag sp. nov. for a detailed discussion on the geographical variation seen in that species).

Sylvicanthon bridarollii is the only representative of the bridarollii subgroup to be found in sympatry with $S$. attenboroughi sp. nov. Both species are differentiated by the tegument of the head, pronotum, metaventrite and pygidium, the presence or absence of setae on the hypomeral cavity (Fig. 35), the shape of protibiae (Fig. 11F-H), the presence or absence of a coarse punctation at the base of the metafemora (Fig. 13F-H) and, finally, by the shape of the parameres (Fig. 18A, D) (Table 4). From S. edmondsi sp. nov., the fourth species of the bridarollii subgroup, $S$. attenboroughi sp. nov. is different 
in colouration (Fig. 38), size, head tegument and hypomeral cavity; the parameres, which are usually very distinctive among the species of Sylvicanthon, do not show any remarkable differences between S. attenboroughi sp. nov. and S. edmondsi sp. nov. (Fig. 18C-D) (Table 4).

Two intraspecifically-variable characters seen in S. attenboroughi sp. nov. call attention: the shape of the protibiae and the presence of coarse punctation at the base of the metafemora. In the great majority of the individuals of this species, the internal margin of the protibiae is straight $($ Fig. $11 \mathrm{H})$ and the metafemora do not show any trace of coarse punctation at their base (Fig. 13F), in the same way as in S. seag sp. nov. and $S$. edmondsi sp. nov. However, some very few specimens from Rondônia (Brazil) have the internal margin of the protibiae with a weak indication of expansion (similar to specimens of $S$. bridarollii from Ecuador and Colombia) and weak traces of a coarse punctation at the base of the metafemora (in the same way as in the populations of $S$. bridarollii from northern Peru). Future phylogenetic analyses will unveil whether those features are homologous to the states seen in S. bridarollii or whether they are homoplastics; if they are homologous, it will be interesting to know whether they constitute a synapomorphy between these two species or a symplesiomorphy in the subgroup that was completely lost independently in the majority of the $S$. attenboroughi sp. nov., the northern populations of S. bridarollii and by $S$. edmondsi sp. nov. and $S$. seag sp. nov..

\section{Natural history}

Very little information on the biology of $S$. attenboroughi sp. nov. is available on specimen labels. Adult activity seems to be restricted to the spring and summer months, with records from all months between September and March. Specimens were collected using pitfall traps baited with human faeces and flight interception traps. In relation to the altitudinal amplitude, $S$. attenboroughi sp. nov. seems to occur between 170 and $864 \mathrm{~m}$ a.s.1.

\section{The securus subgroup}

Sylvicanthon securus (Schmidt, 1920) comb. nov.

Figs 6F, 11C, 15O, 19A, 20, 39, 40A, 41

Canthon securus Schmidt, 1920: 131, 133.

Canthon securus - Schmidt 1922: 64, 80. - Balthasar 1939: 188. — Halffter \& Martínez 1977: 63. — Krajcik 2012: 64.

Canthon securum - Blackwelder 1944: 201.

Glaphyrocanthon (Glaphyrocanthon) securus - Pereira \& Martínez 1956: 126, 128. - Martínez et al. 1964: 5-6, 9, 14, 20. - Vulcano \& Pereira 1964: 664.

Sylvicanthon cf. securus - Larsen 2012: “92", 99.

\section{Etymology}

Possibly from the Latin 'securis', meaning 'axe' or 'hatchet', in reference to the shape of protibiae, which have a strong internal expansion. The Latin word 'securus', 'free of doubts', does not seem to be the origin of this name, unless Schmidt (1920) has referred to the fact that this species is extremely different from the others and, therefore, he had no doubts about its validity.

\section{Material examined}

Lectotype (here designated)

SURINAME: Ō, ("Surinam", "Securus", "Securus / A. Schm.", "Glaphyrocanthon / securus / (Schm.) / P. Pereira det. 60", "3205 / E92 +", "Securus / Schmidt", "34 / 56", "NHRS-JLKB / 000021093 " "LECTOTYPE ô / Canthon / securus / A. Schmidt / des. F. Z. Vaz-de-Mello, 2014") (NHRS) (Fig. 11H). 
Additional material $(22 \widehat{\jmath}, 27 \uparrow++, 1$ unsexed specimen)

BRAZIL: $1 \hat{\jmath}$, no further data (BMNH). - Amazonas: 2 우, Manaus, ZN 03, Km 41, 1996-1997 [Alouatta seniculus (?) dung], Ellen Andressen leg. (CEMT); 1 , same collecting data as for preceding

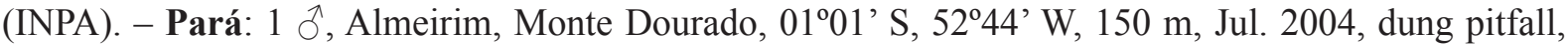
T.A. Gardner leg. (CEMT).

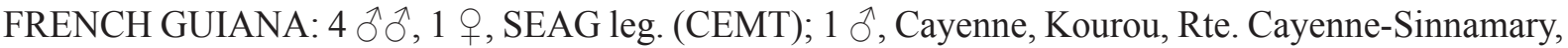
RN1, PK84, Jan. 2013, flight interception trap, SEAG leg. (CEMT); 1 क, Cayenne, Montsinéry-

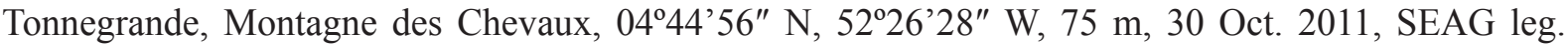

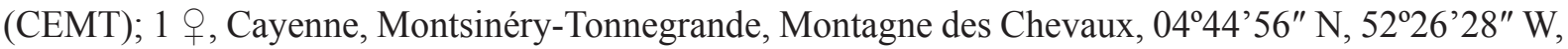
75 m, 27 Jan. 2013, SEAG leg. (CEMT); 1 đૈ, Cayenne, Montsinéry-Tonnegrande, Montagne des

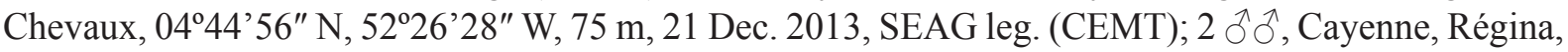
[Réserve naturelle nationale des] Nouragues, Nov. 1996, F. Feer leg. (CEMT); 1 unsexed specimen,

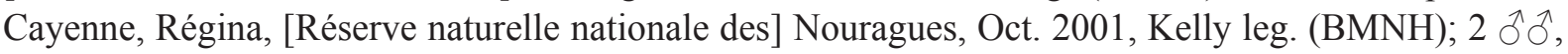
3 우, Cayenne, Régina, [Réserve naturelle nationale des] Nouragues, Inselberg, $04^{\circ} 05^{\prime} \mathrm{N}, 52^{\circ} 41^{\prime} \mathrm{W}$, 411 m, 4 Apr. 2010, SEAG leg. (CEMT); 1 ㅇ, Cayenne, Régina, [Réserve naturelle nationale des]

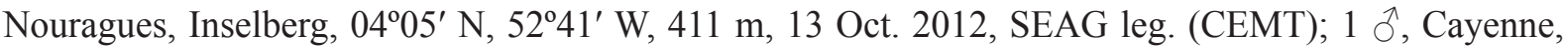
Régina, [Réserve naturelle nationale des] Nouragues, Inselberg, $04^{\circ} 05^{\prime} \mathrm{N}, 52^{\circ} 41^{\prime} \mathrm{W}, 411 \mathrm{~m}, 14 \mathrm{Jun} .2013$, SEAG leg. (CEMT); 1 đ (dissected), Cayenne, Régina, [Réserve naturelle nationale des] Nouragues, Inselberg, 04 $05^{\prime} \mathrm{N}, 52^{\circ} 41^{\prime} \mathrm{W}, 411 \mathrm{~m}, 19$ Sep. 2013, SEAG leg. (CEMT); 2 우, Cayenne, Roura, Montagne de Kaw, Nov. 1996, F. Feer leg. (CEMT); 1 , Cayenne, Roura, Montagne de Kaw, 3 Feb. 2007, F. Feer leg. (CEMT); 1 , , Cayenne, Roura, Montagne de Kaw, 17 Feb. 2009, F. Feer leg. (CEMT); 1 , Cayenne, Roura, Montagne de Kaw, 18 Feb. 2009, F. Feer leg. (CEMT); 2 우, Saint-Laurent- du-

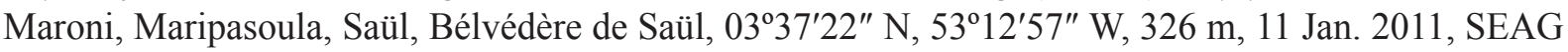

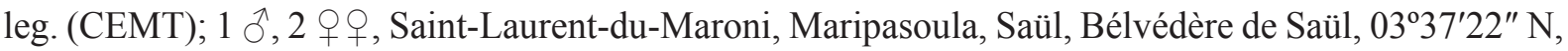

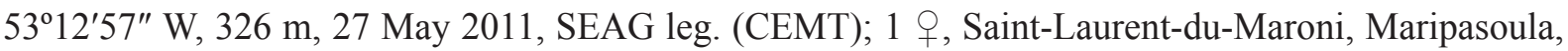

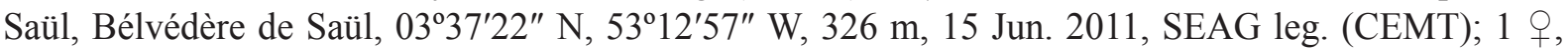

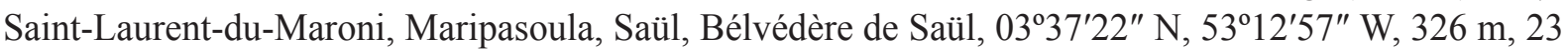
Jun. 2011, SEAG leg. (CEMT); 1 đ̂, 1 क, Saint-Laurent-du-Maroni, Maripasoula, Saül, Bélvédère de Saül, 03037'22" N, 53ำ12'57" W, 326 m, 28 Jul. 2011, SEAG leg. (CEMT); 3 우, Saint-Laurent-du-

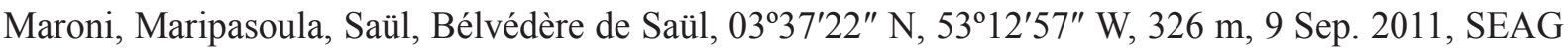
leg. (CEMT); 1 Õ, 1 †, Saint-Laurent-du-Maroni, Maripasoula, Saül, Bélvédère de Saül, 15 Sep. 2011, SEAG leg. (CEMT); 2 ภ̂̉, 2 우, Saint-Laurent-du-Maroni, Maripasoula, Saül, Bélvédère de Saül, Grand Boeuf Mort, 10 Oct. 2007, SEAG leg. (CEMT).

No data: $1 \lesssim$ (ISNB - “Coll. J. Thomson”); $1 \precsim$ (MNHN).

\section{Description}

Colouration. Head bicolour, with wide purplish or coppery area covering in general outer edge (apex of clypeus and genae) and posterior region (frons, posterior portion of clypeus, and, occasionally, part of genae) bright green. Pronotum entirely green, never with purplish or coppery spot. Elytra green, with striae contrasting or not. Metaventrite with greenish shine at centre and purplish or coppery at rest of tegument. Meso- and metafemora yellowish or orangish; profemur slightly darker than others. Pygidium bright green.

HEAD. Tegument with strong alveolar microsculpture throughout dorsal surface; micropunctation strongly marked on frons and progressively more effaced towards outer edge of head (Fig. 6F). Clypeus triangular, with very acute pair of apical teeth; each tooth individually margined at base. Genae with clear denticle immediately behind clypeal-genal juncture (denticle sometimes reduced by wear). Posterior 
edge of head usually with margin at centre (margin absent adjacent to eyes); in some specimens, margin very fine and almost imperceptible, or even absent.

Thorax. Pronotum with shiny tegument and dense, well-marked micropunctation at centre; towards sides, micropunctation progressively less dense and well marked, and sometimes absent; tegument among micropunctation smooth, without microsculpture; alveolar microsculpture restricted to very narrow strip of tegument on anterior edge of pronotum and anterolateral angles. Posterior edge with very fine transverse line at centre (usually extending little beyond the second elytral stria). Hypomeral cavity covered by long yellowish setae; external margin simple, without any trace of tubercle (occasionally, with only very weak callosity marking location of tubercle). Metaventrite glabrous at centre and with a group of very few yellowish setae on sides near external extremity of metacoxae; anterior region of metaventrite with tegument with strong rivose microsculpture; centre and posterior region with strong and dense micropunctation among smooth tegument, without any trace of microsculpture.

Legs. Profemora with tegument with diffuse rivose microsculpture, but hardly visible. Protibiae very narrow at basal half and with strong angulose expansion at apical half of internal edge, making apical half twice as wide as basal half; at apical fourth), with three small acute teeth on external edge - the most basal tooth distinctly smaller than others (Fig. 11C). Mesofemora margined anteriorly only at basal half; unmargined portion of anterior edge with row of very short setae; posterior margin absent; tegument smooth and lustrous, except for narrow strip on anterior edge with effaced rivose microsculpture. Metafemora margined only anteriorly, posterior margin absent; apical third of anterior edge covered by row of setae; tegument almost entirely smooth and lustrous, with weak traces of rivose microsculpture only at some regions; without coarse elongate punctation at base. Metatarsomeres II and V subequal in length and longer than the others; metatarsomere IV shorter than the others.
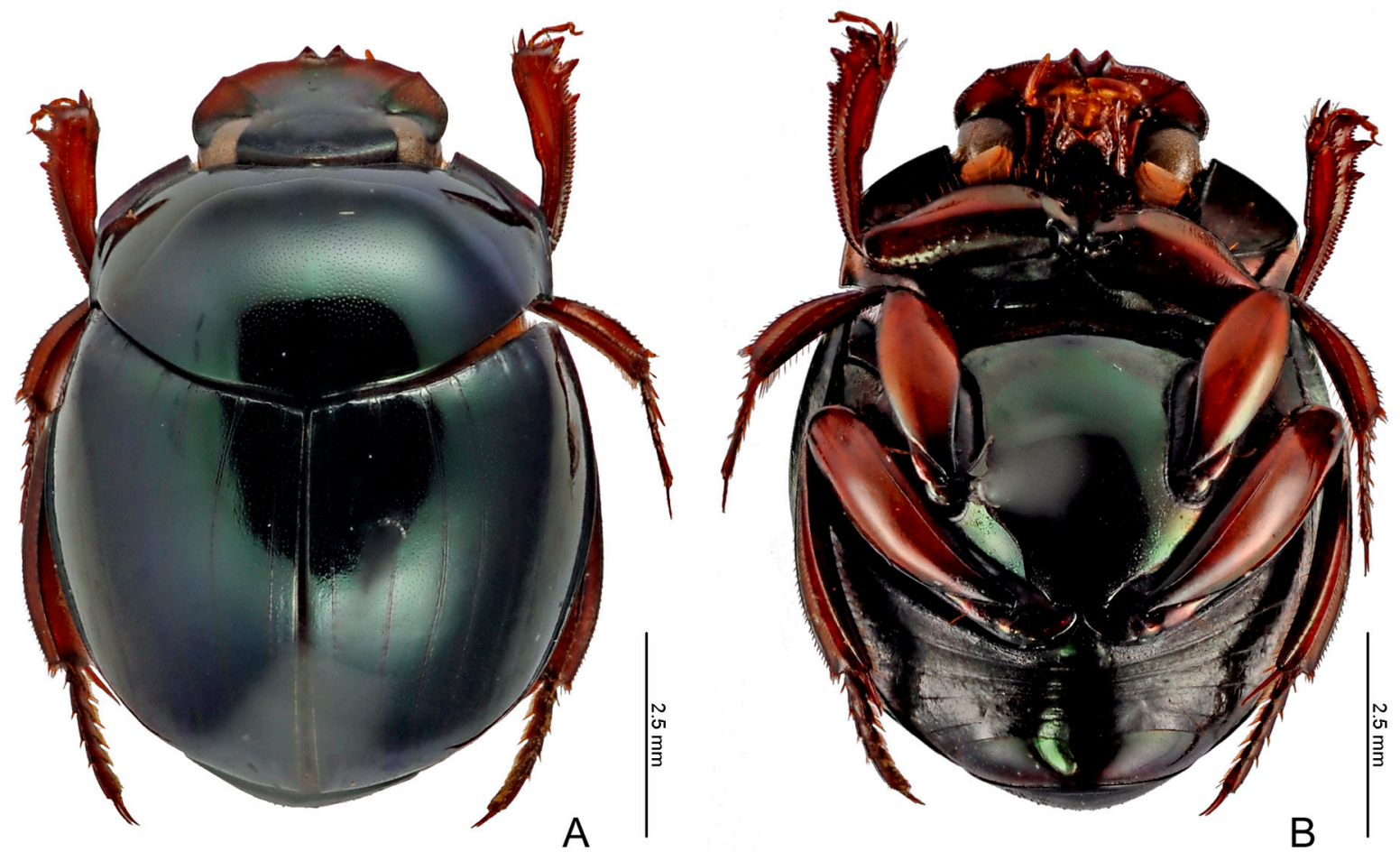

Fig. 39. Sylvicanthon securus (Schmidt, 1920) comb. nov. A. Dorsal view. B. Ventral view. 

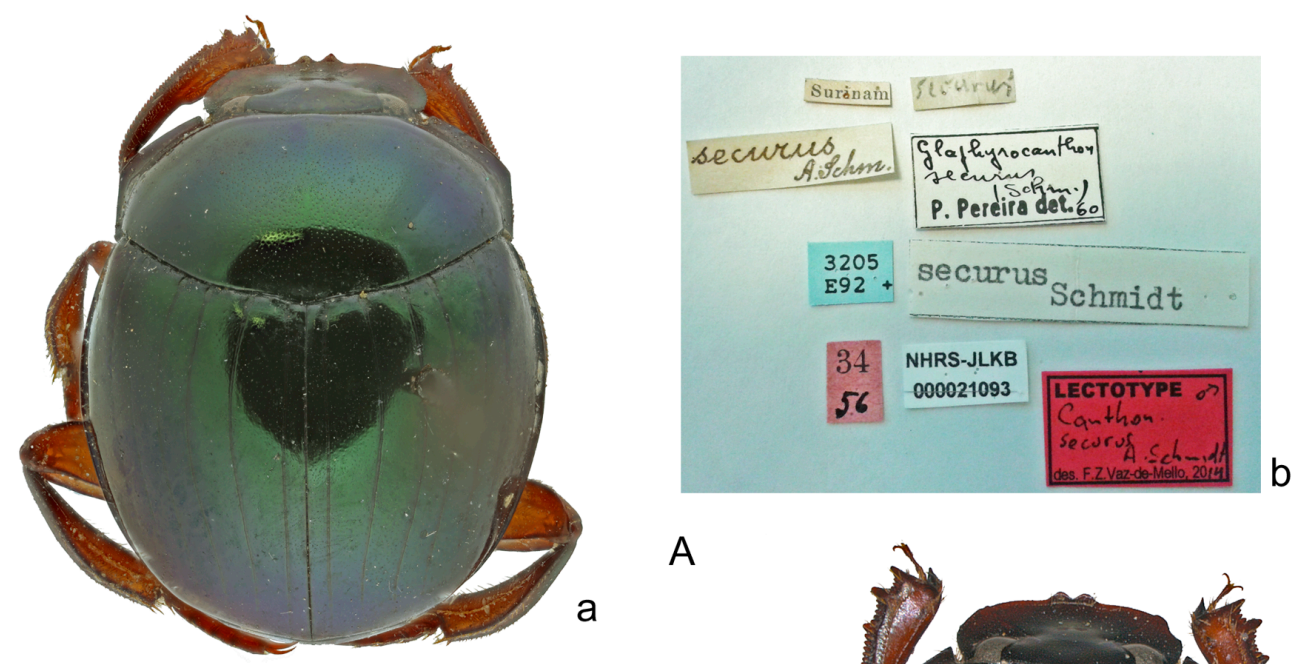

A
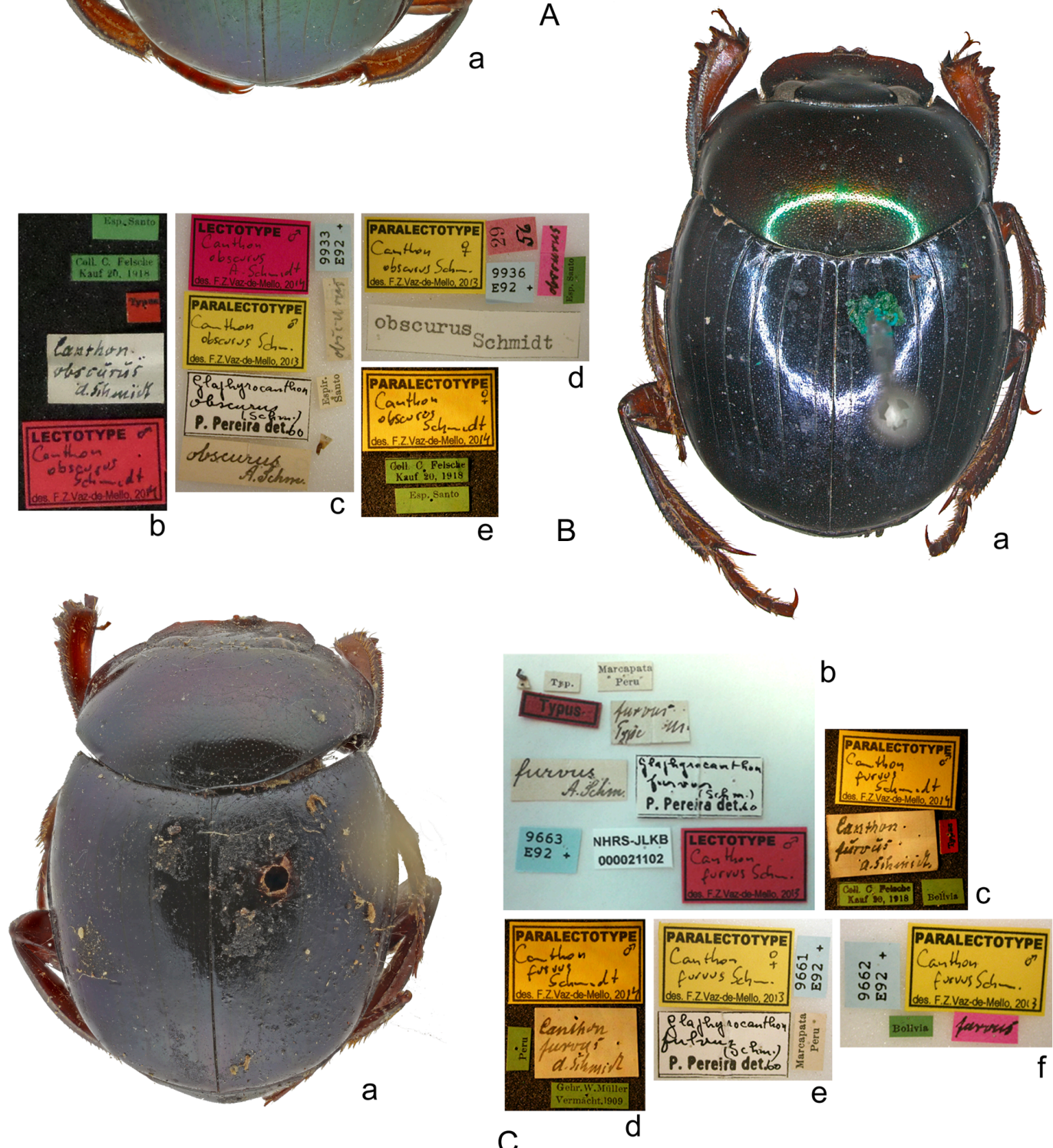

b

Fig. 40. Type material of three species of Sylvicanthon described by Schmidt (1920). A. S. secures (Schmidt, 1920) comb. nov. a. Lectotype. b. Lectotype's labels. B. S. obscurus (Schmidt, 1920). a. Lectotype. b. Lectotype's labels. c. Paralectotype 1. d. Paralectotype 3. e. Paralectotype 9. C. S. furvus (Schmidt, 1920). a. Lectotype. b. Lectotype's labels. c. Paralectotype 4. d. Paralectotype 6. e. Paralectotype 3. f. Paralectotype 1. 
Elytra. With seven very narrow visible striae: first five striae well marked, finely carinulate, and distinctly widened at base; sixth and seventh striae progressively more effaced and interrupted; seventh stria occasionally vestigial or even completely absent; all striae lack carinulae before reaching apex of elytra. Interstriae with dense, well-marked micropunctation at centre among smooth tegument; without any trace of microsculpture.

ABDOMEN. Tegument of ventrites I-V with strong rivose microsculpture; ventrite VI bright, without microsculpture, and with sparse micropunctation at centre, and with very weak rivose microsculpture on sides. Both sexes without lateral foveae. Pygidium with dense, well-marked micropunctation among tegument mostly smooth, with rivose microsculpture restricted to narrow strip adjacent to basal margin.

Aedeagus. Parameres simple, very long (only slightly shorter than phallobase), without ventral keel or notch, and with no noticeable asymmetry: both parameres with flat external face (Fig. 19A).

Sexual dimorphism. Males: Protibial spur broad and bifid, with internal projection broad and much longer than external projection, which is short and spiniform (Fig. 15O). Ventrite VI strongly narrowed at centre by emargination on posterior edge; ventrite $\mathrm{V}$ with weak medial flange on posterior edge covering anterior edge of ventrite VI. Females: Protibial spur spiniform. Ventrite VI very broad at centre, without emargination on posterior edge; ventrite $\mathrm{V}$ as in males.

\section{Measurements}

Males (N = 11). TL: AV: $6.1 \pm 0.14$; MX: 6.9; MN: 6.5. EW: AV: $5.2 \pm 0.28$; MX: 5.9; MN: 4.8 . PrL: AV: $2.3 \pm 0.10$; MX: 2.4; MN: 2.1. PrW: AV: $4.5 \pm 0.22$; MX: 4.9; MN: 4.1. PgL: AV: $1.0 \pm 0.07$; MX: 1.2; MN: 0.9. PgW: AV: $2.1 \pm 0.10 ;$ MX: 2.3; MN: 2.

Females $(\mathrm{N}=11)$. TL: AV: $6.8 \pm 0.21 ; \mathrm{MX}: 7.0 ; \mathrm{MN}: 6.3 . \mathbf{E W}: \mathrm{AV}: 5.0 \pm 0.10 ; \mathrm{MX}: 5.2 ; \mathrm{MN}: 4.9$. PrL: AV: $2.1 \pm 0.07$; MX: 2.3; MN: 2.1. PrW: AV: $4.2 \pm 0.10$; MX: 4.4; MN: 4.1. PgL: AV: $1.0 \pm 0.08$; MX: 1.1; MN: 0.9. PgW: AV: $2.1 \pm 0.11 ;$ MX: 2.3; MN: 1.9.

\section{Geographical distribution}

Northern Amazonia in Suriname, French Guiana and Brazil.

\section{Ecoregions}

Guianan Moist Forests, Marajó Varzea, Uatuma-Trombetas Moist Forests, Japurá-Solimões-Negro Moist Forests

\section{Collecting sites (Fig. 41)}

\section{SURINAME. Sipaliwini: Coeroeni.}

FRENCH GUIANA. Cayenne (Kourou; Montsinéry-Tonnegrande: Montagne des Chevaux Régina: Réserve naturelle nationale des Nouragues; Roura: Montagne de Kaw), Saint-Laurent-du-Maroni (Maripasoula: Saül).

\section{BRAZIL. Amazonas: Manaus. Pará: Almeirim (Monte Dourado).}

\section{Intraspecific variation and taxonomic discussion}

It is interesting to note that $S$. securus is one of the rarest and, at the same time, one of the most easily recognizable species of Sylvicanthon, being the most isolated species in the genus in terms of morphology. Despite that, most of the studied specimens of $S$. securus were either unidentified in collections or mingled among specimens of $S$. seag sp. nov. In fact, throughout its distribution range - 
i.e., in the Guiana Shield and the Amazon region north of the Amazon River-S. securus is sympatric with S. seag sp. nov., a species that in turn extends its distribution far beyond this area both northwestwards, reaching Venezuela and Trinidad, and eastwards, reaching the Amazon fragments of the Brazilian state of Maranhão (Fig. 41). Besides, at first glance, S. securus and S. seag sp. nov. may be confused by colouration which, in the Guianas, is almost always shiny green in both species (Figs 37C, 39A) and by the number of protibial teeth, three (Fig. 11C). Nonetheless, at a closer look, the differences between S. securus and S. seag sp. nov. become evident.

The easiest way to differentiate both species is by examining the protibiae: $S$. seag sp. nov. has their internal margin straight and simple (Fig. $11 \mathrm{H}-\mathrm{I}$ ), while $S$. securus has them strongly expanded, with the apical half of the protibiae almost twice as wide as the basal half (Fig. 11C). In fact, the expanded internal margin of the protibiae is a very common feature in Sylvicanthon, being present in all the four species of the furvus subgroup (S. obscures (Fig. 11D), S. mayri sp. nov., S. monnei sp. nov., and S. furvus (Fig. 11E)), in S. bridarollii (Fig. 11F-G; the other species of the bridarollii subgroup have a simple internal margin), and S. enkerlini (Fig. 11A), but it is much more pronounced in S. securus than in any other species of the genus (something already noted by Schmidt (1922) and Balthasar (1939)). Other groups of Deltochilini also show this feature, e.g., several species of Glaphyrocanthon and Francmonrosia.

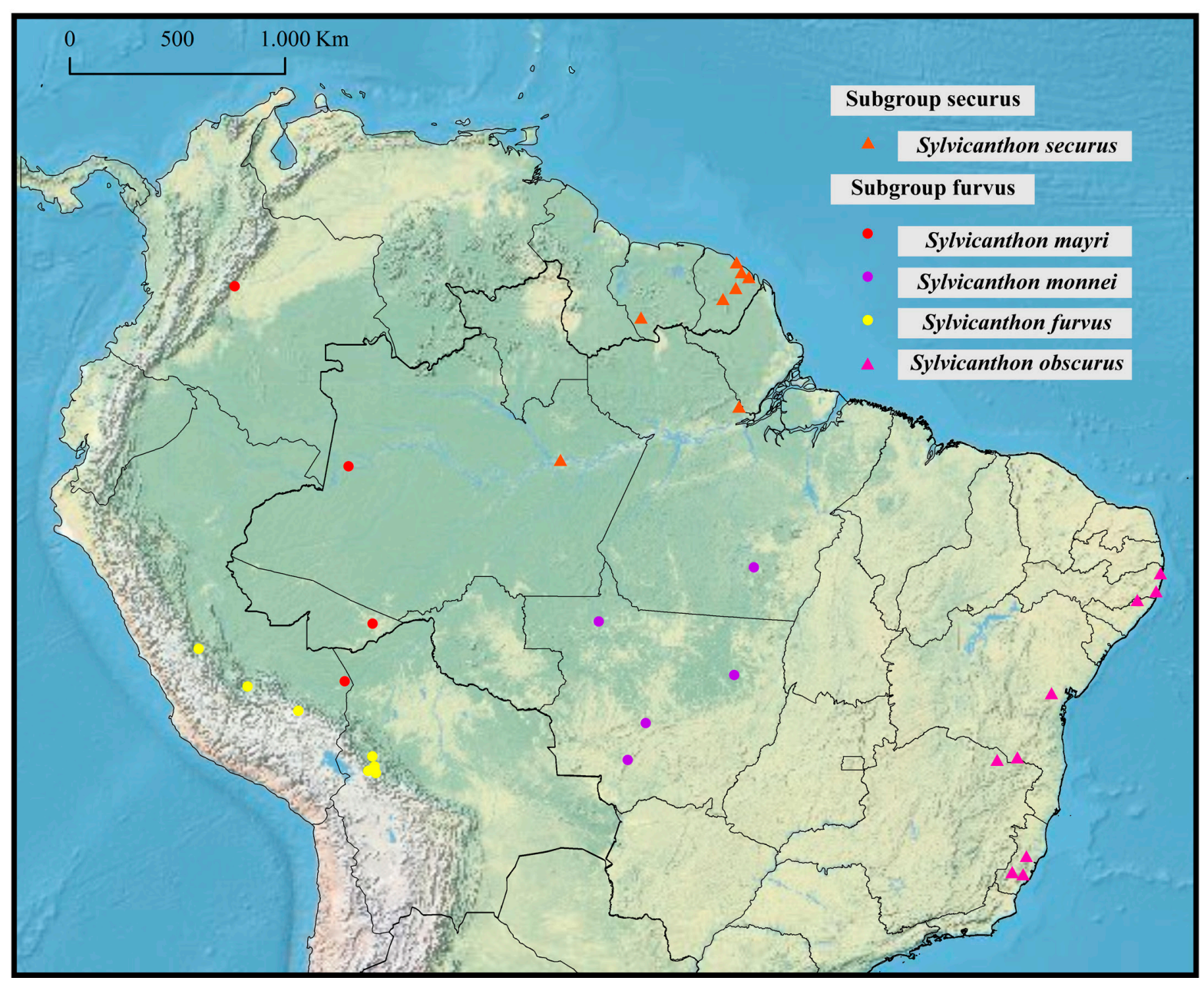

Fig. 41. Distribution of Sylvicanthon securus (Schmidt, 1920) comb. nov. and the four species of the furvus subgroup. 
The overall texture of the tegument is distinct between $S$. seag sp. nov. and $S$. securus: in the former species, the pronotum, metaventrite, elytra and pygidium are covered by a strong alveolar microsculpture which obliterates the micropunctation (which, consequently, is very weak). In S. securus, on the other hand, there is no trace of microsculpture on the pronotum, at the centre of metaventrite, on the elytra or at the centre of the pygidium (in these latter two cases, sometimes there is a very diffuse indication of microsculpture), and the micropunctation is strong and clearly visible. Sylvicanthon securus also differentiates from $S$. seag sp. nov. by the presence of a fine margin at the centre of the posterior edge of the head in the majority of the specimens, while all the examined individuals of the latter species have the posterior edge of the head without any trace of margination. Nonetheless, this characteristic is largely variable in $S$. securus: the fine margin may be clearly present and almost reaches the eyes, or it may be gradually shorter or even almost absent.

Other morphological structures distinguishing $S$. securus from $S$. seag sp. nov. are the shape of the edge of the clypeus, which is completely rounded in $S$. seag sp. nov. (Fig. 6E) and is slightly sinuous adjacently to the apical teeth in S. securus (Fig. 6F); the basal margin of the clypeal teeth, which is divided into two non-continuous parts (i.e., each tooth has its own basal margin) in S. securus, and is one-piece (i.e., a single margin covers the base of both teeth) in $S$. seag sp. nov.; and the shape of the male protibial spur, which has the internal branch much longer than the external one in S. securus (Fig. 15N), whereas the opposite condition is seen in S. seag sp. nov. (Fig. 15J). Clear differences also exist in the shape of the parameres: in $S$. securu comb. nov., they are simple, fine and laterally flat, without any ventral keel or notch (Fig. 19A). In turn, in S. seag sp. nov. the parameres are strongly asymmetrical (the external face of the right paramere flat and the external face of the left paramere excavated) and, in lateral view, there is a ventral keel strongly projected, giving a squarish appearance to the apical half of the parameres and it also has a notch posteriorly to that keel (Fig. 18B).

Differences are seen in the colouration of fully mature specimens (i.e., excluding teneral individuals): in the Guianas, S. seag sp. nov. has an overall dorsal colouration shiny green similar to that seen in $S$. securus, but it differs from this latter species in having the head and, occasionally, the pronotum covered by a purplish spot (Fig. 37C), while in S. securus the pronotum is always as green as the elytra, and head possesses a narrow purplish spot limited to the the apex of the clypeus (Fig. 39A). Ventrally, the differences are seen on the colouration of the metaventrite - which, although sometimes mostly coppercoloured, always shows some greenish reflections at the centre in S. securus (Fig. 39B), while it is always coppery without any greenish reflection in S. seag sp. nov. (Fig. 37D) - and of the profemora - which are light brown in S. securus, and much darker brown in S. seag sp. nov. Farther south, in Brazil, individuals of $S$. seag sp. nov. have a very distinct colouration, with bluish elytra and a purplish pronotum (Fig. 37A), in which they do not resemble in anything the bright green colouration of $S$. securus.

\section{Comments}

Schmidt (1920) did not cite the number of specimens he examined for the description of S. securus, but from his text, it is possible to conclude that he had only males at his disposal, since he described the male shape of the protibial spur, but did not cite how this structure was in females. The only specimen from the type series of S. securus found by us was a male deposited in the NHRS which is here designated as lectotype.

One of the specimens found at the BMNH bears a circular blue label handwritten " 54 / 60", without any further indication. According to Max Barclay (personal communication to MC, 2015), this code refers to a large acquisition of several Brazilian dung beetle species made by the museum from the French entomologist Henri Jekel (1816-1891). This specimen also has another rectangular white label handwritten "N... / serricornis / n...", probably an apocryphal nomen in litteris that we are unware of having been applied to any other specimen or cited in any publication. 


\section{Natural history}

Sylvicanthon securus is a rare species, inhabiting lowland forests in the northern Amazon region (with records from 75 up to $411 \mathrm{~m}$ of altitude), where it is sympatric with $S$. seag sp. nov. Most of the specimens of $S$. securus studied for this work originated from French Guiana and, of the two species of Sylvicanthon that occur there, S. securus was collected in an evident lower abundance: a total of 43 specimens of $S$. securus were caught in French Guiana, in comparison to $601 S$. seag sp. nov., a number almost 15 times higher. Taking the series of specimens studied for this work into account, it was possible to see that, in individual collecting episodes, the ratio between the abundance of $S$. seag sp. nov. and S. securus varied from 3:1 up to 65:1. From Suriname, in turn, only the lectotype of $S$. securus is known, while 25 specimens of $S$. seag sp. nov. were caught in that country.

With such a discrepancy in the relative abundance between these two species, it is really remarkable that S. securus was described still in the early $20^{\text {th }}$ century, while $S$. seag sp. nov. had to wait until now to have its condition as a distinct species recognized. However, an obvious question arises from these observations: what is the ecological factor, or conjunct of factors, responsible for the remarkable difference in abundance between $S$. seag sp. nov. and S. securus? Nonetheless, it would be fair to question whether this apparent rarity of $S$. securus is not a simple artefact generated by some unknown idiosyncratic life habit of the latter species; for example, some other food preference than primate dung (i.e., human faeces used to bait pitfalls). Be that as it may, only with more research on the biology of both $S$. securus and $S$. seag sp. nov. it will be possible to give a proper answer to these questions.

Judging from the specimen labels, we know that S. securus was collected in pitfall traps baited with human faeces and flight interception traps. Besides, the two females from Manaus (Amazonas, Brazil) were attracted to howler monkey dung; although their labels indicate that the primate was an Alouatta seniculus (Linnaeus, 1766), the correct identity of this species should be A. macconnelli Elliot, 1910, or, less probable, A. nigerrima Lönnberg, 1941, the only two species of the A. seniculus complex present in that area (Gregorin 2006). Regarding the species' annual phenology, adults of S. securus were collected throughout the year, including the months of January, February, May, June, July, September, and October.

\section{The furvus subgroup}

Sylvicanthon obscurus (Schmidt, 1920)

Figs 7B, 11D, 12B, 13B, 15M, 16C, 19B, 20, 40B, 41-42

Canthon obscurus Schmidt, 1920: 131-133.

Canthon obscurus - Schmidt 1922: 64, 78. - Balthasar 1939: 187-188. - Halffter \& Martínez 1977: 63. - Krajcik 2012: 64.

Canthon obscurum - Blackwelder 1944: 200.

Glaphyrocanthon (Glaphyrocanthon) obscurus - Pereira \& Martínez 1956: 126, 128. — Pereira \& Martínez 1960: 45. — Martínez et al. 1964: 5, 8, 13. — Vulcano \& Pereira 1964: 663.

Sylvicanthon obscurum: Vaz-de-Mello 2000: 195.

Sylvicanthon sp. - Costa et al. 2009: 90; 2013: 330-331. - Silva et al. 2010: 362. - Iannuzzi et al. 2016: 201.

\section{Etymology}

From the Latin word 'obscurus', meaning 'dark'. Probable reference to the dark green or dark blue elytra. 


\section{Material examined}

Lectotype (here designated)

BRAZIL: Ō, Espírito Santo, ("Esp. Santo", "Coll. C. Felsche / Kauf 20, 1918”, "Typus", "Canthon / obscurus / A. Schmidt", "LECTOTYPE ô / Canthon / obscurus / Schmidt / des. F. Z. Vaz-de-Mello, 2014") (SMTD) (Fig. 40Ba-b).

Paralectotypes $(7 \hat{\jmath}, 4 q q$ q $)$

BRAZIL: 1 ô, ("LECTOTYPE ô / Canthon / obscurus / A. Schmidt / des. F. Z. Vaz-de-Mello, 2014", "PARALECTOTYPE / § / Canthon / obscurus Schm. / des. F. Z. Vaz-de-Mello, 2013", "Glaphyrocanthon / obscurus / (Schm.) / P. Pereira det. 60", "obscurus / A. Schm.", "9933 / E92 +", "obscurus", "Espir. / Santo") (NHRS) (Fig. 40Bc); 1 ठิ, ("PARALECTOTYPE / § / Canthon / obscurus Schmidt / des. F. Z. Vaz-de-Mello, 2013", “obscurus", "Espir. / Santo", "9935 / E92+”) (NHRS); 1 9, ("PARALECTOTYPE / 9 / Canthon / obscurus Schmidt / des. F. Z. Vaz-de-Mello, 2013”, "29 / 56”, "9936 / E92 +”, "obscurus", "Esp. Santo", "obscurus / Schmidt") (NHRS) (Fig. 40Bd); 1 q, ("Glaphyrocanthon / obscurus / (Schm.) / P. Pereira et. 60", "Espir. Santo", "9934 E92 +", "PARALECTOTYPE / q / Canthon / obscurus Schmidt / des. F. Z. Vaz-de-Mello, 2013”) (NHRS); 1 ô, ("PARALECTOTYPE / ô / Canthon / obscurus / Schmidt / des. F. Z. Vaz-de-Mello, 2014", "Coll. C. Felsche / Kauf 20, 1918”, "Coll. C. Feslche / Kauf 20, 1918”) (SMTD); 1 ठ̊, ("PARALECTOTYPE / ठ / Canthon / obscurus / Schmidt / des. F. Z. Vaz-deMello, 2014", "Coll. C. Felsche / Kauf 20, 1918”, "Esp. Santo”), (SMTD); 1 ð, ("PARALECTOTYPE / đ / Canthon / obscurus / Schmidt / des. F. Z. Vaz-de-Mello, 2014", "Coll. C. Felsche / Kauf 20, 1918", "Esp. Santo") (SMTD); 1 o ("PARALECTOTYPE / ô / Canthon / obscurus / Schmidt / des. F. Z. Vaz-deMello, 2014", "Coll. C. Felsche / Kauf 20, 1918”, "Esp. Santo") (SMTD); 1 , ("PARALECTOTYPE / q / Canthon / obscurus / Schmidt / des. F. Z. Vaz-de-Mello, 2014", "Coll. C. Felsche / Kauf 20, 1918", "Esp. Santo") (SMTD) (Fig. 40Be) ; 1 क, ("PARALECTOTYPE / 9 / Canthon / obscurus / Schmidt / des. F. Z. Vaz-de-Mello, 2014", "Coll. C. Felsche / Kauf 20, 1918”, "Esp. Santo") (SMTD); 1 ō, ("S. Amerika / W. Meier / Hamburg", "Ypilissus spec?", "Canthon / obscurus / A. Schmidt", "SYNTYPUS / Canthon / obscurus Schmidt, 1920 / labelled by MNHUB 2014”) (ZMHB).

Additional material (141 $\hat{\partial}, 126 q+$ q $)$

BRAZIL: 1 , no further data (NMPC, ex coll. Balthasar, B. Schwarzer and Lansberge). - Alagoas: 1 ㄱ, 2 우, Ibateguara, edge of Coimbra fragment, 6 Oct. 2011, B. Filgueiras leg. (UFPE). - Bahia: 1 Ĵ, Encruzilhada, Nov. 1980, A. Martínez and M. Alvarenga leg. (CMNC); 1 q, Santa Teresinha, Serra da Jiboia, $12^{\circ} 51,31^{\prime}$ S, 39 $28,575^{\prime}$ W, 2 Feb. 2009, P.P. Lopes and L.R. M. Oliveira leg. (MZFS). - Espírito Santo: 1 , , no further data (BMNH); 1 ô, no further data (MNHN, van de Poll collection); $1 \hat{\partial}$, no further data (ZMHB); $5 \hat{\jmath}$, 3 우, Marechal Floriano, Jan. 2003, pitfall, L. Dias leg. (CEMT);

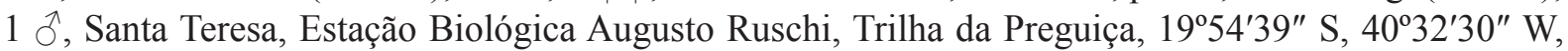
760 m, 29 Jan. 2015, pitfall with human faeces, T. Vargas leg. (CEMT); $3 \hat{\delta} \delta$, Santa Teresa, Estação Biológica Augusto Ruschi, Trilha da Preguiça, 1954'37" S, 40³2'31" W, 761 m, 29 Jan. 2015, pitfall with human faeces, T. Vargas leg. (CEMT); 1 Õ, Santa Teresa, Estação Biológica de Santa Lúcia, $19^{\circ} 58^{\prime} 25^{\prime \prime} \mathrm{S}, 40^{\circ} 31^{\prime} 45^{\prime \prime} \mathrm{W}, 648 \mathrm{~m}, 29$ Jan. 2015, pitfall with human faeces, T. Vargas leg. (CEMT);

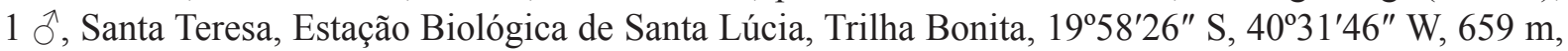
29 Jan. 2015, pitfall with human faeces, T. Vargas leg. (CEMT); 1 + , Santa Teresa, Estação Biológica

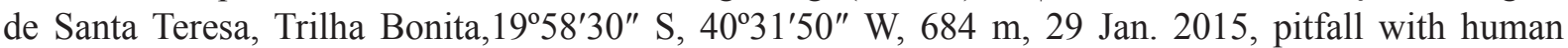
faeces, T. Vargas leg. (CEMT); 1 ô, Santa Teresa, Estação Biológica de Santa Lúcia, Trilha do Rio, $19^{\circ} 58^{\prime 2} 22^{\prime \prime} \mathrm{S}, 40^{\circ} 31^{\prime} 45^{\prime \prime} \mathrm{W}, 649 \mathrm{~m}, 29 \mathrm{Jan} .2015$, pitfall with human faeces, T. Vargas leg. (CEMT); 1 गै, Santa Teresa, Estação Biológica de Santa Lúcia, Trilha Indaia-Açu, 1957'56" S, 40³2'24" W, 626 m, 28 Jan. 2015, pitfall with human faeces, T. Vargas leg. (CEMT); 1 q, Santa Teresa, Estação Biológica de Santa Teresa, 19 $57^{\prime} 57^{\prime \prime}$ S, 40 32'23" W, 631 m, 29 Jan. 2015, pitfall with human faeces, T. Vargas leg. (CEMT); 1 đ̃, Santa Teresa, Estação Biológica de Santa Teresa, Trilha Indaia-Açu, 1957'57" S, 40³2'21" W, $661 \mathrm{~m}, 29$ Jan. 2015, pitfall with human faeces, T. Vargas leg. (CEMT); 3 ô ${ }^{\circ}, 1$ ㅇ, Santa 
Teresa, Estação Biológica de Santa Teresa, Trilha Indaia-Açu, 1958'18" S, 40³2'09" W, 742 m, 29 Jan.

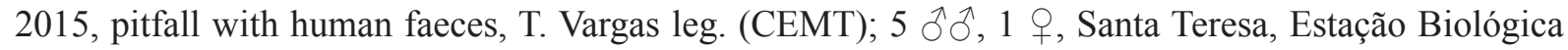
de Santa Lúcia, Trilha Indaia-Açu, 1958'13" S, 40²'06" W, 779 m, 29 Jan. 2015, pitfall with human faeces, T. Vargas leg. (CEMT); 3 đ̂̉ , Santa Teresa, Estação Biológica de Santa Lúcia, Trilha Tapinoã, $19^{\circ} 58^{\prime} 07^{\prime \prime} \mathrm{S}, 40^{\circ} 31^{\prime} 55^{\prime \prime} \mathrm{W}, 679$ m, 29 Jan. 2015, pitfall with human faeces, T. Vargas leg. (CEMT);

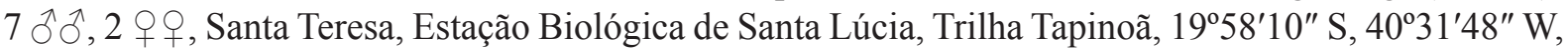
692 m, 29 Jan. 2015, pitfall with human faeces, T. Vargas leg. (CEMT); 1 §, 1 ㅇ, Venda Nova do Imigrante, Dec. 2000, F.Z. Vaz-de-Mello ("V-de-M") leg. (AMBC); 1 ${ }^{\lambda}$, same collecting data as for

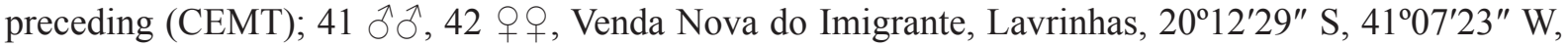
850 m, 10-14 Jan. 2011, human faeces, F.Z. Vaz-de-Mello leg. (CEMT); 31 § $\partial, 39$ 우우, Venda Nova

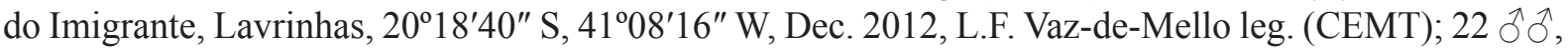
20 우, Venda Nova do Imigrante, Lavrinhas, $20^{\circ} 12^{\prime} 29^{\prime \prime}$ S, 41 $07^{\prime} 23^{\prime \prime}$ W, I.2013, L.F. Vaz-de-Mello leg.

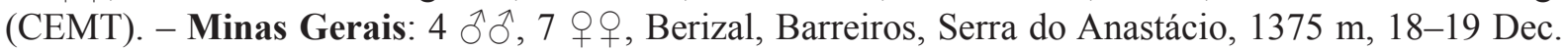
2012, flight interception trap, P. Grossi leg. (CEMT). - Pernambuco: 3 $\lesssim$, 2 우우, Igarassu, Refúgio Ecológico Charles Darwin ("RECD"), 30 Oct. 2006, pitfall, Fernando A.B. Silva et al. leg. (CEMT);

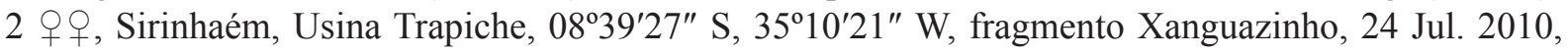
pitfall with human faeces, R.P. Salomão leg. (UFPE).

No data: 1 (CEMT).

\section{Description}

Colouration. Dorsum slightly shiny and lustrous. Head and pronotum with colouration ranging from light green with yellowish reflections to dark purple without any trace of yellowish or greenish sheen; between these two extremes, head and pronotum with mixture of greenish, yellowish, and coppery sheen varying in dominance of some of those tonalities. Elytra usually very dark green or blue, or, more rarely, with strong purplish-blue sheen. Pygidium and metaventrite dark green or blue, without metallic sheen or with reduced sheen. Legs reddish-brown.

HEAD. Tegument with diffuse sheen, with strong alveolar microsculpture obliterating micropunctation. Clypeus with two small apical teeth obtuse and contiguous at base; with single transverse row of very short setae covering base of both teeth. Genae with distinct tooth immediately after clypeal-genal juncture. Posterior edge of head unmargined between eyes.

Thorax. Pronotum with shiny tegument, without microsculpture and with dense micropunctation at centre, punctures denser and with more marked than on head; on sides, micropunctation absent and tegument with diffuse shine due to alveolar microsculpture progressively more well marked towards outer edge. Posterior edge with fine transverse line at centre (usually extending only up to the second elytral stria). Hypomeral cavity with long yellowish setae; external edge with distinct tubercle. Metaventrite glabrous at centre; on the sides, with sparse setae close to anterior margin of metacoxae (Fig. 7B); anterior region of metaventrite with strong rivose microsculpture; centre and posterior region with dense micropunctation among strong alveolar microsculpture.

Legs. Ventral surface of all femora and tibiae bright. Protibiae narrow and with distinct expansion at internal edge; at apical third, with three small acute teeth on external edge, two most apical ones subequal in length and larger than basal (Fig. 11D). Mesofemora margined anteriorly only at basal third or half; unmargined portion of anterior edge with row of setae; posterior margin absent; tegument with micropunctation almost imperceptible. Metafemora margined only anteriorly, posterior margin absent; apical third or half of anterior edge covered by row of setae; tegument with well-marked micropunctation, denser at base than at apex; without coarse elongate punctation at base (Fig. 13B). Metatarsomeres II and $\mathrm{V}$ subequal in length and larger than the others; metatarsomere IV shorter than the others. 
ELYTRA. With nine narrow striae: first six striae strongly marked, finely carinulate and widened at base; seventh stria present only after humerus and always very weak, without carinulae; eighth and ninth striae very tenuous, almost imperceptible; all striae lack carinulae before reaching apex of elytra; humeral carina present or absent. Interstriae with tegument at centre of disc bright, without microsculpture, and with dense micropunctation; on sides and apex, tegument with strong alveolar microsculpture and without distinct micropunctation.

ABDOMEN. Ventrite I-V with strong microsculpture throughout tegument; ventrite VI with microsculpture only slightly more diffuse than others. Pygidium covered by strong alveolar microsculpture obliterating indistinct micropunctation.

Aedeagus. Parameres almost as long as phallobase and symmetrical, with both faces flat. In lateral view, with apices widely bifurcate, with superior branch wider and more strongly projected than inferior one and bent upwards; inferior branch with acute apex and facing forwards; without ventral keel or notch (Fig. 19B).

Sexual Dimorphism. Males: Protibial spur broad and bifid, with long, straight and acute external projection, and internal projection shorter, bent, and wider (Fig. 15M). Abdomen glabrous and without lateral foveae. Ventrite VI strongly narrowed at centre. Pygidium very short (length between 1.5 and $1.2 \mathrm{~mm}$ ); apical margin of pygidium much wider than lateral margin. Females: Protibial spur fine and short, spiniform. Abdomen with three pairs of transverse foveae on the sutures between ventrites I-II, II-III, and III-IV, respectively; foveae margined anteriorly by row of long yellowish setae; row of setae present also on ventrites IV and V (Fig. 16C). Ventrite VI broad at centre, only very slightly narrowed by medial expansion of ventrite V. Pygidium shorter (between 1.2 and $1 \mathrm{~mm}$ ); apical margin of pygidium only slightly wider than lateral margin.

\section{Measurements}

Males $(\mathrm{N}=26)$. TL: AV: $8.5 \pm 0.49$; MX: 9.5; MN: 7.7. EW: AV: $5.9 \pm 0.33$; MX: 6.5; MN: 5.3 . PrL: AV: $2.6 \pm 0.23$; MX: 3; MN: 2.1. PrW: AV: $5.1 \pm 0.28$; MX: 5.7; MN: 4.7. PgL: AV: $1.3 \pm 0.09$; MX: 1.5; MN: 1.2. PgW: AV: $2.6 \pm 0.17$; MX: 2.9; MN: 2.3.

Females $(\mathrm{N}=23)$. TL: AV: $8.2 \pm 0.47$; MX: 9; MN: 7.1. EW: AV: $5.9 \pm 0.36$; MX: 6.4; MN: 5.2 . PrL: AV: $2.6 \pm 0.19$; MX: 2.9; MN: 2. PrW: AV: $5.1 \pm 0.35$; MX: 5.8; MN: 4.5. PgL: AV: $1.1 \pm 0.07$; MX: 1.2; MN: 1. PgW: AV: $2.5 \pm 0.12 ;$ MX: 2.7; MN: 2.3 .

\section{Geographical distribution}

Northern Atlantic Forest from Alagoas to Espírito Santo (Brazil).

\section{Ecoregions}

Pernambuco Coastal Forests, Bahia Coastal Forests, Bahia Interior Forests.

\section{Collecting sites (Fig. 41)}

BRAZIL. Pernambuco: Igarassu (Refúgio Ecológico Charles Darwin), Sirinhaém. Alagoas: Ibateguara. Bahia: Encruzilhada, Santa Teresinha. Minas Gerais: Berizal (Serra do Anastácio). Espírito Santo: Marechal Floriano, Santa Teresa (Estação Biológica Augusto Ruschi, Estação Biológica de Santa Lúcia), Venda Nova do Imigrante. 

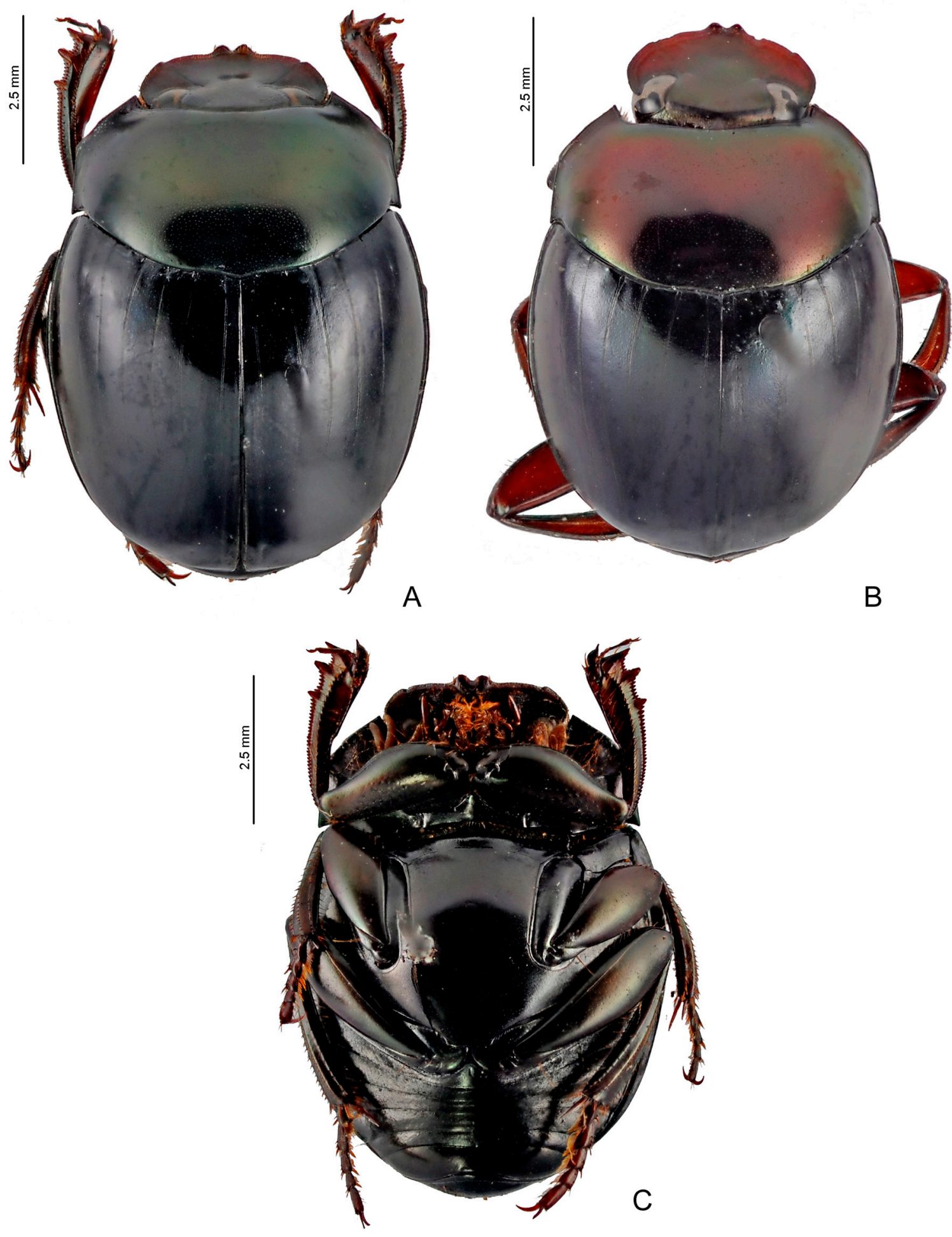

Fig. 42. Sylvicanthon obscurus (Schmidt, 1920). A. Dorsal view of the purplish form. B. Dorsal view of the yellowish form. C. Ventral view. 


\section{Intraspecific variation and taxonomic discussion}

Sylvicanthon obscurus presents two important intraspecific variations, one intrapopulational and the other both geographical and intrapopulational. The former refers to the presence of a humeral carina at the eighth elytral stria (Fig. 12C): of the 267 specimens examined for this work, only 88 (46 $\widehat{\delta} \widehat{\delta}$, 42 우) show some indication of this carina. Schmidt $(1920,1922)$ did not mention any variation on the presence of the humeral carina and considered it to be a characteristic differentiating S. obscurus from $S$. candezei, S. foveiventris, S. furvus and S. securus and that, at the same time, would approximate it to $S$. aequinoctialis, an opinion that was followed by Balthasar (1939), Pereira \& Martínez (1956) and Martínez et al. (1964). Although it is a fact that the humeral carina is present only in S. obscurus, S. aequicnotialis and S. proseni, the first species distinguishes itself from the other two by being the only one in which this feature is not present in all the specimens examined. In S. proseni, and particularly in S. aequinoctialis, the carina may occasionally be only weakly marked, but it is never completely absent. Within a same population of $S$. obscurus, like the large series collected in Venda Nova do Imigrante (Espírito Santo, Brazil) (but also in other localities in the Brazilian northeast), there are specimens both with and without a humeral carina.

The second variation refers to colouration, of which two extreme forms can be observed: at one end of the spectrum, the head and pronotum colouration shows green and dark blue reflections (Fig. 42B); at the other end, head and pronotum are purple or dark purple, while the elytra are bright blue (Fig. 42A). Populations of S. obscurus in the Brazilian northeast (i.e., specimens collected in Alagoas, Pernambuco and Bahia) and in Minas Gerais have a colouration nearer to the latter extreme, with at most only some weak greenish or yellowish metallic reflections on the anterior region of the pronotum. The only specimen known from Bahia and those from Minas Gerais, in particular, show bright blue elytra; the other specimens from the Brazilian northeast have them as dark as in the green-yellowish specimens from Espírito Santo.

Differently, most of the individuals from Espírito Santo, including the lectotype (Fig. 40B), are more similar to the first end of the continuum described above. Nevertheless, there is a gradual intrapopulational variation in those specimens towards the other colour extreme, with individuals gradually showing a larger predominance of coppery sheen over greenish and yellowish tonalities up to a point where almost the totality of the pronotum and head have dark coppery or purple reflections. Therefore, while in the Brazilian northeast only the purple colouration is present, almost the entire variation spectrum is seen in Espírito Santo (although no specimens from this state are as close to the purple extreme as the darkest specimens from the northeast). The specimen from Encruzilhada (Bahia), which came from the former Antonio Martínez collection, bears a handwritten label "Sp nov", probably making reference to its peculiar colouration among the other $S$. obscurus (all the other known specimens with purple colouration were only recently collected, after 2006). However, after seeing that this characteristic varies intrapopulationally, we consider specimens from the Brazilian northeast and Minas Gerais conspecific with those from Espírito Santo under the name S. obscurus.

Despite sharing several characteristics with other members of the furvus subgroup, such as female abdominal foveae, protibiae expanded on their internal margin and parameres apically bifurcate, S. obscurus is the most distinguishable species in the group. It differs from all the others by the absence of coarse punctation at the base of the metafemora (Fig. 13B), the absence of a fine membrane connecting both branches of the apical bifurcation of the parameres, besides both branches being acuminate (Fig. 19B), and the presence of a row of long setae on the anterior margin of the female abdominal foveae (Fig. 16C). Furthermore, the elytral microsculpture pattern seen in S. obscurus is unique to this species among members of the furvus subgroup and its geographical distribution is completely disjunct, with S. obscurus occurring only in the northern portion of the Atlantic Forest, while the other three species are Amazonian. See Table 5 for more information on the differences between $S$. obscurus and 
closely related species; for differences with $S$. foveiventris, a species with which $S$. obscurus can be found in sympatry in Espírito Santo (and, perhaps, in Bahia), see the discussion under that species.

\section{Comments}

We found 11 specimens that, thanks to Adolf Schmidt's handwritten labels, we know are certainly part of the type series of S. obscurus: seven deposited in the SMTD (ex Bang-Hass collection) and four in the NHRS. Additionally, three other specimens deposited in the ZMHB bear modern labels indicating they would also be part of the original syntype series. According to Joachim Willers (personal communication to MC, 2015), curator at the ZMHB: "in our collection the species Canthon obscurus Schmidt, 1920 has a bottom label with an asterisc $(*)$. This means that we should have type(s). Therefore I printed a syntype label for each specimen so that who is working on the species has an up-to-date information". One of those specimens also has a label handwritten by Schmidt and, hence, should indeed be a syntype of S. obscurus (Vaz-de-Mello \& Cupello in press). That specimen also bears a green label handwritten "S. Amerika / W. Meier / Hamburg", information that probably makes reference to the collection of the German entomologist William Meier (1861-1940), from Hamburg, Germany (Joachim Willers, personal communication to MC, 2015; Weidner 1976). On the other hand, the other two specimens have labels indicating they were collected in Peru - therefore, different from the type locality cited by Schmidt (1920), the Brazilian state of Espírito Santo. Furthermore, after studying them, we could see that they are not actual $S$. obscurus, but rather two male $S$. bridarollii. It is, therefore, possible that someone other than Schmidt has positioned those two specimens bellow the label with the asterisk cited by Willers sometime after Schmidt's study of the ZMHB specimens and, consequently, they would not be part of the type series of S. obscurus. In light of all the evidence to the contrary, we decided not to include those two specimens in the S. obscurus type material listed above and not to consider them as true syntypes of this name.

\section{Natural history}

Label information reports collecting in October, November, December, January and July, which perhaps shows an annual activity pattern similar to that of S. foveiventris, species whose adults are active mainly during the hottest and rainiest months of the year. All the specimens with collecting method information were caught in pitfall traps baited with human faeces. Silva et al. (2010) collected S. obscurus (cited by them as "Sylvicanthon sp.") in Pernambuco only in areas of closed forest, although they have also set up traps in open habitats.

Sylvicanthon furvus (Schmidt, 1920)

Figs 6G, 11E, 13E, 15N, 16A, 19C, 20, 40C, 41, 43A-B

Canthon furvus Schmidt, 1920: 130-131, 133.

Canthon furvus - Schmidt 1922: 64, 75. — Balthasar 1939: 188; 1941: 341; 1951: 326. — Halffter \& Martínez 1977: 63. - Krajcik 2012: 63.

Canthon furvum - Blackwelder 1944: 199.

Glaphyrocanthon (Glaphyrocanthon) furvus - Pereira \& Martínez 1956: 126, 129. - Martínez et al. 1964: 5-6, 8, 10, 14, 20-21. - Vulcano \& Pereira 1964: 662.

Sylvicanthon furvus - Halffter \& Martínez 1977: 63. — Ratcliffe et al. 2015: 196.

\section{Etymology}

From the Latin 'furvus', meaning 'black' or 'dark', probable reference to the consistently dark colouration of this species. 


\section{Material examined}

Lectotype (here designated)

PERU: OT, Cuzco, Quispicanchi, Marcapata. Former type locality cited by Schmidt (1920): "Peru, Bolivien", (“Typ.", "Marcapata/Peru”, "Typus", "furvus / Typem.” " furvus / A. Schm.”, "Glaphyrocanthon / furvus / (Schm.) / P. Pereira det. 60", "9663 / E92 +", "NHRS-JLKB / 000021102”, "LECTOTYPE ${ }^{\Uparrow}$ / Canthon / furvus Schm. / des. F. Z. Vaz-de-Mello, 2013”) (NHRS) (Fig. 40Ca-b).

Paralectotypes $(4 \hat{\jmath}, 5$ 우)

BOLIVIA: 1 Oे, ("9662 / E92 +", "PARALECTOTYPE / § / Canthon / furvus Schm. / des. F. Z. Vaz-

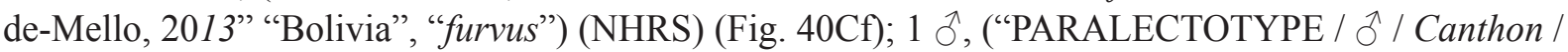
furvus / Schmidt / des. F. Z. Vaz-de-Mello, 2014", "Canthon / furvus / A. Schmidt", "Typus", "Coll. C. Felsche / Kauf 20, 1918", "Bolivia") (SMTD) (Fig. 40Cc); 1 ô, ("PARALECTOTYPE / o / Canthon / furvus / Schmidt / des. F. Z. Vaz-de-Mello, 2014", "Coll. C. Felsche / Kauf 20, 1918", "Bolivia") (SMTD); 1 + , ("PARALECTOTYPE / + / Canthon / furvus / Schmidt / des. F. Z. Vaz-de-Mello, 2014", "Coll. C. Felsche / Kauf 20, 1918", "Bolivia") (SMTD); 1 q, ("PARALECTOTYPE / q / Canthon / furvus / Schmidt / des. F. Z. Vaz-de-Mello, 2014", "Coll. C. Felsche / Kauf 20, 1918", "Bolivia") (SMTD); 1 ㅇ, ("PARALECTOTYPE / + / Canthon / furvus / Schmidt / des. F. Z. Vaz-de-Mello, 2014", "Coll. C. Felsche / Kauf 20, 1918”, "Bolivia") (SMTD).

PERU: 1 q, ("furvus / Schmidt", "Marcapata / Peru", "9664 / E92 +", "PARALECTOTYPE / $q$ / Canthon / furvus Schm. / des. F. Z. Vaz-de-Mello, 2013") (NHRS); 1 q , ("PARALECTOTYPE / $q$ / Canthon / furvus Schm. / des. F. Z. Vaz-de-Mello, 2013", "Glaphyrocanthon / furvus / (Schm.) / P. Pereira det. 60", "Marcapata / Peru", "9661 / E92 +") (NHRS) (Fig. 40Ce); 1 ô, ("PARALECTOTYPE / § / Canthon / furvus / Schmidt / des. F. Z. Vaz-de-Mello, 2014", "Canthon / furvus / A. Schmidt", "Peru", “Gehr. W. Müller / Vermächt. 1909”) (SMTD) (Fig. 40Cd).

Additional material $(17 \widehat{\partial}, 8$ \& $\odot)$

BOLIVIA: 1 $\hat{\delta}$, no further data (MNHN); 1 , no further data [labelled as homeotype of "Canthon candezei" by P. Pereira, 1942] (MZSP). - La Paz: 1 क, Larecaja, Guanay, 10 Nov. 2004, A.U. Peña

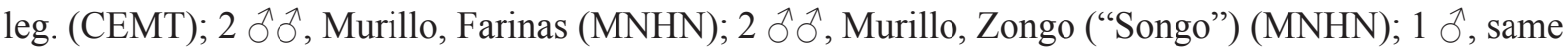
collecting data as for preceding (MZSP); $2 \hat{\jmath} \hat{\partial}, 3$ 우우, Nor Yungas, Coroico (BMNH); $1 \hat{\jmath}$, same collecting data as for preceding (MZSP); 1 , , same collecting data as for preceding (NMPC, ex. leg.

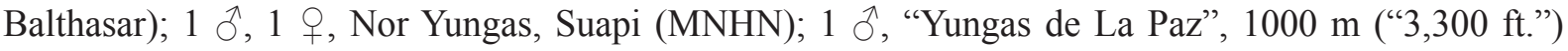
(BMNH).

PERU: Cuzco: 1 đ̄, La Convención, Echarate, Comunidad Campesina Santa Rosa, 12³3'54.41" S, 7305'36.85" W, 26-29 Jan. 2010, C. Carranza and C. Rossi leg. (MUSM); 1 đ’, La Convención, Echarate, Comunidad Campesina Santa Rosa, 12³3'51.29" S, 7305'37.01" W, 1457 m, 18-21 Sep. 2010, pitfall, M. Alvarado and J. Peralta leg. (MUSM); 1 đ, La Convención, Echarate, Comunidad

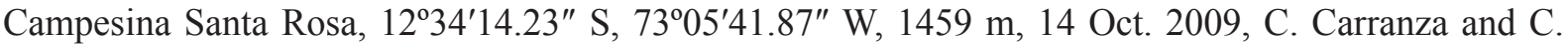
Rossi leg. (MUSM); 1 đ, 1 q, Quispicanchi, Marcapata (NMPC, ex. coll. Balthasar). - Junín: 1 ô, Chanchamayo, O. Schunke leg. (MNHN).

No data: 1 [ [small green label] (MNHN).

\section{Description}

Colouration. Very variable and iridescent. In general, head with greenish or bluish sheen. Pronotum usually purple; occasionally, with greenish sheen. Elytra purple or blue. Meso- and metafemora reddishbrown. Metaventrite with strong green shine. Pygidium of same colour as elytra. 
HEAD. Tegument slightly shiny, with strong alveolar microsculpture obliterating dense surficial micropunctation; micropunctation almost imperceptible or even absent throughout outer edge of head. Clypeus with two apical teeth obtuse and only slightly separated from one another (Fig. 6F); with single transverse row of setae covering base of both teeth. Genae with weak denticle immediately behind clypeal-genal juncture. Posterior edge of head with fine incontinuous line between eyes, or completely unmargined.

THorax. Pronotum with shiny tegument, and dense and well-marked micropunctation at centre; towards sides, micropunctation progressively less dense and well marked, sometimes absent on lateral edge; tegument among micropunctation completely smooth, microsculpture limited to very narrow strip of tegument on anterior edge of pronotum and anterolateral angles. Posterior edge with evident fine transverse line at centre (usually extending almost to third elytral striae). Hypomeral cavity with long yellowish setae at centre; external edge with weak tubercle. Metaventrite glabrous at centre; sides with few and sparse setae close to anterior margin of metacoxae; anterior region of metaventrite with distinct rivose microsculpture; centre and posterior region with dense micropunctation and very effaced, almost imperceptible microsculpture.

Legs. Ventral surface of all femora and tibiae shiny. Profemora with tegument with sparse micropunctation and without microsculpture at anterior half and with strong rivose microsculpture at posterior half and on anterior margin. Protibiae narrow and with distinct expansion on internal edge; at apical third, external edge with three small acute teeth; the two most apical ones subequal in length and larger than basal (Fig. 11E). Mesofemora margined anteriorly only at basal half; unmargined portion of anterior edge with row of short setae; posterior margin absent; tegument with strong rivose microsculpture. Metafemora margined only anteriorly, posterior margin absent; apical third of anterior edge covered by row of setae; with strong coarse elongate punctation at base and with sparse micropunctation on rest of tegument, which is covered by rivose microsculpture (Fig. 13E). Metatarsomeres II and V subequal in length and longer than the others; metatarsomere IV shorter than others.

ELYTRA. With only seven narrow visible striae: the first three or four striae well marked, finely carinulate, and widened at base; fifth to seventh striae progressively more effaced and interrupted; all striae lack carinulae before reaching apex of elytra, marked only by microsculpture or completely indistinct; humeral carina absent. Tegument of interstriae matte, with strong alveolar microsculpture throughout elytra surface; micropunctation totally oblitered by microsculpture and almost imperceptible.

AвDomen. Tegument of ventrites I-V with strong rivose microsculpture; ventrite VI smooth at centre and with weak rivose microsculpture on sides. Pygidium with shiny tegument; at centre, with diffuse microsculpture and dense micropunctation; on sides, with evident rivose microsculpture.

Aedeagus. Parameres longer than half-length of phallobase and with no noticeable asymmetry, both external faces flat. In lateral view, parameres with apices widely bifurcate, with inferior branch distinctly projected and divergent from superior branch; without ventral keel or notch (Fig. 19C).

SeXual Dimorphism. Males: Protibial spur broad and bifid, with external projection spiniform and not much longer than internal projection, which is bent and widened (Fig. $15 \mathrm{~N}$ ). Abdomen without lateral foveae. Ventrite VI strongly narrowed at centre, with posterior posterior edge emarginate; anterior edge covered by weak medial flange of posterior edge of ventrite V. Pygidium very long (length between 1.4 and $1.1 \mathrm{~mm}$ ) and convex; apical margin much wider than lateral margins. Females: Protibial spur simple, spiniform. Abdomen with three pairs of lateral transverse foveae between ventrites I-II, II-III, and III-IV, respectively; foveae not margined by row of long setae (Fig. 16A). Ventrite VI very broad at centre, posterior edge straight, without emargination; anterior edge subtly covered by weak medial 
flange of posterior edge of ventrite V. Pygidium shorter (between 1.1 and $0.9 \mathrm{~mm}$ ) and flat; apical margin of pygidium only slightly wider than lateral margin.

\section{Measurements}

Males $(\mathrm{N}=11)$. TL: AV: $7 \pm 0.53$; MX: 7.9; MN: 6.2. EW: AV: $5.2 \pm 0.29$; MX: 5.8; MN: 4.7. PrL: AV: $2.4 \pm 0.13$; MX: 2.6; MN: 2.2. PrW: AV: $4.4 \pm 0.21$; MX: 4.8; MN: 4.1. PgL: AV: $1.2 \pm 0.07$; MX: 1.4; $\mathrm{MN}: 1.1$. PgC: AV: $2.2 \pm 0.12 ; \mathrm{MX}: 2.4 ; \mathrm{MN}: 2$.

Females $(\mathrm{N}=6)$. TL: AV: $7.4 \pm 0.40$; MX: 8.1; MN: 7.0. EW: AV: $5.4 \pm 0.15$; MX: 5.5; MN: 5.1 . PrL: AV: $2.4 \pm 0.12$; MX: 2.5; MN: 2.2. PrW: AV: $4.6 \pm 0.12$; MX: 4.8; MN: 4.5. PgL: AV: $1.0 \pm 0.09$; MX: 1.1; MN: 0.9. PgW: AV: $2.3 \pm 0.15 ; \mathrm{MX}: 2.4 ; \mathrm{MN}: 2.0$.

\section{Geographical distribution}

Eastern slopes of the Andes in Peru and Bolivia.

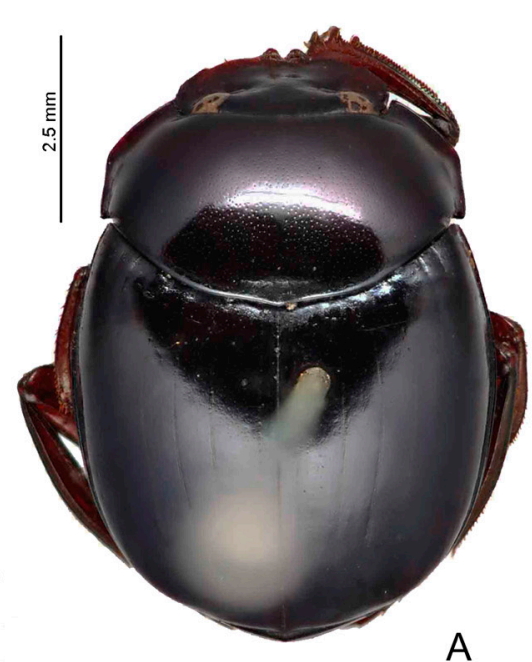

A

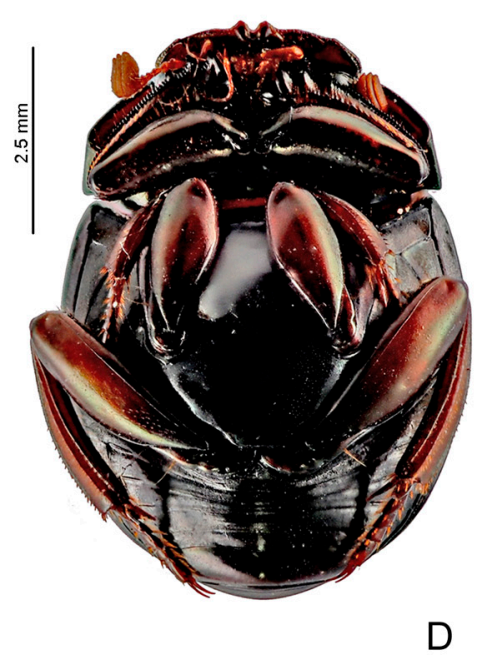

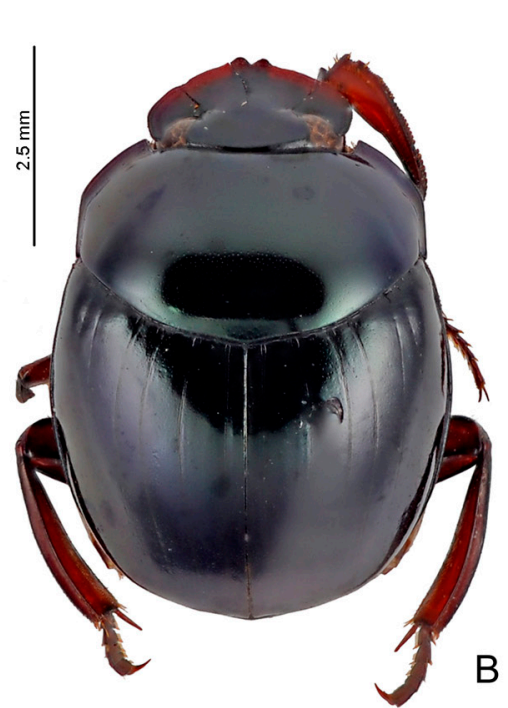

B
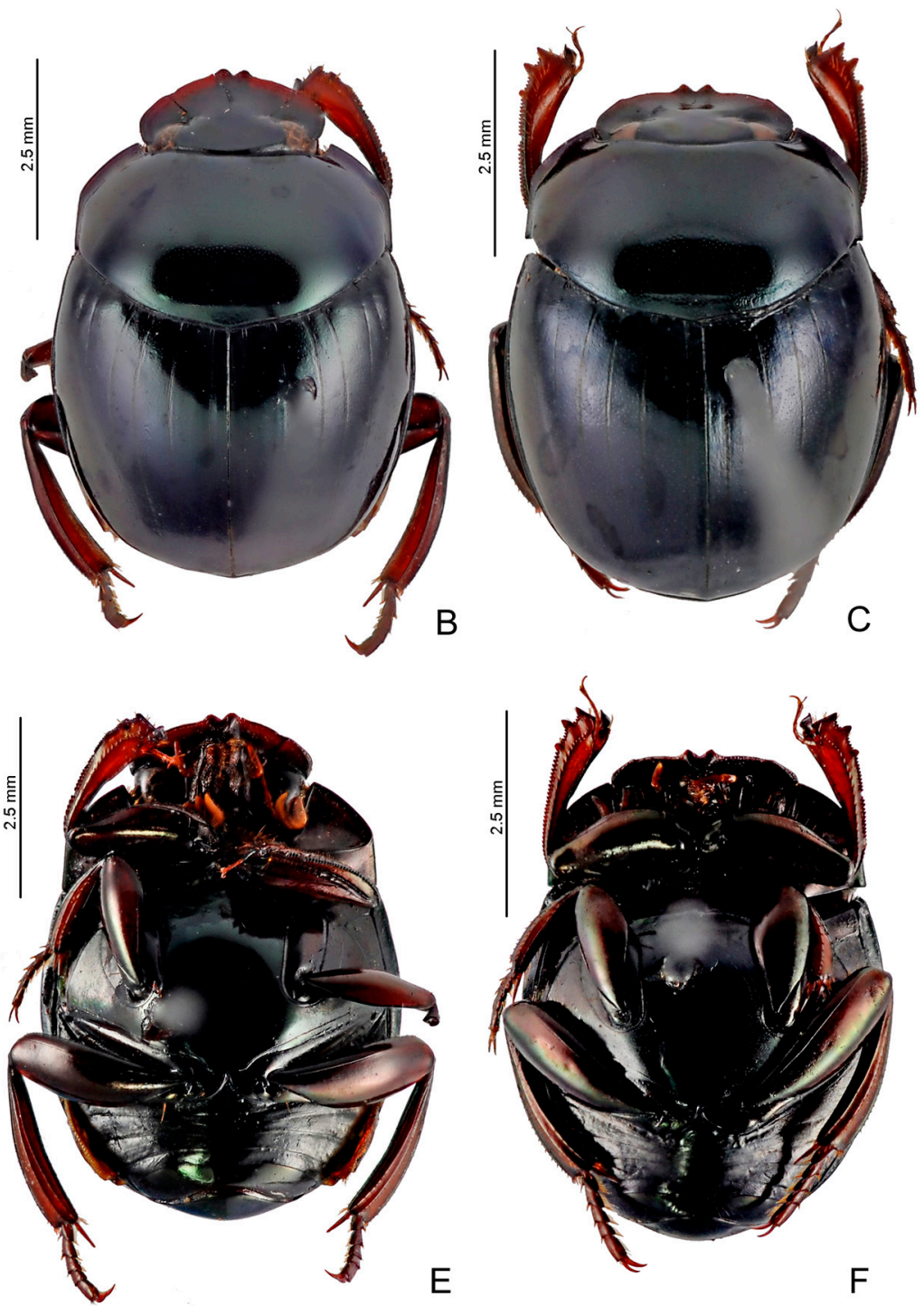

Fig. 43. The three Amazonian species of the furvus subgroup. A, D. Sylvicanthon furvus (Schmidt, 1920). A. Dorsal view. D. Ventral view. B, E. S. monnei sp. nov. B. Dorsal view. E. Ventral view. C, F. S. mayri sp. nov. C. Dorsal view. F. Ventral view. 


\section{Ecoregions}

Peruvian Yungas, Bolivian Yungas. Eastern slopes of the Andes in Peru and Bolivia.

Collecting sites (Fig. 41)

PERU. Junín: Chanchamayo. Cuzco: La Convención (Echarate), Quispicanchi (Marcapata).

BOLIVIA. La Paz: Larecaja (Guanay), Murillo (Farinas, Zongo), Nor Yungas (Coroico, Suapi).

\section{Intraspecific variation and taxonomic discussion}

The furvus subgroup represents the assemblage with the most complex taxonomy in Sylvicanthon. One of the reasons for this is the small number of specimens found in collections: while we could examine 2060 specimens of the species of the bridarollii subgroup, the other subgroup with an intricate taxonomy, we had in front of us only 53 specimens of the three rarest species of the furvus subgroup (i.e., excluding S. obscurus). At least in part, this is a consequence of the small number of collections made in the species' occurrence area (the slopes of the Andes in Bolivia and Peru for S. furvus, southern Amazonia for $S$. monnei sp. nov. and western Amazonia for $S$. mayri sp. nov.). Nevertheless, it is probable that these species should have natural low population densities, since even modern collections made with pitfall traps baited with dung did not yield a large number of individuals (e.g., specimens of $S$. monnei sp. nov. collected in the northern region of Mato Grosso and the holotype of $S$. mayri sp. nov. in Rio Branco, Acre). A second reason for such a complex taxonomy in the furvus subgroup is the tenuous morphological differences found between $S$. mayri sp. nov., S. furvus, and S. monnei sp. nov. (distinctions between $S$. obscurus and these three species were discussed anteriorly; see more details on Table 5).

The differences between $S$. furvus, S. mayri sp. nov. and S. monnei sp. nov. may be classified into two groups: those referring to the microsculpture and those referring to the shape of the parameres. Regarding the former, we observe that $S$. furvus possesses a much stronger microsculpture than $S$. mayri sp. nov. and $S$. monnei sp. nov. over the body. The head of the first species is covered by a dense, strongly impressed alveolar microsculpture, which makes the tegument more opaque, while the other two species have the head largely microsculptured, but this microsculpture is much weaker and, in some areas of the head (especially on frons), it can be totally absent, which makes the tegument much brighter. The meso- and metafemora of $S$. furvus are entirely covered by a strong rivose microsculpture and have micropunctation almost imperceptible, while these structures are smooth in almost the entirety of their tegument (except for the anterior region of the apical area, which has a rivose microsculpture) and show an evident micropunctation in both $S$. mayri sp. nov. and $S$. monnei sp. nov.22 (the profemora also have rivose microsculpture more strongly marked in $S$. furvus than in the other two species, but this difference is less noticeable). The pygidium of $S$. furvus has microsculpture ranging from having a clear alveolation to a completely diffuse one, while the microsculpture in both $S$. mayri sp. nov. and S. monnei sp. nov. is absent in almost the entire tegument and may be present only at the base (and, in this latter case, it is more evident in $S$. monnei sp. nov. than in $S$. mayri sp. nov.). Finally, on the elytra rest the major differences between the three species: in S. furvus, the entire elytral tegument is covered by a strongly-marked alveolar microsculpture so that the tegument has a very weak, diffuse silky shine. In $S$. mayri sp. nov., the tegument presents a very diffuse microsculpture, without an evident alveolar pattern, and, consequently, is more intense bright. Lastly, in S. monnei sp. nov., the microsculpture is completely absent on the elytra, which gives the tegument a smooth appearance with a strong, lustrous shine, and micropunctation is present.

The differences in the shape of the parameres are determinant for the separation of both $S$. furvus and $S$. mayri sp. nov. from $S$. monnei sp. nov. The paramere apex of the first two species, which do not show 
Table 5. Summary of the morphological and distributional differences between the four species of the furvus subgroup.

\begin{tabular}{|c|c|c|c|c|}
\hline & $\begin{array}{c}\text { S. obscurus } \\
\text { (Schmidt, 1920) }\end{array}$ & $\begin{array}{c}\text { S. furvus (Schmidt, } \\
1920)\end{array}$ & S. monnei sp. nov. & S. mayri sp. nov. \\
\hline $\begin{array}{c}\text { Tegument of } \\
\text { head }\end{array}$ & $\begin{array}{l}\text { With diffuse shine, } \\
\text { with strong alveolar } \\
\text { microsculpture } \\
\text { present throughout the } \\
\text { tegument }\end{array}$ & $\begin{array}{l}\text { With diffuse shine, } \\
\text { with strong alveolar } \\
\text { microsculpture } \\
\text { present throughout the } \\
\text { tegument }\end{array}$ & $\begin{array}{c}\text { Shiny, with } \\
\text { weak alveolar } \\
\text { microsculpture, which, } \\
\text { in some areas, is } \\
\text { completely absent }\end{array}$ & $\begin{array}{c}\text { Shiny, with } \\
\text { weak alveolar } \\
\text { microsculpture, which, } \\
\text { in some areas, is } \\
\text { completely absent }\end{array}$ \\
\hline $\begin{array}{l}\text { Tegument of } \\
\text { ventral face } \\
\text { of meso- and } \\
\text { metafemora }\end{array}$ & $\begin{array}{l}\text { Entirely covered by } \\
\text { rivose microsculpture, } \\
\text { with no smooth area; } \\
\text { micropunctation fine, } \\
\text { almost imperceptible }\end{array}$ & $\begin{array}{l}\text { Entirely covered by } \\
\text { rivose microsculpture, } \\
\text { with no smooth area; } \\
\text { micropunctation fine, } \\
\text { almost imperceptible }\end{array}$ & $\begin{array}{l}\text { Smooth throughout } \\
\text { most of tegument, } \\
\text { excepting the anterior } \\
\text { apical area of rivose } \\
\text { microsculpture; } \\
\text { micropunctation fine } \\
\text { and evident in the } \\
\text { smooth areas }\end{array}$ & $\begin{array}{l}\text { Smooth throughout } \\
\text { most of tegument, } \\
\text { excepting the anterior } \\
\text { apical area of rivose } \\
\text { microsculpture; } \\
\text { micropunctation fine } \\
\text { and evident in the } \\
\text { smooth areas }\end{array}$ \\
\hline $\begin{array}{c}\text { Coarse } \\
\text { punctation } \\
\text { at base of } \\
\text { metafemora }\end{array}$ & Absent & $\begin{array}{l}\text { Elongate punctures } \\
\text { usually (but not } \\
\text { always) well marked }\end{array}$ & $\begin{array}{l}\text { Elongate punctures } \\
\text { usually (but not } \\
\text { always) well marked }\end{array}$ & $\begin{array}{l}\text { Modified into simple } \\
\text { fine punctures and } \\
\text { always only slightly } \\
\text { marked }\end{array}$ \\
\hline $\begin{array}{l}\text { Tegument of } \\
\text { elytra }\end{array}$ & $\begin{array}{c}\text { Smooth and } \\
\text { with evident } \\
\text { micropunctation at } \\
\text { centre and with strong } \\
\text { alveolar microsculpture } \\
\text { on sides and apex }\end{array}$ & $\begin{array}{l}\text { Matte, with strong } \\
\text { alveolar microsculpture } \\
\text { present throughout the } \\
\text { tegument }\end{array}$ & $\begin{array}{l}\text { Shiny and smooth, } \\
\text { with almost no trace } \\
\text { of microsculpture } \\
\text { throughout the } \\
\text { tegument }\end{array}$ & $\begin{array}{l}\text { Shiny, with diffuse } \\
\text { microsculpture, } \\
\text { difficult to see and with } \\
\text { ill-delimited alveoli }\end{array}$ \\
\hline $\begin{array}{c}\text { Female } \\
\text { abdomen } \\
\text { lateral foveae }\end{array}$ & $\begin{array}{l}\text { Always strongly } \\
\text { marked and deep; with } \\
\text { row of long setae on } \\
\text { anterior margin }\end{array}$ & $\begin{array}{l}\text { Always strongly } \\
\text { marked and deep; } \\
\text { glabrous }\end{array}$ & $\begin{array}{l}\text { Always strongly } \\
\text { marked and deep; } \\
\text { glabrous }\end{array}$ & $\begin{array}{c}\text { Very shallow } \\
\text { (particularly between } \\
\text { ventrites III-IV) } \\
\text { and poorly marked; } \\
\text { glabrous }\end{array}$ \\
\hline $\begin{array}{l}\text { Tegument of } \\
\text { pygidium }\end{array}$ & $\begin{array}{l}\text { With strong alveolar } \\
\text { microsculpture } \\
\text { throughout the } \\
\text { tegument }\end{array}$ & $\begin{array}{l}\text { With diffuse alveolar } \\
\text { microsculpture, at } \\
\text { centre and apex, } \\
\text { and strong rivose } \\
\text { microsculpture at base }\end{array}$ & $\begin{array}{l}\text { Completely smooth at } \\
\text { centre with occasional } \\
\text { microsculpture present } \\
\text { only on sides }\end{array}$ & $\begin{array}{l}\text { Completely smooth at } \\
\text { centre with occasional } \\
\text { microsculpture present } \\
\text { only on sides }\end{array}$ \\
\hline $\begin{array}{c}\text { Apex of } \\
\text { parameres } \\
\text { (lateral view) }\end{array}$ & $\begin{array}{l}\text { Strongly bifurcate; } \\
\text { without a membrane } \\
\text { connecting apical } \\
\text { branches; superior } \\
\text { branch very projected } \\
\text { upwards, and inferior } \\
\text { branch projected } \\
\text { forwards }\end{array}$ & $\begin{array}{l}\text { Strongly bifurcate; } \\
\text { with fine membrane } \\
\text { connecting apical } \\
\text { branches; inferior } \\
\text { branch well projected } \\
\text { and widely divergent } \\
\text { from superior branch }\end{array}$ & $\begin{array}{l}\text { Only weakly bifurcate; } \\
\text { with fine membrane } \\
\text { connecting apical } \\
\text { branches; inferior } \\
\text { branch slightly } \\
\text { indicated and parallel } \\
\text { to superior branch }\end{array}$ & $\begin{array}{l}\text { Strongly bifurcate; } \\
\text { with fine membrane } \\
\text { connecting apical } \\
\text { branches; inferior } \\
\text { branch well projected } \\
\text { and widely divergent } \\
\text { from superior branch }\end{array}$ \\
\hline Distribution & $\begin{array}{l}\text { Northern portion of } \\
\text { the Brazilian Atlantic } \\
\text { Forest, from Alagoas } \\
\text { south to Espírito Santo }\end{array}$ & $\begin{array}{c}\text { Eastern slopes of the } \\
\text { Andes in Peru and } \\
\text { Bolivia }\end{array}$ & $\begin{array}{l}\text { Southern Amazonia, in } \\
\text { the Brazilian states of } \\
\text { Pará and Mato Grosso }\end{array}$ & $\begin{array}{c}\text { Western Amazonia } \\
\text { Colombia, Brazil } \\
\text { (Amazonas and Acre) } \\
\text { and Peru. Still little } \\
\text { known }\end{array}$ \\
\hline
\end{tabular}


any differences from each other, has a strong bifurcation, with two widely divergent branches, being the inferior branch well developed and with a strong excavation posteriorly to it (Fig. 44A-B). In S. monnei sp. nov., in contrast, the apical bifurcation is much weaker, and the inferior branch is short and straight (Fig. 44C-D).

Distinctions related to the coarse punctation at the base of the metafemora and to the female abdominal foveae approach $S$. furvus to $S$. monnei sp. nov. on the one side, and separate them from S. mayri sp. nov. on the other. The coarse punctures of metafemora are usually longer and more well impressed in the first two species (Fig. 13C, E), while they are finer and much weaker in S. mayri sp. nov. (Fig. 13D). Nonetheless, there is a variation in the intensity on which these punctures are marked in different individuals of a same species (and also in $S$. foveiventris and $S$. bridarollii, the other two species in which these punctures are present). It is important to bear in mind, however, that it is only possible to see this distinction at the populational level, not at the individual one. The real difference should rest, therefore, when we see populations as a whole (in average, punctures are more profound in S. monnei sp. nov. and $S$. furvus than in $S$. mayri sp. nov.). When we have larger series of $S$. furvus, $S$. monnei sp. nov. and, especially, $S$. mayri sp. nov., we will be able to test more firmly whether this observation is correct or not. As for the abdominal foveae, they are as profound and clearly marked in $S$. monnei sp. nov. as in S. furvus (Fig. 16A), while they are very shallow (particularly the one between ventrites III-IV) in the only two known females of $S$. mayri sp. nov. (Fig. 16B).

Along with the morphological differences listed so far, these three species are totally allopatric, without any known overlapping zone between their distributions (Fig. 41). Sylvicanthon furvus is restricted to the cloud forests and the yungas on the eastern slopes of the Andes, in northern Bolivia and southern Peru. Sylvicanthon monnei sp. nov. is widely distributed in southern Amazonia, in the Brazilian states of Mato Grosso and Pará. Finally, S. mayri sp. nov. was recorded from four points very distant from one another in western Amazonia, in the Peruvian department of Madre de Díos, in the Brazilian states of Acre and Amazonas and in the Colombian state of Meta.

\section{Comments}

A male $S$. furvus collected in Bolivia and now housed at the MZSP is labelled "HOMEOTIPO" and "Canthon / candezei / Har. / P. Pereira det. 942". Since the term homeotype refers to an ordinary specimen compared to a type specimen (Evenhuis 2008), it is curious to note that none of the known $S$. candezei syntypes bears any label by Padre Francisco Pereira, so indicating he did not have access to them. Besides, $S$. candezei and $S$. furvus are very distinct in terms of morphology and, therefore, it is improbable that such an experienced entomologist as Pe. Pereira could have confused them. On the other hand, he had access to the type specimens of S. furvus in 1960 (as stated by Pereira \& Martínez 1960), and, hence, it might be possible that the homeotype label refers in fact to this latter name and has nothing to do with the 1942 identification label.

\section{Natural history}

Almost nothing is known on the biology of S. furvus. Most of the specimens examined, having likely been collected in the $19^{\text {th }}$ and early $20^{\text {th }}$ centuries, do not have bionomic data on their labels. The only information on the collecting methods comes from the label of a male collected in a pitfall trap (baited with human faeces?) in La Convención (Cuzco, Peru) in 2010. The only four specimens with data on the collecting month report January, September, October and November. Lastly, concerning the altitudinal range, specimens of $S$. furvus were found mostly between 1350 and $1850 \mathrm{~m}$, being $450 \mathrm{~m}$ the lowest record (the female collected in Guanay, Bolivia). The type locality of S. furvus, Marcapata (Quispicanchi, Cuzco), is located around $3100 \mathrm{~m}$ a.s.1., which, if correct, would represent the highest altitudinal record for an American Deltochilini. 


\section{Sylvicanthon monnei sp. nov. urn:lsid:zoobank.org:act:045BB71E-7DD7-4EE3-B7AE-E087F656F754 \\ Figs 13C, 19D, 20, 41, 43B, E, 44C-D}

\section{Etymology}

A tribute to the Uruguayan-Brazilian entomologist Miguel A. Monné, one of the leading specialists in the New World fauna of Cerambycidae and author of the main catalogue of the family's Neotropical species plus almost 200 papers dealing with longhorn beetle taxonomy. As the first author's supervisor throughout his entire undergraduation (2009-2013), it was prof. Monné who first opened doors so that he could work as a zoologist. Through his example and inspiration, MC's taste for taxonomy, zoological nomenclature and history of entomology, as well as his profound respect for all the great synthesizers of scientific knowledge, quickly flourished.

\section{Material examined}

\section{Holotype}

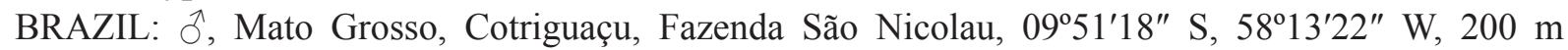
("BRASIL: MatoGrosso.Cotriguaçu, / Faz. São Nicolau. flor.sec.200m / 9 51'18" S, 58 13'22" W. Fezes / hum. X-2009. Vaz-de-Mello") (CEMT).

Paratypes $(8 \hat{\jmath} \hat{\partial}, 5$ + $q)$

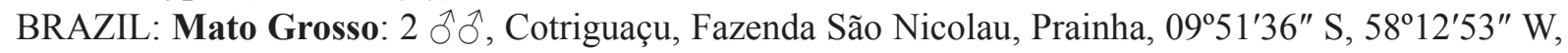
Oct. 2009, pitfall, F.Z. Vaz-de-Mello leg. (CEMT); 2 $\widehat{\jmath}, 1$ †, Diamantino, Fazenda São João, $14^{\circ} 14^{\prime} 10^{\prime \prime}$ S, 56 $06^{\circ} 11^{\prime \prime}$ W, 400 m, 11 Jan. 2001, pitfall with dung, Génier \& Vaz-de-Mello leg. (CMNC); 1 đ̃, 2 우, Porto Estrela, ESEC Serra das Araras, Olho d'Água, 14 Oct. 2011, pitfall, M. Gigliotti leg. (CEMT); $10^{\wedge}$, Porto Estrela, ESEC Serra das Araras, Trilha Bocado do José, $15^{\circ} 38^{\prime} 50^{\prime \prime}$ S, 57 $17^{\prime} 27^{\prime \prime} \mathrm{W}$, 238 m, 10 Oct. 2011, pitfall, F.Z. Vaz-de-Mello leg. (CEMT); 1 đૈ, Querência, Fazenda São Luiz,

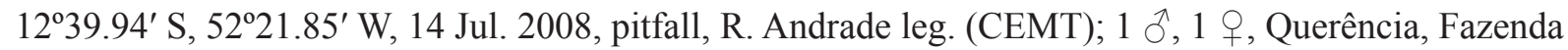
São Luiz, 12³9.64' S, 52²2.74' W, 17 Jul. 2008, pitfall, R. Andrade leg. (CEMT). - Pará: 1 q, São Félix do Xingu, Pinkaití Reserve, 0745' S, 51ํ5' W, 12 Nov. 1998, P.Y. Scheffler leg. (CEMT).

\section{Description}

Colouration. Head, pronotum, elytra and pygidium predominantly dark green. Metaventrite very dark, black with soft greenish reflections. Meso- and metafemora reddish-brown or dark brown.

HEAD. Tegument shiny, with well-marked micropunctation and weak alveolar microsculpture, in some specimens very effaced or even absent in some parts of head; micropunctation almost imperceptible or absent at apex of clypeus. Clypeus with two apical teeth obtuse and only slightly separated from one another; with single transverse row of short setae covering base of both teeth. Genae with weak denticle immediately behind clypeal-genal juncture. Posterior edge of head unmargined between eyes.

Thorax. Pronotum with shiny tegument with dense micropunctation at centre; towards the sides, micropunctation progressively less well marked, but always present and evident; alveolar microsculpture present only on anterolateral angles and in narrow strip on sides; at centre, tegument smooth. Posterior edge with fine transverse line at centre (usually extending up to second elytral stria) which, occasionally, can be difficult to see. Hypomeral cavity with some long yellowish setae at centre; external edge with weak tubercle. Metaventrite glabrous at centre; sides with few sparse setae near anterior margin of metacoxae (Fig. 7B); anterior region of metaventrite with tegument with strong rivose microsculpture; centre and posterior region with dense micropunctation and without microsculpture. 
LEgs. Ventral surface of all femora and tibiae bright. Profemora with tegument with sparse micropunctation and without microsculpture at anterior half and with strong rivose microsculpture at posterior half. Protibiae narrow and with distinct expansion on internal edge; at apical third, external edge with three small acute teeth, two most apical ones subequal in length and larger than basal (Fig. 11E). Mesofemora margined anteriorly only at basal half; unmargined portion of anterior edge with row of very short setae; posterior margin absent; tegument smooth and with sparse micropunctation, except apical anterior half, which has strong rivose microsculpture. Metafemora margined only anteriorly, posterior margin absent; apical third of anterior edge covered by row of setae; tegument with rivose microsculpture at anterior half and smooth with sparse micropunctation at posterior half; with strong coarse elongate punctation at base (Fig. 13C). Metatarsomeres II and V subequal in length and longer than others; metatarsomere IV shorter than others.

ElYTRA. With only seven narrow visible striae: first three or four well marked, finely carinulate, and widened at base; fifth to seventh progressively more effaced and interrupted; all striae lack carinulae before reaching apex of elytra, where they are marked only by microsculpture or completely indistinct; humeral carina absent. Tegument of interstriae shiny, without microsculpture, and with very dense micropunctation.

AвDOMEN. Tegument of ventrites I-IV with strong rivose microsculpture; ventrite VI smooth at centre and with weak rivose microsculpture on sides. Pygidium with bright tegument, without microsculpture, and with dense micropunctation (occasionally, weak microsculpture present on the sides of pygidium).

Aedeagus. Parameres longer than half-length of phallobase and without any noticeable asymmetry, with both external faces flat. In lateral view, parameres with apex slightly bifurcate, with inferior branch of bifurcation only very slightly projected and parallel to superior branch; without ventral keel or notch (Figs 19D, 44C-D).

SeXual Dimorphism. Males: Protibial spur broad and bifid, with external projection spiniform and not much longer than internal projection, which is bent and widened (Fig. 15N). Abdomen without lateral foveae. Ventrite VI strongly narrowed at centre due to a distinct emargination on posterior edge; anterior edge slightly covered by weak medial flange of posterior edge of ventrite V. Pygidium very long (length between 1.2 and $1.0 \mathrm{~mm}$ ) and convex; apical margin of pygidium much wider than lateral margins. Females: Protibial spur spiniform. Abdomen with three pairs of transverse foveae located between ventrites I-II, II-III, and III-IV, respectively; foveae not margined by row of long setae (Fig. 16A). Ventrite VI very broad at centre, posterior edge straight, without emargination; anterior edge subtly covered by weak medial flange of posterior edge of ventrite V. Pygidium shorter (about $0.9 \mathrm{~mm}$ ) and flat; apical margin of pygidium only slightly wider than lateral margins.

\section{Measurements}

Males $(\mathrm{N}=5)$. TL: AV: $6.6 \pm 0.25$; MX: 6.8; MN: 6.3. EW: AV: $4.9 \pm 0.29$; MX: 5.3; MN: 4.6. PrL: AV: $2.2 \pm 0.13$; MX: 2.4; MN: 2.1. PrW: AV: $4.4 \pm 0.21$; MX: 4.6; MN: 4.1. PgL: AV: $1.1 \pm 0.09$; MX: 1.2; MN: 1.0. PgW: AV: $2.2 \pm 0.14$; MX: 2.4; MN: 2.1 .

Females (N =3). TL: AV: $6.5 \pm 0.20$; MX: 6.7; MN: 6.3. EW: AV: $4.9 \pm 0.28$; MX: 5.1; MN: 4.7. PrL: AV: $2.1 \pm 0.21$; MX: 2.3; MN: 1.9. PrW: AV: $4.1 \pm 0.3$; MX: 4.4; MN: 3.8. PgL: AV: $0.9 \pm 0.0$; MX: 0.9 ; MN: 0.9. PgW: AV: $2.1 \pm 0.0 ;$ MX: 2.1; MN: 2.1.

\section{Geographical distribution}

Southern Amazonia in Brazil. 


\section{Ecoregions}

Xingu-Tocantins-Araguaia Moist Forests, Madeira-Tapajós Moist Forests, Mato Grosso Tropical Dry Forests, Chiquitano Dry Forests.

\section{Collecting sites (Fig. 41)}

BRAZIL. Pará: São Félix do Xingu. Mato Grosso: Cotriguaçu, Diamantino, Porto Estrela (Estação Ecológica Serra das Araras), Querência.

\section{Intraspecific variation and taxonomic discussion}

The two most closely related species to $S$. monnei sp. nov. are $S$. mayri sp. nov. and $S$. furvus, from which it can be differentiated by the following combination of characteristics: elytral tegument without any alveolar microsculpture among micropunctation (alveolar microsculpture strongly impressed in S. furvus, and diffuse, but still present in S. mayri sp. nov.), parameres with both branches of apical bifurcation only slightly divergent, the inferior branch being straight and little projected (Fig. 44C-D) (parameres strongly bifurcate at apex in S. mayri sp. nov. (Fig. 44A-B) and S. furvus, with the inferior branch well developed and widely divergent from the superior branch) and distribution in southern Amazonia (Fig. 41) (on the slopes of Andes in Peru and Bolivia for S. furvus and western Amazonia for S. mayri sp. nov.). A detailed comparison between these three species can be found in the discussion of S. furvus and on Table 5.
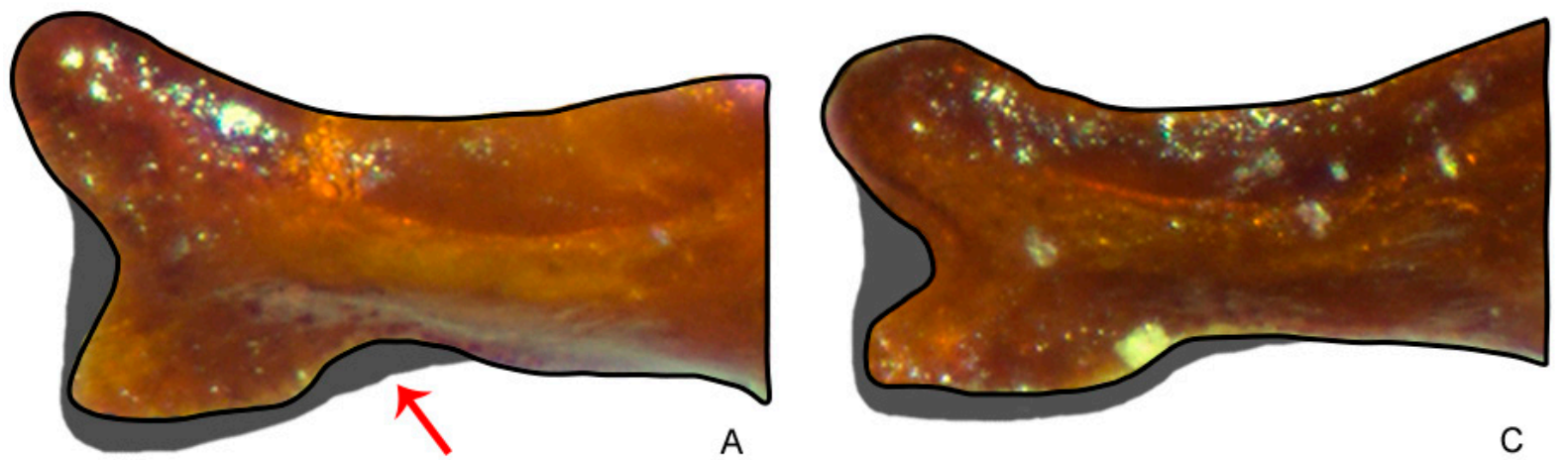

A
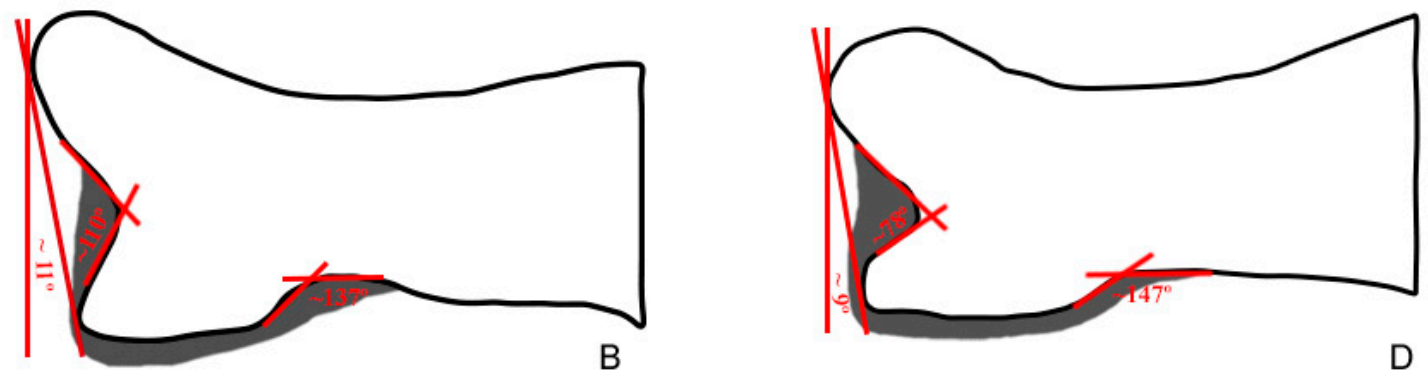

Fig. 44. Differences on the parameres of Sylvicanthon mayri sp. nov. and S. monnei sp. nov. (grayish zones represent original membraneous areas). A-B. S. mayri sp. nov. C-D. S. monnei sp. nov. Note that both branches of the apical bifurcation of the parameres of $S$. mayri sp. nov. are much more divergent than those of $S$. monnei sp. nov., which makes the internal angle between them more open in the first species $\left(\sim 110^{\circ}\right)$ than in the second $\left(\sim 78^{\circ}\right)$. In the same way, as the inferior branch is much more projected in $S$. mayri sp. nov. than in $S$. monnei sp. nov., the angle between the posterior region of that branch and the rest of the paramere is more open in $S$. monnei sp. nov. $\left(\sim 147^{\circ}\right)$ than in S. mayri sp. nov. $\left(\sim 137^{\circ}\right)$, species that seems to have a strong excavation at this point of the paramere (indicated by red arrow in $\mathrm{A})$. 
Two species of Sylvicanthon can be found in sympatry with S. monnei sp. nov.: S. candezei and S. proseni. From the first, $S$. monnei sp. nov. can be readily distinguished as follows: protibiae tridentate and with a distinct expansion on their internal margin (Fig. 11E) (bidentate and straight on its internal margin in S. candezei, Fig. 11J), females with three pairs of abdominal foveae (Fig. 16A) (without foveae in S. candezei) and parameres, in lateral view, without any notch on its inferior edge (Figs 19D, 44C) (with a profound notch on the middle of ventral edge in S. candezei, Fig. 17C). It is interesting to note that individuals from southern populations of $S$. candezei, i.e., those that can be in sympatry with $S$. monnei sp. nov., differ from northern specimens in having elytra without trace of microsculpture in the same way as seen in $S$. monnei sp. nov.

\section{Comments}

The holotype and two paratypes of S. monnei sp. nov. are part of a large series of dung beetles collected during a faunistic survey on the São Nicolau farm ("Fazenda São Nicolau"), in the municipality of Cotriguaçu (Mato Grosso, Brazil), done in two campaigns at the end of 2009; the three type specimens were caught during the first campaign, between the $5^{\text {th }}$ and $16^{\text {th }}$ of October. The survey was published by Vaz-de-Mello et al. (2011b), but, curiously, no Sylvicanthon (except S. proseni, then cited in Canthon) were included in the final list of 118 species present at the farm. Since 2009, three other new species were described from that material: Lobidion punctatissimum Génier, 2010 of Ateuchini (which was recently transferred to Ateuchus by Génier \& Cupello 2018), and Deltochilum (Aganhyboma) schefflerorum Silva et al., 2015 and Hansreia peugeoti Valois et al., 2015 both in Deltochilini.

\section{Natural history}

The little we know on the biology of $S$. monnei sp. nov. is thanks to the information contained on specimen labels. Known specimens were collected in pitfall traps baited with human faeces in January, July, October and November. The species is found in altitudes between 230 and $400 \mathrm{~m}$, in both primary and secondary semideciduous forests, but it is probably rare in both habitats.

\section{Sylvicanthon mayri sp. nov. urn:1sid:zoobank.org:act:260557DD-3E56-47DE-94AC-6F8DD638C039}

Figs 13D, 16B, 19E, 20, 41, 43C, F, 44A-B

\section{Etymology}

A tribute to the German-American ornithologist, evolutionary theorist, philosopher and historian of biology Ernst Mayr (1904-2005), author of some of the major classics in evolutionary biology and, in the first author's view, one of the greatest and most versatile biologists of the $20^{\text {th }}$ century. In special recognition of the immense intellectual influence he had (and continues to have) on MC's formation and in his choice to pursue a career as a systematist. Haffer (2007) presented the most complete biography of Ernst Mayr to date. The specific name is a noun in the genitive case.

\section{Material examined}

\section{Holotype}

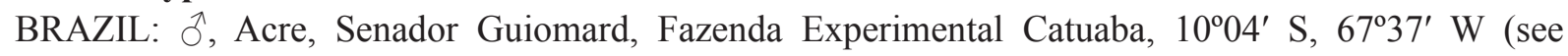
comments below) ("BRASIL: AC. Rio Branco / Faz. Catuaba II - 1997 / F.Z. Vaz-de-Mello leg."), genital capsule extracted and glued to a point card (CEMT).

Paratypes $(1 \hat{\jmath}, 2$ q $q)$

BRAZIL: Amazonas: 1 †, São Paulo de Olivença, Jun.- Jul. 1883, M. de Mathan leg. (CEMT). 
COLOMBIA: Meta: 1 ○ (dissected), “33 km E Villavicencio”, 2-4 Mar. 1972, dung trap, S. and J. Peck leg. (CMNC).

PERU: Madre De Dios: 1 +, Tambopata, Puerto Maldonado, 12²1'19" S, 6901'48" W, 221 m, 26-27 Mar. 2009, L. Figueroa leg. (MUSM).

\section{Description}

Colouration. Head, pronotum, elytra, metaventrite, and pygidium dark green or dark blue. Meso- and metafemora reddish-brown; occasionally, with greenish reflections.

HEAD. Tegument shiny, with weak alveolar microsculpture and covered by dense well-marked micropunctation, which is almost imperceptible or even absent at apex of clypeus. Clypeus with two apical teeth obtuse only and only slightly separated from one another; with single transverse row of very short setae covering base of both teeth. Genae with small denticle immediately behind clypealgenal juncture. Posterior edge of head unmargined between eyes or with very fine, almost imperceptible interrupted line at centre.

Thorax. Pronotoum with shiny tegument and with dense micropunctation at centre; towards the sides, micropunctation progressively less well-marked, but always present, although occasionally almost imperceptible; alveolar microsculpture between micropunctures present only on anterolateral angles and in narrow strip on lateral margins; at centre, tegument between micropunctures smooth or with very subtle microsculpture (as on elytra). Posterior edge with fine transverse line at centre (usually extending up to second elytral stria) which occasionally may be difficult to see. Hypomeral cavity with some long yellowish setae at centre; external margin with slight, almost inconspicuous tubercle. Metaventrite glabrous at centre; sides with few sparse setae near anterior margin of metacoxae (Fig. 7B); posterior region of metaventrite with narrow transverse strip of tegument with distinct rivose microsculpture; centre and posterior region with dense micropunctation and without microsculpture.

LEGs. Ventral surface of all femora and tibiae bright. Profemora with tegument with sparse micropunctation and without microsculpture at anterior half, and with strong rivose microsculpture at posterior half. Protibiae narrow and with distinct expansion on the internal edge; at their apical third, external edge with three small acute teeth, the two most apical ones subequal in length and larger than the basal (Fig. 11E). Mesofemora margined anteriorly only at their basal half; unmargined portion of anterior edge covered by row of very short setae; posterior margin absent; tegument smooth and with sparse micropunctation, except for anterior half, which has rivose microsculpture. Metafemora margined only anteriorly, posterior margin absent; apical third of anterior edge covered by row of setae; tegument with rivose microsculpture at anterior half, and smooth with sparse micropunctation at posterior half; base with very short, ill-delimitated or even almost totally absent coarse punctures (Fig. 13D). Metatarsomeres II and V subequal in length and longer than the others; metatarsomere IV shorter than the others.

ELYTRA. With only six or seven narrow visible striae: the first three striae well marked, finely carinulate, and widened at base; striae IV-VII progressively more effaced and interrupted; all striae lack carinulae before reaching apex of elytra, where they are marked only by microsculpture or are completely indistinct; humeral carina absent. Tegument of interstriae shiny, with very diffuse microsculpture (never in a well-delimitated alveolar pattern as in S. furvus) and with very dense micropunctation.

ABDOMEN. Tegument of ventrites $\mathrm{I}-\mathrm{V}$ with strong rivose microsculpture; ventrite VI smooth at centre and with weaker rivose microsculpture on sides. Pygidium with shiny tegument, without microsculpture, and with dense micropunctation. 
Aedeagus. Parameres much longer than half-length of phallobase, and without noticeable asymmetry, both external faces flat. In lateral view, parameres with apex widely bifurcate, with inferior branch of bifurcation distinctly projected and divergent from superior branch; without ventral keel or notch (Figs 19E, 44A-B).

Sexual dimorphism. Males: Protibial spur broad and bifid, with external projection spiniform and not much longer than internal projection, which is bent and widened (Fig. 15N). Abdomen without lateral foveae. Ventrite VI strongly narrowed at centre due to distinct emargination on posterior edge; anterior edge slightly covered by weak medial flange of posterior edge of ventrite V. Pygidium very long (length between 1.2 and $1.1 \mathrm{~mm}$ ) and convex; apical margin of pygidium much wider than lateral margins. Females: Protibial spur spiniform. Abdomen with three pairs of very shallow transverse foveae located between ventrites I-II, II-III, and III-IV, respectively; foveae not margined by row of long setae (Fig. 16B). Ventrite VI wide at centre, posterior edge straight, without emargination; anterior edge subtly covered by medial flange of posterior edge of ventrite V. Pygidium shorter (between 0.9 and $0.8 \mathrm{~mm}$ ) and flat; apical margin of pygidium only slightly wider than lateral margins.

\section{Measurements}

Males $(\mathrm{N}=2)$. TL: AV: $7.0 \pm 0.35$; MX: 7.3; MN: 6.8. EW: AV: $5.0 \pm 0.21$; MX: 5.2; MN: 4.9. PrL: AV: $2.3 \pm 0.07$ MX: 2.4; MN: 2.3. PrW: AV: $4.4 \pm 0.21$; MX: 4.6; MN: 4.3. PgL: AV: $1.15 \pm 0.07$; MX: 1.2; MN: 1.1. PgW: AV: $2.2 \pm 0.14$; MX: 2.3; MN: 2.1 .

Females (N =2). TL: AV: $6.75 \pm 0.07$; MX: 6.8; MN: 6.7. EW: AV: $4.8 \pm 0.35$; MX: 5.1; MN: 4.6. PrL: AV: $2.05 \pm 0.07$; MX: 2.1; MN: 2.0. PrW: AV: $4.15 \pm 0.21$; MX: 4.3; MN: 4.0. PgL: AV: $0.85 \pm 0.07$; MX: 0.8; MN: 0.9. PgW: AV: $2.05 \pm 0.07$; MX: 2.1; MN: 2.0.

\section{Geographical distribution}

Western Amazonia, in Colombia, Brazil, and Peru.

\section{Ecoregions}

Guianan Moist Forests, Marajó Varzea, Japurá-Solimões-Negro Moist Forests.

Collecting sites (Fig. 41)

COLOMBIA. Meta: Villavicencio.

BRAZIL. Acre: Senador Guiomard. Amazonas: São Paulo de Olivença.

PERU. Madre de Dios: Tambopata (Puerto Maldonado).

\section{Intraspecific variation and taxonomic discussion}

Of all the species of Sylvicanthon, S. mayri sp. nov. is certainly the most enigmatic, with only four known individuals in collections, two males and two females. What we know about its distribution, for instance, is clearly fragmentary. The four known localities lie in western Amazonia and, together, they form a longitudinal arc with almost $2000 \mathrm{~km}$ from one end to the other (namely, Villavicencio, Colombia, in the north, and Puerto Maldonado, Peru, in the south) (Fig. 41). Some questions can be raised from this observation: does $S$. mayri sp. nov. also occur in the interior of Peru and in Ecuador or northern Bolivia? Is its distribution extended eastwards into the lowlands of the Brazilian Amazonia? Does this species also occur across the eastern slopes of the Andes in Peru and Ecuador as it does in Colombia? These questions will only be answered when a larger number of dung beetle collections are 
made throughout the Amazon Basin, especially in the state of Amazonas (Brazil), from where very little Sylvicanthon material is known (mostly from the capital, Manaus).

The morphological differences with the other two species of the furvus subgroup to which $S$. mayri sp. nov. is most similar (S. furvus and S. monnei sp. nov.) are very clear even from the small number of specimens we currently have on hand. Sylvicanthon furvus, in general, is distinguished from $S$. mayri sp. nov. in presenting a very strong microsculpture throughout the body tegument. This is very clear especially on the meso- and metafemora (which are almost entirely smooth, except in the apical areas of rivose microsculpture in $S$. mayri sp. nov., while they are totally covered by rivose microsculpture in $S$. furvus), and elytra (which have a diffuse microsculpture in S. mayri sp. nov., while they have a strong alveolar microsculpture obliterating the micropunctation in $S$. furvus). From $S$. monnei sp. nov., S. mayri sp. nov. is different mainly in the shape of parameres (with a strongly bifurcate apex, with its inferior branch distinctly divergent from the superior one, in S. mayri sp. nov. (Fig. 44A-B), and apical bifurcation branches only weakly divergent and with inferior branch only little projected and straight in S. monnei sp. nov. (Fig. 44C-D)). Lastly, the coarse punctation at the base of metafemora is distinct between $S$. mayri sp. nov., on the one side, and $S$. furvus and $S$. monnei sp. nov., on the other: in the two latter species, those punctures are clearly impressed and are elongated (Fig. 13C, E), while they are very fine and almost indistinguishable from the micropunctation in $S$. mayri sp. nov. (Fig. 13D). For a more detailed comparison between these three species and also with S. obscurus, see the discussions of S. furvus, S. obscurus, and Table 5.

\section{Comments}

The holotype of Sylvicanthon mayri sp. nov. is part of a large series of dung beetles collected in 1997 by the second author in the Brazilian state of Acre (some of the results of those collections were published in Vaz-de-Mello 1999). The Fazenda Experimental Catuaba, research base administered by the Federal University of Acre, contrary to what is said on the holotype's precedence label, is not located at the limits of the municipality of Rio Branco, but rather it is in the municipality of Senador Guiomard, about $25 \mathrm{~km}$ from the centre of Rio Branco. We revised for this work a great volume of envelopes with material collected by FZVM at Fazenda Catuaba and other nearby localities, but we failed to find any other specimens of $S$. mayri sp. nov. As argued earlier in this monograph, this fact should reflect the low population density the species of the furvus subgroup naturally have (see the discussion on $S$. furvus).

\section{Natural history}

The only specimen of $S$. mayri sp. nov. with known food habit data is the paratype from Villavicencio, which was collected in a pitfall trap baited with dung. The collecting months accurately reported were February and March, with the period June-July being the date reported for the São Paulo de Olivença specimen. Nothing more is known about the biology of $S$. mayri sp. nov.

Genus Canthon Hoffmannsegg, 1817

Canthon xanthopus Blanchard, 1846 restauration of original combination Figs $7 \mathrm{C}, 45$

Canthon xanthopum Blanchard, 1846: 166.

Canthon xanthopum - Blackwelder 1944: 202.

Canthon xanthopus - Lacordaire 1856: 78. - Harold 1868a: 140, 144; 1869b: 995. — Gillet 1911: 34. — Schmidt 1922: 72, 82. — Balthasar 1939: 226. — Martínez 1949b: 188; 1959: 45-46. — Vulcano \& Pereira 1964: 636. — Halffter \& Martínez 1977: 63. — Krajcik 2012: 64. 
Glaphyrocanthon xanthopus - Martínez et al. 1964: 8.

Sylvicanthon xanthopus - Halffter \& Martínez 1977: 63.

\section{Etymology}

From the Greek word 'xanthos', meaning 'yellow'. Referring to the leg's yellowish colouration of this species, "Canthon à pattes jaunes" (Blanchard 1846).

\section{Material examined}

Lectotype (here designated)

BOLIVIA: 0 , Santa Cruz, Vallegrande, cited by Blanchard (1846) as "Province de Valle Graude", ("LECTOTYPE § / Canthon / xanthopum / Blanch. / des. F. Z. Vaz-de-Mello, 2014", "Type", "Canthon / xanthopus / Blanch", "Museum Paris / Santa-Cruz / (Valle Grande) / d'Orbigny 1834", "6 B11 / 94 ") (MNHN) (Fig. 45A).

\section{Additional material $(7 \hat{\partial}, 12$ 우)}

BOLIVIA: Santa Cruz: 1 \&, Samaipata, Refugio Los Volcanes, $18^{\circ} 06.3^{\prime} \mathrm{S}, 63^{\circ} 35.9^{\prime} \mathrm{W}, 1050 \mathrm{~m}, 21-$ 25 Feb. 2010, carrion, Edmonds and Vidaurre leg. (TAMU); 7 $\widehat{\jmath}, 11$ q $q$, Samaipata, Refugio Los Volcanes, $18^{\circ} 06.3^{\prime} \mathrm{S}, 63^{\circ} 35.9^{\prime} \mathrm{W}, 1050 \mathrm{~m}, 21-25 \mathrm{Feb} .2010$, dead millipede, Edmonds and Vidaurre leg. (TAMU).

\section{Collecting sites}

BOLIVIA. Santa Cruz: Samaipata (Refugio Los Volcanes), Vallegrande.

\section{Comments}

The internal classification of the genus Canthon, as mentioned before, is extremely confusing and the genus is likely polyphyletic. Therefore, pointing out a clear relationship of C. xanthopus with any of the Canthon species groups could only be done in a tentative manner. By its overall morphology,

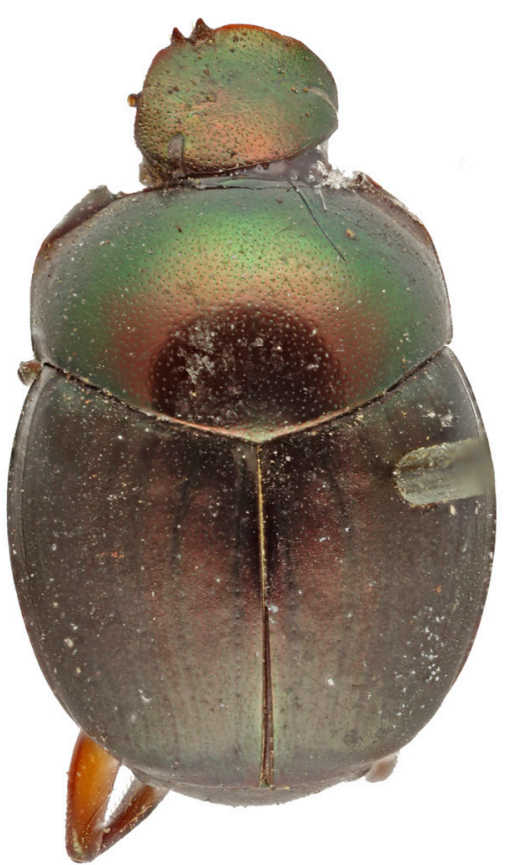

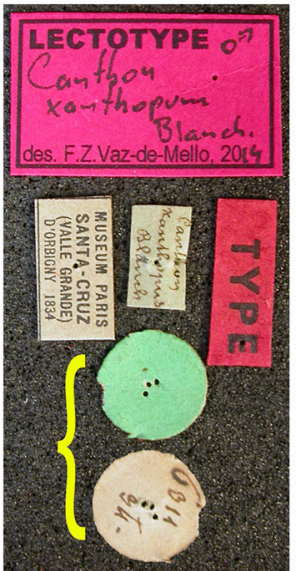

A

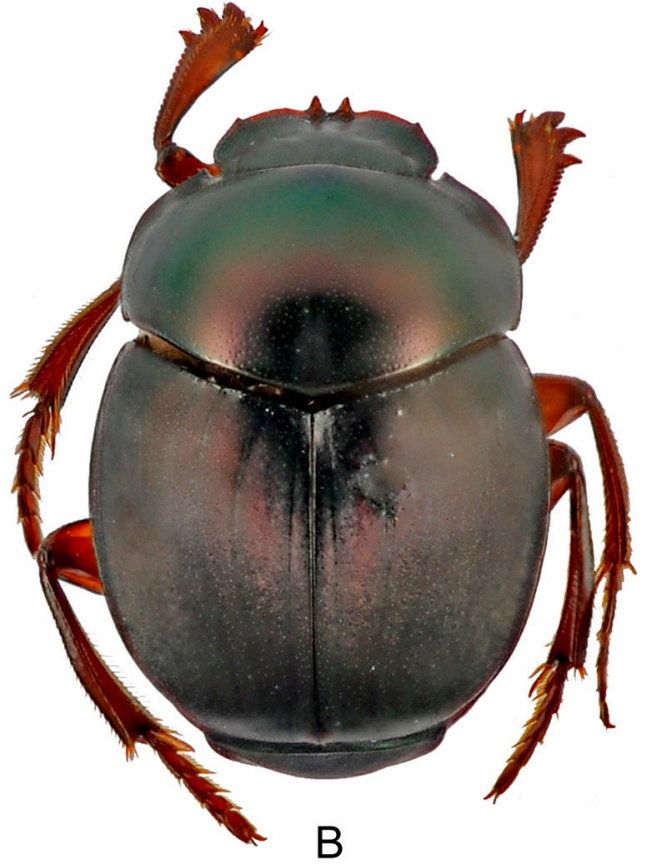

Fig. 45. Canthon xanthopus Blanchard, 1846. A. Lectotype and its labels. B. An ordinary specimen. 
especially regarding the shape of protibiae and the presence of a long humeral carina reaching the apex of elytra, C. xanthopus seems to be close to the four species of the maldonadoi group, which is part of the septemmaculatus lineage as defined by Halffter \& Martínez (1977). Nonetheless, the presence of a carina separating pygidium from propygidium in C. xanthopus is a feature that distinguishes this species from the members of that group - which do not possess any separation between pygidium and propygidium - and places C. xanthopus in the nominotypical subgenus. Therefore, a more careful analysis of the members of Canthon should be performed before a more confident decision is taken on the relationship between $C$. xanthopus and any particular species group. Hence, this species is put in incertae sedis within Canthon $\mathrm{s}$. str.

As discussed earlier in this work, the name Glaphyrocanthon cobosi was considered a junior subjective synonym of C. xanthopus by Halffter \& Martínez (1977) and has remained so up until now. It is interesting to revisit the taxonomic history of both names to understand the historical context that ultimately led Halftter \& Martínez to propose that synonymy.

The true identity of Canthon xanthopus, described from "Province de Valle Graude", Santa Cruz, Bolivia, was a mystery to scarabaeidologists for more than a century since its description by Blanchard (1846), which was based on very vague and imprecize characters such as the shape of the clypeus and the colouration of the tegument. In his revision of Canthon, Harold (1868b) included C. xanthopus in a list of 23 species names he could not relate to any known species taxa, and that situation persisted even after his following year's study of the MNHN collection (Harold 1869c), where until today one of the syntypes of C. xanthopus is housed. The same is true for the revisions of Schmidt (1922) and Balthasar (1939), who did not include C. xanthopus in their identification keys.

The name, then, would not be mentioned again until Martínez et al. (1964). Those authors, in a footnote to their identification key to the species of Glaphyrocanthon, wrote that, judging only from its original description, it could be presumed that C. xanthopus was "very close" to Glaphyrocanthon cobosi Pereira \& Martínez, 1960, a species also described from Santa Cruz, Bolivia. Nevertheless, C. xanthopus was not included in their key because they claimed they had never seen specimens of this species in person. Thirteen years later, Halffter \& Martínez (1977) stated they had finally found "the type" of C. xanthopus in the MNHN. On examining it, they concluded that C. xanthopus and G. cobosi were synonyms and the species had to be transferred to Sylvicanthon.

During the preparation of this work, we found a specimen in the MNHN collected in 1834 by the French explorer and naturalist Alcide d'Orbigny (1802-1857) in the province of Vallegrande, Santa Cruz, Bolivia. That specimen fully agrees with Blanchard's description and collecting data, which led us to consider it one of the syntypes of C. xanthopus, the only one known to us. No specimens found at the MNHN bear any label by Gonzalo Halffter or Antonio Martínez; therefore, we do not know which specimen they were referring to when they wrote they had examined "the type" of C. xanthopus.

The study of that syntype (now lectotype) of C. xanthopus (Fig. 45A) and its comparison with the holotype of G. cobosi (Fig. 46A, deposited in the MACN) leave no doubt that the synonymy proposed by Halffter \& Martínez (1977) is incorrect. Both species are easily distinguishable from one another by the shape of the eyes (with about $1 / 8$ of the width of the interocular space in what is now known as Canthon cobosi, and 1/10, in C.xanthopus), the shape of the protibiae (with tiny teeth and truncate apex in C. cobosi, and with large teeth and an apex occupied by the apical tooth in C.xanthopus), the shape of the clypeal teeth (small, obtuse and separated from one another by a clypeal emargination in C. cobosi, and large, acute, without emargination in C. xanthopus), and the hypomeron (strongly excavated, with a tooth on the external edge, with a complete hipomeral carina in C. cobosi, only slightly depressed, without any teeth, and with a very short hipomeral carina in C. xanthopus). For a discussion on the 
transfer of both species to the genus Canthon, see the section 'Species composition' under Sylvicanthon above.

Canthon cobosi (Pereira \& Martínez, 1960) revalidation and comb. nov.

Fig. 46A

Glaphyrocanthon (Glaphyrocanthon) cobosi Pereira \& Martínez, 1960: 45-47

Glaphyrocanthon (Glaphyrocanthon) cobosi - Martínez et al. 1964: 5, 8, 11, 14. - Vulcano \& Pereira 1964: 662; 1967: 561. - Halffter \& Martínez 1977: 63 (as junior synonym of Sylvicanthon xanthopus).

\section{Etymology}

The specific name refers to the Spanish entomologist Antonio Cobos Sánchez (1922-1998) (Pereira \& Martínez 1960).

\section{Material examined}

Holotype

BOLIVIA: + , Santa Cruz, Cordillera, Las Juntas, ("BOLIVIA / D Sta. Cruz / Pcia. Cordillera / Las Juntas / Maldonado B: ! ! / Coll. Martínez / Oct.-948", "HOLOTYPUS", "Glaphyrocanthon / (Glaph.) / cobosi sp.n. / q / A. Martínez det. 1956", "FICHADO”, "MACN-En / 1009”) (MACN) (Fig. 45B).

Additional material $(22 \hat{\partial} \hat{\partial}, 26 \propto q)$

ARGENTINA: Jujuy: 1 क , Parque Nacional Calilegua, Águas Negras, 500 m, 18 Dec. 1987, S. and J. Peck leg. (CMNC); 3 ๙ึ่ (1 dissected), 5 우우, Santa Barbara, Yuto, Feb. 1982 (CMNC).

BOLIVIA: Santa Cruz: 1 ô, Cordillera, Parabanó (CEMT); 1 o+, Cordillera, Río Seco, Feb. 1961 (CMNC); 1 đิ, 4 우, Cordillera, Río Seco, Feb. 1962 (CMNC); 1 đ̊, Santa Cruz de la Sierra, Río Piraí,

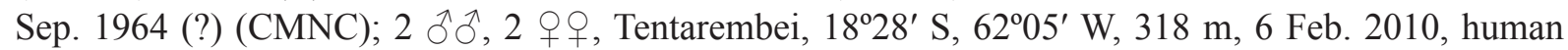

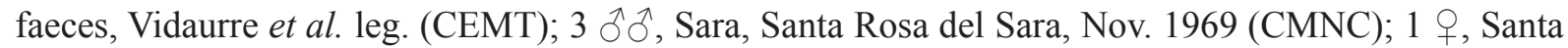
Rosa del Sara, Nov. 1972 (CMNC).

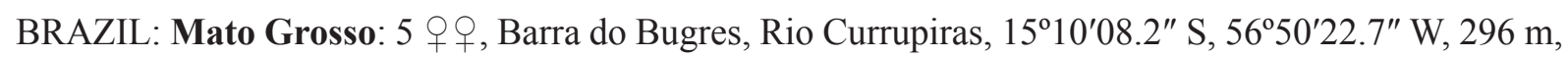
28 Feb. 2010, pitfall with human faeces, J.G. Mota-Souza leg. (CEMT). - Mato Grosso Do Sul: 2 우,

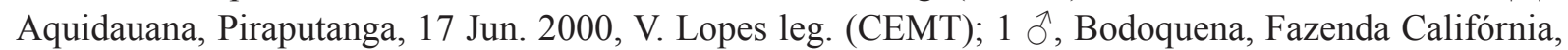
$20^{\circ} 41^{\prime} 05^{\prime \prime} \mathrm{S}, 56^{\circ} 51^{\prime} 33^{\prime \prime} \mathrm{W}$, Mar. 2011, human faeces, L.O. Bavutti leg. (CEMT); 1 , , Bodoquena, Fazenda Califórnia, 2041'08" S, 56 51'31" W, Mar. 2011, human faeces, L.O. Bavutti leg. (CEMT); 1 ㅇ, Bonito, Fazenda Palmeirinhas, $21^{\circ} 11.269^{\prime}$ S, 56 33.701' W, Nov. 2009, banana, F.O. Roque leg.

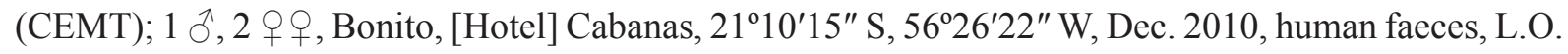
Bavutti leg. (CEMT); 1 q, Bonito, Hotel Cabanas, $21^{\circ} 10^{\prime} 17^{\prime \prime} \mathrm{S}, 56^{\circ} 26^{\prime} 26^{\prime \prime} \mathrm{W}$, Dec. 2010, human faeces,

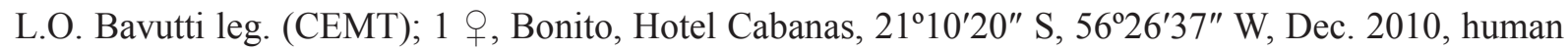
faeces, L.O. Bavutti leg. (CEMT); 1 \%, Bonito, Hotel Cabanas, $21^{\circ} 10^{\prime} 21^{\prime \prime} \mathrm{S}, 56^{\circ} 26^{\prime} 34^{\prime \prime}$ W, Dec. 2010,

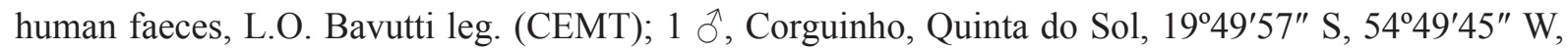
Feb. 2011, human faeces, L.O. Bavutti leg. (CEMT); 1 đ̂, Corumbá, Dec. 2007, C. Aoki leg. (AMBC);

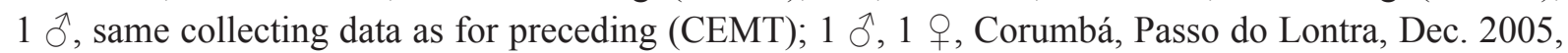

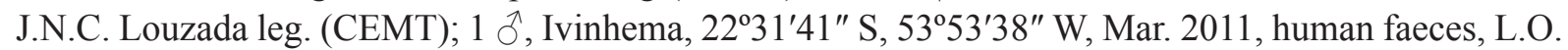
Bavutti leg. (CEMT); 1 đ, 1 q, Jardim, Jun. 2000, V. Lopes leg. (CEMT); 1 \&, Jardim, Rio da Prata, $21^{\circ} 25^{\prime} 40^{\prime \prime}$ S, 56 $27^{\prime} 00^{\prime \prime}$ W, Mar. 2011, human faeces, L.O. Bavutti leg. (CEMT). 

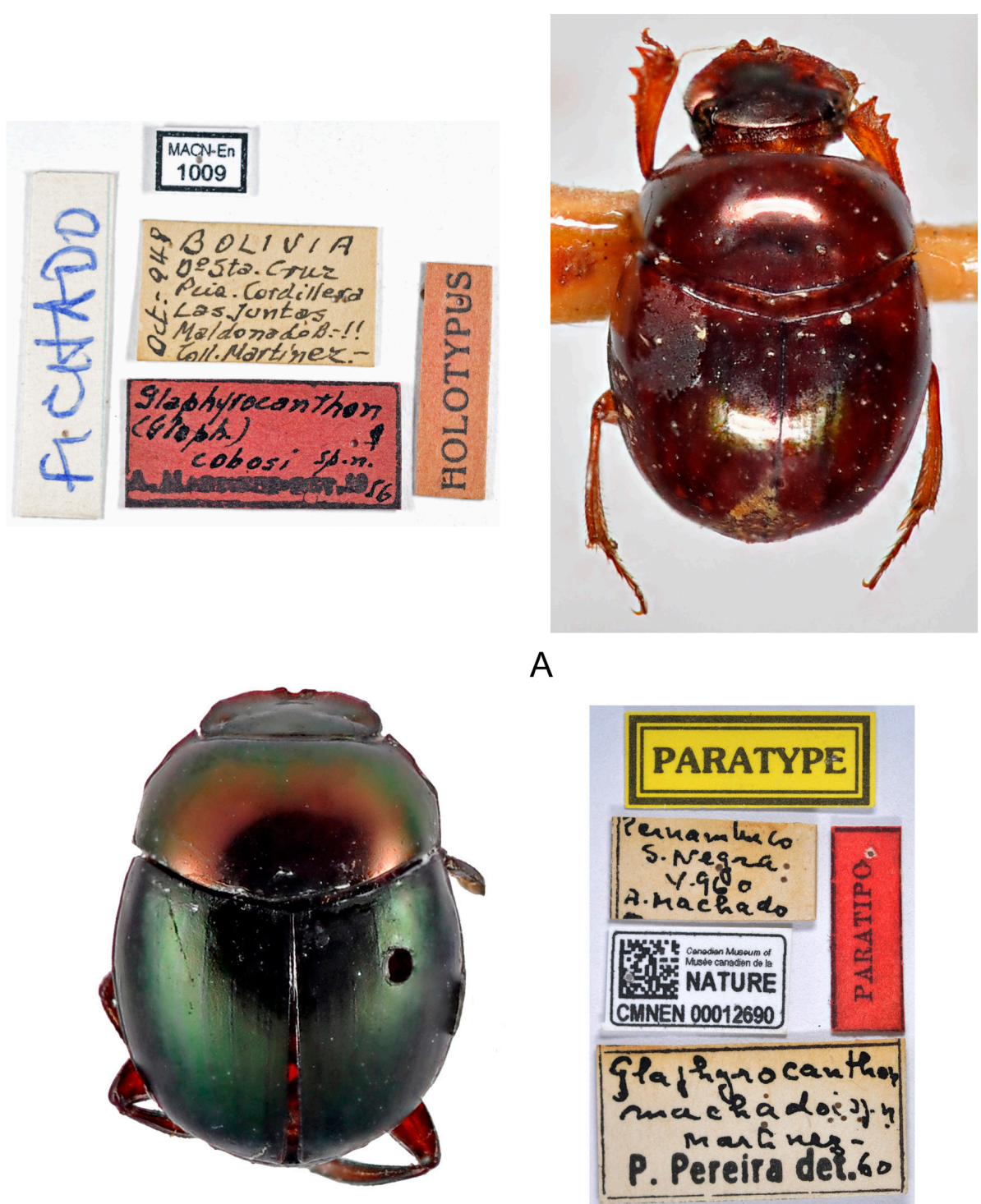

A

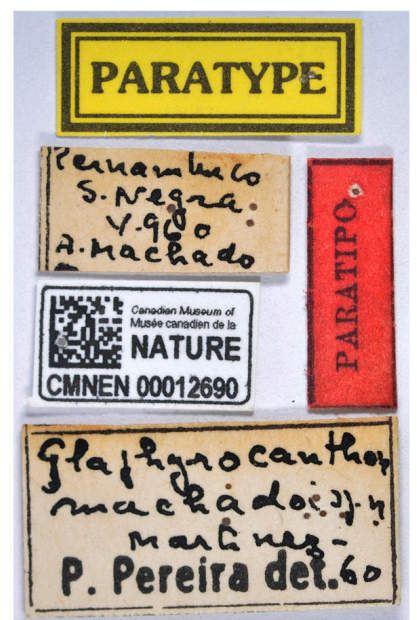

B
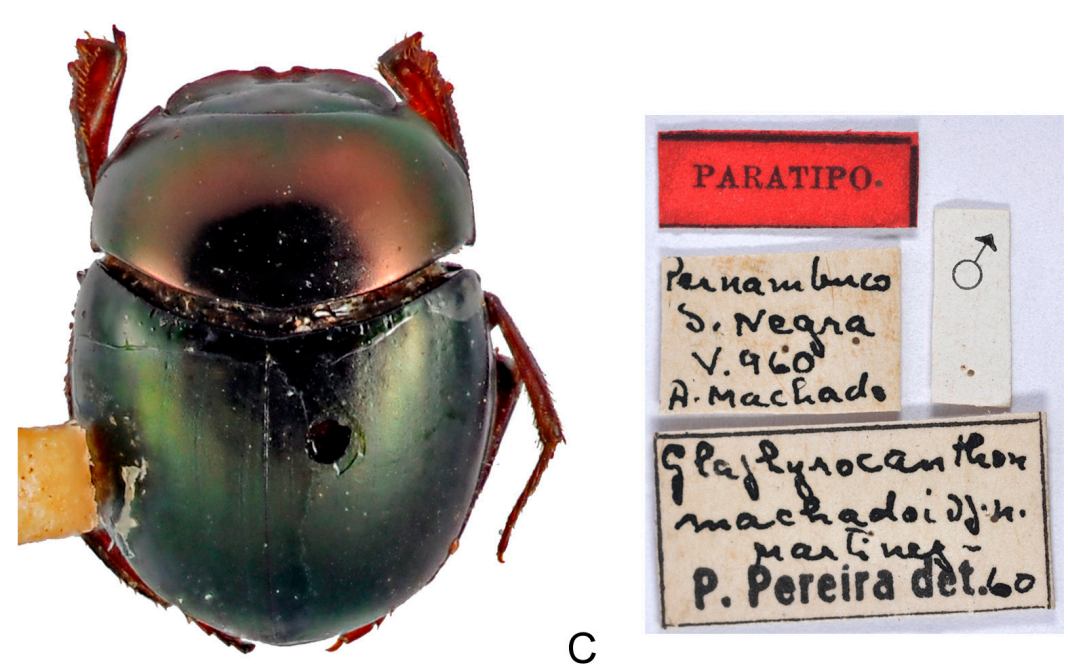

C

Fig. 46. A. Canthon cobosi (Pereira \& Martínez, 1960) stat. et comb. nov., holotype. B-C. Canthon machadoi (Martínez \& Pereira, 1967) comb. nov. B. Paratype 2. C. Paratype 4. 
PARAGUAY: Cordillera: 1 †, 5 Jul. 2005, Naraujo leg. (CEMT); 2 đ̊̄, Caacupé (“ $D^{o}$ Capital / Caa Cupé"), Oct. 1979 (CMNC).

\section{Collecting sites}

BRAZIL. Mato Grosso: Barra do Bugres. Mato Grosso do Sul: Aquidauana (Piraputanga), Bodoquena, Bonito, Corguinho, Corumbá, Ivinhema, Jardim.

BOLIVIA. Santa Cruz: Cordillera (Las Juntas, Río Seco), Santa Cruz de la Sierra, Sara (Santa Rosa del Sara).

PARAGUAY. Cordillera: Caacupé.

ARGENTINA. Jujuy: Parque Nacional Calilegua, Santa Barbara.

\section{Comments}

From the only geographical record ever published for C. cobosi - the locality of Las Juntas, in the province of Cordillera, Santa Cruz, Bolivia -, the known distribution of this species is widened to encompass areas also in Brazil (Mato Grosso and Mato Grosso do Sul), Paraguay and northern Argentina. There is, however, a noteworthy geographical variation that, when studied in more detail, may reveal that what we are considering to be a single species represents, in fact, two: specimens from Brazil, in general, are darker, with few coppery reflections, while individuals from Bolivia, Argentina and Paraguay show a coppery colouration with greenish reflections (Fig. 46A). As no other morphological variations were found and as there is chromatic variation even among individuals from Brazil (being some of them more coppery than others), we do not consider we have at this moment enough evidence for the existence of more than a single species. Nonetheless, we recognize that more research is needed in order to have a deeper understanding of the inter- and intrapopulational variation of $C$. cobosi. For details on the revalidation of this species from its synonymy with C. xanthopus, see the discussion under this latter species, while for details on its transference to Canthon, see section 'Species composition' under Sylvicanthon above.

Canthon machadoi (Martínez \& Pereira, 1967) comb. nov.

Fig. 46B-C

Glaphyrocanthon machadoi Martínez \& Pereira, 1967: 53-55

Glaphyrocanthon machadoi - Halffter \& Martínez 1977: 63.

Sylvicanthon machadoi - Halffter \& Martínez 1977: 63. - Vaz-de-Mello 2000: 195. - Silva et al. 2007: 230. - Costa et al. 2009: 91.

Canthon machadoi - Krajcik 2012: 64.

\section{Etymology}

The specific name refers to the Brazilian odonatologist Ângelo B.M. Machado, collector of the type series (Martínez \& Pereira 1967). Pinto (2016) presented an interesting short biography of Ângelo Machado.

\section{Material examined}

Paratypes (4 $\hat{\partial}, 1$ + )

BRAZIL: 1 đิ ("Glaphyrocanthon / machadoi sp. $n$ / Martinez - / P. Pereira det. 60", "PARATIPO", "PARATYPE", "Pernambuco / S. Negra / V.960 / A. Machado", "Canadian Museum of / Musée canadian 
de la / NATURE / CMNEN 0012690") (CMNC); 1 q ("Pernambuco / S. Negra / V.960 / A. Machado", "Glaphyrocanthon / machadoi sp. n / Martinez - / P. Pereira det. 60", "PARATIPO", "PARATYPE", “O”, "H. \& A. HOWDEN / COLLECTION / ex A. Martínez coll.", "Canadian Museum of / Musée canadian de la / NATURE / CMNEN 00019066") (CMNC); 1 đ̊ ("Pernambuco / S. Negra / V.960 / A. Machado", "Glaphyrocanthon / machadoi sp. n / Martinez - / P. Pereira det. 60", “”", "PARATIPO") (MZS); 1 ô ("Pernambuco / S. Negra / V.960 / A. Machado", "Glaphyrocanthon / machadoi sp. $n$ / Martinez - / P. Pereira det. 60", “”", "PARATIPO”) (MZSP); 1 ठ ("Pernambuco / S. Negra / V.960 / A. Machado", "Glaphyrocanthon / machadoi sp. n / Martinez - / P. Pereira det. 60", " స”, "PARATIPO") (MZSP).

\section{Collecting sites}

BRAZIL. Pernambuco: Reserva Biológica de Serra Negra.

\section{Comments}

The eight specimens of the type series of $C$. machadoi are the only known individuals of this species, which is apparently endemic to a 'brejo de altitude' (Caatinga moist-forest enclave) in the Brazilian state of Pernambuco. However, only five of those specimens were found during this work: three male paratypes housed at the MZSP, and a male and a female paratype at the CMNC. Martínez \& Pereira (1967) mentioned the holotype male and allotype female of C. machadoi were deposited at the "author's collection", without specifying which of the authors. As said earlier in this work, Martínez's holotypes and allotypes are nowadays housed at the MACN, while paratypes and ordinary specimens were incorporated to the CMNC via the Henry and Anne Howden collection. In none of them, however, either the holotype or the allotype of $C$. machadoi is preserved. Therefore, the whereabouts of those two specimens is unknown to us. As for the fifth male paratype, Martínez \& Pereira (1967) stated it was deposited in the personal collection of its collector, Ângelo Machado (Belo Horizonte, Minas Gerais, Brazil), and it is probably still housed there.

\section{Discussion}

As discussed throughout this work, the taxonomy of Sylvicanthon - both the delimitation of its species and the limits of the genus itself - was in great chaos when we decided to undertake the project of revising it. With the findings presented by us in the previous pages, we propose solutions to many of the problems surrounding the systematics of Sylvicanthon and raise questions to be answered by future works. In the following paragraphs, we discuss some of our main proposals.

It was seen throughout this work that the set of taxonomically-informative characters is somewhat limited among Sylvicanthon. The main sources of evidence used for species delimitation and hypotheses of evolutionary relationships were the microsculpture of the tegument of head, pronotum, elytra, pygidium, metaventrite and the ventral surface of the metafemora, the shape of clypeus and protibiae, the pilosity of the hypomeral cavity and of the sides of the metaventrite, and some secondary sexual characteristics such as the shape of the protibial spur, the presence or absence of female abdominal foveae and the shape of the female ventrite $\mathrm{V}$, as well as important characters related to the shape of the parameres. This set of characters, in fact, little differs from the ones used in other recent works dealing with the taxonomy of New World Deltochilini such as Rivera-Cervantes \& Halffter (1999), González-Alvarado \& Vaz-deMello (2014), Valois et al. (2015), Silva et al. (2015) and Nunes et al. (2018). The shape of the parameres and the microsculpture pattern, in particular, appear to bear good signal for very recent relationships (i.e., for species delimitation), showing that they are in a constant and profound evolutionary change. The role of sexual selection in the evolution of the parameres is evident, as discussed in detail in this paper, but the evolutionary forces acting on the microsculpture of the body's surface are not clear yet. One of the next frontiers to be explored by future studies on the morphology of Sylvicanthon is the anatomy of the 
pieces of the internal sac and the female genitalia which should provide some new interesting insights for the understanding of the group's diversity and evolution, especially concerning the role that sexual selection had in the genus' diversification.

Until the present work, very little was known about the distribution of the species of Sylvicanthon. In general, only the type locality or some very imprecize records from countries, states, or departments were known (and very often they were incorrect). With the results here obtained, it was seen that the inference of Halffter \& Martínez (1977) that the Sylvicanthon species were essentially tropical forest dwellers was correct. With the exception of $S$. enkerlini which lives in dry forests between the Amazonia, Cerrado, Caatinga and the Atlantic Forest, all the other 14 species are found exclusively in the New World's four great areas of tropical rainforest: the Central American forests, the Chocó, the Amazonia, and the Atlantic Forest.

Martínez et al. (1964) hypothesized that the ancestral area of Sylvicanthon (cited as "grupo aequinoctialis" of Glaphyrocanthon) was the Amazon Basin. Given that the greatest diversity of the genus is indeed found there, with representatives of all subgroups present in that biome (including all members of the bridarollii and securus subgroups), this hypothesis seems to be correct. From that Amazonian ancestral area, at least three lineages independently dispersed towards the other tropical forest areas of the Americas. Firstly, the ancestors of S. aequinoctilis which probably invaded Central America during the Plio-Pleistocene as part of the Great American Biotic Interchange, at the same time as South American tropical forests spread northwards after the uplift of the Isthmus of Panama. Secondly, the ancestors of $S$. foveiventris and S. obscurus which independently arrived in the Atlantic Forest through the rich gallery forests and pockets of humid forests that flourished throughout the South American Dry Diagonal and connected the Amazonia to the Atlantic Forest during the Neogene. It is interesting to note that no species of Sylvicanthon are present in the Atlantic Forest south of the state of São Paulo, fact possibly explained by the lower average temperature in that southern region.

The major proposals for the relationships of Sylvicanthon with other Deltochilini groups are discussed in detail above. The first one - called by us "the Glaphyrocanthon clade hypothesis" and which is here championed as the most plausible explanation - states that the genus Glaphyrocanthon as defined today (i.e., based on Halffter \& Martínez 1977) represents a large paraphylum from which several deltochiline lineages evolved, such as Sylvicanthon. This hypothesis finds some support in the only cladistics study that aimed at testing the phylogenetic relationship of the members of "Canthon sensu lato" (Medina et al. 2003). A second hypothesis - the Epilissini tribe - was championed by Montreuil (2010) and states that several telecoprid genera whose hypomeron is strongly excavated and protibiae are truncate at the apex would form a monophyletic group that arose in ancient Gondwana and that is nowadays scattered throughout the Americas, Africa, Madagascar, Southeast Asia and Australia. Sylvicanthon, although not cited by Montreuil (2010), would also be part of that clade judging from the characters listed by that author (Montreuil, personal communication to MC in June 2014, confirmed this observation). Finally, the third hypothesis, which is not incompatible with that of the Epilissini tribe, states that Sylvicanthon would be part of a putative clade formed by deltochiline genera with tarsal claws bearing a strong basal tooth, such as Canthonella and Ipselissus, from the New World, Temnoplectron and Sauvagesinella, from Australasia, and Nesovinsonia, from the island of Mauritius. Theorized by Halffter \& Martínez (1967) and Matthews (1974), this group did not originally include Sylvicanthon possibly because those authors were unaware of the presence of a tiny tooth at the base of the claws of the species of Sylvicanthon, which is likely to be homologous to the larger tooth seen in Pseudocanthon and other groups studied by them. It is of great interest that future phylogenetic analyses test these three hypotheses.

In conclusion, therefore, this monograph revised the entire published knowledge, as well as a great volume of new data, on the species of the genus Sylvicanthon and proposed answers to some questions 
long posed by scarab beetle specialists. At the same time, we present new fascinating observations that we hope will instigate researchers to investigate the group's diversity through different perspectives, including the application of distinct morphological, molecular, ecological and evolutionary tools. These future studies, in turn, will shed light on the new questions raised by us throughout this monograph on the evolution of the Sylvicanthon and the rest of the New World dung beetle fauna.

\section{Acknowledgments}

This work presents the results of the first author's Master's thesis, which was supervised by Fernando Z. Vaz de Mello (CEMT) and Marcela L. Monné (MNRJ), to both of whom MC is extremely grateful. We are also grateful to all the curators cited in the Material and methods, who loaned us specimens under their care and made this revision possible. In particular, MC is thankful to Ayr Bello (AMBC), Max Barclay, Malcolm Kerley, Michael Geiser and Hitoshi Takano (BMNH), Ricardo Monteiro and Raissa Drufrayer (CLEI), Márcio Felix (FIOC), Juan José Martínez (MACN), Luciano de Azevedo Moura (MCNZ), Olivier Montreuil and Antoine Mantilleri (MNHN), Sonia Casari and Carlos Campaner (MZSP), Jiř́ Hájek (NMPC), Darren Mann (OUMNH), Joachim Willers (ZMHB), Paul Skelley (FSCA), Sergio Ide (CEAH), Charles Farnum, Rachel Hawkins and Edward O. Wilson (MCZC), Nora Cabrera (Museo de La Plata, La Plata, Argentina), Fernando Meyer (Museu Anchieta de Ciências Naturais, Porto Alegre, Brazil) and Stephan Blank (Senckenberg Deutsches Entomologisches Institut, SDEI, Müncheberg, Germany) for receiving him during his visits to their institutions/personal collection.

We also thank Francisco Eriberto Nascimento, Juan Pablo Botero, Marcela L. Monné, Thainá Côrtes, Thaynara Pacheco and Wagner Rafael de Souza for bringing specimens from other collections to MC at the MNRJ; Brett Ratcliffe for sending label information of specimens deposited in UNSM; Editha Schubert (SDEI) for allowing us to publish Hoffmannsegg's, Harold's, Schmidt's and Balthasar's portraits from her institution's archives; Everardo Grossi (Nova Friburgo, Brazil) for allowing us to reproduce Padre Pereira's photograph from his collection; François Génier for sending photographs of the labels of two paratypes of $S$. proseni deposited in the CMNC; Gabriel Mejdalani (MNRJ) for allowing the first author to use his lab's photograph equipment; Paschoal Grossi (Federal Rural University of Pernambuco, Recife, Brazil) for donating the specimens of $S$. obscurus he collected in Minas Gerais; Frank E. Zachos (NHMW) and Mario Zunino (Università degli Studi di Urbino 'Carlo Bo', Urbino, Italy) for sending eletronic copies of books authored by them to MC; and the people at both the Laboratório de Coleoptera (MNRJ) and the Laboratório de Scarabaeoidologia (CEMT) for their several-year long support to both authors.

Several reseachers shared with us data on the biology and distribution of certain species or on the historical material deposited in their institutions: Max Barclay, on specimens collected by Henry Walter Bates deposited in the BMNH; Joachim Willers, on Edgar von Harold's type material housed in the ZMHB and on the history of other German collections; Olivier Montreuil, on his hypotheses about the classification of Epilissini; Latha Thomas (University of Belize), on the putative presence of S. aequinoctialis in Belize; Jorge A. Noriega (Museo Nacional de Ciencias Naturales, Madrid, Spain), on the Colombian Sylvicanthon; Gabriel Nunes (CEMT), on his views of the "Canthon sensu lato" classification and evolution; and Rafael Nunes (CEMT), on the exact localition of "Serra Negra" (type locality of C. machadoi) in Pernambuco state.

Lastly, we extend our gratitude to Bert Kohlmann (Universidad EARTH, Costa Rica), W.D. Edmonds (Portland, Oregon, USA), Michele Rossini (Instituto Tecnico per l'Agraria, l'Agroalimentare e l'Agroindustria 'A. Cecchi', Italy), Marcela L. Monné, Miguel A. Monné (MNRJ), Gabriel Mejdalani, Nelson Ferreira Junior (Universidade Federal do Rio de Janeiro, Brazil), Allan Santos (Universidade Federal do Estado do Rio de Janeiro, Brazil), Ângelo Parise Pinto (Universidade Federal do Paraná, 
Brazil) and Renato Soares (Universidade do Estado do Rio de Janeiro, Brazil) for their very kind, attentive, and critical reading of different versions and parts of the manuscript.

MC was granted scholarships from the Conselho Nacional de Desenvolvimento Científico e Tecnológico (CNPq) and Programa Bolsa Nota 10, Fundação Carlos Chagas Filho de Amparo à Pesquisa do Estado do Rio de Janeiro (FAPERJ) and received financial and institutional support from the Programa de Pós-Graduação em Zoologia, MNRJ; currently, he is supported by a $\mathrm{PhD}$ scholarship also granted by CNPq. FZVM is a CNPq PQ1 fellow and was supported by CNPq (248299/2012-3, 302997/2013-0, 484035/2013-4, 405697/2013-9, 440604/2015-0, 306745/2016-0), FAPEMAT/CNPq PRONEM (568005/2014), FAPEMAT (0147956/2017), SYNTHESYS Project (GB-TAF-3855, BE-TAF-3985), YSYEB, UMR $7205 \mathrm{CNRS/MNHN,} \mathrm{INCT-CENBAM/CNPq,} \mathrm{and} \mathrm{the} \mathrm{Programa} \mathrm{de} \mathrm{Pesquisa} \mathrm{em}$ Biodiversidade (PPBio).

\section{References}

Agapow P.-M., Bininda-Emonds O.R.P., Crandall K.A., Gittleman J.L., Mace G.M., Marshall J.C. \& Purvis A. 2004. The impact of species concept on biodiversity studies. The Quarterly Review of Biology 72 (2): 161-179. https://doi.org/10.1086/383542

Ah-King M., Barron A.B. \& Herberstein M.E. 2014. Genital evolution: why are females still understudied? PLoS Biology 12 (5): 1-7. https://doi.org/10.1371/journal.pbio.1001851

Almeida S.S.P. \& Louzada J.N.C. 2009. Estrutura da comunidade de Scarabaeinae (Scarabaeidae: Coleoptera) em fitofisionomias do cerrado e sua importância para a conservação. Neotropical Entomology 38 (1): $32-43$.

Amadon D. 1966. The superspecies concept. Systematic Zoology 15 (3): 245-249.

https://doi.org/10.2307/sysbio/15.3.245

Amadon D. 1968. Further remarks on the superspecies concept. Systematic Zoology 17 (3): 345. https://doi.org/10.1093/sysbio/17.3.345a

Amézquita S.J., Forsyth A., Lopera A. \& Camacho A. 1999. Comparación de la composición y riqueza de especies de escarabajos coprófagos (Coleoptera: Scarabaeidae) en remanentes de bosque de la Orinoquia Colombiana. Acta Zoológica Mexicana 76: 113-126.

Anonymous 1899. Obituary. The Entomologist 32 (437): 264.

Available from http://biodiversitylibrary.org/page/11654528 [accessed 30 May 2018].

Arango L. \& Montes J.M. 2010. Caracterización entomológica parcial de la cuenca del río La Miel en el departamento de Caldas (Colombia). Boletín Cientifico, Centro de Museos, Museo de Historia Natural 13 (2): 249-268.

Arias J.A. \& Medina C.A. 2014. Tres nuevas especies de Cryptocanthon Balthasar, 1942 (Coleoptera: Scarabaeidae: Scarabaeinae) para Colombia. Caldasia 36 (1): 165-180.

https://doi.org/10.15446/caldasia.v36n1.43898

Arrow G.J. 1932. New species of lamellicorn beetles (subfam. Coprinae) from South America. Stylops 1 (10): 223-226. https://doi.org/10.1111/j.1365-3113.1932.tb01335.x

Attenborough D. 2002. Life on Air. Memoirs of a Broadcaster. Princeton University Press, Princeton and Oxford.

Balthasar V. 1938. Neue Gattungen und Arten der südamerikanischen Coprophagen. (4. Beitrag zur Kenntnis der Scarabaeiden der neotropischen Region). Entomologische Blätter 34 (4): 210-223. 
Balthasar V. 1939. Eine Vorstudie zur Monographie der Gattung Canthon Hffsg. Folia Zoologica et Hydrobiologica 9 (2): 179-238.

Balthasar V. 1941. Scarabaeidae Laparostictae (Col.). Beitrag Fauna Perus 1: 337-358.

Balthasar V. 1942. Neue Scarabaeiden aus Süd-Amerika. 72. Beitrag zur Kenntnis der Scarabaeiden. Časopis České Společnosti Entomologické 39: 36-44.

Balthasar V. 1951. Scarabaeidae Laparostictae (Col.). Beiträge Fauna Perus 2: 322-344.

Batalha-Filho H., Fjeldså J., Fabre P.H., Miyaki C.Y. 2013. Connections between the Atlantic and the Amazonian forest avifaunas represent distinct historical events. Journal of Ornithology 154: 41-50. https://doi.org/10.1007/s10336-012-0866-7

Bates H.W. 1863. The Naturalist on the River Amazons, a Record of Adventures, Habits of Animals, Sketches of Brazilian and Indian Life, and Aspects of Nature under the Equator, during Eleven Years of Travel. John Murray, London (two volumes). https://doi.org/10.5962/bhl.title.103298

Bates H.W. 1887. Tribe Lamellicornia In: Bates H.W. 1886-1890. Biologia Centrali-Americana. Insecta. Coleoptera. Vol. II. Part 2. Pectinicornia and Lamellicornia: 25-64. Taylor \& Francis, London. Available from http://biodiversitylibrary.org/page/578700 [accessed 30 May 2018].

Bates H.W. 1889. Supplement. In: Bates H.W. 1886-1890. Biologia Centrali-Americana. Insecta. Coleoptera. Vol. II. Part 2. Pectinicornia and Lamellicornia: 385-416, pl. xxiv. Taylor \& Francis, London. Available from http://biodiversitylibrary.org/page/579060 [accessed 30 May 2018].

Beutel R.G. \& Lawrence J.F. 2005. Coleoptera, Morphology. In: Beutel R.G. \& Leschen R.A.B. (eds) Coleoptera, Beetles. Volume 1: Morphology and Systematics (Archostemata, Adephaga, Myxophaga, Polyphaga partim). Handbuch der Zoology: Eine Naturgeschichte der Stämme des Tierreiches. Band IV, Arthropoda: Insecta. Teilband 38. Walter de Gruyter, Berlin and New York.

Beutel R.G. \& Leschen R.A.B. 2005. Handbook of Zoology. A Natural History of the Phyla of the Animal Kingdom. Coleoptera, Beetles. Volume 1: Morphology and Systematics (Archostemata, Adephaga, Myxophaga, Polyphaga partim). Walter de Gruyter, Berlin and New York.

Bidau C.J. 2014. The katydid that was: the tananá, stridulation, Henry Water Bates and Charles Darwin. Archives of Natural History 41 (1): 131-140. https://doi.org/10.3366/anh.2014.0216

Blackwelder R.E. 1944. Checklist of the coleopterous insects of Mexico, Central America, West Indies and South America. Part 2. United States National Museum Bulletin 185: 189-341. https://doi.org/10.5479/si.03629236.185.2

Blackwelder R.E. 1973. Checklist of the Scarabaeidae of Canada, United States, Mexico, Central America and the West Indies. Family no. 30, complete (Red Version). Biological Research Institute of America, Latham, New York.

Blanchard E. 1846. [livraisons 79: pp. 153-168, 80: 169-184]. In: Blanchard E. \& Brullé G.A. 1837-1846. Voyage dans L'Amérique Méridionale (le Brésil, la République orientale de L'Uruguay, la République Argentine, la Patagone, la République du Chili, la République de Bolivia, la République du Pérou), exécuté pendant les années 1826, 1827, 1828, 1829, 1830, 1831, 1832 et 1833, par Alcide D'Orbigny. Tome Sixième. 2. ${ }^{e}$ partie: insectes. P. Bertrand, Paris, and Ve. Lerrault, Strasbourg. [Publication dates follow Evenhuis (1997b: 573) and Sherborn \& Woodward (1901: 389), who based their dating on Wiegmann's Archiv für Naturgeschichte. It is noteworthy, however, that Bousquet (2016: 77) dated those livraisons from 1845 following the information stated on their wrappers, which Evenhuis (1997a: 12) argued was not a reliable source]. https://doi.org/10.5962/bhl.title. 85973

Boilly O. \& Vaz-de-Mello F.Z. 2013. Les Scarabaeinae de Guyane: clé illustrée des genres (Coleoptera, Scarabaeidae). ACOREP-FRANCE: Coléoptères de Guyane 7: 103-112. 
Bouchard P., Bousquet Y., Davies A.E., Alonso-Zarazaga M.A., Lawrence J.F., Lyal C.H.C., Newton A.F., Reid C.A.M., Schmitt M., Slipnski A. \& Smith A.B.T. 2011. Family-group names in Coleoptera (Insecta). Zookeys 88: 1-972. https://doi.org/10.3897/zookeys.88.807

Boucomont A. 1928. Wissenschaftliche Ergebnisse der schwedischen entomologischen Reise des Herrn Dr. A. Roman in Amazonas 1914-1915 (und 1923-1924). 12. Scarabaeidae. Arkiv för Zoologi 19A (22): $1-8$.

Bousquet Y. 2016. Litteratura Coleopterologica (1758-1900): a guide to selected books related to the taxonomy of Coleoptera with publication dates and notes. Zookeys 583: 1-776.

https://doi.org/10.3897/zookeys.583.7084

Brockhaus F. \& Avenarius E. 1839. Répertoire bibliographique de la librairie française modern contenant les ouvrages publiés en France, et ceux en langue française imprimés a l'étranger pendant l'année 1838, ainsi que la liste des Journaux politiques et littéraires en France pour l'année 1939. Avec table systématique pour les ouvrages imprimés en 1838, et les journaux de 1839. Deuxième année. Brockhaus and Avenarius, Paris and Leipzig.

Brown R.W. 1956. Composition of Scientific Words. A Manual of Methods and a Lexicon of Materials for the Practice of Logotechnics. Smithsonian Books, Washington D.C.

Brullé A. 1838. Histoire naturelle des insectes, comprenant leur classification, leurs moeurs et la description des espèces. In: Audouin M.V. \& Brullé A. 1837-1838 (eds) Histoire naturelle des insectes, comprenant leur classification, leurs moeurs, et la Description des espèces. Tome VI. Coléoptères III. F.D. Pillot, Paris. Available from http://biodiversitylibrary.org/page/25546183 [accessed 30 May 2018].

Burger B.V., Munro Z. \& Brandt W.F. 1990. Pheromones of the Scarabaeinae, II*: Composition of the pheromone disseminating carrier material secreted by male dung beetles of the genus Kheper. Zeitschrift für Naturforschung 45: 863-872.

Burger B.V., Petersen W.G.B. \& Tribe G.D. 1995a. Semiochemicals of the Scarabaeinae, IV*: Identification of an attractant for the dung beetle Pachylomerus femoralis in the abdominal secretion of the dung beetle Kheper lamarcki. Zeitschrift für Naturforschung 50: 675-680.

Burger B.V., Petersen W.G.B. \& Tribe G.D. 1995b. Semiochemicals of the Scarabaeinae, V*: Characterization of the defensive secretion of the dung beetles Oniticellus egregius. Zeitschrift für Naturforschung 50: 681-684.

Burger B.V., Petersen W.G.B., Weber W.G. \& Munro Z.M. 2002. Semiochemicals of the Scarabaeinae. VII: Identification and synthesis of EAD-active constituents of abdominal sex attracting secretion of the male dung beetle, Kheper subaeneus. Journal of Chemical Ecology 28 (12): 2527-2539. https://doi.org/10.1023/A:1021440220329

Burger B.V., Petersen W.G.B., Ewig B.T., Neuhaus J., Tribe G.D., Spies H.S.C. \& Burger W.J.G. 2008. Semiochemicals of the Scarabaeinae VIII. Identification of active constituents of the abdominal sexattracting secretion of the male dung beetle, Kheper bonellii, using gas chromatography with flame ionization and electroantennographic detection in parallel. Journal of Chromatography 1186: 245-253. https://doi.org/10.1016/j.chroma.2007.09.041

Burmeister H. 1874. Lamellicornia Argentina. Entomologische Zeitung 35: 120-133. Available from http://biodiversitylibrary.org/page/9236010 [accessed 30 May 2018].

Byers J.R. \& Hinks C.F. 1973. The surface sculpturing of the integument of lepidopterous larvae and its adaptive significance. Canadian Journal of Zoology 51: 1171-1179. https://doi.org/10.1139/z73-170 
Cain J. 2009. [entry on] Systematics and the origin of species (Ernst Mayr). In: Ruse M. \& Travis J. (eds) Evolution: The First Four Billion Years. The Belknap Press of Harvard University Press, Cambridge (MA) and London.

Canhedo V.L. 2006. Revisão taxonômica do gênero Anomiopus Westwood, 1842 (Coleoptera, Scarabaeidae, Scarabaeinae). Arquivos de Zoologia, Museu de Zoologia da Univerisdade de São Paulo 37 (4): 349-502. https://doi.org/10.11606/issn.2176-7793.v37i4p349-502

Carpio C., Donoso D.A., Ramón G. \& Dangles O. 2009. Short term response of dung beetle communities to disturbance by road construction in the Ecuadorian Amazon. Annales de la Société entomologique de France (N.S.) 45 (4): 455-469. https://doi.org/10.1080/00379271.2009.10697629

Carrington J.T. 1899. Samuel Stevens. Science-Gossip, new series 6 (66): 161-162. Available from http://biodiversitylibrary.org/page/34123288 [accessed 30 May 2018].

Carvajal V., Villamarín S. \& Ortega A.M. 2011. Escarabajos del Ecuador. Principales géneros. Instituto de Ciencias Biológicas, Escuela Politécnica Nacional, Quito.

Castelnau Comte de. 1840. Histoire naturelle des insectes coléoptères. Tome deuxiéme. Duménil, Paris.

Caveney S. \& McIntyre P. 1981. Design of graded-index lenses in the superposition eyes of scarab beetles. Philosophical Transactions of the Royal Society of London B 294: 589-632.

https://doi.org/10.1098/rstb.1981.0119

Celi J., Terneus E., Torres J. \& Ortega M. 2004. Dung beetles (Coleoptera: Scarabaeinae) diversity in an altitudinal gradient in the Cutucú Range, Morona Santiago, Ecuadorian Amazon. Lyonia 7 (2): 37-52.

Chamorro W., Marín-Armijos D., Granda V. \& Vaz-de-Mello F.Z. 2018. Listado de especies y clave de géneros y subgéneros de escarabajos estercoleros (Coleoptera: Scarabaeidae: Scarabaeinae) presentes y presuntos para Ecuador. Revista Colombiana de Entomología 44 (1): 72-100.

Chapin E.A. 1930. Canthonella, a new genus of Scarabæidæ (Coleoptera). American Museum Novitates 409: 1-2. Available from http://hdl.handle.net/2246/4407 [accessed 5 Sep. 2018].

Chapin E.A. 1934. A new genus and species of dung-inhabiting Scarabaeidae from Puerto Rico, with notes on the Coprinae of the Greater Antilles (Coleoptera). Proceedings of the Biological Society of Washington 47: 99-102. Available from http://biodiversitylibrary.org/page/34575349 [accessed 5 Sep. 2018].

Coates A.G. \& Stallard R.F. 2013. How old is the Isthmus of Panama? Bulletin of Marine Science 89 (4): 801-813. https://doi.org/10.5343/bms.2012.1076

Cook J. 2002. A revision of the Neotropical genus Cryptocanthon Balthasar (Coleoptera: Scarabaeidae: Scarabaeinae). Coleopterists Society Monograph 1: 1-96. https://doi.org/10.1649/0010-065X(2002)56\%5B3:AROTNG\%5D2.0.CO;2

Costa C. 1999. Coleoptera. In: Joly C.A. \& Bicudo C.E.M. (eds.) Biodiversidade do estado de São Paulo, Brasil: síntese do conhecimento ao final do século XX. Invertebrados terrestres. Vol. 5: 113-122. Museu de Zoologia, Universidade de São Paulo, São Paulo.

Costa L.P. 2003. The historical bridge between the Amazon and the Atlantic Forest of Brazil: a study of molecular phylogeography with small mammals. Journal of Biogeography 30: 71-86.

https://doi.org/10.1046/j.1365-2699.2003.00792.x

Costa C.M.Q., Silva F.A.B., Farias A.I. \& Moura R.C. 2009. Diversidade de Scarabaeinae (Coleoptera, Scarabaeidae) coletados com armadilha de interceptação de vôo no Refúgio Ecológico Charles Darwin, Igarassu-PE, Brasil. Revista Brasileira de Entomologia 53 (1): 88-94. 
Costa F.C., Pessoa K.K.T., Liberal C.N., Filgueiras B.K.C., Salomão R.P. \& Iannuzzi L. 2013. What is the importance of open habitat in a predominantly closed forest to the dung beetle (Coleoptera, Scarabaeinae) assemblage? Revista Brasileira de Entomologia 57 (3): 329-334.

https://doi.org/10.1590/S0085-56262013000300012

Cracraft J. 1997. Species concepts in systematics and conservation biology - an ornithological viewpoint. In: Claridge M.F., Dawah H.A. \& Wilson M.R. (eds) Species: the Units of Biodiversity: 325-339. Chapman and Hall, London.

Cracraft J. 2000 [consulted version from 2003]. Species concepts in theorical and applied biology: a systematic debate with consequences. In: Wheeler Q.D. \& Meier R. (eds) Species Concepts and Phylogenetic Theory. A Debate: 3-14. Bishen Singh Mahendra Pal Singh, Dehra Dun.

Culot L., Mann D.J., Lazo F.J.J.M., Huynen M.-C. \& Heymann E.W. 2011. Tamarins and dung beetles: an efficient diplochorous dispersal system in the Peruvian Amazonia. Biotropica 43 (1): 84-92. https://doi.org/10.1111/j.1744-7429.2010.00655.x

Culot L., Bovy E., Vaz-de-Mello F.Z., Guevara R. \& Galetti M. 2013. Selective defaunation affects dung beetle communities in continuous Atlantic rainforest. Biological Conservation 163: 79-89.

https://doi.org/10.1016/j.biocon.2013.04.004

Cupello M. \& Vaz-de-Mello F.Z. 2013. Taxonomic revision of the South American dung beetle genus Gromphas Brullé, 1837 (Coleoptera: Scarabaeidae: Scarabaeinae: Phanaeini: Gromphadina). Zootaxa 3722: 439-482. https://doi.org/10.11646/zootaxa.3722.4.2

Cupello M. \& Vaz-de-Mello F.Z. 2014. Revalidation of the Brazilian Atlantic Forest dung beetle species Coprophanaeus (Metallophanaeus) machadoi (Pereira \& d'Andretta, 1955) (Coleoptera: Scarabaeidae: Scarabaeinae: Phanaeini) based on morphological and distributional evidence. Zootaxa 3869 (4): 435451. https://doi.org/10.11646/zootaxa.3869.4.7

Cupello M. \& Vaz-de-Mello F.Z. 2016. A new species and the phylogeny of the South American genus Gromphas Brullé 1837 (Coleoptera: Scarabaeidae: Scarabaeinae: Phanaeini). Journal of Natural History 50 (15-16): 943-969. https://doi.org/10.1080/00222933.2015.1091099

Daniel G.M. \& Vaz-de-Mello F.Z. 2016. Biotic components of dung beetles (Insecta: Coleoptera: Scarabaeidae: Scarabaeinae) from Pantanal - Cerrado Border and its implications for Chaco regionalization. Journal of Natural History 50 (17-18): 1159-1173.

https://doi.org/10.1080/00222933.2015.1103909

Dejean P.F.M.A. 1833. [Livraison 2.]. In: Dejean P.F.M.A. 1833-1836. Catalogue des Coléoptères de la collection de M. le Comte Dejean: 97-176. Méquignon-Marvis Père et Fils, Paris. [Publication date according to Madge 1988.] Available from http://biodiversitylibrary.org/page/9322478 [accessed 30 May 2018].

Dejean P.F.M.A. [Livraisons 1-4]. In: Dejean P.F.M.A. 1836-1837. Catalogue des Coléoptères de la collection de M. le Comte Dejean. Troisième édition, revue, corrigée et augmentée: 1-384. MéquignonMarvis Père et Fils, Paris. [publication date according to Madge 1988].

De Queiroz K. 1998. The general lineage concept of species, species criteria, and the process of speciation. A conceptual unification and terminological recommendations. In: Howard D.J. \& Berlocher S.H. (eds) Endless Forms: Species and Speciation: 57-75. Oxford University Press, Oxford.

De Queiroz K. 1999. The general lineage concept of species and the defining properties of the species category. In: Wilson R.A. (ed.) Species: New Interdisciplinary Essays: 49-89. MIT Press, Cambridge.

De Queiroz K. 2005a. Ernst Mayr and the modern concept of species. Proceedings of the National Academy of Sciences 102, suppl. 1: 6600-6607. https://doi.org/10.1073/pnas.0502030102 
De Queiroz K. 2005b. A unified concept of species and its consequences for the future of taxonomy. Proceedings of the California Academy of Sciences 56, suppl. I (18): 196-215.

De Queiroz K. 2007. Species concepts and species delimitation. Systematic Biology 56 (6): 879-886. https://doi.org/10.1080/10635150701701083

Dobzhansky T. 1973. Nothing in biology makes sense except in the light of evolution. The American Biology Teacher 35 (3): 125-129. https://doi.org/10.2307/4444260

Dubois A. 2011. Species and "Strange species" in zoology: do we need a "unified concept of species"? Comptes Rendus Palevol 10: 77-94. https://doi.org/10.1016/j.crpv.2011.01.002

Durães R., Martins W.P. \& Vaz-de-Mello F.Z. 2005. Dung beetle (Coleoptera: Scarabaeidae) assemblages across a natural forest-cerrado ecotone in Minas Gerais, Brazil. Neotropical Entomology 34 (5): $721-$ 731. https://doi.org/10.1590/S1519-566X2005000500003

Edmonds W.D. 1972. Comparative skeletal morphology, systematics and evolution of the Phanaeine dung beetles (Coleoptera: Scarabaeidae). The University of Kansas Science Bulletin 49: 731-874. Available from http://biodiversitylibrary.org/page/4385744 [accessed 30 May 2018].

Edmonds W.D. 1994. Revision of Phanaeus MacLeay, a New World genus of Scarabaeinae dung beetles (Coleoptera: Scarabaeidae, Scarabaeinae). Natural History Museum of Los Angeles County Contributions in Science 443: 1-105. Available from http://biodiversitylibrary.org/page/52114491 [accessed 30 May 2018].

Edmonds W.D. \& Zídek J. 2012. Taxonomy of Phanaeus revisited: revised keys to and comments on species of the New World dung beetle genus Phanaeus MacLeay, 1819 (Coleoptera: Scarabaeidae: Scarabaeinae: Phanaeini). Insecta Mundi 274: 1-108.

Emlen D.J. \& Philips T.K. 2006. Phylogenetic evidence for an association between tunneling behavior and the evolution of horns in dung beetles (Coleoptera: Scarabaeidae: Scarabaeinae). Coleopterists Society Monograph 5: 47-56.

Erichson W.F. 1847. Naturgeschichte der Insecten Deutschlands. Erste Abtheilung. Coleoptera. Dritter Band. Fünfte Lieferung: 641-800. Nicolaische Buchhandlung, Berlin.

https://doi.org/10.5962/bhl.title.8270

Escobar F. 2000a. Diversidad y distribución de los escarabajos del estiércol (Coleoptera: Scarabaeidae: Scarabaeinae) de Colombia. In: Martín-Piera F., Morrone J.J. \& Melic A. (eds) Hacia un proyecto CYTED para el Inventario y Estimación de la Diversidad entomológica en Iberoamérica: PRIBES-2000: 197-210. Monografías Tercer Milenio 1, Sociedad Entomológica Aragonesa (SEA), Zaragoza.

Escobar F. 2000b. Diversidad de coleópteros coprofagos (Scarabaeidae: Scarabaeinae) en un mosaico de habitats en la Reserva Natural Nukak, Guaviare, Colombia. Acta Zoológica Mexicana (n.s.) 79: $103-121$.

Espinoza V.R. \& Noriega J.A. 2018. Diversity of the dung beetles (Coleoptera: Scarabaeinae) in an altitudinal gradient in the east slope of los Andes, Napo province, Ecuador. Neotropical Biodiversity 4 (1): 144-150. https://doi.org/10.1080/23766808.2018.1512199

Evenhuis N.L 1997a. Litteratura taxonomica dipterorum (1758-1930). Volume I. A-K. Backhuys, Leiden.

Evenhuis N.L. 1997b. Litteratura taxonomica dipterorum (1758-1930). Volume II. L-Z. Backhuys, Leiden.

Evenhuis N.L. 2008. A compendium of zoological type nomenclature: a reference source. Bishop Museum Technical Report 41: 1-23. 
Falqueto S.A., Vaz-de-Mello F.Z. \& Schoereder J.H. 2005. Are fungivorous Scarabaeidae less specialist? Ecología Austral 15: 17-22.

Feer F. 2000. Les coléoptères coprophages et nécrophages (Scarabaeidae s. str. et Aphodiidae) de la forêt de Guyane française: composition spécifique et structure des peuplements. Annales de la Société entomologique de France (N.S.) 36 (1): 29-43.

Feer F. 2008. Responses of dung beetle assemblages to characteristics of rain forest edges. Ecotropica 14: 49-62.

Feer F. 2015. Les modalités du percher dans un assemblage de Scarabaeinae de la forêt de Guyane française. Annales de la Société entomologique de France (N.S.) 51 (4): 331-340. https://doi.org/10.1080/00379271.2016.1146633

Feer F. \& Pincebourde S. 2005. Diel flight activity and ecological segregation within an assemblage of tropical forest dung and carrion beetles. Journal of Tropical Ecology 21:21-30.

Ferreira M.C. 1964. Contribuição para o estudo do género Epirinus Reiche (Col. Lamellicornia). Novos Taxa Entomológicos 37: 3-13.

Ferreira V.S., Prado P.L. \& Seripierri D. 2016. The entomological collection of Ricardo von Diringshofen (1900-1986) and its incorporation to the Museu de Zoologia da Universidade de São Paulo. Revista Brasileira de Entomologia 60 (2): 117-122. https://doi.org/10.1016/j.rbe.2016.01.005

Figueroa L. \& Alvarado M. 2011. Coleópteros coprófagos (Scarabaeidae: Scarabaeinae) de la Reserva Nacional Tambopata, Madre de Dios, Peru. Revista Peruana de Biología 18 (2): 209-212.

Forgie S.A., Philips T.K. \& Scholtz C.H. 2005. Evolution of the Scarabaeini (Scarabaeidae: Scarabaeinae). Systematic Entomology 30: 60-96. https://doi.org/10.1111/j.1365-3113.2004.00273.x

Forgie S.A., Kryger U., Bloomer P. \& Scholtz C.H. 2006. Evolutionary relationships among the Scarabaeini (Coleoptera: Scarabaeidae) based on combined molecular and morphological data. Molecular Phylogenetics and Evolution 40: 662-678. https://doi.org/10.1016/j.ympev.2006.04.018

Fritz M.A. 1994. Necrológio: Antonio Martínez (1922-1993). Revista Brasileira de Entomologia 38 (3-4): 781-791.

Gacharná G.C. 1951. Catálogo de los coleópteros colombianos. Revista de la Academia Colombiana de Ciencias Exactas, Físicas y Naturales 8: 221-229.

Gaedike R. 1995. Deutsches Entomologisches Institut: origin, history and present. Holartic Lepidoptera 2 (2): 51-56.

Génier F. \& Cupello M. 2018. Canthidium alvarezi Martínez and Halffter, 1986: a remarkable Ateuchus Weber, 1801 (Coleoptera: Scarabaeidae: Scarabaeinae). Insecta Mundi 646: 1-4.

Ghiselin M.T. 1974. A radical solution to the species problem. Systematic Zoology 23: 536-544. https://doi.org/10.1093/sysbio/23.4.536

Ghiselin M. 1997. Metaphysics and the Origin of Species. State University of New York Press, Albany, NY.

Gill B.D. 1991. Dung beetles in tropical American forests. In: Hanski I. \& Cambefort Y. (eds) Dung Beetle Ecology: 211-229. Princeton University Press, Princeton.

Gillet J.J.E. 1911. Coleopterorum catalogus. Pars 38: Scarabaeidae: Coprinae I. W. Junk, Berlin.

Gillet J.J.E. 1933. Lamellicornes Coprophages (Coléopt.). Bulletin \& Annales de la Sociétéentomologique de Belgique 72 (11-12): 323-332. 
González-Alvarado A. \& Vaz-de-Mello F.Z. 2014. Taxonomic review of the subgenus Hybomidium Shipp 1897 (Coleoptera: Scarabaeidae: Scarabaeinae: Deltochilum). Annales de la Société entomologique de France (N.S.) 50 (3-4): 431-476. https://doi.org/10.1080/00379271.2014.989178

Gregorin R. 2006. Taxonomia e variação geográfica das espécies do gênero Alouatta Lacépède (Primates, Atelidae) no Brasil. Revista Brasileira de Zoologia 23 (1): 64-144.

Haffer J. 1986. Superspecies and species limits in vertebrates. Zeitschrift für Zoologische Systematik und Evolutionsforschung 24 (3): 169-190. https://doi.org/10.1111/j.1439-0469.1986.tb00626.x

Haffer J. 2007. Ornithology, Evolution, and Philosophy: The Life and Science of Ernst Mayr 19042005. Springer-Verlag, Berlin and Heidelberg.

Halffter G. 1958. Dos nuevos géneros de Canthonini. Ciencia, Revista Hispano-Americana de Ciencias Puras y Aplicadas 17 (10-12): 207-212.

Halffter G. 1961. Monografia de las especies norteamericanas del género Canthon Hoffsg. (Coleopt., Scarab.). Ciencia, Revista Hispano-Americana de Ciencias Puras y Aplicadas 20 (9-12): 225-320.

Halffter G. 2003. Tribu Scarabaeini, subtribu Canthonina. In: Morón M.A. (ed.) Atlas de los escarabajos de México. Coleoptera: Lamellicornia. Vol. II. Familias Scarabaeidae, Trogidae, Passalidae y Lucanidae: 21-43. Argania Editio, Barcelona.

Halffter G. \& Edmonds W.D. 1982. The Nesting Behavior of Dung Beetles (Scarabaeinae). An Ecological and Evolutive Approach. Instituto de Ecología, Mexico, D.F.

Halffter G. \& Martínez A. 1966. Revision monográfica de los Canthonina americanos (Coleoptera, Scarabaeidae) (I Parte). Revista de la Sociedad Mexicana de Historia Natural 27: 89-177.

Halffter G. \& Martínez A. 1967. Revision monográfica de los Canthonina americanos (Coleoptera, Scarabaeidae) (2 2 Parte). Revista de la Sociedad Mexicana de Historia Natural 28: 79-117.

Halffter G. \& Martínez A. 1968. Revision monográfica de los Canthonina americanos (Coleoptera,

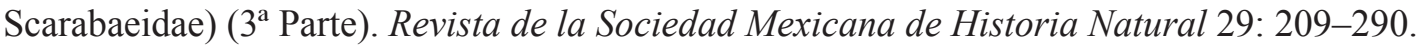

Halffter G. \& Martínez A. 1977. Revisión monográfica de los Canthonina americanos, IV parte. Clave para géneros y subgéneros. Folia Entomológica Mexicana 38: 29-107.

Halffter G. \& Matthews E.G., 1966. The natural history of dung beetles of the subfamily Scarabaeinae (Coleoptera: Scarabaeidae). Folia Entomológica Mexicana 12-14: 1-312.

Halffter G. \& Morrone J.J. 2017. An analytical review of Halffter's Mexican transition zone, and its relevance for evolutionary biogeography, ecology and biogeographical regionalization. Zootaxa 4226 (1): 1-46. https://doi.org/10.11646/zootaxa.4226.1.1

Hamel-Leigue A., Mann D.J., Vaz-de-Mello F.Z. \& Herzog S.K. 2006. Hacia un inventario de los escarabajos peloteros (Coleoptera: Scarabaeidae) de Bolivia: primera compilación de los géneros y espécies registrados para el país. Revista Boliviana de Ecología y Conservación Ambiental 20: 1-18.

Hanski I. \& Cambefort Y. 1991. Dung Beetle Ecology. Princeton University Press, Princeton.

Harold E. 1867. Zur Kenntniss der Gattung Canthidium und ihrer nächsten Verwandten. Coleopterologische Hefte 1: 1-61. Available from http://biodiversitylibrary.org/page/16069237 [accessed 30 May 2018].

Harold E. 1868a. Monographie der Gattung Canthon. Berliner Entomologische Zeitschrift 12: 1-144. https://doi.org/10.1002/mmnd.18680120104

Harold E. [signed as the 'Herausgeber'] 1868b. Die Arten der Gattung Choeridium. Coleopterologische Hefte 4: 32-76. Available from https://biodiversitylibrary.org/page/16069599 [accessed 30 May 2018]. 
Harold E. 1869a. Diagnosen neuer Coprophagen. Coleopterologische Hefte 5: 95-104. Available from https://biodiversitylibrary.org/page/16069770 [accessed 30 May 2018].

Harold E. 1869b. Catalogus coleopterorum. Hucusque descriptorum, synonymicus et systematicus. Tom. IV. Scarabaeidae: 979-1346. Sumptu E.H. Gummi, Munich.

Available from http://biodiversitylibrary.org/page/9641549 [accessed 30 May 2018].

Harold E. [signed as the 'Herausgeber'] 1869c. Ueber Coprophage Lamellicornien mit besonderer Berücksichtigung der Pariser Sammlungen. Coleopterologische Hefte 5: 46-70. Available from https://biodiversitylibrary.org/page/16069721 [accessed 30 May 2018].

Harold E. 1880. Verzeichniss der von E. Steinheil in Neu-Granada gesammelten coprophagen Lamellicornien. Entomologischen Vereine zu Stettin 41: 13-46.

Available from https://biodiversitylibrary.org/page/8989387 [accessed 30 May 2018].

Harris R.A. 1979. A glossary of surface sculpturing. Occasional Papers in Entomology 28: 1-31.

Hausdorf B. 2011. Progress toward a general species concept. Evolution 65 (4): 923-931.

https://doi.org/10.1111/j.1558-5646.2011.01231.x

Hegna T.A., Legg D.A., Møller O.S., Roy P. van \& Lerosey-Aubril R. 2013. The correct authorship of the taxon name 'Arthropoda'. Arthropod Systematics et Phylogeny 71 (2): 71-74.

Hennig W. 1966. Phylogenetic Systematics. University of Illinois Press, Urbana.

Hernández M.I.M. 2002. The night and day of dung beetles (Coleoptera, Scarabaeidae) in the Serra do Japi, Brazil: elytra colour related to daily activity. Revista Brasileira de Entomologia 46 (4): 597-600. https://doi.org/10.1590/S0085-56262002000400015

Hernández M.I.M. \& Vaz-de-Mello F.Z. 2009. Seasonal and spatial species richness variation of dung beetle (Coleoptera, Scarabaeidae s. str.) in the Atlantic Forest of southeastern Brazil. Revista Brasileira de Entomologia 53 (4): 607-613.

Hernández M.I.M., Monteiro L.R. \& Favila M.E. 2011. The role of body size and shape in understanding competitive interactions within a community of Neotropical dung beetles. Journal of Insect Science 11 (13): 1-13. https://doi.org/10.1673/031.011.0113

Herrera E.R.T., Vulinec K., Knogge C. \& Heymann E.W. 2002. Sit and wait at the source of dung - an unusual strategy of dung beetles. Ecotropica 81: 87-88.

Hey J., Waples R.S., Arnold M.L., Butlin R.K. \& Harrison R.G. 2003. Understanding and confronting species uncertainty in biology and conservation. TRENDS in Ecology and Evolution 18 (11): 597-603. https://doi.org/10.1016/j.tree.2003.08.014

Hoffmannsegg J.C. Graf von. 1817. Entomologische Bemerkungen bei Gelegenheit der Abhandlungen über amerikanische Insecten, in der vierten bis sechsten Lieferung von den Recueils d'observations de Zoologie et d'Anotomie comparée, oder dem 2ten Theile der Reise, der Herren Al. v. Humboldt und A. Bonpland, nemlich: No. IX. in Livr. 4. p. 197-283. und No. XI. XII. in Livr. 5. 6. p. 294-397. Zoologisches Magazin 1 (1): 8-56.

Available from http://biodiversitylibrary.org/page/14928895 [accessed 30 May 2018].

Horgan F.G. 2005a. Aggregated distribution of resources creates competition refuges for rainforest dung beetles. Ecography 28: 603-618. https://doi.org/10.1111/j.2005.0906-7590.04177.x

Horgan F.G. 2005b. Effects of deforestation on diversity, biomass and function of dung beetles on the eastern slopes of the Peruvian Andes. Forest Ecology and Management 216: 117-133. https://doi.org/10.1016/j.foreco.2005.05.049 
Horgan F.G. 2006. Aggregation and coexistence of dung beetles in montane rain forest and deforested sites in central Peru. Journal of Tropical Ecology 22: 359-370. https://doi.org/10.1017/S026646740600321X

Horgan F.G. 2009. Invasion and retreat: shifting assemblages of dung beetles amidst changing agricultural landscapes in central Peru. Biodiversity and Conservation 18: 3519-3541.

https://doi.org/10.1007/s10531-009-9658-7

Horn W. \& Kahle I. 1935. Über entomologische Sammlungen (Ein Beitrag zur Geschichte der EntomoMuseologie). Teil I. Entomologische Beihefte aus Berlin-Dahlem 2: 1-160.

Horn W. \& Kahle I. 1936. Über entomologische Sammlungen (Ein Beitrag zur Geschichte der EntomoMuseologie). Entomologische Beihefte aus Berlin-Dahlem 3: 161-296.

Horn W. \& Kahle I. 1937. Über entomologische Sammlungen (Ein Beitrag zur Geschichte der EntomoMuseologie). Entomologische Beihefte aus Berlin-Dahlem 4: 297-388.

House C.M. \& Simmons L.W. 2003. Genital morphology and fertilization success in the dung beetle Onthophagus taurus: an example of sexually selected male genitalia. Proceedings of the Royal Society of London B 270: 447-455. https://doi.org/10.1098/rspb.2002.2266

Houston W.W.K. 1986. Exocrine glands in the forelegs of dung beetles in the genus Onitis F. (Coleoptera: Scarabaeidae). Journal of the Australian Entomological Society 25: 161-169. https://doi.org/10.1111/j.1440-6055.1986.tb01096.x

Howden H.F. 1966. Notes on Canthonini of the "Biologia Centrali-Americana" and Descriptions of new species (Coleoptera: Scarabaeidae). The Canadian Entomologist 98 (7): 725-741.

Howden H.F. \& Cook J. 2002. Paracryptocanthon, a new Canthonine genus from Brazil (Coleoptera: Scarabaeidae: Scarabaeinae). The Coleopterists Bulletin 56 (4): 585-588.

https://doi.org/10.1649/0010-065X(2002)056\%5B0585:PANCGF\%5D2.0.CO;2

Howden H.F. \& Young O.P. 1981. Panamanian Scarabaeinae: taxonomy, distribution, and habits (Coleoptera, Scarabaeidae). Contributions of the American Entomological Institute 18 (1): 1-204.

Huang J.-P. 2016. The great American biotic interchange and diversification history in Dynastes beetles (Scarabaeidae; Dynastinae). Zoological Journal of the Linnean Society 178 (1): 88-96.

https://doi.org/10.1111/zoj.12393

Huang J.-P. 2017. The Hercules beetles (subgenus Dynastes, genus Dynastes, Dynastidae): a revisionary study based on the integration of molecular, morphological, ecological, and geographic analyses. Miscellaneous Publications, Museum of Zoology, University of Michigan 206: 1-31.

Hull D. 1976. Are species really individuals? Systematic Zoology 25: 174-191. https://doi.org/10.2307/2412744

Humboldt A. \& Bonpland A. 1805-1810. Recueil d'observations de zoologie et d'anatomie comparée, faites dans l'océan Atlantique, dans l'intérieur du nouveau continent et dans la mer du Sud pendant les années 1799, 1800, 1801, 1802 et 1803. Premier volume. Schoell and Dufour, Paris.

https://doi.org/10.5962/bhl.title.43770

Iannuzzi L., Salomão R.P., Costa F.C. \& Liberal C.N. 2016. Environmental patterns and daily activity of dung beetles (Coleoptera: Scarabaeidae) in the Atlantic Rainforest of Brazil. Entomotropica 31 (23): 196-207.

ICZN (International Commission on Zoological Nomenclature) 1999. International Code of Zoological Nomenclature. Fourth Edition Adopted by the International Union of Biological Sciences. International Trust for Zoological Nomenclature, London.

Available from http://www.nhm.ac.uk/hosted-sites/iczn/code/ [accessed 30 May 2018]. 
Isaac N.J.B., Mallet J. \& Mace G.M. 2004. Taxonomic inflation: its influence on macroecology and conservation. TRENDS in Ecology and Evolution 19 (9): 464-469.

https://doi.org/10.1016/j.tree.2004.06.004

Ivie M.A. \& Philips T.K. 2008. Three new species of Canthonella Chapin from Hispaniola, with new records and nomenclatural changes for West Indian dung beetles (Coleoptera: Scarabaeidae: Scarabaeinae). Zootaxa 1701: 1-14.

Jacobs J., Nole I., Palminteri S. \& Ratcliffe B. 2008. First come, first serve: "Sit and wait" behavior in dung beetles at the source of primate dung. Neotropical Entomology 37 (6): 641-645.

https://doi.org/10.1590/S1519-566X2008000600003

Jaramillo C., Montes C., Cardona A., Silvestro D., Antonelli A. \& Bacon C.D. 2017. Comment (1) on "Formation of the Isthmus of Panama" by O'Dea et al. Science Advances 6 (3): 1-8. https://doi.org/10.1126/sciadv.1602321

Kirk A.A. 1992. Dung beetles (Coleoptera: Scarabaeidae) active in patchy forest and pasture habitats in Santa Cruz province, Bolivia, during spring. Folia Entomológica Mexicana 84: 45-54.

Klapperich H. 1948. Notes about German and Austrian coleopterists and collections. The Coleopterists Bulletin 2: 67 Available from http://www.jstor.org/stable/i383575 [accessed 30 May 2018].

Kluge N.J. 2010. Circumscriptional names of higher taxa in Hexapoda. Bionomina 1: 15-55.

Kohlmann B. \& Halffter G. 1988. Cladistic and biogeographical analysis of Ateuchus (Coleoptera: Scarabaeidae) of Mexico and United States. Folia Entomológica Mexicana 74: 109-130.

Kohlmann B. \& Halffter G. 1990. Reconstruction of a specific example of insect invasion waves: the cladistic analysis of Canthon (Coleoptera: Scarabaeidae) and related genera in North America. Quaestiones Entomologicae 26: 1-26. Available from http://biodiversitylibrary.org/page/52013236 [accessed 30 May 2018].

Kohlmann B., Roderus D., Elle O., Solís Á., Soto X. \& Russo R. 2010. Biodiversity conservation in Costa Rica: a correspondence analysis between identified biodiversity hotspots (Araceae, Arecaceae, Bromeliaceae, and Scarabaeinae) and conservation priority life zones. Revista Mexicana de Biodiversidad 81: 511-559.

Kohlmann B., Solís Á., Elle O., Soto X. \& Russo R. 2007. Biodiversity, conservation, and hotspot atlas of Costa Rica: a dung beetle perspective (Coleoptera: Scarabaeidae: Scarabaeinae). Zootaxa 1457: 1-34.

Kolbe H.J. 1893. Beiträge zur Kenntniss der Mistkäfer, Lamellicornia onthophila. Stettiner Entomologische Zeitung 54: 188-202. Available from http://biodiversitylibrary.org/page/8932278 [accessed 30 May 2018].

Korasaki V., Vaz-de-Mello F.Z., Braga R.F., Zanetti R. \& Louzada J. 2012. Taxocenose de Scarabaeinae (Coleoptera: Scarabaeidae) em Benjamin Constant, AM. Acta Amazonica 42 (3): 423-432.

https://doi.org/10.1590/S0044-59672012000300015

Krajcik M. 2012. Animma. X. Supplement 5. Checklist of the World Scarabaeoidea. Privately published, Plzen.

Krell F.-T. 1994. Phylogenetic and taxonomic considerations on the variability of cuticular surface micromorphology within one species, Aphodius (Nialus) varians Duftschmid (Insecta: Coleoptera: Scarabaeidae: Aphodiinae). Revue Suisse de Zoologie 101 (1): 265-287.

https://doi.org/10.5962/bhl.part.79907

Lacordaire J.T. 1856. Histoire naturelle des insectes. Genera des coléoptères, ou exposé méthodique et critique de tous lês genres proposés jusqu'ici dans cet ordre d'insectes. Tome troisième. Contenant les 
familles des Pectinicornes et Lamellicornes. Librarie Encyclopédique de Roret, Paris. Available from http://biodiversitylibrary.org/page/9612631 [accessed 30 May 2018].

Lamichhaney S., Han F., Webster M.T., Andersson L., Grant B.R. \& Grant P.R. 2018. Rapid hybrid speciation in Darwin's finches. Science 359 (6372): 224-228. https://doi.org/10.1126/science.aao4593

Larsen T. 2004. Dung beetles (Coleoptera: Scarabaeidae: Scarabaeinae). In: Vriesendorp C., Chavez L.R., Moskovits D. \& Shopland J. (eds) Peru: Megantoni: 185-192 + 259-261. Rapid Biological Inventories Report 15, The Field Museum, Chicago.

Larsen T. 2012. Dung beetles of the Kwamalasamutu region, Suriname (Coleoptera: Scarabaeidae: Scarabaeinae). In: O'Shea B.J., Alonso L.E. \& Larsen T. (eds) A Rapid Biological Assessment of the Kwamalasamutu Region, Southwestern Suriname. RAP Bulletin of Biological Assessment 63: 91-103.

Larsen T.H., Lopera A. \& Forsyth A. 2009. Understanding trait-dependent community disassembly: dung beetles, density functions, and forest fragmentation. Conservation Biology 22 (5): 1288-1298. https://doi.org/10.1111/j.1523-1739.2008.00969.x

Latreille P.A. 1807. Insectes de l'Amérique équinoxiale, recueillis pendant le voyage de MM. de Humboldt et Bonpland. In: Humboldt A. \& Bonpland A. 1805-1810 (eds) Recueil d'observations de zoologie et d'anatomie comparée, faites dans l'océan Atlantique, dans l'intérieur du nouveau continent et dans la mer du Sud pendant les années 1799, 1800, 1801, 1802 et 1803. Premier volume: 105-196. Schoell \& Dufour, Paris (livraison 3). [See Bousquet 2016 for the dating of this work.] https://doi.org/10.5962/bhl.title.43770

Latreille P.A. 1829. Crustacés, arachnides et partie des insectes. In: Cuvier G. Le Régne Animal distribué d'après son organisation, pour servir de base a l'Histoire naturelle des animaux et d'introduction a l'anatomie comparée. Avec figures dessinées d'après nature. Nouvelle édition, revue et augmentée. Tome IV. Déterville \& Crochard, Paris. Available from https://biodiversitylibrary.org/page/33374495 [accessed 30 May 2018].

Lawrence J.F., Beutel R.G., Leschen R.A.B. \& Slipinski A. 2010. Glossary of morphological Terms. In: Leschen R.A.B., Beutel R.G. \& Lawrence J.F. (eds) Coleoptera, Beetles. Volume 2: Morphology and Systematics (Elateroidea, Bostrichiformia, Cucujiformia partim). Handbook of Zoology. Arthropoda: Insecta. Walter de Gruyter, Berlin and New York.

Lebis E. 1953. Revision des Canthoninae de Madagascar [Col. Scarabaeidae]. Mémoires de l'Institut scientifique de Madagascar E (3): 107-252.

Ledo R.M.D. \& Colli G.R. 2017. The historical connections between the Amazon and the Atlantic Forest revisited. Journal of Biogeography 44 (11): 2551-2563. https://doi.org/10.1111/jbi.13049

Lima M.G.A., Silva R.P.A., Sousa M.D.F. \& Costa E.M. 2013. Diversidade de Scarabaeinae (Coleoptera: Scarabaeidae) no Parque Botânico do Ceará, Caucaia - CE, Brasil. Revista Agroambiente 7 (1): 89-94.

Löwenberg-Neto P. 2014. Neotropical region: a shapefile of Morrone's (2014) biogeographical regionalisation. Zootaxa 3802 (2): 300. https://doi.org/10.11646/zootaxa.3802.2.12

Lyal C.H.C. 2011. The dating of the Biologia Centrali-Americana. Zoological Bibliography 1 (2): 67100.

Madge R.B. 1988. The publication dates of Dejean's catalogues. Archives of Natural History 15 (3): 317-321. https://doi.org/10.3366/anh.1988.15.3.317

Mallet J. 2007. Subspecies, semispecies, superspecies. In: Levin S.A. (ed.) Encyclopeia of Biodiversity: 1-5. Elsevier, Oxford. 
Marchisio R. \& Zunino M. 2012. Il genere Copris Müller: tassonomia, filogenesi e note di zoogeografía. World Biodiversity Association, Monografía 2, Verona.

Martínez A. 1948a. Notas coleopterólogicas. I. Un género nuevo y dos especies nuevas de Canthonini (Col. Scarab.) de Venezuela. Anales de la Sociedad Científica Argentina 146: 41-41. Available from http://biodiversitylibrary.org/page/48990363 [accessed 30 May 2018].

Martínez A. 1948b. Insectos nuevos o poco conocidos - VI (Col. Scarabaeidae). Revista de la Sociedad Entomológica Argentina 14: 3-11.

Martínez A. 1949a. Notas coleopterológicas III. Dos nuevas especies de Glaphyrocanthon Martínez, 1948, con clave para las especies del género (Col. Scarab.). Anales de la Sociedad Cientifica Argentina 148: 281-291. Available from http://biodiversitylibrary.org/page/48991419 [accessed 30 May 2018].

Martínez A. 1949b. Insectos nuevos o poco conocidos VII. Algunas especies nuevas o poco conocidas de Canthon y Description de un nuevo Scybalocanthon Col. (Scarabaeinae). Revista de la Sociedad Entomologica Argentina 14 (4): 175-193.

Martínez A. 1950. Notas coleopterólogicas IV. Nuevo subgénero y especies de Glaphyrocanthon Martínez, 1948 (Col. Scarabaeinae). Anales de la Sociedad Científica Argentina 150: 159-172. Available from http://biodiversitylibrary.org/page/48987483 [accessed 30 May 2018].

Martínez A. 1952. Scarabaeidae nuevos o poco conocidos, III. Misión de Estudios de Patología Regional Argentina 23 (81-82): 53-118.

Martínez A. 1953. Un nuevo género y especie de Canthonina (Coleopt. Scarabaeid.). Boletin de la Sociedad Entomologica Argentina 2: 3.

Martínez A. 1959. Catálogo de los Scarabaeidae Argentinos. Revista del Museo Argentino de Ciencias Naturales "Bernardino Rivadavia”, Ciencias Zoológicas 5: 1-126.

Martínez A. 1987. La entomofauna de Scarabaeinae de la provincia de Salta (Col. Scarabaeoidea). Revista de la Sociedad Científica Argentina 216: 45-69.

Martínez A. \& Halffter G. 1972. New taxa of American Canthonina (Coleoptera, Scarabaeinae). Entomologische Arbeiten aus dem Museum G. Frey 23: 33-66.

Available from http://biodiversitylibrary.org/page/45978703 [accessed 30 May 2018].

Martínez A. \& Pereira F.S. 1956. Dois gêneros novos de Canthonini americanos (Col. Scarabaeoidea, Scarabaeidae). Papéis Avulsos do Departamento de Zoologia 12 (19): 363-388.

Martínez A. \& Pereira F.S. 1959. Dos géneros nuevos de Canthonini etiópicos insulares. Revista de la Sociedad Entomológica Argentina 21: 89-95.

Martínez A. \& Pereira F.S. 1967. Notas escarabeidológicas III (Col. Scarabaeidae-Scarabaeinae). Revista de la Sociedad Entomológica Argentina 29: 53-69.

Martínez A., Halffter G. \& Halffter V. 1964. Notas sobre el género Glaphyrocanthon (Coleopt., Scarab., Canthonina). Acta Zoologica Mexicana 7 (3): 1-42.

Martínez N.J., Cañas L.M., Rangel J.L., Barraza J.M., Montes J.M. \& Blanco O.R. 2010. Coleópteros coprófagos (Scarabaeidae: Scarabaeinae) en un fragmento de bosque seco tropical en el departamento del Atlántico, Colombia. Boletín del Museo de Entomología de la Universidad del Valle 11 (1): 21-30.

Matthews E.G. 1966. A taxonomic and zoogeographic survey of the Scarabaeinae of the Antilles (Coleoptera: Scarabaeidae). Memoirs of the American Entomological Society 21: 1-134. Available from http://biodiversitylibrary.org/page/38924033 [accessed 30 May 2018]. 
Matthews E.G. 1969. New data on Antillean scarabaeine beetles, and two new species from Hispaniola. Psyche 76: 114-125. https://doi.org/10.1155/1969/24060

Matthews E.G. 1972. A revision of the scarabaeine dung beetles of Australia. I. Tribe Onthophagini. Australian Journal of Zoology, Supplementary Series 9: 1-330. https://doi.org/10.1071/AJZS009

Matthews E.G. 1974. A revision of the scarabaeine dung beetles of Australia. II. Tribe Scarabaeini. Australian Journal of Zoology, Supplementary Series 24: 1-211. https://doi.org/10.1071/AJZS024

Matthews E.G. \& Weir T.A. 2002. Two new species of the genus Lepanus Balthasar from South Australia (Coleoptera: Scarabaeidae). Records from the South Australian Museum 35 (1): 79-84.

Mayr E. 1931. Birds collected during the Whitney South Sea Expedition. XII. Notes on Halcyon chloris and some of its subspecies. American Museum Novitates 469: 1-10.

Available from http://hdl.handle.net/2246/3018 [accessed 30 May 2018].

Mayr E. 1940. Speciation phenomena in birds. The American Naturalist 74 (752): 249-278.

https://doi.org/10.1086/280892

Mayr E. 1942. Systematics and the Origin of Species from the Viewpoint of a Zoologist. Harvard University Press, Cambridge (MA).

Mayr E. 1957. Difficulties and importance of the Biological Species. In: Mayr E. (ed.) The Species Problem: A Symposium Presented at the Atlanta Meeting of the American Association for the Advancement of Science, December 28-29, 1955: 371-388. American Association for the Advancement of Science, Washington D.C.

Mayr E. 1963. Animal Species and Evolution. The Belknap Press of Harvard University Press, Cambridge (MA).

Mayr E. 1970. Populations, Species, and Evolution. An Abridgment of Animal Species and Evolution. The Belknap Press of Harvard University Press, Cambridge (MA).

Mayr E. 1982. The Growth of Biological Thought. Diversity, Evolution, and Inheritance. The Belknap Press of Harvard University Press, Cambridge (MA).

Mayr E. 1985. Darwin's five theories of evolution. In: Kohn D. (ed.) The Darwinian Heritage: 755-772. Princeton University Press, Princeton (NJ).

Mayr E. 1988a. The species category. In: Mayr E. (ed.) Toward a new Philosophy of Biology: Observations of an Evolutionist: 315-334. Harvard University Press, Cambridge (MA) and London.

Mayr E. 1988b. The ontology of the species taxon. In: Mayr E. (ed.) Toward a new Philosophy of Biology: Observations of an Evolutionist: 335-358. Harvard University Press, Cambridge (MA) and London.

Mayr E. 2000 [consulted edition from 2003]. The Biological Species Concept. In: Wheeler Q.D. \& Meier R. (eds) Species Concepts and Phylogenetic Theory. A Debate: 17-29. Bishen Singh Mahendra Pal Singh, Dehra Dun.

Mayr E. 2004a. Another look at the species problem. In: Mayr E. (ed.) What Makes Biology Unique? Considerations on the Autonomy of a Scientific Discipline: 171-193. Cambridge University Press, Cambridge.

Mayr E. 2004b. Darwin's five theories of evolution. In: Mayr E. (ed.) What Makes Biology Unique? Considerations on the Autonomy of a Scientific Discipline: 97-115. Cambridge University Press, Cambridge. 
Mayr E. \& Diamond J. 2001. The Birds of Northern Melanesia: Speciation, Ecology, and Biogeography. Oxford University Press, New York.

Mayr E., Linsley E.G. \& Usinger R.L. 1953. Methods and Principles of Systematic Zoology. McGrawHill Book Company, New York, Toronto and London.

McIntyre P. \& Caveney S. 1998. Superposition optics and the time of flight in onitine dung beetles. Journal of Comparative Physiology A 183: 45-60. https://doi.org/10.1007/s003590050233

Medina C.A. \& Lopera-Toro A. 2000. Clave ilustrada para la identificación de géneros de escarabajos coprófagos (Coleoptera: Scarabaeidae) de Colombia. Caldasia 22: 299-315.

Medina C.A. \& Pulido L.A. 2009. Escarabajos coprófagos (Coleoptera: Scarabaeinae) de la Orinoquia colombiana. Biota Colombiana 10: 55-62.

Medina C.A., Lopera-Toro A., Vítolo A. \& Gill B. 2001. Escarabajos coprófagos (Coleoptera: Scarabaeinae) de Colombia. Biota Colombiana 2: 131-144.

Medina C.A., Scholtz C.H. \& Gill B.D. 2003. Morphological variation and systematics of Canthon Hoffmansegg, 1817 and related genera of New World Canthonini dung beetles (Coleoptera, Scarabaeinae). Deutsche Entomologische Zeitschrift 50 (1): 23-68. https://doi.org/10.1002/mmnd.20030500105

Medina C.A.C., Medina-Uribe C.A., Quintero B.G.M., Escobar-Villa A.F., Chuaire L.M.C. \& Posada N.J.B. 2012. Escarabajos coprófagos (Scarabaeinae) del eje cafetero: Guía para el estudio ecológico. No editor, Villa María.

Medina C.A., Molano F. \& Scholtz C.H. 2013. Morphology and terminology of dung beetles (Coleoptera: Scarabaeidae: Scarabaeinae) male genitalia. Zootaxa 3626: 455-476.

https://doi.org/10.11646/zootaxa.3626.4.3

Meier R. \& Willmann R. 2000 [consulted version from 2003]. The Hennigian Species Concept. In: Wheeler Q.D. \& Meier R. (eds) Species Concepts and Phylogenetic Theory. A Debate: 30-43. Bishen Singh Mahendra Pal Singh, Dehra Dun.

Méndez V. \& Córdoba-Aguilar A. 2004. Sexual selection and animal genitalia. Trends in Ecology and Evolution 19 (5): 224-225. https://doi.org/10.1016/j.tree.2004.03.012

Mlmambo S., Sole C.L. \& Scholtz C.H. 2013. Affinities of the Canthonini dung beetles of the Eastern Arc Mountains. Organisms Diversity \& Evolution 14 (1): 115-120.

https://doi.org/10.1007/s13127-013-0158-y

Molnar P. 2017. Comment (2) on "Formation of the Isthmus of Panama" by O'Dea et al. Science Advances 3 (6): 1-4. https://doi.org/10.1126/sciadv.1602320

Monaghan M.T., Inward D.J.G., Hunt T. \& Vogler A.F. 2007. A molecular phylogenetic analysis of the Scarabaeinae (dung beetles). Molecular Phylogenetics and Evolution 45: 674-692.

https://doi.org/10.1016/j.ympev.2007.06.009

Montes C., Bayona G., Cardona A., Buchs D.M., Silva C.A., Morón S., Hoyos N., Ramírez D.A., Jaramillo C.A. \& Valencia V. 2012a. Arc-continent collision and orocline formation: closing of the Central American seaway. Journal of Geophysical Research 117: B04105, 1-25.

https://doi.org/10.1029/2011JB008959

Montes C., Cardona A., McFadden R., Morón S.E., Silva C.A., Restrepo-Moreno S., Ramírez D.A., Hoyos N., Wilson J., Farris D., Bayona G.A., Jaramillo C.A., Valencia V., Bryan J. \& Flores J.A. 2012b. Evidence for middle Eocene and younger land emergence in central Panama: implications for Isthmus closure. Geological Society of America Bulletin 124 (5-6): 780-799. https://doi.org/10.1130/B30528.1 
Montes C., Cardona A., Jaramillo C., Pardo A., Silva J.C., Valencia V., Ayala C., Pérez-Angel L.C., Rodriguez-Parra L.A., Ramirez V. \& Niño H. 2015. Middle Miocene closure of the Central American Seaway. Science 348 (6231): 226-229. https://doi.org/10.1126/science.aaa2815

Montreuil O. 2008. Révision du genre Cambefortantus Paulian, 1986 (Insecta, Coleoptera, Scarabaeidae). Zoosystema 30 (3): 641-650.

Montreuil O. 2010. Première espèce du genre Haroldius Boucomont, 1914, à Madagascar, et redéfinition des Epilissini (Coleoptera, Scarabaeidae, Ateuchini). Bulletin de la Société entomologique de France 115 (1): 73-76.

Montreuil O. 2011. Monophylie du "groupe Epilissus" et refonte des genres Epilissus Reiche, 1841, Arachnodes Westwood, 1847 et Apterepilissus n. gen. de Madagascar (Insecta, Coleoptera, Scarabaeidae, Epilissini). Zoosystema 33 (1): 101-122.

Montreuil O. \& Théry T. 2011. Revision of the New Caledonian genus Pseudonthobium Paulian, 1984 (Coleoptera: Scarabaeidae: Epilissini). Zootaxa 2863: 49-62.

Montreuil O. \& Théry T. 2016. A revision of the genus Paronthobium from New Caledonia (Coleoptera: Scarabaeidae: Scarabaeinae: Epilissini). Annales de la Société entomologique de France (N.S.) 52 (1): 1-25. https://doi.org/10.1080/00379271.2016.1187079

Montreuil O. \& Viljanen H. 2011. Deux nouvelles espèces du genre Nanos Westwood, 1847, de Madagascar (Coleoptera, Scarabaeidae, Epilissini). Bulletin de la Société entomologique de France 116 (1): 25-28.

Montreuil O., Viljanen H. \& Miraldo A. 2014. Evolution of the Malagasy endemic genus Nanos Westwood, 1842 (Coleoptera, Scarabaeidae, Epilissini). Systematic Entomology 39: 442-459. https://doi.org/10.1111/syen.12063

Morrone J.J. 2014. Biogeographical regionalisation of the Neotropical region. Zootaxa 3782 (1): 1-110. https://doi.org/10.11646/zootaxa.3782.1.1

Morrone J.J. 2015a. Halffter's Mexican transition zone (1961-2014), cenocrons and evolutionary biogeography. Journal of Zoological Systematics and Evolutionary Research 53 (3): 249-257. https://doi.org/10.1111/jzs.12098

Morrone J.J. 2015b. Biogeographical regionalisation of the world: a reappraisal. Australian Systematic Botany 28: 81-90. https://doi.org/10.1071/SB14042

Noriega J.A. 2012. Dung beetles (Coleoptera: Scarabaeinae) attracted to Lagothrix lagotricha (Humboldt) and Alouatta seniculus (Linnaeus) (Primates: Atelidae) dung in a Colombian Amazon Forest. Psyche Article ID 437589: 1-6.

Noriega J.A., Realpe E. \& Fagua G. 2007a. Diversidad de escarabajos coprófagos (Coleoptera: Scarabaeidae) en un bosque de galería con tres estadios de alteración. Revista de la Facultad de Ciencias, Edición Especial I 12: 51-63.

Noriega J.A., Solis C., Escobar F. \& Realpe E. 2007b. Escarabajos coprófagos (Coleoptera: Scarabaeidae) de la provincia de la Sierra Nevada de Santa Marta. Biota Colombiana 8 (1): 77-86.

Noriega J.A., Cubillos A.M., Castañeda C. \& Sanchez A.M. 2008. Actividad diaria de colonización del recurso alimenticio en un ensamblaje de escarabajos coprófagos (Coleoptera: Scarabaeidae) en la amazonía colombiana. Acta Biológica Colombiana 13 (3): 75-86.

Noriega J.A., Camero E., Arias-Buriticá J., Pardo-Locarno L.C., Montes J.M., Acevedo A.A., Esparza A., Ordóñes B.M., Garcia H. \& Solís C. 2015. Grado de cobertura del muestreo de escarabajos coprófagos (Coleoptera: Scarabaeidae: Scarabaeinae) en Colombia. Revista de Biología Tropical 63 (1): 97-125. 
Noriega-Alvarado J.A. 2004. Preliminary checklist of the scarab community (Coleoptera: Scarabaeidae) at CIEM, Tinigua National Park, Meta-Colombia. Field Studies of Fauna and Flora, La Macarena, Colombia 14: 37-44.

Noriega-Alvarado J.A. 2009. Análisis de la diversidad de escarabajos coprófagos (Coleoptera: Scarabaeidae) en el departamento de Cundinamarca. Revista de Tecnología 8 (1): 83-89.

Nunes R.V., Carvalho M.S.G., Vaz-de-Mello F.Z., Dáttilo W. \& Izzo T.J. 2014. Taxonomic composition of Scarabaeinae dung beetles (Coleoptera: Scarabaeidae) inhabiting fluvial islands in the southern Brazilian Amazon. Annales de la Société entomologique de France (N.S.) 50 (3-4): 407-413. https://doi.org/10.1080/00379271.2014.984955

Nunes L.G.O.A., Nunes R.V. \& Vaz-de-Mello F.Z. 2018. Taxonomic revision of the South American subgenus Canthon (Goniocanthon) Pereira \& Martínez, 1956 (Coleoptera: Scarabaeidae: Scarabaeinae: Deltochilini). European Journal of Taxonomy 437: 1-31. https://doi.org/10.5852/ejt.2018.437

Ocampo F.C. \& Hawks D.C. 2006. Molecular phylogenetics and evolution of the food relocation behaviour of the dung beetle tribe Eucraniini (Coleoptera: Scarabaeidae: Scarabaeinae). Invertebrate Systematics 20: 557-570. https://doi.org/10.1071/IS05031\#sthash.QD72poF6.dpuf

Ocampo F.C. \& Molano F. 2011. Revision and biogeography of the Neotropical dung beetle genus Scybalophagus (Coleoptera: Scarabaeidae). Revista de la Sociedad Entomológica Argentina 70 (3-4): 231-253.

O’Dea A., Lessios H.A., Coates A.G., Eytan R.I., Restrepo-Moreno S.A., Cione A.L., Collins L.S., de Queiroz A., Farris D.W., Norris R.D., Stallard R.F., Woodburne M.O., Aguilera O., Aubry M.P., Berggren W.A., Budd A.F., Cozzuol M.A., Coppard S.E., Duque-Caro H., Finnegan S., Gasparini G.M., Grossman E.L., Johnson K.G., Keigwin L.D., Knowlton N., Leigh E.G., LeonardPingel J.S., Marko P.B., Pyenson N.D., Rachello-Dolmen P.G., Soibelzon E., Soibelzon L., Todd J.A., Vermeij G.J. \& Jackson J.B.C. 2016. Formation of the Isthmus of Panama. Science Advances 2 (8): 1-11. https://doi.org/10.1126/sciadv. 1600883

Olson A.L., Hubbell T.H. \& Howden H.F. 1954. The burrowing beetles of the genus Mycotrupes (Coleoptera: Scarabaeidae: Geotrupinae). Miscellaneous Publications, Museum of Zoology, University of Michigan 84: 1-59.

Olson D.M., Dinerstein E., Wikramanayake E.D., Burgess N.D., Powell G.V.N., Underwood E.C., d'Amico J.A., Itoua I., Strand H.E., Morrison J.C., Loucks C.J., Allnutt T.F., Ricketts T.H., Kura Y., Lamoreux J.F., Wettengel W.W., Hedao P. \& Kassem K.R. 2001. Terrestrial ecoregions of the world: a new map of life on Earth. BioScience 51 (11): 933-938.

https://doi.org/10.1641/0006-3568(2001)051\%5B0933:TEOTWA\%5D2.0.CO;2

d'Olsoufieff G. 1935. Note critique sur l'essai d'une phylogénie des lamellicornes coprophages. Entomologisches Nachrichtenblatt 9: 32-35.

d’Olsoufieff G. 1947. Les Epilissiens de Madagascar. Bulletin de l'Académie Malgache 26: 169-174.

Pacheco T.L. \& Vaz-de-Mello F.Z. 2017. Rediscovery of the Neotropical genus Paracryptocanthon Howden \& Cook, 2002 (Coleoptera: Scarabaeidae: Scarabaeinae) in the Brazilian Atlantic Forest. Annales de la Société entomologique de France (N.S.) 53 (2): 99-105.

https://doi.org/10.1080/00379271.2017.1308809

Pacheco T.L., Silva J.L., Magalhães L.K.F. \& Vaz-de-Mello F.Z. 2016. Besouros rola-bostas (Insecta: Coleoptera: Scarabaeidae: Scarabaeinae). In: Rodrigues D.J., Noronha J.C., Vindica V.F. \& Barbosa F.R. (eds) Biodiversidade do Parque Estadual Cristalino: 141-153. Áttema Editorial, Sinop. 
Paulian R. 1938. Contribution à l'étude des Canthonides américans [Coleopt. Lamellic.]. Annales de la Société entomologique de France 107: 213-296.

Paulian R. 1939. Contribution à l'étude des Canthonides américans [Coleopt. Lamellic.] (suite et fin). Annales de la Société entomologique de France 108: 1-40.

Paulian R. 1947. Scarabaeoidea. In: Fleutiaux E., Legros C., Lepesme P. \& Paulian R. (eds) Faune de l'Empire français. VII. Coléoptères des Antilles (Volume I): 17-84. Office de la Recherche scientifique coloniale, Paris.

Paulian R. 1985. Les coléoptères Scarabaeidae Canthonines de Nouvelle-Guinée. Annales de la Société entomologique de France (N.S.) 21 (2): 219-238.

Pereira F.S. 1946. Escarabeídeos americanos. In: Sociedade Brasileira de Entomologia (ed.) Livro de Homenagem a Romualdo Ferreira d'Almeida: 289-294. Imprensa Oficial do Estado, São Paulo.

Pereira F.S. 1949. Escarabeídeos americanos (Coleopt.-Scarabaeidae). Arquivos do Museu Paranaense 7: 231-246.

Pereira F.S. 1953. Notas sinonímicas (Col. Scarabaeidae). Dusenia 4 (5-6): 387-402.

Pereira F.S. \& Martínez A. 1956. Os gêneros de Canthonini americanos (Col. Scarabaeidae). Revista Brasileira de Entomologia 6: 91-192.

Pereira F.S. \& Martínez A. 1959. Tres nuevos géneros de "Canthonini" americanos (Coleoptera, Scarabaeidae). Acta Zoológica Lilloana 17: 164-184.

Pereira F.S. \& Martínez A. 1960. Notas escarabeidológicas - II. Revista Brasileira de Entomologia 9: $37-55$

Philips T.K. \& Ivie M.A. 2008. Seven new species of Canthochilum Chapin from Hispaniola (Coleoptera: Scarabaeidae: Scarabaeinae). Zootaxa 1730: 27-42.

Philips T.K., Pretorius E. \& Scholtz C.H. 2004. A phylogenetic analysis of dung beetles (Scarabaeinae: Scarabaeidae): unrolling an evolutionary history. Invertebrate Systematics 18: 53-88. https://doi.org/10.1071/IS03030

Pinto Â.P. 2016. The dragonfly's face of the multidimensional Dr. Angelo Barbosa Monteiro Machado: a short bio-bibliography. Zootaxa 4078 (1): 8-27. https://doi.org/10.11646/zootaxa.4078.1.4

Pinto Â.P. \& Lamas C.J.E. 2011. Oligoclada mortis sp. nov. from Rondônia State, Brazil, and distributional records of other species of the genus (Odonata: Libellulidae). International Journal of Odonatology 14 (4): 291-303. https://doi.org/10.1080/13887890.2011.629942

Pluot-Sigwalt D. 1982. Diversité et dimorphisme sexuel de glandes tégumentaires abdominales chez les Coléoptères Scarabaeidae. Comptes rendus des séances de l'Académie des sciences. Série 3, Sciences de la vie 294: 945-948.

Price D.L. 2009. Phylogeny and biogeography of the dung beetle genus Phanaeus (Coleoptera: Scarabaeidae). Systematic Entomology 34: 137-150. https://doi.org/10.1111/j.1365-3113.2008.00443.x

Price D.L. \& Feer F. 2012. Are there pitfalls to pitfalls? Dung beetle sampling in French Guiana. Organisms Diversity \& Evolution 12: 325-331. https://doi.org/10.1007/s13127-012-0106-2

Ratcliffe B. 1980. New species of Coprini (Coleoptera: Scarabaeidae: Scarabaeinae) taken from the pelage of three toed sloths (Bradypus tridactylus L.) (Edentata: Bradypodidae) in Central Amazonia with a breif commentary on scarab-sloth relationships. The Coleopterists Bulletin 34 (4): 337-350. Available from http://www.jstor.org/stable/4007913 [accessed 30 May 2018].

Ratcliffe B.C. 2002. A checklist of the Scarabaeoidea (Coleoptera) of Panama. Zootaxa 32: 1-48. 
Ratcliffe B.C. 2013. Best writing and curatorial practices for describing a new species of beetle: a primer. The Coleopterists Bulletin 67 (2): 107-111. https://doi.org/10.1649/0010-065X-67.2.107

Ratcliffe B.C. \& Smith A.B.T. 1999. New species of Canthonella Chapin (Scarabaeidae: Scarabaeinae) from Amazonian Brazil. The Coleopterists Bulletin 53 (1): 1-7.

Available from http://www.jstor.org/stable/4009281 [accessed 30 May 2018].

Ratcliffe B.C., Jameson M.L., Figueroa L., Cave R.D., Paulsen M.J., Cano E.B., Beza-Beza C., Jimenez-Ferbans L. \& Reyes-Castillo P. 2015. Beetles (Coleoptera) of Peru: a survey of the families. Scarabaeoidea. Journal of the Kansas Entomological Society 88 (2): 186-207. https://doi.org/10.2317/kent-88-02-186-207.1

Reiche M. 1841. Tableau d'une division systématique de la tribu des Coprophages, dans la famille des Lamellicornes. Revue et Magazine de Zoologie, Pure et Appliquée 4: 211-213.

Ridley M. 2004. Evolution. $3^{\text {rd }}$ Edition. Blackwell Publishing, Oxford.

Rivera-Cervantes L.E. \& Halffter G. 1999. Monografia de las especies mexicanas de Canthon del subgenero Glaphyrocanthon (Coleoptera: Scarabaeidae: Scarabaeinae). Acta Zoológica Mexicana (n.s.) 77: $23-150$.

Rossini M., Vaz-de-Mello F.Z. \& Zunino M. 2018a. Toward a comprehensive taxonomic revision of the "hirculus" group of American Onthophagus Latreille, 1802 (Coleoptera, Scarabaeidae, Scarabaeinae). European Journal of Taxonomy 432: 1-21. https://doi.org/10.5852/ejt.2018.432

Rossini M., Vaz-de-Mello F.Z. \& Zunino M. 2018b. A taxonomic revision of the New World Onthophagus Latreille, 1802 (Coleoptera: Scarabaeidae: Scarabaeinae) of the osculatii species-complex, with Description of two new species from South America. Journal of Natural History 52 (9-10): 541-586. https://doi.org/10.1080/00222933.2018.1437230

Scheffler P.Y. 2005. Dung beetle (Coleoptera: Scarabaeidae) diversity and community structure across three disturbance regimes in eastern Amazonia. Journal of Tropical Ecology 21: 9-19. https://doi.org/10.1017/S0266467404001683

Schenk E.T. \& McMasters J.H. 1956. Procedure in Taxonomy. Third Edition. Stanford University Press, Standford.

Schmidt A. 1920. Beitrag zur Kenntnis der Gattungen Canthon Hffsg., Sybax Boh., Aphodius Ill., Simogenius Har., Ataenius Har. Archiv für Naturgeschichte, Abteilung A 86 (9): 114-147. Available from http://biodiversitylibrary.org/page/13314274 [accessed 30 May 2018].

Schmidt A. 1922. 1. Bestimmungstabelle der mir bekannten Canthon-Arten. 2. Verbreitungsgebiete der Canthon-Arten. 3. Neubeschreibungen von Canthon, Saprositis, Mendidius, Euparia und Ataenius. Archiv für Naturgeschichte Abteilung A 88 (3): 61-103.

Available from http://biodiversitylibrary.org/page/13259701 [accessed 30 May 2018].

Scholtz C.H. 2009. Section C. Phylogeny of the Scarabaeinae. In: Scholtz C.H., Davis A.L.V. \& Kryger U. (eds) Evolutionary Biology and Conservation of Dung Beetles: 225-327. Pensoft Publishers, Sofia.

Scholtz C.H. \& Howden H.F. 1987. A revision of the African Canthonina (Coleoptera: Scarabaeidae: Scarabaeinae). Journal of the Entomological Society of Southern Africa 50 (1): 75-119.

Scholtz C.H., Davis A.L.V. \& Kryger U. 2009. Evolutionary Biology and Conservation of Dung Beetles. Pensoft Publishers, Sofia. 
Schoolmeesters P. 2017. Scarabs: World Scarabaeidae Database (version January 2017). In: Roskov Y., Abucay L., Nicolson D., Kunze T., Flann C., Baily N., Kirk P., Bourgoin T., DeWalt R.E., Decock W., De Wever A. (eds). Species 2000 \& ITIS Catalogue of Life.

Available from http://www.catalogueoflife.org/ [accessed on 13 Jun. 2017].

Sherborn C.D. 1899. A note on the date of the parts of 'Humboldt and Bonpland's Voyage: Observations de Zoologie'. Annals and Magazine of Natural History, Seventh Series 4: 428. https://doi.org/10.1080/00222939908678146

Sherborn C.D. \& Woodward B.B. 1901. Notes on the dates of publication of the natural history portions of some French Voyages - Part I. 'Amérique méridionale'; 'Indes orientales', 'Pôle Sud' ('Astrolabe' and 'Zélée'); 'La Bonite'; 'La Coquille'; and 'L'Uranie et Physicienne'. The Annals and Magazine of Natural History, Seventh Series 7: 388-392. https://doi.org/10.1080/00222930108678490

Sikes D.S. \& Barclay M.V.L. 2017. The type of Nicrophorus chryseus Mazokhin-Porshnyakov, 1953 (Coleoptera: Silphidae) rediscovered and a commentary on "accidental" taxonomy. The Coleopterists Bulletin 71 (4): 721-726. https://doi.org/10.1649/0010-065X-71.4.721

Silva F.A.B., Costa C.M.Q., Moura R.C. \& Farias A.I. 2010. Study of the dung beetle (Coleoptera: Scarabaeidae) community at two sites: Atlantic Forest and clear-cut, Pernambuco, Brazil. Environmental Entomology 39 (2): 359-367. https://doi.org/10.1603/EN09180

Silva F.A.B., Hernández M.I.M., Ide S. \& Moura R.C. 2007. Comunidade de escarabeíneos (Coleoptera, Scarabaeidae) copro-necrófagos da região de Brejo Novo, Caruaru, Pernambuco, Brasil. Revista Brasileira de Entomologia 51 (2): 228-233. https://doi.org/10.1590/S0085-56262007000200014

Silva R.J., Coletti F., Costa D.A. \& Vaz-de-Mello F.Z. 2014. Rola-bostas (Coleoptera: Scarabaeidae: Scarabaeinae) de florestas e pastagens no sudoeste da Amazônica brasileira: levantamento de espécies e guildas alimentares. Acta Amazonica 44 (3): 345-352. https://doi.org/10.1590/1809-4392201304472

Silva F.A.B., Louzada J. \& Vaz-de-Mello F.Z. 2015. A revision of the Deltochilum subgenus Aganhy-boma Kolbe, 1893 (Coleoptera: Scarabaeidae: Scarabaeinae). Zootaxa 3925 (4): 451-504. https://doi.org/10.11646/zootaxa.3925.4.1

Silva R.J., Pelissari T.D., Krinski D., Canale G. \& Vaz-de-Mello F.Z. 2017. Abrupt species loss of the Amazonian dung beetle in pastures adjacent to species-rich forests. Journal of Insect Conservation 21 (3): 487-494. https://doi.org/10.1007/s10841-017-9988-9

Simmons L.W. 2014. Sexual selection and genital evolution. Austral Entomology 53 (1): 1-17. https://doi.org/10.1111/aen.12053

Simpson G.G. 1951. The species concept. Evolution 5 (4): 285-298.

https://doi.org/10.1111/j.1558-5646.1951.tb02788.x

Simpson G.G. 1961. Principles of animal Taxonomy. Columbia University Press, New York, NY.

Simpson G.G. 1980. Splendid Isolation: The curious History of South American Mammals. Yale University Press, New Haven, CT.

Sites J.W. jr. \& Marshall J.C. 2004. Operational criteria for delimiting species. Annual Review of Ecology, Evolution and Systematics 35: 199-227. https://doi.org/10.1146/annurev.ecolsys.35.112202.130128

Smith A.B.T. 2006. A review of the family-group names for the superfamily Scarabaeoidea (Coleoptera) with corrections to nomenclature and a current classification. The Coleopterists Society Monograph 5: 144-204. https://doi.org/10.1649/0010-065X(2006)60\%5B144:AROTFN\%5D2.0.CO;2 
Sole C.L. \& Scholtz C.H. 2010. Did dung beetles arise in Africa? A phylogenetic hypothesis based on five gene regions. Molecular Phylogenetics and Evolution 56: 631-641.

https://doi.org/10.1016/j.ympev.2010.04.023

Solís Á. \& Kohlmann B. 2002. El género Canthon (Coleoptera: Scarabaeidae) en Costa Rica. Giornale Italiano di Entomologia 10: 1-68.

Solís Á \& Kohlmann B. 2012. Checklist and distribution atlas of the Scarabaeinae (Coleoptera: Scarabaeidae) of Costa Rica. Zootaxa 3482: 1-32.

Solís C., Noriega J.A. \& Herrera G. 2011. Escarabajos coprófagos (Coleoptera: Scarabaeinae) en tres bosques secos del departamento del Atlático-Colombia. Boletín del Museo de Entomología de la Universidad del Valle 12 (1): 33-41.

Streit B. 2012. Edmonds Phanaeini collection donated to Texas A\&M. Scarabs 70: 14-15.

Sturm J. 1826. Catalog meiner Insecten-Sammlung. Erster Theil. Käfer. Privately published, Nurembergue [Nürnberg], III-VIII. Available from http://biodiversitylibrary.org/page/14964994 [accessed 30 May 2018].

Sturm J. 1843. Catalog der Kaefer-Sammlung von Jacob Sturm. Privately published, Nurembergue [Nürnberg], III-XII. Available from http://biodiversitylibrary.org/page/26204927 [accessed 30 May 2018].

Takiya D.M., Mejdalani G. \& Webb M.D. 2003. Notes on the Amazonian genus Hyogonia China (Hemiptera: Cicadellidae: Proconiini) with a Description of a new species. Journal of Natural History 37: 2863-2869. https://doi.org/10.1080/0022293021000007444

Tarasov S. \& Dimitrov D. 2016. Multigene phylogenetic analysis redefines dung beetles relationships and classification (Coleoptera: Scarabaeidae: Scarabaeinae). BMC Evolutionary Biology 16 (257): 1-19. https://doi.org/10.1186/s12862-016-0822-x

Tarasov S. \& Génier F. 2015. Innovative bayesian and parsimony phylogeny of dung beetles (Coleoptera, Scarabaeidae, Scarabaeinae) enhanced by ontology-based partitioning of morphological characters. Plos One 10 (3): 1-86. https://doi.org/10.1371/journal.pone.0116671

Tarasov S.I. \& Solodovnikov A.Y. 2011. Phylogenetic analyses reveal reliable morphological markers to classify mega-diversity in Onthophagini dung beetles (Coleoptera: Scarabaeidae: Scarabaeinae). Cladistics 27: 1-39. https://doi.org/10.1111/j.1096-0031.2011.00351.x

Torre-Bueno J.R. de la. 1989. The Torre-Bueno Glossary of Entomology. The New York Entomological Society, New York, NY.

Tribe G.D. 1975. Pheromone release by dung beetles (Coleoptera: Scarabaeidae). South African Journal of Science 71: 277-278.

Valois M., Vaz-de-Mello F.Z. \& Silva F.A.B. 2015. A taxonomic review of the Neotropical genus Hansreia Halffter \& Martínez, 1977 (Coleoptera: Scarabaeidae: Scarabaeinae). Zootaxa 4027 (2): 205226. https://doi.org/10.11646/zootaxa.4027.2.2

Vaz-de-Mello F.Z. 1999. Scarabaeidae s. str. (Coleoptera: Scarabaeoidea) de um fragmento de floresta amazônica no estado do Acre, Brasil. 1. Taxocenose. Anais da Sociedade Entomológica do Brasil 28 (3): 447-453.

Vaz-de-Mello F.Z. 2000. Estado atual de conhecimentos dos Scarabaeidae s. str. (Coleoptera: Scarabaeoidea) do Brasil. In: Martín-Piera F., Morrone J.J. \& Melic A. (eds) Hacia un proyecto CYTED para el inventario y estimación de la diversidad entomológica en Iberoamérica: PRIBES-2000: 183-195. Monografías Tercer Milenio 1, Sociedad Entomológica Aragonesa (SEA), Zaragoza. 
Vaz-de-Mello F.Z. 2007a. Revision and phylogeny of the dung beetle genus Zonocopris Arrow 1932 (Coleoptera: Scarabaeidae: Scarabaeinae), a phoretic of land snails. Annales de la Société entomologique de France (n.s.) 43 (2): 231-239. https://doi.org/10.1080/00379271.2007.10697516

Vaz-de-Mello F.Z. 2007b. Revisión taxonómica y análisis filogenético de la tribu Ateuchini (Coleoptera: Scarabaeidae: Scarabaeinae). PhD thesis, Instituto de Ecología, Xalapa, Mexico.

Vaz-de-Mello F.Z. 2008. Synopsis of the new subtribe Scatimina (Coleoptera: Scarabaeidae: Scarabaeinae: Ateuchini), with descriptions of twelve new genera and review of Genieridium, new genus. Zootaxa 1955: 1-75.

Vaz-de-Mello F.Z. \& Cupello M. 2018. The type specimens of South American dung beetles, Part II: The species described by the Austrian coleopterist Ludwig Redtenbacher (1814-1876) in the 1868 part of the Reise der österreichischen Fregatte Novara um die Erde (Insecta: Coleoptera: Scarabaeidae: Scarabaeinae). Annalen des Naturhistorischen Museums in Wien, serie B 120: 41-58.

Vaz-de-Mello F.Z. \& Cupello M. in press. The type specimens of the New World dung beetles. Part I: On the species described in the genus Canthon Hoffmannsegg, 1817 (Coleoptera: Scarabaeidae: Scarabaeinae) by the German entomologist Adolf Schmidt (1856-1923). Spixiana.

Vaz-de-Mello F.Z. \& Halffter G. 2006. A new dung beetle genus with two new species from Chile (Coleoptera: Scarabaeidae: Scarabaeinae). Zootaxa 1193: 59-68.

Vaz-de-Mello F.Z. \& Louzada J.N.C. 1997. Considerações sobre forrageio arbóreo por Scarabaeidae (Coleoptera, Scarabaeoidea), e dados sobre sua ocorrência em floresta tropical do Brasil. Acta Zoológica Mexicana (n.s.) 72: 55-61.

Vaz-de-Mello F.Z. \& Silva F.A.B. 2017. A new species of the genus Scybalocanthon (Coleoptera, Scarabaeidae, Scarabaeinae) from the Atlantic rainforest, with an identification key to species from South America south of the Amazon basin. Zootaxa 4300 (1): 142-146.

https://doi.org/10.11646/zootaxa.4300.1.9

Vaz-de-Mello F.Z., Edmonds W.D., Ocampo F.C. \& Schoolmeesters P. 2011a. A multilingual key to the genera and subgenera of the subfamily Scarabaeinae of the New World (Coleoptera: Scarabaeidae). Zootaxa 2854: 1-73.

Vaz-de-Mello F.Z., Silva R.L.R., Nunes L.G.O.A. \& Corrêa P.R.O.A. 2011b. Os besouros rola-bosta (Insecta: Coleoptera: Scarabaeidae: Scarabaeinae) da Fazenda São Nicolau. In: Rodrigues D.J., Izzo T.J. \& Battirola L.D. (eds.) Descobrindo a Amazônica Meridional: Biodiversidade da Fazenda São Nicolau: 77-102. Pau e Prosa Comunicação, Cuiabá.

Vulcano M.A. \& Pereira F.S. 1964. Catalogue of the Canthonini (Col. Scarab.) inhabiting the Western Hemisphere. Entomologische Arbeiten aus dem Museum G. Frey 15 (2): 570-685. Available from https://biodiversitylibrary.org/page/45986646 [accessed 30 May 2018].

Vulcano M.A. \& Pereira F.S. 1966. Canthonini das Antilhas (Col., Scarabaeidae). Arquivos de Zoologia 14 (2): $115-154$.

Vulcano M.A. \& Pereira F.S. 1967. Sinopse dos Passalidae e Scarabaeidae s. str. da região amazônica (Insecta, Coleoptera). Atas do Simpósio sobre a Biota Amazônica 5 (Zoologia): 533-603.

Weidner H. 1976. Die entomologischen Sammlungen des Zoologischen Instituts und des Zoologischen Museums der Universität Hamburg. IX Teil. Insecta VI. 31. Ordnung: Coleoptera. Mitteilungen aus dem Hamburgischen Zoologischen Museum 73: 87-264.

Weir J.T., Bermingham E. \& Schluter D. 2009. The Great American Biotic Interchange in birds. Proceedings of the National Academy of Sciences 106 (51): 21737-21742.

https://doi.org/10.1073/pnas.0903811106 
Werner M. \& Simmons L.W. 2008. The evolution of male genitalia: functional integration of genital sclerites in the dung beetle Onthophagus taurus. Biological Journal of the Linnean Society 93: 257-266. https://doi.org/10.1111/j.1095-8312.2007.00924.x

Wiley E.O. 1978. The evolutionary species concept reconsidered. Systematic Zoology 27: 17-26. https://doi.org/10.2307/2412809

Wiley E.O. 1980. Is the evolutionary species fiction? - A consideration of classes, individuals and historical entities. Systematic Zoology 29 (1): 76-80. https://doi.org/10.1093/sysbio/29.1.76

Wiley E.O. 1981. Phylogenetics: The Theory and Practice of Phylogenetic Systematics. John Wiley \& Sons, New York, Chichester, Brisbane, Toronto and Singapore.

Wiley E.O. \& Mayden R.L. 2000 [consulted version from 2003]. The Evolutionary Species Concept. In: Wheeler Q.D. \& Meier R. (eds) Species Concepts and Phylogenetic Theory. A Debate: 70-89. Bishen Singh Mahendra Pal Singh, Dehra Dun.

Wilkins J.S. 2009. Species: A History of the Idea. University of California Press, Berkeley, Los Angeles and London.

Wilson E.O. \& Brown W.L. jr. 1953. The subspecies concept and its taxonomic application. Systematic Zoology 2 (3): 97-111. https://doi.org/10.2307/2411818

WWF (World Wildlife Fund) 2006. WildFinder: online database of species distributions, ver. Jan-06. Available from http://www.worldwildlife.org/science/wildfinder/ [accessed 18 Jan. 2016].

Young O.P. 1978. Resource Partitioning in a Neotropical Necrophagous Scarab Guild. PhD thesis, University of Maryland, College Park, MD.

Young O.P. 1980. Bone burial by a Neotropical dung beetle (Coleoptera: Scarabaeidae). The Coleopterists Bulletin 34 (2): 253-255. Available from http://www.jstor.org/stable/4000139 [accessed 30 May 2018].

Young O.P. 2009. Observations on burrowing behavior by Panamanian Scarabaeinae (Coleoptera: Scarabaeidae). The Coleopterists Bulletin 63 (3): 319-324. https://doi.org/10.1649/1164.1

Zachos F.E. 2014. Taxonomic inflation, the Phylogenetic Species Concept and lineages in the Tree of Life - a cautionary comment on species splitting. Journal of Zoological Systematics and Evolutionary Research 53 (2): 180-184. https://doi.org/10.1111/jzs.12088

Zachos F.E. 2016. Species Concepts in Biology. Historical Development, Theoretical Foundations and Practical Relevance. Springer, New York (NY).

Zachos F.E. 2018. Mammals and meaningful taxonomic units: the debate about species concepts and conservation. Mammal Review [online version] 48 (3): 153-159. https://doi.org/10.1111/mam.12121

ZSM (Zoologische Staatssammlung München) 2014. Collections of the Coleoptera section.

Available from http://www.zsm.mwn.de/col/e/collection.htm [accessed on 11 Dec. 2015].

Zunino M. 1971. Importanza dell'apparato genitale femminile nella sistematica del genere Onthophagus Latr. (Coleoptera Scarabaeoidea). Bollettino della Società Entomologica Italiana 103 (1-2): 26-31.

Zunino M. 1972. Revisione delle specie paleartiche del genere Onthophagus Latr. (Coleoptera, Scarabaeoidea). I. - Il sottogenere Euonthophagus Balth. Bollettino del Museo di Zoologia dell'Università di Torino 1: 1-28.

Zunino M. 1975. Revisione delle specie paleartiche del sottogenere Onthophagus (sensu stricto) Latr. (Coleoptera, Scarabaeoidea). I tipo di H. d'Orbigny, A. Raffray e A. Boucomont nel Muséum National d'Histoire Naturelle di Parigi. Bollettino del Museo di Zoologia dell'Università di Torino 7: 151-194. 
Zunino M. 1976. Revisione delle species paleartiche del sottogenere Onthophagus (sensu stricto) Latr. (Coleoptera, Scarabaeoidea). I tipo di H.W. Bates, L. Fairmaire, E. von Harold, G. van Lansberge, S.A. de Marseul, L. Reiche e D. Sharp nel Muséum National d'Histoire Naturelle di Parigi. Bollettino del Museo di Zoologia dell'Università di Torino 4: 71-110.

Zunino M. 1978. Revisione delle species paleartiche del sottogenere Onthophagus (sensu stricto) Latr. (Coleoptera, Scarabaeoidea). I tipo di E. Reitter ed E. Csiki. Bollettino del Museo di Zoologia dell'Università di Torino 6: 75-122.

Zunino M. 1987. La evolución de los aparatos copuladores: comentarios a W.G. Eberhard, "Sexual selection and animal genitalia". Elytron 1: 105-107.

Zunino M. 2012. Cuarenta años de anatomía de las piezas genitales en la taxonomía de los escarabajos (Coleoptera: Scarabaeoidea): el estado del arte. Dugesiana 18 (2): 197-206.

Zunino M. 2014. About dung beetles (Coleoptera: Scarabaeoidea) genitalia: some remarks to a recent paper. Acta Zoológica Mexicana (n.s.) 30 (2): 438-442.

Zunino M. \& Halffter G. 1988. Análisis taxonómico, ecológico y biogeográfico de un grupo americano de Onthophagus (Coleoptera: Scarabaeidae). Museo Regionale di Scienze Naturali Monografie IX: $1-211$.

Manuscript received: 3 September 2017

Manuscript accepted: 7 February 2018

Published on: 16 October 2018

Topic editor: Gavin Broad

Section editor: Max Barclay

Desk editor: Kristiaan Hoedemakers

Printed versions of all papers are also deposited in the libraries of the institutes that are members of the EJT consortium: Muséum national d'Histoire naturelle, Paris, France; Botanic Garden Meise, Belgium; Royal Museum for Central Africa, Tervuren, Belgium; Natural History Museum, London, United Kingdom; Royal Belgian Institute of Natural Sciences, Brussels, Belgium; Natural History Museum of Denmark, Copenhagen, Denmark; Naturalis Biodiversity Center, Leiden, the Netherlands; Museo Nacional de Ciencias Naturales-CSIC, Madrid, Spain; Real Jardín Botánico de Madrid CSIC, Spain; Zoological Research Museum Alexander Koenig, Bonn, Germany. 


\section{Appendix 1: Endnotes}

1 Throughout this monograph, the words systematics and taxonomy are treated as synonyms and, therefore, interchangeable. The following working definition is given: Systematics (= taxonomy) is the comparative study of the biological diversity, including the delimitation all of its hierarchical constituents (e.g., genes, populations, species and superior taxa), these constituents' evolutive (i.e., phylogenetic) relationships, and the ultimate (i.e., historical) causes that explain current and past states in terms of morphology, genetics, and distribution of Earth's biodiversity and each of its constituents.

2 In fact, this and the other theoretical discussions present in this work (e.g., the definition of systematics, the critique of the 'extinction by speciation' idea, the use of the superspecies concept, and so on) were developed and written by the first author and are not necessarily endorsed either in full or in part by the second author. Therefore, for the sake of accuracy, they should be cited as 'Cupello in Cupello \& Vaz-de-Mello'.

3 According to Mayr $(1982,1985,2004 b)$, what is usually regarded by many authors as 'the' Darwinian Theory is, actually, a set of five major independent theories developed by Charles Darwin over several decades, namely the non-fixism ('evolution as such'), common descent, gradualism, populational speciation ('multiplication of species'), and natural selection. MC would also add the theory of sexual selection to this list due to the theory's key role both in Darwin's own view of the dynamics of the evolutionary process and in the modern evolutionary thinking.

4 The case of new species originating from small, hybrid founder populations like the one described in Lamichhaney et al. (2018) clearly shows how problematic the procedure adopted by Hennig (1966) and the advocates of the so-called Hennigian species concept (e.g., Meier \& Willmann 2000) - the so-called Hennigian Convention (Wilkins 2009; Zachos 2016) - of considering that an ancestral species always becomes extinct while giving origin to daughter species (i.e., when a speciation event involving some of its members occurs) can be. In the illustrative example in Lamichhaney et al., a single male of the Darwin's finch Geospiza conirostris Ridgway, 1890 immigrated from its original endemic range on the small island of Española to the also small island of Daphne Major, both in the Galapagos Archipelago, but distant from one another by more than $100 \mathrm{~km}$. On Daphne Major, that errant G. conirostris male bred with a resident G. fortis Gould, 1837 female, a crossing that gave origin to a new inbreeding lineage that, with just a single case of backcrossing between a $F_{1}$ male and a female of $G$. fortis, has remained isolated and both ecologically and morphologically distinct from the remainder populations of Geospiza Gould, 1937 on the island over the past 37 years. This fact led Lamichhaney et al. to infer that a rapid hybrid speciation event had occurred on Daphne Major. Consequently, should we apply the Hennigian procedure of considering the ancestral species extinct once a new daughter species arises, then both G. fortis and G. conirostris would now have to be considered extinct and new names would have to be established for them, even though no more than two individuals of each (only one of the latter) participated in that speciation event and their population structure as a whole was not affected by that event (in other words, it would have be indifferent for the population structure of G. fortis whether that errant male had died in the sea or given origin to a new hybrid species somewhere else). Besides, if we consider that the speciation process was fully completed as soon as the last backcrossing occurred, then individuals of G. fortis and G. conirostris living on their respective islands would have been born as part of one species and, in the course of their lives, would have changed to another species as soon as the hybrid species had been established. Finally, if we were to accept that an ancestral species must be automatically considered extinct as soon as a single errant individual forms a new hybrid species elsewhere, then we would never know whether the species we are dealing with today is the same as yesterday, since there will always be the possibility that some individual has interbred with a member of another species over the past night and potentially started the formation of a new hybrid species. The most reasonable 
procedure, therefore, is to apply the concept of extinction by speciation only to populational processes and, especially, to events of dicopatric speciation, when the structure of the entire metapopulation is affected, not just a small subset of it or some few peripheral isolates as in the cases of peripatric and hybrid speciation.

5 The difficulty in interpreting the populational nature of the Biological Concept is clear, for example, in Hausdorf (2011), who stated that it would make no difference in replacing the expression 'natural populations' with 'individuals' in the definition given by Mayr (1942). In fact, the difference between these terms becomes evident as soon as one realizes that 'natural populations' gives a probabilistic character to the concept, whereas 'individuals' makes it essentialist and deterministic. In the same way, the assertion of Cain (2009) that Mayr defended reproductive isolation as a "simple test for species rank" is a clear misunderstanding of the distinction between the species category and the species taxa (although it would be fair to say that some of Mayr's later writings (e.g., Mayr 2000) are indeed fairly confusing on this point).

6 Authorship following Hegna et al. (2013).

7 Subphylum's and class' authorship following Kluge (2010).

8 Order's and suborder's authorship following Beutel \& Leschen (2005).

9 Family-group names' authorship following Bouchard et al. (2011).

${ }^{10}$ With the term 'Canthon sensu lato', we intend neither to refer to a natural (i.e., monophyletic) group nor to propose a new formal classification. In fact, as we shall discuss, it is certain that this assemblage is rather artificial. When this term is employed, therefore, we only refer to a group of genera that were proposed based on species originally described in Canthon or which have had at some moment of their history been considered as close relatives to Canthon and with which they share great part of their taxonomic history. See Table 1 for more details.

11 As well argued by Vaz-de-Mello (2008: 13), this was also the case for several other dung beetle genera that were highly heterogeneous in the $19^{\text {th }}$ and early $20^{\text {th }}$ centuries and were eventually split out into a myriad of new genera in the $20^{\text {th }}$ and the early $21^{\text {st }}$ centuries (e.g., Panelus Lewis, 1895 , Epilissus Dejean, 1836, Stiptopodius Harold, 1871, Trichillum Harold, 1868 and Pedaridium, 1868). Although, as written by Vaz-de-Mello (2008), this was particularly true for genera poorly represented in collections, this has never been the case with Canthon, which is fairly common in any European natural history museum.

${ }^{12}$ Interestingly enough, Scholtz (2009) discussed that the same problem should possibly occur with the classification of the African genera formely placed in Deltochilini (i.e., prior to Tarasov \& Génier 2015 and Tarasov \& Dimitrov 2016).

13 This identification is probably incorrect. Medina et al. (2003) observed that the hypomeral cavity of the specimens they studied (which are from Colombia) was glabrous. True $S$. bridarollii, as seen in the present revision, have a long pilosity on the hypomeral cavity. The species studied by Medina et al. (2003) should have been $S$. edmondsi sp. nov., a species that is found in sympatry with $S$. bridarollii and with which it is commonly mistaken.

${ }^{14}$ Halffter \& Martínez (1977), for instance, stated that some "phyletic lineages" could be delimited within Glaphyrocanthon: the "Coprocanthon", "variabilis", "rubrescens", and "pallidus" species groups. 
${ }^{15}$ Although some results of that analysis are indeed quite questionable, as the positioning of the genus Gromphas Brullé, 1838 at the base of the phylogeny and totally apart from the Phanaeini, tribe which it belongs to (Cupello \& Vaz-de-Mello 2013, 2016).

${ }^{16}$ Although Canthon (Glaphyrocanthon) ibarragrassoi (Martínez, 1952), from South America, may be an exception, depending on the interpretation of the nature of the fine line that runs horizontally across the midline of the ventral surface of its hindfemora. Martínez (1952: 62) interpreted this possible margin as being a "thin, sinuous median sulcus" ("fino surco medial sinuoso"), while Pereira \& Martínez (1956: 144) described it as a "Weak, irregular sulcus at the middle of the ventral surface [of metafemora]" ("débil sulco irregular no meio da face ventral"). Nevertheless, judging from our examination of specimens of $C$. ibarragrassoi (including the holotype deposited at the $\mathrm{MACN}$ ), this structure does not seem to be an impression on the surface of the tegument, but rather a thin elevation. Hence, it would be better described as a margin instead of a sulcus, notwithstanding its central positioning on the metafemora. It is possible therefore that this margin may be homologous to the margin seen in Canthon s. str. and other groups. A scanning electron microscope examination can certainly give us more details as to the nature of this structure.

${ }^{17}$ Each of these polygons corresponds to an individual cell from the tegument that produced it (Krell 1994; Byers \& Hinks 1973).

${ }_{18}$ Matthews (1966), who discussed in detail the dispersal of Scarabaeinae in the Antilles, had already noted that the dung beetle fauna of Central and North Americas was dominated by South American elements. See also the extensive discussion on the New World dung beetle biogeography presented by Halffter \& Morrone (2017) and Halffter's numerous articles cited therein.

${ }^{19}$ After completion of the first draft of this work, Bert Kohlmann (EARTH University, Costa Rica) brought to our attention that populations from Osa Peninsula (e.g., Parque Nacional Corcovado), on the Pacific coast of Costa Rica, are different from others in Central America in both morphology (especially the elytral microsculpture) and genetics. According to Kohlmann, the Osa Peninsula had a rather particular geological history and many of its biotic elements seem to be endemic to it; in several cases, the sister species of Osa's species are distributed in other parts of Costa Rica and Central America, particularly along the Caribbean coast, so revealing a very intriguing vicariant pattern. Based on these observations, the Osa Peninsula populations of the aequinoctialis subgroup are currently under in-depth study by Bert Kohlmann, Ángel Solís (Museo Nacional de Costa Rica) and MC. In the meantime, we maintain our original identification of those specimens as $S$. aequinoctialis comb. nov.

${ }^{20}$ In Colombia, the Andes, in its northernmost portion, are divided into three independent mountain ranges: the Cordilleras Ocidental, Central, and Oriental. The latter, the longest one, extends northwards, from near the border of Ecuador and Colombia to close to the Caribbean Sea, branching south of Lake Maracaibo into the Cordillera de Mérida, which penetrates Venezuela and almost reaches the coast. This creates a group of long and high mountain ranges that acts as an important barrier largely preventing animal movements between regions east and west of the Andes.

${ }^{21}$ Michele Rossini (Instituto Tecnico per l'Agraria, l'Agroalimentare e l'Agroindustria "A. Cecchi", Italy; personal communication to MC, 2018), who revised the taxonomy of the Onthophagus belonging to the New World hircus species group for his $\mathrm{PhD}$ thesis (whose partial results were published in Rossini et al. 2018a, 2018b), informed us that in fact O. haematopus is not present in Colombia, but instead it is endemic to the Atlantic Forest. Therefore, this must be a misidentification. 
22 In general, an easy way to see the distinction on metafemora is as follows: in $S$. furvus, the coarse punctures at the base of metafemora are mingled among a strong rivose microsculpture, while in $S$. mayri sp. nov. and $S$. monnei sp. nov. the area covered by the rivose microsculpture usually does not reach those punctures, which, then, rest among a smooth tegument. However, in some specimens, the rivose microsculpture extends farther inferiorly on the metafemora and reaches some of the superior coarse punctures. 


\section{Appendix 2: Additional material examined}

Between the acceptance of the manuscript of the monograph and the production of its first proofs, the senior author (MC) had the opportunity to visit three other natural history museums - CEAH, FSCA and MCZC - and was able to examine some additional specimens of Sylvicanthon, including some further paratypes of two of the new species. This new material examined is listed in the following sections:

Sylvicanthon aequinoctialis (Harold, 1868)

\section{Material examined}

COSTA RICA: Heredia: 12 $\precsim$, 4 $+q$, Sarapiquí, Puerto Viejo, Finca La Selva, Jun. 1979, trap with human faeces, T. Ray and C. Andrews leg. (MCZC). - Limón: 1 đ, Guácimo, EARTH University, pitfall with human faeces, Oct. 2004, K. Beucke leg. (FSCA).

PANAMA: Bocas del Toro: 1 ô, "12-15 km W Punta Peña", 21-22 Feb. 1999, pitfall with pig dung, Turnbow and Wappes leg. (FSCA). - Chiriquí: 2 ふึ, 3 우, Gualaca, Hornito, Finca la Suzia, 9-15 May 1999, dung trap, Morris and Wappes leg. (FSCA). - Colón: 1 q, Fuerte Sherman, 15-24 Feb. 1999, pitfall with pig dung, R. Turnbow leg. (FSCA). - Panama: 3 $\widehat{\jmath}$, “ $0.3 \mathrm{~km}$ W El Llano", 12 May

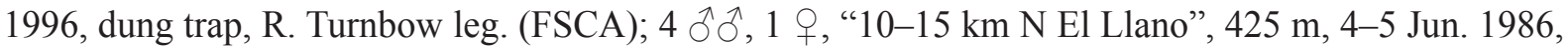
E. Giesbert, P.H. Sullivan and F.T. Hovore leg. (FSCA); 1 §, Barro Colorado Island, K.W. Cooper leg. (FSCA, ex R.E. Woodruff collection); 1 , 2 우, same collecting data as for preceding (MCZC);

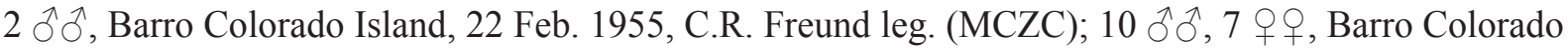
Island, Jul. 1969, J. Lawrence, B. Hlavac and T. Hlavac leg. (MCZC); 256 §̂ત, 97 우우, Barro Colorado

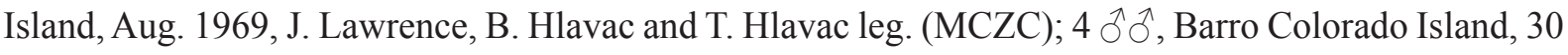

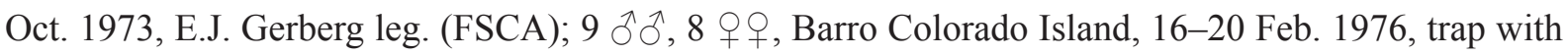
human faeces, A. Newton leg. (MCZC); 1 Oे, 1 q, Barro Colorado Island, 31 Aug. 1978, trap with dung, A. Forsyth leg. (FSCA); 2 §ð, 1 †, Barro Colorado Island, "Shannon Trail", 15 Jun. 1961, leaf litter, E.O. Willis leg. (MCZC); 1 + , "Canal Zone, Madden Forest", 14 Dec. 1971, dung trap, H.P. Stockwell leg. (FSCA); 77 đิ $\partial$, 55 우, “Canal Zone, Pipeline Road, Limbo Hunt Club”, 26 May 1977, pitfall with

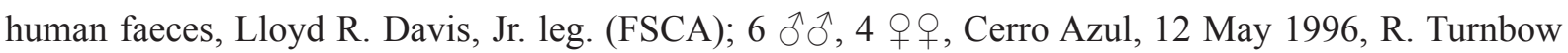
leg. (FSCA); 2 ○ึ, 4 우, Cerro Azul, 12-13 May 1996, Wappes, Huether and Morris leg. (FSCA); $8 \hat{\jmath}$, 3 우, Cerro Azul, 21 May 1996, R. Turnbow leg. (FSCA); 7 $\partial^{\lambda}, 5$ q $q$, Cerro Azul, 21-27 May 1996, Wappes, Huether and Morris leg. (FSCA); 3 $\lesssim$, Cerro Azul, 24 May 1996, pitfall with pig dung,

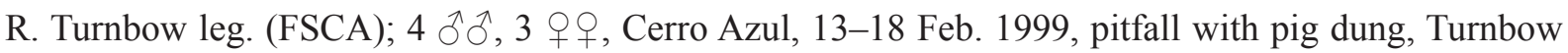

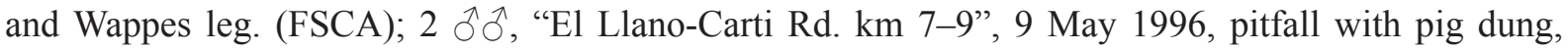

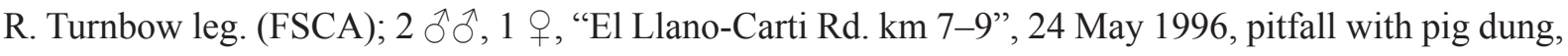
R. Turnbow leg. (FSCA); 1 ठ̊, "El Llano-Carti Rd. K 8-11”, 1100 m, 24 May-2 Jun. 1992, J.E. Wappes

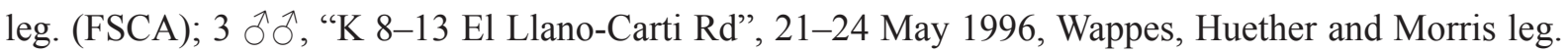

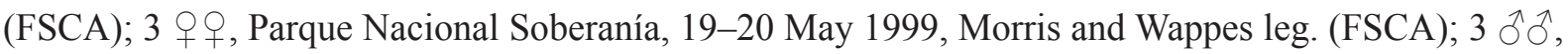
3 우, Parque Nacional Soberanía, 23-27 May 1996, Wappes, Huether and Morris leg. (FSCA); 1 ðૈ, 2 우, Parque Nacional Soberanía, 26 May 1996, pitfall with pig dung, R. Turnbow leg. (FSCA); 1 ,

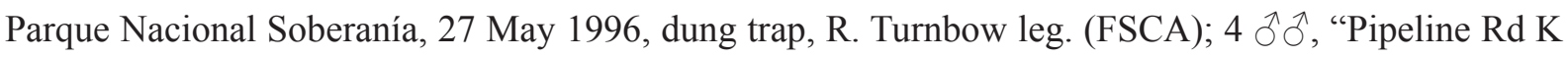
1-12”, 26-30 Jun. 1997, Wappes and Morris leg. (FSCA); 4 우, "Pipeline Rd K 1-12”, 30 Jun. 1997, dung trap, Morris and Wappes leg. (FSCA); 1 ○, 4 우, "Pipeline Rd K 1-12”, 8-9 Jul. 1997, dung trap, Morris and Wappes leg. (FSCA); $13 \widehat{\jmath}, 5$ 우, "Pipeline Rd”, 28 Jun.-9 Jul. 1997, R. Turnbow leg. (FSCA). 
Sylvicanthon bridarollii (Martínez, 1948)

\section{Material examined}

BOLIVIA: Cochabamba: 1 , Chapare (FSCA, ex E.N. Kellesvig-Waering collection); 1 , Chapare, 15 May 1951, no collector (FSCA, ex E.N. Kellesvig-Waering collection); 2 q , Chapare, $400 \mathrm{~m}$, 5 May 1951, no collector (FSCA, ex E.N. Kellesvig-Waering collection). - Santa Cruz: 1 , Ichilo, "3.7 km SSE Buena Vista, Hotel Flora \& Fauna", 430 m, 14-19 Oct. 2000, M.C. Thomas leg. (FSCA); 1 + , Ichilo, "3.7 km.SSE Buena Vista, Hotel Flora \& Fauna”, 430 m, 14-28 Oct. 2000, B.K. Dozier leg. (FSCA); 1 ㅇ, Ichilo, "4-6 km SSE Buena, Vista Fauna \& Flora Hotel”, 420-450 m, 2-12 Feb. 2000, pitfall with dung and carrion, J.E. Wappes leg. (FSCA); 2 $ぇ$, Ichilo, “5km SSE Buena Vista, Hotel Fauna \& Flora”, 17²9.935' S, 6339.129’ W, 440 m, 24-31 Dec. 2003, S. and J. Peck leg. (FSCA).

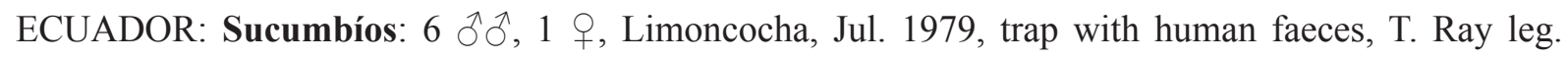

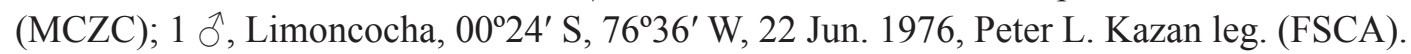

PERU: Huánuco: 1 q, Leoncio Prado, Rupa-Rupa, Tingo María, Universidad Nacional Agraria de la Selva ("Tingo María Universidad"), Dec. 1974, Martínez leg. (FSCA).

Sylvicanthon foveiventris (Schmidt, 1920)

\section{Material examined}

BRAZIL: Rio de Janeiro: 1 đૈ, Itatiaia, 700 m, Feb. 1959, W. Zikan leg. (CEAH).

\section{Material examined}

Sylvicanthon genieri sp. nov.

\section{Paratypes}

ECUADOR: Pastaza: 2 ๙ $\precsim$, “38 km E of Baños”, 1500 m, 9 Feb. 1990, dung bait, J. Watts and R. Beard leg. (FSCA).

PERU: Huánuco: 1 + , Leoncio Prado, Rupa-Rupa, Tingo María, Universidad Nacional Agraria de la Selva ("Tingo María Universidad"), Dec. 1974, Martínez leg. (FSCA).

\section{Sylvicanthon seag sp. nov.}

\section{Material examined}

\section{Paratypes}

BRAZIL: Amazonas: $6 \hat{\partial} \hat{\partial}, 4$ $\propto \propto+$, Manaus, 3 Jan. 1978, B.C. Ratcliffe leg. (FSCA); $1 \hat{\partial}, 1 \stackrel{+}{\circ}$, Manaus, BR 174, km 64, 20 Aug. 1984, Milan Hrabovsky leg. (FSCA).

FRENCH GUIANA: 1 , Cayenne, Roura, Amazon Nature Lodge, "30 km SE Roura on Kaw Rd.", $04^{\circ} 33.570^{\prime} \mathrm{N}, 52^{\circ} 12.433^{\prime} \mathrm{W}, 300 \mathrm{~m}, 3-10 \mathrm{Jun} .2005$, pitfall with human faeces, J.E. Eger leg. (FSCA); 1 o', "D-5 / 4k SE Tngmd Jct", 17-18 Aug. 1995, J.E. Wappes leg. (FSCA); 1 đ, 2 우, "D-5 / 4k SE Tngmd Jct", 21-22 Aug. 1995, J.E. Wappes leg. (FSCA); 1 J, 4 q $q$, "D-5 / 4k SE Tngmd Jct”, 24-27 Aug. 1995, J.E. Wappes leg. (FSCA); 3 우, “D-5 / 4k SE Tngmd Jct”, 25-27 Aug. 1995, J.E. Wappes leg. (FSCA).

TRINIDAD AND TOBAGO: 1 ð, “1 mi. W. Morne / Bleu Trinidad”, 23 Jun. 1968, Julius Boos leg. (FSCA). 
Sylvicanthon proseni (Martínez, 1948)

\section{Material examined}

BOLIVIA: Cochabamba: 1 ก, 1 \%, Chapare, 400 m, 1 Oct. 1950, no collector (FSCA).

BRAZIL: Rondônia: 1 đ, "62 km SW Ariquemes, near Fazenda Rancho Grande”, 3-15 Dec. 1996,

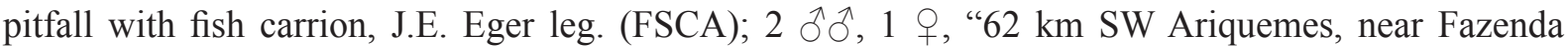
Rancho Grande", 4-16 Nov. 1997, pitfall with fish carrion, J.E. Eger leg. (FSCA).

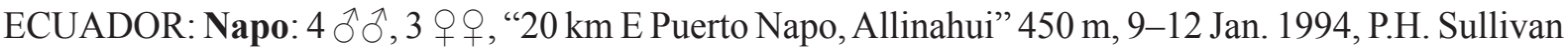
leg. (FSCA); 14 $\widehat{\jmath}, 4$ 우 , Limoncocha, Jul. 1979, trap with human faeces, T. Ray leg. (MCZC); 1 , Limoncocha, 00²4' S, 76³6' W, 29 Jun. 1972, Peter L. Kazan leg. (FSCA).

PERU: Loreto: 1 ô, " 80 km NE Iquitos, Explorama Lodge, 1 km from Amazon River on Rio Yanamono", 25-28 Aug. 1992, pitfall with human faeces, Castner and Skelley leg. (FSCA); 3 $え \hat{\jmath}, 2$ 우, "80 km NE Iquitos, Explorama Lodge, $1 \mathrm{~km}$ from Amazon River on Rio Yanamono", 1-5 Sep. 1992, pitfall with

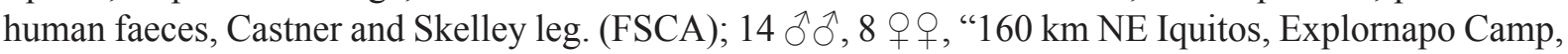
$2 \mathrm{~km}$ from Rio Napo on Rio Sucusari”, 27-31 Aug. 1992, pitfall with human faeces, J. Castner and Skelley leg. (FSCA); 1 ㅇ, "Explorama Lodge, 50 mi NE Iquitos on Amazon River", 12-19 Mar. 1988, J.E. Eger leg. (FSCA); 1 §ิ, 1 , Iquitos, Jungle Amazon Inn, 30 Dec. 1986-2 Jan. 1987, M.J. Halter

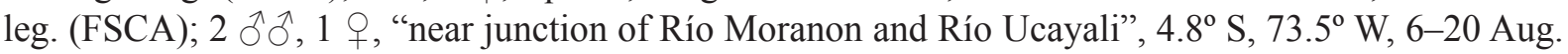
1994, P. Skelley leg. (FSCA). 